\title{
ESTIMATION OF AIR QUALITY CRITERION-BASED BUILDING SETBACK DISTANCE FROM URBAN ROADS AND FREEWAYS USING MICROSCOPIC SIMULATION OF TRAFFIC, EMISSIONS, AND POLLUTION DISPERSION
}

by

\section{Sujit Das}

A thesis submitted to the Faculty of Graduate and Postdoctoral Affairs in partial fulfillment of the requirements for the degree of

\section{Doctor of Philosophy}

in

\section{Civil and Environmental Engineering \\ Carleton University \\ Ottawa, ON, Canada}

April 10, 2017

(C) Sujit Das, Ottawa, 2017

The Doctor of Philosophy in Civil and Environmental Engineering Program is a joint program with the University of Ottawa, administrated by the Ottawa-Carleton Institute of Civil and Environmental Engineering 


\begin{abstract}
Emissions from road vehicles and other sources that exceed well-defined concentrations affect human health. To protect people, especially vulnerable members of population, ambient air quality standards and guidelines should be met. According to projections, the internal combustion engine vehicles are likely to maintain their dominance for many decades and only marginal improvements in emission reduction can be expected. Therefore, it is necessary to investigate separation distance between vulnerable receptors and high traffic roads and highways.
\end{abstract}

Available guidelines on setback distance from urban roads and highways and the associated land use considerations do not account for pollutant dispersion and air quality standards. Also, methods are not available to predict pollutant concentration at various setback distances and heights under worst case of traffic and wind condition.

This research is aimed at the development of methods for determining air quality criterionbased building setback distance from urban roads and freeways. The research approach integrates microscopic models for simulating vehicle trajectories, emission factors and pollutant dispersion. Prior to application, the models were verified with field data on vehicle trajectories and emissions. In addition, data on background pollution concentrations were investigated. The integrated simulation model when applied to selected building locations in Ottawa produced logical results.

To meet the objective of developing tools that could be used to check pollutant concentrations at various distances and heights or to find setback distance for specified conditions, the simulation design methodology was developed and applied while meeting 
the statistical reliability requirements. Simulation results were used to develop statistically significant predictive models for $\mathrm{CO}, \mathrm{NO}_{2}$, and $\mathrm{PM}_{2.5}$ concentration. The non-linear regression models are better than linear regression models and the ANN models compare well with non-linear models. The new predictive models are designed to provide 1-hour pollutant concentration on the worst case basis.

Example applications show logical results of potential interest to professional persons and researchers. In addition, ideas are advanced for future research. It is contended that the products of this research can be of immediate assistance to the real-world planners and policy analysts in establishing setback guidelines that take into account air quality standards. 


\section{ACKNOWLEDGEMENT}

I would like to dedicate this thesis to my family members, especially to my parents Mr. Sadhan and Mrs. Nihar for their long vision, to my lovely wife Sharmila for her patience and understanding, and to my adorable son Shuvom for bravely accepting the distance that separated us.

I would like to take the opportunity to thank my supervisor, Professor Ata M. Khan for his acceptance of my multi-disciplinary research idea, indicating me the findings, and guiding me with enthusiasm. His enormous support and continuous encouragement during the last four years at Carleton University is deeply appreciated. I would also like to thank the members in my advisory committee for their support and ideas.

I would like to thank Mr. Kenneth Akhiwu for his support regarding troubleshooting software, library stuff for their patience and understanding, City of Ottawa officials for their assistance and providing the relevant data.

I would like to express my appreciation to the Government of India for funding my research.

I must thank my friends and colleagues who supported me in several ways to complete my research. 


\section{TABLE OF CONTENTS}

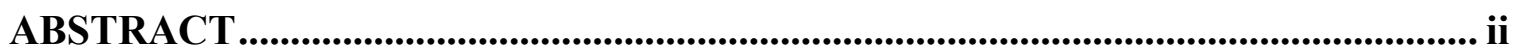

CH 1: PROBLEM DEFINITION.......................................................................................1

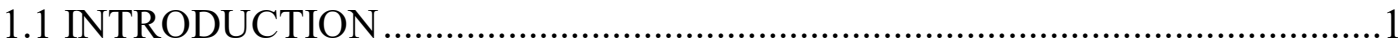

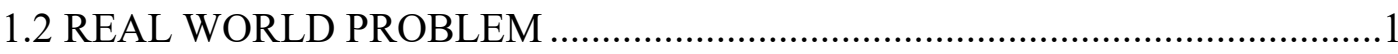

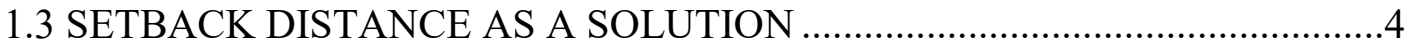

CH 2: RESEARCH OBJECTIVES AND SCOPE......................................................6

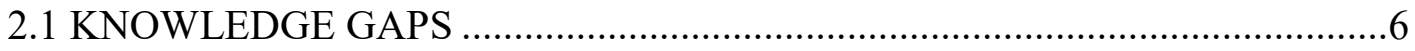

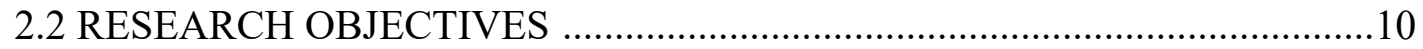

2.3 SCOPE

2.3.1 Land Use Planner's Point of View.......................................................11

2.3.2 Definition of Setback Distance ................................................................11

2.3.3 Existing Setback Distance Definitions at Policy Level ..........................12

2.3.4 Required Setback Distance Criteria Based on Air Quality .....................14

CH 3: RESEARCH METHODOLODY .........................................................................16

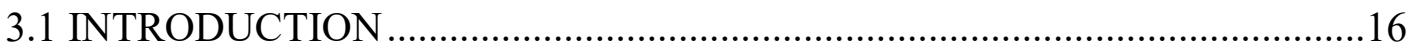

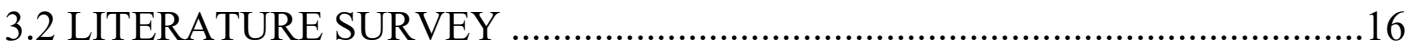

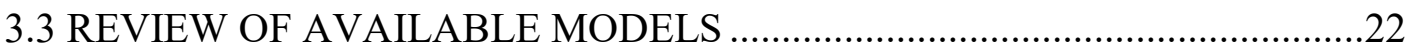

3.4 RESEARCH FRAMEWORK AND METHODOLOGY ...................................32 
3.4.1 Traffic Micro-Simulator.

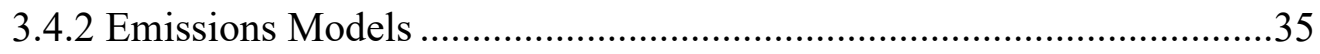

3.4.3 Air Quality (Dispersion) Model ......................................................36

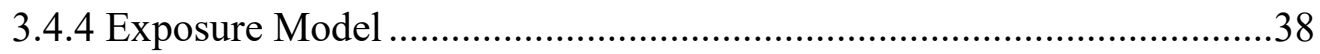

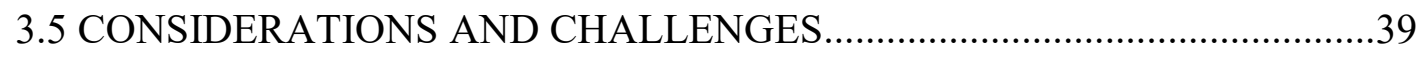

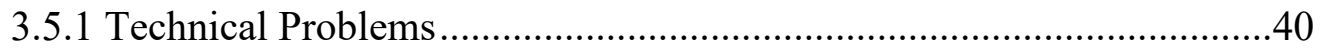

3.5.2 Analytical Problems ...............................................................45

3.5.3 Software Issues and Reliability of Using Integrated Software ..............52

CH 4: TRAFFIC MODEL (VISSIM) ....................................................................56

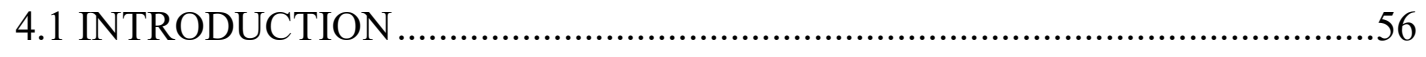

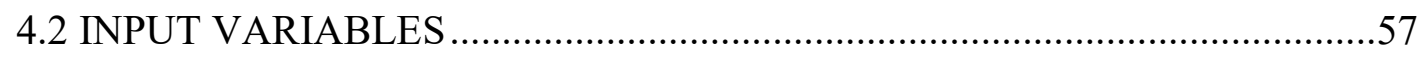

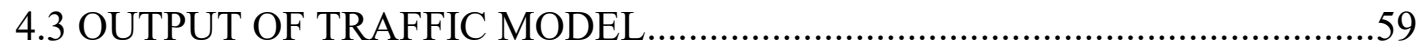

4.4 MODEL CALIBRATION AND VALIDATION ..........................................60

4.4.1 Reason for Model Calibration and Validation .................................60

4.4.2 Calibration and Validation Objectives ...........................................61

4.4.3 Data Preparation for VISSIM Model .............................................62

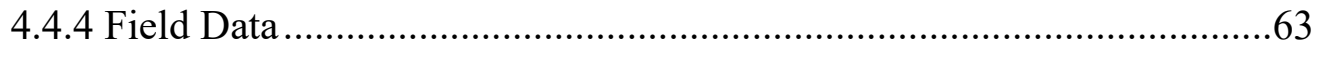

4.4.5 Observations on the Calibration Step..............................................64

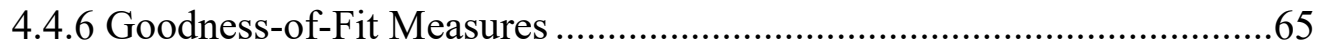

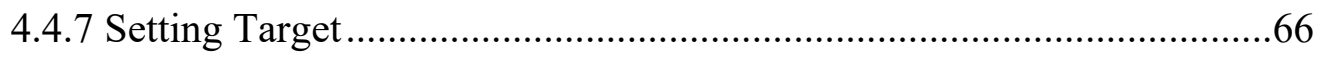

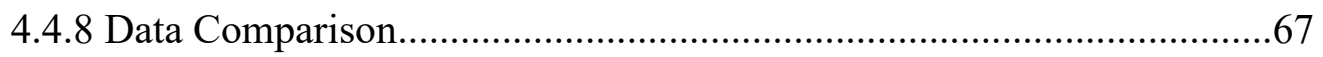

4.5 INPUT DATA PREPARATION FOR EMISSION MODEL ...........................71 


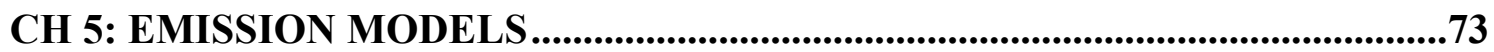

5.1 INTRODUCTION

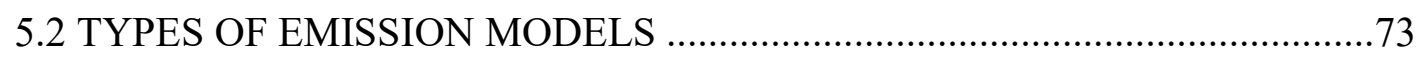

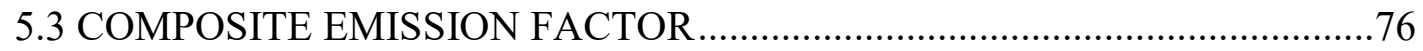

5.4 MODEL COMPARISON (CMEM VS MOVES) ………………...................78

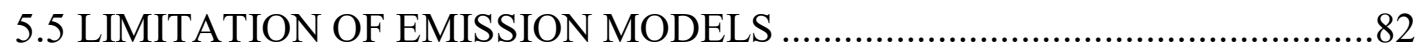

CH 6: GAUSSIAN DISPERSION MODEL ..................................................................84

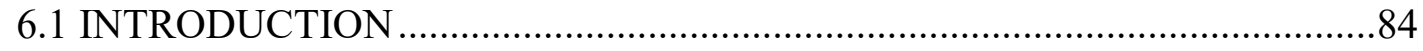

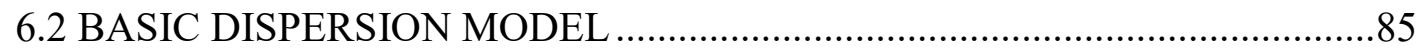

6.3 DEVELOPMENT OF LINE SOURCE FORMULATION …………………......8

6.4 SOFTWARE PACKAGE FOR LINE SOURCE MODELLING ……...............90

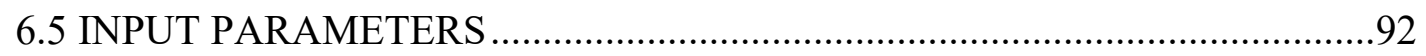

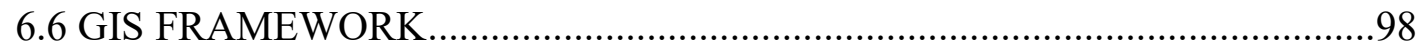

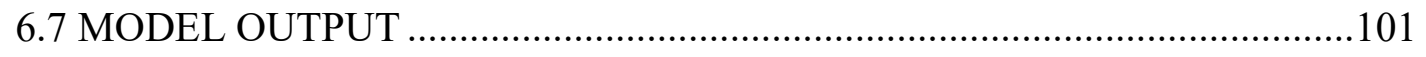

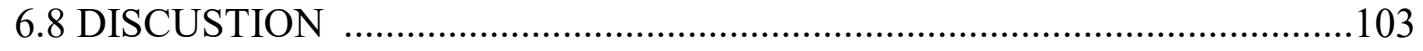

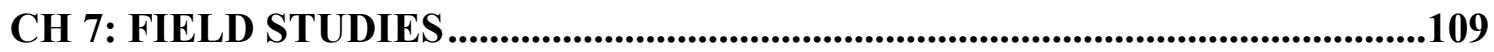

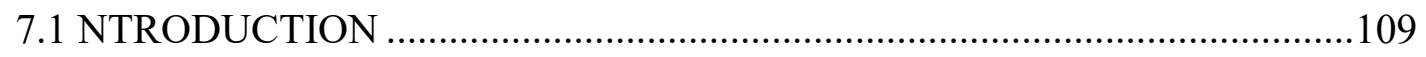

7.2 POLLUTION MEASURING INSTRUMENTS ………………….................109

7.3 ADDITIONAL SURVEY INSTRUMENTS ……………………..................110

7.4 SURVEY PLAN AND STUDY AREA IDENTIFICATION ............................111 


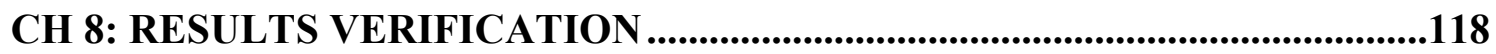

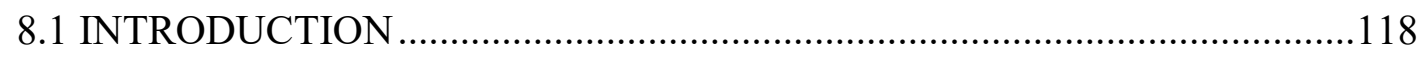

8.2 RESULT COMPARISON AND ERROR CALCULATION ………...............120

8.3 ANALYSIS OF RESULTS AND LIMITATIONS ………………………....140

CH 9: SIMULATION DESIGN......................................................................................146

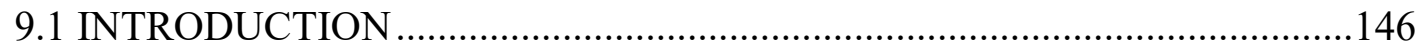

9.2 DECISION MAKING ON VALUES OF VARIABLES …………...................147

9.2.1 Capacity Level Traffic for Urban Roads/Intersections .........................147

9.2.2 Finalization of Heavy Duty Vehicle for Planning ................................157

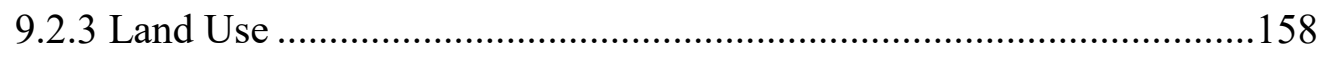

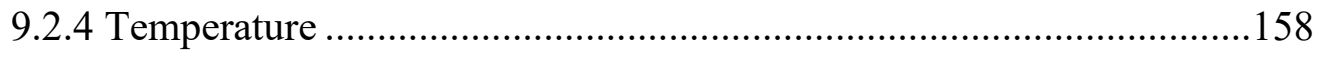

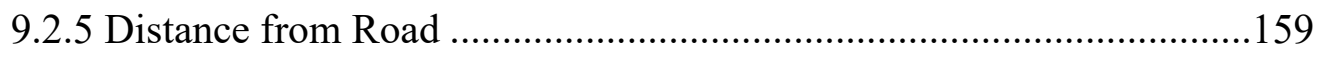

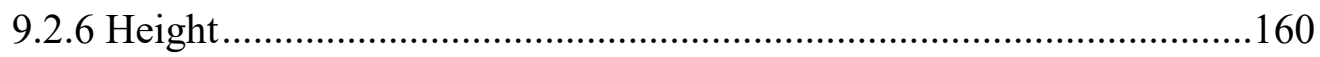

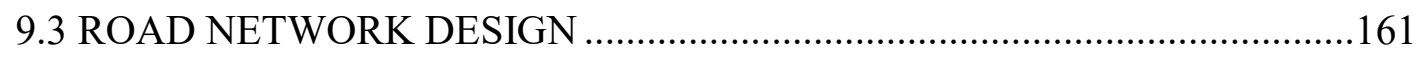

9.3.1 Desirable Space between Signalized Intersections ...............................162

9.3.2 Deceleration Lane Length ................................................................164

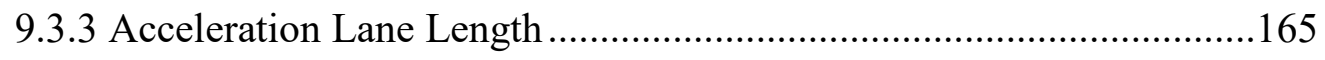

9.3.4 Sample Road Network inside and outside of CBD ..............................166

9.4 RANDOM NUMBER SELECTION PROCEDURE........................................170

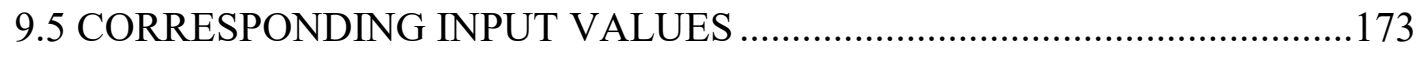

9.6 SIMULATION DESIGN FOR FREEWAY ……………….........................175 
9.6.1 Variables Selection for Running Simulation 176

9.6.2 Input Data Preparation Corresponding to Random Number.

.177

CH 10: SIMULATION RESULTS FOR URBAN ROADS AND FREEWAYS....179

10.1 INTRODUCTION. .179

10.2 SIMULATION OF EMISSION RATES OR CEF: URBAN ROADS 180

10.3 POLLUTION CONCENTRATION RESULTS FOR ROADS AND

INTERSECTIONS

10.4 SIMULATION RESULTS FOR FREEWAY.... .200

CH 11: STATISTICAL MODEL DEVELOPMENT .203

11.1 INTRUDUCTION .203

11.2 TYPES OF EQUATIONS ...... .204

11.3 MULTIPLE LINEAR REGRESSION EQUATIONS .204

11.3.1 Linear Regression Equations for Freeway . .205

11.3.2 Multiple Linear Regression Equations for Urban Road Network......205 11.4 REQUIREMENT OF DATA TRANSFORMATION .212

11.5 TYPES OF DATA TRANSFORMATION .214

11.5.1 Data Transformation for Freeway case. .215

11.5.2 Data Transformation for Urban Road Network .220

11.6 DEVELOPMENT OF NON-LINEAR EQUATIONS .225

11.6.1 Non-Linear Equations for Freeway. .225

11.6.2 Non-Linear Equations for Urban Road Network .230

11.7 ARTIFICIAL NEURAL NETWORK .231 
11.7.1 Definition

11.7.2 Need for a Predictive Tool: The ANN Model.

11.7.3 Best fit of ANN Model. .233

11.8 ANALYSIS AND MODEL SELECTION

.237

CH 12: MODEL APPLICATIONS ...............................................................240

12.1 AREA OF APPLICATION .240

12.2 DETERMINATION OF SETBACK DISTANCE FOR URBAN ROADS

AND FREEWAY .241

12.3 SETBACK DISTANCE AROUND MAJOR INTERSECTIONS. .249

CHAPTER 13: CONCLUSIONS, RECOMMENDATIONS, AND CONTRIBUTIONS. .254

13.1 CONCLUSIONS .254

13.2 RECOMMENDATIONS .257

13.3 CONTRIBUTIONS .258

REFERENCES R-1

APPENDICIES A-1

APPENDIX: BACKGROUND INFORMATION ON EMISSIONS, AIR POLLUTION, HEALTH EFFECTS, AND NAAQ STANDARDS....... A-1

A.1 ROAD TRANSPORTATION EMISSIONS A-2 A.2 AIR POLLUTION A-6 
A.2.1 Air Pollution from Mobile Sources

A.2.2 Motor Vehicles Emissions

A-10

A.2.3 Mobility and Human Health: Effect of Traffic-related Pollution ...A-11

A.3 HEALTH EFFECT

A-11

A.3.1 Effects of Carbon Monoxide

A.3.2 Effects of Oxides of Nitrogen

A.3.3 Effects of Particulate Matter A-14

A.4 RECEPTOR TYPE A-14

A.5 NATIONAL AMBIENT AIR QUALITY STANDARDS (NAAQS) A-15

APPENDIX GROUP 1

APPENDIX-I: CAPACITY LEVEL TRAFFIC CALCULATIONS A-17

APPENDIX GROUP 2 A-40

APPENDIX-II: RANDOM NUMBER GENERATION A-41

APPENDIX-III: DUST METER READING A-44 APPENDIX-IV: GAS ANALYZER READING A-45

APPENDIX-V: VELOCITY METER READING A-47 APPENDIX-VI: OUTPUT FROM VISSIM (TRAFFIC SIMULATION) MODEL A-48 APPENDIX-VII: INPUT FILES FOR MOVES EMISSION MODEL .... A-50 APPENDIX-VIII: COMPOSITE EMISSION FACTORS FOR GASEOUS POLLUTANTS USING CMEM EMISSION MODEL A-54 
APPENDIX-IX: EMISSION RATES FROM MOVES EMISSION MODEL A-55

APPENDIX-X: SIMULATION 18 AC 15 CO .................................... A-55

APPENDIX-XI: SIMULATION 12 AC $19 \mathrm{NO}_{2}$................................. A-59

APPENDIX-XII: FREEWAY SAMPLE \#3 FOR PM 2.5

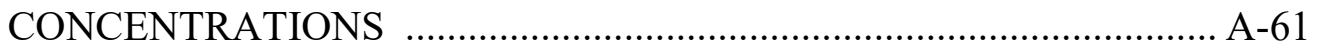

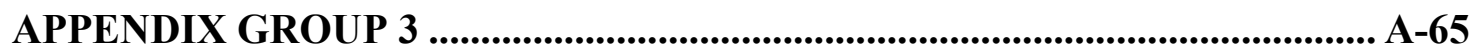

APPENDIX-XIII: STATISTICAL MODEL REPORT ……..................... A-66

APPENDIX-XIV: ANN MODEL REPORT FOR COLLECTOR ROAD

LINK CASE ….......................................................................... A-74 


\section{LIST OF TABLES}

Table 1-1: National ambient air quality standards (NAAQS) ........................................2

Table 3-1: Hourly average and minimum wind speed data analysis for July 2013 ........47

Table 3-2: Frequency distribution of minimum wind speed ......................................48

Table 4-1: Traffic speed data (bin wise) on hunt club road .......................................64

Table 4-2: Default driving behaviour for urban road by Weidemann 74 .......................65

Table 4-3: Travel time comparison in Sault Ste. Marie, ON, Canada .............................68

Table 4-4: Hunt club road WB traffic summary from either sources ............................69

Table 4-5: Error percentage for different study types and locations $\quad$.............................71

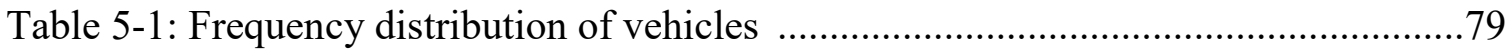

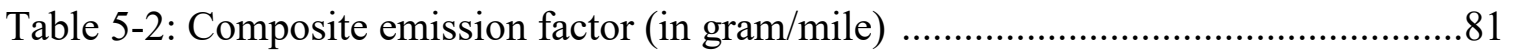

Table 5-3: Output files from MOVES emission model (in gram/mile) ..........................82

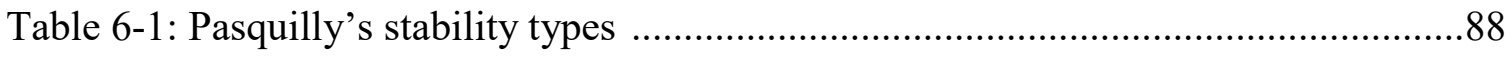

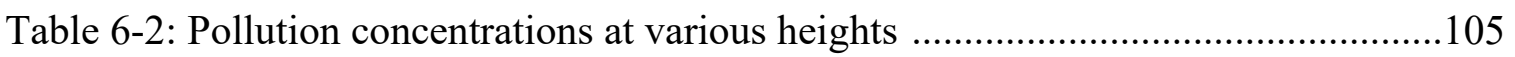

Table 6-3: Variation of pollution concentration with horizontal distance .....................106

Table 7-1: Locations selected for field data collection ..............................................111

Table 7-2: Data collection using field book (pollutants and meteorological data) .........116

Table 8-1: Comparison of gas pollutants estimated from model and field study ...........141

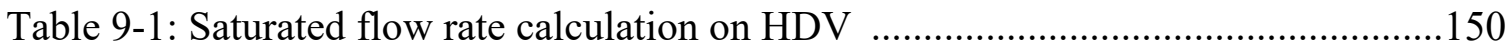

Table 9-2: Saturated flow rate calculation on lane adjustment factor and turning movement

Table 9-3:Saturated flow rate calculation by area type 151 
Table 9-4(A): Random number assignment based on traffic capacity in an intersection with arterial vs arterial road

Table 9-4 (B): Random number assignment based on traffic capacity in an arterial vs collector intersection 155

Table 9-4 (C): Random number assignment based on traffic capacity in a collector vs collector intersection .155

Table 9-4 (D): Random number assignment based on traffic capacity in an arterial vs local road intersection .156

Table 9-4 (E): Random number assignment based on traffic capacity in a collector vs local road intersection 156

Table 9-5: Random number assignment based on urban land use 158

Table 9-6: Random number assignment based on temperature 159

Table 9-7: Random number assignment based on distance .160

Table 9-8: Random number assignment based on height and corresponding distance ...161

Table 9-9: Desirable spacing between signalized intersections, $\mathrm{m}$ .163

Table 9-10: Deceleration lane length with respect to design speed on urban roads .165

Table 9-11: Accelerating lane length with respect to design speed on urban roads 166

Table 9-12: Spacing between intersections .166

Table 9-13: Random numbers selected for input variables 170

Table 9-14: Selected input variables corresponding to random numbers .174

Table 9-15: Decision on random number assignment for input variables .176

Table 9-16: Assigned random number and their corresponding input variables 177

Table 10-1: Composite emission factor (CEF) or emission rates .181 
Table 10-2: Pollution concentrations for arterial road link 190

Table 10-3: Pollution concentrations for collector road link .191

Table 10-4: Pollution concentrations for an intersection with arterial road vs arterial road with four way crossing (4-leg type)

Table 10-5: Pollution concentrations for an intersection with arterial road vs arterial road with three way crossing (' $T$ ' type)

Table 10-6: Pollution concentrations for an intersection with arterial road vs collector road with four way crossing (4-leg type)

Table 10-7: Pollution concentrations for an intersection with arterial road vs collector road with three way crossing ('T' type)

Table 10-8: Pollution concentrations for an intersection with collector road vs collector road with four way crossing (4-leg type)

Table 10-9: Pollution concentrations for an intersection with collector road vs collector road with three way crossing (' $\mathrm{T}$ ' type)

Table 10-10: Input variables and their corresponding outputs .200

Table 11-1: Statistical summary report for CO pollution for urban road .207

Table 11-2: Statistical summary report .224

Table 11-3: Correlations of parameter estimates for CO pollutants .227

Table 12-1: CO pollution concentrations varies with distances from arterial road at breathing height based on equation-12.1 .244

Table 12-2: $\mathrm{CO}$ and $\mathrm{NO}_{2}$ pollution concentrations vary with distances and heights ......245

Table 12-3: Approximate setback distance at different heights .251

Table A1-1: Sources of pollutants A-2 


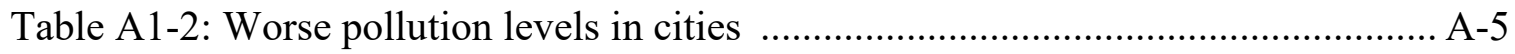

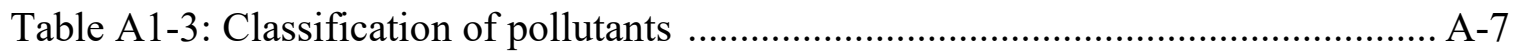

Table A1-4: Basic characteristics and related parameters responsible for vehicular

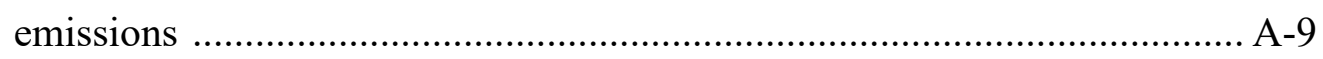

Table A1-5: National ambient air quality standards (NAAQS) .............................. A-15 


\section{LIST OF FIGURES}

Figure 1-1 (a \& b): Land use activities in slum areas in India ...........................................

Figure 2-1: Air pollution concentrations vary with distances ..........................................8

Figure 2-2: Retirement home located on Hunt Club Road, Ottawa ....................................9

Figure 2-3: Design standard for 4-lane arterial road ..................................................13

Figure 3-1: Research framework ……………………….....................................33

Figure 3-2: Hourly traffic-volume expansion factor ....................................................46

Figure 3-3: Selected season and daytime for making decision of 'worse case' conditions

Figure 4-1: Road links and connectors using VISSIM-7 ………………......................57

Figure 4-2: (a) 2-D and (b) 3-D view of simulation run ............................................59

Figure 4-3: Road segment and intersection in Sault Ste. Marie study area .....................63

Figure 4-4: Comparison of instrumented vehicle travel time with VISSIM results .........69

Figure 4-5: Comparison of speed distribution from simulation model vs radar meter .....70

Figure 4-6: VISSIM output file components based on link and intersection name ..........71

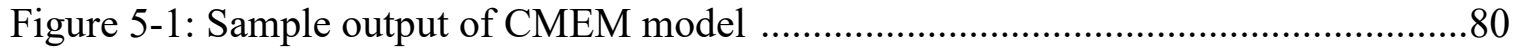

Figure 6-1: Coordinate system showing Gaussian distribution of flume in the horizontal

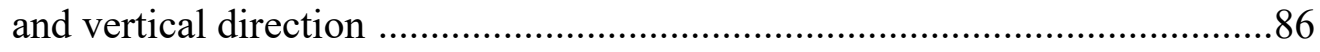

Figure 6-2 (a \& b): Lateral diffusion coefficient $\sigma y$ vs. downwind distance from source and vertical diffusion coefficient $\sigma \mathrm{Z}$ vs. downwind distance from source $\quad$...........87

Figure 6-3: Lapse rate (dry and wet) and atmospheric stability class .............................94

Figure 6-4: Atmospheric stability conditions ……………..........................................96

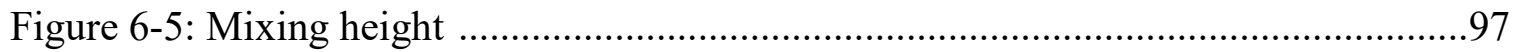


Figure 6-6: Multiple buffer lines generation from outer edge of a road using GIS .99

Figure 6-7: 3-D view of pollutant concentrations on roads in GIS plat-form 100

Figure 6-8: CO concentration contours and levels at receptors site .102

Figure 6-9: $\mathrm{CO}$ concentrations at the closest edge of the retirement home .106

Figure 6-10: CO concentration vs horizontal distance from edge of road at breathing height, which is 1.8 meter from surface .107

Figure 7-1: Gaseous pollutions $\left(\mathrm{CO}\right.$ and $\left.\mathrm{NO}_{2}\right)$ monitoring device 110

Figure 7-2: Dust $\left(\mathrm{PM}_{2.5}\right)$ tracking instrument 110

Figure 7-3: Velocity measuring instruments 110

Figure 7-4: Satellite view of residential building on Rideau Street, Ottawa, ON, Canada at south-east corner of the intersection of Rideau Street and Wurtemburg Street

Figure 7-5: Street view of residential building on Rideau Street .113

Figure 7-6: Field data collection from the roof of Apollo management property 114

Figure 7-7: Field data was recording in field sheet at the intersection of Walkley road and McCarthy road 115

Figure 7-8: Instruments set-up on Carling Road near Ottawa Civic hospital 115

Figure 8-1: Gas analyzer (extreme right) and Dust meter (extreme left) 118

Figure 8-2: Gas analyzer showing $\mathrm{CO}$ an $\mathrm{NO}_{2}$ reading 119

Figure 9-1: Sample road network for simulation design .162

Figure 9-2: Sample road network with an intersection of arterial vs collector road .164

Figure 9-3: Sample of acceleration and deceleration lane length showing on road network .164 
Figure 9-4: Bronson Avenue within CBD-central city 167

Figure 9-5: Vanier Parkway within urban but outside CBD

Figure 9-6: Road network in CBD-central city area with access facility to local road with stop sign 168

Figure 9-7: Sample road network in urban - outside CBD area 169

Figure 10-1: CO concentrations of sample number-15 with arterial vs collector 4 leg intersection (represented in table 10-6) .188

Figure 10-2: $\mathrm{NO}_{2}$ concentrations for sample number-19 .188

Figure 10-3: Simulation run for sample number three for $\mathrm{PM}_{2.5}$ concentrations .202

Figure 11-1: Graphical representations of normality test with temperature data sets after transformation for the freeway case 215

Figure 11-2: Graphical representations of normality test with distance data sets after transformation in freeway case .216

Figure 11-3: Graphical representations of normality test with height data sets after transformation in freeway case

Figure 11-4: Graphical representations of normality test with $\mathrm{CO}$ pollution concentrations data sets without transformation in freeway case .217

Figure 11-5: Graphical representations of normality test with $\mathrm{NO}_{2}$ pollution concentrations data sets without transformation in freeway case 218

Figure 11-6: Graphical representations of normality test with $\mathrm{PM}_{2.5}$ pollution concentrations data sets using transformation in freeway case .219

Figure 11-7: Graphical representations of normality test of capacity level traffic data sets without transformation for urban road network .220 
Figure 11-8: Graphical representations of normality test of temperature data .222

Figure 11-9: Graphical representations of normality test of temperature data with reflected square root transformation .223

Figure 11-10: Histogram plot and normal P-P plot developed for CO pollutants in nonlinear regression model .226

Figure 11-11: Histogram and normal P-P plot for $\mathrm{NO}_{2}$ using non-linear regression .....228 Figure 11-12: Histogram and normal P-P plot for $\mathrm{PM}_{2.5}$ using non-linear regression ...228 Figure 11-13: Histogram and normal P-P plot for transforming $\mathrm{PM}_{2.5}$ using non-linear regression .230

Figure 11-14: The structure of artificial neural network with connection between nodes and links .232

Figure 11-15: Predictive 'goodness-of-fit' using ANN for CO pollutants in freeway ...234 Figure 11-16: Predictive 'goodness-of-fit' using ANN for CO pollutants on collector road .235

Figure 11-17: Predictive 'goodness-of-fit' using ANN for $\mathrm{PM}_{2.5}$ pollutants .236

Figure 11-18: Errors in histogram using ANN for $\mathrm{PM}_{2.5}$ pollutants in a 4-leg arterial vs collector intersection 237

Figure 12-1: CO pollution concentration decreases with distances from road edge at breathing height .244

Figure 12-2: CO pollution concentration decreases with distance and height .247

Figure 12-3: The joint effect of setback distance and height .252

Figure A1-1: Distribution of air pollutant emissions A-3

Figure A1-2: Primary air pollution sources from road transportation A-3 


\section{Chapter 1: PROBLEM DEFINITION}

\subsection{INTRODUCTION}

Motor vehicles emit pollutants that affect human health (background information on emissions and health effects is provided in the Appendix). Emissions of interest in this research are carbon monoxide $(\mathrm{CO})$, nitrogen di-oxide $\left(\mathrm{NO}_{2}\right)$ and Particulate Matter $\left(\mathrm{PM}_{2.5}\right)$. Real world observations on the effects of emissions on a vulnerable person at nearby locations raise the question of setback distances in order to meet the applicable standards. Ambient air quality standards for $\mathrm{CO}, \mathrm{NO}_{2}$ and $\mathrm{PM}_{2.5}$ for Canada, the World Health Organization (WHO) and the USA are presented in Table 1-1. Although much research has been carried out on providing well-defined distance for reducing the noise effects, not much is known about setback distance for locating vulnerable receptors sensitive to emissions. There is a need for such information in site planning of new developments or for re-developing land in urban areas.

The quality of air near roads is mainly degraded by the pollution from road transportation, but background pollution sources should also be considered. The sources of background pollutions are non-road emissions, such as heating system and cooking in houses.

\subsection{REAL WORLD PROBLEM}

People do not generally perceive the severity of effects of air pollution unless they are admitted to hospital for treatment. Pollution near roads and highways as a cause of health- 
related effects assumes much importance for some receptor groups such as older adults, infants, children and low-income group (USEPA, 2014).

It is highly relevant to investigate setback distances in residential, institutional, and mixed development areas where vulnerable receptors spend bulk of their time. Due to the trend to achieve high density, inadequate distance between the road and buildings may be the result. Although there are technologies that have the potential to filter air in order to overcome air quality concerns, opening windows for obtaining "fresh" air is a common practice.

Table 1-1: National ambient air quality standards (NAAQS)

(Sources: 1. Canada AQS (2013), 2. Boyd, D.R. (2006), 3. U.S. EPA, Please refer to Table A1-5 in APPENDIX for details)

\begin{tabular}{|l|c|c|c|}
\hline & Canada $^{\mathbf{1}}$ & $\begin{array}{l}\text { World Health } \\
\text { Organization (WHO) }\end{array}$ & $\boldsymbol{U S A}^{\mathbf{3}}$ \\
\hline CO(ppm) & 13 & 9 & 9 \\
8-hr & 31 & - & 35 \\
1-hr & & & 53 \\
\hline NO2(ppb) & 53 & 21 & 100 \\
Annual & 213 & - & - \\
1-hr & 106 & 25 & 35 \\
24-hr & 28 & - & 12 \\
\hline PM2.5( $\left.\mu \mathrm{g} / \mathrm{m}^{3}\right)$ & 10 & & \\
24-hr & & & \\
Annual & & & \\
\hline
\end{tabular}

Therefore, outdoor as well as indoor air quality irrespective of ventilation becomes an important concern unless carefully studied setback distances are provided. In core urban areas, houses are generally built very close to the road even in developed counties. In later chapters of this thesis, examples are provided where residential buildings are located very close to urban busy roads in Canada. 
The practice of subjecting vulnerable receptors to traffic-generated pollution is much more apparent in developing countries. Many low-income people are living in slum areas. As an example, Dharavi is the largest slum in the world. It is situated in Mumbai, India. The total population in this slum area is even more than for some of the European countries. Figure 1-1 presents a view that land use activities near the road result in much vulnerability in slum areas.
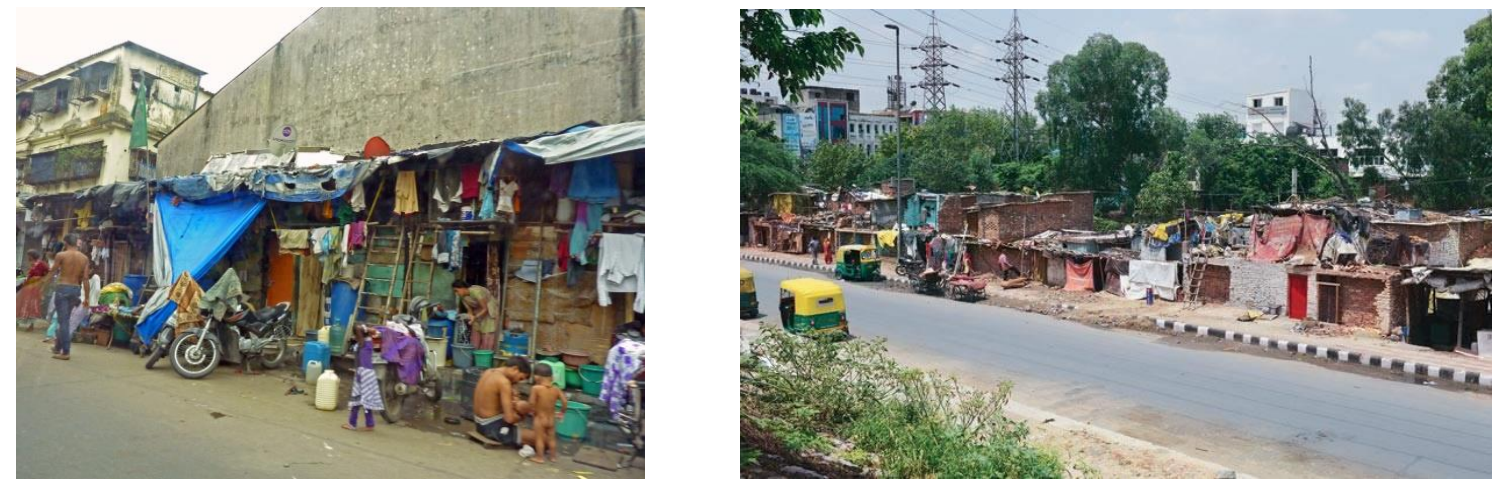

Figure 1-1 (a \& b): Land use activities in slum areas in India (Source: https://newdadsonthe block.com/2012/07/24/a-tour-of-mumbai-the-photosfrom-day-one/)

If the roadside pollution levels are higher than certain levels, these directly effect the human health. The activity level and duration are among the factors that explain these effects. Moreover, children are more vulnerable than adults because of their immature respiratory system.

On the solution side, technological advances to reduce emissions from vehicles are well known. However, even with the available technologies, there are limits to control roadside pollution levels. The use of electric vehicle (EV) in urban areas is encouraged in developed countries. For example, in the USA, there is a specific target of achieving thirty percent electric vehicles on urban roads in cities by 2030 (UEMI, 2014). This level of EV presence 
in the fleet is highly optimistic and hundred percent implementation of electric vehicles on road will take much time. Of course, implementation of EVs is nearly impossible in developing countries due to the budgetary constraints.

Consequently, it is prudent to expect that petroleum fuel based internal combustion engine vehicles will continue to operate on urban roads. This calls for proper planning of urban land use, especially roadside land use. In other words, sufficient space should be allowed between the road and buildings (e.g. houses). There is a need for research to investigate setback guides (criteria) for locating buildings.

\subsection{SETBACK DISTANCE AS A SOLUTION}

To avoid negative health effects, available ambient air quality standards for $\mathrm{CO}, \mathrm{NO}_{2}$ and $\mathrm{PM}_{2.5}$ should be met (Table 1-1). These have resulted from scientific studies carried out by very well known groups that are given the responsibility to recommend air quality criteria/standards. Although these standards are not identical for various countries, these are generally similar. Regardless of variation, this research aims to define the setback criteria for urban land use following the above noted air quality standards.

For planning urban land use, setback criteria are needed. These are discussed further in chapter two. For land use planning around roads, the setback is measured as the distance from the edge of the road to the buildings or location of human activity. In the core part of the city, setback criteria play an important role due to scarcity of space and high traffic levels. For low density suburban areas, due to low traffic volume and availability of space, there may not much of an issue to apply these criteria. However, it will be prudent to check 
if setbacks to be provided as a part of site plans will enable the achievement of air quality standards. A brief introduction to the general subject of setbacks is in order here and more explanation is provided in the following chapters. In the current practice, the municipality specifies location of building with respect to the road. Although there are considerations for providing sidewalks, street furniture, etc., no attempt is made to take into account air quality. To protect human health from emissions generated by the road vehicles, a new criterion is needed to provide guidance to urban planners.

The current reality is that urban planners attempt to increase land use density and build more residential buildings close to road to accommodate high population growth. At the same time, it is important to build such buildings in locations where people can inhale fresh air. In other words, planner should consider health impacts to those who live near roads. To maintain the quality of healthy life, it is important to follow the national ambient air quality standards. It is known that quality of health in a community closely relates to the social costs.

This research has defined the need to estimate roadside pollution levels. To go beyond this step, setback criteria based on air quality considerations are investigated for planning the location of new residential buildings. Although the need for a new criterion is recognized for urban land use design, the implementation of this criterion is entirely up to the municipality. The philosophical basis for investigating air quality-related setbacks is to advance the science and to provide guides for the use of planners that are tasked to take into account air quality in locating residential buildings near roads. 


\section{Chapter 2: RESEARCH OBJECTIVES AND SCOPE}

\subsection{KNOWLEDGE GAPS}

The intent of this research is to avoid the effects of vehicular emissions on human health by using setback distance as a policy and planning instrument. The specific topic to be researched covers the pollutant exposure to humans, who are in close proximity of the road. Well-researched methods that can estimate air quality at the recipient location will enable planners to take important decisions regarding suitable living places for vulnerable people.

The two main variables in this research are vehicular traffic and land use adjacent to roads. As a part of transportation planning, access and mobility functions of roads are defined, which in turn influence land use. In urban municipalities, transportation and land use are planned jointly and the land use planning decisions are made from the perspective of providing a balance between transportation demand generated by land use and the trafficserving capability of roads. The urban planner and the transportation engineer jointly define road cross-section and land use. The land use decision implies the use of land (e.g. residential, institutional) as well as intensity of development.

In land use planning and design, the location of buildings and other utilities for human activities is guided by setback distance criteria/standards, usually measured from the edge of the outer lane in central part of cities. Although for rural and suburban highways, the setback distance is measured from the edge of the right-of-way, in this research the setback 
distance is defined from the edge of the closest lane to the building or the location of human activity.

In the central city, due to lack of space, the residential and other buildings are usually located close to the road. Under "worst-case" condition defined by high traffic volume and low average operating speed, and speed and direction of wind, people near buildings and occupants of buildings may be subjected to high levels of emissions. Given that internal combustion engine vehicles will continue to be used for many decades and that further tightening of fuel consumption and emission standards, even in developed countries, is likely to be marginal at best, it is necessary to study the pollution contaminant level at the location of the receptor defined by setback distance and height.

At present, there is a lack of methods and information on how to estimate pollution concentrations under "worst case conditions" at specified locations around roads. Actual measurements can be taken at receptor locations of interest, but these measurements will reflect "prevailing condition" which may not be worst condition characterized by traffic jam, presence of heavy vehicles, and characteristics of wind. For the estimation of air pollution concentrations under worst-case condition, modelling and simulation is the correct approach.

In support of the above observation, Figure 2-1 can be examined. This figure is sourced from a recent Government of British Columbia publication on general guidelines for setback distance (Bauer et.al. 2012). Although graphs shown may not represent worst-case condition, these do suggest the need for a closer look at setback distances. This figure 
represents pollution concentration normalized to edge of pavement against distance. The pollution concentration levels were obtained from actual measurements.

The approach to study the profile of a drop in pollution concentration as a function of distance as illustrated in Figure 2-1 is a step in the right direction. These illustrations benefited from near-roadway air quality study based on a synthesis of the findings from real-world data reported by Karner, Eisinger and Niemeier (2010). However, for setting central city setback guidelines, it is not fine-grained. Moreover, height from ground has an influence in the form of reducing air pollution concentration. The research that resulted in Figure 2-1 did not include the effect of height.

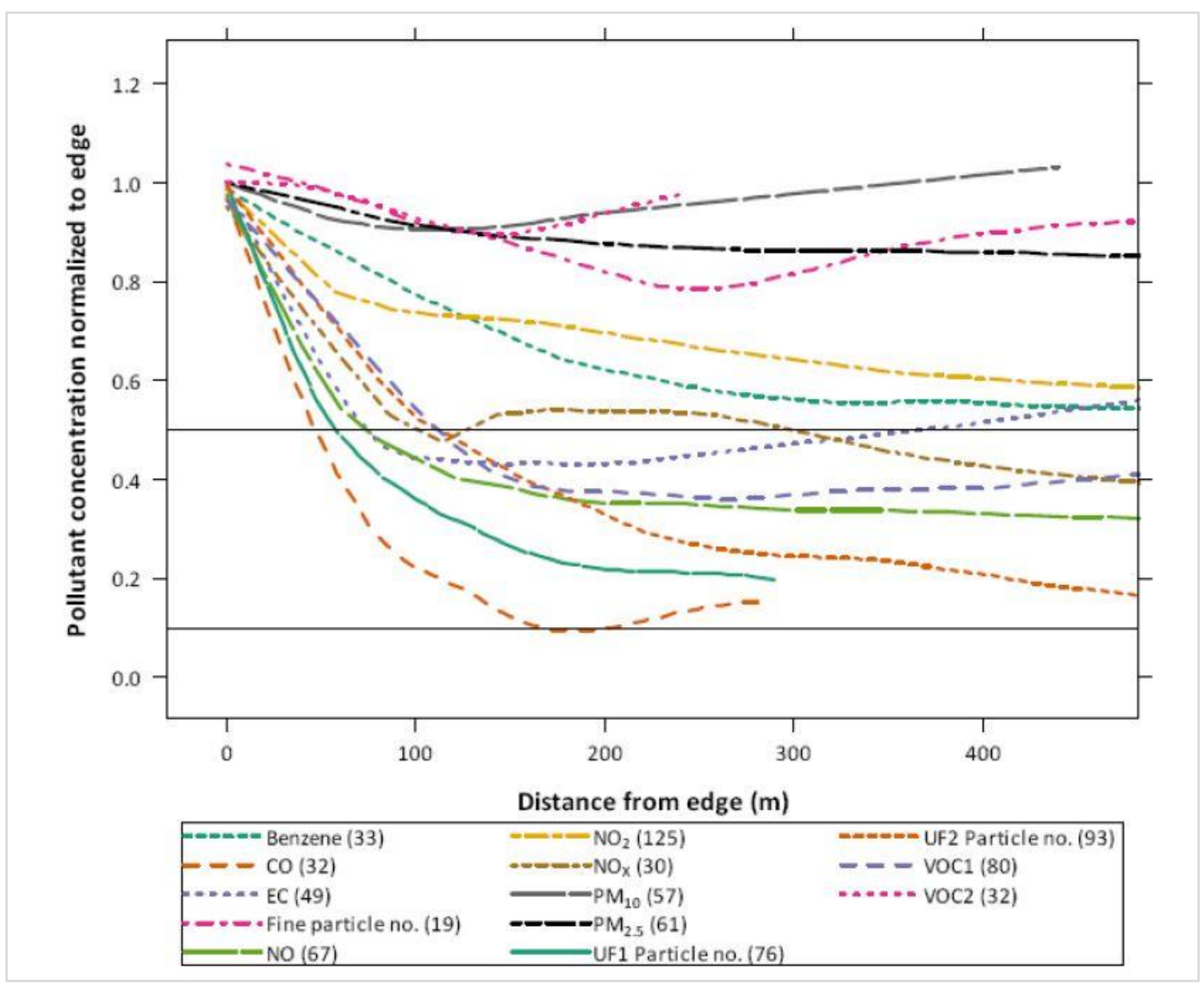

Figure 2-1: Air pollution concentrations vary with distances

(Source: Bauer et al 2012) 
There is a need to develop fine-grained guidelines potentially applicable at sites which are considered "in-fill/re-developed grey-field or brown-field" type of developments. The term "in-fill" represents a new development side, whereas re-development can be done by demolishing industrial areas such as grey-field or brown-field. For such developments, involving either new or re-use of land, much less than $50 \mathrm{~m}$ setback distances from roads may be realistic. Moreover, pollutant concentration for these setbacks should be studied under "worst-case condition", which was not considered in the above referenced study.

Figure 2-1 demonstrates that within 100 meters from a road, CO drops dramatically. It is also shown that nitric oxide (NO) drops gradually with respect of distance, but the behaviour of $\mathrm{NO}_{2}$ is different. $\mathrm{NO}_{2}$ drops for a certain distance and then increases due to photochemical reaction. The settling characteristics of particulate matter depends on size. $\mathrm{PM}_{10}$ drops progressively than $\mathrm{PM}_{2.5}$. A closer look at this figure suggests that there is a need for detailed research in such setbacks regarding road emissions.

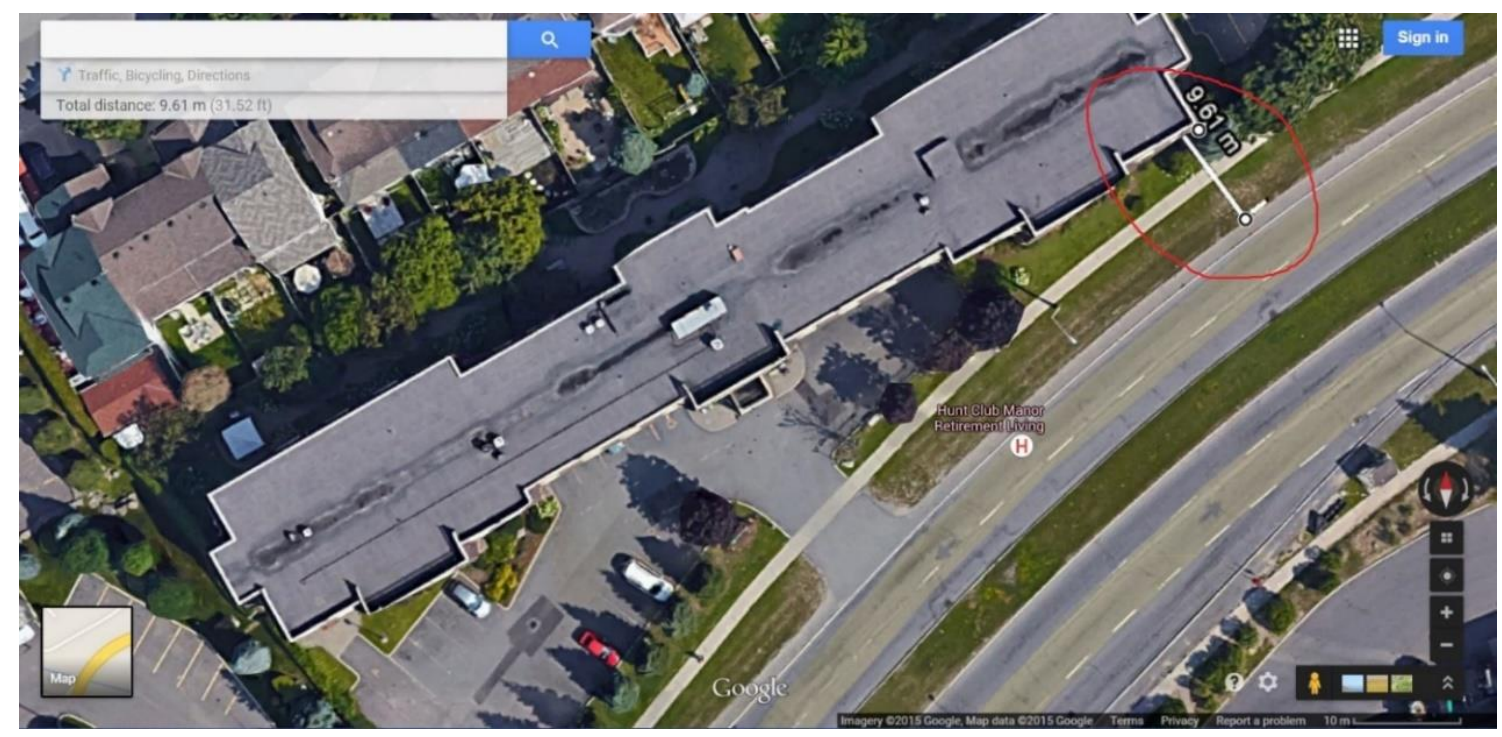

Figure 2-2: Retirement home located on Hunt Club Road, Ottawa (Source: Google map) 
Real world examples can be found that residential buildings with vulnerable residents are situated very close to busy urban roads. The building shown in Figure 2-2 is a retirement home, which is classified as sensitive land use where vulnerable residents live, and built very close to a major arterial road. Moreover, this building is very close to a major intersection. Although it is built far away from the CBD, but it is within the urban area. An examination of such examples suggests that there is a need to define setback guidelines guided by air quality criteria/standards.

\subsection{RESEARCH OBJECTIVES}

The objectives of this research are:

(1) To develop methodological capability to estimate pollution concentration at receptor locations in the vicinity of collectors, arterials, and freeways.

(2) To develop predictive models that can be used by planners to estimate worst-case conditions based pollution concentration at specified receptor locations.

(3) To demonstrate the application of developed models to predict pollutant concentration at specified distance away from road/freeway and at specified heights.

(4) To explain the application of developed models to find suitable setback distances for applicable roads and freeway.

\subsection{SCOPE}

Study of air quality is essential at all spatial levels. This research is focussed on a local scale and has investigated exposure to harmful emissions near urban collectors, arterials 
and freeways. It has produced methods for estimating air quality at locations of human activities (e.g. in living place in buildings) of sensitive receptors near roads. In addition, it is intended to define required setback distance based on national ambient air quality. As noted in the methodology of this research, the use of modelling and simulation tools is expected to define suitable locations for living areas near roadways, so that the health effects from road emissions are minimized.

In the following sections of this research, further explanations of the context and scope of research are provided.

\subsubsection{Land Use Planner's Point of View}

A number of land uses have been identified to warrant special care due to sensitivity of receptors to pollutants that have adverse health effects. These include residential areas, schools, retirement homes, and health care facilities. Land use planners attempt to plan such sensitive land uses according to available guidelines. But guidelines on setbacks from the perspective of air quality are not available.

\subsubsection{Definition of Setback Distance}

In land use planning, a building or other structure is set back from a street or road for a number of reasons. Historically, noise has been a reason and it continues to receive attention. The municipal government guidelines regarding setback distance exhibit much variation and are difficult to generalize. From the perspective of this research, in general, air quality has not been a consideration. In Canada, the Government of British Columbia guidelines of 2012 referenced earlier is an exception (Bauer et al 2012). As for definition 
of setback distance in the central part of the city, the setback is commonly defined as the distance between the front wall of a building and the edge of pavement.

The transportation departments of provinces have defined setback guidelines based on considerations other than air quality. According to the Ministry of Transportation of Ontario (MTO), "setback distance for buildings and fences shall be measured from the nearest extremity (wall of building including the wall or support, but not the eave, of any deck, veranda, porch, outside stairway, deck, canopy) to the property line" (Building and land use policy, MTO- 2009). According to the Ministry of Transportation of British Columbia, a minimum setback of 4.5 metres, for any building, mobile home, retaining wall or other structure, from all highway rights-of-ways is to be used. If there is access from another street, the allowed setback is 3 metres. (Ministry of Transportation, British Colombia).

According to Alberta Transportation, the general minimum setback for all development is 70 metres from the highway centre-line and no closer than 40 metres from the highway right-of-way boundary except where these distances must be increased to allow for highway widening (Govt. of Alberta, Transportation).

\subsubsection{Existing Setback Distance Definitions at Policy Level}

Land use planners approve a new plan for construction or re-construction of a building complex based on available guidelines. Developer follows the existing guidelines during planning stage.

\subsubsection{Setback Distance on Horizontal Alignment}


A number of factors (but not air quality) are commonly considered in planning setback distances. For example, these are important elements related to horizontal alignment in highway design. A necessary consideration is adequate sight distance on a horizontal curve in order to avoid the obstructions such as building, trees, cut slopes etc., along the inner side of the horizontal curve for safety and efficiency in driving.

\subsubsection{Setback Distance on Landscape Architecture}

In suburban/urban land use plans, setback distance is defined as a part of landscape architecture. The provision of appropriate setback insures building separations, yard areas that are usable, ample sun light, and enables substantial landscaping for screening, privacy, etc. According to design guideline by the City of Fremont, California, for small lot singlefamily residential developments in basically suburban settings, the required distance from the centre line of the road to the building is $36 \mathrm{ft}$ or $11 \mathrm{~m}$, whereas the setback from road edge to the building should be $16 \mathrm{ft}$ or $5 \mathrm{~m}$. On the other hand, as suggested by the Niagara area urban government, if available space permits, a 4-lane arterial road can be developed as shown in Figure 2-3.

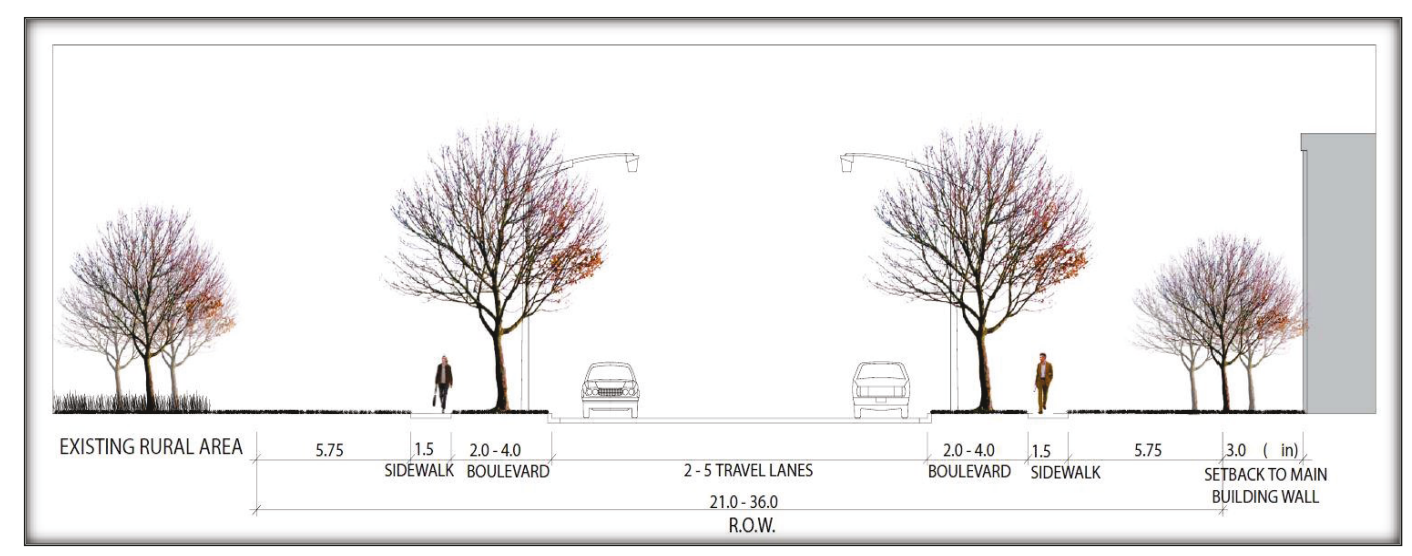

Figure 2-3: Design standard for 4-lane arterial road (Source: http://www.niagararestoration.org) 


\subsubsection{Setback Distance based on Noise generated by Road Vehicles}

Recent land use and transportation planning regulations include noise as an important factor. This is due to objection of residents to loud noise caused by road vehicle. A study report by the Montana Department of Transportation (March 2014) shows that $60 \mathrm{~dB}_{\mathrm{A}}$ noise contours vary from 100 feet to 375 feet from the roads, whereas $65 \mathrm{~dB}_{\mathrm{A}}$ noise contours are located at a minimum distance of 45 feet and maximum of 225 feet from the different roads.

\subsubsection{Required Setback Distance Criteria Based on Air Quality}

Urban land use planners follow setback distance criteria that were noted in previous sections of this document. However, in spite of known human health effects of emissions, there appears to be a general lack of research-based guidelines regarding setback distance. A check on available information on setback distance criteria suggests that in the past, these have not taken into account air quality.

However, several states in the USA have started to define and implement such criteria. For example, California State education department and natural resource agencies now consult with local air quality officials to identify suitable setback distances. Many school districts in the USA, such as the Los Angeles Unified School District (LAUSD), take into account effect of emissions in new school siting projects and define distance criterion (e.g., 1000 feet away from freeways, major roadways, and industrial facilities). Although these land use planning guidelines are a step in the right direction, there is a need to investigate setback guidelines for applicable land uses in central city areas and relevant suburban areas on the basis of scientific methods. 
This research has investigate setback distance guidelines for sensitive receptor locations based on road class, traffic volume and composition, traffic control system, and generation of pollutants from road vehicles. This research is intended to be mainly at the proposed site level, and setback distances will be studied on the basis of road classification (e.g. urban arterial, collector, etc.) and "worst case" condition including capacity-level traffic volume and wind characteristics. 


\section{Chapter 3: RESEARCH METHODOLODY}

\subsection{INTRODUCTION}

The literature survey, presented first in this chapter, is intended to gauge the state of knowledge in the field regarding research approaches and models. Next, capabilities of air quality model are presented and linkages between models are described. The pro and cons of models are discussed. In the last part of the chapter, the methodological framework is described and its constituent parts are defined. For enhanced appreciation of methods, model comparisons and applications are introduced.

\subsection{LITERATURE SURVEY}

In addition to literature reviewed here, the Appendix covers in detail emissions and health effects. In addition, when applicable, literature sources are provided throughout this thesis. In the literature reported here, among other key words, traffic-related exposure to primary emissions from motor vehicles and setback distance were used. The Health Effect Institute (HEI, 2010) reported specific scenarios with high densities of motor vehicles and people in urban settings where residences were in proximity to busy roadways. Studies examined gradients in pollutant concentration as a function of distance from busy roadways. These indicated exposure zones for traffic-related air pollution in the range of 50 to $1500 \mathrm{~m}$ from major roads and highways, depending on the pollutants and the meteorological conditions. Wald (2010) found that the highest effects occurred among people who lived within 300 
to 500 meters from highways and major roads. According to the author, that applies to 30 to 45 percent of the population of North America.

A study by Batterman et. al. (2014) developed and evaluated several metrics for characterizing exposure to traffic-related air pollutants for 218 residential locations that participated in the NEXUS epidemiology study conducted in Detroit. Exposure metrics included proximity to major roads, traffic volume, vehicle mix, traffic density, vehicle exhaust emissions density, and pollutant concentrations predicted by dispersion models. Information provided by the metric of kilometers traveled (VKT) per day within a $300 \mathrm{~m}$ buffer around each home, was reasonably consistent with the more sophisticated metrics. Dispersion model provided spatially and temporally resolved concentrations and the study method used separated concentrations attributable to traffic and other sources. The results suggested the potential for exposure misclassification and the need for refined and validated exposure metrics.

Exposure models were studied by Isakov et al. (2009) with the capability to predict the distribution of personal exposures to pollutants of outdoor origin. A variety of inputs were used including air pollution concentrations; human activity patterns, such as the amount of time spent outdoors versus indoors, commuting, walking, and indoors time at home; microenvironmental infiltration rates; and pollutant removal rates in indoor environments. They presented a methodology for combining multiple types of air quality models and linked the resulting hourly concentrations to population exposure models in order to enhance estimates of air pollution exposures. 
Rebolj \& Sturm (1999) provide up-to-date vehicular emissions information to the decision makers in an easily understandable form by using GIS. After the emissions were calculated, the dispersion of emitted substances was evaluated according to the dispersion model. The methodology produced results from crosswind distances away from the road. Based on the specific concentration of a specific substance, the visualization procedure interpolated the concentration buffer and generated a new polygon on the geographic map. This research suggests that overlay of relevant geographic themes with concentration buffer can be applied for evaluation of impacts of specific concentrations of specific substances on sensitive areas.

Pandian et al. (2009) researched urban air quality by emphasizing that composition of vehicles in the traffic stream among other factors affects vehicular emissions. They suggested that renewal of fleets, exclusive separate lane for buses, land use and traffic planning regulations might improve the air quality in urban areas. It can be appreciated that emission and flow models can be combined together for better estimates of emissions and may further be integrated with urban transportation and air quality planning system.

Zhu \& Zhang (2014) worked on characterizing ultrafine particles and other air pollutants in and around school buses. Their aim was to characterize UFP, $\mathrm{PM}_{2.5}$ (particulate matter $\leq 2.5 \mu \mathrm{m}$ in aerodynamic diameter), and other vehicular-emitted pollutants in and around school buses on Interstate Highway (Freeway) 405 in Los Angle, CA, USA. A total of 24 school buses were employed to identify particle number concentration (PNC), fine and UFP size distribution in the size range 7.6-289 nm, $\mathrm{PM}_{2.5}$ mass concentration, black carbon (BC) concentration, and carbon monoxide $(\mathrm{CO})$ concentrations. Four sub-studies were conducted. These are noted below. 
1. On-road measurement of in-cabin air pollutant levels;

2. Idling tests to quantify the contributions of tailpipe emissions from idling school buses to air pollutant levels in and around school buses under different conditions;

3. Evaluation of the performance of two retrofit systems, a diesel oxidation catalyst (DOC) muffler and a crankcase filtration system (CFS), on reducing tailpipe emissions and in-cabin air pollutant concentrations under idling and driving conditions; and 4. Test of high efficiency particulate air (HEPA) filter air purifier in order to evaluate the effectiveness of in-cabin filtration.

The characterization of pollutants and other observations drawn from the study were useful contribution to literature.

Afroz et al. (2003) reviewed air pollution and health impact in Malaysia that attracted attention of the government regarding the growing environmental concerns. This is basically a review paper and it concentrated on several big cities in Malaysia and monitored most of the pollutants. It confirmed that about 82 percent of air emission sources were motor vehicles, so land transportation was noted as a big threat for health impact. The results show that restricted activity days accounted for about $79.3 \%$ of the health damage cost while asthma attack contributed $10.7 \%$ to the total health damage cost. Consequently, production opportunities were idled during workdays as workers were in the hospital and on sick leave. The total health damage cost was assessed to be significantly high and losses were estimated to be RM 4.3 million (approx. 1.02 million U.S. dollars).

Brown \& Affum (2002) assessed the environmental effects of road traffic plans. A travel demand model, often called TRAEMS (TRansport planning Add-on Environmental Modelling System), was used with the intent to obtain information for the design of 
transport networks that allow optimum and efficient movement of traffic. TREAMS is capable of enabling planners to test transport-related environmental impacts at the same time as they are testing the traffic carrying efficiencies of network plans. This paper reported the effect of constructing a bypass on the existing network. Results showed about 14.7\% increase in vehicle kilometers travelled (VKT) between 1995 and 2011 with the construction of the bypass, whereas without bypass the VKT increased only $10.5 \%$. The $\mathrm{NO}_{\mathrm{x}}$ emission increased due to an increase of VKT. However, the bypass scenario improved noise emission. The results were demonstrated on the road networks of inner Brisbane City using GIS environment.

Bachman et al. (2000) have reported GIS-based modeling approach called the Mobile Emission Assessment System for Urban and Regional Evaluation (MEASURE), which provides researchers and planners with a means of assessing motor vehicle emission reduction strategies. They also compared MEASURE and MOBILE-5a software in terms of differences in their emission rates. In this comparison, the regional fleet distribution was used to estimate emissions for Interstate Highway Level of Service LOS-A to F. Mean emission rates in $\mathrm{g} / \mathrm{s}$ were within $20 \%$ of each software for LOS A. They reported that MEASURE emission rates were 50\% higher than for MOBILE for LOS B and C, and twice as high for LOS D and E. However, emission rates were back to within $20 \%$ for LOS F.

The authors explained the reasons for differences as follows. Since MEASURE's functions take into account the effect of accelerations at high speed, its emission rates were much higher for moderate congestion levels where high speeds and variable acceleration are experienced due to increased vehicle interaction. MEASURE has already shown to be capable of analyzing policies, because of the realistic scenarios adopted in this model. As 
an example mentioned by the authors, MEASURE was already applied in Atlanta by the Georgia Department of Transportation to evaluate the emission impacts of proposed intelligent transportation systems (ITS) projects. As for emission studies, the authors noted that progress has been made in reduction of mobile emissions. They expressed their view that there will be a need to gather comprehensive spatial and temporal distributions of emissions, especially for urban areas. For this purpose, they emphasised the role of GISbased emissions modeling framework.

The literature review indicates that most references are on traffic related pollution. However, there is an evidence of application of GIS-based methodology to spatial distribution of emissions from a broader level inventory to gridded small area level (Dalvi et al., 2006). The authors point out that their methodology makes it possible to distinguish between high and low emission regions at a finer scale than was possible with conventional methods. The results provide detailed information on emission "hot spots" and the relative contribution of various sources.

Nijkamp (1994) explored roads in terms of environmental sustainability, with particular emphasis on removing bottlenecks that prevent the achievement of policy objectives of reconciling the economic interests of the transport sector and environmental quality. Several arguments that were supported by empirical evidences from various countries are put forward to show current megatrends in transportation that are at odds with sustainable development and lead to high social costs. This research discussed a variety of policy strategies to improve the current situation. 
Jayaratne et al. (2009) assessed the increase in various emissions from motor vehicles during a stop-and-go driving mission. In literature, driving mission implies that the motor vehicle was travelling at a steady speed; a stop was made at a crossing and then accelerated from the stopped position. Emissions were approximately 13 times higher for this stopand-start mission than the condition where vehicles do not need to stop and they passed at their cruising speed without stopping. The authors also mentioned that the highest emissions occurred near the crossing within 5 meter of either side of the crossing, and the value was approximately 80 times higher than at the cruising speed.

A research study by Wang et al. (2008) produced information in support of decisionmaking process, such as air quality impact analysis, and human health assessment. Their research study required spatial modelling of traffic-induced air pollution dispersion in urban areas at street level. The 3D GIS environment enabled the visualization of pollution levels in the form of maps, in both planar and non-planar view. The visualization facility for better understanding by the planner improved interpretability. Hot spots, where the highest pollution occurs, were shown on a colour map. In non-planar view, variation in pollution was presented along building facades. Furthermore, researchers emphasised the incorporation of vertical dimension of an impact area, including the number of floors affected. The authors presented the variation of vertical pollution concentration using GIS environment in an Asian mega city.

\subsection{REVIEW OF AVAILABLE MODELS}

The available air pollution exposure models that are used to study health effects are reviewed in this section. These models have their strengths and weaknesses in terms of 
technical, financial and temporal features. Most of the models are intended for use within cities. Surrogate measures, such as distance to roads, have been related to major health effects (Hoek et al., 2002). In the last part of this section, empirical comparisons are presented and future directions of research are noted.

\subsubsection{Proximity Models}

Proximity models usually enable a quick assessment of air pollution's health effect based on the closeness to the source of pollution. Jerrett et al. (2005) used buffers at different distances from major roads to assess distance decay of concentration (i.e. 0-50, 51-100, and 101-150 m). English et al. (1999) implemented a traffic emissions model and combined this with circular buffers around the subjects' home. A study on adult asthma in Hamilton by Jerrett et al. (2001a), found that women, aged 20-44 years, within $50 \mathrm{~m}$ of a major road were associated with a 50\% increased risk of reporting asthma symptoms. Although the proximity model is popular within the research community, the main disadvantage of such models is that parameters affecting the dispersion and physicochemical activity of pollutants are not considered. These models are limited to the statistical association of traffic activity and possible risk of health effect.

\subsubsection{Interpolation Models}

Interpolation models based on deterministic as well as stochastic geo-statistical techniques are used to estimate the concentration of pollutants at sites other than the location of monitoring stations. The most common geo-statistical techniques used in the air pollution field are 'kriging' methods (Jerrett et al., 2001a). These methods are known as optimal interpolators because of their best linear unbiased estimate (BLUE). Mulholland et al. 
(1998) analysed the spatial and temporal distributions of ozone in the 20th-county. Atlanta metropolitan area used this technique to generate concentration levels over the study area. Jerrett et al. (2001a) modelled total suspended particulates (TSP) in Hamilton, Canada by using this technique. Ritz et al. (2000) applied a modified Theissen triangulation for a number of pollutants to assess the health effects of pollution on pre-term birth in Southern California. They assigned pollution values to zip code locations within $3.2 \mathrm{~km}$ ( 2 miles) of the air quality monitor.

Interpolation techniques have an advantage over proximity models due to their use of real pollution measurements in their computation of exposure estimates. If implemented correctly, they can provide credibility to the analysis by quantifying the level of exposure difference between subjects and in computing dose-response relationships (Mulholland et al., 1998; Jerrett et al., 2001b). These models are beneficial for estimating pollution concentration over several time intervals, subject to the availability of a number of measurement periods. For the implementation of a geospatial model, improved hardware, spatial statistics software, and appropriate expertise are mandatory. These requirements have cost implications and render these models to be most expensive among proximity models.

\subsubsection{Land Use Regression Models}

The land-use regression methodology provides an empirical approach for explaining and predicting pollution concentrations at a given site based on surrounding land use and traffic characteristics. Regression mapping is a practical approach for an assessment of exposure to traffic-related pollution (Briggs et al., 1997; Lebret et al., 2000). A calibrated least- 
squares regression model can predict pollution surfaces. For calibrating such a model, pollution monitoring data and existing exogenous independent variables are essential. Two studies (Briggs et al., 1997; Lebret et al., 2000) were carried out as a part of the Small Area Variation in Air pollution Health $(S A V I A H)$ Project that examined traffic-related air pollution in four European cities (Amsterdam, Huddersfield, Prague, Poznan). A revised model described by Briggs et al (1997) was employed to investigate traffic-related air pollution in four UK urban areas (Huddersfield, Hammersmith and Ealing, Northampton, and Sheffield).

The cost of developing land-use regression models is higher than for other models reviewed earlier. Once calibrated, these are relatively inexpensive to implement and can provide reliable estimates of traffic-related air pollution when adequate land use, transportation, and pollution monitoring data are available. The limitation of the regression model arises from its area-specificity. Moreover, Briggs et al (1997) have argued that it is possible to pool effects into a random effects framework within areas of relative homogeneity of land use, meteorology, and vehicle mix.

\subsubsection{Dispersion Models}

Literature sources are available that serve as good practice guide for atmospheric dispersion modelling. For example see Ministry of the Environment of New Zealand (2004). Likewise, on the related subject of air pollution exposure models, literature sources are available on model review and evaluation (Jerrett, Arain, Kanaroglou et al 2005).

In this research study, it was considered essential to decide on the use of a Gaussian plume model or a street canyon model or a Computational Fluid Dynamics (CFD) model for the 
dispersion part of the study. The strengths and weaknesses of each approach were studied and it was decided that due to the worst-case condition philosophy which in part is based is based on very calm wind speed, the canyon and CFD models were not applicable. Therefore, software containing the Gaussian plume model was selected for use in this research study.

Most dispersion models are based on Gaussian plume equations (Bellander et al., 2001). In their formulation, the following are the variables: deterministic processes making use of data on emissions, meteorological conditions, and topography. Their outputs are spatial exposure estimates of air pollution concentrations. In recent research and applications, dispersion models are popular due to their conjunction with GIS. When these models use the topography of the study area, an abstraction of the road network and its traffic is formed, which is a more realistic representation of the area. Available sources indicate that these models have been used for different kinds of pollutants such as TSP (Bartonova et al., 1999), nitrogen oxides $\left(\mathrm{NO}_{x}\right)$ (Bartonova et al. 1999; Bellander et al., 2001) and $\mathrm{CO}$ (Benson, 1989).

The Integrated Model of Urban Land-use and Transportation for Environmental analysis (IMULATE) was used to estimate $\mathrm{CO}, \mathrm{NO}_{x}$ and hydrocarbon (HC) emissions from passenger cars for all the links of the transportation network of Hamilton, Ontario (Anderson et al., 1996). This study estimated traffic volumes at the link level and then used MOBILE5C through an automatic interface to translate traffic volumes into emissions. The MOBILE5C is the Canadian equivalent of MOBILE5 that was developed by US Environmental Protection Agency. Potoglou and Kanaroglou (2002) applied the emissions 
output of IMULATE model in the California Line Source Dispersion model (CALINE) and displayed the results using GIS software.

The resulting receptor locations, derived from the Anderson et al. (1996) study's emission estimates were displayed by applying a weighted kernel estimate to the CALINE output to show a density of emissions in part per billion per square kilometre. A follow-up study of 16,209 men reported by Nafstad et al. (2003) found an increased risk of lung cancer for a $10 \mu \mathrm{g} / \mathrm{m}^{3}$ increase in $\mathrm{NO}_{2}$ at the home address. Based on results, they concluded that urban air pollution might increase the risk of developing lung cancer.

In a 2015 paper, Shekarrizfard and Hatzopoulou presented an application of fine-scaled dispersion modelling method. Their study used a site in Montreal to model NOx by using a transportation and emissions model. They found a reasonable performance of the dispersion model with 0.77 correlation between simulated and observed concentrations in January.

Although the canyon model and the CFD mode are not used in this research, a brief introduction is provided for the information of the reader. These models calculate emissions per street section. An approach is developed that links the multi-agent based transport model (MATDim) with the calculation of air pollution using the Operational Street Pollution Model (OSPM). CALPUFF calculates emissions per street section based on dispersion modelling with consideration of spatial resolution of land uses. It considers complex building structures in urban areas and therefore air circulation effects due to urban land uses are taken into account. However, in this research, due to worst-case condition of very calm wind, this model is not of assistance (Hulsmann, Gerike, and Ketzel 2014). 
The Computational Fluid Dynamics (CFD) model can represent canyon effects. The choice of CFD approach (mainly the Reynold-Averaged Navier-Stokes (RANS) and Large-Eddy Simulation (LES) model) depends on the computational cost, the accuracy required and hence the application context (Cai and Blass, 2016). However, given the very calm wind conditions to be modelled in this research, the use of the CFD model cannot be justified.

A review of modelling air quality in street canyons is presented by Vardoulakis, Fisher, Pericleous and Gonzalez-Flesca (2014). Their approach is applicable to high pollution levels that can be experienced in conditions of reduced natural ventilation due to very highdensity land uses and high traffic conditions. Since these conditions do not fully apply to this research, this modelling approach is not of immediate interest.

\subsubsection{Integrated Meteorological-Emission Model}

In integrated meteorological-emission (IME) models, meteorological data can be applied to the chemistry modules at every time step of a simulation. However, due to their high implementation cost, data requirements and complexity, IME models have not been used for studies attempting to link air quality to health in spite of their considerable potential, especially for highly populated areas. An example of IME modelling framework is United States' CALPUFF (Scire et al., 1997). The advantages of integrated meteorologicalemission model over dispersion model have been recognized as the capability to incorporate chemical transport of pollutants and the ability to represent complex pollutant pathways that lead to secondary pollutants, such as ozone and secondary particles.

Dispersion models and IME models are considered more sophisticated and reliable than other models. These models can be used at the regional and the intra-urban scale. Their 
applications call for substantial amount of data on emissions and meteorology. In addition, these models require improved management tools, specialized software (i.e. GIS, dispersion software, and their integration) and computer hardware that are capable of handling, storing and processing these data. Furthermore, there is a need for specialized personnel trained in GIS, statistics, mathematics, and computer science. Given these requirements, their cost of implementation is significantly higher than for other models.

\subsubsection{Hybrid Models}

Hybrid models combine personal/household or regional level exposure monitoring with other air pollution exposure models. At the detailed level, personal monitoring enables a direct measurement of exposure of subjects to air pollutants. This is a very useful attribute. However, the drawback of such models is the high cost of implementation. For this reason, personal monitoring is often used within a "hybrid framework" as a complement to one of the other model types. Most studies that used these models were conducted at intra-urban scale (Liu et al., 1997). Some studies have used personal monitoring methods in conjunction with fixed outdoor stations to compare their difference in derived health outcomes (Liu et al., 1997; Kramer et al., 2000; Mukala et al., 2000).

As for methodology, these empirical models employed a mixture of multiple linear (Liu et al., 1997; Mukala et al., 2000) and logistic regressions (Kramer et al., 2000) to link exposure estimates to health outcomes. Schoolchildren are the primary receptor groups with the exception of the work done by Liu et al. (1997), which treated children and adults as a collective group. Interested reader may wish to refer to the following for site-specific findings: Kramer et al (2000), Mukala et al (2000). 


\subsubsection{Comparison of Methods}

Collins (1998) calculated an annual mean of $\mathrm{NO}_{2}$ at eight monitoring locations and then calculated mean pollution values from 80 monitoring sites, but excluded those eight permanent locations. The data enabled comparisons of the $\mathrm{NO}_{2}$ pollution surfaces estimated using kriging, hybrid and land-use regression techniques. Her analysis revealed that land-use regression techniques predicted $\mathrm{NO}_{2}$ levels most accurately with an $\mathrm{R}^{2}$ of 0.82 , compared to kriging and a hybrid approach yielded $\mathrm{R}^{2}$ of 0.44 and 0.63 , respectively.

de Hoogh et al. (2002) compared concentrations of $\mathrm{PM}_{10}$ and $\mathrm{NO}_{2}$ obtained from modelling approaches to commonly used source-activity indicators based on traffic and road characteristics. In the case of proximity measure and regression approach, $30 \%$ were classified in the same quintile, while $26 \%$ of the sites were similarly classified for proximity and dispersion approaches. Only $30 \%$ of the postal codes were classified within the same quintile when comparing regression and disruption approaches. The highest comparability was found at $68 \%$ for dispersion modelled $\mathrm{NO}_{2}$ and $\mathrm{PM}_{10}$.

On the basis of the then current state of knowledge of intra-urban (i.e. within city scale) air pollution assessment, Jerrett et al. (2005) evaluated models and found a growing emphasis on increasingly sophisticated land use, dispersion, and integrated meteorological models. Beyond refinements in these models, researchers suggested the need for more research in three areas: (1) remote sensing models, (2) mobility or activity-space analysis, and (3) personal monitoring to cross validate estimates and improve understanding of the role that measurement errors play in risk assessment models. 
If accuracy and cost factors are favourable, remote sensing for exposure assessment appears to be a promising avenue to implement extensive ground monitoring programs. This method relies on high-resolution satellite observations in combination with existing fixed-site monitoring stations. Mobility or activity-space analysis is an interesting area of research. Time-activity studies have found that individuals spend an average of about $66 \%$ of their time at their residential location (Leech et al., 2002). However, an important question remains, "where" individuals spend rest of the time? A related question is that who is likely to be impacted during temporal peaks in air pollution (e.g., during p.m. peak travel period). Potentially, a detailed study of "spatial and temporal" facets of human activities may lead to answers for these questions (Axhausen et al., 2001). In the case of validation, predictions against personal exposure measurements is desirable. Although in aggregate form, the daily averages correlate highly with central monitor estimates, sitespecific comparisons are desirable (Mage et al., 1999).

\subsubsection{Integrated Models for Policy Analysis}

The review of literature suggests that the state of knowledge in modelling pollution dispersion and population exposure within GIS environment has advanced to a sufficient degree so that policy scenarios can be simulated. Amirjamshidi et. el. (2013) have reported an integrated model for microsimulating vehicle emissions, pollution dispersion and population exposure. They applied their research to the Toronto Waterfront Area.

An introductory research study to integrate traffic, emissions, and dispersion processes was reported by Ma, Huang, and Koutsopoulos (2014). They describe a common distributed computational framework that makes it efficient to quantify and analyze correlations 
among dynamic traffic conditions, emission impacts, and air quality consequences. A model calibration approach is proposed in this paper when on-road or in-laboratory instantaneous emission measurements are not directly available.

A study of air quality assessment, namely CO pollutant, was carried out in 2003 for Lisbon at the local scale. The analysis interlinked two numerical tools (i) the Transportation Emission Model for Line Sources (TREM) and (ii) the Local Scale Dispersion Model (VADIS) (Borrego, Techepel, Costa, Amorim, and Miranda (2003). Another Lisbon air quality management study applied integrated modelling approach to road traffic emissions. The integrated models include VISUM (applied to private and public transport), TREM and Variable Dispersion (VADIS) model for characterizing the traffic fluxes, to quantify the emission amounts, and finally to evaluate the air quality (Borrego, Tchepel, Salmim, Amorim, Costs and Janko, 2004 and 2010).

The above reviews have helped in defining the research framework and methodology presented below.

\subsection{RESEARCH FRAMEWORK AND METHODOLOGY}

As previously noted, this research is intended to investigate road traffic-generated air pollutants as a factor in defining land use and associated building setback guidelines along urban collectors, arterials and freeways. The basic features of the research framework are presented in Figure 3-1. This research relies primarily on modelling and simulation approach. The following is an outline of the components of the research framework. In the following chapters, full details are provided. 


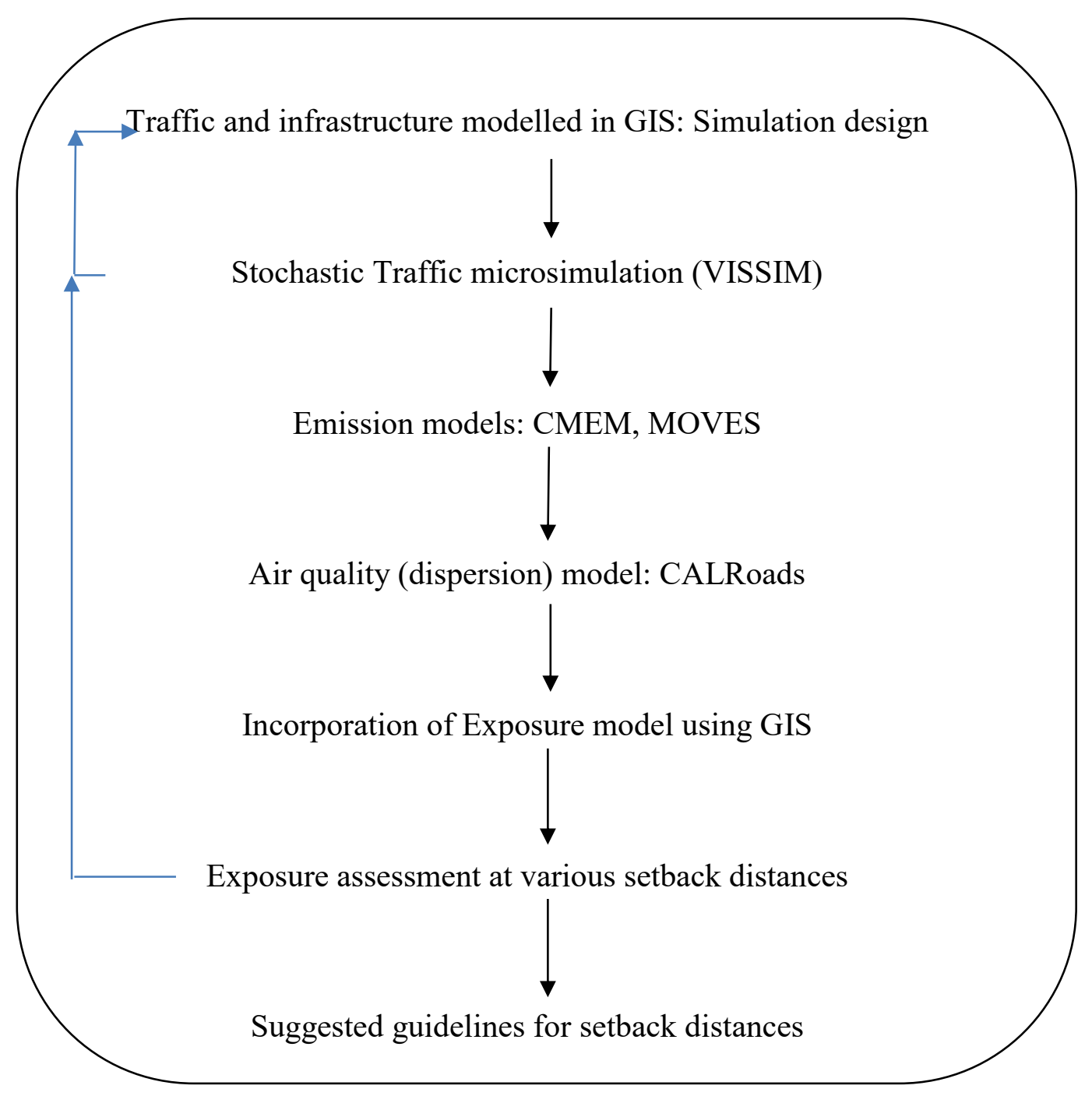

Figure 3-1: Research framework

According to this research approach, a stochastic traffic micro-simulator (i.e. VISSIM) was used to generate capacity-level traffic flow and a microscopic emission estimator (CMEM) was used that takes traffic trajectories as input. Due to limited capability of the microscopic emissions model in terms of pollutants, the MOVES model was used to estimate emission that is not obtainable from the microscopic model. The emissions outputs were used by CALRoads software (modified by Lakes Environmental, based in Waterloo, Ontario) to 
find out how air quality pollutants are transmitted horizontally and vertically. The GIS software was used to provide geographic addresses of pollutants' travel.

Following numerous simulations, a large data bank became available on characteristics of roads, traffic, traffic flow, emissions, travel of emissions, etc. In order to find out relationships between inputs (i.e. road, traffic, distance, height, meteorology etc.) and outputs (i.e. emission intensity at specified points and contours), predictive models (i.e. statistical equations) were developed. To supplement statistical models, in a few cases, Artificial Neural Nets (ANN) models were trained and validated. These models are known to work well as predictive methods for tasks of this nature, which involve multicollinearities and non-linearity.

Data needed for modelling and simulation tasks were obtained from municipal, provincial and federal government sources. Also open sources provided useful data. These include land use, road infrastructure, traffic control, capacities of various road types, traffic composition, etc. Although those data were used for validation of model results with field data, the data required for simulation runs were prepared with statistical design concepts and methods. In order to run the air quality model for typical roads and intersections, the meteorological data were acquired. These data were analysed for selected sites and were used to make decisions regarding "worst case" condition.

The following sections provide brief descriptions of the integration of three different simulation models applied as a part of the research framework. Details of models are presented in the following chapters. 


\subsubsection{Traffic Micro-Simulator}

The stochastic traffic micro-simulator model used in this research is VISSIM, developed and marketed by the PTV Company. VISSIM provided the study results of traffic flow characteristics on a one-second interval basis. The input variables were road infrastructure, vehicles on the road, traffic control devices and driver characteristics. The presence of onroad traffic in every state was generated on a second basis. The numerous outputs enabled the characterization of trajectories of vehicle motion. Researchers are generally interested in on-road performance studies for evaluation of implemented projects, but the purpose of the using VISSIM this research was to generate trajectories that represent instantaneous speed, acceleration, etc. for use in the estimation of emissions.

\subsubsection{Emissions Models}

The second model used in this research is an emission model, which takes input data from the traffic model. The output of this model is composite emission factor (CEF). The CEF is the emission rate in terms of amount of pollutants per unit distance travelled.

In the research framework, the outputs from the traffic model were used as input data in the emission model, following slight format modification for compatibility with the emission model.

It is noted in the next chapter that estimation of on-road emissions from road vehicles is a challenging task. Moreover, emission estimates were based on the specific design of road infrastructure, which added further complexity. This research used a microscopic level emission model, namely the Comprehensive Modal Emission Model (CMEM). The 
CMEM model is developed by the University of California, Riverside Campus. As this model is not fully developed regarding some emissions, this model could not carry out the estimation of dust pollution rate. Therefore, the US EPA MOVES model was used for estimating particular matter emission rate.

As explained later in this chapter and in Chapter 5, each emission model has limitations. However, the use of the two models, namely CMEM and MOVES, enabled this research to be completed.

\subsubsection{Air Quality (Dispersion) Model}

The source-oriented air quality models are intended to estimate pollutant concentrations at receptor site. Such an air quality dispersion model is used in this research. Although dispersion model can handle the emission sources from point, line, or area, the line source (i.e. traffic lanes) dispersion model (CALINE) is used in this research to analyze the effects of traffic.

CALINE predicts air quality impacts of pollutants on and near roadways. It is a component of CALRoads View, an air dispersion-modeling package. It combines the following models into one seamless integrated graphical interface: CALINE4, CAL3QHC, and CAL3QHCR. These software are based on US EPA models and the EPA uses these for their studies on a routine basis. These can predict air pollution concentrations of carbon

monoxide $(\mathrm{CO})$, nitrogen dioxide $\left(\mathrm{NO}_{2}\right)$, particulate matter $(\mathrm{PM})$, and other inert gases from idling or moving motor vehicles. 
The inputs of an air quality model are traffic, emission rate, and meteorological data. The output of the model is pollution concentration at receptor sites. This model has the ability to incorporate spatial distribution of earth surface. So, the pollution concentrations can be estimated either at a specific receptor or in the form of contour line surrounding the pollutant source.

The CALINE-4 module is designed to predict air concentrations of carbon monoxide (CO), nitrogen dioxide $\left(\mathrm{NO}_{2}\right)$, and suspended particles near roadways. Options are available that cover most components of traffic facilities (i.e. near intersections, parking lots, elevated or depressed freeways, and tunnels/canyons).

The CAL3QHC module has the capability to estimate total air pollutant concentrations near highways from both moving and idling vehicles. This model can also handle queues at signalized intersections.

The CAL3QHCR module is a more advanced version of CAL3QHC that can process up to a year of hourly meteorological data. This model can work with vehicular emissions, traffic volume, and signalization (ETS) data for each hour of a week (Cal R, 2014).

The inputs to these models consist of traffic and meteorological data. The inputs vary from location to location, and pollutant concentrations are based on source characteristics. The output provides the pollutant concentrations at specific locations of a receptor in terms of parts per millions (ppm) or micro-gram $(\mu \mathrm{g}) / \mathrm{m}^{3}$. 


\subsubsection{Exposure Model}

Population-based human exposure models are required to predict the distribution of personal exposures to pollutants of outdoor origin using a variety of inputs. These include air pollution concentrations; human activity patterns, such as the amount of time spent outdoors versus indoors, commuting, walking, and indoors at home; micro-environmental infiltration rates; and pollutant removal rates in indoor environments (Isakov, 2009). Specifically, population exposure models that can permit study of hourly concentration i.e. (the Hazardous Air Pollutant Exposure Model [HAPEM] or the Stochastic Human Exposure and Dose Simulation [SHEDS] model) could be used to estimate air pollution exposures.

The concentration of pollutants changes from outdoor to indoor based on filtration rate. The filtration rate differs due to ventilation process if the windows are closed and close to outdoor concentrations if the windows are open. Isokav (2009) studied the distribution of personal exposures to pollutants of outdoor origin. Zhu (2014) measured in-cabin pollutant concentrations for school bus by using Q-trak indoor air quality monitor. The air exchange rate can be calculated using the following formula:

$$
\lambda=\frac{1}{t-t_{0}} \ln \left(\frac{C_{\text {in }}(t)-\overline{C_{\text {out }}}}{C_{\text {in }}\left(t_{0}\right)-\overline{C_{\text {out }}}}\right)
$$

Where, $\lambda$ is the air exchange rate (per hour), and $t_{0}$ and $t$ are the beginning and end of the sampling interval (in hours); the averaged ambient CO concentrations (ppm) for the period from $t_{0}$ to $t$ is $\mathrm{C}_{\text {out }}$; the indoor $\mathrm{CO}$ concentrations ( $\mathrm{ppm}$ ) measured at time $t_{0}$ and $t$ are indicated as $\mathrm{C}_{i n}\left(t_{0}\right)$ and $\mathrm{C}_{i n}(t)$, respectively. 
It is noted in the introduction section that the prediction of the distribution of personal exposure is not intended in this research. This research deals with the reception level concentration with the use of the dispersion model in association with GIS. This is in accordance with the objective of the research for prediction of concentrations at the receptor level. The intent here is to estimate concentration level as a setback planning factor. It should be noted that the effect of ventilation is not included in this research.

\subsection{CONSIDERATIONS AND CHALLENGES IN IMPLEMENTING RESEARCH FRAMEWORK AND METHODOLOGY}

The section describes the problems that were faced in conducting this research and approaches followed to overcome these problems.

(a) Defining the research boundaries and assumptions were difficult tasks at the planning level of the research methodology.

(b) Each of the computer simulation models has its own limitations. The drawback of those models are not only limited to the format of inputs and outputs, but also unit conversions and file modifications were challenging issues.

(c) For microscopic analysis, the stochastic traffic model required validation. Although default values have general validity since these were verified by the software developer based on data obtained from highly developed traffic network and freeway facilities, it was prudent to take the extra steps to verify the simulator for application in this research. 
(d) The input data collection and its analysis for model calibration, validation, and simulation runs are difficult tasks. Challenges in input data analysis are noted in this chapter. For validation of model results, field studies were conducted using several instruments. Road traffic movements were counted using video files obtained as part of field studies.

(e) The roadside pollution concentrations were recorded using gas analyzer and dust track. The use instruments was not free of challenges (e.g. displaying data, recording data, and understanding precision and accuracy).

(f) As a part of "worst case" scenario approach for estimating pollution concentration at the receptor level, capacity level traffic had to be used. In order to produce models that could be applied to future site planning tasks in Canada, USA and possibly other highly developed countries, detailed state of knowledge of methods had to applied.

In the following sections, selected challenges are explained in detail. These are technical problems, analytical problems, and rationale for simulation model applications.

\subsubsection{Technical Problems}

A number of technical problems were faced in the design of the road segments/networks that were to be simulated and defining of input data requirement for simulation models, etc. The limitations of the pollution measuring instruments and difficulties faced during field surveys are also technical difficulties that were overcome.

The simulation design platform implies typical road networks to be simulated. The challenge was to specify urban road segments, their intersections, and freeway segment for 
simulation purposes. The road network design is explained in detail in the simulation chapter. The difficulties related to input data requirements for simulation models and conducting field studies using pollution-measuring instruments are described below.

\subsubsection{Traffic Count Data}

Traffic count data for intersections was provided by the City of Ottawa and the City of Sault Ste. Marie (Ontario). Traffic data were also obtained by surveying several locations in Ottawa using video camera. The purpose was to capture traffic movements at the same time as pollution concentration instruments collected roadside pollution data. These data were intended for verification purposes.

For simulation design, the capacity level traffic volumes were calculated for road segments, intersections and freeway segments. Technical information was obtained on geometric design and signal control system for intersections. Although capacity level traffic was considered for each lane (or lane combinations) for simulation planning, the traffic input data were slightly different following the balancing of traffic at intersections. For balancing of traffic at the two ends of a road section, it was assumed that the traffic volumes in and out from the main street in between the major intersections are equal.

The air quality criteria and standards are defined for a single hour as well as for multiple hours. For multiple hour analysis, namely 8 hours, 24 hours, annually etc., hourly expansion factors (HEF) were required. The city officials provided daily and monthly expansion factors, but HEF was not readily available. The HEF varies with spatial distribution. The difficulties to prepare HEF are explained further in the next section. It is 
noted that in this research, simulations are run for the "one-hour" case only due to time constraints.

\subsubsection{Signalizing Data}

The signal data for an intersection includes cycle length, time split for direction and turning movements, etc. Although the signal system data were collected from city offices, the time slit and cycle length for simulation planning were assumed based on the practice in cities. The details of directional split and turning movement split are tabulated in Appendix Group-1.

\subsubsection{Vehicle Records}

Archived vehicle records are generally available that can be used to infer vehicle classes, especially the percentage of heavy-duty vehicles. However, updated vehicle records were not available from government sources. So, the yearly growth factor was used to update the record for target year. The vehicle composition is an important data item for calculating on road emission factor.

\subsubsection{Brief Notes on Background pollution concentration}

The pollution concentration data are available as open source from the Ontario Ministry of Environment and Climate Change (http://www.airquality ontario.com) or from Environment Canada website. The latest emission inventory report provides pollution concentrations for $\mathrm{CO}$ and $\mathrm{NO}_{\mathrm{x}}$ at the downtown Ottawa ambient air quality monitoring station, which is situated at 197 Wurtemburg Street (Ottawa). These were $0.208 \mathrm{ppm}$ and $18.7 \mathrm{ppb}$, respectively. 
In the air quality research, simulation models require background pollution concentrations. The background pollution concentration is explained further in Chapter 6 . The above noted concentrations reflect contribution of all pollution sources. Although such data are useful, these do not necessarily apply at various locations in the urban area.

\subsubsection{Meteorological Conditions}

Meteorological data are also available from government of Canada's website (http://climate.weather.gc.ca). The difficulty in the use of these data in this research was that they were not compatible with microscopic level studies. Field data collected by climate measuring instruments demonstrated that meteorological data vary from location to location, even within short distances, due to land features, buildings, infrastructure, etc.

For the result validation purpose, the field study areas were chosen in different locations in Ottawa. The meteorological data were obtained from available meteorological stations that were not in the same geo-locations but were the closest possible match with the study sites. Further, wind turbulence in the study area due to urban structure could not be accounted for at the microscopic level. However, rationale for data/estimates used are provided in the following chapters. These are believed to be acceptable for use in this research.

\subsubsection{Difficulties of Conducting Survey using Pollution Measuring Instruments}

The data collection near roadways using pollution-measuring instruments is a challenging task. It is difficult to identify suitable places to install pollution concentration collecting devices. Moreover, facing of adverse climate conditions during survey with lot of instruments is a challenge. Roadside pollution concentration depends on traffic volume on 
the road and meteorological conditions at study locations. The wind speed and temperature change with land use. The results verification chapter explains the approach to handling this difficulty.

Although emissions from the road traffic are the main source of roadside air pollution, the volume of road traffic fluctuates over time. The emission rate for a specific vehicle depends upon vehicle type, vehicle, age, and emission control device installed in the vehicle. In addition, features of the road, such as separate lane for turning, and directional and turning movement split in a complete signal cycle, are also responsible for varying emissions from individual vehicles.

\subsubsection{Limitations of Pollution Measuring Instruments}

The pollution measuring instruments are different for gas pollutants and dust track. The data displayed by the gas analyzer is shown in Figure 8-2. The precision of the data provided by the gas analyzer is too low. The CO results displayed in gas analyzer are in integer format, whereas $\mathrm{NO}_{2}$ results are provided in decimal format. Although the results are recorded in memory card inside of an instrument (attached in the Appendix), most records were missing and displayed zero values. Moreover, the format of data displayed in instruments for manual reading and for the downloaded data from these instruments were different. Anticipating the uncertainties of data processing from instruments, the field data were collected manually in 15 (fifteen) minutes intervals. 


\subsubsection{Analytical Problems}

Most of the input parameters are discussed in the Gaussian dispersion model chapter. The difficulties faced during the analysis of those input data are introduced in this section.

\subsubsection{Transportation Related Data}

Transportation related data consists of data on static components and data on mobile entities. The static data apply to road network geometry and the signal system. The infrastructure data or road network data are available in open source website, such as google maps, and these were downloaded using GIS platform. Traffic count data were provided by the City of Ottawa. The City of Ottawa records traffic movements for every 15 minute time interval for morning peak hours (i.e. 7:00 AM to 10:00 AM), noon times (11:30 AM - 1:30 PM), and afternoon peak hours (i.e. 3:00 PM to 6:00 PM). Additionally, 24-hr average total traffic was also provided. The signal system data were supplied by the above mentioned city offices.

The traffic movement or on road vehicle count data include turning movement, percentage of heavy-duty vehicles, etc. It was found that data gap had to be addressed using a video camera. As an example, data were available on morning and afternoon peak traffic as well as daytime off-peak traffic. However, this research required hourly traffic for a number of hours. Therefore, continuous traffic data collection filled that gap. The sample traffic data analysis for the Baseline Road link between Fisher Avenue and Prince of Wales Drive is shown in Figure 3-2 below. 


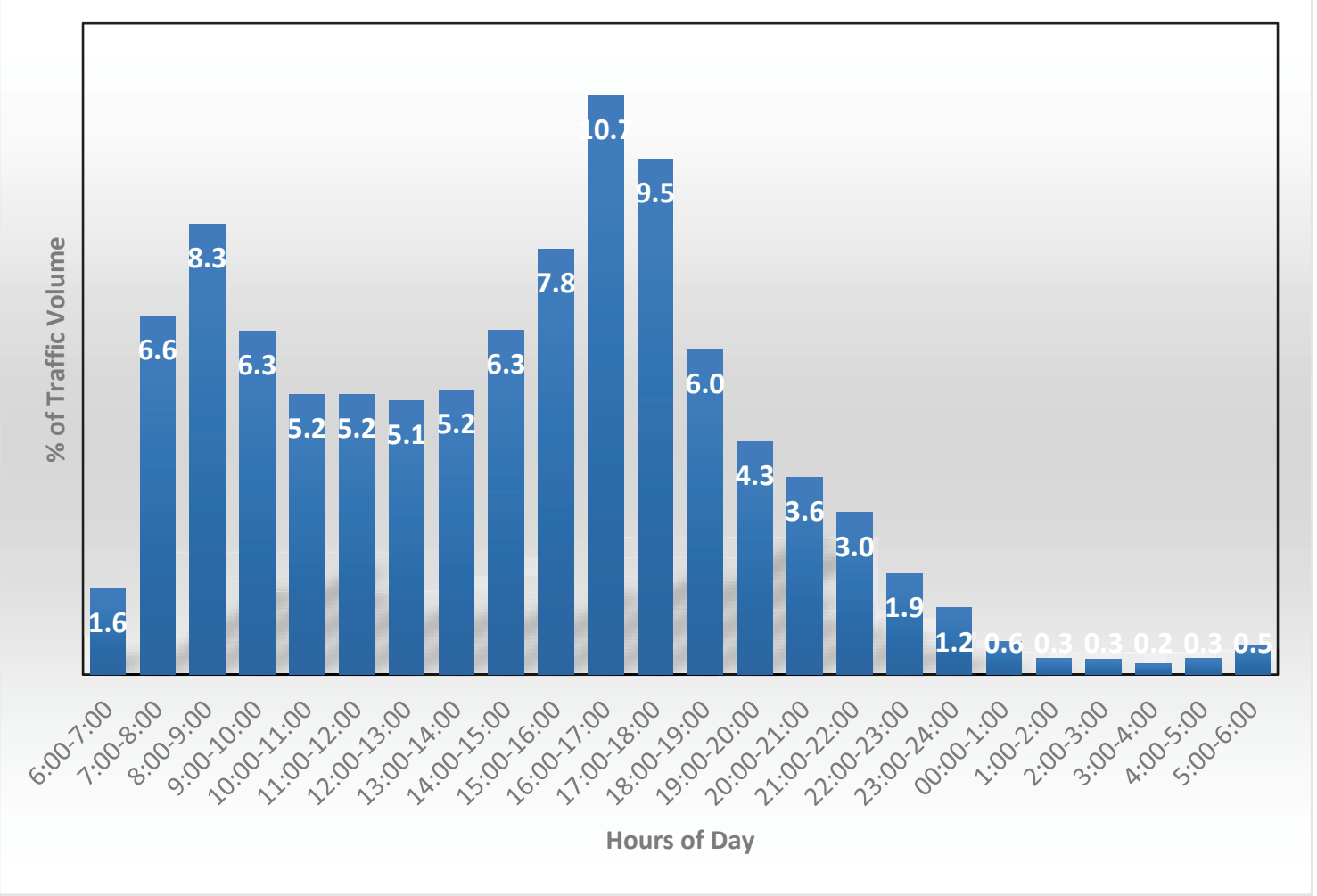

Figure 3-2: Hourly traffic-volume expansion factor

The above figure characterizes traffic variation. The morning peak traffic is varying 6.5 to 8.5 percent of total 24-hour traffic and the afternoon peak traffic is varying 9.5 to 10.7 percent. The peak hour traffic variation was checked and verified for other intersections around the City of Ottawa. The off peak hour daytime traffic is almost 5.2 percent and midnight traffic is 0.3 percent only. Final HEF were calculated based on weighted average of directional traffic movement on baseline road. This sample traffic variation can be used as model case where hourly traffic data are not available to match the air quality criteria.

\subsubsection{Meteorological Input Data}

As noted earlier, the local meteorological conditions affect the pollution concentrations. The influencing factors related to climate conditions are wind, temperature, and 
atmospheric stability class, etc. The data source and descriptions with their units are explained in chapter six. The hourly data were downloaded from website. The climate data were analyzed according to software requirement. Decision-making is an important task before analyzing meteorological data. Moreover, this research is emphasizing worst-case conditions. Therefore, minimum wind speed is a main concern. The decision for the seasonal and time of the day was carried out based on the structure below.

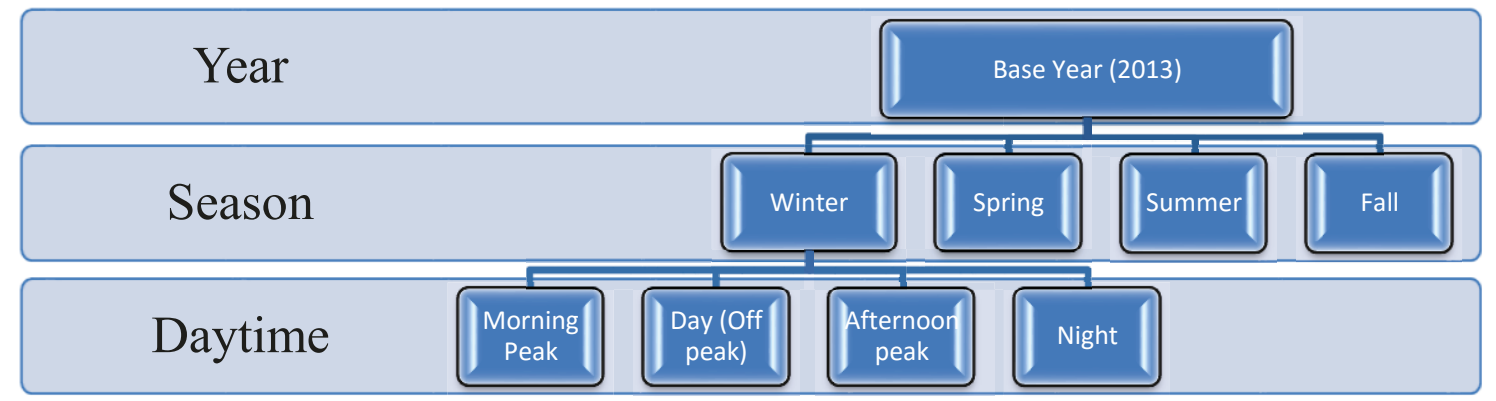

Figure 3-3: Selected season and daytime for making decision of 'worse case' conditions

Seasons are chosen according to the Canadian calendar. Although in the Canadian calendar each season is consisting of three months, the main two months' data were taken into account. For winter, January and February data were taken in average form. Whereas for summer, July and August data were considered. Climate data analysis is a sensitive task. As temperature during day and night are varying dramatically, the data are averaged on an hourly basis.

Table 3-1: Hourly average and minimum wind speed data analysis for July 2013

\begin{tabular}{|c|c|c|}
\hline Hour of the Day & Average Wind Speed (m/s) & Min Wind Speed (m/s) \\
\hline $00: 00-1: 00$ & 1.73 & 0.00 \\
\hline $1: 00-2: 00$ & 1.79 & 0.00 \\
\hline
\end{tabular}




\begin{tabular}{|c|c|c|}
\hline $2: 00-3: 00$ & 1.86 & 0.00 \\
\hline $3: 00-4: 00$ & 1.85 & 0.00 \\
\hline $4: 00-5: 00$ & 1.84 & 0.00 \\
\hline $5: 00-6: 00$ & 1.94 & 0.56 \\
\hline $6: 00-7: 00$ & 1.85 & 0.00 \\
\hline $7: 00-8: 00$ & 2.48 & 0.56 \\
\hline $8: 00-9: 00$ & 2.72 & 0.56 \\
\hline $9: 00-10: 00$ & 2.74 & 0.56 \\
\hline $10: 00-11: 00$ & 2.85 & 0.56 \\
\hline $11: 00-12: 00$ & 2.90 & 0.56 \\
\hline $12: 00-13: 00$ & 3.06 & 1.67 \\
\hline $13: 00-14: 00$ & 3.23 & 1.11 \\
\hline $14: 00-15: 00$ & 2.96 & 0.56 \\
\hline $15: 00-16: 00$ & 3.29 & 1.11 \\
\hline $16: 00-17: 00$ & 3.14 & 0.56 \\
\hline 17:00-18:00 & 3.19 & 0.00 \\
\hline 18:00-19:00 & 2.82 & 1.11 \\
\hline 19:00-20:00 & 2.50 & 0.56 \\
\hline $20: 00-21: 00$ & 2.36 & 0.56 \\
\hline $21: 00-22: 00$ & 2.07 & 0.00 \\
\hline $22: 00-23: 00$ & 2.00 & 0.00 \\
\hline $23: 00-24: 00$ & 1.71 & 0.00 \\
\hline
\end{tabular}

The above Table 3-1 shows the hourly average and hourly minimum wind speed in meter per second. Although the hourly average wind speed for the summer season (July and August) is $2.47 \mathrm{~m} / \mathrm{s}$, the hourly minimum wind speed is either zero or $0.56 \mathrm{~m} / \mathrm{s}$, except for a few hours shown in Table 3-1.

Table 3-2: Frequency distribution of minimum wind speed

\begin{tabular}{|l|c|c|}
\hline \multirow{2}{*}{ Min. Wind Speed (m/s) } & \multicolumn{2}{|c|}{ Frequency } \\
\cline { 2 - 3 } & Winter (January) & Summer (July) \\
\hline
\end{tabular}




\begin{tabular}{|c|c|c|}
\hline 0.0 & 37 & 29 \\
\hline 0.6 & 58 & 51 \\
\hline 1.1 & 70 & 73 \\
\hline 1.7 & 92 & 113 \\
\hline 1.9 & 76 & 117 \\
\hline 2.5 & 80 & 94 \\
\hline 3.1 & 60 & 76 \\
\hline 3.6 & 47 & 76 \\
\hline 4.2 & 42 & 48 \\
\hline 4.7 & 42 & 31 \\
\hline 5.3 & 57 & 14 \\
\hline 5.6 & 27 & 8 \\
\hline 6.1 & 14 & 3 \\
\hline 6.7 & 13 & 7 \\
\hline 7.2 & 11 & 4 \\
\hline 7.8 & 2 & 0 \\
\hline 8.3 & 3 & 0 \\
\hline 8.9 & 3 & 0 \\
\hline 9.2 & 3 & 0 \\
\hline 9.7 & 3 & 0 \\
\hline 10.3 & 1 & 0 \\
\hline 10.8 & 3 & 0 \\
\hline Average & 3.12 & 2.45 \\
\hline
\end{tabular}

Table 3-2 shows the frequency distribution of wind speed data for summer and winter seasons. In this table, zero refers to either velocity data close to zero or that were not available. Data analysis demonstrates that the highest wind speed during summer is $7.2 \mathrm{~m} / \mathrm{s}$ $(26 \mathrm{~km} / \mathrm{h})$, but during winter, it is $10.8 \mathrm{~m} / \mathrm{s}(39 \mathrm{~km} / \mathrm{h})$. The average wind speed in winter days is $3.12 \mathrm{~m} / \mathrm{s}(11.25 \mathrm{~km} / \mathrm{h})$ and for summer days, it is $2.45 \mathrm{~m} / \mathrm{s}(8.82 \mathrm{~km} / \mathrm{h})$. 
Minimum wind speed analysis is also important for air quality criteria, especially for 1-hr pollution concentration study. The frequency distribution table also shows that the minimum wind speed (below $0.5 \mathrm{~m} / \mathrm{s}$ ) occurs 12.5 percent of time, which amounts to 3 hours in a day. Therefore, the above analysis implies that the study of the worst-case condition based on wind speed is relevant.

\subsubsection{Background Pollution Concentrations}

An introduction to background pollution concentration was provided in Section 3.5.1.4 and the air quality chapter provides further details on this input parameter in the model. Here, analytical challenges are noted. As defined earlier, background pollution concentration refers to pollutants that come from non-motorized sources. The pollution concentration data are available at free access website published by Environment Canada. There are two stations in Ottawa. One station is located in the experimental farm and another is located in downtown near Rideau Street. Though both the stations provide pollution concentrations data, the sources of air pollution were not segregated in the website. It should be noted that such detailed information is not available from any source.

Email communications in December 2015 with the Ontario Ministry of the Environment suggested to view Environment Canada's comprehensive provincial level emission inventory and the City of Ottawa's study titled “Local Air Quality Assessment Scott Street/Albert Street Bus Detour and LRT Construction Ottawa, Ontario" prepared by Novus Environment.

Novus environment used downtown Ottawa station's pollution level as background pollution. Through their study, it was concluded that pollution-measuring stations were far 
away from major roads and therefore motorised vehicles did not contribute to emissions measured at stations. In other words, the pollution concentrations at a station were sourced from non-motorized sources only (Novus Environment, 2015).

For improved accuracy of background pollution concentration data, an analysis was carried out. According to analysis on downtown Ottawa pollution concentration measuring station, it was found that background concentration of carbon monoxide (CO) is 66 percent and 34 percent of pollution is contributed by road vehicle sources. For nitrogen-di-oxide $\left(\mathrm{NO}_{2}\right)$, background concentration sources are 75 percent and 25 percent of pollution is sourced from road vehicles.

To support the Air Quality Health Index (AQHI), Environment Canada published the comprehensive provincial level emission inventory in 2012. According to that report 42 percent $\mathrm{CO}$ is contributed by road vehicle sources and for $\mathrm{NO}_{2}$, it is 22 percent. These data were analysed on an average for all pollution measuring stations placed around Ontario. So, the analysis results done for this research are considered as final for Ottawa downtown pollution measuring station. Therefore, 66 percent of $\mathrm{CO}$ and 75 percent of $\mathrm{NO}_{2}$ of pollution concentration at station were considered background pollution concentrations.

At the same time, the analysis on experimental farm station near Carling Avenue showed that pollutant concentrations are not influenced by emissions from road traffic for the reason that it is placed far away from major roads (more than 1200 meters from Carling Avenue and 1700 meter from Highway 417). Therefore, the data published by Environment Canada for experimental farm station can be considered as background pollution concentrations outside the core part of the CBD. For core part of the CBD, background 
pollution concentrations can be assumed as 66 percent of $\mathrm{CO}$ and 75 percent of $\mathrm{NO}_{2}$ of concentrations recorded at the station.

\subsubsection{Software Issues and Reliability of Using Integrated Software}

The research methodology required the application of simulation models in an integrated form. This form of model application is discussed here in order to clarify if model inaccuracies (if any) are propagated in the series format. Another issue to be studied is model limitations. It is known that each simulation model used has merits but also there are some limitations as well. This section addresses the limitation of software.

Three simulation models are applied in an integrated form. These are traffic, emission, and air quality models. These models produce results that correspond to inputs provided. Although there may be a concern that errors (in the form of over estimates or under estimates) may propagate through the series format. It should be noted that this series application resembles the four-step urban transportation demand prediction model. Other examples can be found in published literature (Amirjamshidi, et al 2013).

As noted below, although there are limitations of these models, there is no evidence of any inherent structural problems in model logic or parameters used. In other words, the models are equally likely to under-estimate and over-estimate and there is no known information on model bias. When used in series, and accepting that under-estimations and overestimation (if any) are random phenomena, reliability theory can provide estimates of error propagation. 
Scenario 1: Model 1 estimates is 1.1 (as compared to correct estimate equal to 1.0); Model 2 estimate is 0.9 (an underestimate), and Model 3 estimate is 1.00 (no error). Assume that all models are inherently equally reliable to the $90 \%$ level. Therefore, the result obtained from the series format is:

Series $\mathrm{R}=\mathrm{r} 1$ x $\mathrm{r} 2 \times \mathrm{r} 3$

Where $\mathrm{R}$ is the reliability of the integrated model, $\mathrm{r} 1$ is the reliability of model $1, \mathrm{r} 2$ is the reliability of model 2 , and $\mathrm{r} 3$ is the reliability of model 3.

Expected output $=\mathrm{P}(1.1) \times \mathrm{P}(0.90) \times \mathrm{P}(1.00)=(0.9)(1.1) \times(0.9)(0.9) \times(0.9)(1.0)=0.722$

Scenario 2: Now assume that Model 1 estimate is 0.9 (underestimate), Model 2 estimate is 1.0 (no error), and Model 3 estimate is 1.1 (over estimate).

Expected output $=0.722$

In the above analysis, for the purpose of illustration, model reliability was set at $90 \%$. However, there is little basis to justify less than $100 \%$ reliability. Repeating the above calculations with model reliability of $100 \%$ results in expected output of approximately 1.00 for both scenarios. The above analysis shows that in integrated modelling, there is no error propagation.

Now we look at limitations of the simulation models. The microscopic traffic simulation model (VISSIM) is used to get the on-road vehicle activities. The outputs VISSIM are used in the emission model. VISSIM can produce velocity profile on a second-by-second basis or on a fraction of a second basis. The outputs of VISSIM are very large. 
The emission model could not read the database as produced by VISSIM. There is a mismatch of interlinking the outputs from traffic model as inputs in emission models. This difficulty arises due to file format differences. To change the file format, the output file from VISSIM could be opened in Microsoft Excel platform. However, MS Excel has a limitation to display data if it is more than certain number of rows.

To solve this issue, the VISSIM input file was further modified. The road links and intersections were renamed so that the output file (attached as Appendix VI) can be split according to link and intersection. This gap was solved using "Cygwin" software shell.

As is common in research and practical studies, VISSIM was customized to obtain the output in the same unit as required by the emission model. This task was carried out using the above-noted software shell.

The traffic varies in different sections of road links and approaches of intersections, but the emission rates are calculated as an average for each link and an intersection. There is no such facility in any emission model to incorporate the spatial data in terms of road network. Therefore, it is considered as a limitation of the emission model.

Composite emission factors can be found with the commonly used emission model (MOVES) developed for the USEPA. Due to the inability of this model to provide microscopic level analyses, noted in a later chapter, the CMEM developed by the University of California was implemented in addition to MOVES. The reason for incorporating CMEM model in this research was its ability to estimate emission factors at the microscopic level. The velocity profiles for fraction of a second can be used as an input in this model. The differences between the emission models are discussed in chapter five. 
However, MOVES model was used in this research for estimating the emission rates for dust pollution, namely particulate matter because the CMEM model is not fully developed yet for this pollutant.

The Gaussian dispersion model was implemented for the estimation of air pollutants from line sources. Moreover, this model has a facility to link spatial distribution of the road network. However, this model requires background pollution concentration that is not readily available. In this research, as described earlier, this issue was overcome. 


\section{Chapter 4: $\quad$ TRAFFIC MODEL (VISSIM)}

\subsection{INTRODUCTION}

The stochastic traffic micro-simulator (e.g. VISSIM) enables the study of traffic flow. VISSIM software was developed and is marketed by the PTV Company. It was originally developed in Karlsruhe, Germany and PTV America re-designed the software program based on North American traffic characteristics. Vehicle-following and lane change models suitable for application in this research are included in this simulation model. The VISSIM version-7.2 used in this research has a facility of incorporating satellite data as a background image.

Numerous input variables to run model characterize infrastructure, vehicles, traffic control and driver's behavior. The traffic "states" are modelled on a fraction of a second basis and numerous outputs become available that characterize trajectories of vehicle motion. Although most users are interested in congestion and related delay information, this research obtains trajectories that represents instantaneous speed and speed changes, distance covered, etc.

As noted above, the vehicular traffic and existing road networks are the basic inputs for a traffic microsimulation model. Required traffic data are obtained from government sources. The existing road networks are extracted using high-resolution remote sensing (RS) data, which can be collected using satellite and displayed as an image. Satellite images should be geo-coded using geographic projection and datum. 
Microscopic models enable the analysis of the effectiveness of each road link of a network. This model can test performance even when both conventional and new intelligent adaptive traffic control systems are used (Alkadry and Khan, 2001). In addition to the commonly used measures-of-effectiveness, advance traffic control systems can be modelled in the simulator for the study of fuel consumption and emissions (Jagannathan and Khan, 2001).

\subsection{INPUT VARIABLES}

The input variables for the traffic simulation model include the fixed infrastructure and movable entities. Fixed infrastructures encompass road network and traffic control facilities, whereas the movable entities are motor vehicles (and pedestrians, cyclists, if applicable). Road networking infrastructure includes the facilities available on surface of the ground. These can be easily captured by remote sensing data and by drawing existing facilities on earth surface. Other transportation data were collected from government offices. For simulation design, the capacity level traffic volume was calculated using highway capacity software.

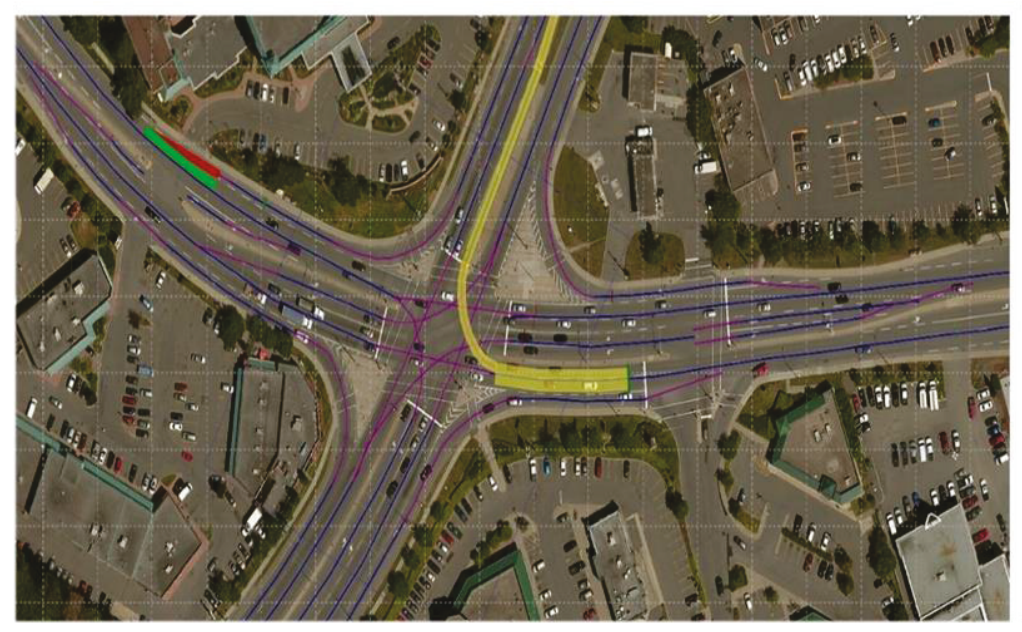

Figure 4-1: Road links and connectors using VISSIM-7 
The initial step of microsimulation of traffic is drawing the road links and connectors. A view of road network shown in Figure 4-1 for the intersection of Hunt Club Road and Bank Street (Ottawa), where blue lines indicates links and red lines indicate connectors. The exact area of interest is obtained by zooming the geo-referenced satellite image. Next step is to provide input variables to the network as noted next:

1. Define traffic volume: The capacity level vehicles per hour per lane computed for saturation run, whereas actual traffic volume used for model validation.

2. Vehicle composition: Composition of traffic at this site, such as light duty vehicle (LDV) and heavy-duty vehicle (HDV), is an important input, especially percentage of HDV.

3. Speed limit: Actual on road speed limit used for model run. As an example the speed limit for both roads considered in Figure $4-1$ is $60 \mathrm{~km} / \mathrm{h}(37.5 \mathrm{mph})$. However, for simulation design, the speed limits are $60 \mathrm{~km} / \mathrm{h}$ for arterial roads, $50 \mathrm{~km} / \mathrm{h}$ for collector roads, and $40 \mathrm{~km} / \mathrm{h}$ for local roads.

4. Routing decisions applicable at this site are according to the logic of VISSIM.

5. Vehicle conflict areas applicable to this site.

6. Signalling system factors obtained from field check (cycle length $=140 \mathrm{sec}, 4$ phases, amber $=4 \mathrm{~s} /$ phase), etc. The details about cycle length and splits are presented in the Appendix.

Once input data are provided to the model, it is ready to run the simulation. A sample of simulation run is illustrated in Figure 4-2 (a). This is a snap shot captured during simulation run. The actual number of vehicles and their locations are demonstrated in the figure. 


\subsection{OUTPUT OF TRAFFIC MODEL}

The output of traffic model is microscopic scale velocity trajectories. Velocity profile implies the speed and acceleration of each vehicle in every second. The slices of output file from VISSIM model on a one-second interval basis are illustrated in Appendix VI. Although researchers use this model for different purposes, this research focuses on the use of its outputs for obtaining emission rates of vehicles obtainable from the emission model. Ultimately, these integrated models contribute the estimation of roadside air quality. Therefore, the characteristics of vehicle movements on road is the main focus.
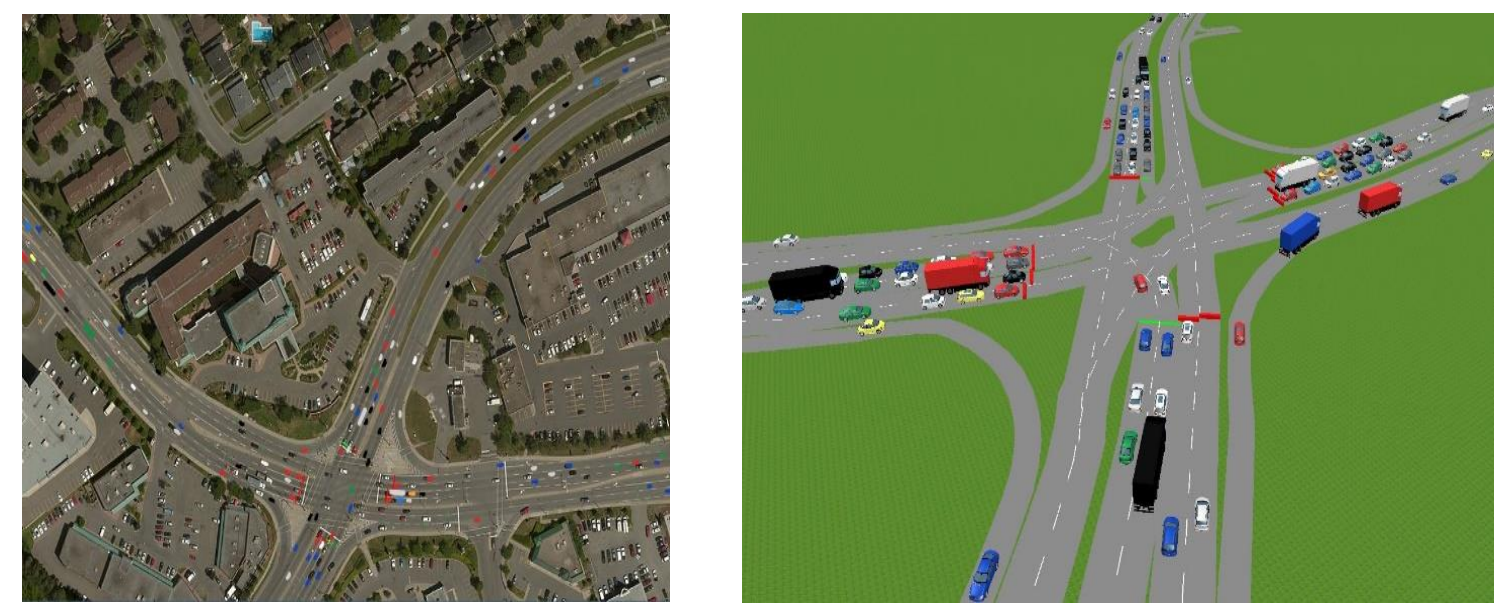

Figure 4-2: (a) 2-D and (b) 3-D view of simulation run

A 3-D view of on-road traffic in simulation run is presented in Figure 4-2(b). Based on above noted inputs, the second-by-second activity of vehicles on roads was computed by the micro-simulator. The added advantage of the new version of the software is the use of high-resolution satellite image as the background. This adds convenience and efficiency in research. In addition, the imagery is geo-referenced, and therefore no scaling is required. Therefore, the dimensions of the road links are same as the earth surface. That means the 
actual traffic activity profiles are reflected in the output of the updated version of traffic model.

\subsection{MODEL CALIBRATION AND VALIDATION}

\subsubsection{Reason for Model Calibration and Validation}

Each model has a reasonable degree of accuracy. The accuracy of traffic model depends on representation of fixed infrastructure, moveable entities, control system, driver characteristics etc. The microscopic traffic simulation model used in this research is VISSIM, which was originally designed in Europe and customised in the USA. Although the customised VISSIM model is applicable to the USA and Canada, the reason to check/verify model's applicability is to ensure that it represents driving at the microscopic level in a general geographic area (e.g. Ontario).

The local traffic movement characteristics can vary from place to place. Therefore, model calibration/validation is required before using it for a specific purpose. The calibration and validation techniques of VISSIM parameters match the simulation results from model with the observed field data (Rrecaj and Bombol, 2015).

Since the results of this research are intended for wider application, this objective is kept in mind in validation of models. Therefore, the calibration/validation is carried out for two different locations in Ontario. Two geographic locations selected are Ottawa and Sault Saint-Marie (Ontario). Moreover, two different approaches were used for model calibration/validation. 
Two categories of model calibration parameters are of interest. Operational calibration parameters and system calibration parameters. Operational calibration focuses on driver behaviour, whereas system calibration investigates the model input assumptions.

The parameter adjustments vary from model to model, based on different road networks. For the freeway car-following model (Weidemann 99), driver behaviour parameters are emphasized. However, for urban road (Weidemann 74), model input parameters namely link behaviours are emphasized.

VISSIM calibration refers to the process of analysing error between computer simulation results and field data. The statistical tool, namely root mean square error (RMSE), is a common method used for checking model calibration.

The most common parameter used for calibration of traffic simulation model is travel time. Speed is another common parameter used in the calibration process. In this research, both parameters were used for calibration purposes. However, this process was limited to locations, for which the required field data were available. For Sault Ste. Marie, the space mean speed data were available, so the travel time was compared. However, for Hunt Club road in Ottawa, the only available speed data were spot speed data for westbound traffic. So, the speed parameter was compared in this case.

\subsubsection{Calibration and Validation Objectives}

In a previous Carleton University thesis (Fukutomi 20014), detailed sensitivity analyses of VISSIM parameters were reported. Therefore, such results were not repeated in this thesis. The purpose of validating VISSIM was to verify that default driver factors were applicable in different geographic locations. The model validation checks were made at two different geographic locations (Ottawa 
and Sault Ste. Marie) and results were satisfactory. Details of validation are presented in this chapter.

The traffic simulation model, especially microscopic analysis software model, has been used for evaluating geometry changes, updating traffic signal plan, or the benefit estimation of intelligent transportation systems (ITS) strategies etc. (Park et al). In this study, the

model is used in general, for both urban roads as well as the freeway. No specific existing road segment or intersection is emphasised.

\subsubsection{Data Preparation for VISSIM Model}

The road link was drawn using open source satellite data, which are georeferenced. Therefore, the dimensions of the link are same as on ground or in real network. There is no question of scaling error as images are already registered. Other input data, such as traffic count and signal control, are collected from the applicable authorities.

The input data used for VISSIM validation were collected from two authorities. Traffic related data for Black road (National Highway-17) in Sault St.-Marie (Ontario) collected from the Public Works and Transportation Department, Corporation of the City of Sault Ste. Marie. For Hunt Club Road (Ottawa), traffic movement was filmed using video camera and control data was supplied by the City of Ottawa. Note that, the video camera was placed at the same spot as the permanent radar meter station.

The VISSIM model is a stochastic simulator. A selected car can drive on different links in different simulation runs. For obtaining reliable results, Vissim model was run 60 (sixty) times. The average value of travel time for a certain distance in each road segment was taken into consider for comparison with field data. 

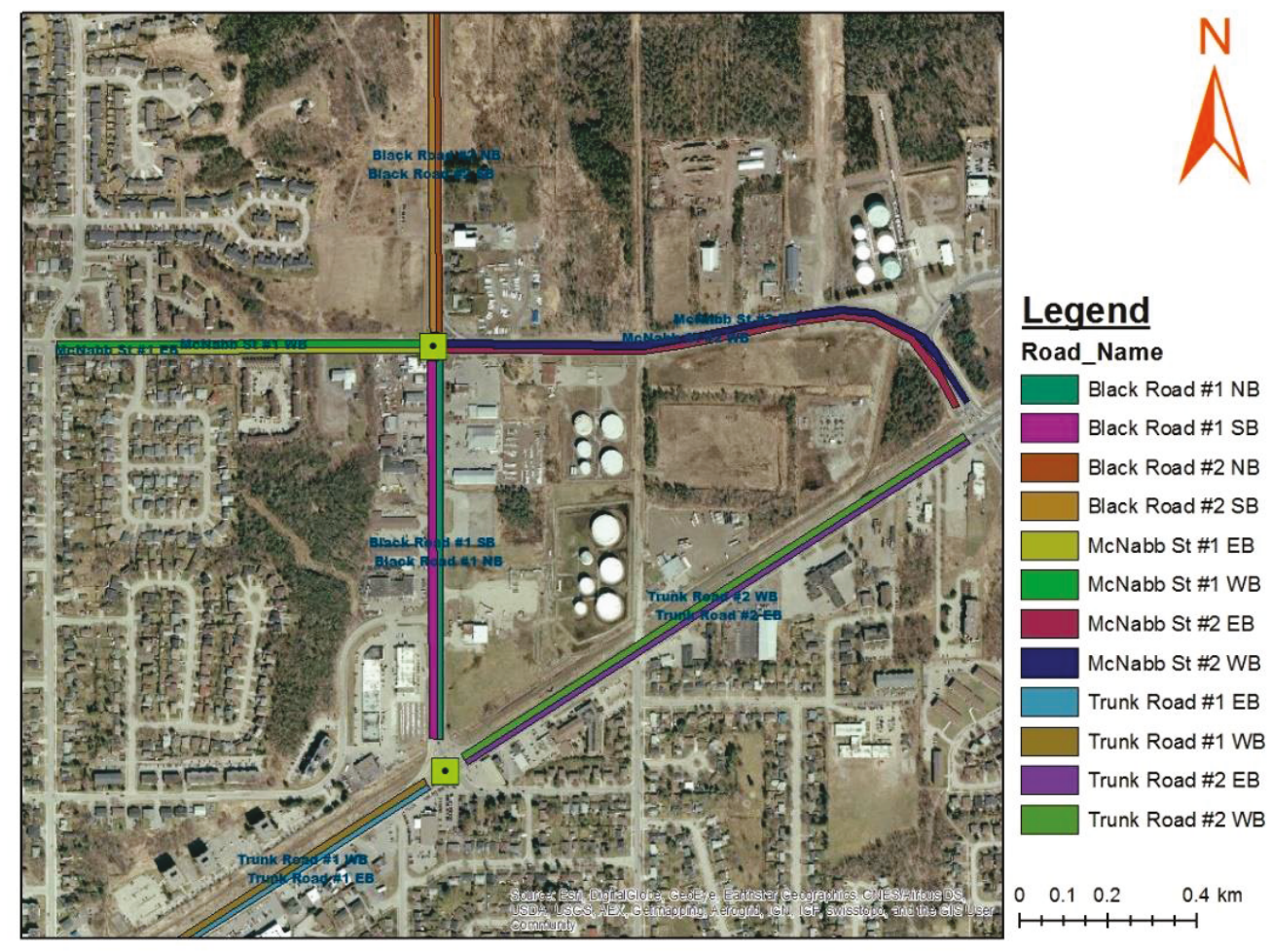

Figure 4-3: Road segment and intersection in Sault Ste. Marie study area

\subsubsection{Field Data}

The field data collection is a difficult task, especially arranging all necessary instruments and to capture the vehicle movements at an appropriate time of the day. As was noted earlier, travel time is an important parameter for calibration. It can only be possible if a global positioning system (GPS)-enabled vehicle with data storage facility and laser beam arrangement for getting reference movement of another vehicle are available. Fortunately, such data were available for Highway 17 through Sault St. Marie, Ontario from a previous project carried out for the Nuclear Waste Management Organization (NWMO). The GPSequipped van was driven through $\mathrm{NH}-17$ (trunk road and black road) and travel time was 
calculated for each segment of road on a directional basis. Figure 4-3 shows the road segment and intersection in the Sault Ste. Marie study area, where the national highway17 is renamed as Trunk Road (segment \#2) and Black Road within the city area.

For Hunt Club road, which is in the southeast part of Ottawa, a permanent radar meter station is placed by the city of Ottawa in between Cahill Drive and Dunston Terrace. The radar for westbound traffic movement collected the speed data. Table 4-1 shows the speed data for April 13, 2016 for 5:00 PM to 6:00 PM. The data were compiled by the City of Ottawa for every 15 minutes interval. The columns represented in this table are the ranges of speed or speed bin in $\mathrm{km} / \mathrm{h}$.

Table 4-1: Traffic speed data (bin wise) on hunt club road

\begin{tabular}{|l|l|l|l|l|l|l|l|l|l|l|l|l|}
\hline Date/Time & $\mathbf{2 0 - 2 4}$ & $\mathbf{2 5 - 2 9}$ & $\mathbf{3 0 - 3 4}$ & $\begin{array}{l}\mathbf{3 5}- \\
\mathbf{3 9}\end{array}$ & $\mathbf{4 0 - 4 4}$ & $\mathbf{4 5 - 4 9}$ & $\mathbf{5 0 - 5 4}$ & $\mathbf{5 5 - 5 9}$ & $\mathbf{6 0 - 6 4}$ & $\begin{array}{l}\mathbf{6 5 -} \\
\mathbf{6 9}\end{array}$ & $\mathbf{7 0 - 7 4}$ & $\mathbf{7 5 - 7 9}$ \\
\hline $\begin{array}{l}\mathbf{2 0 1 6 - 0 4 - 1 3} \\
\mathbf{1 7 : 1 5 : 0 0}\end{array}$ & 0 & 1 & 0 & 1 & 1 & 1 & 4 & 7 & 14 & 7 & 1 & 1 \\
\hline $\begin{array}{l}\mathbf{2 0 1 6 - 0 4 - 1 3} \\
\mathbf{1 7 : 3 0 : 0 0}\end{array}$ & 0 & 2 & 0 & 3 & 0 & 2 & 5 & 8 & 8 & 5 & 3 & 0 \\
\hline $\begin{array}{l}\mathbf{2 0 1 6 - 0 4 - 1 3} \\
\mathbf{1 7 : 4 5 : 0 0}\end{array}$ & 1 & 0 & 1 & 3 & 3 & 2 & 0 & 5 & 5 & 5 & 1 & 0 \\
\hline $\begin{array}{l}\mathbf{2 0 1 6 - 0 4 - 1 3} \\
\mathbf{1 8 : 0 0 : 0 0}\end{array}$ & 0 & 1 & 0 & 1 & 4 & 2 & 2 & 6 & 7 & 6 & 1 & 0 \\
\hline
\end{tabular}

\subsubsection{Observations on the Calibration Step}

The field data were used to plot speed distribution graph (speed vs time) in excel. The GIS environment was used to get road segment distance that was used in VISSIM during simulation run.

Operational calibration parameters were used as default to run the VISSIM model. The default driving behaviour used for urban road (Weidemann 74) are tabulated below. 
Table 4-2: Default driving behaviour for urban road by Weidemann 74

\begin{tabular}{|l|l|}
\hline Wiedemann 74 default parameters & default value \\
\hline Simulation Resolution (time steps/ Sim. Sec.) & 10.00 \\
\hline No. of observed preceding vehicles & 4.00 \\
\hline Avg. stand still distance (m) & 0.5 \\
\hline Additive part of safety distance (m) & 2.00 \\
\hline Multiplicative part of safety distance (m) & 3.00 \\
\hline Headway time & 0.9 \\
\hline Lateral Min. distance at $50 \mathrm{~km} / \mathrm{hr}$ & 1 \\
\hline Lateral Min. distance at $0 \mathrm{~km} / \mathrm{hr}$ & 0.2 \\
\hline Look Back distance $(\mathrm{m})$ & 200 \\
\hline Emergency stop distance $(\mathrm{m})$ & 5.00 \\
\hline Waiting time before diffusion $(\mathrm{sec})$ & 60 \\
\hline
\end{tabular}

System calibration parameters were adjusted in VISSIM model based on field observations. Those parameters are geometric design of road network, posted speed limit, etc. Though the parameters were adjusted to get better results, it was observed that there were differences between field data and simulation model data. It was found that the actual driving speed on the road was approximately $10 \mathrm{~km} / \mathrm{h}$ higher than the posted speed.

\subsubsection{Goodness-of-Fit Measures}

As a part of the calibration process, error between the simulation results and field observations is analyzed using statistical tools. As noted earlier, travel time is the most common parameter used for calibration of traffic simulation model. The quality index by root mean square error (RMSE) is a common method to measure quality of the predictive link travel time (FISITA, 2012). There are a numbers of ways to measure the goodness-offit. Among a number of available measures, four popular measures were used in this study. 
These are root mean square error (RMSE), root mean square percent error (RMSPE), mean error (ME), and mean percent error (MPE). The corresponding equations are noted below:

$$
\begin{aligned}
& \text { RMSE }=\sqrt{\frac{1}{N} \sum_{n=1}^{N}\left(\mathrm{M}_{\mathrm{n}}-\mathrm{C}_{\mathrm{n}}\right)^{2}} \\
& \mathrm{RMSPE}=\sqrt{\frac{1}{N} \sum_{n=1}^{N}\left(\frac{\mathrm{M}_{\mathrm{n}}-\mathrm{C}_{\mathrm{n}}}{\mathrm{C}_{\mathrm{n}}}\right)^{2}} \\
& \mathrm{ME}=\frac{1}{\mathrm{~N}} \sum_{n=1}^{N}\left(\mathrm{M}_{\mathrm{n}}-\mathrm{C}_{\mathrm{n}}\right) \\
& \mathrm{MPE}=\frac{1}{\mathrm{~N}} \sum_{n=1}^{N}\left(\frac{\mathrm{M}_{\mathrm{n}}-\mathrm{C}_{\mathrm{n}}}{\mathrm{C}_{\mathrm{n}}}\right)
\end{aligned}
$$

Where

$$
\begin{aligned}
& \mathrm{N}=\text { total number of measurement points; } \\
& \mathrm{M}_{\mathrm{n}}=\text { simulation value at point } \mathrm{n} ; \\
& \mathrm{C}_{\mathrm{n}}=\text { observed value at point } \mathrm{n} ;
\end{aligned}
$$

RMSE and RMSPE indicate the overall fit of the model, whereas ME and MPE indicate system wide over /under prediction of the model. Among them, RMSE is the primary measure.

\subsubsection{Setting Target}

Model calibration involves the process of identification of errors. Even though error can be minimized, there is an error after modification of calibration parameters. Allowable 
error can be set-up based on purpose of project. In the case of this research, The VISSIM model output was to be used in two other models to get the final output. Therefore, the purpose of overall output was to make decisions for wider applications, not for a specific road and an intersection.

According to Model Methodology Report, SR 710, Los angel County Metropolitan Transportation Authority, 2012:

"Current FHWA guidelines do not specify a particular percent error by functional class, but instead display example validation standards from multiple states. Guidelines set for RMSE in the Caltrans and FHWA documents are rather general and varied based on the midpoint of the link volume group. As with all model validation metrics, these are guidelines or thresholds, not standards that must be met or once they are met indicates "an acceptable model." Based on this information, the study team set a \%RMSE goal to be below $30 \%$ on a daily basis and $40 \%$ for the peak periods."

Returning to this research, there was no interest in a specific geographic location. Therefore, the confidence interval was a bit flexible, but it was definitely within the acceptable limit.

According to Kentucky Transportation Cabinet report-2014, the goal of the calibration model based on average travel time is 15 percent. Keeping the objectives of this research in mind and given the above literature review, the target was set so that $15 \%$ of error was considered acceptable.

\subsubsection{Data Comparison}

The VISSIM results were compared with field data. Based on available field data, the model results were compared in two different ways for two different urban roads. First, Black Road segments in Sault Ste. Marie area was compared with field data that was collected by a GPS-enabled vehicle. Second, Hunt Club Road in Ottawa was compared with radar meter data. 
For the freeway, Fukutomi (2004) carried out the calibration and validation process using Ottawa Queensway. The Queensway section used is on Highway-417 in Ottawa west-end from Carp road to Moodie drive. He concluded that the time headway parameter $(\mathrm{CC} 1)$ is in need of change from default vale of 0.9 to the new value of $1.31 \mathrm{sec}$. For this research this calibration and its associated validation were considered as final for the urban freeway facility.

\subsubsection{Black Road, Sault St. Marie}

The VISSIM results were compared with available GPS-based instrumented vehicle data for Sault Ste. Marie area. Though instrumented vehicle was run on National Highway-17, the data were compared for an intersection (i.e. Black road and McNabb St), where Hwy17 becomes an arterial road shown in Figure 4-3. The road segment name with direction was noted in the figure for better understanding.

Table 4-3: Travel time comparison in Sault Ste. Marie, ON, Canada

\begin{tabular}{|c|c|c|c|c|c|c|c|}
\hline \multirow[t]{2}{*}{$\begin{array}{l}\text { Road link } \\
\text { name }\end{array}$} & \multirow{2}{*}{$\begin{array}{l}\text { Segment } \\
\text { distance } \\
\text { (m) }\end{array}$} & \multicolumn{2}{|c|}{$\begin{array}{l}\text { Travel time } \\
\text { (Sec) }\end{array}$} & \multirow[t]{2}{*}{$E$} & \multirow[t]{2}{*}{$S E$} & \multirow[t]{2}{*}{$P E$} & \multirow[t]{2}{*}{$S P E$} \\
\hline & & Vissim & Field & & & & \\
\hline Black Rd\#1 SB & 500 & 31.23 & 31.67 & -0.44 & 0.19 & -0.01 & 0.00 \\
\hline Black Rd\#2 NB & 1000 & 57.83 & 51.53 & 6.30 & 39.69 & 0.12 & 0.01 \\
\hline Black Rd\#2 SB & 1000 & 57.35 & 48.98 & 8.37 & 70.06 & 0.17 & 0.03 \\
\hline \multirow{2}{*}{\multicolumn{4}{|c|}{ Goodness of fit }} & $M E$ & $R M S E$ & $M P E$ & $R M S P E$ \\
\hline & & & & 4.74 & 6.05 & 0.09 & 0.1216 \\
\hline
\end{tabular}

Table 4-3 presents the statistical reports to compare the travel time on Black Road, where the directional traffic flow characteristics are different. Moreover, the road segment was renamed in slides of the intersection for ease of understanding. Based on available field data and geometry, the segment distance was decided. Figure 4-4 shows the travel time 
comparison by the GPS instrumented vehicle run to the microscopic traffic simulation model.

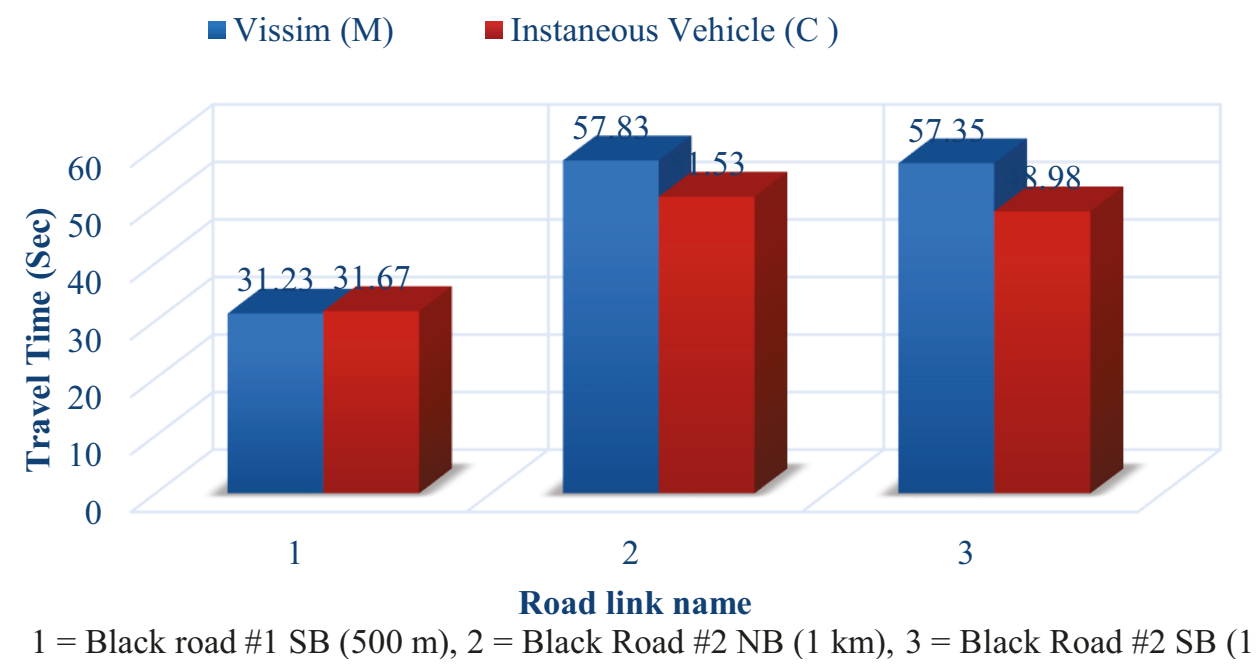

Figure 4-4: Comparison of instrumented vehicle travel time with VISSIM results

The Table 4-3 and Figure 4-4 show that the best result is on Black road link \#1 southbound, which shows $1.38 \%$ error only. The overall root mean square percent error is 12.16 percent, which is within the limit set in target.

\subsubsection{Hunt Club Road, Ottawa}

The VISSIM results were compared with radar meter data on Hunt Club road. The radar meter data was collected by the City of Ottawa for every 15 minutes intervals on April 13, 2016 at 5-6 PM for westbound traffic. The data is tabulated in field data section (in Table 4-1).

Table 4-4: Hunt club road WB traffic summary from either sources

\begin{tabular}{|c|c|c|c|c|}
\hline & & & Lane\#1 & Lane\#2 \\
\hline Speed bin $(\mathrm{Km} / \mathrm{h})$ & Mean Speed & Radar meter & \multicolumn{2}{|c|}{ VISSIM } \\
\hline $0-4$ & 2.5 & 0 & 0 & 0 \\
\hline
\end{tabular}




\begin{tabular}{|c|c|c|c|c|}
\hline $5-9$ & 7.5 & 0 & 0 & 0 \\
\hline $10-14$ & 12.5 & 0 & 0 & 0 \\
\hline $15-19$ & 17.5 & 0 & 0 & 0 \\
\hline $20-24$ & 22.5 & 0.8 & 0 & 0 \\
\hline $25-29$ & 27.5 & 3.1 & 0.4 & 0 \\
\hline $30-34$ & 32.5 & 0.8 & 1.7 & 0.4 \\
\hline $35-39$ & 37.5 & 6.2 & 1.3 & 4.3 \\
\hline $40-44$ & 42.5 & 6.2 & 5.6 & 4.9 \\
\hline $45-49$ & 47.5 & 5.4 & 1.5 & 1.9 \\
\hline $50-54$ & 52.5 & 8.5 & 3.0 & 1.9 \\
\hline $55-59$ & 57.5 & 20 & 4.5 & 3.4 \\
\hline $60-64$ & 62.5 & 26.2 & 34.0 & 36.7 \\
\hline $65-69$ & 67.5 & 17.7 & 43.2 & 41.4 \\
\hline $70-74$ & 72.5 & 4.6 & 4.7 & 4.9 \\
\hline $75-79$ & 77.5 & 0.8 & 0.0 & 0.0 \\
\hline $80-84$ & 82.5 & 0 & 0.0 & 0.0 \\
\hline $85-89$ & 87.5 & 0 & 0.0 & 0.0 \\
\hline
\end{tabular}

In Table 4-4, the speed data are shown in bin wise, which show a range of speed. The third column shows the radar meter speed observation frequency distribution. The last two columns are showing the speed observations report on each lane of Hunt club road west bound traffic.

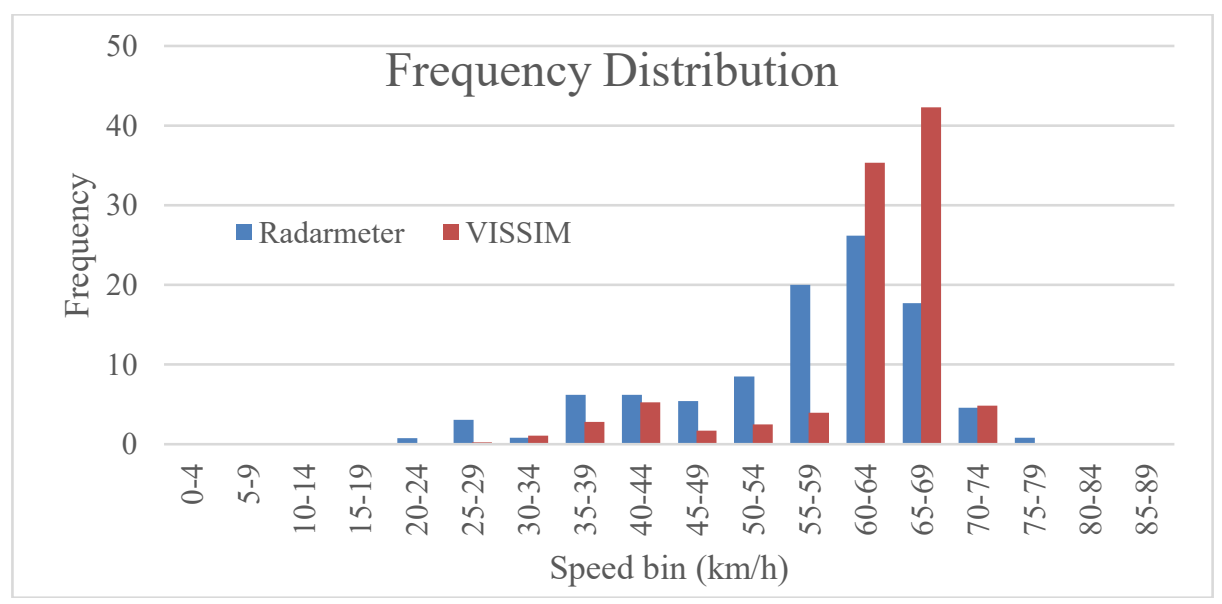

Figure 4-5: Comparison of speed distribution from simulation model vs radar meter 
Figure 4-5 shows the frequency distribution of speed bins from radar meter in field and outputs run by the traffic simulation model. Though some of the differences are visible, the overall difference is within the limit. Analysis results show that the weighted average of radar meter speed is $56.90 \mathrm{~km} / \mathrm{h}$, whereas the simulation model speed is $62.25 \mathrm{~km} / \mathrm{h}$. Therefore, the error percentage is $8.58 \%$, which is less than our target limit $15 \%$.

Table 4-5: Error percentage for different study types and locations

\begin{tabular}{|c|l|l|c|}
\hline $\begin{array}{c}\text { Study } \\
\text { Number }\end{array}$ & Road type & \multicolumn{1}{|c|}{ Study Location } & Error Percentage \\
\hline 1. & Urban & Black road, Sault Ste. Marie, ON & 12.16 \\
\hline 2. & Urban & Hunt Club road, Ottawa, ON & 8.58 \\
\hline 3. & Freeway & Queensway, Ottawa, ON, Canada & 5.20 \\
\hline
\end{tabular}

Table 4-5 illustrates error percentages for different study types and locations. All of those results are within the set of target. Therefore, system calibration parameters are acceptable in VISSIM model. As noted previously, the operational calibration parameters are using the default value for urban road network. In the case of freeway, CC1 was set as $1.31 \mathrm{sec}$.

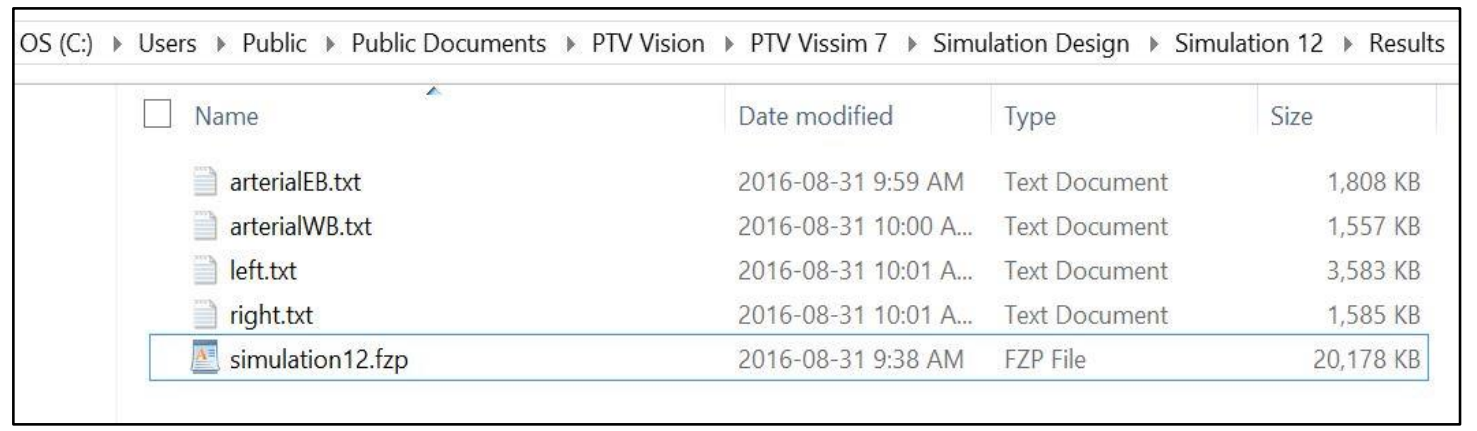

Figure 4-6: VISSIM output file components based on link and intersection name

\subsection{INPUT DATA PREPARATION FOR EMISSION MODEL}

The outputs of the traffic model for every second are illustrated in Appendix VI, where every vehicle on the road at a particular time is reflected in the output file. Although the 
microscopic emission model can accept the output files from traffic simulation model with slight modification of file format, the data size did matter during file conversion. The difficulties faced during file modification were described in the previous chapter. Appendix VI shows the name of individual road links and intersections. The purpose of renaming those links and intersections was to be able to split output velocity profile. Figure 4-6 shows the original velocity trajectory file (*.fzp) format for simulation number 12 as output. The original file from traffic simulator was split into different files based on road links and intersection name. The above picture illustrates that there are four text files, where two are showing the database for either direction of road of traffic movement. The left and right intersection velocity profiles are separated for better understanding of activities at an intersection. 


\section{Chapter 5: $\quad$ EMISSION MODELS}

\subsection{INTRODUCTION}

Emission models estimate composite emission factor or emission rates. Emission rate from stationary sources is calculated in terms of amount of emission per unit time. However, this research deals with road vehicular emissions, which is a mobile source. Therefore, the emission rates from road vehicles are estimated as amount of emissions per unit distance of travel.

The main source of emissions from motor vehicles is the tail pipe. Moreover, there are other sources of emissions as well. Petroleum fuels evaporate continuously from fuel tank due to their high volatility characteristics. The most significant source of particular matter is diesel fuel, but wear and tire is considered another source of dust pollution. The road vehicular emissions can be measured by attaching a measuring instrument to tail pipe of vehicles. Although tail pipe emissions from vehicles travelling on roads and highways can be measured, measuring on-road emissions from road traffic is challenging as well as costly (Zhu \& Zhang, 2014). This technique is not only expensive, it is also time consuming. In addition, some of the emission sources will be missed. Therefore, researchers rely upon simulation models for estimation of emissions.

\subsection{TYPES OF EMISSION MODELS}

Simulation models are either microscopic or mesoscopic as well as macroscopic. The model selection decision is based on project objectives and level of detail required. For high-resolution estimates, microsimulation emission model is preferred. 
An introduction to two emissions factors models is presented here and elaborations are provided in the following text. MOVES calculates emissions for different operating mode, namely staring, running, idling. The database used in moves for estimate emissions were validated by the developer against portable emissions measurement systems (PEMS) data. At the Transportation Research Board Annual Meeting of January 2017, presentations were made by the developer/EPA on new capabilities of MOVES and it was noted that MOVES is ready to generate emissions on a "second" basis. At the time of initiating this research, this capability was not highlighted.

In CMEM, although emissions are simulated based on trajectories of individual cars/vehicles, the dispersion model requires emission rates for each segment of the road. It is impossible to separate emissions for each vehicle in a segment. But, the thesis shows that a road network can be split into different segments. As an example, emission rates from sample road design are generated separately for individual road links and intersections. Moreover, directional emission rates are generated for a road link. It is also possible to estimate emission rates in different sections of a road link.

Vehicular emission modelling software are available for use by researchers. These range from macroscopic/mesoscopic to microscopic in design. The MOVES model use for predicting emissions (in gram per mile) from cars, trucks, and motorcycles under various conditions. It is the US EPA's latest official model for estimating emissions. This model includes different vehicle types for emissions of Hydrocarbons (HC), Carbon Monoxide (CO), Nitrogen Oxides (NOx), Carbon Dioxide $\left(\mathrm{CO}_{2}\right)$, Particulate Matter (PM), and toxics pollutants. It has replaced the macroscopic MOBILE model and works at a higher level of 
detail. The main inputs of the emission software are vehicle miles travel (VMT), driving speed, and the outputs is rate of emissions.

Since MOVES has limitations in modelling emissions from vehicles in terms of input and output format, the comprehensive modal emission model (CMEM), developed by researchers at the University of California (Riverside), and was used for $\mathrm{CO}$ and $\mathrm{NO}_{\mathrm{x}}$ emissions. The velocity trajectories input file in MOVES are define as frequent distribution as different bin speed, and outputs are in integer format. However, the PM emission is not yet obtainable from CMEM at the microscopic level. Therefore, for PM emission, the MOVES model was used.

This CMEM model was initially developed in the late 1990's with sponsorship from the U.S. National Cooperative Highway Research Program (NCHRP) and the U.S. EPA to fulfill the need for microscopic emissions modeling. The CMEM is designed to compute emissions based on instantaneous speed of the engine and it can accept vehicle trajectories from the traffic microsimulation model VISSIM. This model has been tested and verified. The CMEM is microscopic in the sense that it predicts on a second-by-second basis emissions and fuel consumption for various modal operations of in-use vehicle fleet. This level of detail supported by this type of model is necessary for evaluating emission reduction benefits of project-level or corridor-specific transportation control measures (e.g. HOV lanes), intelligent transportation systems (ITS) implementations (e.g. electronic toll collection), and traffic flow improvements (e.g. traffic signal coordination). It should be noted that CMEM calculates $\mathrm{NO}_{\mathrm{x}}$ emission rates, not $\mathrm{NO}_{2}$. Although $\mathrm{NOx}$ is used in air quality model to estimate $\mathrm{NO}_{2}$ concentrations, because of the following reason. 
1. For freeway case, $\mathrm{NOx}$ from CMEM is $4.362 \mathrm{~g} / \mathrm{v}-\mathrm{mi}$, whereas $\mathrm{NO}_{2}$ from MOVES is $3 \mathrm{~g} / \mathrm{v}-\mathrm{mi}$.

2) In an intersection, $\mathrm{NO}_{2}$ from MOVES is $3 \mathrm{~g} / \mathrm{v}-\mathrm{mi}$, whereas NOx from CMEM is $3.556 \mathrm{~g} / \mathrm{V}-\mathrm{mi}$.

\subsection{COMPOSITE EMISSION FACTOR}

The composite emission factor $(\mathrm{CEF})$ is defined in terms of gram per vehicle mile (g/v-mi) or its metric equivalent, which is the output from any emissions model. As previously noted, several emissions models are available for research purposes as well as for practical applications. This research used the latest emissions model sponsored by the US EPA, namely MOVES, and the microscopic level model, CMEM introduced above.

The input and output parameters for CMEM are tabulated below.

\begin{tabular}{|l|l|}
\hline \multicolumn{1}{|c|}{ Input parameters } & \multicolumn{1}{c|}{ output } \\
\hline Vehicle definition (model default is used that comes with & Fuel consumption and \\
the software with modification and tabulated below) & vehicular emissions (CO, \\
Vehicle Activity (sec-by-sec vehicle state) such as speed, & $\mathrm{NO}_{\mathrm{x}}$ etc.). \\
acceleration, grade, use of air conditioning, etc. & \\
\hline
\end{tabular}

It should be noted that vehicle definitions are different for CMEM and MOVES. The vehicle category types are tabulated in the next section. Other inputs data noted below may be required, depending upon the purpose of the study.

Vehicle registration distribution data are as follows:

Vehicle Miles of Travel (VMT) Mix 
Local travel data

Local control programs (I/M, anti-tampering programs)

Local atmospheric data

Diesel fractions

Although input files are almost the same for two emission models, the input file formats are slightly different. For CMEM, the calibration parameters can be changed at the planning stage and saved for future run. The calibration parameters are types of engine, test of engine (I/M), meteorological conditions, etc. Moreover, fleet distribution can be saved for further use. Therefore, the calibration parameters need not change for multiple times/runs.

The remaining variables are vehicle trajectories that need to be inputted for different road links and intersections. The acceptable file format for input velocity profile is text file. For MOVES, the acceptable file format is excel file. The details of the input files are described in the next section.

The output from each model is CEF, which is averaged for a vehicle in terms of gram $/ \mathrm{mile}$. The emission rates from different models are present below. The sample composite emission factors from CMEM model are:

- Composite CO $14.501 \mathrm{~g} / \mathrm{km}$

- Composite $\mathrm{NO}_{\mathrm{X}} \quad 1.159 \mathrm{~g} / \mathrm{km}$

Whereas, the CEF from MOVES model are

\begin{tabular}{|llll|}
\hline Hour & $\mathrm{CO}$ & $\mathrm{NO}_{2}$ & Total_PM 2.5 \\
\hline 24 & 17 & 1 & 1 \\
\hline
\end{tabular}


Although both models produce composite emission factors, the results vary. This should not be a surprise since there are fundamental difference between chemistry acting behind the model. The output formats are different as well. As can be seen above, the CMEM provides results in three decimal format of numeric value, whereas MOVES provides results in integer form.

\subsection{MODEL COMPARISON (CMEM VS MOVES)}

The stochastic traffic micro-simulator generates traffic trajectories for "capacity-level traffic flow" at an intersection, and the microscopic emissions estimator (CMEM) accepted these traffic trajectories as input. As previously explained, CMEM was used for CO and $\mathrm{NO}_{2}$ emissions and MOVES provided PM emissions. It should be noted that MOBILE 6C could also be used, if necessary.

The MOVES application provided a rough comparison with the CMEM outputs for CO and NOx. The difference between the two models is that the CMEM is able to estimate emissions based on instantaneous speed changes of the engine and MOVES estimates packets of vehicles rather individual vehicles for emissions generation.

The activity summary of a road link obtained from the traffic microsimulation was used as an input to CMEM following necessary format changes with Microsoft Excel. The activity summary file includes link id, velocity, acceleration/deceleration, etc. on a second-bysecond basis. Other inputs to the CMEM model are available vehicle information that should link to the sample emission database. Following that step, the fleet activity can be defined based on fleet composition for the roads at the site of interest. 
Moreover, the definition of vehicle categories are not clear. The correlation on vehicle categories for both the models are tabulated below. In Table 5-1, third column shows the vehicle types following MOBILE emission model and those are similar to MOVES model. A sample of vehicle category frequency distribution applicable to Ottawa area roads is presented in table below.

Table 5-1: Frequency distribution of vehicles

\begin{tabular}{|c|c|c|c|}
\hline No. & Vehicle Category for CMEM & $\begin{array}{l}\text { Vehicle type for } \\
\text { MOBILE }\end{array}$ & Frequency \\
\hline 1 & No Catalyst & LDV1 & 0 \\
\hline 2 & 2-way Catalyst & LDV2 & 0 \\
\hline 3 & 3-way Catalyst, Carbureted & LDV3 & 0.0162 \\
\hline 4 & $\begin{array}{l}\text { 3-way Catalyst, FI, }>50 \mathrm{~K} \text { miles, low } \\
\text { power/weight }\end{array}$ & LDV4 & 0.0967 \\
\hline 5 & $\begin{array}{l}\text { 3-way Catalyst, FI, >50K miles, high } \\
\text { power/weight }\end{array}$ & LDV5 & 0.145 \\
\hline 6 & $\begin{array}{l}\text { 3-way Catalyst, FI, }<50 \mathrm{~K} \text { miles, low } \\
\text { power/weight }\end{array}$ & LDV6 & 0.0046 \\
\hline 7 & $\begin{array}{l}\text { 3-way Catalyst, FI, <50K miles, high } \\
\text { power/weight }\end{array}$ & LDV7 & 0.0085 \\
\hline 8 & Tier $1,>50 \mathrm{~K}$ miles, low power/weight & LDV8 & 0 \\
\hline 9 & Tier $1,>50 \mathrm{~K}$ miles, high power/weight & LDV9 & 0.1005 \\
\hline 10 & Tier $1,<50 \mathrm{~K}$ miles, low power/weight & LDV10 & 0.0588 \\
\hline 11 & Tier $1,<50 \mathrm{~K}$ miles, high power/weight & LDV11 & 0.1643 \\
\hline 12 & Tier $1,<50 \mathrm{~K}$ miles, high power/weight & LDV12 & 0 \\
\hline 13 & 1979 to $1983(<=8500 \mathrm{GVW})$ & LDV13 & 0 \\
\hline 14 & 1984 to $1987(<=8500 \mathrm{GVW})$ & LDV14 & 0.006 \\
\hline 15 & 1988 to $1993,<=3750 \mathrm{LVW}$ & LDV15 & 0.0118 \\
\hline 16 & 1988 to $1993,>3750 \mathrm{LVW}$ & LDV16 & 0.0642 \\
\hline 17 & $\begin{array}{l}\text { Tier } 1 \text { LDT2/3 (3751-5750 LVW or Alt. } \\
\text { LVW) }\end{array}$ & LDV17 & 0.149 \\
\hline 18 & $\begin{array}{l}\text { Tier 1 LDT4 (6001-8500 GVW, >5750 } \\
\text { Alt. LVW) }\end{array}$ & LDV18 & 0.0113 \\
\hline 19 & Runs lean & LDV19 & 0.0204 \\
\hline 20 & Runs rich & LDV20 & 0.0146 \\
\hline
\end{tabular}




\begin{tabular}{|r|l|l|r|}
\hline 21 & Misfire & LDV21 & 0.0409 \\
\hline 22 & Bad catalyst & LDV22 & 0.0275 \\
\hline 23 & Runs very rich & LDV23 & 0.0036 \\
\hline 24 & Tier 1, >100K miles & LDV24 & 0.0003 \\
\hline 25 & Gasoline-powered, LDT $(>8500$ GVW) & LDV25 & 0 \\
\hline 26 & LEV PC \& ULEV PC & LDV26 & 0 \\
\hline 27 & PZEV & LDV27 & 0 \\
\hline 28 & Diesel-powered, LDT $(>8500$ GVW) & LDV40 & 0.0105 \\
\hline 29 & HDGV2B & HDV5 & 0.0125 \\
\hline 30 & HDDV8A & HDV6 & 0.0201 \\
\hline 31 & HDDV8B & HDV7 & 0.0127 \\
\hline
\end{tabular}

A description of model application will be useful here. When all inputs were provided, the CMEM application resulted in computed composite emission factors for individual road links and intersections. A sample of results produced by CMEM model is shown in Figure 5-1.

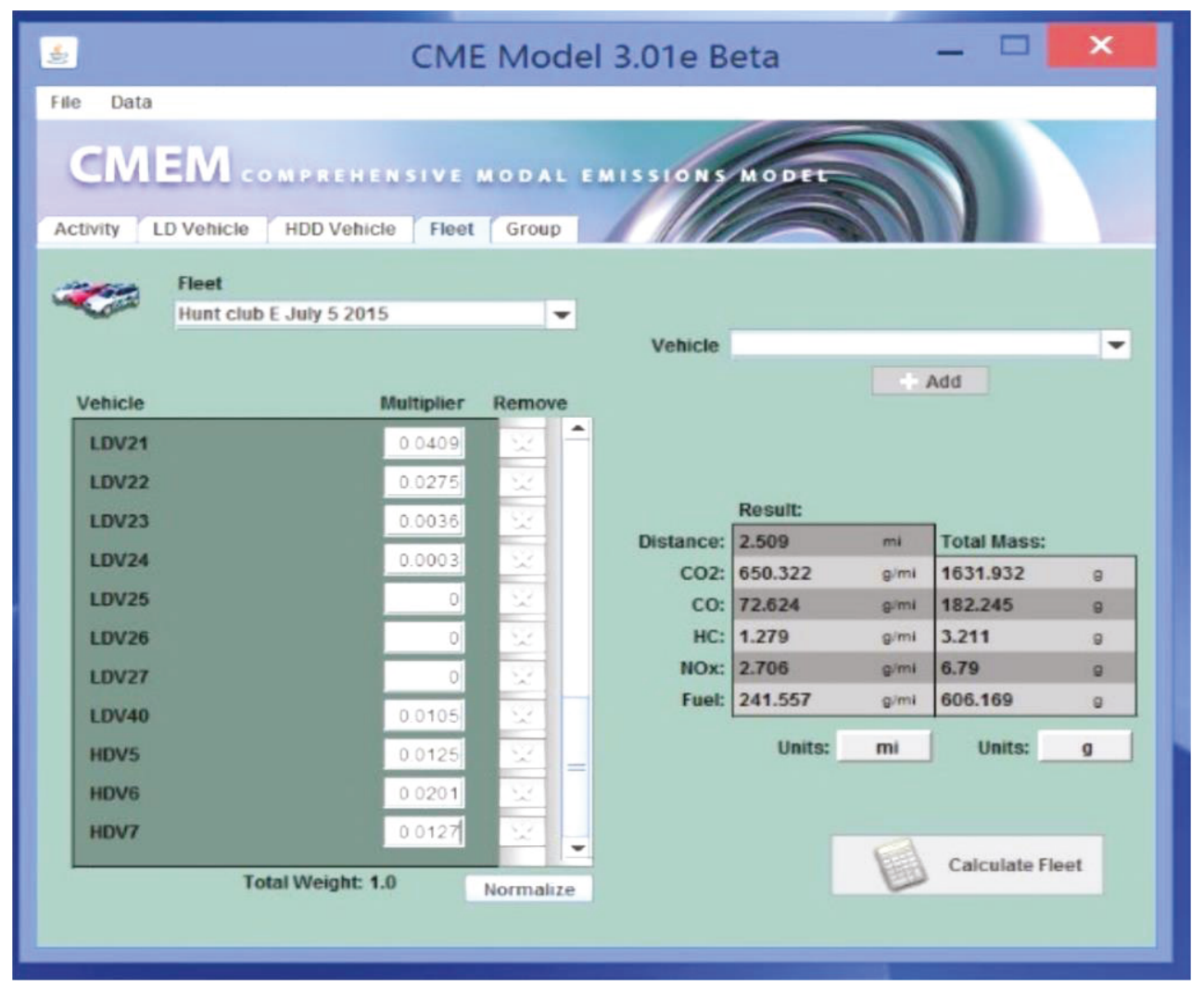

Figure 5-1: Sample output of CMEM model 
The screenshot of emission model presents the CEF for the gaseous emissions. It shows the results for Hunt Club road east bound traffic, whereas the CEF for other road links are tabulated below.

Table 5-2: Composite emission factor (in gram/mile)

\begin{tabular}{|l|c|c|}
\hline \multicolumn{1}{|c|}{ Link Name } & $C O$ & $N O_{x}$ \\
\hline Bank St. (North Bound) & 69.655 & 2.850 \\
\hline Bank St. (South Bound) & 85.377 & 2.944 \\
\hline Hunt club Road (East Bound) & 72.624 & 2.706 \\
\hline Hunt club Road (West Bound) & 80.830 & 2.631 \\
\hline
\end{tabular}

The advantage of using CMEM model is its micro-level emission estimation capability based on second-by-second vehicle movement trajectories obtained from VISSIM-7. On the other hand, it has a limitation, which is inability to estimate PM emissions.

The MOVES (a replacement of MOBILE model) has the capability to produce emission factors for each hour, each county, all speeds, all vehicle categories, and all roadway types. The details of the input files and related parameters are illustrated in Appendix VII. The basic input files in MOVES model are

1. Source type vehicle populations

2. Zone (i.e. geographic location)

3. Vehicle age distribution

4. Average speed distribution

5. Fuel 


\section{Meteorological conditions}

7. Road type distribution

8. Vehicle miles travelled (VMT), etc.

The details of input parameters are illustrated in appendices under an input file. As an example, fuel table contains fuel distribution fraction, whereas other information like fuel type, sub type, fuel combination, fuel use fraction in study area, fuel formula, and market share etc. are detailed as per software requirement.

Table 5-3: Output files from MOVES emission model (in gram/mile)

\begin{tabular}{|c|c|c|c|c|c|c|}
\hline Hour & Source & Fuel & $\mathrm{CO}$ & $\mathrm{NO}_{2}$ & $\mathrm{NO}_{\mathrm{x}}$ & $\mathrm{PM}_{2.5}$ \\
\hline 18 & 21 & 1 & 12 & 0 & 2 & 0 \\
\hline 18 & 31 & 1 & 26 & 0 & 4 & 0 \\
\hline 18 & 42 & 2 & 6 & 1 & 24 & 1 \\
\hline 18 & 62 & 2 & 6 & 2 & 32 & 1 \\
\hline
\end{tabular}

The output (emission rate) from MOVES model is a single result for each pollutants. However, it can be separated based on vehicle types and fuel types. Table 5-3 shows the details of output from the MOVES model.

\subsection{LIMITATION OF EMISSION MODELS}

This research is dealing with microscopic pollution concentrations, which are varying with spatial distribution and time of the day. Therefore, microscopic level composite emission factor is expected. However, the composite emission factor for each road link is assumed 
a constant value. Although, vehicle emissions were stimulated based on trajectories of individual cars, dispersion model needs emission rates in each road segment. It is impossible to separate emission for each car in a segment.

This thesis shows that a road network can be split into different segments. As an example, emission rates from sample road design are generated separately for individual road links and intersections. Moreover, directional emission rates are generated in a road link. It is also possible to estimate emission rates in different sections of a road link. 


\section{Chapter 6: GAUSSIAN DISPERSION MODEL}

\subsection{INTRODUCTION}

A key model for determination of air quality at the receptor site is a Gaussian Dispersion model. The use of such a model was proposed as a part of the research framework, because this model has the ability to estimate pollution concentration at any location surrounding the source of emissions. Although the model was primed for estimation of concentrations surrounding the point source of pollution, it was modified for mobile emissions source.

The Gaussian model follows the dispersion rate of pollution from source to its neighbouring locations. This model analyzes emission rate and provides concentrations that reflect meteorological conditions. The quality of air surrounding a highway or an urban road depends on emissions produced from motor vehicles. The wind speed and its direction are important factors for surrounding air quality. It is possible to estimate air contaminant levels at any position with known coordinates in crosswind direction from roads. Moreover, the dispersion rate calculation can be possible in vertical direction too.

An introduction to the dispersion model has already been presented in the methodology chapter. This chapter explains basic theory on dispersion model with equations. The development of the model for line source is highlighted. A software package was developed based on Gaussian dispersion theory with funds from the U.S. EPA. This package namely CALRoad view (with its three components), was exclusively prepared for the line source of emissions. 
The Gaussian dispersion-based air quality model was used in this research for the reason that for intended application conditions, it is the correct model (i.e., its conditions/assumptions are met in application contexts and the recirculation effects of air pollutants near road and canyon effect are not encountered. The two sources of sophisticated street models such as the Danish OSPM and French SIRANE are acknowledged. However, this research has focused on the definition of criteria that can be used in planning. From this perspective, the worst-case wind conditions (low wind speed, but within the guidelines of the model used) is considered in this research. Since the wind speed is low, the incorporation of air recirculation effects due to tall buildings is not necessary. Further, this research is not focusing on very high density central business districts with tall buildings around streets and their intersections.

Also presented in this chapter are the input parameters and outputs of the dispersion model. The GIS platform enabled the demonstration part of the results. The model output is demonstrated with graphical presentation. Finally, results are highlighted and requirements for design of simulations are described.

\subsection{BASIC DISPERSION MODEL}

Several empirical dispersion models have been reported. These models are based on mathematical descriptions of the meteorological transport and dispersion of air contaminants in an area. These enable estimate of contaminant concentrations, either in the plume from an elevated or ground level source. The most useful equations in use today are based on the following general equation, which was developed by Pasquill and modified by Gifford (1985).

$$
\frac{\mathrm{dC}}{\mathrm{dt}}=\frac{\partial}{\partial \mathrm{x}}\left(K_{x} \frac{\partial x}{\partial x}\right)+\frac{\partial}{\partial \mathrm{y}}\left(K_{y} \frac{\partial x}{\partial y}\right)+\frac{\partial}{\partial \mathrm{z}}\left(K_{z} \frac{\partial x}{\partial z}\right)
$$


The variable ' $\mathrm{C}$ ' is the pollution concentration in this equation and other variables are noted in the figure below. In Figure 6-1, dispersion in the $\mathrm{x}$ (downwind) direction is presented as a function of variables in all directions of a three-dimensional space. This formulation assumes that the plume follows Gaussian concentration distribution in both the $\mathrm{z}$ (vertical) and y (horizontal) directions.

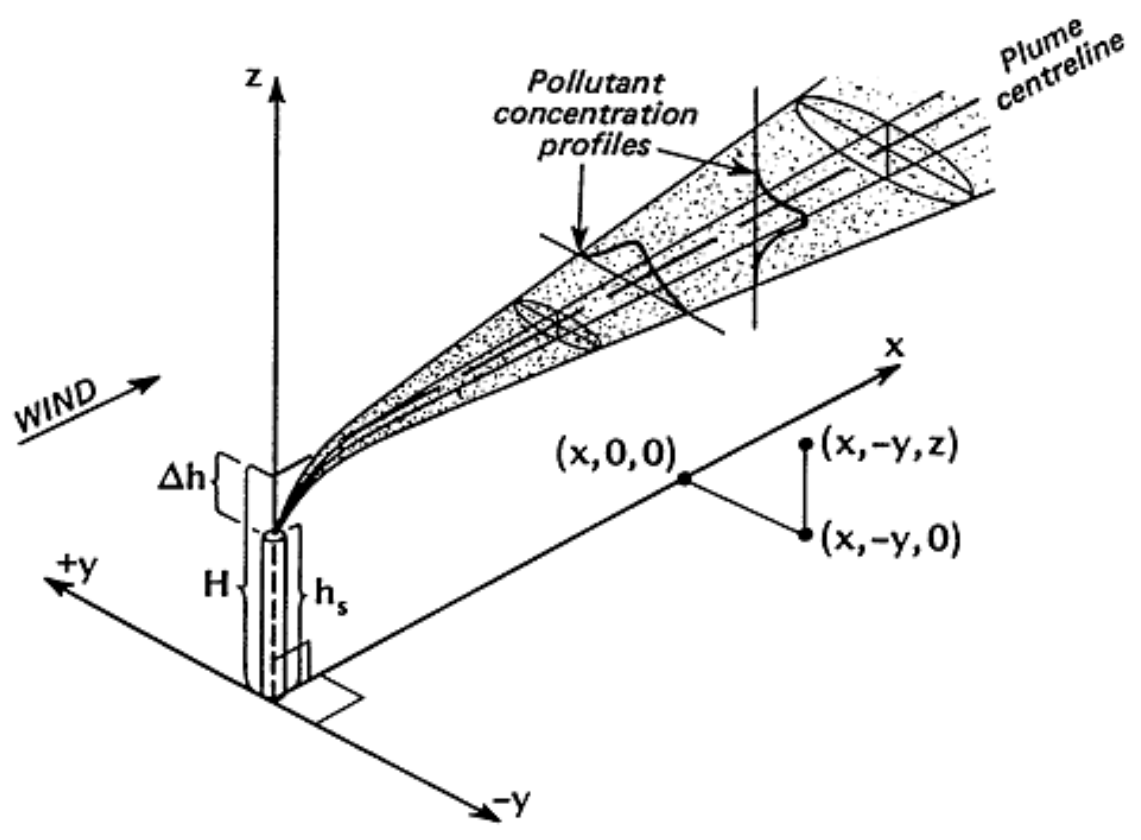

Figure 6-1: Coordinate system showing Gaussian distribution of flume in the horizontal and vertical direction

(Source: Peavy and Rowe, 1985)

The ground level concentration (C) of a gas or aerosol calculated for a distance downwind (x) is given by the following equation (Peavy and Rowe, 1985):

$$
C_{x, y}=\frac{Q}{\pi u \sigma_{z} \sigma_{y}} e^{\left[-\frac{1}{2}\left(\frac{H}{\sigma_{z}}\right)^{2}\right]} e^{\left[-\frac{1}{2}\left(\frac{y}{\sigma_{y}}\right)^{2}\right]}
$$

Where $\mathrm{C}=$ pollutant concentration at any point of receptor position, $\mathrm{g} / \mathrm{m}^{3}$ $\mathrm{Q}=$ pollutant emission rate, $\mathrm{g} / \mathrm{s}$ 
$\mathrm{u}=$ mean wind speed, $\mathrm{m} / \mathrm{s}$

$\sigma_{y}=$ standard deviation of horizontal plume concentration, evaluated in terms of downwind distance $\mathrm{x}, \mathrm{m}$

$\sigma_{z}=$ standard deviation of vertical plume concentration, evaluated in terms of downwind distance $\mathrm{x}, \mathrm{m}$

$\mathrm{H}=$ Effective stack height, $\mathrm{m}$

$\mathrm{x}=$ downwind distance along plume mean centreline from point source, $\mathrm{m}$

$\mathrm{y}=$ crosswind distance from the centreline of the plume, $\mathrm{m}$

This equation may be simplified by the modification of effective stack height. The stack height can be set equal to zero for situation of ground level combustion of fuel. As an example, an exhaust of a tailpipe in a vehicle close to surface of road. It is also simplified if crosswind distance equals to zero. That means the requirement of pollution concentrations along the plume centreline (e.g. pollutants concentration level on the highway). The standard deviation values for both horizontal and vertical direction of plume concentrations can be appreciated from the figures below.
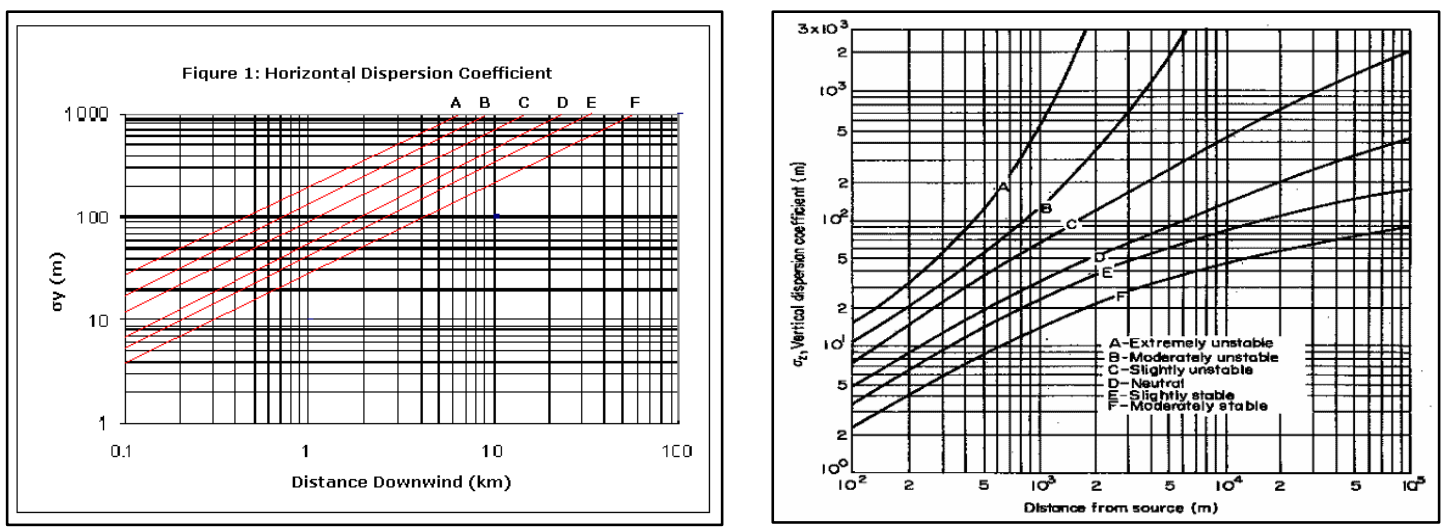

Figure 6-2 (a \& b): Lateral diffusion coefficient $\sigma_{\mathrm{y}}$ vs. downwind distance from source and vertical diffusion coefficient $\sigma_{z}$ vs. downwind distance from source

(Source: Peavy and Rowe, 1985) 
The values for $\sigma_{y}$ and $\sigma_{z}$ are a function of downwind distances as well as atmospheric stability. Values of $\sigma_{y}$ and $\sigma_{z}$ for various distances downwind (x), with various stability categories are shown in Figures 6-2 and 6-3. Generalized categories are noted in Table 61 as Pasquill stability types.

Table 6-1: Pasquilly's stability types

(Source: Peavy and Rowe, 1985)

\begin{tabular}{|c|c|c|c|c|c|}
\hline \multirow{2}{*}{$\begin{array}{c}\text { Wind velocity }(\mathrm{V}) \text { on } \\
\text { reference height of } 10 \mathrm{~m}(\mathrm{~m} / \mathrm{s})\end{array}$} & \multicolumn{2}{|c|}{ Daytime period - Insolation } & \multicolumn{2}{c|}{ Nighttime period - Cloudiness } \\
\cline { 2 - 6 } & Strong & Moderate & Slight & Thinly overcast & $<=3 / 8$ cloud \\
\hline $\mathrm{V} \leq 2$ & $\mathrm{~A}$ & $\mathrm{~A}-\mathrm{B}$ & $\mathrm{B}$ & - & - \\
$2<\mathrm{V} \leq 3$ & $\mathrm{~A}-\mathrm{B}$ & $\mathrm{B}$ & $\mathrm{C}$ & $\mathrm{E}$ & $\mathrm{F}$ \\
$3<\mathrm{V} \leq 5$ & $\mathrm{~B}$ & $\mathrm{~B}-\mathrm{C}$ & $\mathrm{C}$ & $\mathrm{D}$ & $\mathrm{E}$ \\
$5<\mathrm{V} \leq 6$ & $\mathrm{C}$ & $\mathrm{C}-\mathrm{D}$ & $\mathrm{D}$ & $\mathrm{D}$ & $\mathrm{D}$ \\
$6<\mathrm{V}$ & $\mathrm{C}$ & $\mathrm{D}$ & $\mathrm{D}$ & $\mathrm{D}$ & $\mathrm{D}$ \\
\hline
\end{tabular}

\subsection{DEVELOPMENT OF LINE SOURCE FORMULATION}

The Gaussian formulation of the concentration field for pollutants emitted from a line source is the result of the integration of the point source solution over the line source (Briant et. al., 2013).

$$
\mathrm{C}(\mathrm{x}, \mathrm{y}, \mathrm{z})=\int_{y_{1}}^{y_{2}} \frac{Q}{2 \pi u \sigma_{\mathrm{y}}(\mathrm{s}) \sigma_{\mathrm{z}}(\mathrm{s})} \exp \left(\frac{-z^{2}}{2 \sigma_{z}^{2}(s)}-\frac{(y-s)^{2}}{2 \sigma_{y}^{2}(s)}\right) d s
$$

Where, $\mathrm{C}$ is the pollutant concentration in $\mathrm{g} / \mathrm{m}^{3}$ at location $(\mathrm{x}, \mathrm{y}, \mathrm{z})$, $\mathrm{x}$ is the distance from the source along the wind direction in $\mathrm{m}$, $\mathrm{y}$ is the horizontal crosswind distance from the plume centerline in $\mathrm{m}$, $\mathrm{z}$ is the vertical crosswind distance from the plume centerline in $\mathrm{m}$, $\mathrm{u}$ is the wind velocity in $\mathrm{m} / \mathrm{s}$, 
$\mathrm{Q}$ is the emission rate in $\mathrm{g} / \mathrm{s}$,

$y_{1}$ and $y_{2}$ the ordinates of the source extremities,

$\sigma_{\mathrm{y}}$ and $\sigma_{\mathrm{z}}$ are the standard deviations representing pollutant dispersion in the crosswind directions in $\mathrm{m}$, which are derived from experimental datasets.

This formulation was proposed by Venkatram and Horst (2006) and is commonly referred to as Horst-Venkatram (HV) Model. It consists of solving the integral by approximating the integrand and excluding from the computation part of the line source that is downwind of a given receptor. The effective distance $d_{\text {eff }}\left(\right.$ Eq. 6-4) is needed to compute $\sigma_{z}$ and a distance $d_{i}$ (Eq. 6-5) from each extremity of the line source section in the wind direction for $\sigma_{\mathrm{y}}$.

$$
\begin{aligned}
& \mathrm{d}_{\mathrm{eff}}=\mathrm{x} / \cos \theta \\
& \mathrm{d}_{\mathrm{i}}=\left(\mathrm{x}-\mathrm{x}_{\mathrm{i}}\right) \cos \theta+\left(\mathrm{y}-\mathrm{y}_{\mathrm{i}}\right) \sin \theta
\end{aligned}
$$

Where, $\mathrm{x}$ and $\mathrm{y}$ are the coordinates of the receptor,

$x_{i}$ and $y_{i}$ the coordinates of the source extremity $i$ (with $i=1$ or 2 ) in the source coordinate system.

$\theta$ represents the angle between the normal to the line source and the wind direction.

Solving Equation 6-3 with HV approximation leads to Equation 6-6. This equation provides the concentration field for all wind directions. The term $u \cos \theta$ in the equation represents the projection of the wind velocity onto the normal direction to the source.

$$
\begin{aligned}
\mathbf{C}(\mathrm{x}, \mathrm{y}, \mathrm{z})= & \frac{Q}{2 \sqrt{2 \pi} u \cos \theta \sigma_{z}\left(d_{e f f}\right)} \exp \left(\frac{-z^{2}}{2 \sigma_{z}^{2}\left(d_{e f f}\right)}\right) X\left[\operatorname{erf}\left(\frac{\left(y-y_{1}\right) \cos \theta-x \sin \theta}{\sqrt{2} \sigma_{y}\left(d_{1}\right)}\right)-\right. \\
& \left.\operatorname{erf}\left(\frac{\left(y-y_{2}\right) \cos \theta-x \sin \theta}{\sqrt{2} \sigma_{y}\left(d_{2}\right)}\right)\right]
\end{aligned}
$$


If $\mathrm{d}_{\mathrm{i}}$, the distance used to compute $\sigma_{\mathrm{yi}}$ from both extremities, turns out to be negative, the receptor is not downwind of the extremity i. According to the formulation, a receptor can be downwind of an extremity and upwind of the other. In that case, in the HV formulation, a segment of the source is excluded from calculation by setting the term: $\operatorname{erf}\left(\frac{\left(y-y_{i}\right) \cos \theta-x \sin \theta}{\sqrt{2} \sigma_{\mathrm{y}}\left(d_{i}\right)}\right)$ of Equation 6-6 to: $-\operatorname{sign}(\sin \theta)$.

\subsection{SOFTWARE PACKAGE FOR LINE SOURCE MODELLING}

This software package was developed based on the theory discussed in the earlier section. It is known as the CALRoads View. This package was developed by the United States government agency (the U.S. EPA) and is marketed by Lakes Environment. The CALRoads View is a dynamic and intuitive user-friendly interface for three air dispersion models:

- CALINE-4 model,

- $\quad$ CAL3QHC model, and

- CAL3QHCR model.

CALINE-4 is an air quality model, which analyzes the emissions from line sources. It was developed to assess air quality impacts of carbon monoxide, nitrogen di-oxide, and suspended particles near roadways. This model supports transportation-related studies and was developed with the collaboration of the California Department of Transportation (CALTRANS).

The CALINE model has the following features:

predict pollutant concentrations for receptors located within 500 meters of the roadway 
be used to model multiple sources and receptors, curved alignments, or roadway segments with varying emission factors

model air quality near intersections, street canyons, and parking facilities

summarize the contributions from each link to each receptor

CAL3QHC is a model designed to predict $\mathrm{CO}$ and other pollutant concentrations from motor vehicles at roadway intersections. It was developed by/for the U.S. Environmental Protection Agency and includes the CALINE-3 line source dispersion model and a traffic algorithm for estimating vehicular queue lengths at signalized intersections. In this model, the input requirements are roadway geometric design factors, receptor locations, meteorological conditions, and vehicular emission rates. The model assumes flat topography.

CAL3QHCR is an advanced version of the CAL3QHC model. It allows processing of up to one year of meteorological data and vehicular emissions, traffic volume, and signalization (ETS) data in one run using the basic algorithms from CAL3QHC. Daily to seasonal runs can also be made with CAL3QHCR, whereas CAL3QHC was designed to process only one hour of ETS and meteorological data.

- CAL3QHCR allows for two tiers approach. These two approaches enhance the basic approach used in CAL3QHC.

Tier I Approach: A full year of hourly meteorological data is entered into CAL3QHCR in place of the one hour of artificial meteorological data that are commonly used in CAL3QHC model. One hour of ETS data are also entered as is done for the use of CAL3QHC. 
Tier II Approach: The same MET data as used in the Tier I approach are used in the model. The ETS data however, are more detailed and these reflect traffic conditions for each hour of a week. CAL3QHCR reads the ETS data as up to 7 sets of hourly ETS data (in the form of diurnal patterns). These are processed into a week of hourly ETS data. The weekly ETS data are synchronized with the meteorological data year. The weekly traffic conditions are assumed to be the same for each week throughout the specified modeled period.

- CAL3QHCR is programmed to calculate 1-hour and running 8-hour averaged CO or 24-hour and annual block averaged PM concentrations while CAL3QHC only prints maximum hourly averages. Additionally, the CAL3QHCR outputs include:

A table of calm wind durations with their respective frequencies

$>$ Identification of truncated queues due to queues exceeding the physical constraints of the intersection

$>$ Optional link contribution results for each printed average

$>$ Optional use of variable ambient background concentration data in calculating the various maxima concentrations

$>$ Maximum design concentrations for all receptors

\subsection{INPUT PARAMETERS}

In this research, our primary concern is to predict the air quality near the roadways. For this purpose, the input parameters to the CALRoads software are classified into four groups. Those four groups of data are

1. Transportation Related Data

2. Meteorological Inputs 


\section{Background Pollution Concentrations}

\section{Composite Emission Factor}

Transportation related data includes roadway geometry and link activity. Road geometric features are road length, and road direction. Link type could be at grade, depressed, fill, bridge, and intersection. Link height represents the elevation with respect to surroundings surface. Mixing zone width is the road width plus shoulder width (shoulder that equals to 6 meter as default). Link activity data includes hourly traffic volume in vehicles per hour (vph) and emission rate (in $\mathrm{g} /$ mile) for individual road link. For the intersection study, the queue information and traffic signalling information such as cycle length, green time, red time etc. are required as input. The composite emission factor (equals to the emission rate of pollutants) is needed to input as a link activity data. It was noted earlier that background pollution concentrations are simply added with the concentration from mobile sources to represent the quality of air at receptor site. The meteorological conditions influence the pollution dispersion rate from the source to receptors. So, meteorological data are needed to understand the phenomenon. The next section illustrates the meteorological inputs and their characteristics.

The meteorological phenomenon influences air quality. Understanding the relationship between atmospheric conditions and air pollutions can lead to a reduction of adverse effect of the relationship.

Dilution of air contaminants in the atmosphere is a natural process. This process helps to reduce undesirable levels of pollutants in the ambient air. Atmospheric dispersion of air contaminant results from ventilation, atmospheric turbulence, and molecular diffusion. 
However, gaseous and particulate air contaminants are primarily dispersed into ambient air through wind action and atmospheric turbulence. Much of this takes place at the microscale level. For calculation of pollutant dispersion rate, some of meteorological parameters have to be considered. The mixing height and atmospheric stability class can be explained by the theory of lapse rate. Please see below the lapse rate variation with atmospheric conditions.

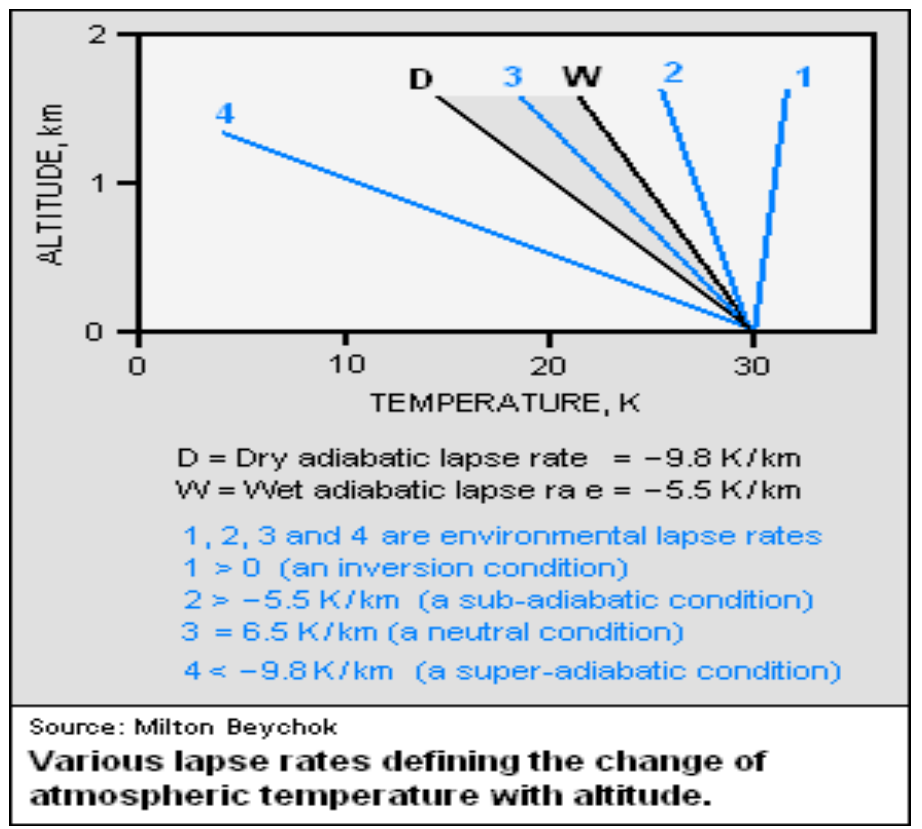

Figure 6-3: Lapse rate (dry and wet) and atmospheric stability class

The lapse rate is the rate at which atmospheric temperature decreases with increase in altitude. The rate at which atmospheric temperature decreases with increasing altitude in conditions of thermal equilibrium is known as adiabatic lapse rate. The contaminant removal process can be predicted by comparing the ambient lapse rate to the adiabatic lapse rate. 
If the environmental lapse rate (ELR) is equal to or very close to dry adiabatic lapse rate (DALR), the flume from the source will rise directly into the atmosphere. This type of emission is called a neutral plume. When the ELR is super adiabatic (more than adiabatic), the turbulence of air itself will cause the atmosphere to be severe. In this unstable atmospheric condition, the emitted pollutants undergo rapid mixing. Under conditions when the ambient lapse rate is sub-adiabatic, the atmosphere is slightly stable. Figure 6-3 illustrates the atmospheric stability (either stable or unstable) classes and directions with its gradient.

The following meteorological data are the inputs into the CALRoads software for a specific road link or an intersection. The brief definition of those terms are discussed below.

Wind Speed (in $\mathrm{m} / \mathrm{s}$ ): The actual wind speed data are available in meteorological stations. For micro level studies, the wind speed should be measured close to the study location. For simulation design and planning, the 'worst-case' wind speed for the study area is to be considered as input in software. The worst case in terms of wind speed is the minimum speed of the wind. Because, low wind speed means the removal rate of pollutants are close to zero. The minimum accepted wind speed value in the above software is $0.5 \mathrm{~m} / \mathrm{s}$.

Wind Direction (in Degrees): Wind directions are calculated with respect to the direction of vehicles moving on the road. The statistical standard deviation of the wind direction, which is $0<=\mathrm{BRG}<=360 \mathrm{deg}$. Wind azimuth bearing measured relative to positive $\mathrm{Y}$ axis (e.g., 90 deg equivalent to a wind directly from the east).

Atmospheric Temperature $\left(\right.$ in $^{O} \mathrm{C}$ ): The atmospheric temperature influences the pollutants concentrations, because of diurnal effects. It is proved that concentration at receptor 
locations are greater for high temperature. So, temperature is considered as a variable for modelling purposes.

Atmospheric Stability Class (A to G): Figure 6-4 illustrates atmospheric stability conditions. The effects are illustrated in Figure 6-3. The stable atmospheric conditions arise when the actual lapse rate is greater than dry adiabatic lapse rate. The significance of stable atmosphere implies pollutants removal rate close to zero.
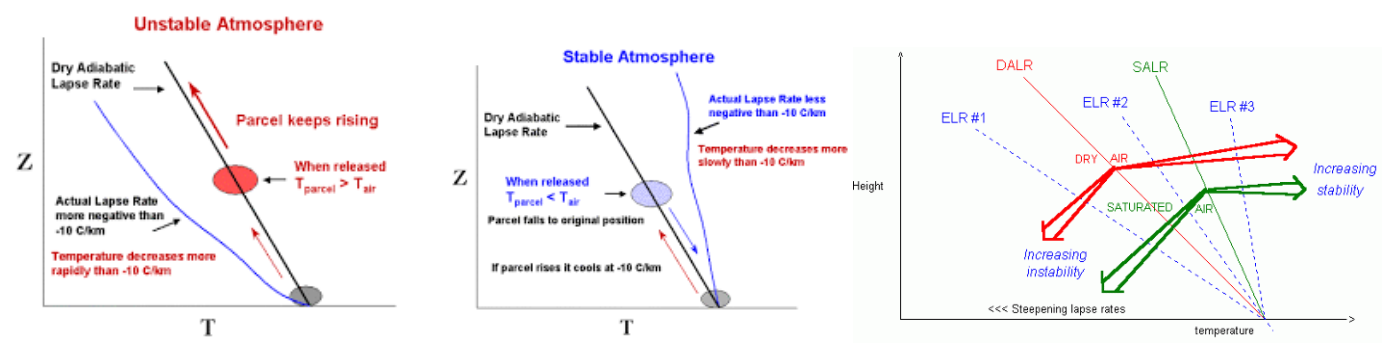

Figure 6-4: Atmospheric stability conditions (Source: http://www.recreationalflying.com/tutorials/meteorology)

In the above figure, DALR $=$ dry adiabatic lapse rate $(\mathrm{dT} / \mathrm{dZ})$, which means change in temperature with respect to height from ground. ELR = environmental lapse rate that changes with time of the day, season, cloud coverage etc. The 'worst case' condition refers to low pollutants removal rate.

Mixing height (in $\mathrm{m}$ ): Mixing height is the altitude at which thermal turbulence occurs due to solar heating of the ground. In other words, the mixing height defines the height of vertical mixing of air and suspended particles above the ground. This height is decided by the observation of the atmospheric temperature profile. 


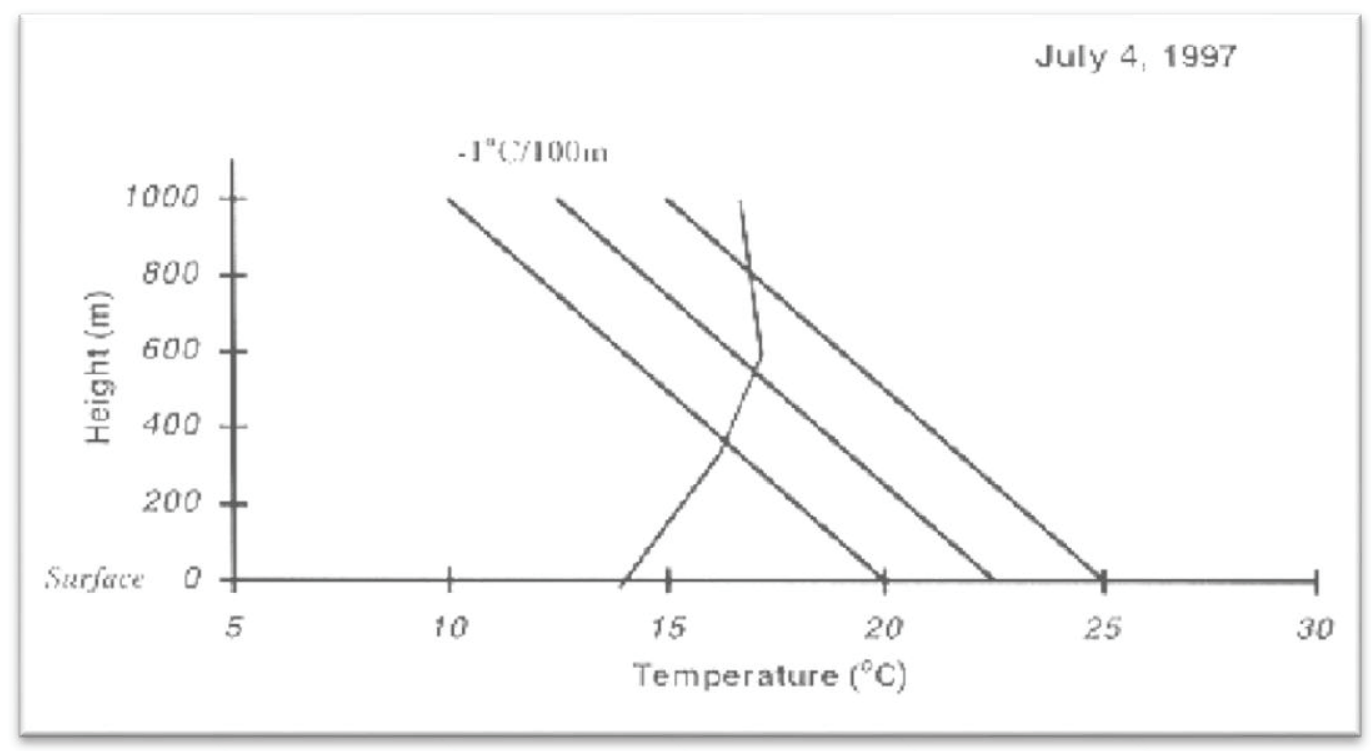

Figure 6-5: Mixing height

(Source: http://www.eng.utoledo.edu/aprg/courses/iap/text/met/15_max_mix_ht.html)

Mixing Height represents the height above the surface where a pollutant such as smoke can be dispersed.

$$
\mathrm{MIXH}=(0.185 * \mathrm{U} * \mathrm{k}) /\left(\ln \left(\mathrm{Z} / \mathrm{Z}_{0}\right) * \mathrm{f}\right)
$$

Whereas,

$$
\begin{aligned}
& \mathrm{U}=\text { wind speed }(\mathrm{m} / \mathrm{s}), \mathrm{Z}=\text { height } \mathrm{U} \text { measured at }(\mathrm{m}) \\
& \mathrm{Z}_{0}=\text { Surface roughness }(\mathrm{m}), \mathrm{k}=\text { von Karman constant }(0.35) \\
& \mathrm{f}=\text { Coriolis parameter }=1.45 \times 10^{\wedge}-4 \cos \text { theta }(\mathrm{radians} / \mathrm{sec}) \\
& \text { theta }=90 \text { degree }- \text { site latitude }
\end{aligned}
$$

The wind speed, wind direction, and ambient temperature data are available from open source climate data. Whereas wind speed and atmospheric temperature are measured using instrument in field during field survey. The next chapter covers the field survey. But, the 
atmospheric stability class and mixing height are to be specified for the 'worst case' conditions.

\subsection{GIS FRAMEWORK}

Geographic Information System (GIS) is a planning tool used in multi-disciplinary research. It is a very effective tool for natural resource-based information. Therefore, any kind of land-based research incorporates GIS. There are two reasons for GIS to become an effective tool. First, it enables accurate data analysis. Second, it has a very useful and effective facility to display data.

As noted earlier, the GIS serves a useful purpose in this research by showing roads and surrounding land use. GIS becomes a crucial tool due to its precise data analysis capabilities. Moreover, it can be used to associate the spatial data with attributes such as demographic data. Geographic information system is an indispensable tool for use in transportation emissions research (Liu et.al. 2010; Patil et. al. 2003; Reddy, 2011, Goodchild, 1980; Mark \& Aroson, 1984). This research uses a tool within Arc-GIS version-10.2 that facilitates the task to draw multiple buffer lines surrounding a road line. Figure 6-6 shows the multiple buffers from the roadway. Roadway pavement is highlighted with solid color, whereas lines surrounding the pavement are illustrating the tangential distances from road edge. Those lines can be termed as 'set-back' distances. The thematic color demonstrates the crosswind distance from the pavement edge. 


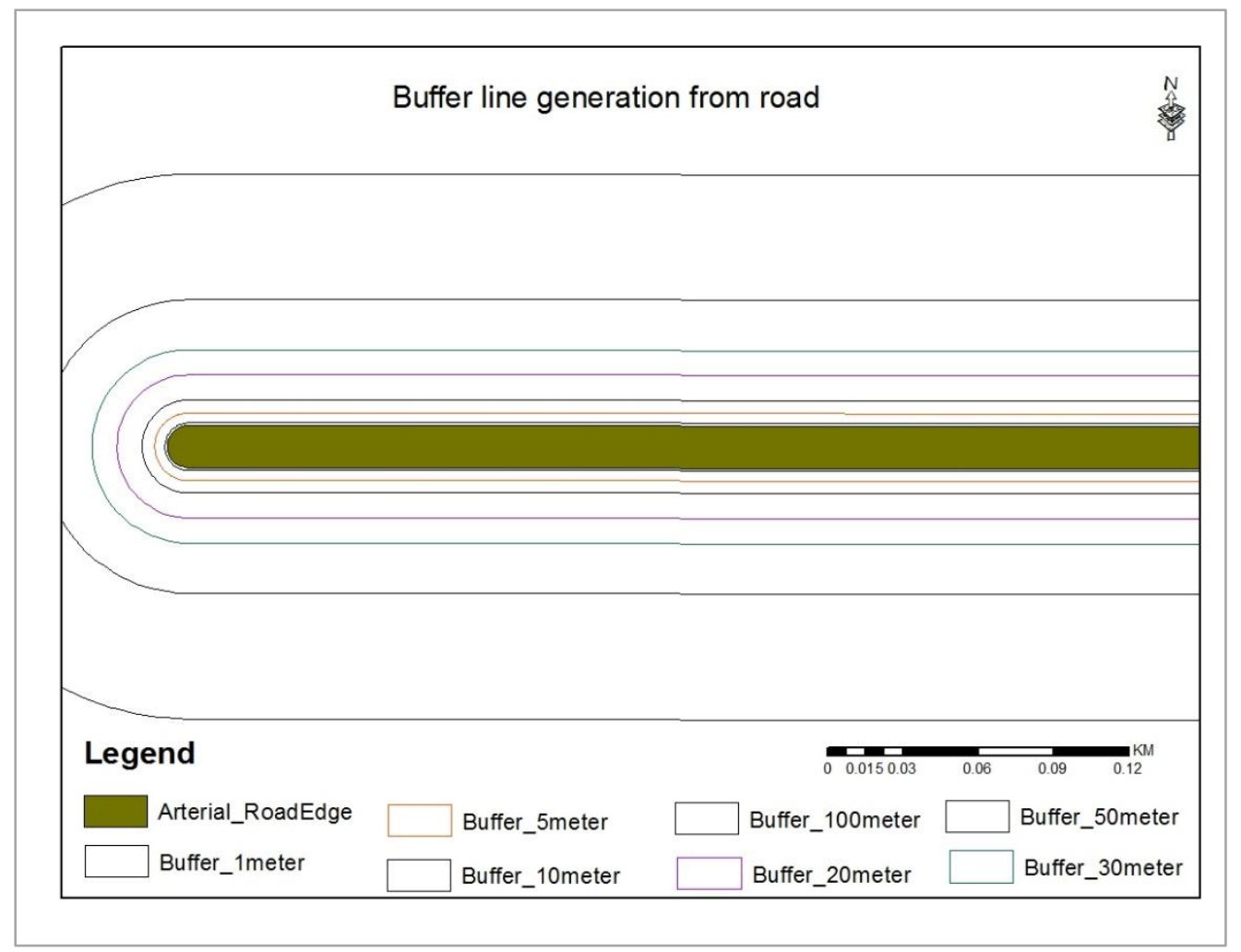

Figure 6-6: Multiple buffer lines generation from outer edge of a road using GIS software

Historically, a number of GIS-based case studies of transportation emissions have been reported prior to and around 2000. These include research reported by Thrill, 2000 as noted by Sikdar 2001, which advanced the use of GIS for air pollution profiling for Delhi city, India, from monitored short-term (hourly) data. This study report was used in support of managing transportation systems. In general, GIS can be used in almost all parts of transportation planning, operations, and management (e.g. estimation of travel demand and emissions) (Alterkawi, 2001).

GIS enables the estimation of detailed link and node level emissions. Such detailed estimates can be used to identify "hot spots" in the transportation network (Armstrong \& Khan 2004). Other examples of the use of GIS as a framework for the investigation of 
emissions can be found in the following references: Charlot et. al. (2002), and Ganguly \& Broderick (2009). The above literature survey demonstrates that GIS is not only used for data analysis, but it can be useful for display of results. The GIS tool is a great source for making intelligent maps in the form of displaying overlapping results. An example of the spatial coverage of GIS-based emission study presented in Figure 6-7 shows the nitrogen dioxide concentrations for 24-hrs on different roadways in greater Toronto area, where inset- 1 is the downtown area and inset-2 is the Greater Toronto Area's Highway 401.

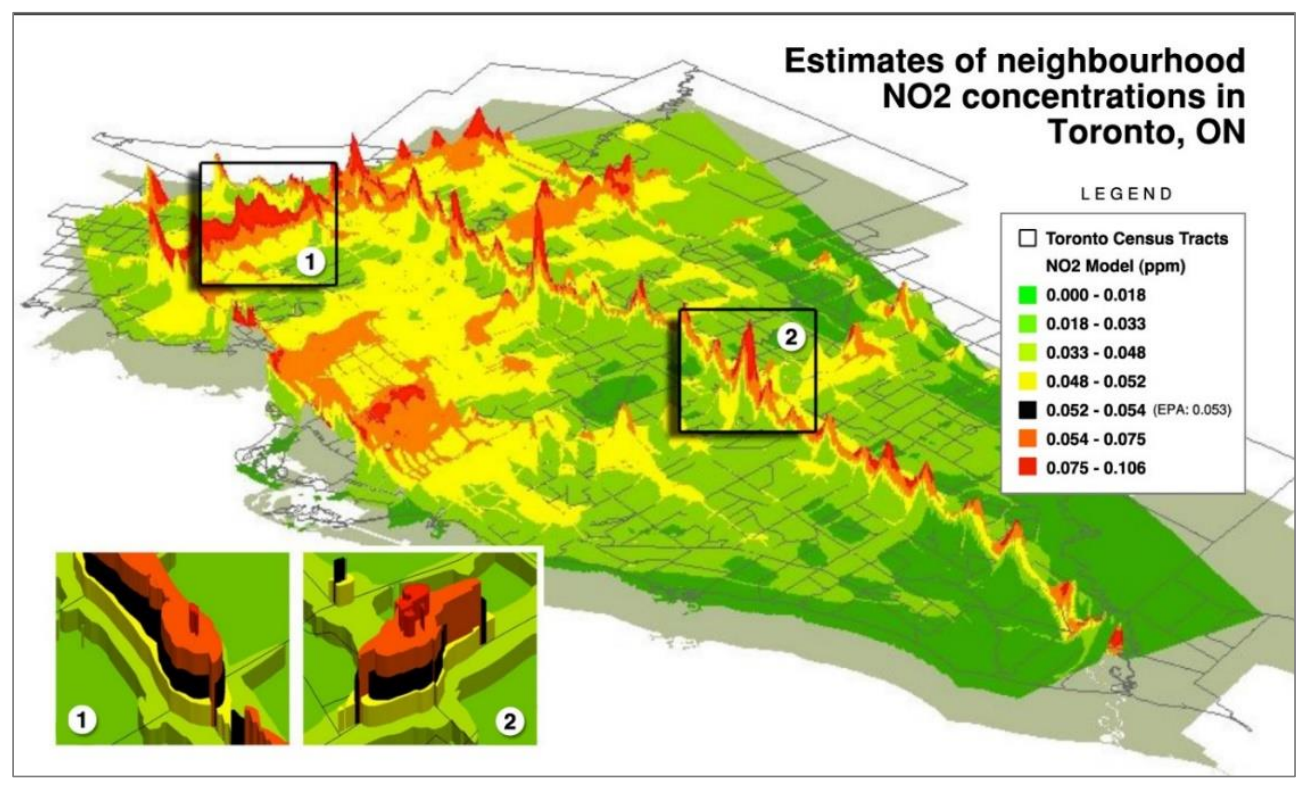

Figure 6-7: Three-dimensional view of pollutant concentrations on roads in GIS platform

(Source: http://www.ehatlas.ca/air-pollution/case-study/urban-pollution)

The above figure represents a three-dimensional view of on road pollution concentrations. The color represents the intensity of pollutants. The on-road $\mathrm{NO}_{2}$ pollutant concentration in Toronto downtown areas and in some portions of Highway-401 are higher than the 
EPA's standards (equals to 53 parts per billions). This attractive presentation in GIS environment illustrates the on-road pollution concentrations.

\subsection{MODEL OUTPUT}

As an illustration of the model output, an Ottawa case study is presented in Figure 6-8 for the intersection of Bank Street and Hunt Club Road. The results are overlapped with highresolution map extracted from Google site. In this figure, the blue straight lines represent the segments of road link and dash lines surrounding road lines present the road edge. The characteristics of road links (such as VPH, CEF) were input in the software. The next step of the work was providing meteorological parameters.

Now the model was ready to run and outputs could be provided for pollutant concentrations, such as $\mathrm{CO}, \mathrm{NO}_{2}$ or PM. The output could be obtained in the form of pollutant concentration at the site of a receptor, or in the form of contour lines of pollutant concentration. Figure 6-8 illustrates the carbon monoxide concentration level, whereas the green plus $(+)$ indicates the $\mathrm{CO}$ levels at receptors or building locations. The thematic colors bounded by the contours show the quality of air within the study area. The color codes (bar line) in the right hand side of this figure shows the $\mathrm{CO}$ concentration levels in parts per million (ppm). 


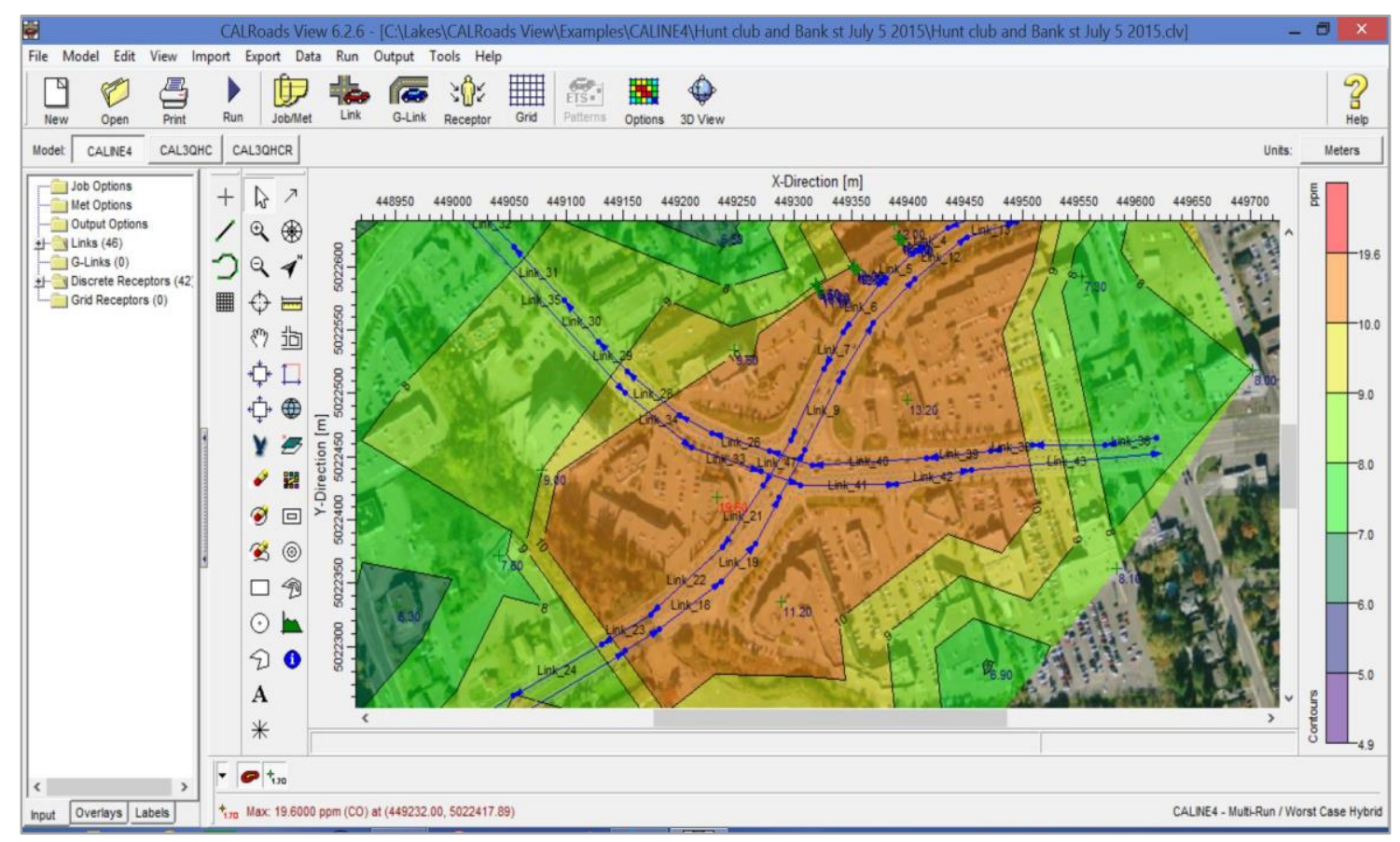

Figure 6-8: $\mathrm{CO}$ concentration contours and levels at receptors site

Figure 6-8 is a sample example run that demonstrates the type of outputs obtains from the model. These results generated are based on pre-defined receptor locations (indicated as plus sign). The maximum concentration occurs in the south-west side of the intersection, which is $19.6 \mathrm{ppm}$.

The outputs of the model are presented in Appendix IV and V, where road link numbers are represented as alphabets $(\mathrm{A}, \mathrm{B}, \mathrm{C}$, and $\mathrm{D})$ and receptors are represented as numbers $(1$, 2, 3 and 4). The coordinates of receptor points are represent by (X, Y) in meters. Moreover, the contributions of pollutant concentrations from each link for a specific receptor are also presented in detail. 


\subsection{DISCUSSION}

Returning to the research methods, the air quality software (i.e. CALRoads View version6.2.6) is used with its incorporated of GIS environment. The GIS environment facilitates the study of geo-coded satellite image of a study area of interest. Therefore, the real road line with exact dimensions can be drawn from the imagery. In addition to roadway lines, the surrounding land use can be studied. The software can demonstrate the concentrations of pollutants in the form of contour lines, distance from roadways, and at building locations.

An example case in Ottawa was presented in the previous section. In addition, the example of a retirement home located on the Hunt Club Road near a major intersection was provided. A retirement home is usually treated as a "sensitive land use class". This facility was built very close to Hunt Club Road. The setback distance from the road edge to a wall of one wing of the building is less than 10 meters. Please see Figure 2-2 for reference.

In this example, the model produced $\mathrm{CO}$ concentration for Hunt Club and Bank Street intersection (Ottawa) for both run types noted earlier, which are maximum 1-hour worst case and 8-hours multi run/worse case hybrid condition. Computations were carried out for both seasons by changing the meteorological conditions. The example case was run for winter using January 1, 2015 climate data and for summer using July 1, 2015 climate data.

It was noted earlier that receptor locations as shown as plus sign before running the software. For 1-hour $\mathrm{CO}$ concentration study, winter season shows the maximum concentration as $4.5 \mathrm{ppm}$, but summer season shows the maximum concentration as 21.4 ppm. The results were produced for the pre-defined receptor locations. According to 
Canadian Standard, 1-hour maximum concentration level is $31 \mathrm{ppm}$ and the US NAAQ Standard is $35 \mathrm{ppm}$. Therefore, the one-hour carbon monoxide study implies that the concentration level is safe for both seasons.

For 8-hour CO study, the maximum concentration at the receptor level during summer is 19.6 (displayed in Figure 6-8). However, according to the Canadian and US standards 8hour worse case $\mathrm{CO}$ concentration level should not be more than $9 \mathrm{ppm}$. The result implies that this particular intersection is polluted due to traffic related air pollution in the summer. Therefore, according to the results of this preliminary example case, the receptors living near this intersection, are not likely to be safe in respect of health. Specifically, the retirement home situated very close to Hunt Club Road, which is considered as a sensitive land use, should be studied further in terms of $\mathrm{CO}$ concentration.

The 8-hour worse case study for winter season shows the maximum $\mathrm{CO}$ concentration as 4.48 ppm, which is less than the Canadian and US standards. Therefore, on the basis of these results, winter season is safe for this intersection. However, it should be noted that according to general literature, winter season is worse than the summer in terms of CO concentration. However, this example case study shows that winter season for this intersection is safe. The reason is the high wind speed during winter that is $7.9 \mathrm{~m} / \mathrm{s}$ and it is more than five (5) times the summer wind speed.

It is interesting to further review results for the retirement home, which is a sensitive land use as compared to other land uses in the study area. Google imagery shows that this building is situated along Hunt Club Road, on the east side of the above-mentioned intersection. It is a three-storey building and most of the first level serves as a parking area. 
Using the google measuring tool, it is found that the building is approximately $97.5 \mathrm{~m}$ in length and $16.5 \mathrm{~m}$ in width. Although the main entrance of this building is approximately 20 meters away from the edge of Hunt Club Road pavement, the closest edge is approximately ten meter $(10 \mathrm{~m})$ away. The estimation of $\mathrm{CO}$ concentration levels are presented in Table 6-3 below, where three different sections of the retirement home are taken into consideration. Those sections are considered perpendicular lines from the outer edge of Hunt Club Road. Those are entrance of the building and two other front edges of the building.

Table 6-2: Pollution concentrations at various heights

\begin{tabular}{|c|c|l|c|c|c|}
\hline ID & $\begin{array}{c}\text { Height } \\
\text { (in } \\
\text { meter) }\end{array}$ & description & $\begin{array}{c}\text { CO concentration } \\
\text { at closest edge (at } \\
10.5 \mathrm{~m} \text { ) in ppm }\end{array}$ & $\begin{array}{c}\text { CO concentration } \\
\text { at entrance (in } \\
\text { ppm) }\end{array}$ & $\begin{array}{c}\text { CO concentrations } \\
\text { at farthest edge (at } \\
37 \text { m) in ppm }\end{array}$ \\
\hline 1 & 0.0 & At Ground & 17.0 & 13.2 & 10.8 \\
\hline 2 & 1.8 & Breathing height & 15.7 & 12.8 & 10.7 \\
\hline 3 & 3.0 & Roof of the $1^{\text {st }}$ floor & 14.7 & 12.2 & 10.5 \\
\hline 4 & 6.0 & Roof of the $2^{\text {nd }}$ floor & 13.3 & 11.2 & 9.8 \\
\hline 5 & 9.0 & Roof of the $3^{\text {rd }}$ floor & 11.7 & 10.0 & 8.9 \\
\hline
\end{tabular}

As expected, Table 6-2 shows that CO concentration level decreases with height of location in the building. This phenomenon can be seen in Figure 6-9. The maximum concentration is at the ground level, but the height of 1.8 meter is important for research since receptor (human) breathing height is approximately $1.8 \mathrm{~m}$. Even though the figure shows that concentration level decreases $1 \mathrm{ppm}$ for every 3 meter of vertical height at the entrance of the building, the drop is not uniform for other two locations shown in Table 6-2. If this level of detail is desired from the integrated simulation model, the non-linear relationship between height and concentration level can be found. 


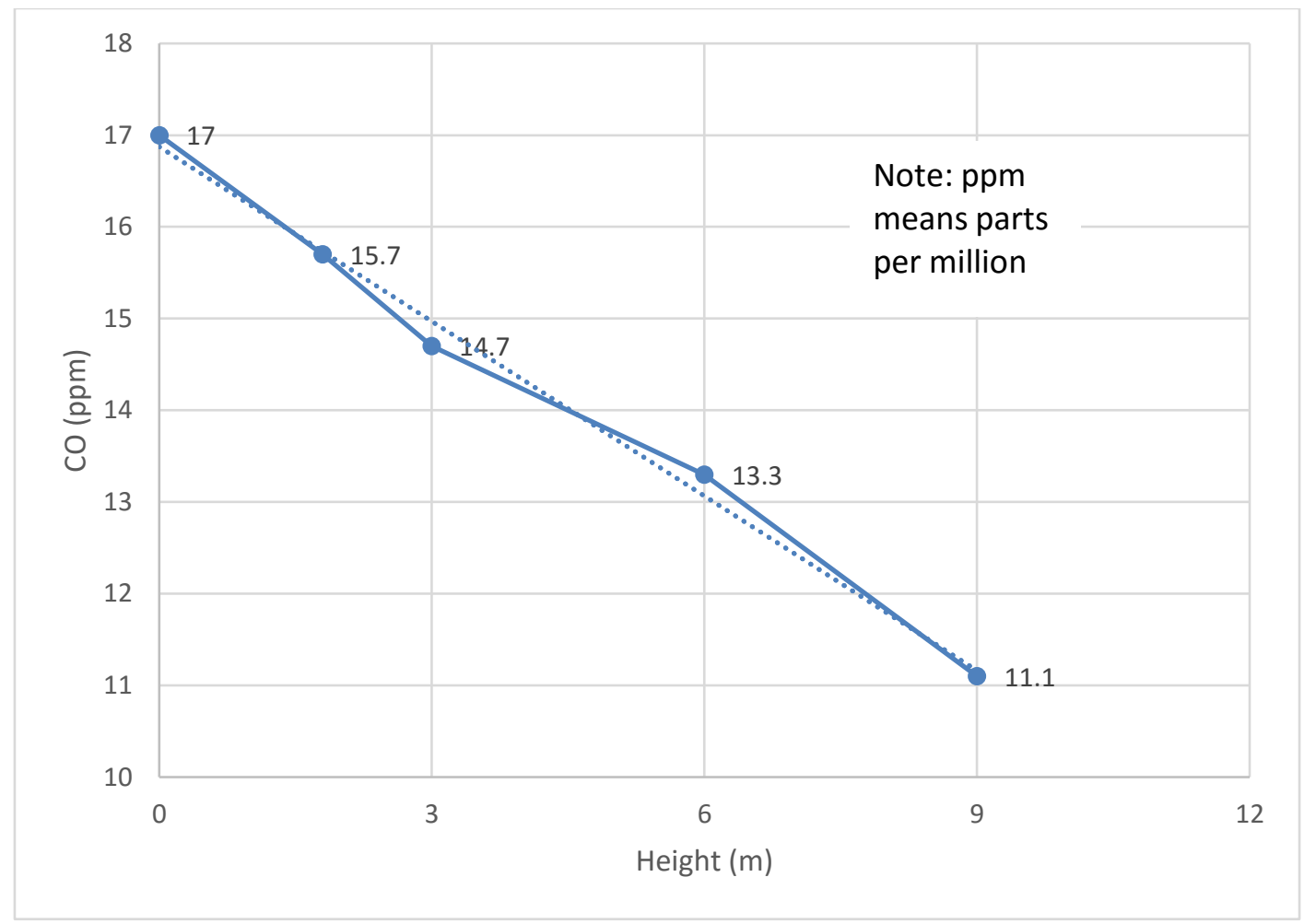

Figure 6-9: $\mathrm{CO}$ concentrations at the closest edge of the retirement home (here 3 meter height means at the floor of second floor and similar)

Table 6-3 shows variation of pollution concentrations with horizontal distance from the road edge for every 10-meter intervals at breathing height. These distances were measured through the closest edge of the building. As expected, results show that the maximum concentration is at the road edge and it is decreasing with horizontal distance from the road.

Table 6-3: Variation of pollution concentration with horizontal distance

\begin{tabular}{|l|c|c|l|l|l|}
\hline Sl No. & $\begin{array}{l}\text { Horizontal } \\
\text { distance (in } \\
\text { meter) }\end{array}$ & $\begin{array}{l}\text { CO concentration } \\
\text { (ppm) }\end{array}$ & $\begin{array}{l}\text { Sl } \\
\text { No. }\end{array}$ & $\begin{array}{l}\text { Horizontal } \\
\text { distance (in } \\
\text { meter) }\end{array}$ & $\begin{array}{l}\text { CO concentration } \\
\text { (ppm) }\end{array}$ \\
\hline 1. & 0 & 28.2 & 8. & 70 & 8.1 \\
\hline 2. & 10 & 16.5 & 9. & 80 & 7.7 \\
\hline 3. & 20 & 13.1 & 10. & 90 & 7.3 \\
\hline
\end{tabular}




\begin{tabular}{|l|l|l|l|l|l|}
\hline 4. & 30 & 11.3 & 11. & 100 & 7.0 \\
\hline 5. & 40 & 10.1 & 12. & 110 & 6.8 \\
\hline 6. & 50 & 9.3 & 13. & 120 & 6.5 \\
\hline 7. & 60 & 8.7 & 14. & 140 & 6.3 \\
\hline
\end{tabular}

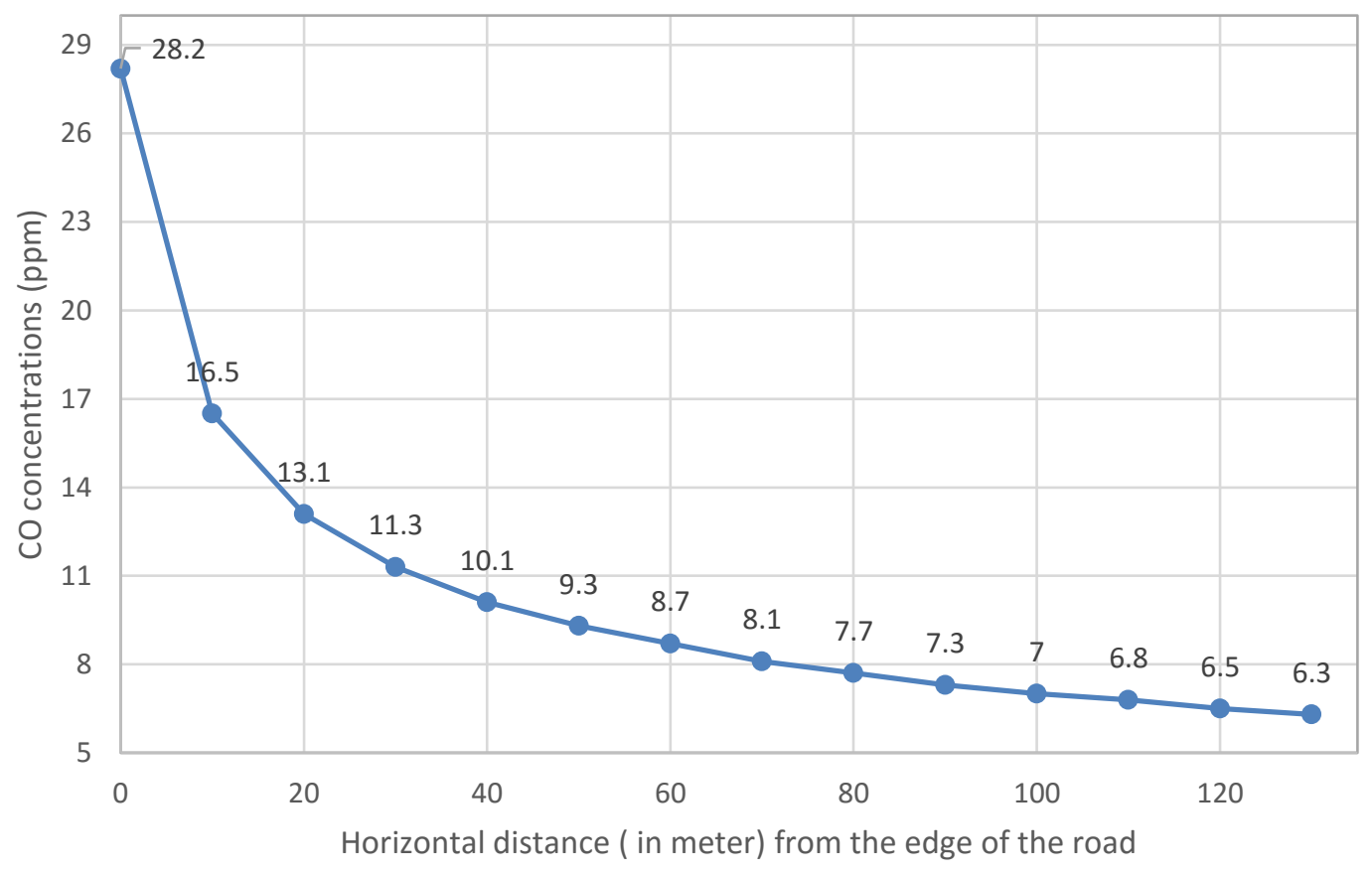

Figure 6-10: CO concentration vs horizontal distance from edge of road at breathing height, which is 1.8 meter from surface

Figure 6-10 illustrates that the concentration level decreases dramatically within the first 10 meters of horizontal distance from the roadway. After that, it decreases gradually and less rapidly. The Canadian and US Standard for 8-hour CO concentration level is $9 \mathrm{ppm}$, which occurs between $50 \mathrm{~m}$ and $60 \mathrm{~m}$. The $\mathrm{CO}$ concentration for the closest edge of the building was studied and results show that at $40 \mathrm{~m}$ distance the $\mathrm{CO}$ concentration levels are very close to $10 \mathrm{ppm}$. 
It is clear from the preliminary results of the example case shown in Table 6-3 that, approximately 55-meter setback distance (i.e. distance from the outer road edge to front wall of the building) is suitable for the traffic scenario analyzed for the example study area. Moreover, this is a sample study for a cross-section of a particular building from an arterial road. The objective of this research is to investigate setback distance for different types of roads as well as intersections based on worst-case condition. Therefore, it is necessary to take into account capacity level traffic and worst-case wind condition.

Before setting up the simulation design, verification of model is essential. The next two chapters discus field data collection and results verification. The field data are compared with model results in chapter eight. Chapter nine covers simulation design. 


\section{Chapter 7: FIELD STUDIES}

\subsection{NTRODUCTION}

This research focuses on estimation of pollution concentration at various distances and heights. According to the research approach, the estimation process applies integrated verified simulation models. For verification purpose, a field survey was carried out at selected road sites in Ottawa. This chapter covers pollution-measuring instruments used for field study, additional instruments used in support of data analysis, study plan and study area identification, data acquisition procedure, and a sample of completed datasheet.

\subsection{POLLUTION MEASURING INSTRUMENTS}

For conducting field survey, pollution-measuring instruments were rented. The selection procedure of field instruments was guided by advice received from specialists in pollution measurement. An analysis was carried out on equipment accuracy, suitability for use in road site environment, etc.

Figure 7-1 shows the gaseous pollutions measuring device and Figure 7-2 shows the dusttracking instrument. The Galson Laboratory was asked to install $\mathrm{CO}$ and $\mathrm{NO}_{2}$ sensors in gas analyzer, because those pollutants are of interest in this research study. The results were recorded using built-in memory card in these machines. The experts of Galson laboratory downloaded the data. Sample results from dust tracker and gas analyser are presented in Appendix III and Appendix IV, respectively. The company calibrated the 
Multi-RAE gas-monitoring device for $\mathrm{CO}$ and $\mathrm{NO}_{2}$ before shipping it to Carleton University. The dust tracker used for field data collection had better accuracy in terms of measurements than the gas analyser, which had some precision limitations. The limitations of gas pollution measuring instrument are described in the methodology chapter.
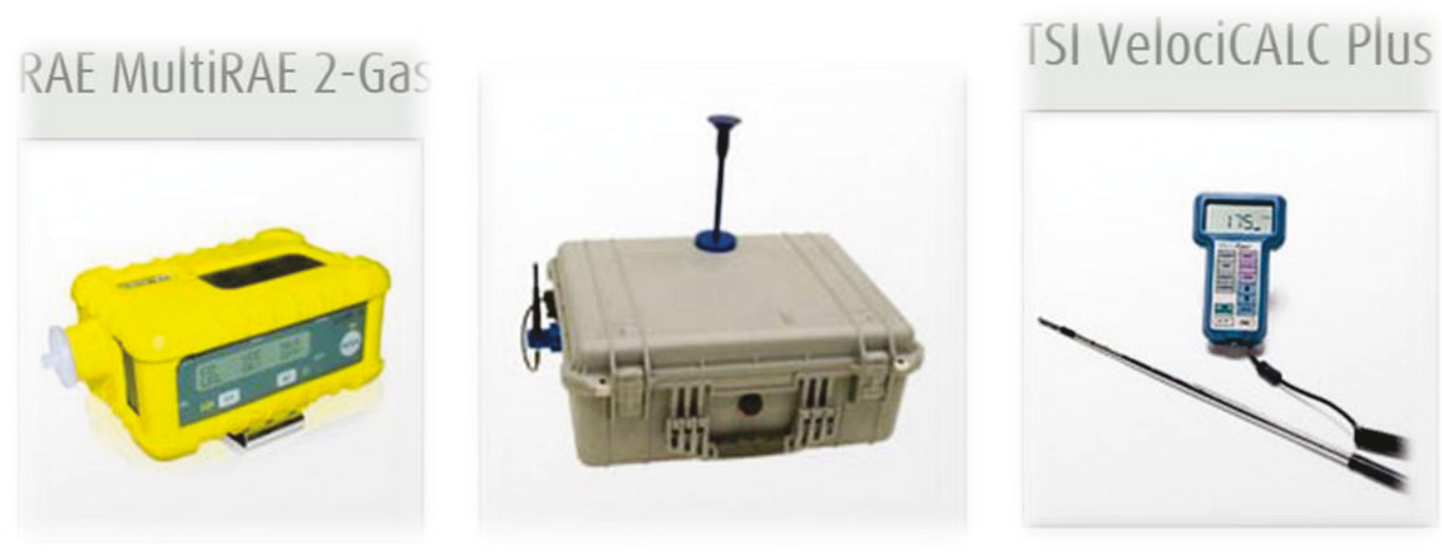

Figure 7-1: Gaseous pollutions ( $\mathrm{CO}$ and $\left.\mathrm{NO}_{2}\right)$ monitoring device,

Figure 7-2: Dust $\left(\mathrm{PM}_{2.5}\right)$ tracking instrument, and

Figure 7-3: Portable meteorological device

In field data collection, the dust tracker for $\mathrm{PM}_{2.5}$ data collection and gas analyzer for $\mathrm{CO}$ and $\mathrm{NO}_{2}$ data collection were used. The Gas analyzer used in the field had $\mathrm{CO}$ and $\mathrm{NO}_{2}$ sensors, because these two pollutants are important according to national ambient air quality standards (NAAQS). Moreover, a portable meteorological device was used during survey to collect the meteorological data such as wind speed and temperature. Results from the portable device show that wind speed and temperature vary spatially and temporally.

\subsection{ADDITIONAL SURVEY INSTRUMENTS}

Other instruments were also used in field data collection. An important instrument was TSI velociCALC meter. Figure 7-3 shows the portable meteorological device. This instrument 
recorded wind speed and ambient temperature. Appendix-V shows the sample data recorded by this meter. These data were used as a part of analysis of results. Moreover, there were some other devices used in field studies. These are video camera, handheld GPS, measuring tape etc.

The pollution concentrations in the field should compare well with the simulation results obtained with same traffic recorded during the field data collection. Keeping this in mind, traffic movement was filmed using the video camera. Figure 7-6 displays the tripod that held the video camera. Moreover, local climate data, such as wind speed and atmospheric temperature, were captured at the same time.

\subsection{SURVEY PLAN AND STUDY AREA IDENTIFICATION}

Field studies was conducted at selected sites in the City of Ottawa. The focus was to cover all applicable road types and intersections. Some of the data were collected in the downtown area, and other sites were outside the central business district. Data were collected for an hour as well as in continuous mode. The morning peak and evening peak hour data were captured for both traffic and corresponding roadside pollution concentrations. The locations of data collection sites are tabulated below.

Table 7-1: Locations selected for field data collection

\begin{tabular}{|c|c|c|l|}
\hline $\begin{array}{c}\text { S.L. } \\
\text { No. }\end{array}$ & \multicolumn{1}{|c|}{ Date } & \multicolumn{1}{|c|}{ Time } & \multicolumn{1}{c|}{ Study Location in Ottawa } \\
\hline 1 & April 12, 2016 & 4:30 PM - 5:30 PM & Bronson Avenue and Carling Avenue \\
\hline 2 & April 13,2016 & 8:00 AM - 9:00 AM & Walkey road and Riverside Drive \\
\hline 3 & April 13,2016 & 10:00 AM - 11:00 AM & Walkey road and Mccarthy road \\
\hline
\end{tabular}




\begin{tabular}{|c|l|l|l|}
\hline 4 & April 13,2016 & 5:00 PM - 6:00 PM & $\begin{array}{l}\text { Hunt club road (between Cahill Ave } \\
\text { and Dunston terrace) }\end{array}$ \\
\hline 5 & April 14,2016 & $\begin{array}{l}\text { 8:00 AM - 9:00 AM } \\
\text { 9:00 AM - 10:00 AM }\end{array}$ & $\begin{array}{l}\text { Rideau street and Wurtemburg street } \\
\text { (Downtown Ottawa) }\end{array}$ \\
\hline 6 & April 14,2016 & 5:00 PM - 6:00 PM & Carling Ave (Ottawa Hospital) \\
\hline 7 & April 15,2016 & $\begin{array}{l}\text { 3:00 PM - 4:00 PM } \\
\text { 6:00 PM - 7:00 PM }\end{array}$ & Carling Ave and Bayshore drive \\
\hline 8 & April 17,2016 & $\begin{array}{l}\text { 10:00 AM - 11:00 AM } \\
\text { 4:00 PM - 5:00 PM }\end{array}$ & Carling Ave and Wylie drive \\
\hline 9 & April 18,2016 & $\begin{array}{l}\text { 10:00 AM - 11:00 AM } \\
\text { 11:00 PM - 12:00 AM }\end{array}$ & $\begin{array}{l}\text { Baseline road and Prince of wales } \\
\text { drive }\end{array}$ \\
\hline 10 & April 19,2016 & 5:00 PM - 6:00 PM & Highway-417 (near Via Rail Station) \\
\hline
\end{tabular}

It is noted that field data were collected in continuous mode for site serial number S. L. No.-9 at Baseline Road and Prince of Wales Drive for 24 hours. In addition, the video camera was set up to film in continuous mode for S. L. No.-7 at Carling Avenue and Bayshore Drive sites, but field data were collected for 8 (eight) hours that covered weekdays as well as weekends.

The field study was carried out with the approval of the City of Ottawa. Details of sites and schedules were provided for this purpose. Moreover, the city provided the radar meter data for Hunt Club Road, which were used for VISSIM model calibration. Chapter 6 describes VISSIM model calibration.

\subsection{DATA COLLECTION PROCEDURE AND RESULTS}

Table 7-1 presents survey dates and times. Among the above list of study locations, the downtown Ottawa (serial number \# 5) is discussed here for a detailed explanation of the 
procedure for field data collection. Figures 7-4 and 7-5 illustrate the data collection site, which is the intersection of Rideau Street and Wurtemburg Street. Figure 7-4 shows the satellite photo (top view) of a residential building located at 630 Rideau Street at the same intersection. It should be noted that the Rideau Street is located in the east-west direction and Wurtemburg Street is in the north-south direction. The location of the building is at the South East corner of the same intersection, and Figure 7-5 shows the street view of the same residential building.
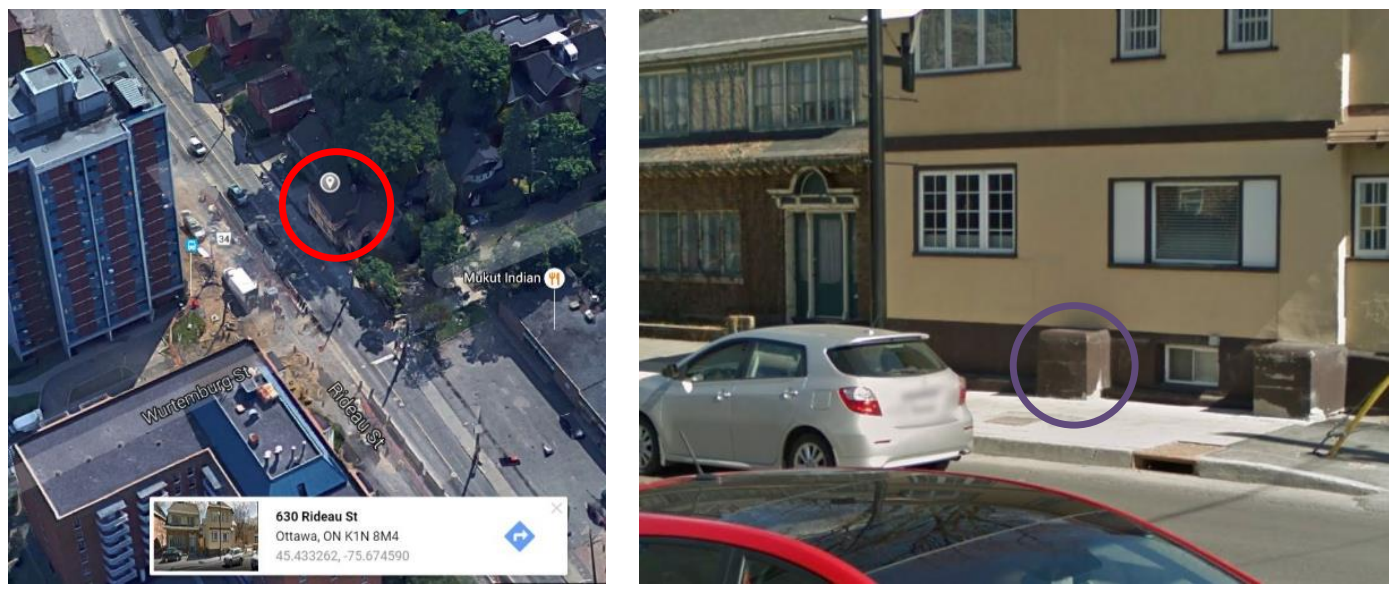

Figure 7-4: Satellite view of residential building on Rideau Street, Ottawa, ON, Canada at southeast corner of the intersection of Rideau Street and Wurtemburg Street, and Figure 7-5: Street view of residential building on Rideau Street (Source: https://www.google.ca/maps)

The residential building is highlighted by a red circle in Figure 7-4, whereas Figure 7-5 shows the wall of the same building. One of the reasons for choosing this study location is that the residential building is situated very close to the Rideau Street. The purpose of data collection at this spot was that the house is built right after the sidewalk. Moreover, this house is located very close to the intersection. The instruments were placed near the wall 
of the residential building. The purple color circle in Picture 7-5 shows the position, where pollutions measuring instruments were placed during survey. It can be noted that there are some windows in this house, but according to observations made it appears that these are rarely opened due to high level of pollutants. Please refer field sample-4 in next chapter for details of results about pollution concentrations at this study location.

The data were collected for two hours (8:00 AM - 10:00 AM) at this intersection. The pollutant measuring devices were placed at Northeast corner of the intersection from 8:00 AM to 9:00 AM, whereas data were collected at South-West corner (shown in Picture 7-5) in between 9:00 $\mathrm{AM}$ and 10:00 $\mathrm{AM}$. The pollution concentration results are illustrated in chapter eight.

The field data were collected in the sample mode as well as in the continuous mode. The sample mode implies the data collection for an hour. Continuous data were collected from the intersection of Baseline Road and Prince of Wales Drive. With the permission from the building authority, the machine was set up at the roof of Apollo Property Management office for 24-hours. Figure 7-6 shows the picture from the roof of that building.

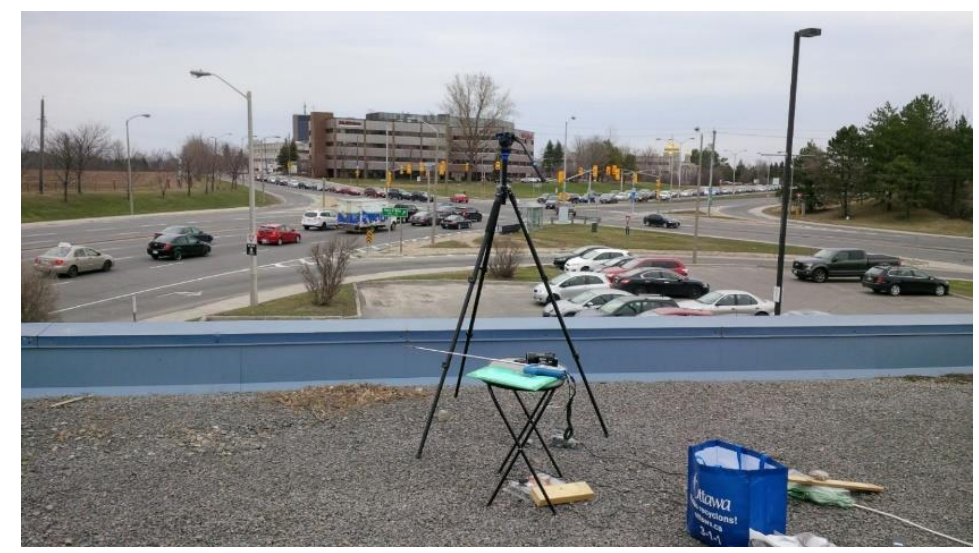

Figure 7-6: Field data collection from the roof of Apollo management property 
The dust meter and gas analyzer collected the field data on a one-minute interval basis. These are attached in appendices. Appendix III and Appendix IV represent the slices of downloaded data from dust meter and gas analyzer, respectively. The dust meter readings are satisfactory, whereas gas meter data show zero values in most of the cases. There are two sensors placed in the gas analyzer. Due to low accuracy of gas analyzer, data were not recorded in the continuous mode. Therefore, most of data are showing zero values. However, the field data were collected on a 15 minutes interval basis whenever possible. A brief explanation of pros and cons of data collection are noted in the data analysis section of chapter eight. Moreover, data were recorded in continuous mode by the dust meter. Appendix III represents dust meter results in $\mathrm{mg} / \mathrm{m}^{3}$ up to three decimal places.
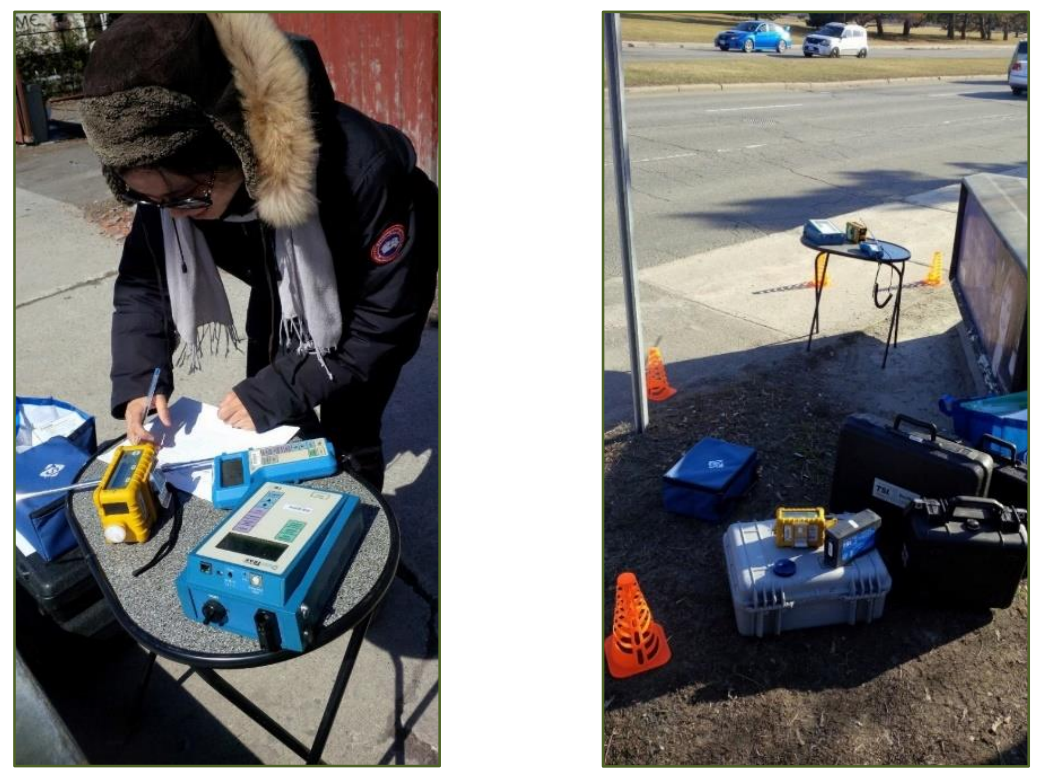

Figure 7-7: Field data was recording in field sheet at the intersection of Walkley road and McCarthy road,

Figure 7-8: Instruments set-up on Carling Road near Ottawa Civic hospital

Another instrument provided weather report for every $1 / 2$-second interval. The field readings are attached as Appendix V. It is extremely important to mention that the weather conditions are not uniform in the urban area and urban land use has an effect on some 
characteristics. As an example, the average data indicates that temperature at the sample location (please refer to field sample \# 7 in chapter eight) on April 18, 2016 between 10:0011:00 AM was $15.6^{\circ} \mathrm{C}$ and wind speed was $1.3 \mathrm{~m} / \mathrm{s}$. The weather report published by the experimental farm station shows that temperature was $13.4^{\circ} \mathrm{C}$ and wind speed was $3.6 \mathrm{~m} / \mathrm{s}$ at the same time of the day. The experimental farm weather station is located within 1000 m (exactly $985 \mathrm{~m}$ using google technology) from the Baseline and Prince of wales site.

\begin{tabular}{|c|c|c|c|c|c|c|c|c|c|c|c|}
\hline \multirow{3}{*}{ ص̃ँّ } & \multirow{3}{*}{ 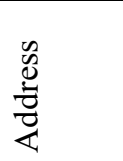 } & \multirow[t]{3}{*}{ Time } & \multicolumn{2}{|c|}{ Meter location } & \multirow{2}{*}{\multicolumn{2}{|c|}{$\begin{array}{l}\text { Gas meter\#1 } \\
\text { reading }\end{array}$}} & \multirow{2}{*}{\multicolumn{2}{|c|}{$\begin{array}{c}\text { Gas Meter\#2 } \\
\text { reading }\end{array}$}} & \multirow{3}{*}{$\begin{array}{c}\text { Temp } \\
\left({ }^{\circ} \mathrm{F}\right)\end{array}$} & \multirow{3}{*}{$\begin{array}{c}\text { Wind } \\
\text { Speed } \\
(\mathrm{Ft} / \mathrm{m} \\
\text { in) }\end{array}$} & \multirow{3}{*}{$\begin{array}{c}\text { Dust } \\
\text { meter } \\
(\mathrm{mg} / \\
\left.\mathrm{m}^{3}\right)\end{array}$} \\
\hline & & & \multirow{2}{*}{$\begin{array}{l}\text { Heigh } \\
t(m)\end{array}$} & \multirow{2}{*}{$\begin{array}{l}\text { Distanc } \\
\text { e (m) }\end{array}$} & & & & & & & \\
\hline & & & & & $\mathrm{CO}$ & $\mathrm{NO}_{2}$ & $\mathrm{CO}$ & $\mathrm{NO}_{2}$ & & & \\
\hline & & & & & & & & & & & \\
\hline \multirow{4}{*}{$\begin{array}{l}\frac{n}{2} \\
\frac{\bar{z}}{2}\end{array}$} & \multirow{4}{*}{ 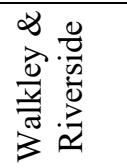 } & $8: 15$ & 0.75 & \multirow{4}{*}{ 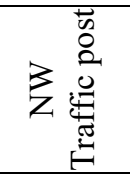 } & 0 & 0.2 & & & 37.6 & 38 & 0.010 \\
\hline & & $8: 30$ & & & 0 & 0.2 & 1 & 0.1 & 37.4 & 67 & 0.018 \\
\hline & & $8: 45$ & & & 0 & 0.2 & 1 & 0.1 & 34.5 & 37 & 0.013 \\
\hline & & $9: 00$ & & & 0 & 0.2 & 1 & 0.1 & 37.2 & 64 & 0.012 \\
\hline \multirow{4}{*}{$\begin{array}{l}\frac{n}{2} \\
\overline{\bar{z}} \\
\frac{\bar{\alpha}}{4}\end{array}$} & \multirow{4}{*}{ 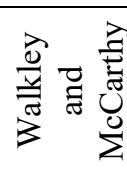 } & $10: 15$ & 0.5 & \multirow{4}{*}{ 之总 } & 1 & 0.1 & 1 & 0.0 & 45.2 & 83 & 0.109 \\
\hline & & $10: 30$ & & & 1 & 0.1 & 1 & 0.0 & 44.3 & 34 & 0.031 \\
\hline & & $10: 45$ & & & 3 & 0.1 & 1 & 0.1 & 42.7 & 75 & 0.015 \\
\hline & & $11: 00$ & & & 3 & 0.1 & 1 & 0.1 & 45.6 & 89 & 0.016 \\
\hline \multirow{7}{*}{$\begin{array}{l}\stackrel{n}{\bar{E}} \\
\frac{\bar{z}}{4}\end{array}$} & \multirow{7}{*}{ 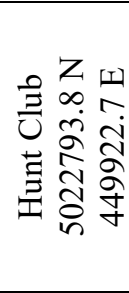 } & & & \multirow{7}{*}{ 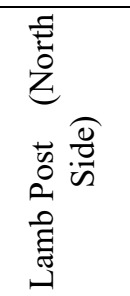 } & & & & & & & \\
\hline & & $5: 15$ & 0.5 & & 0 & 0.3 & 1 & 0.0 & 48.8 & 64 & 0.026 \\
\hline & & $5: 30$ & & & 0 & 0.3 & 2 & 0.0 & 48.2 & 56 & 0.074 \\
\hline & & $5: 45$ & & & 0 & 0.3 & 2 & 0.0 & 45.4 & 40 & 0.009 \\
\hline & & $6: 00$ & & & 0 & 0.3 & 2 & 0.0 & 46 & 37 & 0.007 \\
\hline & & $6: 15$ & & & 1 & 0.0 & & & 46.7 & 79 & 0.061 \\
\hline & & $6: 30$ & & & 1 & 0.0 & & & 44.7 & 35 & 0.008 \\
\hline \multirow{4}{*}{$\frac{ \pm}{\bar{E}}$} & \multirow{4}{*}{ 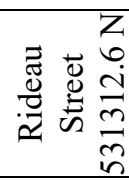 } & $8: 15$ & \multirow[t]{4}{*}{0.5} & \multirow{4}{*}{ 乙总总 } & 0 & 0.1 & 0 & 0.2 & 44.5 & 36 & 0.044 \\
\hline & & $8: 30$ & & & & & & & & & \\
\hline & & $8: 45$ & & & 0 & 0.3 & & & 41.9 & 60 & 0.065 \\
\hline & & 9:00 & & & 0 & 0.4 & & & 40.8 & 67 & 0.028 \\
\hline \multirow{4}{*}{$\begin{array}{l} \pm \\
\bar{\Xi} \\
\frac{0}{2}\end{array}$} & \multirow{4}{*}{ 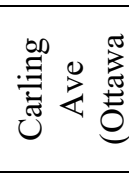 } & 5:15 PM & \multirow[t]{4}{*}{0.5} & \multirow{4}{*}{ 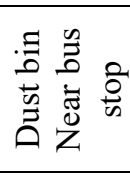 } & 0 & 0.2 & & & 57.5 & 124 & 0.096 \\
\hline & & $5: 30$ & & & 0 & 0.3 & & & 57.7 & 70 & 0.129 \\
\hline & & $5: 45$ & & & 1 & 0.2 & & & 57.4 & 45 & 0.025 \\
\hline & & $6: 00$ & & & 1 & 0.2 & & & 56.6 & 42 & 0.105 \\
\hline & & & & & & & & & & & \\
\hline
\end{tabular}

Table 7-2: Data collection using field book (pollutants reading and meteorological data) 
In the air quality model, wind conditions are important factors. Wind speed and directions are dramatically varying according the urban land use activities. The sample wind speed at study location indicates $1.3 \mathrm{~m} / \mathrm{s}$, whereas the station shows $3.6 \mathrm{~m} / \mathrm{s}$, which is almost three times. Therefore, it is concluded that local infrastructure such as residential buildings affect wind speed and change its direction.

The following photographs (Picture 7-7 and Picture 7-8) show field data collection activity. Field data were collected using the field notebook in every fifteen minutes intervals. Although the instruments recorded field data, the downloaded data imply that some of data are missing. The results displayed on instrument screen are shown in the next chapter. Table 7-2 was prepared based on results display on screens of these instruments.

The sample of field data is presented in Table 7-2. The local address and global address are presented in the table. The geo-locations were collected using GPS borrowed from Civil and Environmental Engineering Department, Carleton University. The global address contain longitude, latitude, and altitude of a certain location. Moreover, the measuring tape was used to measure distance of instrument location from outer edge of road. The sample field data collected is noted on field sheet in Table 7-2. These show weather report as well as road-site pollution concentrations. It should be noted that there are two gas analyzers. Table 7-2 shows that there is no data recorded by the gas meter \# 2 on April 14, 2016 at the field study site located in front of the Ottawa Civic hospital on Carling Road. Picture 7-8 captured from the same location indicates that one of the gas analyzer was not used for data collection. Therefore, there is no data in the field of gas meter $\# 2$ reading in the table. Although field data are presented here, the average field data for each survey location is tabulated in the next chapter. 


\section{Chapter 8: $\quad$ RESULTS VERIFICATION}

\subsection{INTRODUCTION}

Here, the verification of simulation model results with field data is described. The simulation model outputs are pollution concentrations estimated by the integrated simulation models. Field data refers to the pollution concentrations measured by the instruments near roads. The pollution measuring instruments are gas analyzer and dust meter. Gas analyzer was used for measuring carbon monoxide $(\mathrm{CO})$ and nitrogen dioxide $\left(\mathrm{NO}_{2}\right)$ pollution concentrations in air, whereas particulate matter $\left(\mathrm{PM}_{2.5}\right)$ was measured using the dust meter.

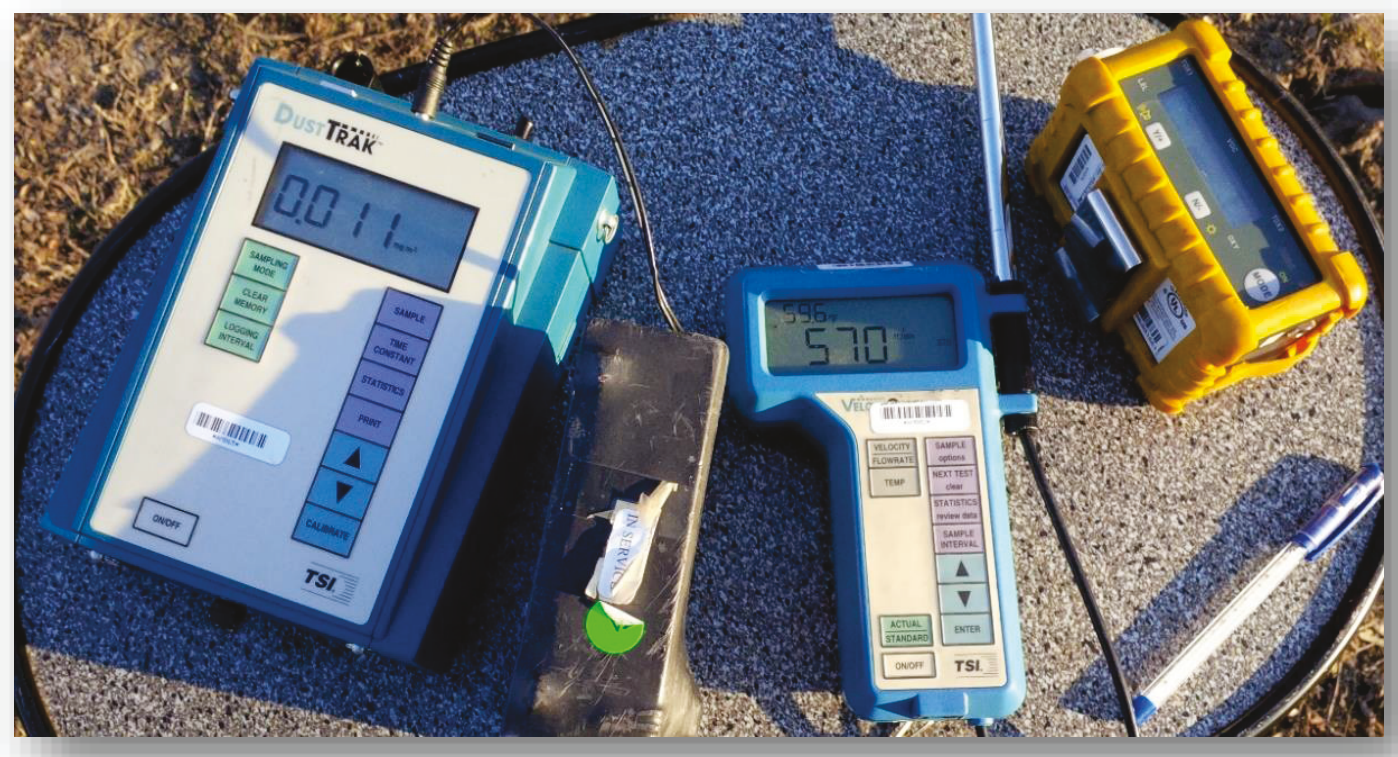

Figure 8-1: Gas analyzer (extreme right) and Dust meter (extreme left)

The pollution measuring instruments were rented from Galson Laboratory's New York office. Figure 8-1 shows the gas analyser, an instrument that is yellow in color. It contains two sensors. One is a $\mathrm{CO}$ sensor and another is $\mathrm{NO}_{2}$ sensor. In Figure 8-2, the left display 
shows $\mathrm{CO}$ reading and the right display is showing $\mathrm{NO}_{2}$ reading. The extreme left instrument in Figure 8-1 is a dust meter, which measures $\mathrm{PM}_{2.5}$. The wind speed and temperatures are displayed in TSI velocity meter, which appears in the middle of the picture.

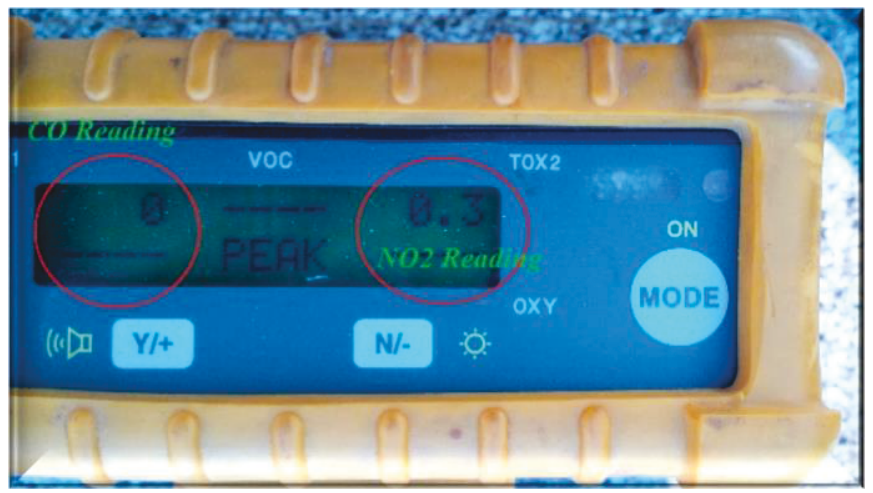

Figure 8-2: Gas analyzer showing $\mathrm{CO}$ an $\mathrm{NO}_{2}$ reading

To measure the actual roadside pollution concentrations emitted by vehicles, pollutionmeasuring instruments were placed close to road. In addition, road traffic and other data were captured at the same time as pollution measurements were taken by the instruments. For obtaining emissions from models, the necessary input values are traffic volume, percentage of heavy-duty vehicles (HDV), and meteorological data. The input meteorological data are temperature, wind speed, and wind direction, etc.

A combination of three simulation models were used in an integrated manner to estimate roadside pollutants. Actual traffic volume and composition of traffic were counted from video files. Following the collection of road traffic data, the VISSIM model was run to get velocity profiles. Using road vehicular activity, the emission rates were calculated for each road link and intersection. The climate data and composite emission factors were used in the air quality model for the estimation of pollution concentrations. 
For acceptance of research methodology, it is necessary to compare the model output with field data. The pollution concentration results from model and instruments are tabulated in the next section. The results are compared in summary report at the end of each field sample.

\subsection{RESULT COMPARISON AND ERROR CALCULATION}

This section highlights the comparison of field results with simulation results. The steps of data tabulation in field sample are as follows.

1. Traffic data count from video film; HDV percentage computed

2. Meteorological data collection by TSI velocity meter

3. Additional climate data from meteorological station

4. Composite emission factor (CEF) from emission models

5. Background pollution concentrations from air quality control station

6. Pollution concentrations from field using gas analyzer and dust tracker

7. Pollution concentrations from simulation models

8. Summary report showing results and discussion of differences.

The microscopic traffic simulation model requires traffic data for each road link with directions and turning movements. The percentage of HDV is required for vehicle composition. All necessary traffic data are tabulate in the first section of field sample. The second section presents the climate data from instruments as well as meteorological station. The next section highlights the composite emission factor. The emission rates or CEF from both emission models are displayed in the table, but the results from CMEM model were used in the air quality model. It was noted earlier that CMEM produces $\mathrm{NO}_{\mathrm{x}}$ and MOVES 
produces $\mathrm{NO}_{2}$. Both results are close. Moreover, CMEM does not prepare $\mathrm{NO}_{2}$. Irrespective of analysis behind the chemistry acting on emission models, it was considered that $\mathrm{NO}_{\mathrm{x}}$ from $\mathrm{CMEM}$ is taken as input to analyze $\mathrm{NO}_{2}$ pollution concentration in air quality model.

The background pollution concentrations are noted and then the pollution concentrations from field measuring instruments are presented. The averaging process uses field value either from memory card of the instruments or data recorded in the field sheet. Next, the results are shown for pollution concentrations estimated by the simulation models. The last section of the report of each field sample compares the results. The error is the difference between results.

\subsubsection{Field Sample \# 1}

Study Area: Carling Avenue and Bronson Avenue, Ottawa.

Data Collection Date and Time: April 12, 2016 (Tuesday), between 4:30 - 5:30 PM.

Traffic Count: $\quad$ Heavy Duty Vehicles $=6.8 \%$

Glebe Avenue $=138$, Intersection traffic volume $=3850$

\begin{tabular}{|c|c|c|c|c|}
\hline Road link/ Intersection name & Left Turn & Through & Right Turn & Total \\
\hline Carling Avenue (EB traffic) & 188 & 108 & 550 & 846 \\
\hline Bronson Ave (SB traffic) & 0 & 1422 & 190 & 1612 \\
\hline Bronson Avenue (NB traffic) & 290 & 1072 & 30 & 1392 \\
\hline
\end{tabular}

Climate data collected from field using Instrument (velocity meter):

\begin{tabular}{|c|c|c|}
\hline Time & Temperature $\left({ }^{\circ} \mathrm{F}\right)$ & Wind speed $(\mathrm{ft} / \mathrm{min})$ \\
\hline $5: 00 \mathrm{PM}$ & 45.8 & 155 \\
\hline
\end{tabular}




\begin{tabular}{|c|c|c|}
\hline $5: 15$ PM & 44.3 & 103 \\
\hline \multirow{2}{*}{ Average } & 45.05 & 129 \\
\cline { 2 - 3 } & $7.25^{\circ} \mathrm{C}$ & $0.65 \mathrm{~m} / \mathrm{s}$ \\
\hline
\end{tabular}

Additional Climate data from Station (Experimental Farm)

Temperature $=5.1{ }^{\circ} \mathrm{C}, \quad$ Relative Humidity $=57 \%, \quad$ Wind Speed $=23 \mathrm{~km} / \mathrm{h}=6.38$ $\mathrm{m} / \mathrm{s}$, Wind Direction $=285$ degree, Std. Dev. for wind direction $=10$ degree

Composite Emission Factor (EF) in $\mathrm{g} / \mathrm{v}-\mathrm{mi}$

\begin{tabular}{|l|c|c|c|c|c|}
\hline \multirow{2}{*}{ Link/ Intersection Name } & \multicolumn{2}{|c|}{$\mathrm{CO}$} & $\mathrm{NO}_{x}$ & $\mathrm{NO}_{2}$ & $\mathrm{PM}_{2.5}$ \\
\cline { 2 - 6 } & $\mathrm{CMEM}$ & MOVES & CMEM & MOVES & MOVES \\
\hline Bronson Ave (North) & 72.432 & 37 & 2.888 & 3 & 1 \\
\hline Bronson Ave (South) & 64.961 & 35 & 2.665 & 3 & 1 \\
\hline $\begin{array}{l}\text { Carling Ave and } \\
\text { Bronson Ave }\end{array}$ & 64.656 & 51 & 4.423 & 5 & 2 \\
\hline Carling Ave & 26.768 & 29 & 2.131 & 2 & 1 \\
\hline Glebe Ave & 44.053 & 20 & 1.999 & 1 & 1 \\
\hline
\end{tabular}

Gas Analyzer (instrument) reading from field:

$$
\mathrm{CO}=1 \mathrm{ppm} \quad \mathrm{NO}_{2}=0.1 \mathrm{ppm}=100 \mathrm{ppb}
$$

Dust Meter reading from field: $\quad \mathrm{PM}_{2.5}=0.1637 \mathrm{mg} / \mathrm{m}^{3}=163.7 \mu \mathrm{g} / \mathrm{m}^{3}$

\begin{tabular}{|c|c|c|}
\hline Sample Number & Time & PM2.5 concentrations $\left(\mathrm{mg} / \mathrm{m}^{3}\right)$ \\
\hline 1 & $4: 45 \mathrm{PM}$ & 0.027 \\
\hline 2 & $5: 00 \mathrm{PM}$ & 0.058 \\
\hline 3 & $5: 15 \mathrm{PM}$ & 0.406 \\
\hline \multicolumn{2}{|c|}{ Average } & 0.1637 \\
\hline
\end{tabular}

Computer Simulation Model:

$$
\mathrm{CO}=12.6 \text { ppm, }
$$




$$
\begin{aligned}
& \mathrm{NO}_{2}=0.1 \mathrm{ppm}=100 \mathrm{ppb}, \\
& \mathrm{PM}_{2.5}=190 \mu \mathrm{g} / \mathrm{m}^{3}
\end{aligned}
$$

Summary Report

\begin{tabular}{|l|c|c|c|}
\hline & $\mathrm{CO}(\mathrm{ppm})$ & $\mathrm{NO}_{2}(\mathrm{ppb})$ & $P M_{2.5}\left(\mu \mathrm{g} / \mathrm{m}^{3}\right)$ \\
\hline Model & 12.6 & 100 & 190 \\
\hline Instrument & 1 & 100 & 163.7 \\
\hline Difference & - & $0 \%$ & $13.8 \%$ \\
\hline
\end{tabular}

Note: This is first sample collected in field and only one reading collected from field by the gas analyzer at 4:45 PM. Therefore, the data are mismatched for CO pollutants.

\subsubsection{Field Sample \# 2}

Study Area: Walkley Road and McCarthy Road, Ottawa.

Data Collection Date and Time: April 13, 2016 (Wednesday) 10:00 AM -11:00 AM.

Traffic Count: $\quad$ Heavy Duty Vehicles $=15.65 \%$

Number of Vehicles at Intersection $=1131$

\begin{tabular}{|l|c|c|c|c|c|}
\hline $\begin{array}{c}\text { Road link/Intersection } \\
\text { name }\end{array}$ & $\begin{array}{c}\text { Left } \\
\text { Turn }\end{array}$ & Through & $\begin{array}{c}\text { Right } \\
\text { Turn }\end{array}$ & Total & $\begin{array}{c}\text { Opposite } \\
\text { direction }\end{array}$ \\
\hline McCarthy Road (NB traffic) & 94 & 0 & 130 & 224 & 191 \\
\hline Walkley Road (EB traffic) & 0 & 333 & 75 & 408 & 477 \\
\hline Walkley Road (WB traffic) & 116 & 383 & 0 & 499 & 463 \\
\hline
\end{tabular}

Climate data from instrument:

\begin{tabular}{|c|c|c|c|}
\hline \multicolumn{2}{|c|}{ Temperature } & \multicolumn{2}{c|}{ Wind Speed } \\
\hline${ }^{o} \mathrm{~F}$ & ${ }^{\circ} \mathrm{C}$ & $\mathrm{ft} / \mathrm{min}$ & $\mathrm{m} / \mathrm{s}$ \\
\hline
\end{tabular}




\begin{tabular}{|l|l|l|l|}
\hline 44.87 & 7.15 & 69.86 & 0.35 \\
\hline
\end{tabular}

Station (Experimental Farm)

Temperature $=2^{\circ} \mathrm{C}, \quad$ Relative Humidity $=58 \%$, Wind Speed $=10$

$\mathrm{Km} / \mathrm{h}=2.77 \mathrm{~m} / \mathrm{s}$, Wind Direction $=250$ degree

Composite Emission Factor (EF)

\begin{tabular}{|l|c|c|c|c|c|}
\hline \multicolumn{1}{|c|}{$\begin{array}{c}\text { Road Link/Intersection } \\
\text { Name }\end{array}$} & \multicolumn{2}{|c|}{$\mathrm{CO}(\mathrm{g} / \mathrm{v}-\mathrm{mi})$} & $\begin{array}{c}\mathrm{NO}_{2} \\
(\mathrm{~g} / \mathrm{v}-\mathrm{mi})\end{array}$ & $\begin{array}{c}\mathrm{NO} \mathrm{O}_{X} \\
(\mathrm{~g} / \mathrm{v}-\mathrm{mi})\end{array}$ & $P M$ \\
\cline { 2 - 6 } & MOVES & CMEM & MOVES & CMEM & MOVES \\
\hline McCarthy Road & 22 & 10.208 & 2 & 2.506 & 1 \\
\hline Walkley and McCarthy & 40 & 14.518 & 3 & 3.945 & 1 \\
\hline Walkley Road & 19 & 15.29 & 1 & 2.686 & 1 \\
\hline
\end{tabular}

Gas Analyzer (instrument):

$$
\mathrm{CO}=1.33 \mathrm{ppm}, \quad \mathrm{NO}_{2}=0.05 \mathrm{ppm}=50 \mathrm{ppb}
$$

\begin{tabular}{|c|c|c|}
\hline Time & $\mathrm{CO}(\mathrm{ppm})$ & $\mathrm{NO}_{2}(\mathrm{ppm})$ \\
\hline $10: 15$ & 1 & 0 \\
\hline $10: 30$ & 1 & 0 \\
\hline $10: 45$ & 0.33 & 0.1 \\
\hline $11: 00$ & 3 & 0.1 \\
\hline Average & 1.33 & 0.05 \\
\hline
\end{tabular}

Dust meter: $\quad \mathrm{PM}_{2.5}=0.015683 \mathrm{mg} / \mathrm{m}^{3}=15.683 \mu \mathrm{g} / \mathrm{m}^{3}$

Computer Simulation Model:

$$
\mathrm{CO}=1.1 \mathrm{ppm}, \quad \mathrm{NO}_{2}=0.03 \mathrm{ppm}=30 \mathrm{ppb}, \quad \mathrm{PM}_{2.5}=15 \mu \mathrm{g} / \mathrm{m}^{3}
$$


Summary Report:

\begin{tabular}{|l|c|c|c|}
\hline & $\mathrm{CO}(\mathrm{ppm})$ & $\mathrm{NO}_{2}(\mathrm{ppb})$ & $P M_{2.5}\left(\mu \mathrm{g} / \mathrm{m}^{3}\right)$ \\
\hline Model & 1.1 & 30 & 15 \\
\hline Instrument & 1.33 & 50 & 15.68 \\
\hline Difference & $17.3 \%$ & - & $4.3 \%$ \\
\hline
\end{tabular}

Note: There is a difference of $\mathrm{NO}_{2}$ results due to accuracy of gas analyzer. Please refer to the gas analyzer reading from field.

\subsubsection{Field Sample \# 3}

Study Area: Hunt Club Road in between Cahill Drive and Dunston Terrace, Ottawa.

Data Collection Date and Time: April 13, 2016 (Wednesday) 5:00-6:00 PM.

Traffic Count: $\quad$ Heavy Duty Vehicles $=8.1 \%$

\begin{tabular}{|l|c|}
\hline \multicolumn{1}{|c|}{ Road Link Name } & Number of Traffic \\
\hline Hunt Club Road East Bound (EB) & 1350 \\
\hline Hunt Club Road West Bound (WB) & 1239 \\
\hline
\end{tabular}

Climate data from instrument (continuous reading):

\begin{tabular}{|c|c|c|c|}
\hline \multicolumn{2}{|c|}{ Temperature } & \multicolumn{2}{c|}{ Wind Speed } \\
\hline${ }^{\circ} \mathrm{F}$ & ${ }^{o} \mathrm{C}$ & $\mathrm{ft} / \mathrm{min}$ & $\mathrm{m} / \mathrm{s}$ \\
\hline 48.01 & 8.9 & 50.218 & 0.255 \\
\hline
\end{tabular}

Station (Experimental Farm):

$$
\text { Temperature }=6.3{ }^{\circ} \mathrm{C}, \quad \text { Relative Humidity }=34 \%,
$$


Wind Speed $=4 \mathrm{~km} / \mathrm{h}=1.11 \mathrm{~m} / \mathrm{s}, \quad$ Wind Direction $=240$ degree, Std. Dev. for Wind Direction $=50$ degree

Composite Emission Factor (EF)

\begin{tabular}{|c|c|c|c|c|c|}
\hline Road Link Name & \multicolumn{2}{|c|}{$C O(g / v-m i)$} & $\begin{array}{c}\mathrm{NO}_{2} \\
(\mathrm{~g} / \mathrm{v}-\mathrm{mi})\end{array}$ & $\begin{array}{c}\mathrm{NO}_{X} \\
(\mathrm{~g} / \mathrm{v}-\mathrm{mi})\end{array}$ & PM \\
\cline { 2 - 6 } & MOVES & CMEM & MOVES & CMEM & MOVES \\
\hline Hunt Club Road EB & 22 & 27.688 & 2 & 1.814 & 1 \\
\hline Hunt Club Road WB & 19 & 16.002 & 2 & 1.72 & 1 \\
\hline
\end{tabular}

Background Pollution Concentrations: $\quad \mathrm{CO}=0.105 \mathrm{ppm}$

Gas Analyzer (instrument):

\begin{tabular}{|c|c|c|c|c|}
\hline \multirow{2}{*}{ Time } & \multicolumn{2}{|c|}{$\mathrm{CO}(\mathrm{ppm})$} & \multicolumn{2}{c|}{$\mathrm{NO}_{2}(\mathrm{ppm})$} \\
\cline { 2 - 5 } & Gas Analyzer \#1 & Gas Analyzer \#2 & Gas Analyzer \#1 & Gas Analyzer \#2 \\
\hline 5:15 PM & 0 & 1 & 0.3 & 0.0 \\
\hline $5: 30 \mathrm{PM}$ & 0 & 2 & 0.3 & 0.0 \\
\hline $5: 45 \mathrm{PM}$ & 0 & 2 & 0.3 & 0.0 \\
\hline 6:00 PM & 0 & 2 & 0.3 & 0.0 \\
\hline Average & - & $1.75 \mathrm{ppm}$ & $\begin{array}{c}0.3 \mathrm{ppm} \\
(300 \mathrm{ppb})\end{array}$ & - \\
\hline
\end{tabular}

Dust Meter (Continuous reading):

$$
\mathrm{PM}_{2.5}=0.093 \mathrm{mg} / \mathrm{m}^{3}=93 \mu \mathrm{g} / \mathrm{m}^{3}
$$

Computer Simulation Model:

$$
\mathrm{CO}=2.2 \mathrm{ppm}, \quad \mathrm{NO}_{2}=0.04 \mathrm{ppm}=40 \mathrm{ppb}, \quad \mathrm{PM}_{2.5}=94 \mu \mathrm{g} / \mathrm{m}^{3}
$$


Summary Report:

\begin{tabular}{|l|c|c|c|}
\hline & $\mathrm{CO}(\mathrm{ppm})$ & $\mathrm{NO}_{2}(\mathrm{ppb})$ & $P M_{2.5}\left(\mu \mathrm{g} / \mathrm{m}^{3}\right)$ \\
\hline Model & 2.2 & 40 & 94 \\
\hline Instrument & 1.75 & 300 & 93 \\
\hline Difference & $20.4 \%$ & - & $1.06 \%$ \\
\hline
\end{tabular}

\subsubsection{Field Sample \# 4-1}

Study Area: Rideau Street and Wurtemburg Street, Downtown, Ottawa.

Data Collection Date and Time: April 14, 2016 (Thursday) 8:00 AM -9:00 AM.

Traffic Count: $\quad$ Heavy Duty Vehicles $=5 \%$

Number of Vehicles at Intersection $=1749$

\begin{tabular}{|l|c|c|c|c|c|}
\hline $\begin{array}{c}\text { Road link/ Intersection } \\
\text { name }\end{array}$ & $\begin{array}{c}\text { Left } \\
\text { Turn }\end{array}$ & Through & $\begin{array}{c}\text { Right } \\
\text { Turn }\end{array}$ & Total & $\begin{array}{c}\text { Opposite } \\
\text { direction }\end{array}$ \\
\hline Wurtemburg Street (SB) & 63 & 0 & 34 & 97 & 64 \\
\hline Rideau Street (EB traffic) & 9 & 769 & 0 & 778 & 853 \\
\hline Rideau Street (WB traffic) & 0 & 819 & 55 & 874 & 832 \\
\hline
\end{tabular}

Instrument:

Temperature $=43.14{ }^{\circ} \mathrm{F}=6.2{ }^{\circ} \mathrm{C}$, Wind speed $=46.44 \mathrm{ft} / \mathrm{min}=0.236 \mathrm{~m} / \mathrm{s}$

Station:

Temperature $=2.7{ }^{\circ} \mathrm{C}$, Relative Humidity $=52 \%$, Wind Direction $=60$ degree

Wind speed $=13 \mathrm{~km} / \mathrm{h}=3.61 \mathrm{~m} / \mathrm{s}, \quad$ Std. Dev. of wind Direction $=10$ degree 
Composite Emission Factor (EF)

\begin{tabular}{|c|c|c|c|c|c|}
\hline $\begin{array}{c}\text { Road Link/ Intersection } \\
\text { Name }\end{array}$ & \multicolumn{2}{|c|}{$\mathrm{CO}(\mathrm{g} / \mathrm{v}-\mathrm{mi})$} & $\begin{array}{c}\mathrm{NO}_{2} \\
(\mathrm{~g} / \mathrm{v}-\mathrm{mi})\end{array}$ & $\begin{array}{c}\mathrm{NO}_{x} \\
(\mathrm{~g} / \mathrm{v}-\mathrm{mi})\end{array}$ & $\mathrm{PM}_{2.5}$ \\
\cline { 2 - 6 } & MOVES & CMEM & MOVES & CMEM & MOVES \\
\hline $\begin{array}{c}\text { Rideau and Wurtemburg } \\
\text { intersection }\end{array}$ & 34 & 47.503 & 3 & 3.51 & 1 \\
\hline Wurtemburg Street & 15 & 3.83 & 0 & 0.425 & 0 \\
\hline Rideau Street (East) & 20 & 6.335 & 1 & 1.256 & 1 \\
\hline Rideau Street (West) & 20 & 7.613 & 1 & 1.47 & 1 \\
\hline
\end{tabular}

Background Pollutants:

$$
\mathrm{CO}=0.22 \mathrm{ppm}, \quad \mathrm{O}_{3}=0.009 \mathrm{ppm}, \quad \mathrm{NO}_{2}=0.016 \mathrm{ppm}, \quad \mathrm{PM}_{2.5}=9 \mu \mathrm{g} / \mathrm{m}^{3}
$$

Gas Analyzer:

$$
\mathrm{CO}=0 \mathrm{ppm}, \quad \mathrm{NO}_{2}=0.06053 \mathrm{ppm}=60.53 \mathrm{ppb}(\text { continuous reading at 8:19-8:56 } \mathrm{AM})
$$

Dust Meter:

$\mathrm{PM}_{2.5}=0.04314 \mathrm{mg} / \mathrm{m}^{3}$ (continuous reading at 8:31:52 -8:59:52 AM) $=43.14 \mu \mathrm{g} / \mathrm{m}^{3}$

Simulation Model:

$$
\mathrm{CO}=0.7 \mathrm{ppm}, \quad \mathrm{NO}_{2}=0.06 \mathrm{ppm}=60 \mathrm{ppb}, \quad \mathrm{PM}_{2.5}=45 \mu \mathrm{g} / \mathrm{m}^{3}
$$

\section{Summary Report:}

\begin{tabular}{|c|c|c|c|}
\hline & $\mathrm{CO}(\mathrm{ppm})$ & $\mathrm{NO}_{2}(\mathrm{ppb})$ & $P M_{2.5}\left(\mu \mathrm{g} / \mathrm{m}^{3}\right)$ \\
\hline Model & 0.7 & 60 & 45 \\
\hline Instrument & 0 & 60.53 & 43.14 \\
\hline Difference & - & $0.87 \%$ & $4.13 \%$ \\
\hline
\end{tabular}




\subsubsection{Field Sample \# 4-2}

Study Area: Rideau Street and Wurtemburg Street, Downtown, Ottawa.

Data Collection Date and Time: April 14, 2016 (Thursday) 9:00 AM -10:00 AM.

Traffic Count: $\quad$ Heavy Duty Vehicles $=5 \%$

Number of Vehicles at Intersection $=1388$

\begin{tabular}{|c|c|c|c|c|c|}
\hline $\begin{array}{c}\text { Road link/ Intersection } \\
\text { name }\end{array}$ & $\begin{array}{c}\text { Left } \\
\text { Turn }\end{array}$ & Through & $\begin{array}{c}\text { Right } \\
\text { Turn }\end{array}$ & Total & $\begin{array}{c}\text { Opposite } \\
\text { direction }\end{array}$ \\
\hline Wurtemburg Street (SB) & 61 & 0 & 27 & 88 & 75 \\
\hline Rideau Street (EB traffic) & 28 & 606 & 0 & 634 & 646 \\
\hline Rideau Street (WB traffic) & 0 & 619 & 47 & 666 & 667 \\
\hline
\end{tabular}

Instrument (in field):

Temperature $=39.08{ }^{\circ} \mathrm{F}=3.93{ }^{\circ} \mathrm{C}$, Wind speed $=103.33 \mathrm{ft} / \mathrm{min}=0.525 \mathrm{~m} / \mathrm{s}$

Climate Station (Experimental Farm, Ottawa):

Temperature $=5{ }^{\circ} \mathrm{C}, \quad$ Relative Humidity $=49 \%, \quad$ Wind Direction $=50$ degree,

Wind speed $=9 \mathrm{~km} / \mathrm{h}=2.5 \mathrm{~m} / \mathrm{s}, \quad$ Std. Dev. of wind Direction $=20$ degree

Composite Emission Factor (EF)

\begin{tabular}{|l|c|c|c|c|c|}
\hline $\begin{array}{c}\text { Road Link/Intersection } \\
\text { Name }\end{array}$ & \multicolumn{2}{|c|}{$\mathrm{CO}(\mathrm{g} / \mathrm{v}-\mathrm{mi})$} & $\begin{array}{c}\mathrm{NO}_{2} \\
(\mathrm{~g} / \mathrm{v}-\mathrm{mi})\end{array}$ & $\begin{array}{c}\mathrm{NO}_{x} \\
(\mathrm{~g} / \mathrm{v}-\mathrm{mi})\end{array}$ & $P_{2.5}(\mathrm{~g} / \mathrm{v}-\mathrm{mi})$ \\
\cline { 2 - 6 } & MOVES & CMEM & MOVES & $C M E M$ & MOVES \\
\hline Rideau and Wurtemburg & 39 & 39.15 & 3 & 3.556 & 1 \\
\hline Rideau Street & 20 & 8.432 & 1 & 1.889 & 1 \\
\hline Wurtemburg St. & 15 & 3.801 & 0 & 0.44 & 0 \\
\hline
\end{tabular}

Background Pollution Concentrations (Ottawa Downtown Station):

$$
\mathrm{CO}=0.22 \mathrm{ppm}, \mathrm{O}_{3}=0.019 \mathrm{ppm}, \mathrm{NO}_{2}=0.012 \mathrm{ppm}, \mathrm{PM}_{2.5}=7 \mu \mathrm{g} / \mathrm{m}^{3}
$$


Gas Analyzer: $\quad \mathrm{CO}=1.67 \mathrm{ppm}, \quad \mathrm{NO}_{2}=0.10 \mathrm{ppm}=100 \mathrm{ppb}$

\begin{tabular}{|c|c|c|}
\hline \multirow{2}{*}{ Time } & \multicolumn{2}{|c|}{ Gas Analyzer Reading in field } \\
\cline { 2 - 3 } & $\mathrm{CO}$ & $\mathrm{NO}_{2}$ \\
\hline $9: 15 \mathrm{AM}$ & 2 & 0.1 \\
\hline $9: 30 \mathrm{AM}$ & 2 & 0.1 \\
\hline $9: 45 \mathrm{AM}$ & 1 & 0.1 \\
\hline Average $=$ & 1.67 & 0.10 \\
\hline
\end{tabular}

Dust Meter reading: $\quad \mathrm{PM}_{2.5}=0.04345 \mathrm{mg} / \mathrm{m}^{3}=43.45 \mu \mathrm{g} / \mathrm{m}^{3}$

From Simulation Model:

$$
\mathrm{CO}=1.6 \mathrm{ppm}, \quad \mathrm{NO}_{2}=0.11 \mathrm{ppm}=110 \mathrm{ppb}, \quad \mathrm{PM}_{2.5}=45 \mu \mathrm{g} / \mathrm{m}^{3}
$$

Summary Report:

\begin{tabular}{|l|c|c|c|}
\hline & $\mathrm{CO}(\mathrm{ppm})$ & $\mathrm{NO}_{2}(\mathrm{ppb})$ & $P M_{2.5}\left(\mu \mathrm{g} / \mathrm{m}^{3}\right)$ \\
\hline Model & 1.6 & 110 & 45 \\
\hline Instrument & 1.67 & 100 & 43.45 \\
\hline Difference & $4.2 \%$ & $9.1 \%$ & $3.4 \%$ \\
\hline
\end{tabular}

\subsubsection{Field Sample \# 5}

Study Area: Carling Avenue (Civic Campus, Ottawa Hospital).

Data Collection Date and Time: April 14, 2016 on Thursday at 5:00 - 6:00 PM.

Traffic Count: $\quad$ Heavy Duty Vehicles $=8 \%$

\begin{tabular}{|c|c|c|}
\hline Sl No. & Road link Name with Direction & Number of Vehicles \\
\hline 1. & Carling Avenue East Bound Traffic & 764 \\
\hline 2. & Carling Avenue West Bound Traffic & 1292 \\
\hline
\end{tabular}


Climate data from instrument:

\begin{tabular}{|c|c|c|c|}
\hline \multicolumn{2}{|c|}{ Temperature } & \multicolumn{2}{c|}{ Wind Speed } \\
\hline${ }^{\circ} \mathrm{F}$ & ${ }^{\circ} \mathrm{C}$ & $\mathrm{ft} / \mathrm{min}$ & $\mathrm{m} / \mathrm{s}$ \\
\hline 57.37 & 14.1 & 68.96 & 0.35 \\
\hline
\end{tabular}

Station (Experimental Farm):

Temperature $=9.8{ }^{\circ} \mathrm{C}$, Relative Humidity $=30 \%$, Wind Speed $=11 \mathrm{~km} / \mathrm{h}=3.05$ $\mathrm{m} / \mathrm{s}, \quad$ Wind Direction $=30$ degree, $\quad$ Std. Dev. of Wind Dir. $=40$ degree

\section{Composite Emission Factor (EF)}

\begin{tabular}{|c|c|c|c|c|c|}
\hline \multirow{2}{*}{$\begin{array}{c}\text { Link/ Intersection } \\
\text { Name }\end{array}$} & \multicolumn{2}{|c|}{$C \mathrm{O}(\mathrm{g} / \mathrm{v}$-mi $)$} & $\begin{array}{c}\mathrm{NO}_{2} \\
(\mathrm{~g} / \mathrm{v} \text {-mi })\end{array}$ & $\begin{array}{c}\mathrm{NO}_{x} \\
(\mathrm{~g} / \mathrm{v}-\mathrm{mi})\end{array}$ & $P M_{2.5}(\mathrm{~g} / \mathrm{v}-\mathrm{mi})$ \\
\cline { 2 - 6 } & MOVES & CMEM & MOVES & CMEM & MOVES \\
\hline Carling EB & 26 & 52.536 & 2 & 2.711 & 1 \\
\hline Carling WB & 32 & 69.923 & 3 & 3.136 & 1 \\
\hline
\end{tabular}

Gas Analyzer (instrument):

$$
\mathrm{CO}=0.5 \mathrm{ppm}, \quad \mathrm{NO}_{2}=0.02174 \mathrm{ppm}=21.74 \mathrm{ppb} \text { (from continuous reading) }
$$

\begin{tabular}{|c|c|}
\hline Time & CO (ppm) \\
\hline $5: 15 \mathrm{PM}$ & 0 \\
\hline $5: 30 \mathrm{PM}$ & 0 \\
\hline $5: 45 \mathrm{PM}$ & 1 \\
\hline $6: 00 \mathrm{PM}$ & 1 \\
\hline Average & 0.5 \\
\hline
\end{tabular}

Dust Meter: $\quad \mathrm{PM}_{2.5}=0.09 \mathrm{mg} / \mathrm{m}^{3}=90 \mu \mathrm{g} / \mathrm{m}^{3}$ 
Computer Simulation Model:

$$
\mathrm{CO}=2.4 \mathrm{ppm}, \quad \mathrm{NO}_{2}=0.02 \mathrm{ppm}=20 \mathrm{ppb}, \quad \mathrm{PM}_{2.5}=92 \mu \mathrm{g} / \mathrm{m}^{3}
$$

Summary Report:

\begin{tabular}{|l|c|c|c|}
\hline & $C O(p p m)$ & $N_{2}(p p b)$ & $P M_{2.5}\left(\mu g / m^{3}\right)$ \\
\hline Model & 0.5 & 21.74 & 90 \\
\hline Instrument & 2.4 & 20 & 92 \\
\hline Difference & - & $7.8 \%$ & $2.2 \%$ \\
\hline
\end{tabular}

\subsubsection{Field Sample \# 6-1}

Study Area: Carling Avenue and Bayshore Drive, Ottawa.

Data Collection Date and Time: April 15, 2016 (Friday) at 3:00-4:00 PM.

Traffic Count: $\quad$ Heavy Duty Vehicles $(\mathrm{HDV})=5.8 \%$

Intersection Traffic volume $=2394$

\begin{tabular}{|c|c|c|c|c|c|}
\hline \multirow{3}{*}{ NB } & Left & Through & Right & Total & Opposite Direction \\
\hline & 85 & 10 & 285 & 380 & 495 \\
\hline & $22 \%$ & $3 \%$ & $75 \%$ & & \\
\hline \multirow[b]{2}{*}{ SB } & 22 & 22 & 0 & 44 & 46 \\
\hline & $50 \%$ & $50 \%$ & & & \\
\hline \multirow[b]{2}{*}{ EB } & 16 & 591 & 158 & 765 & 955 \\
\hline & $2 \%$ & $77 \%$ & $21 \%$ & & \\
\hline \multirow[b]{2}{*}{ WB } & 315 & 870 & 20 & 1205 & 898 \\
\hline & $26 \%$ & $72 \%$ & $2 \%$ & & \\
\hline
\end{tabular}

Climate data from instrument: 


\begin{tabular}{|c|c|c|c|}
\hline${ }^{O} F$ & ${ }^{o} \mathrm{C}$ & $\mathrm{ft} / \mathrm{min}$ & $\mathrm{m} / \mathrm{s}$ \\
\hline 62.14 & 16.75 & 378.08 & 1.92 \\
\hline
\end{tabular}

Station (Experimental Farm):

Temperature $=13.5^{\circ} \mathrm{C}, \quad$ Relative Humidity $=26 \%$

Wind Speed $=13 \mathrm{~km} / \mathrm{h}=3.6 \mathrm{~m} / \mathrm{s}$, Wind Direction $=90$ degree

Std. Dev. of wind direction $=20$ degree

Composite Emission Factor (EF)

\begin{tabular}{|l|c|c|c|c|c|}
\hline \multicolumn{1}{|c|}{ Link/ Intersection Name } & \multicolumn{2}{|c|}{$C O(g / v-m i)$} & $\begin{array}{c}N_{2} \\
(g / v-m i)\end{array}$ & $\begin{array}{c}N_{x} \\
(g / v-m i)\end{array}$ & $P M_{2.5}$ \\
\cline { 2 - 6 } & MOVES & CMEM & MOVES & CMEM & MOVES \\
\hline Bayshore Drive & 31 & 48.995 & 3 & 2.675 & 1 \\
\hline Birchdale Ave & 22 & 33.443 & 0 & 0.854 & 0 \\
\hline Carling Ave and Bayshore Dr & 39 & 84.465 & 3 & 4.146 & 1 \\
\hline Carling Avenue East & 35 & 90.69 & 3 & 2.782 & 1 \\
\hline Carling Avenue West & 23 & 21.154 & 2 & 1.527 & 1 \\
\hline
\end{tabular}

Gas Analyzer (instrument):

$$
\mathrm{CO}=3.5 \mathrm{ppm}, \quad \mathrm{NO}_{2}=0.2 \mathrm{ppm}=200 \mathrm{ppb}
$$

\begin{tabular}{|c|c|c|}
\hline \multirow{2}{*}{ Time } & \multicolumn{2}{|c|}{ Pollutants from Manual data collection from Gas Analyzer } \\
\cline { 2 - 3 } & CO (ppm) & $\mathrm{NO}_{2}(\mathrm{ppm})$ \\
\hline $3: 15 \mathrm{PM}$ & 3 & 0.1 \\
\hline $3: 30 \mathrm{PM}$ & 3 & 0.1 \\
\hline $3: 45 \mathrm{PM}$ & 4 & 0.3 \\
\hline $4: 00 \mathrm{PM}$ & 4 & 0.3 \\
\hline Average & 3.5 & 0.2 \\
\hline
\end{tabular}

Dust Meter: $\quad \mathrm{PM}_{2.5}=0.034 \mathrm{mg} / \mathrm{m}^{3}=34 \mu \mathrm{g} / \mathrm{m}^{3}$ 
Computer Simulation Model:

$$
\mathrm{CO}=3.5 \mathrm{ppm}, \quad \mathrm{NO}_{2}=0.02 \mathrm{ppm}=20 \mathrm{ppb}, \quad \mathrm{PM}_{2.5}=36 \mu \mathrm{g} / \mathrm{m}^{3}
$$

Summary Report:

\begin{tabular}{|l|c|c|c|}
\hline & $\mathrm{CO}(\mathrm{ppm})$ & $\mathrm{NO}_{2}(\mathrm{ppm})$ & $P M_{2.5}\left(\mu \mathrm{g} / \mathrm{m}^{3}\right)$ \\
\hline Model & 3.5 & 0.2 & 36 \\
\hline Instrument & 3.5 & 0.02 & 34 \\
\hline Difference & $0 \%$ & - & $5.5 \%$ \\
\hline
\end{tabular}

\subsubsection{Field Sample \# 6-2}

Study Area: Carling Avenue and Wylie Ave (near Bayshore Drive), Ottawa.

Data Collection Date and Time: April 17, 2016 (Sunday) at 4:00-5:00 PM.

Traffic Count: $\quad$ Intersection Traffic Volume $=952$

Weighted Average HDV $=6.1 \%$

\begin{tabular}{|c|c|c|}
\hline Road link Name with Direction & Number of Vehicles & \% of HDV \\
\hline Carling Avenue East Bound Traffic & 718 & 6.4 \\
\hline Carling Avenue West Bound Traffic & 762 & 5.9 \\
\hline
\end{tabular}

Climate data from instrument:

\begin{tabular}{|c|c|c|c|}
\hline \multicolumn{2}{|c|}{ Temperature } & \multicolumn{2}{c|}{ Wind Speed } \\
\hline${ }^{O} F$ & ${ }^{O} C$ & $f t / m i n$ & $m / s$ \\
\hline 76.95 & 24.97 & 90.94 & 0.462 \\
\hline
\end{tabular}


Station (Experimental Farm): Temperature $=22.3^{\circ} \mathrm{C}, \quad$ Relative Humidity $=18 \%$, Wind Speed $=9 \mathrm{~km} / \mathrm{h}=2.5 \mathrm{~m} / \mathrm{s}, \quad$ Wind Direction $=260$ degree, $\quad$ Std. Dev. of wind direction $=20$ degree, Ambient Air Pressure $=101.67 \mathrm{kpa}$

Composite Emission Factor (EF)

\begin{tabular}{|c|c|c|c|c|c|}
\hline Link/ Intersection Name & \multicolumn{2}{|c|}{$\mathrm{CO}(\mathrm{g} / \mathrm{v}-\mathrm{mi})$} & $\begin{array}{c}\mathrm{NO}_{2} \\
(\mathrm{~g} / \mathrm{v}-\mathrm{mi})\end{array}$ & $\begin{array}{c}\mathrm{NO}_{x} \\
(\mathrm{~g} / \mathrm{v}-\mathrm{mi})\end{array}$ & $\mathrm{PM}_{2.5}$ \\
\cline { 2 - 6 } & MOVES & $\mathrm{CMEM}$ & $\mathrm{MOVES}$ & $\mathrm{CMEM}$ & MOVES \\
\hline Bayshore Drive & 30 & 47.97 & 2 & 2.717 & 1 \\
\hline Birchdale Ave & 22 & 34.953 & 0 & 0.835 & 0 \\
\hline Carling and Bayshore & 37 & 82.217 & 3 & 4.141 & 1 \\
\hline Carling Avenue East & 27 & 50.802 & 2 & 2.216 & 1 \\
\hline Carling Avenue West & 23 & 19.873 & 2 & 1.555 & 1 \\
\hline
\end{tabular}

Gas Analyzer (instrument): $\quad \mathrm{CO}=2.25 \mathrm{ppm}, \quad \mathrm{NO}_{2}=0.2 \mathrm{ppm}$

\begin{tabular}{|c|c|c|}
\hline \multirow{2}{*}{ Time } & \multicolumn{2}{|c|}{ Pollutants from Manual data collection from Gas Analyzer } \\
\cline { 2 - 3 } & $\mathrm{CO}(\mathrm{ppm})$ & $\mathrm{NO}_{2}(\mathrm{ppm})$ \\
\hline $4: 15 \mathrm{PM}$ & 1 & 0.2 \\
\hline $4: 30 \mathrm{PM}$ & 1 & 0.2 \\
\hline $4: 45 \mathrm{PM}$ & 3 & 0.2 \\
\hline $5: 00 \mathrm{PM}$ & 4 & 0.2 \\
\hline Average & 2.25 & 0.2 \\
\hline
\end{tabular}

Dust Meter: $\quad \mathrm{PM}_{2.5}=0.01224 \mathrm{mg} / \mathrm{m}^{3}=12.24 \mu \mathrm{g} / \mathrm{m}^{3}$

Computer Simulation Model:

$$
\mathrm{CO}=2.1 \mathrm{ppm}, \quad \mathrm{NO}_{2}=0.02 \mathrm{ppm}=20 \mathrm{ppb}, \quad \mathrm{PM}_{2.5}=12 \mu \mathrm{g} / \mathrm{m}^{3}
$$


Summary Report:

\begin{tabular}{|l|c|c|c|}
\hline & $\mathrm{CO}(\mathrm{ppm})$ & $\mathrm{NO}_{2}(\mathrm{ppm})$ & $P M_{2.5}\left(\mu \mathrm{g} / \mathrm{m}^{3}\right)$ \\
\hline Model & 2.1 & 0.02 & 12 \\
\hline Instrument & 2.25 & 0.2 & 12.24 \\
\hline Difference & $6.6 \%$ & - & $1.9 \%$ \\
\hline
\end{tabular}

\subsubsection{Field Sample \# 7}

Study Area: Baseline road and Prince of Wales drive, Ottawa.

Data Collection Date and Time: April 18, 2016 (Monday) in between 10:00-11:00 AM.

Traffic Count: $\quad$ Heavy Duty Vehicles (HDV) $=5.8 \%$

\begin{tabular}{|l|c|}
\hline \multicolumn{1}{|c|}{ Road link name with direction } & Number of vehicle \\
\hline Baseline Road East Bound traffic & 826 \\
\hline Baseline Road West Bound traffic & 945 \\
\hline
\end{tabular}

Climate data from instrument:

\begin{tabular}{|c|c|c|c|}
\hline \multicolumn{2}{|c|}{ Temperature } & \multicolumn{2}{c|}{ Wind Speed } \\
\hline${ }^{O} \mathrm{~F}$ & ${ }^{o} \mathrm{C}$ & $\mathrm{ft} / \mathrm{min}$ & $\mathrm{m} / \mathrm{s}$ \\
\hline 60.1 & 15.6 & 254 & 1.3 \\
\hline
\end{tabular}

Station (Experimental Farm):

Wind Speed $=13 \mathrm{~km} / \mathrm{h}=3.6 \mathrm{~m} / \mathrm{s}$, Wind Direction $=50$ degree, Temperature $=$ $13.4^{\circ} \mathrm{C}, \quad$ Relative Humidity $=42 \%, \quad$ Wind direction Std. Dev. $=20$ degree

Composite Emission Factor (EF)

\begin{tabular}{|c|c|c|c|c|}
\hline $\begin{array}{c}\text { Road Link/ } \\
\text { Intersection Name }\end{array}$ & $\mathrm{CO}(\mathrm{g} / \mathrm{v}-\mathrm{mi})$ & $\begin{array}{c}\mathrm{NO}_{2} \\
(\mathrm{~g} / \mathrm{v}-\mathrm{mi})\end{array}$ & $\begin{array}{c}\mathrm{NO}_{X} \\
(\mathrm{~g} / \mathrm{v}-\mathrm{mi})\end{array}$ & $\begin{array}{c}\mathrm{PM}_{2.5} \\
(\mathrm{~g} / \mathrm{v}-\mathrm{mi})\end{array}$ \\
\hline
\end{tabular}




\begin{tabular}{|l|c|c|c|c|c|}
\hline & MOVES & CMEM & MOVES & CMEM & MOVES \\
\hline $\begin{array}{l}\text { Baseline Road East } \\
\text { Bound }\end{array}$ & 19 & 11.311 & 1 & 1.005 & 1 \\
\hline $\begin{array}{l}\text { Baseline Road West } \\
\text { Bound }\end{array}$ & 18 & 13.78 & 1 & 0.66 & 1 \\
\hline $\begin{array}{l}\text { Baseline and Prince of } \\
\text { Wales }\end{array}$ & 43 & 80.677 & 4 & 2.407 & 1 \\
\hline
\end{tabular}

Background Pollution Concentrations:

$$
\begin{array}{lll}
\mathrm{CO}=0.12 \mathrm{ppm} & \mathrm{NO}_{2}=0.002 \mathrm{ppm} \quad \mathrm{O}_{3}=0.04 \mathrm{ppm} \\
\mathrm{NO}=0.001 \mathrm{ppm} & \mathrm{NO}_{2} \text { Photolysis rate }=0.008271 / \mathrm{s}
\end{array}
$$

Gas Analyzer (instrument): $\quad \mathrm{CO}=3 \mathrm{ppm} \quad \mathrm{NO}_{2}=0.016949 \mathrm{ppm}=16.95 \mathrm{ppb}$

Dust Meter: $\quad \mathrm{PM}_{2.5}=0.01088 \mathrm{mg} / \mathrm{m}^{3}=10.88 \mu \mathrm{g} / \mathrm{m}^{3}$

Computer Simulation Model:

$$
\mathrm{CO}=3.2 \mathrm{ppm} \quad \mathrm{NO}_{2}=0.02 \mathrm{ppm}=20 \mathrm{ppb} \quad \mathrm{PM}_{2.5}=11 \mu \mathrm{g} / \mathrm{m}^{3}
$$

Summary Report:

\begin{tabular}{|l|c|c|c|}
\hline & $\mathrm{CO}(\mathrm{ppm})$ & $\mathrm{NO}_{2}(\mathrm{ppb})$ & $P M_{2.5}\left(\mu \mathrm{g} / \mathrm{m}^{3}\right)$ \\
\hline Model & 3.2 & 20 & 11 \\
\hline Instrument & 3 & 16.95 & 10.88 \\
\hline Difference & $6.25 \%$ & $15.25 \%$ & $1.09 \%$ \\
\hline
\end{tabular}

\subsubsection{Field Sample \# 8}

Study Area: Highway-417 near via railway station, Ottawa.

Data Collection Date and Time: April 19, 2016 (Tuesday) in between 5:00-6:00 PM. 
Traffic Count:

\begin{tabular}{|c|c|c|c|}
\hline East Bound Traffic & HDV\% (EB) & West Bound Traffic & HDV\% (WB) \\
\hline 7188 & 7.5 & 4032 & 5.2 \\
\hline
\end{tabular}

Climate data from instrument:

\begin{tabular}{|c|c|c|c|}
\hline \multicolumn{2}{|c|}{ Temperature } & \multicolumn{2}{c|}{ Wind Speed } \\
\hline${ }^{O} \mathrm{~F}$ & ${ }^{O} \mathrm{C}$ & $\mathrm{ft} / \mathrm{min}$ & $\mathrm{m} / \mathrm{s}$ \\
\hline 61.05 & 16.1 & 290.56 & 1.47 \\
\hline
\end{tabular}

Field Temperature $\left({ }^{\rho} F\right)$ Reading:

\begin{tabular}{|c|c|c|}
\hline $5: 15 P M$ & $6: 00 P M$ & Average \\
\hline 58.8 & 63.3 & 61.05 \\
\hline
\end{tabular}

Field Wind Speed (ft/min) Reading:

\begin{tabular}{|c|c|}
\hline Reading & Speed $(f t / m)$ \\
\hline 1 & 335 \\
\hline 2 & 324 \\
\hline 3 & 414 \\
\hline 5 & 238 \\
\hline 6 & 266 \\
\hline 7 & 135 \\
\hline 8 & 317 \\
\hline 9 & 230 \\
\hline 10 & 356 \\
\hline Average & 290.56 \\
\hline
\end{tabular}


Station (Experimental Farm):

Temperature $=13.9^{\circ} \mathrm{C} \quad$ Wind Speed $=23 \mathrm{Km} / \mathrm{h}=6.38 \mathrm{~m} / \mathrm{s}$

Wind Direction $=310$ degree

Composite Emission Factor (EF)

\begin{tabular}{|c|c|c|c|}
\hline Link/ Intersection Name & $C O(g / v-m i)$ & $\begin{array}{c}N O_{X}(g / v-m i) \\
\text { from CMEM }\end{array}$ & $P M_{2.5}(\mathrm{~g} / \mathrm{v}-\mathrm{mi})$ \\
\hline $\mathrm{EB}$ & 136.082 & 4.362 & 2 \\
\hline WB & 17.168 & 1.781 & 2 \\
\hline
\end{tabular}

Gas Analyzer (instrument):

$\mathrm{CO}=3.0 \mathrm{ppm} \quad \mathrm{NO}_{2}=25 \mathrm{ppb}$

\begin{tabular}{|c|c|c|}
\hline Time & $\mathrm{CO}(\mathrm{ppm})$ & $\mathrm{NO}_{2}(\mathrm{ppm})$ \\
\hline $8: 15 \mathrm{AM}$ & 0 & 0.1 \\
\hline $8: 30 \mathrm{AM}$ & 4 & 0.0 \\
\hline $8: 45 \mathrm{AM}$ & 4 & 0.0 \\
\hline $9: 00 \mathrm{AM}$ & 4 & 0.0 \\
\hline Average & 3 & $0.025 \mathrm{ppm}(25 \mathrm{ppb})$ \\
\hline
\end{tabular}

Dust Analyzer Readings:

\begin{tabular}{|c|c|}
\hline Reading & $P M_{2.5}\left(\mathrm{mg} / \mathrm{m}^{3}\right)$ \\
\hline 1 & 0.009 \\
\hline 2 & 0.026 \\
\hline 3 & 0.012 \\
\hline 4 & 0.018 \\
\hline 5 & 0.014 \\
\hline 6 & 0.015 \\
\hline Average & $0.156 \mathrm{mg} / \mathrm{m}^{3}\left(15.667 \mu \mathrm{g} / \mathrm{m}^{3}\right)$ \\
\hline
\end{tabular}


Computer Simulation Model:

$$
\mathrm{CO}=4.0 \mathrm{ppm}, \quad \mathrm{NO}_{2}=0.01 \mathrm{ppm}=10 \mathrm{ppb}, \quad \mathrm{PM}_{2.5}=14 \mu \mathrm{g} / \mathrm{m}^{3}
$$

Summary Report:

\begin{tabular}{|l|c|c|c|}
\hline & $\mathrm{CO}(\mathrm{ppm})$ & $\mathrm{NO}_{2}(\mathrm{ppb})$ & $P M_{2.5}\left(\mu \mathrm{g} / \mathrm{m}^{3}\right)$ \\
\hline Model & 4 & 10 & 14 \\
\hline Instrument & 3 & 25 & 15.667 \\
\hline Difference & $25 \%$ & - & $10.2 \%$ \\
\hline
\end{tabular}

Based on the comparison of results, it can be seen that the best result belongs to field sample \# 4.2 at the Rideau Street and Wurtemburg Street intersection, and worst result occurs for the freeway case. It is contended that the error differences depend on field condition and coarse readings obtained manually. Low errors were noticed for $\mathrm{PM}_{2.5}$ pollutants as compared to $\mathrm{CO}$ and $\mathrm{NO}_{2}$ reading. The reason is that the dust meter recorded field results in the memory card. For most of the cases, the gas analyser data was obtained from the field book. The reason for worst results belonging to the freeway sample is described later. The results are analyzing in the next section and applicable limitations for each study location are highlighted.

\subsection{ANALYSIS OF RESULTS AND LIMITATIONS}

The pollution-measuring instruments recorded the roadside pollution concentrations. Results show that the minimum $\mathrm{CO}$ concentrations recorded by the machine is $1 \mathrm{ppm}$ and highest is $4 \mathrm{ppm}$. The minimum $\mathrm{NO}_{2}$ concentration is zero and maximum is $300 \mathrm{ppb}$. The average $\mathrm{NO}_{2}$ concentration from instruments shows the minimum of $16.95 \mathrm{ppb}$ for field sample \#7, and $60.53 \mathrm{ppb}$ for field sample 4-1. The field sheet shows the maximum $\mathrm{NO}_{2}$ 
as $0.3 \mathrm{ppm}$ or $300 \mathrm{ppb}$. The dust meter recorded the minimum $\mathrm{PM}_{2.5}$ concentration as 10.88 $\mu \mathrm{g} / \mathrm{m}^{3}$ at field sample seven and maximum of $406 \mu \mathrm{g} / \mathrm{m}^{3}$.

A study report presented at the Transportation Research Board's 2017 Annual Conference shows that the maximum near-road site concentrations for $\mathrm{CO}$ is $4.5 \mathrm{ppm}$ at a Pittsburgh, PA station. In the case of $\mathrm{NO}_{2}$ and $\mathrm{PM}_{2.5}$ corresponding measurements are $78.5 \mathrm{ppb}$ and 30 $\mu \mathrm{g} / \mathrm{m}^{3}$ at a Riverside, CA station (Presentation by a representative of the US EPA at the 2017 Annual Meeting of the Transportation Research Board). From these observations, it can be inferred that although the gas analyzer used in Ottawa field studies has low precision, but the results are satisfactory.

The results comparison section presents both sources and their differences. A sample of data from simulation model and field study shown in Table 8-1 indicates that the results using computer simulation models match well with field data. This table is based on results for field sample \# 7, where the error of $\mathrm{PM}_{2.5}$ pollutants is close to one percent.

Table 8-1: Comparison of gas pollutants estimated from model and field study

\begin{tabular}{|c|c|c|c|c|c|}
\hline Date & Time & $\begin{array}{l}\text { CO from } \\
\text { MODEL } \\
(\text { ppm })\end{array}$ & $\begin{array}{l}\text { CO in } \\
\text { Field } \\
(\text { ppm })\end{array}$ & $\begin{array}{l}\mathrm{NO}_{2} \text { from } \\
\mathrm{MODEL} \\
(p p m)\end{array}$ & $\begin{array}{l}\text { Average } \\
\mathrm{NO}_{2} \text { in } \\
\text { Field }(p p m)\end{array}$ \\
\hline April 18, 2016 & $10: 00-11: 00 \mathrm{AM}$ & 3.2 & 3 & 0.02 & 0.016949 \\
\hline
\end{tabular}

The output of model for $\mathrm{CO}$ is shown with one decimal place accuracy, but for $\mathrm{NO}_{2}$ in two decimal places. Table 8-1 shows that $\mathrm{CO}$ reading from field using gas analyzer is in integer form. With reference to field sample \# 7, it should be noted that the field data were read manually for every 15 minutes intervals due to the reason that the CO sensor for automated 
recording of data in the gas analyzer was not working. Whereas, the $\mathrm{NO}_{2}$ sensor used in gas analyzer recorded data.

Table 8-1 shows that $\mathrm{CO}$ level from model is $3.2 \mathrm{ppm}$ and based on instrument it is 3.0 $\mathrm{ppm}$. At the same time, $\mathrm{NO}_{2}$ level in model provides $0.02 \mathrm{ppm}$ (equal to $20 \mathrm{ppb}$ ), but the average value of $\mathrm{NO}_{2}$ from field is $16.95 \mathrm{ppb}$. It should be pointed out that the simulation model provides $\mathrm{NO}_{2}$ value in ppm and is limited to two decimal places.

In the following part of this chapter, clarifications of causes of differences between simulation and field measurements are presented.

- At field sample-1 at Bronson road and Carling Avenue, the instruments were used for testing purposes and data were collected in the manual mode. None of the data was recorded in the continuous mode. Therefore, the results are very different. It is noted that the dust meter displayed the maximum $\mathrm{PM}_{2.5}$ concentrations at 5:15 $\mathrm{PM}$, which is $406 \mu \mathrm{g} / \mathrm{m}^{3}$.

- In the case of field sample number two at Wakley Road and McCarthy Road intersection, the gas analyzer reading (for $\mathrm{CO}$ and $\mathrm{NO}_{2}$ ) is not satisfactory due to precision of instruments, but the dust meter collected data on a one second interval basis and the result is very close to the model. Moreover, continuous data was collected by gas analyzer from 10:33 AM to 10:43 $\mathrm{AM}$ and average $\mathrm{CO}$ was $=0.33 \mathrm{ppm}$. Rest of the data were collected manually in 15 minutes interval. It should be mentioned that that the gas analyzer has two sensors. $\mathrm{CO}$ sensors have a limitation and provide reading in integer form only and the unit for $\mathrm{CO}$ concentration is in ppm. Therefore, the $\mathrm{CO}$ result is either 1.0 or 2.0 , no decimal results are provided. For $\mathrm{NO}_{2}$ sensor, the results 
are limited to one decimal form and the unit is ppm. Therefore, the results are either 0.0 or 0.1 . That means either $0 \mathrm{ppb}$ or $100 \mathrm{ppb}$. That is the reason why the results vary much.

Another observation is worth noting. The velocity meter recorded reading in every 30 seconds interval. However, this meter cannot provide wind direction. The wind direction data was collected from the nearest climate station. The wind direction varied dramatically at this location, which was 360 degree at 9:00 AM, but 20 degree at 11:00 AM. So, standard deviation is considered as 50 degree.

- For field sample number three at Hunt club road in between Cahill drive and Duston terrace, video was filming on the road link for recording directional traffic flow. The turning movement and control data were sourced from the data supplied by the city of Ottawa. Vehicles are balanced at intersections based on segment flow rate. It should be pointed out that VISSIM was run further for an additional half hour in order to meet the input requirement for CMEM. Moreover, no data were collected by gas analyzer in the continuous mode. Therefore, results are different. However, the dust meter reading for $\mathrm{PM}_{2.5}$ data compare well with simulation result.

- At the field sample \# 4.1 (Rideau Street and Wurtemburg Street), instruments were placed at the north east corner of the intersection, which is opposite to the wind direction. Therefore, the pollution concentration results are low. The $\mathrm{CO}$ sensor placed in the gas analyzer showed zero value as $\mathrm{CO}$ pollution concentration is low, which is even less than $1 \mathrm{ppm}$. However, the error is minimum in this case. This is one of the best results among the survey locations, for the reason that the instruments recorded field values. 
- Field sample \# 4.2 belongs to the same location and field sample 1. Here, the $\mathrm{NO}_{2}$ and $\mathrm{PM}_{2.5}$ emission rates are zero in MOVES output since heavy duty vehicles do not run on Wurtemberg Street. Though road link activities are different from two types of emission models, the composite emission factors (CEF) at the intersection of Rideau Street and Wurtemburg Street are very close to two different models. For CO emission rate, MOVES generated $39 \mathrm{~g} / \mathrm{v}-\mathrm{mi}$ and CMEM generated $39.15 \mathrm{~g} / \mathrm{v}-\mathrm{mi}$. Therefore, the difference from two models is $0.15 \mathrm{~g} / \mathrm{v}-\mathrm{mi}$, which is less than 1 percent. However, it should be noted that MOVES produces $\mathrm{NO}_{2}$ and CMEM produces $\mathrm{NO}_{\mathrm{X}}$, which is a combination of $\mathrm{NO}$ and $\mathrm{NO}_{2}$. There are few differences in results. As noted above, there were no heavy-duty vehicles on Wurtemburg Street during the survey period. Therefore, MOVES provided $\mathrm{NO}_{2}$ emission rate equal to zero, but CMEM provided $\mathrm{NO}_{\mathrm{x}}$ emission rate as $0.44 \mathrm{~g} / \mathrm{v}$-mi. The reason is that CMEM model produces results at the microscopic level.

- At the field sample \#5 location on Carling Avenue in front of Ottawa Civic Hospital, the velocity trajectories for Carling Avenue west bound traffic were numerous. This overload of data could be a reason that the CMEM did not produce composite emission factor (EF) results for an hour. Therefore, VISSIM was further run for half an hour and velocity trajectories were used for the calculation of CEF on Carling Avenue west bound traffic in the CMEM software. It is noted that the carbon monoxide sensor attached to the gas analyzer did not collect reading in the continuous mode. Another gas analyzer was also not working during the survey period. That is why the CO pollution concentration data do not match. 
- Field sample \# 6-1 at Carling avenue and Bayshore drive, and field sample \#6-2 at carling avenue and Weily road illustrate that the $\mathrm{CO}$ and $\mathrm{PM}_{2.5}$ compare well, whereas $\mathrm{NO}_{2}$ sensor attached to gas analyzer was not able to display reading in two decimal places.

- Field sample \# 7 at Baseline road and Prince of Wales drive, VISSIM was run for $1 / 2-$ hour time slices in order to produce inputs required by CMEM. Ignoring this limitation, the results are matched well.

- Field sample \# 8 near freeway-417 (close to VIA railway station) shows that the results are not satisfactory. There are number reasons for such differences in results. None of the machines recorded data, because all memory cards were full including velocity meter. Therefore, data were read manually. This is the main reason of such error. Due to inaccessibility of the freeway right-of-way, the instruments were placed near a transit road. Therefore, the movement of transit busses on this road affected the results of this study location.

The comparison of field samples with simulations provides differences in results from two sources. These differences are within the limits discussed earlier. Some of the results show that error percentages are comparatively higher. The reasons for higher differences were discussed above. Based on above discussion and considering the pros and cons of field instruments, it may concluded that the research methodology provides results that are similar to field data. 


\section{Chapter 9: $\quad$ SIMULATION DESIGN}

\subsection{INTRODUCTION}

The output of the integrated simulation models is a predicted emission concentration at the receptor level who is away from the road by a defined distance and is at a defined height. Such predictions can be obtained with the use of the simulation models that were validated in this research. However, for practical "worst case" applications, predictive models are required that can be developed from inputs to the models and outputs of simulation results. In this chapter, the simulation design is described and results of simulations are presented in chapter ten. In chapter-11, the developed statistical models are presented.

The following interrelationships provide the starting point for urban road and intersection simulations.

Pollution Concentration $=\mathbf{f}$ (traffic, control, HDV, LU, velocity profile, EF, temperature, distance, height)

In the above equation,

Traffic $=$ capacity level traffic volume

Control $=$ signalize control system or stop sign

HDV $($ in $\%)=$ percentage of heavy duty vehicles

On Road Infrastructure $=$ number of lanes, intersection design, etc .

Land Use $(\mathrm{LU})=\mathrm{CBD}$, urban-outside CBD

$\mathrm{EF}=$ emission factor 
Temperature $=$ local temperature (approx. range is $-30^{\circ} \mathrm{C}$ to $55^{\circ} \mathrm{C}$ )

Distance $(m)=$ cross wind distance from road edge

Height $(\mathrm{m})=$ human breathing height at different elevation levels

The methods and models used to obtain all factors noted above were described in detail in previous chapters. This chapter covers the selection of explanatory or independent variables, road network design, and random number assignment procedure for the selection of values of variables. Among those independent variables, the capacity level traffic is a significant one. The systematic procedures for capacity level traffic are explained next. The steps include saturation traffic flow on road infrastructure and capacity calculations in terms of green time allocation, and other considerations.

\subsection{DECISION MAKING ON VALUES OF VARIABLES}

\subsubsection{Capacity Level Traffic for Urban Roads/Intersections}

Traffic Capacity $=\mathrm{f}$ (numbers of lane, exclusive turning lane, lane width, percentage of heavy duty vehicles, speed, signal cycle and phases, land use)

These terms were addressed in earlier sections with the definition of pollution concentrations. The capacity level traffic was decided on the following assumptions available in Highway Capacity Manual -2010 (HCM-2010, Volume-3, page 16-26 and TRB 2010).

1. All segments of road have same number of through lanes.

2. Only signal control is used. 
3. Coordinated signal with arrival type 4, whereas cycle length is 120 seconds and weighted average $\mathrm{g} / \mathrm{C}$ ratio is 0.45 for through movement.

4. Exclusive left turns with protected phasing.

5. Left turning and right turning traffic are $10 \%$ of the total traffic on road link.

6. $\mathrm{PHF}=0.92$

7. Base saturation flow rate $\left(\mathrm{S}_{\mathrm{o}}\right)=1900 \mathrm{pc} / \mathrm{h} / \mathrm{ln}$

Other assumptions are considered at the time of using the Highway Capacity Software 2010. These are:

1. Lane width is 3.5 meter

2. Percentage of heavy duty vehicle $=3 \%$ (assumed; please refer to note below)

3. At level grade.

4. Turning adjustment factors (Left, $E_{L}=1.05$, and Right, $\left.E_{R}=1.18\right)$.

5. Speed for Arterial Road $=60 \mathrm{~km} / \mathrm{h}$, Collector $\mathrm{Road}=50 \mathrm{~km} / \mathrm{h}$, and Local road $=$ $40 \mathrm{~km} / \mathrm{h}$.

6. Right turning movement on red (RTOR) flow rate equals to 0 (zero) veh $/ \mathrm{h}$ (conservative assumption).

7. Pedestrian, bicycle, and bus stops are considered to be zero.

8. Local roads with stop signs are not considered at an intersection. The outgoing traffic from that local access are equal to the incoming traffic, and 10 percent of $1^{\text {st }}$ lane traffic to be calculated as turning movement.

Note: In the HCS-2010, 2 x passenger cars $=\mathrm{HDV}$, whereas DHV is defined as any vehicle with more than four tires touching the pavement. Local busses are not included in the count of heavy vehicles (HCM-2010, Volume-3, Page 18-10, and Garber and Hoel, page 533). 
According to Ontario province vehicle population statistics the HDV $=3.4 \%(2013)$. Fukutomi (1999) reports HDV on Highway-417=3.13\%. Whereas in the above statistics, HDVs include transit busses. Therefore, 3 (three) percent of heavy-duty vehicles are assumed to be on road.

\subsubsection{Saturation Flow Rate Calculation}

The saturation flow rate is the maximum flow rate on an approach or lane group when 100 percent effective green time is available. Basically, the adjusted number of vehicles flowing on the lane group in prevailing conditions per hour per lane for $100 \%$ green time. A standard equation is provided in the highway capacity manual to compute the saturation flow rate (HCM-2010, volume-3, page 18-35, and Garber and Hoel, page 389).

$$
S=S_{o} N f_{w} f_{H V} f_{g} f_{p} f_{b b} f_{a} f_{L U} f_{L T} f_{R T} f_{L p b} f_{R p b}
$$

Where

$\mathrm{S}=$ saturation flow rate for subject lane group in veh/h

$\mathrm{S}_{\mathrm{o}}=$ base saturation flow rate in $\mathrm{pc} / \mathrm{h} / \mathrm{ln}$

$\mathrm{N}=$ number of lanes

$\mathrm{f}_{\mathrm{w}}=$ lane width adjustment factor

$\mathrm{f}_{\mathrm{HV}}=$ heavy vehicle adjustment factor

$f_{g}=$ adjustment factor for approach grade

$\mathrm{f}_{\mathrm{p}}=$ adjustment factor for parking lane and parking activity

$f_{b b}=$ adjustment factor for blocking effects by local busses at stop

$\mathrm{f}_{\mathrm{a}}=$ area type adjustment factor

$\mathrm{f}_{\mathrm{LU}}=$ land utilization adjustment factor 


$$
\begin{aligned}
& \mathrm{f}_{\mathrm{LT}}=\text { adjustment factor for left turns in the lane group } \\
& \mathrm{f}_{\mathrm{RT}}=\text { adjustment factor for right turns in the lane group } \\
& \mathrm{f}_{\mathrm{Lpb}}=\text { pedestrian adjustment factor for left turn group } \\
& \mathrm{f}_{\mathrm{Rpb}}=\text { pedestrian/ bicycle adjustment factor for right turning movement }
\end{aligned}
$$

\subsubsection{Heavy Duty Vehicle Percentage (\% of HDV)}

The saturation level flows vary with respect to number of HDVs available on the road. However, it was decided that there is $3 \% \mathrm{HDV}$ on the road for planning purpose and simulation design is based on the assumptions of these statistics. Table 9-1 provides the saturation traffic flow $(\mathrm{veh} / \mathrm{h} / \mathrm{ln})$ by varying percentage of HDV.

Table 9-1: Saturated flow rate calculation on HDV

\begin{tabular}{|c|c|c|}
\hline \multirow{2}{*}{ Turning Movement } & \multicolumn{2}{|c|}{ Adjusted Saturation Flow Rate (S) veh/h/ln } \\
\cline { 2 - 3 } & $H D V=0 \%$ & $H D V=3 \%$ \\
\hline Left & 1810 & 1757 \\
\hline Through & 1900 & 1845 \\
\hline Right & 1610 & 1563 \\
\hline
\end{tabular}

\subsubsection{Lane utilization adjustment factor $\left(f_{L U}\right)$}

The lane utilization factor is used to adjust the ideal saturation flow rate. It is used for lane groups that have more than one exclusive lanes. Considering 3\% HDV on road, the following table was prepared. Table 9-2 illustrates that the saturation flow rate varies with numbers of lane. 
Table 9-2: Saturated flow rate calculation on lane adjustment factor and turning movement

\begin{tabular}{|l|c|c|c|c|}
\hline \multirow{2}{*}{ Number of lanes } & \multicolumn{4}{|c|}{ Saturation Flow Rate (S) in veh/h/ln } \\
\cline { 2 - 5 } & Left Turn & Through & Right Turn & Right and Through \\
\hline Single lane & 1757 & 1845 & 1563 & 1563 \\
\hline Double lanes & 1706 & 1756 & 1383 & - \\
\hline Triple lanes & - & 1675 & - & - \\
\hline
\end{tabular}

\subsubsection{Area type adjustment factor $\left(f_{a}\right)$}

Saturation flow rate also varies with area type, such as "within central business district (CBD)" or "outside CBD". The type of activities at the intersection have a significant effect on speed and saturation flow rate. For example, narrow sidewalk, frequent parking maneuvers, vehicle blockages, narrow streets, and high pedestrian activities are the factors for operating vehicles with less efficiency. This can be corrected by multiplying with 0.9 for CBD. However, $\mathrm{f}_{\mathrm{a}}=0.9$ is used for CBDs, but should not be limited only to CBDs. It can be applied to an intersection, where a significant impact on the intersection capacity can be anticipated (HCM-2010, volume-3, page 18-37).

Table 9-3: Saturated flow rate calculation by area type

\begin{tabular}{|c|c|c|}
\hline \multirow{2}{*}{ Turning Movement } & \multicolumn{2}{|c|}{ Adjusted Saturation Flow Rate (S) veh/h/ln } \\
\cline { 2 - 3 } & Urban-outside CBD & CBD-central city \\
\hline Left & 1757 & 1581 \\
\hline Through & 1845 & 1660 \\
\hline Right & 1563 & 1407 \\
\hline
\end{tabular}

Most residential areas are located outside of the core $\mathrm{CBD}$, but within the center of large towns or cities including irregular forests with scattered clearings. The primary objective of this research is to identify the setback distance for new development or re-development 
of residential building at locations where due space is constrained and the setback distance consideration is relevant. Basically, new developments are expected in urban areas but outside CBD locations, and redevelopment of land in CBD-central city area. Therefore, two types of land use classes are taken into consideration (Table 9-3).

\subsubsection{Signal Control}

The traffic is controlled by the signal system, which is an important function in calculation of capacity level traffic at an intersection. Using HCM-2010, it is assumed that the $\mathrm{g} / \mathrm{C}$ ratio is 0.45 , which means $50-50$ time slit in either directional traffic (following amber consideration). The above concept is applicable only for arterial vs arterial road in either direction of 4-leg intersection. However, directional signal timing can be varied based on the types of road in an intersection. As an example, if an arterial road crosses a collector road in an intersection, the possible directional slit are $2: 1$ or $3: 1$. Table A-1 (C) in Appendix A-I shows the applicable directional time split for an arterial vs collector 4-leg intersection. Appendix A-I (in Table A-1) illustrates that directional time split is varying and included in details with capacity calculation.

Even though the control system is a variable for velocity trajectories, this variable is not tabulated in random number selection process. The reason is that it is included in the decision-making process of capacity level traffic volume at an intersection.

Roadside stop sign is a common control system other than the signal system. The stop sign control system is usually applicable to low traffic areas. Keeping in mind the objectives of research, stop sign signal control is not included in the simulation design. 


\subsubsection{Capacity Calculation}

Capacity is the maximum hourly flow rate. The capacity analysis typically focuses on peak hourly traffic volume. However, peak hour traffic is varies on a daily basis and by season. Reasonable expectancy is the basis for defining capacity that is not the absolute maximum flow rate observed on such a system element. The absolute maximum flow rate can vary from day to day and from one location to another location (HCM-2010, Volume-1, page 37, and 4-18).

The capacity of an approach or lane group depends on the percentage of cycle length that is applied to that approach or lane group. According to the highway capacity method, the capacity can be determined by the following equation (Garber and Hoel, page 552).

$$
c=(g / C) \times S \times N
$$

Whereas,

$$
\begin{aligned}
& \mathrm{c}=\text { capacity of lane group in } \mathrm{veh} / \mathrm{h} \\
& \mathrm{S} \text { = saturation flow rate for lane group or approach in veh } / \mathrm{h} \text { of green } \\
& \mathrm{g} \text { = effective green time for lane group or approach } \\
& \mathrm{C}=\text { cycle length in second } \\
& \mathrm{N} \text { = number of lanes }
\end{aligned}
$$

Using the above formula, the capacity level traffic was calculated. Once saturated flow rate is fixed with turning movement and area type, the capacity varies with allotted green time and number of lanes in a lane group. For planning purpose, an intersection traffic capacity 
was calculated for both 4-leg intersection and T-intersection (3-leg), and tabulated in Appendix-I.

In order to design simulation runs, it was necessary to prepare a random number table. The random number tables are different, based on intersection types. Intersection combination with road types are explained in road network design section in detail. Table 9-4 (A-E) are showing random number selection criteria based on intersection traffic volume, whereas traffic ranges are decided based on the calculation that is described in Appendix B-I.

Table 9-4(A): Random number assignment based on traffic capacity in an intersection with arterial vs arterial road

\begin{tabular}{|c|c|c|c|c|}
\hline \multirow{2}{*}{$\begin{array}{c}\text { Random } \\
\text { Number }\end{array}$} & \multicolumn{2}{|c|}{ 4-leg intersection } & \multicolumn{2}{c|}{ 'T' intersection } \\
\cline { 2 - 5 } & $\begin{array}{c}\text { Capacity level } \\
\text { traffic volume } \\
\text { range }(\text { veh/h) }\end{array}$ & $\begin{array}{l}\text { Traffic } \\
\text { Capacity use } \\
\text { in Simulation }\end{array}$ & $\begin{array}{l}\text { Capacity level } \\
\text { traffic volume } \\
\text { range (veh/h) }\end{array}$ & $\begin{array}{l}\text { Traffic } \\
\text { Capacity use } \\
\text { in Simulation }\end{array}$ \\
\hline 0 & $4700-4950$ & 4910 & $4200-4500$ & 4463 \\
\hline 1 & $4951-5200$ & 5174 & $4501-4800$ & 4783 \\
\hline 2 & $5201-5450$ & 5344 & $4801-5100$ & 5077 \\
\hline 3 & $5451-5700$ & 5636 & $5101-5400$ & 5385 \\
\hline 4 & $5701-5950$ & 5774 & $5401-5700$ & 5516 \\
\hline 5 & $5951-6200$ & 6142 & $5701-6000$ & 5892 \\
\hline 6 & $6201-6450$ & 6260 & $6001-6300$ & 6135 \\
\hline 7 & $6451-6700$ & 6658 & $6301-6600$ & 6578 \\
\hline 8 & $6701-5950$ & 6950 & $6601-6900$ & 6841 \\
\hline 9 & $5951-7200$ & 7136 & $6901-7200$ & 7164 \\
\hline
\end{tabular}

Note: Capacity used in simulation column are chosen from Table A-3 included in Appendix-I. The combination of traffic in directional flow are used for intersection capacity calculation. In Appendix-I at Table A-3 (A), the minimum and maximum value 
of intersection capacities are $4780 \mathrm{veh} / \mathrm{h}$ and $7136 \mathrm{veh} / \mathrm{h}$ respectively. Based on the range, the bins are decided and the increase traffic volume in each bin is $250 \mathrm{veh} / \mathrm{h}$.

Table 9-4 (B): Random number assignment based on traffic capacity in an arterial vs collector intersection

\begin{tabular}{|c|c|c|c|c|}
\hline \multirow{2}{*}{$\begin{array}{c}\text { Random } \\
\text { Number }\end{array}$} & $\begin{array}{c}\text { 4-leg intersection } \\
\text { Capacity level } \\
\text { traffic volume } \\
\text { range (veh/h) }\end{array}$ & $\begin{array}{l}\text { Traffic } \\
\text { Capacity use } \\
\text { in Simulation }\end{array}$ & $\begin{array}{l}\text { Capacity level } \\
\text { traffic volume } \\
\text { range }(\text { veh/h) }\end{array}$ & $\begin{array}{l}\text { Traffic } \\
\text { Capacity use } \\
\text { in Simulation }\end{array}$ \\
\hline 0 & $3900-4100$ & 3918 & $5000-5100$ & 5085 \\
\hline 1 & $4101-4300$ & 4244 & $5101-5200$ & 5168 \\
\hline 2 & $4301-4500$ & 4354 & $5201-5300$ & 5246 \\
\hline 3 & $4501-4700$ & 4568 & $5301-5400$ & 5350 \\
\hline 4 & $4701-4900$ & 4892 & $5401-5500$ & 5444 \\
\hline 5 & $4901-5100$ & 5016 & $5501-5600$ & 5538 \\
\hline 6 & $5101-5300$ & 5150 & $5601-5700$ & 5618 \\
\hline 7 & $5301-5500$ & 5490 & $5701-5800$ & 5750 \\
\hline 8 & $5501-5700$ & 5668 & $5801-5900$ & 5830 \\
\hline 9 & $5701-5900$ & 5866 & $5901-7000$ & 5912 \\
\hline
\end{tabular}

Table 9-4 (C): Random number assignment based on traffic capacity in a collector vs collector intersection

\begin{tabular}{|c|c|c|c|c|}
\hline \multirow{2}{*}{$\begin{array}{c}\text { Random } \\
\text { Number }\end{array}$} & \multicolumn{2}{|c|}{ 4-leg intersection } & \multicolumn{2}{c|}{ ' $\boldsymbol{T}$ ' intersection } \\
\cline { 2 - 5 } & $\begin{array}{c}\text { Capacity level } \\
\text { traffic volume } \\
\text { range (veh/h) }\end{array}$ & $\begin{array}{l}\text { Traffic } \\
\text { Capacity use } \\
\text { in Simulation }\end{array}$ & $\begin{array}{l}\text { Capacity level } \\
\text { traffic volume } \\
\text { range (veh/h) }\end{array}$ & $\begin{array}{l}\text { Traffic } \\
\text { Capacity use } \\
\text { in Simulation }\end{array}$ \\
\hline 0 & $2350-2600$ & 2380 & $2300-2550$ & 2533 \\
\hline 1 & $2601-2850$ & 2736 & $2551-2800$ & 2787 \\
\hline 2 & $2851-3100$ & 2868 & $2801-3050$ & 2855 \\
\hline 3 & $3101-3350$ & 3304 & $3051-3300$ & 3298 \\
\hline 4 & $3351-3600$ & 3368 & $3301-3550$ & 3411 \\
\hline 5 & $3601-3850$ & 3804 & $3551-3800$ & 3665 \\
\hline
\end{tabular}




\begin{tabular}{|c|c|c|c|c|}
\hline 6 & $3851-4100$ & 4100 & $3801-4050$ & 4020 \\
\hline 7 & $4101-4350$ & 4136 & $4051-4300$ & 4289 \\
\hline 8 & $4351-4600$ & 4394 & $4301-4550$ & 4521 \\
\hline 9 & $4601-4850$ & 4782 & $4551-4800$ & 4797 \\
\hline
\end{tabular}

Table 9-4 (D): Random number assignment based on traffic capacity in an arterial vs local road intersection

\begin{tabular}{|c|c|c|c|c|}
\hline \multirow{2}{*}{$\begin{array}{c}\text { Random } \\
\text { Number }\end{array}$} & \multicolumn{2}{|c|}{ 4-leg intersection } & \multicolumn{2}{c|}{ 'T' intersection } \\
\cline { 2 - 5 } & $\begin{array}{c}\text { Capacity level } \\
\text { traffic volume } \\
\text { range (veh/h) }\end{array}$ & $\begin{array}{l}\text { Traffic } \\
\text { Capacity use } \\
\text { in Simulation }\end{array}$ & $\begin{array}{l}\text { Capacity level } \\
\text { traffic volume } \\
\text { range (veh/h) }\end{array}$ & $\begin{array}{l}\text { Traffic } \\
\text { Capacity use in } \\
\text { Simulation }\end{array}$ \\
\hline 0 & $3000-4000$ & 3498 & $3000-3500$ & 3331 \\
\hline 1 & $4001-5000$ & 4998 & $3501-4000$ & 3582 \\
\hline 2 & $5001-5500$ & 5076 & $4001-4500$ & 4118 \\
\hline 3 & $5501-6000$ & 5664 & $4501-5000$ & 4811 \\
\hline 4 & $6001-6500$ & 6438 & $5001-5500$ & 5480 \\
\hline 5 & $6501-7000$ & 6726 & $5501-6000$ & 5967 \\
\hline 6 & $7001-7500$ & 7310 & $6001-6500$ & 6357 \\
\hline 7 & $7501-8000$ & 7750 & $6501-7000$ & 6657 \\
\hline 8 & $8001-8500$ & 8468 & $7001-7500$ & 7124 \\
\hline 9 & $8500-9500$ & 9302 & $7501-8000$ & 7959 \\
\hline
\end{tabular}

Table 9-4 (E): Random number assignment based on traffic capacity in a collector vs local road intersection

\begin{tabular}{|c|c|c|c|c|}
\hline \multirow{2}{*}{$\begin{array}{c}\text { Random } \\
\text { Number }\end{array}$} & \multicolumn{2}{|c|}{ 4-leg intersection } & \multicolumn{2}{c|}{ 'T' intersection } \\
\cline { 2 - 5 } & $\begin{array}{l}\text { Capacity level } \\
\text { traffic volume } \\
\text { range (veh/h) }\end{array}$ & $\begin{array}{l}\text { Traffic } \\
\text { Capacity use } \\
\text { in Simulation }\end{array}$ & $\begin{array}{l}\text { Capacity level } \\
\text { traffic volume } \\
\text { range (veh/h) }\end{array}$ & $\begin{array}{l}\text { Traffic } \\
\text { Capacity use } \\
\text { in Simulation }\end{array}$ \\
\hline 0 & $2400-2700$ & 2558 & $1800-2100$ & 2045 \\
\hline 1 & $2701-3000$ & 2994 & $2101-2400$ & 2367 \\
\hline 2 & $3001-3300$ & 3134 & $2401-2700$ & 2653 \\
\hline 3 & $3301-3600$ & 3450 & $2701-3000$ & 2850 \\
\hline
\end{tabular}




\begin{tabular}{|l|l|l|l|l|}
\hline 4 & $3601-3900$ & 3868 & $3001-3300$ & 3250 \\
\hline 5 & $3901-4200$ & 4122 & $3301-3600$ & 3372 \\
\hline 6 & $4201-4500$ & 4336 & $3601-3900$ & 3811 \\
\hline 7 & $4500-4800$ & 4750 & $3901-4200$ & 4131 \\
\hline 8 & $4801-5100$ & 5092 & $4201-4500$ & 4324 \\
\hline 9 & $5100-5400$ & 5250 & $4501-4800$ & 4653 \\
\hline
\end{tabular}

\subsubsection{Finalization of Heavy Duty Vehicle for Planning}

The traffic composition has a direct effect on pollution concentration. For a road with high volume of traffic, a combination of heavy-duty vehicles and passenger cars can be expected. The percentage of heavy-duty vehicle on road varies from location to location and time of the day. According to Ontario provincial vehicular population survey, the percentage of HDV is close to 3 percent (in Ottawa). For simulation design, the HDV is considered as 3 percent on the urban roads. However, there is an option open in simulation design to change the percentage of heavy-duty vehicle if required. Based on available field data, it is noticed that the heavy-duty vehicles on traditional urban road is close to 2.5 percent, whereas in commercial areas the maximum percentage of HDV is 15 percent. Although the HDV volume can be high in some industrial areas, such land uses are usually not mixed with residential developments. It should be noted that in this research the percentage of heavy-duty vehicles is considered to be fixed for simulation planning purposes. 


\subsubsection{Land Use}

The types of urban land use has an effect on pollution rate. Urban activity changes the local meteorological behaviour that is shown in the result verification chapter. In this research, urban land use is broadly classified as either central business district (CBD) - central city area or urban - outside CBD. The random number assignment table for both land use types are presented in the following Table 9-5.

Table 9-5: Random number assignment based on urban land use

\begin{tabular}{|c|c|}
\hline Random number & Urban land use \\
\hline 0 & CBD-central city \\
\hline 1 & Urban-outside CBD \\
\hline
\end{tabular}

\subsubsection{Temperature}

Temperature is an important parameter in this research. It varies from season to season, and from one geographic location to another location. Though dust pollution does not vary with temperature, the gas pollution concentrations change much due to heat effects of ultraviolet ray. Among gas pollutants, nitrogen dioxide varies with the change of local temperature. Considering above concepts, temperature is treated as a variable in this research.

It is noted that although the basic idea of this research is applicable worldwide, but the samples of vehicular emissions are collected in Ottawa (Ontario, Canada) where pollution inspection and maintenance $(\mathrm{I} / \mathrm{M})$ program is in effect. Therefore, the emission models are logically applicable to Canada and the USA. An inspection and maintenance program is influenced by local climate. 
An extreme temperature analysis report by the Environment Canada shows that the minimum and maximum temperature in Canada are $-63^{\circ} \mathrm{C}$ and $45^{\circ} \mathrm{C}$, respectively. As this research is aiming to be applicable in Canada as well as outside Canada, the temperature range is selected accordingly. The bins are prepared based on range of temperatures, but the mean data is to be used as input in simulation model. Although first and last ranges are not limited, the minimum input data is equal to $-25^{\circ} \mathrm{C}$ for bin 0 , and the maximum data for bin 9 to be used in the model equals to $50^{\circ} \mathrm{C}$. Table 9-6 shows the random number assignment based on local temperature considerations.

Table 9-6: Random number assignment based on temperature

\begin{tabular}{|c|c|c|}
\hline Random number & Temperature Ranges & Model Input Value \\
\hline 0 & $-88^{\circ} \mathrm{C}$ to $-20^{\circ} \mathrm{C}$ & -25 \\
\hline 1 & $-19.9^{\circ} \mathrm{C}$ to $-10^{\circ} \mathrm{C}$ & -15 \\
\hline 2 & $-9.9^{\circ} \mathrm{C}$ to $0^{\circ} \mathrm{C}$ & -5 \\
\hline 3 & $0.1^{\circ} \mathrm{C}$ to $10^{\circ} \mathrm{C}$ & +5 \\
\hline 4 & $10.1^{\circ} \mathrm{C}$ to $20^{\circ} \mathrm{C}$ & +15 \\
\hline 5 & $20.1^{\circ} \mathrm{C}$ to $25^{\circ} \mathrm{C}$ & +22.5 \\
\hline 6 & $25.1^{\circ} \mathrm{C}$ to $30^{\circ} \mathrm{C}$ & +27.5 \\
\hline 7 & $30.1^{\circ} \mathrm{C}$ to $35^{\circ} \mathrm{C}$ & +32.5 \\
\hline 8 & $35.1^{\circ} \mathrm{C}$ to $45^{\circ} \mathrm{C}$ & +40 \\
\hline 9 & $45^{\circ} \mathrm{C}$ to $58^{\circ} \mathrm{C}$ & +50 \\
\hline
\end{tabular}

\subsubsection{Distance from Road}

The distance from the road link is simply termed as "distance". It is the distance from the outer edge of a road, where the pavement ends or curb begins. In this research, the term distance is the same as the definition of the setback distance. 
The pollution concentrations are measured at different distances; those were prepared using buffer line in GIS environment. Table 9-7 shows the random number assignment based on distance.

Table 9-7: Random number assignment based on distance

\begin{tabular}{|c|c|c|}
\hline Random number & Distance $(\mathrm{m})$ & Explanation \\
\hline 0 & 0 & At the edge of the road segment \\
\hline 1 & 1 & Centre of the side walk without boulevard \\
\hline 2 & 2.5 & Centre of the side walk with boulevard \\
\hline 3 & 5 & Approximate set-back distance within CBD \\
\hline 4 & 10 & Approx. set-back distance outside CBD \\
\hline 5 & 15 & - \\
\hline 6 & 20 & - \\
\hline 7 & 30 & - \\
\hline 8 & 50 & - \\
\hline 9 & 100 & \\
\hline
\end{tabular}

\subsubsection{Height}

The term height refers to the vertical distance from the road surface. The unit of the height is in meter. Though the primary objective of this research is to estimate the setback distance, the height is included for the purpose so that emission concentration at the receptor location can be measured (e.g. a person walking or biking, a person on the second floor of the building in front of an open window or sitting on a porch or on a balcony).

Taking the distance and height together, as an example, the approximate setback distance required for a road segment is 10 meter. However, policy can allow building a high-rise 
building very close to the road, provided the ground floor will be used for commercial purpose, such as a parking garage, and the second floor can be used for residential purposes.

Based on the above considerations, the following height and corresponding distance combination are defined below. Table 9-8 is shows the random number assignment scheme based on height from road surface and their corresponding distances. Moreover, the last column of the following table explains the rationale for their inclusion.

Table 9-8: Random number assignment based on height and corresponding distance

\begin{tabular}{|c|c|c|c|}
\hline $\begin{array}{l}\text { Random } \\
\text { number }\end{array}$ & $\begin{array}{l}\text { Height } \\
\text { (m) }\end{array}$ & $\begin{array}{l}\text { Distance } \\
(\mathrm{m})\end{array}$ & Selection criteria \\
\hline 0 & 0 & 0 & At the edge of the road segment \\
\hline 1 & 1 & 1 & $\begin{array}{l}\text { Breathing height of a baby in baby carriage OR a } \\
\text { person sitting in waiting chair for public transport } \\
\text { on the side walk without boulevard }\end{array}$ \\
\hline 2 & 1 & 2.5 & $\begin{array}{l}\text { Breathing height of a baby with moving in baby } \\
\text { carriage on the side walk with boulevard }\end{array}$ \\
\hline 3 & 1.8 & 1 & $\begin{array}{l}\text { People are in standing position and waiting for } \\
\text { public transport }\end{array}$ \\
\hline 4 & 1.8 & 2.5 & $\begin{array}{l}\text { People are walking or jogging through side walk } \\
\text { with boulevard }\end{array}$ \\
\hline 5 & 1 & 5 & Sitting with chair in balcony OR yard \\
\hline 6 & 1.8 & 5 & $\begin{array}{l}\text { Walking or standing in balcony OR Yard } \\
\text { including gardening }\end{array}$ \\
\hline 7 & $\begin{array}{c}4 \\
(3+1)\end{array}$ & 5 & Activities in first floor (height of a floor $=3 \mathrm{~m}$ ) \\
\hline 8 & 7 & 5 & Activities in second floor \\
\hline 9 & 4 & 10 & - \\
\hline
\end{tabular}

\subsection{ROAD NETWORK DESIGN}

A road network is a combination of road segment and intersection. Road segments or simply roads differ in terms of function (i.e. freeway, arterial, collector, and local road). 
Each road has its own behaviours, like access, and mobility function. Intersections can exhibit different characteristics, depending upon the intersecting roads and the location. Most intersections are either 4-leg intersection $(+)$ or ' $T$ ' intersections. Based on different combinations of roads and intersection types, the following cases were designed for simulation.

Case-I

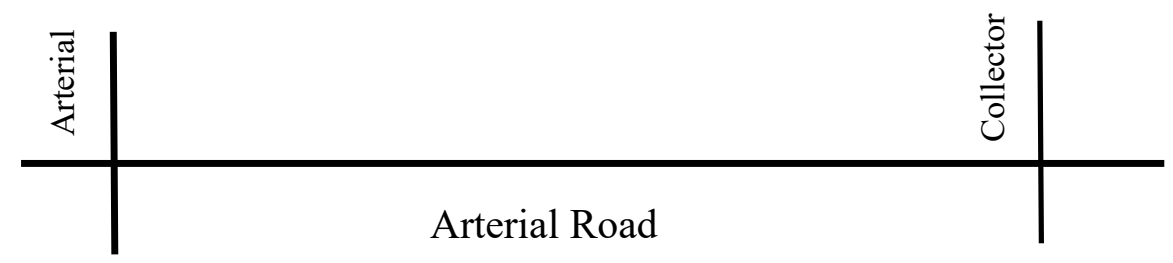

Case-II

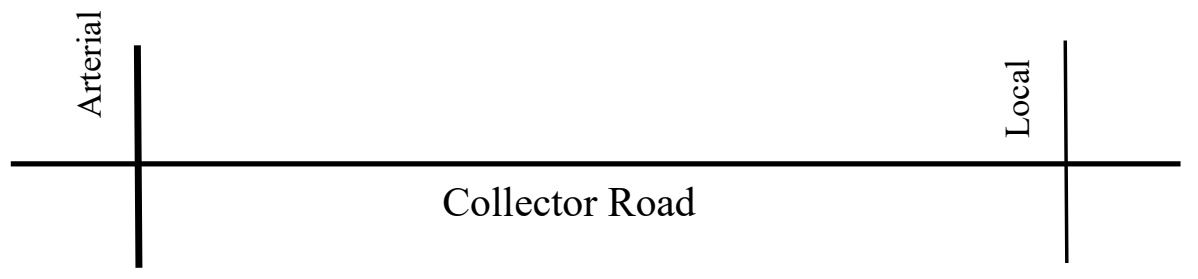

Figure 9-1: Sample road network for simulation design

Two cases are shown in the figure above, but there are a total 6 (six) cases based on combinations. Three cases are for arterial road and three cases for collector road. The intersection combinations are Arterial-Arterial, Arterial-Collector, and Arterial-Local. Similarly Collector-Arterial, Collector-Collector, and Collector-Local.

\subsubsection{Desirable Space between Signalized Intersections}

The spacing between two signalized intersections depends on the desired traffic progression speed and signal cycle length. In mixed development and/or commercial areas, 
where the traffic is generated by employment and retail shopping centre, the spacing can be reduced as required.

The spacing between arterial streets in urban residential areas is typically in the range of 1200 to $2000 \mathrm{~m}$. In mixed land use areas, the required spacing can be reduced to approximately $800 \mathrm{~m}(T A C, 1995)$. The desirable spacing between signalized intersections (in meter) are tabulated below.

Table 9-9: Desirable spacing between signalized intersections, $\mathrm{m}$

(Source: Table U.D.2, TAC)

\begin{tabular}{|c|c|c|c|c|c|}
\hline $\begin{array}{c}\text { Average Speed, } \\
\mathrm{km} / \mathrm{h}\end{array}$ & \multicolumn{5}{|c|}{ Cycle length, $\mathrm{s}$} \\
\cline { 2 - 6 } & $\mathbf{6 0}$ & $\mathbf{7 0}$ & $\mathbf{8 0}$ & $\mathbf{9 0}$ & $\mathbf{1 0 0}$ \\
\hline $\mathbf{4 0}$ & 335 & 390 & 445 & 500 & 555 \\
\hline $\mathbf{5 0}$ & 415 & 485 & 555 & 625 & 695 \\
\hline $\mathbf{6 0}$ & 500 & 585 & 665 & 750 & 835 \\
\hline $\mathbf{7 0}$ & 585 & 680 & 780 & 875 & 970 \\
\hline $\mathbf{8 0}$ & 665 & 780 & 890 & 1000 & 1110 \\
\hline $\mathbf{9 0}$ & 750 & 875 & 1000 & 1125 & 1250 \\
\hline
\end{tabular}

It is noted that the optimal intersection spacing changes in proportion to the average running speed. According to the assumptions of HCM-2010, the cycle length is 120 seconds. If the desired running speed on road network is $60 \mathrm{~km} / \mathrm{h}$, the approximate signal spacing between two intersections is $1000 \mathrm{~m}$ or $1 \mathrm{~km}$. The sample design of road network used in simulation runs is shown in Figure 9-2, which is directly imported from traffic microscopic simulation model. 


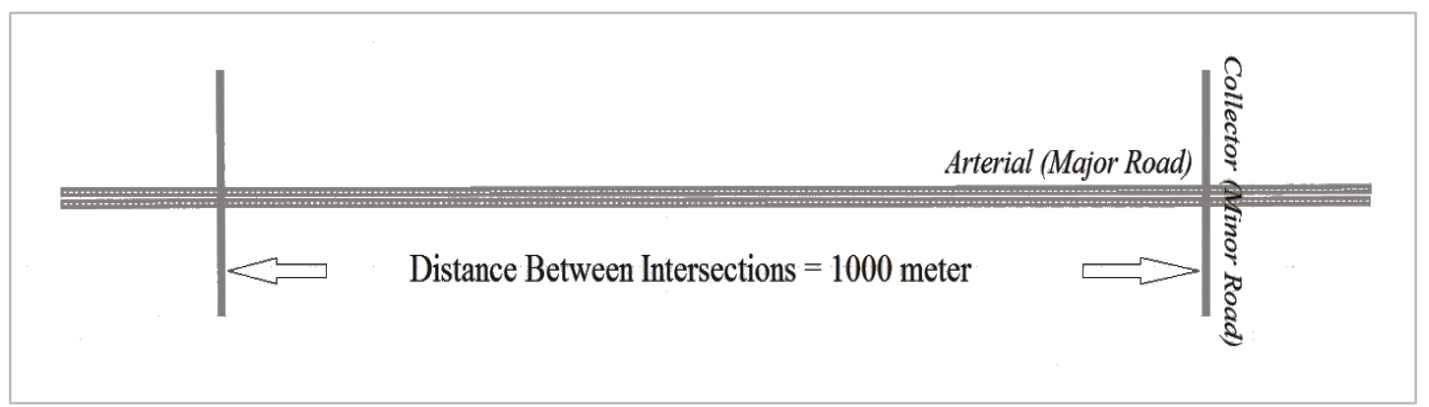

Figure 9-2: Sample road network with an intersection of arterial vs collector road (Source: VISSIM Model)

Figure 9-2 shows a sample of road link in between two intersections. In this figure, both intersections are a crossing between an arterial road (major) and a collector road (minor). The theoretical distance between two intersections is 1000 meters.

\subsubsection{Deceleration Lane Length}

The next important parameter in road geometric design after intersection spacing is the length of the deceleration lane. The estimation of deceleration lane length is the distance to decelerate from through traffic to a stop line.

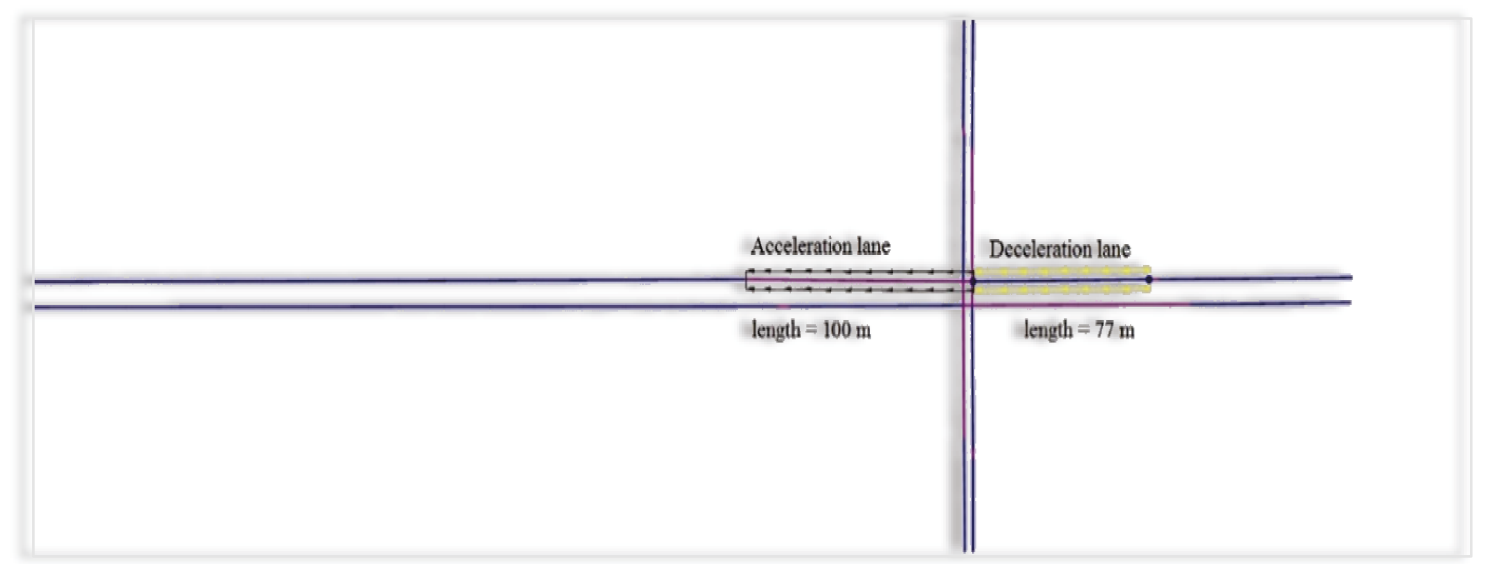

Figure 9-3: Sample of acceleration and deceleration lane length showing on road network (Source: VISSIM Model) 
Deceleration lane length includes three components: taper, deceleration length, and storage length. AASHTO guidelines mentioned that the approximate taper length is $30 \mathrm{~m}$ for a single turning lane and $45 \mathrm{~m}$ for a duel-turning lane in urban roads. Table 9-10 demonstrates the distance of deceleration lane length according to the design speed in desirable and limiting conditions (AASHTO, 2004).

Table 9-10: Deceleration lane length with respect to design speed on urban roads

\begin{tabular}{|c|c|c|}
\hline S.L. No. & Design Speed $(\mathrm{km} / \mathrm{h})$ & *Deceleration lane distance $(\mathrm{m})$ \\
\hline 1 & 50 & 55 \\
\hline 2 & 60 & 77 \\
\hline 3 & 70 & 100 \\
\hline 4 & 80 & 125 \\
\hline
\end{tabular}

Note: AASHTO provided values are in feet and data are rounded to closest decimal place.

Tables 9-10 and 9-11 are showing deceleration and acceleration lane lengths, respectively. Those lane lengths were calculated with respect to design speed of an urban road. The deceleration lane ends at stop line and acceleration lane starts from stop line. Figure 9-3 shows the acceleration and deceleration lane length for an arterial road with design speed of $60 \mathrm{~km} / \mathrm{h}$. The figure demonstrates the deceleration lane length to be equal to $77 \mathrm{~m}$ and acceleration lane length is equal to $100 \mathrm{~m}$.

\subsubsection{Acceleration Lane Length}

The acceleration lane length is of same importance as deceleration lane length from a design perspective. Acceleration lane is either taper type or parallel type. Irrespective of 
types, an estimation of acceleration lane length with respect to design speed is tabulated below.

Table 9-11: Accelerating lane length with respect to design speed on urban roads (Source: DOT)

\begin{tabular}{|c|c|c|}
\hline S.L. No. & Design Speed $(\mathrm{km} / \mathrm{h})$ & *Accelerating lane distance $(\mathrm{m})$ \\
\hline 1 & 50 & 60 \\
\hline 2 & 60 & 100 \\
\hline 3 & 80 & 220 \\
\hline
\end{tabular}

Note: data are rounded to closest decimal place and lengths start from stop line.

\subsubsection{Sample Road Network inside and outside of CBD}

As mentioned earlier, the signal spacing is affected by land use activity. Though there is a guideline for distance between two intersections, the field experience is slightly different. The distance also varies within CBD or outside CBD. As an example, Bronson Avenue in between Somerset street west and Christie street is only 215 meter, whereas in between Fifth avenue and Carling avenue is 420 meter. There are some samples of spacing distances shown in Table 9-12 below; those distances were measured using google technology.

Table 9-12: Spacing between intersections

(Source: Goggle image)

\begin{tabular}{|c|l|l|c|}
\hline $\begin{array}{c}S L \\
\text { No. }\end{array}$ & \multicolumn{1}{|c|}{ Road Name } & \multicolumn{1}{|c|}{ In Between Roads } & Distance $(\mathrm{m})$ \\
\hline 1 & Bronson Avenue & Somerset Street - Christie Street & 215 \\
\hline 2 & Bronson Avenue & Fifth Avenue - Carling Avenue & 420 \\
\hline 3 & McCarthy Road & Walkley road - Fielding drive & 295 \\
\hline 4 & Hunt Club Road & Cahill drive - Lorry Greenberg drive & 500 \\
\hline
\end{tabular}




\begin{tabular}{|c|l|l|c|}
\hline 5 & Hunt Club Road & Knoxdale road - Woodroffe avenue & $2000(2 \mathrm{~km})$ \\
\hline 6 & Hunt Club Road & Woodroffe Avenue - Cleopatra Drive & $\begin{array}{l}1700(1.7 \\
\mathrm{km})\end{array}$ \\
\hline 7 & Holly Acres Road & Richmond road - Ramp to highway & 325 \\
\hline 8 & Carling Avenue & Woodroffe Avenue - Fairlawn Avenue & 200 \\
\hline 9 & Carling Avenue & Clyde Avenue - Broadview Avenue & 400 \\
\hline 10 & Carling Avenue & Preston avenue - Booth street & 315 \\
\hline 11 & Carling Avenue & Booth Street - Bronson Avenue & 420 \\
\hline 12 & Montreal Road & Vanier Pkwy - Montgomery Street & 285 \\
\hline 13 & Vanier Pkwy & Donald Street - Queen Mary Street & 320 \\
\hline 14 & Rideau Street & Wurtemberg Street - N River Road & 405 \\
\hline 15 & Rideau Street & Coburg Street - Charlotte Street & 145 \\
\hline
\end{tabular}

There is a relationship between intersection-to-intersection distance and length of the signal phasing, especially for major roads. However, the access to the major road is a common phenomenon within the CBD-central city area due to mixed land use characteristics.
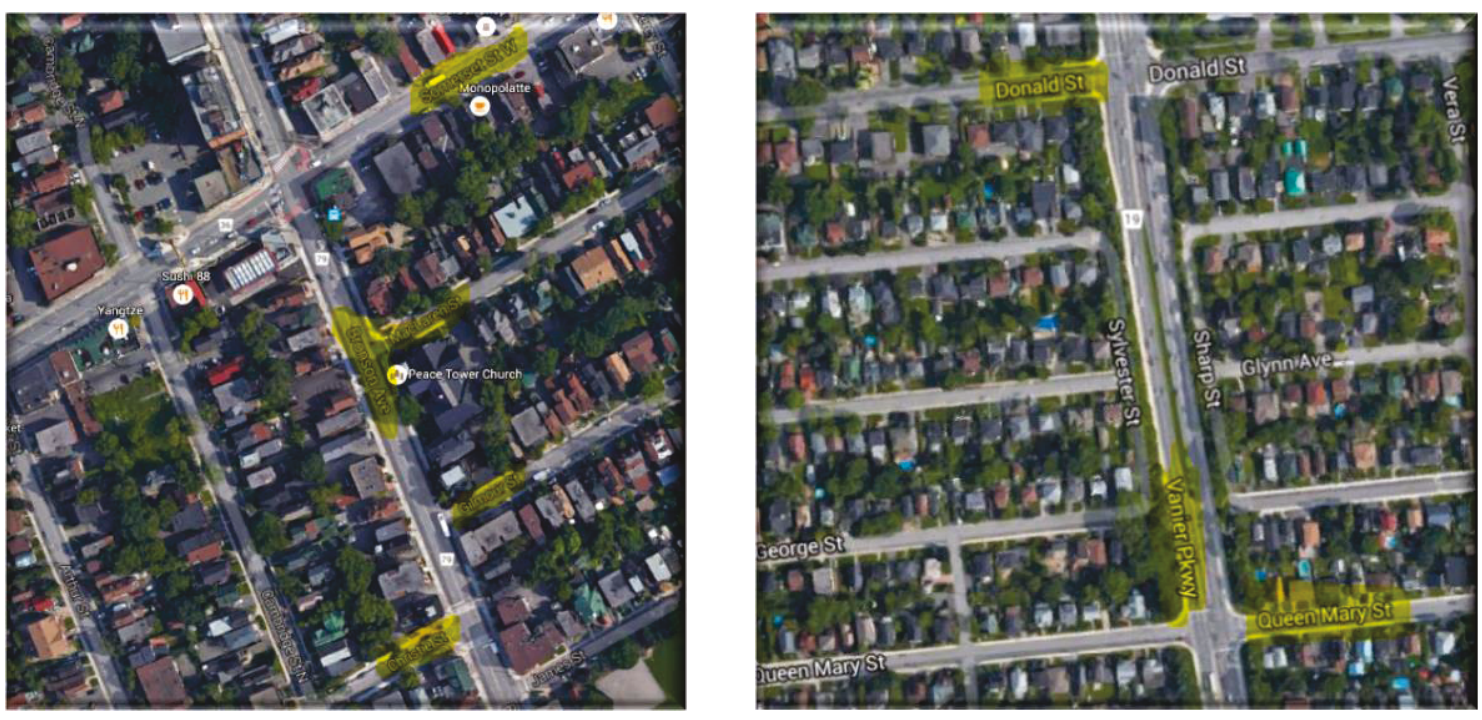

Figure 9-4: Bronson Avenue within CBD-central city

Figure 9-5: Vanier Parkway within urban but outside CBD 
Figure 9-4 presents the land use characteristics within CBD-central city area. In this figure, the Bronson Avenue (an arterial road segment) in between Somerset Street West and Christie Street shows that there are two local roads access into the arterial road. Those are MacLaren Street and Gilmour Street. The traffic from those local access road are either merging and/or diverging, or both, but not interfering the through traffic on arterial road. Because, the traffic coming from local road can take right turn only. Moreover, they are given access to Bronson Avenue through stop sign, not signal system. Therefore, those access points are not treated as intersections.

At the same time, there is no access in between intersections in the outside CBD areas. Figure 9-5 represents the Vanier Parkway in between Donald Street and Queen Mary Street. Though there are some local roads in between intersections, they have no access to the arterial road directly. That traffic may access Vanier Pkwy via collector roads. This important characteristic shapes the capacity on the road segment and is included in this research.

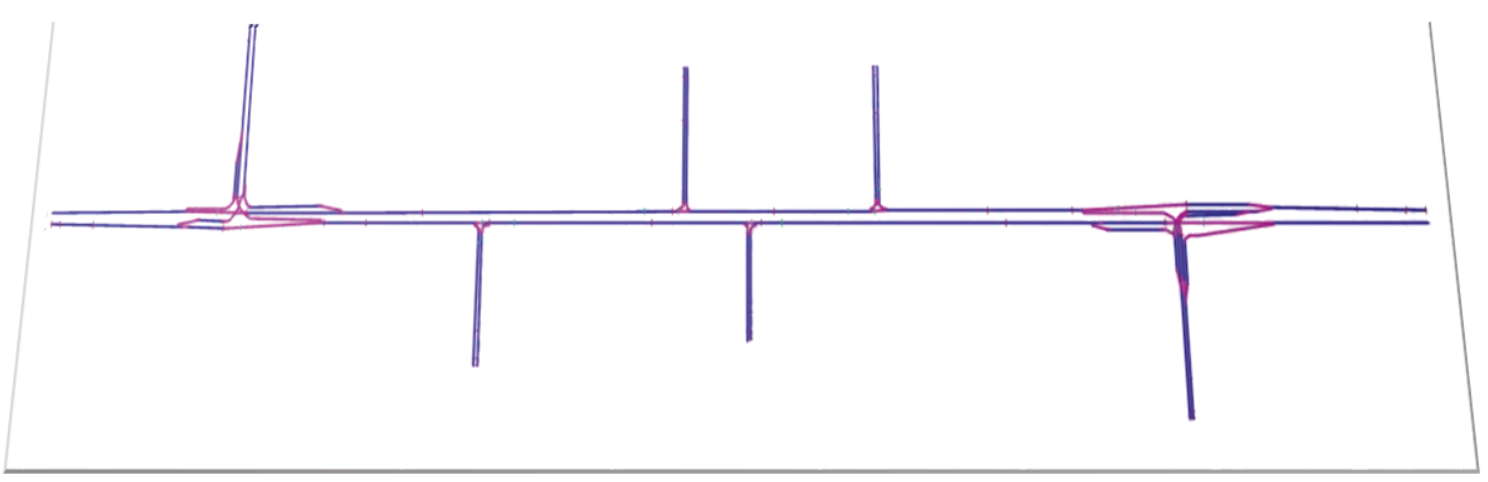

Figure 9-6: Road network in CBD-central city area with access facility to local road with stop sign 


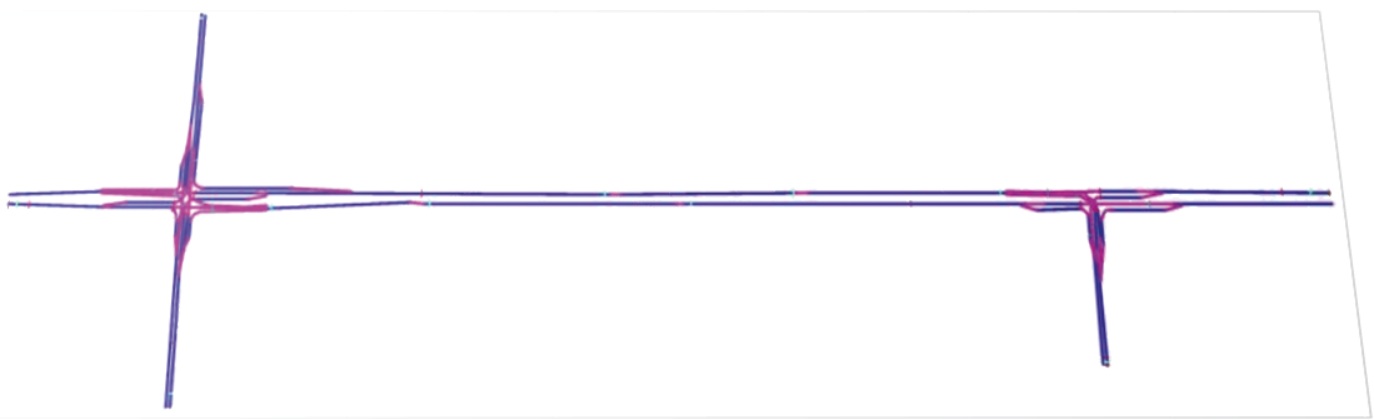

Figure 9-7: Sample road network in urban - outside CBD area

For practical reasons, the road types and their corresponding intersection combinations were selected using google image either in CBD-central city area or in Urban-outside CBD. This is an attempt to make this research to be of maximum importance to the real world.

It is noted that the intersection length equals to the deceleration lane length plus acceleration lane length. According to Figure 9-3, the summation of deceleration lane length and acceleration lane length equals to 177 meter. This calculation was carried out for an arterial road with speed limit of $60 \mathrm{~km} / \mathrm{h}$. However, for a collector (minor road), it is equal to $115 \mathrm{~m}$. It is to be noted that the design speed for arterial is $60 \mathrm{~km} / \mathrm{h}$, for collector road, it is $50 \mathrm{~km} / \mathrm{h}$, and for local road, it is $40 \mathrm{~km} / \mathrm{h}$. Although, Figure $9-2$ shows that the total length in between two intersections is 1000 meter, the actual road segment length becomes approximately 840 meter.

The sample road network drawing for the simulation run is shown in Figures 9-6 and 9-7. Figure 9-6 shows the sample road network in CBD-central city area, where access to local road is a common phenomenon with stop sign. Figure 9-7 shows the sample road network in urban areas, but outside the CBD area. In this network, traffic from local roads should merge to a major road through a signalized intersection. Figure 9-5 shows a satellite view 
and demonstrates that local road has no direct connection to an arterial road. Traffic generated from local roads merge to an arterial road via collector roads. The above discussion suggests that the decisions regarding the design of sample road networks are appropriate. Moreover, spacing distance between intersections are acceptable from a planning perspective.

\subsection{RANDOM NUMBER SELECTION PROCEDURE}

Sampling is a technique to choose a particular character among all characteristics using probability concept. In this research, the simple random sampling technique is used. The random numbers are available in random digit sheets. Appendix-II illustrates the random numbers for variables. Appendix-II (B) shows readily available random digit sheet (Source: Krueckeberg and Silvers).

Table 9-13 presents the complete selection of random numbers; these were chosen for values of input variables. It should be noted here that a minimum of 30 (thirty) samples are required for an accurate sampling process. In table, the thirty samples are illustrated in rows, whereas columns represents the values of variables.

Table 9-13: Random numbers selected for input variables

\begin{tabular}{|c|c|c|c|c|c|c|c|c|c|c|c|c|}
\hline \multirow{4}{*}{ 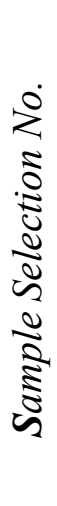 } & \multicolumn{12}{|c|}{ Selected Random Number for Input Variables } \\
\hline & 1 & \multicolumn{6}{|c|}{2} & 3 & 4 & 5 & 6 & 7 \\
\hline & \multirow[b]{2}{*}{ 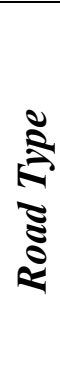 } & \multicolumn{3}{|c|}{$\begin{array}{c}\text { Left side } \\
\text { Intersection Traffic }\end{array}$} & \multicolumn{3}{|c|}{$\begin{array}{c}\text { Right side } \\
\text { Intersection Traffic }\end{array}$} & \multirow[b]{2}{*}{$\vec{\gtrless}$} & \multirow[b]{2}{*}{ 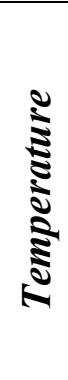 } & \multirow[b]{2}{*}{ 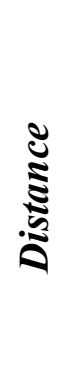 } & \multirow[b]{2}{*}{$\frac{\sqrt{2}}{\sqrt[3]{80}}$} & \multirow[b]{2}{*}{ 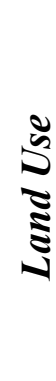 } \\
\hline & & 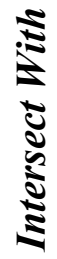 & 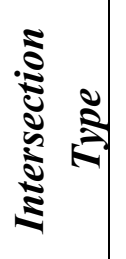 & $\underset{\mathbf{5}}{\mathbf{\Xi}}$ & 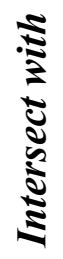 & 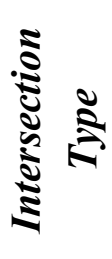 & 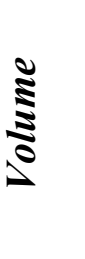 & & & & & \\
\hline
\end{tabular}




\begin{tabular}{|c|c|c|c|c|c|c|c|c|c|c|c|c|}
\hline 1 & 0 & 2 & 1 & 0 & 1 & 1 & 3 & 0 & 7 & 9 & 3 & 0 \\
\hline 2 & 0 & 2 & 0 & 3 & 2 & 1 & 8 & 5 & 8 & 8 & 8 & 1 \\
\hline 3 & 1 & 1 & 1 & 1 & 1 & 0 & 7 & 3 & 0 & 1 & 7 & 0 \\
\hline 4 & 0 & 2 & 1 & 3 & 1 & 0 & 2 & 2 & 8 & 3 & 0 & 1 \\
\hline 5 & 0 & 3 & 0 & 6 & 1 & 1 & 9 & 8 & 5 & 0 & 4 & 0 \\
\hline 6 & 0 & 2 & 0 & 2 & 2 & 1 & 4 & 6 & 6 & 9 & 2 & 1 \\
\hline 7 & 1 & 3 & 0 & 6 & 3 & 1 & 1 & 0 & 9 & 7 & 9 & 0 \\
\hline 8 & 0 & 2 & 1 & 3 & 2 & 1 & 0 & 1 & 2 & 0 & 5 & 1 \\
\hline 9 & 0 & 3 & 0 & 0 & 1 & 0 & 3 & 7 & 8 & 1 & 7 & 0 \\
\hline 10 & 0 & 3 & 0 & 4 & 3 & 0 & 8 & 3 & 7 & 1 & 1 & 1 \\
\hline 11 & 1 & 3 & 1 & 8 & 3 & 0 & 8 & 9 & 2 & 1 & 7 & 0 \\
\hline 12 & 0 & 2 & 0 & 7 & 3 & 1 & 1 & 3 & 8 & 1 & 4 & 1 \\
\hline 13 & 1 & 1 & 0 & 2 & 2 & 0 & 7 & 8 & 4 & 0 & 1 & 0 \\
\hline 14 & 0 & 3 & 1 & 8 & 1 & 0 & 0 & 0 & 2 & 5 & 7 & 0 \\
\hline 15 & 0 & 3 & 1 & 3 & 1 & 1 & 3 & 0 & 4 & 5 & 1 & 1 \\
\hline 16 & 0 & 1 & 0 & 9 & 1 & 0 & 0 & 5 & 8 & 8 & 1 & 1 \\
\hline 17 & 0 & 3 & 1 & 7 & 3 & 1 & 8 & 0 & 5 & 1 & 4 & 0 \\
\hline 18 & 0 & 2 & 0 & 5 & 2 & 1 & 5 & 6 & 7 & 3 & 4 & 0 \\
\hline 19 & 1 & 3 & 0 & 8 & 2 & 0 & 7 & 8 & 8 & 0 & 5 & 0 \\
\hline 20 & 1 & 1 & 1 & 1 & 2 & 1 & 6 & 0 & 4 & 6 & 8 & 0 \\
\hline 21 & 1 & 2 & 1 & 3 & 1 & 0 & 4 & 8 & 9 & 4 & 5 & 1 \\
\hline 22 & 1 & 2 & 1 & 4 & 3 & 0 & 5 & 7 & 3 & 5 & 3 & 0 \\
\hline 23 & 0 & 2 & 1 & 5 & 1 & 0 & 9 & 7 & 5 & 1 & 7 & 0 \\
\hline 24 & 0 & 1 & 1 & 1 & 2 & 1 & 6 & 9 & 6 & 9 & 1 & 0 \\
\hline 25 & 1 & 2 & 1 & 6 & 3 & 1 & 8 & 7 & 8 & 6 & 8 & 1 \\
\hline 26 & 1 & 2 & 1 & 7 & 2 & 1 & 2 & 5 & 1 & 6 & 2 & 0 \\
\hline 27 & 1 & 2 & 0 & 3 & 2 & 1 & 4 & 6 & 8 & 4 & 5 & 1 \\
\hline 28 & 1 & 1 & 0 & 5 & 3 & 1 & 9 & 9 & 8 & 7 & 7 & 0 \\
\hline 29 & 0 & 2 & 1 & 2 & 2 & 0 & 6 & 1 & 2 & 5 & 6 & 0 \\
\hline 30 & 0 & 3 & 0 & 5 & 1 & 0 & 8 & 2 & 9 & 8 & 2 & 0 \\
\hline
\end{tabular}


In the above table, road types are either arterial or collector. Arterial roads are represented as zero (0) and collector roads are represents as one (1). Next column represents capacity level traffic at an intersection. According to Figures 9-6 and 9-7, there are two intersections in each case study. Those intersections are classified as left intersection and right intersection. Each intersection has three sub-columns. First sub column denotes intersection combination type, which is road type intersecting with another road type. Suppose road type is arterial, so the intersection combinations are Arterial-Arterial (1), Arterial-Collector (2), and Arterial-Local (3). Second sub-column represent intersection types, such as 4-leg intersection (0) and ' $T$ ' intersection (1). The last sub-column signifies the traffic capacity in the intersection.

Table 9-13 was prepared based on the following considerations:

1. Column 1 represents road types, where $0=$ Arterial, and $1=$ Collector road. The random number for road types was generated in Excel in Appendix-II (A).

2. Capacity level traffic at intersections represented in column 2, which has two intersections. The last sub column of each intersection represents traffic capacity. $1^{\text {st }}$ digit of the first column in Appendix-II (B) represents left intersection traffic, whereas $2^{\text {nd }}$ digit of the first column represents right intersection traffic.

3. For percentage of HDV in traffic, $2^{\text {nd }}$ digit of the second column of Appendix-II (B) is selected.

4. $3^{\text {rd }}$ digit of the third column is selected for the temperature.

5. $4^{\text {th }}$ digit of the fourth column is tabulated for the distance.

6. For height and distance combination, $5^{\text {th }}$ digit of the fifth column is selected. 
Finally, $7^{\text {th }}$ column in input variable is showing the random number for land use class. In this case, random number table for land use class was generated using excel random number function for 0 or 1 value.

It is noted that, though percentage of HDV is included in the input variables list, it is not taken into account in the random number selection based on vehicle population survey and/or for simplification of planning.

\subsection{CORRESPONDING INPUT VALUES}

The corresponding input values are tabulated below based on random digit selection. Table 9-14 represents input variables used for simulation design. The notations and their corresponding attributes are noted below.

1. In column $1, \mathrm{~A}=$ Arterial road, $\mathrm{C}=$ Collector road.

2. In column 2, Intersection Combinations are:

$$
\begin{aligned}
& \text { A-A }=\text { Arterial road vs Arterial road } \\
& \text { A-C }=\text { Arterial road vs Collector road } \\
& \text { C-C }=\text { Collector road vs Collector road } \\
& \text { A-L }=\text { Arterial road vs Local road } \\
& \text { C-L }=\text { Collector road vs Local road; and }
\end{aligned}
$$

Whereas, Intersection Types are: ' + ' $=4$-leg intersection, ' $\mathrm{T}$ ' $=3$-leg intersection

3. In column $3, \mathrm{CBD}=\mathrm{CBD}$-central city, and OUT $=$ Urban-outside CBD. 
Table 9-14: Selected input variables corresponding to random numbers in table 9-14

\begin{tabular}{|c|c|c|c|c|c|c|c|c|c|c|c|c|}
\hline \multirow{4}{*}{ 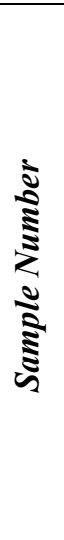 } & \multicolumn{12}{|c|}{ INPUTS } \\
\hline & 1 & \multicolumn{6}{|c|}{2} & \multirow{3}{*}{$\begin{array}{r}3 \\
\\
\\
5 \\
5 \\
5 \\
5 \\
5 \\
5\end{array}$} & \multirow{3}{*}{ 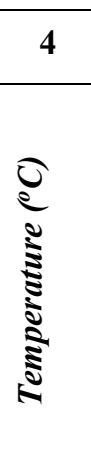 } & \multirow{3}{*}{ 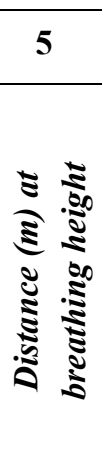 } & \multirow{2}{*}{\multicolumn{2}{|c|}{ 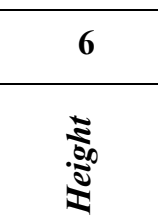 }} \\
\hline & \multirow{2}{*}{ 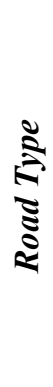 } & \multicolumn{3}{|c|}{$\begin{array}{c}\text { Left side } \\
\text { Intersection }\end{array}$} & \multicolumn{3}{|c|}{$\begin{array}{c}\text { Right side } \\
\text { Intersection }\end{array}$} & & & & & \\
\hline & & 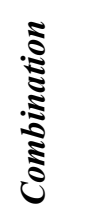 & $\stackrel{\Xi}{\Xi}$ & $\stackrel{\Xi}{\Xi}$ & 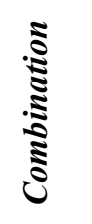 & 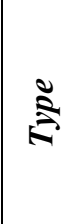 & $\stackrel{\Xi}{\Xi}$ & & & & 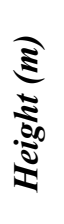 & 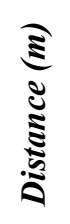 \\
\hline 1 & A & A-C & $\mathrm{T}$ & 5085 & $\mathbf{A}-\mathbf{A}$ & $\mathrm{T}$ & 5385 & CBD & 32.5 & 100 & 1.8 & 1 \\
\hline 2 & A & A-C & + & 4568 & A-C & $\mathrm{T}$ & 5830 & OUT & 40 & 50 & 7 & 5 \\
\hline 3 & $\mathrm{C}$ & C-A & $\mathrm{T}$ & 5168 & C-A & + & 5490 & CBD & -25 & 1 & 4 & 5 \\
\hline 4 & $A$ & A-C & $\mathrm{T}$ & 5350 & A-A & + & 5344 & OUT & 40 & 5 & 0 & 0 \\
\hline 5 & A & A-L & + & 7310 & A-A & $\mathrm{T}$ & 7164 & CBD & 22.5 & 0 & 1.8 & 2.5 \\
\hline 6 & A & A-C & + & 4354 & A-C & $\mathrm{T}$ & 5444 & OUT & 27.5 & 100 & 1 & 2.5 \\
\hline 7 & $\mathrm{C}$ & C-L & + & 4122 & C-L & $\mathrm{T}$ & 2367 & CBD & 50 & 30 & 4 & 10 \\
\hline 8 & A & A-C & $\mathrm{T}$ & 5350 & A-C & $\mathrm{T}$ & 5085 & OUT & -5 & 0 & 1 & 5 \\
\hline 9 & $\mathrm{~A}$ & A-L & + & 3498 & A-A & + & 5636 & CBD & 40 & 1 & 4 & 5 \\
\hline 10 & A & A-L & + & 6438 & A-L & + & 8468 & OUT & 32.5 & 1 & 1 & 1 \\
\hline 11 & $\mathrm{C}$ & C-L & $\mathrm{T}$ & 4324 & C-L & + & 4750 & CBD & -5 & 1 & 4 & 5 \\
\hline 12 & $\mathrm{~A}$ & A-C & + & 5490 & A-L & $\mathrm{T}$ & 3582 & OUT & 40 & 1 & 1.8 & 2.5 \\
\hline 13 & $\mathrm{C}$ & C-A & + & 4354 & C-C & + & 4136 & CBD & 15 & 0 & 1 & 1 \\
\hline 14 & $\mathrm{~A}$ & A-L & $\mathrm{T}$ & 7124 & $\mathbf{A}-\mathbf{A}$ & + & 4910 & CBD & -5 & 15 & 4 & 5 \\
\hline 15 & A & A-L & $\mathrm{T}$ & 4811 & $\mathbf{A}-\mathbf{A}$ & $\mathrm{T}$ & 5385 & OUT & 15 & 15 & 1 & 1 \\
\hline 16 & $\mathrm{~A}$ & A-A & + & 7136 & A-A & + & 4910 & OUT & 40 & 50 & 1 & 1 \\
\hline 17 & A & A-L & $\mathrm{T}$ & 6657 & A-L & $\mathrm{T}$ & 7124 & CBD & 22.5 & 1 & 1.8 & 2.5 \\
\hline 18 & $\mathrm{~A}$ & A-C & + & 5016 & A-C & $\mathrm{T}$ & 5538 & CBD & 32.5 & 5 & 1.8 & 2.5 \\
\hline
\end{tabular}




\begin{tabular}{|c|c|c|c|c|c|c|c|c|c|c|c|c|}
\hline 19 & $\mathrm{C}$ & C-L & + & 4750 & $\mathrm{C}-\mathrm{C}$ & + & 4136 & CBD & 40 & 0 & 1 & 5 \\
\hline 20 & $\mathrm{C}$ & C-A & $\mathrm{T}$ & 5168 & $\mathrm{C}-\mathrm{C}$ & $\mathrm{T}$ & 4020 & CBD & 15 & 20 & 7 & 5 \\
\hline 21 & $\mathrm{C}$ & $\mathrm{C}-\mathrm{C}$ & $\mathrm{T}$ & 3298 & $\mathrm{C}-\mathrm{A}$ & + & 4892 & OUT & 50 & 10 & 1 & 5 \\
\hline 22 & $\mathrm{C}$ & C-C & $\mathrm{T}$ & 3411 & C-L & + & 3868 & CBD & 5 & 15 & 1.8 & 1 \\
\hline 23 & A & A-C & $\mathrm{T}$ & 5538 & $\mathbf{A}-\mathbf{A}$ & + & 7136 & CBD & 22.5 & 1 & 4 & 5 \\
\hline 24 & A & $\mathbf{A}-\mathbf{A}$ & $\mathrm{T}$ & 4783 & $A-C$ & $\mathrm{~T}$ & 5618 & CBD & 27.5 & 100 & 1 & 1 \\
\hline 25 & $\mathrm{C}$ & $\mathrm{C}-\mathrm{C}$ & $\mathrm{T}$ & 5618 & C-L & $\mathrm{T}$ & 4324 & OUT & 40 & 20 & 7 & 5 \\
\hline 26 & $\mathrm{C}$ & C-C & $\mathrm{T}$ & 4289 & C-C & $\mathrm{T}$ & 2855 & CBD & -15 & 20 & 1 & 2.5 \\
\hline 27 & $\mathrm{C}$ & C-C & + & 3304 & C-C & $\mathrm{T}$ & 3411 & OUT & 40 & 10 & 1 & 5 \\
\hline 28 & $\mathrm{C}$ & C-A & + & 5016 & C-L & $\mathrm{T}$ & 4653 & CBD & 40 & 30 & 4 & 5 \\
\hline 29 & A & A-C & $\mathrm{T}$ & 5168 & $A-C$ & + & 5150 & CBD & -5 & 15 & 1.8 & 5 \\
\hline 30 & $\mathrm{~A}$ & A-L & + & 6726 & $\mathbf{A}-\mathbf{A}$ & + & 6950 & CBD & 50 & 50 & 1 & 2.5 \\
\hline
\end{tabular}

The sample numbers and their corresponding results are displayed in the next chapter.

\subsection{SIMULATION DESIGN FOR FREEWAY}

The simulation design and planning procedures are presented in this chapter for the urban roads. The decisions on variable selection for freeway are almost similar to the urban roads except distances. Here, the distances from freeway are definitely different because of the function that the freeway serves as opposed to urban roads. The urban roads provide access to properties as well as serve the traffic movement function. On the other hand the freeway is a limited access facility and is intended to carry large volumes of traffic at higher speed. For the investigation of setback distance, although the variables are the same as for urban roads, the values of variables are much different. For simulation, a random study area for 
the freeway case was selected. This study area is located on Highway 417 near the VIA railway station in Ottawa.

\subsubsection{Variables Selection for Running Simulation}

The multilane freeway is assumed to flow at capacity and therefore traffic volume is not considered to experience variation in different simulations. For this reason, the capacity level traffic is not included in Table 9-15. The calculation of traffic capacity is simple and straightforward. The saturation level traffic is equal to the capacity level traffic. Only laneutilization adjustment factor, and on-and-off ramp factor can be incorporated in calculation. However, the traffic capacity data is taken from field sample. The design plan for distance and height are included in one table. Table 9-15 shows the decision on random number assignment for input variables., The land use is considered to be urban, but outside the central business district (i.e. it is an urban freeway).

Table 9-15: Decision on random number assignment for input variables

\begin{tabular}{|c|c|c|c|c|}
\hline \multicolumn{2}{|c|}{ Temperature } & \multicolumn{3}{|c|}{ Distance and Height Combination } \\
\hline $\begin{array}{l}\text { Random } \\
\text { Number }\end{array}$ & $\begin{array}{l}\text { Temperature } \\
\text { Value }\left(\text { in }^{\circ} \mathrm{C}\right)\end{array}$ & $\begin{array}{l}\text { Random } \\
\text { Number }\end{array}$ & Distance (m) & Height $(m)$ \\
\hline 0 & -25 & 0 & 10 & 0 \\
\hline 1 & -15 & 1 & 10 & 1.8 \\
\hline 2 & -5 & 2 & 20 & 3 \\
\hline 3 & +5 & 3 & 20 & 6 \\
\hline 4 & +15 & 4 & 30 & 1.8 \\
\hline 5 & +25 & 5 & 40 & 1.8 \\
\hline 6 & +27.5 & 6 & 50 & 1.8 \\
\hline 7 & +32.5 & 7 & 100 & 1.8 \\
\hline 8 & +40 & 8 & 200 & 1.8 \\
\hline 9 & +50 & 9 & 500 & 1.8 \\
\hline
\end{tabular}




\subsubsection{Input Data Preparation Corresponding to Random Number}

Table 9-15 presents variables used for the simulation of a freeway segment. The random numbers are listed and corresponding values of these variables are presented in the table. The temperature values and combination of distance and height are noted. Next, assigned random numbers and their corresponding values of variables for thirty simulations are presented in Table 9-16. As noted above, the capacity level traffic is considered to have the same value for all segments of the freeway and also it is the same value for either direction of traffic flow in terms of setback distance consideration.

Table 9-16: Assigned random number and their corresponding input variables

\begin{tabular}{|c|c|c|c|c|c|}
\hline \multirow{2}{*}{$\begin{array}{c}\text { Sample } \\
\text { Selection }\end{array}$} & \multicolumn{5}{|c|}{ Selection of Random Numbers for input variables and their corresponding } \\
\cline { 2 - 6 } & $\begin{array}{c}\text { Random No.for } \\
\text { Temperature }\end{array}$ & $\begin{array}{c}\text { Temperature } \\
\left({ }^{\circ} \text { C) }\right.\end{array}$ & $\begin{array}{c}\text { Random No. for } \\
\text { Length \& Height }\end{array}$ & Distance & Height \\
\hline 1 & 6 & 27.5 & 0 & 10 & 0 \\
\hline 2 & 6 & 27.5 & 6 & 50 & 1.8 \\
\hline 3 & 2 & -5 & 3 & 20 & 6 \\
\hline 4 & 8 & 40 & 4 & 30 & 1.8 \\
\hline 5 & 6 & 27.5 & 7 & 100 & 1.8 \\
\hline 6 & 8 & 40 & 9 & 500 & 1.8 \\
\hline 7 & 0 & -25 & 3 & 20 & 6 \\
\hline 8 & 4 & 22.5 & 0 & 10 & 0 \\
\hline 9 & 3 & 5 & 7 & 100 & 1.8 \\
\hline 10 & 4 & 22.5 & 9 & 500 & 1.8 \\
\hline 11 & 8 & 40 & 6 & 50 & 1.8 \\
\hline 12 & 3 & 5 & 3 & 20 & 6 \\
\hline 13 & 0 & -25 & 5 & 40 & 1.8 \\
\hline 14 & 4 & 15 & 4 & 100 & 1.8 \\
\hline 15 & 9 & 50 & 7 & 5 & 1.8 \\
\hline
\end{tabular}




\begin{tabular}{|c|c|c|c|c|c|}
\hline 16 & 1 & -15 & 7 & 100 & 1.8 \\
\hline 17 & 5 & 22.5 & 8 & 200 & 1.8 \\
\hline 18 & 2 & -5 & 6 & 50 & 1.8 \\
\hline 19 & 3 & 5 & 5 & 40 & 1.8 \\
\hline 20 & 9 & 50 & 1 & 10 & 1.8 \\
\hline 21 & 7 & 32.5 & 4 & 30 & 1.8 \\
\hline 22 & 1 & -15 & 2 & 20 & 3 \\
\hline 23 & 4 & 22.5 & 3 & 20 & 6 \\
\hline 24 & 6 & 27.5 & 2 & 20 & 3 \\
\hline 25 & 9 & 50 & 4 & 30 & 1.8 \\
\hline 26 & 9 & 50 & 9 & 500 & 1.8 \\
\hline 27 & 0 & -25 & 7 & 100 & 1.8 \\
\hline 28 & 9 & 50 & 5 & 40 & 1.8 \\
\hline 29 & 8 & 40 & 7 & 100 & 1.8 \\
\hline 30 & 9 & 50 & 3 & 20 & 6 \\
\hline
\end{tabular}

A comment is in order regarding height values that are relevant for the freeway (Table 915). It can be noted that starting $30 \mathrm{~m}$ distance, the applicable receptor height is $1.8 \mathrm{~m}$. The rational is that persons may be walking or biking on facilities that are usually provided for such purposes along the freeway right-of-way. Also, maintenance workers could be receptors. 


\section{Chapter 10: SIMULATION RESULTS FOR URBAN ROADS AND FREEWAYS}

\subsection{INTRODUCTION}

Before presenting results of simulations that were intended for predictive (statistical) model development, it is useful to review capabilities of the modelling system in producing results of scientific interest. Referring back to chapter six, a sample of model output was obtained with the contribution of the micro-simulators of traffic and emission factors. The final output from the integrated simulation model is pollution concentrations at specified receptor locations. This is made possible due to the capability of the air quality model that generates pollution concentration output for various points surrounding the pollution source. Before running the air-quality Gaussian (CALINE) model, receptor points can be identified in the study area. The model has the ability to generate contour lines based on concentration values. Due to its flexible design, environmental scientists use this model to obtain results for various purposes and it is possible to customize the results to suit research needs (e.g. concentrations at vulnerable receptor sites).

To go beyond a general description of the simulation model capabilities, the reader is referred to Figure 6-8, which shows CO concentration results for a case study. These results are presented in Tables 6-2 and 6-3. It can be observed that the pollutants are varying with distance as well as elevation (i.e., vertical height). The graphical representation of pollutant variation is illustrated in Figures 6-9 and 6-10. As expected Figure 6-10 shows that CO pollution concentration is decreasing with increasing horizontal distance from the road. The discussion of results focusses only on a sensitive building located near a major arterial 
road and not very far from a major intersection of two arterial roads. At the end of the analysis, an approximate setback distance is suggested for this building.

In addition to observations on a simulation case study presented above, this chapter is mainly intended for the presentation of results obtained from simulations of urban roads and freeway segment described in chapter 9. In addition, the selection of input variables and ranges of their values were described in chapter 9. For statistical validity, the input variables were selected on a random basis. The decision regarding variables and random selection procedure was described as a part of simulation design.

While the case study in chapter six concentrates on a particular road type, the aim of this research is to cover all applicable types of roads and intersections. In addition, emission concentrations close to an urban freeway are of interest and therefore a typical freeway segment was simulated.

At the risk of repetition, the statistical models for use in the estimation of setback distance are to be based on worst-case condition. Therefore, in the simulation designs, capacity level traffic is used in simulations. Additionally, the 'worst case' wind conditions are taken into account. For statistical validity, thirty samples were simulated for urban roads and for freeway.

\subsection{SIMULATION OF EMISSION RATES OR CEF: URBAN ROADS}

Table 10-1 presents the composite emission factors (CEF) or emission rates. The unit of $\mathrm{CEF}$ or emission rate is gram per vehicle mile $(\mathrm{g} / \mathrm{v}-\mathrm{mi})$. The composite emission factors for gas pollutants $\left(\mathrm{CO}\right.$ and $\left.\mathrm{NO}_{\mathrm{x}}\right)$ were generated using $\mathrm{CMEM}$ emission model. 
The $\mathrm{PM}_{2.5}$ (dust pollutant) emission factor was generated with the use of MOVES Model. Since the MOVES model generates integer values only, the output of 1 (one) for each vehicle is not shown in Table 10-1. Since the output is in gm/vehicle-mile, CEF multiply by the number of vehicles in the input of pollutant dispersion based air quality model.

Table 10-1: Composite emission factor (CEF) or emission rates in gram/vehicle-mile

\begin{tabular}{|c|c|c|c|c|c|}
\hline \multirow[b]{2}{*}{ 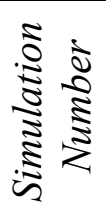 } & \multirow{2}{*}{$\begin{array}{l}\text { Road typel } \\
\text { intersection } \\
\text { combination }\end{array}$} & \multirow[b]{2}{*}{$\begin{array}{l}\text { Traffic } \\
\text { Volume }\end{array}$} & \multirow{2}{*}{$\begin{array}{c}\text { Road } \\
\text { direction/ } \\
\text { intersection } \\
\text { leg type }\end{array}$} & & \\
\hline & & & & $\begin{array}{c}C O C E F \\
(g / m i)\end{array}$ & $\begin{array}{c}N O_{x} C E F \\
(g / m i)\end{array}$ \\
\hline \multirow{4}{*}{1} & $\mathrm{~A} / \mathrm{C}$ & 5085 & $\mathrm{~T}$ & 93.996 & 2.882 \\
\hline & \multirow[t]{2}{*}{ Arterial Road } & 2445 & $\mathrm{~EB}$ & 40.515 & 1.344 \\
\hline & & 2517 & WB & 66.971 & 1.616 \\
\hline & $\mathrm{A} / \mathrm{A}$ & 5385 & $\mathrm{~T}$ & 57.481 & 2.068 \\
\hline \multirow{4}{*}{2} & $\mathrm{~A} / \mathrm{C}$ & 4568 & 4-leg & 28.393 & 1.649 \\
\hline & \multirow[t]{2}{*}{ Arterial Road } & 1801 & EB & 32.511 & 1.279 \\
\hline & & 2856 & WB & 60.574 & 1.73 \\
\hline & $\mathrm{A} / \mathrm{C}$ & 5830 & $\mathrm{~T}$ & 35.558 & 1.48 \\
\hline \multirow{4}{*}{3} & $\mathrm{~A} / \mathrm{C}$ & 5168 & $\mathrm{~T}$ & 104.313 & 3.141 \\
\hline & \multirow{2}{*}{$\begin{array}{c}\text { Collector } \\
\text { Road }\end{array}$} & 697 & $\mathrm{~EB}$ & 24.848 & 1.284 \\
\hline & & 716 & WB & 25.579 & 1.237 \\
\hline & $\mathrm{A} / \mathrm{C}$ & 5490 & 4-leg & 110.782 & 3.836 \\
\hline \multirow{4}{*}{4} & $\mathrm{~A} / \mathrm{C}$ & 5350 & $\mathrm{~T}$ & 35.237 & 1.422 \\
\hline & \multirow[t]{2}{*}{ Arterial Road } & 1428 & EB & 34.245 & 1.432 \\
\hline & & 2323 & WB & 34.782 & 1.348 \\
\hline & $\mathrm{A} / \mathrm{A}$ & 6276 & 4-leg & 79.418 & 2.889 \\
\hline
\end{tabular}




\begin{tabular}{|c|c|c|c|c|c|}
\hline \multirow{4}{*}{5} & $\mathrm{~A} / \mathrm{L}$ & 7310 & 4-leg & 48.322 & 1.726 \\
\hline & Arterial Road & 2568 & EB & 115.512 & 2.354 \\
\hline & & 3473 & WB & 46.326 & 1.556 \\
\hline & $\mathrm{A} / \mathrm{A}$ & 7164 & $\mathrm{~T}$ & 68.606 & 2.395 \\
\hline \multirow{4}{*}{6} & $\mathrm{~A} / \mathrm{C}$ & 4354 & 4-leg & 35.862 & 2.014 \\
\hline & Arterial Road & 1292 & EB & 25.32 & 1.226 \\
\hline & & 1427 & WB & 29.816 & 1.339 \\
\hline & $\mathrm{A} / \mathrm{C}$ & 5444 & $\mathrm{~T}$ & 21.259 & 1.209 \\
\hline \multirow{4}{*}{7} & $\mathrm{~A} / \mathrm{L}$ & 4122 & 4 leg & 54.345 & 2.265 \\
\hline & Collector & 975 & EB & 30.137 & 1.277 \\
\hline & Road & 1495 & WB & 98.548 & 1.996 \\
\hline & $\mathrm{A} / \mathrm{L}$ & 2367 & $\mathrm{~T}$ & 102.795 & 2.702 \\
\hline \multirow{4}{*}{8} & $\mathrm{~A} / \mathrm{C}$ & 5350 & $\mathrm{~T}$ & 62.751 & 1.942 \\
\hline & Arterial Road & 2351 & EB & 61.653 & 1.675 \\
\hline & & 2323 & WB & 113.696 & 2.223 \\
\hline & $\mathrm{A} / \mathrm{C}$ & 5085 & $\mathrm{~T}$ & 60.157 & 1.884 \\
\hline \multirow{4}{*}{9} & $\mathrm{~A} / \mathrm{L}$ & 3500 & 4 leg & 30.255 & 1.491 \\
\hline & Arterial Road & 1428 & EB & 51.488 & 1.686 \\
\hline & & 1567 & WB & 35.484 & 1.383 \\
\hline & $\mathrm{A} / \mathrm{A}$ & 5783 & 4 leg & 35.873 & 2.033 \\
\hline \multirow{3}{*}{10} & $\mathrm{~A} / \mathrm{L}$ & 6353 & 4 leg & 53.606 & 2.078 \\
\hline & Arterial Road & 2297 & EB & 28.447 & 1.258 \\
\hline & & 2952 & WB & 31.996 & 1.323 \\
\hline
\end{tabular}




\begin{tabular}{|c|c|c|c|c|c|}
\hline & $\mathrm{A} / \mathrm{L}$ & 6844 & 4 leg & 39.247 & 1.776 \\
\hline \multirow{4}{*}{11} & $\mathrm{C} / \mathrm{L}$ & 4324 & $\mathrm{~T}$ & 88.836 & 2.466 \\
\hline & Collector & 2028 & EB & 26.179 & 1.221 \\
\hline & Road & 1958 & WB & 71.622 & 1.769 \\
\hline & $\mathrm{C} / \mathrm{L}$ & 4750 & 4 leg & 92.392 & 2.798 \\
\hline \multirow{4}{*}{12} & $\mathrm{~A} / \mathrm{C}$ & 5490 & 4 leg & 45.560 & 2.206 \\
\hline & Arterial Road & 1903 & EB & 27.099 & 1.231 \\
\hline & & 1576 & WB & 28.506 & 1.286 \\
\hline & $\mathrm{A} / \mathrm{L}$ & 3582 & $\mathrm{~T}$ & 24.650 & 1.377 \\
\hline \multirow{4}{*}{13} & $\mathrm{~A} / \mathrm{C}$ & 4354 & 4 leg & 82.006 & 2.728 \\
\hline & Collector & 1415 & EB & 116.058 & 2.307 \\
\hline & Road & 871 & WB & 20.623 & 1.217 \\
\hline & $\mathrm{C} / \mathrm{C}$ & 4136 & 4 leg & 60.152 & 2.610 \\
\hline \multirow{4}{*}{14} & $\mathrm{~A} / \mathrm{L}$ & 7124 & $\mathrm{~T}$ & 68.969 & 2.201 \\
\hline & Arterial Road & 1244 & EB & 43.351 & 1.575 \\
\hline & & 2325 & WB & 108.741 & 2.253 \\
\hline & $\mathrm{A} / \mathrm{A}$ & 4910 & 4 leg & 48.596 & 2.213 \\
\hline \multirow{4}{*}{15} & $\mathrm{~A} / \mathrm{L}$ & 4811 & $\mathrm{~T}$ & 27.925 & 1.256 \\
\hline & Arterial Road & 2322 & EB & 69.936 & 1.801 \\
\hline & & 2444 & WB & 26.771 & 1.175 \\
\hline & $\mathrm{A} / \mathrm{A}$ & 5385 & $\mathrm{~T}$ & 46.481 & 1.755 \\
\hline & $\mathrm{A} / \mathrm{A}$ & 7136 & 4 leg & 61.576 & 2.464 \\
\hline & Arterial Road & 1569 & EB & 30.508 & 1.305 \\
\hline
\end{tabular}




\begin{tabular}{|c|c|c|c|c|c|}
\hline \multirow[t]{2}{*}{16} & & 1428 & WB & 55.777 & 1.678 \\
\hline & $\mathrm{A} / \mathrm{A}$ & 4910 & $4 \mathrm{leg}$ & 60.714 & 2.671 \\
\hline \multirow{4}{*}{17} & $\mathrm{~A} / \mathrm{L}$ & 6657 & $\mathrm{~T}$ & 78.628 & 2.39 \\
\hline & \multirow[t]{2}{*}{ Arterial Road } & 3575 & $\mathrm{~EB}$ & 56.661 & 1.667 \\
\hline & & 3172 & WB & 68.540 & 1.800 \\
\hline & $\mathrm{A} / \mathrm{L}$ & 7124 & $\mathrm{~T}$ & 78.530 & 2.371 \\
\hline \multirow{4}{*}{18} & $\mathrm{~A} / \mathrm{C}$ & 5016 & $4 \mathrm{leg}$ & 30.71 & 1.817 \\
\hline & \multirow[t]{2}{*}{ Arterial Road } & 2166 & EB & 40.509 & 1.445 \\
\hline & & 2048 & WB & 39.06 & 1.45 \\
\hline & $\mathrm{A} / \mathrm{C}$ & 5538 & $\mathrm{~T}$ & 34.002 & 1.53 \\
\hline \multirow{4}{*}{19} & $\mathrm{C} / \mathrm{L}$ & 4750 & $4 \mathrm{leg}$ & 67.290 & 2.459 \\
\hline & \multirow{2}{*}{$\begin{array}{c}\text { Collector } \\
\text { Road }\end{array}$} & 1796 & $\mathrm{~EB}$ & 23.508 & 1.142 \\
\hline & & 1928 & WB & 90.611 & 2.036 \\
\hline & $\mathrm{C} / \mathrm{C}$ & 4136 & $4 \mathrm{leg}$ & 97.218 & 2.780 \\
\hline \multirow{4}{*}{20} & $\mathrm{~A} / \mathrm{C}$ & 5168 & $\mathrm{~T}$ & 28.323 & 1.432 \\
\hline & \multirow{2}{*}{$\begin{array}{c}\text { Collector } \\
\text { Road }\end{array}$} & 1234 & EB & 39.278 & 1.361 \\
\hline & & 646 & WB & 26.571 & 1.291 \\
\hline & $\mathrm{C} / \mathrm{C}$ & 4020 & $\mathrm{~T}$ & 75.2323 & 2.419 \\
\hline \multirow{5}{*}{21} & $\mathrm{C} / \mathrm{C}$ & 2861 & $\mathrm{~T}$ & 56.039 & 2.224 \\
\hline & \multirow{2}{*}{$\begin{array}{c}\text { Collector } \\
\text { Road }\end{array}$} & 720 & EB & 19.856 & 1.159 \\
\hline & & 975 & WB & 39.593 & 1.315 \\
\hline & $\mathrm{A} / \mathrm{C}$ & 4892 & $4 \mathrm{leg}$ & 34.927 & 1.883 \\
\hline & $\mathrm{C} / \mathrm{C}$ & 3411 & $\mathrm{~T}$ & 59.292 & 2.146 \\
\hline
\end{tabular}




\begin{tabular}{|c|c|c|c|c|c|}
\hline \multirow{3}{*}{22} & Collector & 1613 & EB & 57.868 & 1.619 \\
\hline & Road & 1015 & WB & 18.412 & 1.093 \\
\hline & $\mathrm{C} / \mathrm{L}$ & 3868 & 4 leg & 47.302 & 2.182 \\
\hline \multirow{4}{*}{23} & $\mathrm{~A} / \mathrm{C}$ & 5538 & $\mathrm{~T}$ & 34.241 & 1.672 \\
\hline & Arterial Road & 2140 & EB & 88.954 & 2.044 \\
\hline & & 2564 & WB & 38.634 & 1.411 \\
\hline & $\mathrm{A} / \mathrm{A}$ & 7136 & 4 leg & 55.097 & 2.267 \\
\hline \multirow{4}{*}{24} & $\mathrm{~A} / \mathrm{A}$ & 4783 & $\mathrm{~T}$ & 72.874 & 2.378 \\
\hline & Arterial Road & 2458 & EB & 92.802 & 2.057 \\
\hline & & 2285 & WB & 63.782 & 1.737 \\
\hline & $\mathrm{A} / \mathrm{C}$ & 5620 & $\mathrm{~T}$ & 48.95 & 1.624 \\
\hline \multirow{4}{*}{25} & $\mathrm{C} / \mathrm{C}$ & 4818 & $\mathrm{~T}$ & 75.128 & 2.413 \\
\hline & Collector & 1992 & EB & 26.098 & 1.168 \\
\hline & Road & 2114 & WB & 77.899 & 1.940 \\
\hline & $\mathrm{C} / \mathrm{L}$ & 4324 & $\mathrm{~T}$ & 113.574 & 2.986 \\
\hline \multirow{4}{*}{26} & $\mathrm{C} / \mathrm{C}$ & 4289 & $\mathrm{~T}$ & 127.315 & 2.894 \\
\hline & Collector & 1142 & EB & 19.142 & 1.111 \\
\hline & Road & 1603 & WB & 109.427 & 2.130 \\
\hline & $\mathrm{C} / \mathrm{C}$ & 2855 & $\mathrm{~T}$ & 107.214 & 2.794 \\
\hline \multirow{4}{*}{27} & $\mathrm{C} / \mathrm{C}$ & 3304 & 4 leg & 71.635 & 2.871 \\
\hline & Collector & 1443 & EB & 18.094 & 1.027 \\
\hline & Road & 1060 & WB & 100.455 & 2.036 \\
\hline & $\mathrm{C} / \mathrm{C}$ & 2987 & $\mathrm{~T}$ & 66.158 & 2.126 \\
\hline
\end{tabular}




\begin{tabular}{|c|c|c|c|c|c|}
\hline \multirow{4}{*}{28} & $\mathrm{~A} / \mathrm{C}$ & 5084 & 4 leg & 67.084 & 2.473 \\
\cline { 2 - 6 } & Collector & 979 & $\mathrm{~EB}$ & 16.390 & 1.040 \\
\cline { 3 - 6 } & $\mathrm{Road}$ & 1454 & $\mathrm{WB}$ & 39.940 & 1.528 \\
\cline { 2 - 6 } & $\mathrm{C} / \mathrm{L}$ & 3627 & $\mathrm{~T}$ & 56.737 & 1.882 \\
\hline \multirow{3}{*}{29} & $\mathrm{~A} / \mathrm{C}$ & 5168 & $\mathrm{~T}$ & 36.45 & 1.678 \\
\cline { 2 - 6 } & Arterial Road & 2384 & $\mathrm{~EB}$ & 40.232 & 1.497 \\
\cline { 2 - 6 } & & 1641 & $\mathrm{WB}$ & 31.747 & 1.333 \\
\cline { 2 - 6 } & $\mathrm{A} / \mathrm{C}$ & 5150 & 4 leg & 41.07 & 1.953 \\
\hline \multirow{3}{*}{30} & $\mathrm{~A} / \mathrm{L}$ & 5897 & 4 leg & 33.143 & 1.544 \\
\cline { 2 - 6 } & Arterial Road & 2080 & $\mathrm{~EB}$ & 114.321 & 2.326 \\
\cline { 2 - 6 } & & 2221 & $\mathrm{WB}$ & 39.766 & 1.424 \\
\cline { 2 - 6 } & $\mathrm{A} / \mathrm{A}$ & 6950 & 4 leg & 59.927 & 2.382 \\
\hline
\end{tabular}

In the above table, the CEFs are presented for thirty simulation cases. Each simulation case has four results based on sample road network presented in figure 9-2. Two results for two intersections (left and right) are presented according to this figure. Those two results (e.g. $\mathrm{A} / \mathrm{A}=$ an intersection of arterial vs arterial, and $\mathrm{A} / \mathrm{C}=$ an intersection of arterial with collector) are first and fourth rows of each simulation case. The middle two results represent the emission rates for road link (e.g. arterial/ collector road). Moreover, the emission rates vary with direction. Therefore, CEFs for a road type split into two results because of direction of each road link. 


\subsection{POLLUTION CONCENTRATION RESULTS FOR ROADS AND INTERSECTIONS}

The Gaussian dispersion air- quality model was used for analysis of the pollution concentrations. Tables 10-2 to 10-9 present the concentration results for different road links and intersections. Table 10-2 shows the thirty simulation results for the arterial road link, whereas Table 10-3 shows results for 30 simulations for the collector road. The local road is not considered in this research, because traffic volume on a local road is comparatively very low. Therefore, pollution concentration levels near local road are not significant. Rest of the tables show the results for different intersection types.

It should be highlighted that for statistical significance, thirty simulations were implemented for each road link and intersection type. The input data and results are shown in Tables 10-2 to 10-9, but the random number selection tables are not included here in order to avoid duplication. There is a link between sample number and simulation number (column two) in tables. This means that the CEF values are sourced from table 10-1.

Each simulation case was run three times for three pollutants. Outputs for sample number 15 are illustrated in Figure 10-1. This case represents a four-leg intersection of an arterial road with a collector. It is referenced in Table 10-6. Whereas, the inputs values for CEF interlink with simulation number 18 (eighteen) in Table 10-1. In this figure, the road link is denoted in blue color and dotted lines surrounding the road links represent the width of the road. The directions of these road links are shown with arrow sign. A five-meter buffer line from road edge is shown in the figure. It should be pointed out that this buffer line is generated using the GIS software. 


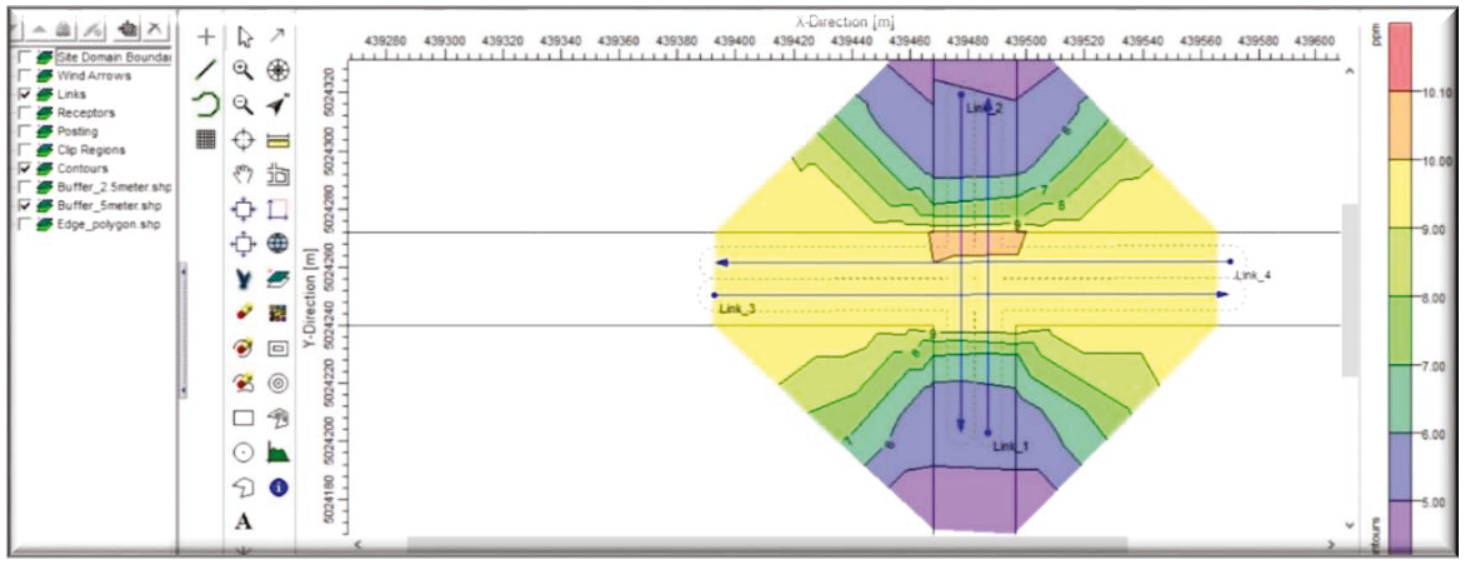

Figure 10-1: CO concentrations of sample number-15 with arterial vs collector 4 leg intersection (represented in table 10-6)

Figure 10-1 demonstrates the CO concentration contours. Table 10-6 was prepared based on maximum concentrations from each simulation run. As can be seen in Figure10-1, the maximum $\mathrm{CO}$ concentration at this intersection is $10.1 \mathrm{ppm}$. The color bar in the right hand side of the figure shows the concentration level.

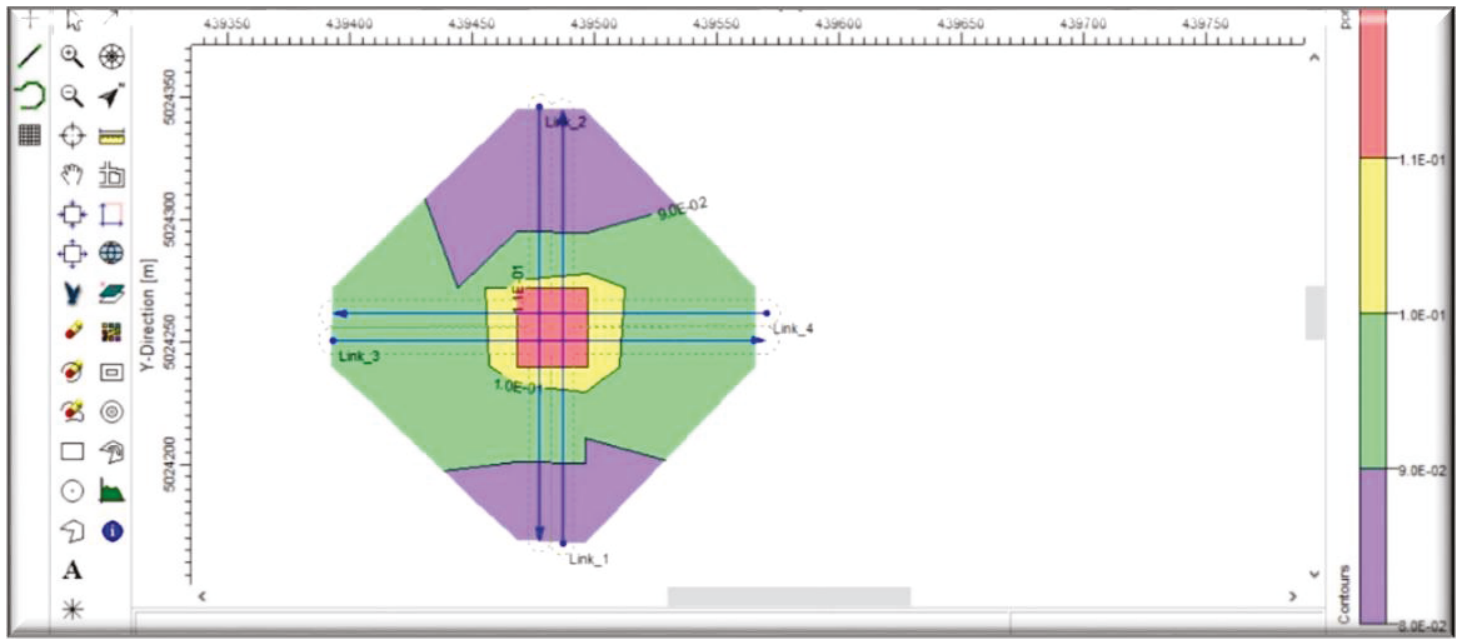

Figure 10-2: NO2 concentrations for sample number-19

Figure 10-2 represents the $\mathrm{NO}_{2}$ concentration contours. The details of input data are available in Table 10-6 for sample number 19, whereas the CEF values presented in table 
10-1. The input variables are land use, traffic volume, temperature, distance from road edge, and height from the road surface. All input values are represented in table columns. Although the emission rates are not included in the table, these are linked with the simulation number in the CEF table. In the table, the input section and output section are separated clearly.

There are three outputs for three different pollutants. Note that the units for each pollutant are different; they are the same as those used for the national ambient air quality standards. Accordingly, the unit for carbon monoxide is parts per million (ppm), for nitrogen dioxide is parts per billion (ppb), and the unit for particulate matter is micro-gram per cubic meter. All simulations were run for an hour, so the pollution concentration is for one hour only.

A snap shot from the model shows the $\mathrm{NO}_{2}$ contour lines in Figure10-2. The color bar represents the concentration levels. The green color areas in this figure corresponds to $\mathrm{NO}_{2}$ concentration level 90-100 ppb, whereas the yellow color area shows that the $\mathrm{NO}_{2}$ concentration is more than $100 \mathrm{ppb}$. The maximum concentration that occurs in this intersection is $110 \mathrm{ppb}$.

The above figures are the graphical representation of output from the air quality model. The numerical results are included in appendices. This report is classified into four sections. The first section shows the meteorological variables. The link variables are displayed in the second section, which contain vehicle numbers, emission factor, and link characteristics. The next section illustrates receptor locations. The altitude of the receptors can be changed based on requirements. The last section provides the model results, which are predicted concentrations. 
Here, the $\mathrm{CO}$ concentrations are recorded in ppm. The maximum concentration occurs at receptor number 24. Moreover, the contributions of pollutants from each link are displayed in the report. At the above receptor, the maximum share from link D is $5.5 \mathrm{ppm}$ and minimum from link $\mathrm{B}$ is $0.9 \mathrm{ppm}$. Appendix-XI presents $\mathrm{NO}_{2}$ results for sample number 19 in the same table.

The above discussion applies to one case only (such as CO concentrations in sample \# 15). For model development, results of thirty simulations are available for each type of road and intersection. These are presented in the following tables. In the tables, 'CBD' means CBD-central city area, whereas 'Urban' means urban-outside CBD area.

Table 10-2: Pollution concentrations for arterial road link

\begin{tabular}{|c|c|c|c|c|c|c|c|c|c|}
\hline \multicolumn{7}{|c|}{ INPUT } & \multicolumn{3}{|c|}{ OUTPUT } \\
\hline $\begin{array}{l}\text { S.L. } \\
\text { No. }\end{array}$ & 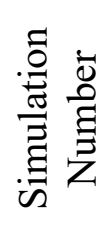 & $\begin{array}{c}\text { Land } \\
\text { Use }\end{array}$ & $\begin{array}{l}\text { Traffic } \\
\text { Volume }\end{array}$ & 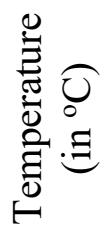 & 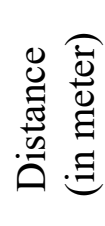 & 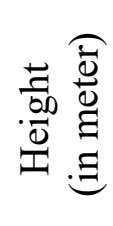 & $\begin{array}{l}\text { CO } \\
\text { (ppm) }\end{array}$ & $\begin{array}{l}\mathrm{NO}_{2} \\
(p p b)\end{array}$ & $\begin{array}{l}P M_{2.5} \\
\left(\mu g / m^{3}\right)\end{array}$ \\
\hline 1 & 1 & CBD & 4962 & 32.5 & 1 & 1.8 & 38.4 & 120 & 446 \\
\hline 2 & 1 & CBD & 4962 & 32.5 & 100 & 1.8 & 6.1 & 20 & 144 \\
\hline 3 & 2 & Urban & 4657 & 40 & 50 & 1.8 & 7.8 & 30 & 145 \\
\hline 4 & 2 & Urban & 4657 & 40 & 5 & 7 & 22.3 & 80 & 280 \\
\hline 5 & 4 & Urban & 3751 & 40 & 5 & 1.8 & 12.7 & 80 & 283 \\
\hline 6 & 4 & Urban & 3751 & 40 & 0 & 0 & 30.7 & 170 & 478 \\
\hline 7 & 6 & Urban & 2719 & 27.5 & 100 & 1.8 & 1.9 & 20 & 51 \\
\hline 8 & 6 & Urban & 2719 & 27.5 & 2.5 & 1 & 8.1 & 90 & 232 \\
\hline 9 & 8 & Urban & 4674 & -5 & 0 & 1.8 & 78.2 & 170 & 514 \\
\hline 10 & 8 & Urban & 4674 & -5 & 5 & 1 & 33.5 & 80 & 341 \\
\hline 11 & 16 & Urban & 2997 & 40 & 50 & 1.8 & 4.7 & 30 & 92 \\
\hline
\end{tabular}




\begin{tabular}{|c|c|c|c|c|c|c|c|c|c|}
\hline 12 & 16 & Urban & 2997 & 40 & 1 & 1 & $\mathbf{2 1 . 6}$ & $\mathbf{1 2 0}$ & $\mathbf{3 0 1}$ \\
\hline 13 & 18 & CBD & 4214 & 32.5 & 5 & 1.8 & $\mathbf{1 4 . 5}$ & $\mathbf{8 0}$ & $\mathbf{2 9 4}$ \\
\hline 14 & 18 & CBD & 4214 & 32.5 & 2.5 & 1.8 & $\mathbf{1 8 . 1}$ & $\mathbf{9 0}$ & $\mathbf{3 3 9}$ \\
\hline 15 & 24 & CBD & 4743 & 27.5 & 100 & 1.8 & $\mathbf{7 . 8}$ & $\mathbf{2 0}$ & $\mathbf{8 4}$ \\
\hline 16 & 24 & CBD & 4743 & 27.5 & 1 & 1 & $\mathbf{5 5 . 1}$ & $\mathbf{1 4 0}$ & $\mathbf{4 5 7}$ \\
\hline 17 & 29 & CBD & 4025 & -5 & 5 & 1.8 & $\mathbf{1 2 . 1}$ & $\mathbf{7 0}$ & $\mathbf{2 9 0}$ \\
\hline 18 & 29 & CBD & 4025 & -5 & 15 & 1.8 & $\mathbf{7 . 8}$ & $\mathbf{4 0}$ & $\mathbf{2 0 6}$ \\
\hline 19 & 5 & CBD & 6041 & 22.5 & 0 & 1.8 & $\mathbf{9 8 . 4}$ & $\mathbf{2 1 0}$ & $\mathbf{6 6 4}$ \\
\hline 20 & 5 & CBD & 6041 & 22.5 & 2.5 & 1.8 & $\mathbf{5 2}$ & $\mathbf{1 2 0}$ & $\mathbf{5 0 1}$ \\
\hline 21 & 9 & CBD & 2995 & 40 & 1 & 1.8 & $\mathbf{2 0 . 5}$ & $\mathbf{1 2 0}$ & $\mathbf{2 7 9}$ \\
\hline 22 & 9 & CBD & 2995 & 40 & 5 & 4 & $\mathbf{1 2 . 9}$ & $\mathbf{8 0}$ & $\mathbf{1 9 8}$ \\
\hline 23 & 10 & Urban & 5249 & 32.5 & 1 & 1.8 & $\mathbf{2 3 . 4}$ & $\mathbf{1 3 0}$ & $\mathbf{5 1 8}$ \\
\hline 24 & 10 & Urban & 5249 & 32.5 & 1 & 1 & $\mathbf{2 3 . 6}$ & $\mathbf{1 3 0}$ & $\mathbf{5 3 4}$ \\
\hline 25 & 30 & CBD & 4301 & 50 & 2.5 & 1 & $\mathbf{4 2 . 7}$ & $\mathbf{1 1 0}$ & $\mathbf{3 5 3}$ \\
\hline 26 & 30 & CBD & 4301 & 50 & 50 & 1.8 & $\mathbf{1 1}$ & $\mathbf{3 0}$ & $\mathbf{1 2 6}$ \\
\hline 27 & 23 & CBD & 4704 & 22.5 & 1 & 1.8 & $\mathbf{4 3}$ & $\mathbf{1 3 0}$ & $\mathbf{4 4 4}$ \\
\hline 28 & 23 & CBD & 4704 & 22.5 & 5 & 4 & $\mathbf{2 5 . 6}$ & $\mathbf{8 0}$ & $\mathbf{3 1 3}$ \\
\hline 29 & 12 & Urban & 5490 & 40 & 1 & 1.8 & $\mathbf{1 4 . 2}$ & $\mathbf{1 1 0}$ & $\mathbf{3 4 3}$ \\
\hline 30 & 12 & Urban & 5490 & 40 & 2.5 & 1.8 & $\mathbf{1 1 . 3}$ & $\mathbf{9 0}$ & $\mathbf{2 9 5}$ \\
\hline
\end{tabular}

Table 10-3: Pollution concentrations for collector road link

\begin{tabular}{|c|c|c|c|c|c|c|c|c|c|}
\hline \multicolumn{7}{|c|}{ INPUT } & \multicolumn{3}{|c|}{ OUTPUT } \\
\hline $\begin{array}{l}\text { S.L. } \\
\text { No. }\end{array}$ & 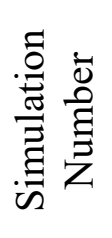 & $\begin{array}{l}\text { Land } \\
\text { Use }\end{array}$ & $\begin{array}{l}\text { Traffic } \\
\text { Volume }\end{array}$ & 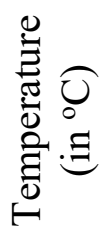 & 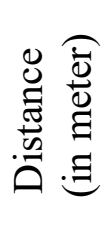 & 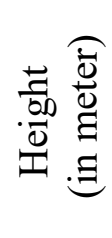 & $\begin{array}{l}C O \\
(\text { ppm) }\end{array}$ & $\begin{array}{l}\mathrm{NO}_{2} \\
(p p b)\end{array}$ & $\begin{array}{l}P M_{2.5} \\
\left(\mu g / m^{3}\right)\end{array}$ \\
\hline 1 & 3 & CBD & 1413 & -25 & 1 & 1.8 & 5.6 & 50 & 146 \\
\hline 2 & 25 & Urban & 4106 & 40 & 0 & 0 & 83.5 & 250 & 621 \\
\hline 3 & 11 & CBD & 3986 & -5 & 5 & 1.8 & 16.9 & 70 & 283 \\
\hline 4 & 11 & CBD & 3986 & -5 & 30 & 1.8 & 7 & 30 & 129 \\
\hline
\end{tabular}




\begin{tabular}{|c|c|c|c|c|c|c|c|c|c|}
\hline 5 & 3 & CBD & 1413 & -25 & 5 & 4 & 3.1 & 30 & 97 \\
\hline 6 & 28 & CBD & 2433 & 40 & 5 & 4 & 7.6 & 70 & 166 \\
\hline 7 & 13 & CBD & 2286 & 15 & 50 & 1.8 & 5.3 & 20 & 51 \\
\hline 8 & 25 & Urban & 4106 & 40 & 5 & 1.8 & 22.8 & 90 & 305 \\
\hline 9 & 26 & CBD & 2745 & -15 & 0 & 0 & 69.3 & 160 & 409 \\
\hline 10 & 28 & CBD & 2433 & 40 & 2.5 & 1.8 & 10.6 & 90 & 216 \\
\hline 11 & 13 & CBD & 2286 & 15 & 5 & 1 & 17.9 & 70 & 166 \\
\hline 12 & 27 & Urban & 2503 & 40 & 5 & 7 & 13.7 & 70 & 150 \\
\hline 13 & 7 & CBD & 2470 & 50 & 1 & 1.8 & 38.5 & 140 & 268 \\
\hline 14 & 7 & CBD & 2470 & 50 & 50 & 1.8 & 5.8 & 20 & 55 \\
\hline 15 & 21 & Urban & 1695 & 50 & 5 & 1 & 5.9 & 60 & 129 \\
\hline 16 & 21 & Urban & 1695 & 50 & 5 & 1.8 & 5.9 & 60 & 128 \\
\hline 17 & 3 & CBD & 1413 & -25 & 2.5 & 1.8 & 4.0 & 40 & 122 \\
\hline 18 & 3 & CBD & 1413 & -25 & 100 & 1.8 & 0.7 & 10 & 21 \\
\hline 19 & 20 & CBD & 1880 & 15 & 5 & 1 & 6.4 & 60 & 137 \\
\hline 20 & 21 & Urban & 1695 & 50 & 15 & 1.8 & 3.5 & 40 & 84 \\
\hline 21 & 13 & $\mathrm{CBD}$ & 2286 & 15 & 100 & 1.8 & 3.5 & 10 & 33 \\
\hline 22 & 26 & CBD & 2745 & -15 & 2.5 & 1.8 & 24.1 & 80 & 242 \\
\hline 23 & 11 & CBD & 3986 & -5 & 15 & 1.8 & 10 & 40 & 186 \\
\hline 24 & 28 & CBD & 2433 & 40 & 0 & 0 & 28.9 & 180 & 367 \\
\hline 25 & 22 & CBD & 2628 & 5 & 1 & 1.8 & 21.0 & 110 & 283 \\
\hline 26 & 13 & CBD & 2286 & 15 & 10 & 1.8 & 12.6 & 50 & 126 \\
\hline 27 & 25 & Urban & 4106 & 40 & 1 & 1 & 45.1 & 160 & 460 \\
\hline 28 & 11 & CBD & 3986 & -5 & 10 & 1.8 & 12.2 & 50 & 221 \\
\hline 29 & 26 & CBD & 2745 & -15 & 30 & 1.8 & 6.9 & 20 & 90 \\
\hline 30 & 19 & CBD & 3724 & 40 & 5 & 1.8 & 22.6 & 80 & 266 \\
\hline
\end{tabular}

Table 10-4: Pollution concentrations for an intersection with arterial road vs arterial road with four way crossing (4-leg type)

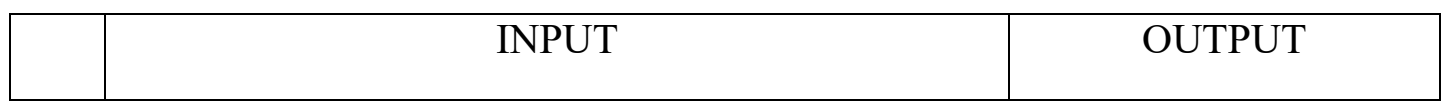




\begin{tabular}{|c|c|c|c|c|c|c|c|c|c|c|}
\hline $\begin{array}{l}\text { S.L. } \\
\text { No. }\end{array}$ & 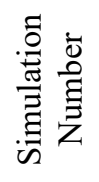 & 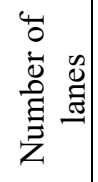 & $\begin{array}{l}\text { Land } \\
\text { Use }\end{array}$ & $\begin{array}{l}\text { Traffic } \\
\text { Volume }\end{array}$ & 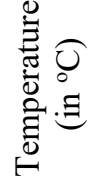 & 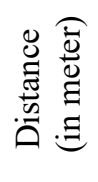 & 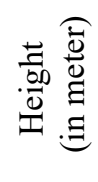 & $\begin{array}{l}\text { CO } \\
\text { (ppm) }\end{array}$ & $\begin{array}{l}\mathrm{NO}_{2} \\
(p p b)\end{array}$ & $\begin{array}{l}P M_{2.5} \\
\left(\mu g / m^{3}\right)\end{array}$ \\
\hline 1 & $16 \mathrm{~L}$ & $4 \times 5$ & Urban & 7136 & 40 & 0 & 0 & 40.0 & 190 & 376 \\
\hline 2 & 14 & $4 \times 3$ & CBD & 4910 & -5 & 1 & 1 & 19.5 & 110 & 254 \\
\hline 3 & 23 & $5 \times 4$ & CBD & 7136 & 22.5 & 5 & 1.8 & 23.0 & 120 & 275 \\
\hline 4 & $16 \mathrm{R}$ & $4 \times 3$ & Urban & 4910 & 40 & 50 & 1.8 & 7.8 & 50 & 85 \\
\hline 5 & 14 & $4 \times 3$ & CBD & 4910 & -5 & 5 & 4 & 11.3 & 70 & 156 \\
\hline 6 & 23 & $5 \times 4$ & CBD & 7136 & 22.5 & 5 & 4 & 19.8 & 100 & 224 \\
\hline 7 & 14 & $4 \times 3$ & CBD & 4910 & -5 & 50 & 1.8 & 5.3 & 40 & 83 \\
\hline 8 & 30 & $5 \times 4$ & CBD & 6950 & 50 & 2.5 & 1 & 30.4 & 140 & 300 \\
\hline 9 & $16 \mathrm{~L}$ & $4 \times 5$ & Urban & 7136 & 40 & 1 & 1 & 36.5 & 170 & 348 \\
\hline 10 & $16 \mathrm{~L}$ & $4 \times 5$ & Urban & 7136 & 40 & 2.5 & 1.8 & 30.2 & 140 & 308 \\
\hline 11 & 23 & $5 \times 4$ & CBD & 7136 & 22.5 & 5 & 1 & 23.8 & 120 & 287 \\
\hline 12 & $16 \mathrm{~L}$ & $4 \times 5$ & Urban & 7136 & 40 & 5 & 7 & 19.3 & 90 & 188 \\
\hline 13 & $16 \mathrm{R}$ & $4 \times 3$ & Urban & 4910 & 40 & 1 & 1 & 28.3 & 140 & 236 \\
\hline 14 & 14 & $4 \times 3$ & CBD & 4910 & -5 & 5 & 7 & 9.7 & 70 & 128 \\
\hline 15 & 4 & $4 \times 4$ & Urban & 6276 & 40 & 5 & 1.8 & 31.4 & 130 & 258 \\
\hline 16 & 30 & $5 \times 4$ & CBD & 6950 & 50 & 10 & 1.8 & 20.1 & 100 & 216 \\
\hline 17 & 23 & $5 \times 4$ & CBD & 7136 & 22.5 & 2.5 & 1.8 & 28.4 & 140 & 312 \\
\hline 18 & 4 & $4 \times 4$ & Urban & 5344 & 40 & 5 & 1.8 & 26.8 & 120 & 209 \\
\hline 19 & 30 & $5 \times 4$ & CBD & 6950 & 50 & 5 & 1 & 25.7 & 120 & 263 \\
\hline 20 & 14 & $4 \times 3$ & CBD & 4910 & -5 & 15 & 1 & 9.0 & 60 & 137 \\
\hline 21 & 23 & $5 \times 4$ & CBD & 7136 & 22.5 & 1 & 1.8 & 30.1 & 150 & 329 \\
\hline 22 & 9 & $4 \times 4$ & CBD & 5783 & 40 & 5 & 4 & 11.3 & 90 & 184 \\
\hline 23 & 30 & $5 \times 4$ & CBD & 6950 & 50 & 15 & 1.8 & 17.8 & 80 & 189 \\
\hline 24 & 9 & $4 \times 4$ & CBD & 5783 & 40 & 1 & 1.8 & 18 & 140 & 283 \\
\hline 25 & $16 \mathrm{~L}$ & $4 \times 5$ & Urban & 7136 & 40 & 1 & 1.8 & 33.9 & 160 & 333 \\
\hline 26 & $16 \mathrm{~L}$ & $4 \times 5$ & Urban & 7136 & 40 & 10 & 1.8 & 20.6 & 100 & 226 \\
\hline 27 & 4 & $4 \times 4$ & Urban & 6276 & 40 & 0 & 0 & 56.9 & 210 & 425 \\
\hline
\end{tabular}




\begin{tabular}{|c|c|c|c|c|c|c|c|c|c|c|}
\hline 28 & 4 & $4 \times 4$ & Urban & 5344 & 40 & 0 & 0 & $\mathbf{4 3 . 7}$ & $\mathbf{1 8 0}$ & $\mathbf{3 3 4}$ \\
\hline 29 & $16 \mathrm{~L}$ & $4 \times 5$ & Urban & 7136 & 40 & 50 & 1.8 & $\mathbf{1 0 . 9}$ & $\mathbf{5 0}$ & $\mathbf{1 2 4}$ \\
\hline 30 & 30 & $5 \times 4$ & CBD & 6950 & 50 & 50 & 1.8 & $\mathbf{1 0 . 5}$ & $\mathbf{5 0}$ & $\mathbf{1 1 8}$ \\
\hline
\end{tabular}

Table 10-5: Pollution concentrations for an intersection with arterial road vs arterial road with three way crossing (' $T$ ' type)

\begin{tabular}{|c|c|c|c|c|c|c|c|c|c|c|}
\hline & \multicolumn{7}{|c|}{ INPUT } & \multicolumn{3}{|c|}{ OUTPUT } \\
\hline $\begin{array}{l}\text { S.L. } \\
\text { No. }\end{array}$ & 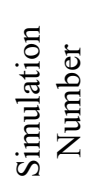 & 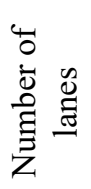 & $\begin{array}{l}\text { Land } \\
\text { Use }\end{array}$ & $\begin{array}{l}\text { Traffic } \\
\text { Volume }\end{array}$ & 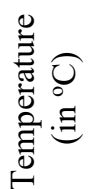 & 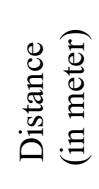 & 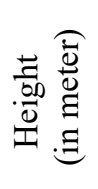 & $\begin{array}{l}\text { CO } \\
(\text { ppm) }\end{array}$ & $\begin{array}{l}\mathrm{NO}_{2} \\
(p p b)\end{array}$ & $\begin{array}{l}P M_{2.5} \\
\left(\mu g / m^{3}\right)\end{array}$ \\
\hline 1 & 5 & $4 \times 4$ & CBD & 7164 & 22.5 & 0 & 0 & 57.0 & 190 & 521 \\
\hline 2 & 24 & $3 \times 3$ & CBD & 4783 & 27.5 & 1 & 1 & 49.3 & 170 & 408 \\
\hline 3 & 24 & $3 \times 3$ & CBD & 4783 & 27.5 & 5 & 1.8 & 34.9 & 140 & 313 \\
\hline 4 & 24 & $3 \times 3$ & CBD & 4783 & 27.5 & 30 & 1.8 & 20.8 & 90 & 195 \\
\hline 5 & 15 & $4 \times 2$ & Urban & 5385 & 15 & 5 & 4 & 15.7 & 80 & 262 \\
\hline 6 & 1 & $4 \times 2$ & CBD & 5385 & 32.5 & 5 & 4 & 20.2 & 100 & 249 \\
\hline 7 & 24 & $3 \times 3$ & CBD & 4783 & 27.5 & 50 & 1.8 & 16.4 & 70 & 150 \\
\hline 8 & 5 & $4 \times 4$ & CBD & 7164 & 22.5 & 5 & 1.8 & 33.5 & 120 & 347 \\
\hline 9 & 1 & $4 \times 2$ & CBD & 5385 & 32.5 & 0 & 0 & 39.5 & 150 & 434 \\
\hline 10 & 5 & $4 \times 4$ & CBD & 7164 & 22.5 & 2.5 & 1.8 & 40.6 & 140 & 391 \\
\hline 11 & 1 & $4 \times 2$ & CBD & 5385 & 32.5 & 5 & 1 & 21.0 & 120 & 273 \\
\hline 12 & 24 & $3 \times 3$ & CBD & 4783 & 27.5 & 5 & 7 & 21.7 & 90 & 166 \\
\hline 13 & 1 & $4 \times 2$ & CBD & 5385 & 32.5 & 1 & 1.8 & 33.9 & 130 & 253 \\
\hline 14 & 5 & $4 \times 4$ & CBD & 7164 & 22.5 & 50 & 1.8 & 15.6 & 60 & 170 \\
\hline 15 & 15 & $4 \times 2$ & Urban & 5385 & 15 & 5 & 1 & 16.3 & 100 & 287 \\
\hline 16 & 1 & $4 \times 2$ & CBD & 5385 & 32.5 & 5 & 1.8 & 20.8 & 120 & 269 \\
\hline 17 & 5 & $4 \times 4$ & CBD & 7164 & 22.5 & 5 & 1 & 34.4 & 130 & 359 \\
\hline 18 & 5 & $4 \times 4$ & CBD & 7164 & 22.5 & 100 & 1.8 & 10.9 & 40 & 111 \\
\hline 19 & 1 & $4 \times 2$ & CBD & 5385 & 32.5 & 10 & 1.8 & 17.0 & 110 & 214 \\
\hline 20 & 1 & $4 \times 2$ & CBD & 5385 & 32.5 & 15 & 1.8 & 15.0 & 50 & 186 \\
\hline
\end{tabular}




\begin{tabular}{|c|c|c|c|c|c|c|c|c|c|c|}
\hline 21 & 24 & $3 \times 3$ & CBD & 4783 & 27.5 & 100 & 1.8 & $\mathbf{1 1 . 7}$ & $\mathbf{5 0}$ & $\mathbf{1 0 3}$ \\
\hline 22 & 1 & $4 \times 2$ & CBD & 5385 & 32.5 & 2.5 & 1.8 & $\mathbf{2 5 . 7}$ & $\mathbf{1 3 0}$ & $\mathbf{3 2 4}$ \\
\hline 23 & 5 & $4 \times 4$ & CBD & 7164 & 22.5 & 15 & 1.8 & $\mathbf{2 5 . 2}$ & $\mathbf{9 0}$ & $\mathbf{2 7 0}$ \\
\hline 24 & 1 & $4 \times 2$ & CBD & 5385 & 32.5 & 100 & 1.8 & $\mathbf{6}$ & $\mathbf{4 0}$ & $\mathbf{4 3}$ \\
\hline 25 & 5 & $4 \times 4$ & CBD & 7164 & 22.5 & 1 & 1.8 & $\mathbf{4 7 . 6}$ & $\mathbf{1 6 0}$ & $\mathbf{4 3 2}$ \\
\hline 26 & 24 & $3 \times 3$ & CBD & 4783 & 27.5 & 10 & 1.8 & $\mathbf{3 0 . 1}$ & $\mathbf{1 2 0}$ & $\mathbf{2 7 9}$ \\
\hline 27 & 5 & $4 \times 4$ & CBD & 7164 & 22.5 & 0 & 1.8 & $\mathbf{5 1 . 9}$ & $\mathbf{1 8 0}$ & $\mathbf{4 7 1}$ \\
\hline 28 & 24 & $3 \times 3$ & CBD & 4783 & 27.5 & 15 & 1.8 & $\mathbf{2 6 . 8}$ & $\mathbf{1 1 0}$ & $\mathbf{2 5 2}$ \\
\hline 29 & 5 & $4 \times 4$ & CBD & 7164 & 22.5 & 30 & 1.8 & $\mathbf{1 9 . 6}$ & $\mathbf{7 0}$ & $\mathbf{2 1 6}$ \\
\hline 30 & 24 & $3 \times 3$ & CBD & 4783 & 27.5 & 2.5 & 1 & $\mathbf{4 0 . 2}$ & $\mathbf{1 6 0}$ & $\mathbf{3 5 1}$ \\
\hline
\end{tabular}

Table 10-6: Pollution concentrations for an intersection with arterial road vs collector road with four way crossing (4-leg type)

\begin{tabular}{|c|c|c|c|c|c|c|c|c|c|c|}
\hline & \multicolumn{7}{|c|}{ INPUT } & \multicolumn{3}{|c|}{ OUTPUT } \\
\hline $\begin{array}{l}\text { S.L. } \\
\text { No. }\end{array}$ & 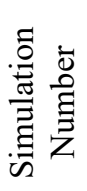 & 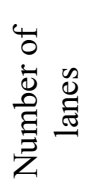 & $\begin{array}{l}\text { Land } \\
\text { Use }\end{array}$ & $\begin{array}{l}\text { Traffic } \\
\text { Volume }\end{array}$ & 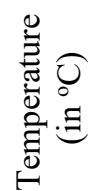 & 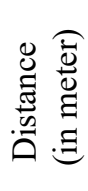 & 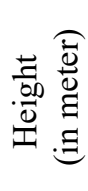 & $\begin{array}{l}\text { CO } \\
\text { (ppm) }\end{array}$ & $\begin{array}{l}\mathrm{NO}_{2} \\
(p p b)\end{array}$ & $\begin{array}{l}P M_{2.5} \\
\left(\mu g / m^{3}\right)\end{array}$ \\
\hline 1 & 6 & $4 \times 3$ & Urban & 4354 & 27.5 & 100 & 1.8 & 3.0 & 30 & 54 \\
\hline 2 & 29 & $4 \times 3$ & CBD & 5150 & -5 & 1 & 1 & 16.9 & 110 & 285 \\
\hline 3 & 3 & $3 \times 4$ & CBD & 5490 & -25 & 5 & 1.8 & 29.4 & 90 & 214 \\
\hline 4 & 28 & $3 \times 4$ & CBD & 5084 & 40 & 30 & 1.8 & 11.0 & 50 & 112 \\
\hline 5 & 18 & $4 \times 3$ & CBD & 5016 & 32.5 & 5 & 1.8 & 9.9 & 80 & 224 \\
\hline 6 & 29 & $4 \times 3$ & CBD & 5150 & -5 & 5 & 1.8 & 10.5 & 70 & 192 \\
\hline 7 & 2 & $3 \times 3$ & Urban & 4568 & 40 & 50 & 1.8 & 3.4 & 30 & 85 \\
\hline 8 & 12 & $4 \times 3$ & Urban & 5490 & 40 & 5 & 1.8 & 16.5 & 110 & 258 \\
\hline 9 & 6 & $4 \times 3$ & Urban & 4354 & 27.5 & 2.5 & 1 & 12.6 & 110 & 221 \\
\hline 10 & 12 & $4 \times 3$ & Urban & 5490 & 40 & 2.5 & 1.8 & 21.2 & 120 & 324 \\
\hline 11 & 3 & $3 \times 4$ & CBD & 5490 & -25 & 5 & 4 & 26.7 & 90 & 192 \\
\hline 12 & 2 & $3 \times 3$ & Urban & 4568 & 40 & 5 & 7 & 8 & 70 & 173 \\
\hline 13 & 12 & $4 \times 3$ & Urban & 5490 & 40 & 1 & 1.8 & 27.4 & 150 & 376 \\
\hline
\end{tabular}




\begin{tabular}{|c|c|c|c|c|c|c|c|c|c|c|}
\hline 14 & 28 & $3 \times 4$ & CBD & 5084 & 40 & 50 & 1.8 & $\mathbf{8 . 7}$ & $\mathbf{4 0}$ & $\mathbf{8 8}$ \\
\hline 15 & 18 & $4 \times 3$ & CBD & 5016 & 32.5 & 5 & 1 & $\mathbf{1 0 . 1}$ & $\mathbf{8 0}$ & $\mathbf{2 2 7}$ \\
\hline 16 & 2 & $3 \times 3$ & Urban & 4568 & 40 & 5 & 1.8 & $\mathbf{8 . 4}$ & $\mathbf{7 0}$ & $\mathbf{2 1 7}$ \\
\hline 17 & 18 & $4 \times 3$ & CBD & 5016 & 32.5 & 2.5 & 1.8 & $\mathbf{1 2 . 6}$ & $\mathbf{1 0 0}$ & $\mathbf{2 8 1}$ \\
\hline 18 & 3 & $3 \times 4$ & CBD & 5490 & -25 & 100 & 1.8 & $\mathbf{9 . 2}$ & $\mathbf{3 0}$ & $\mathbf{6 6}$ \\
\hline 19 & 12 & $4 \times 3$ & Urban & 5490 & 40 & 5 & 1 & $\mathbf{1 6 . 8}$ & $\mathbf{1 1 0}$ & $\mathbf{2 6 1}$ \\
\hline 20 & 2 & $3 \times 3$ & Urban & 4568 & 40 & 0 & 0 & $\mathbf{1 8 . 3}$ & $\mathbf{1 5 0}$ & $\mathbf{3 9 4}$ \\
\hline 21 & 3 & $3 \times 4$ & CBD & 5490 & -25 & 1 & 1.8 & $\mathbf{3 9 . 8}$ & $\mathbf{1 2 0}$ & $\mathbf{2 8 3}$ \\
\hline 22 & 12 & $4 \times 3$ & Urban & 5490 & 40 & 50 & 1.8 & $\mathbf{6 . 3}$ & $\mathbf{4 0}$ & $\mathbf{9 9}$ \\
\hline 23 & 6 & $4 \times 3$ & Urban & 4354 & 27.5 & 15 & 1.8 & $\mathbf{6 . 8}$ & $\mathbf{6 0}$ & $\mathbf{1 2 7}$ \\
\hline 24 & 28 & $3 \times 4$ & CBD & 5084 & 40 & 0 & 1.8 & $\mathbf{3 8 . 5}$ & $\mathbf{1 6 0}$ & $\mathbf{3 3 4}$ \\
\hline 25 & 29 & $4 \times 3$ & CBD & 5150 & -5 & 15 & 1.8 & $\mathbf{7 . 0}$ & $\mathbf{5 0}$ & $\mathbf{1 3 9}$ \\
\hline 26 & 18 & $4 \times 3$ & CBD & 5016 & 32.5 & 10 & 1.8 & $\mathbf{7 . 8}$ & $\mathbf{7 0}$ & $\mathbf{1 8 5}$ \\
\hline 27 & 29 & $4 \times 3$ & CBD & 5150 & -5 & 0 & 0 & $\mathbf{1 9 . 3}$ & $\mathbf{1 2 0}$ & $\mathbf{3 1 6}$ \\
\hline 28 & 2 & $3 \times 3$ & Urban & 4568 & 40 & 15 & 1.8 & $\mathbf{5 . 9}$ & $\mathbf{5 0}$ & $\mathbf{1 5 7}$ \\
\hline 29 & 21 & $3 \times 4$ & Urban & 4892 & 50 & 30 & 1.8 & $\mathbf{5 . 8}$ & $\mathbf{5 0}$ & $\mathbf{1 1 2}$ \\
\hline 30 & 6 & $4 \times 3$ & Urban & 4354 & 27.5 & 5 & 1.8 & $\mathbf{1 0 . 0}$ & $\mathbf{9 0}$ & $\mathbf{1 7 9}$ \\
\hline
\end{tabular}

Table 10-7: Pollution concentrations for an intersection with arterial road vs collector road with three way crossing (' $\mathrm{T}$ ' type)

\begin{tabular}{|c|c|c|c|c|c|c|c|c|c|c|}
\hline & \multicolumn{7}{|c|}{ INPUT } & \multicolumn{3}{|c|}{ OUTPUT } \\
\hline $\begin{array}{l}\text { S.L. } \\
\text { No. }\end{array}$ & 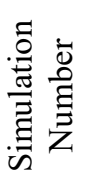 & 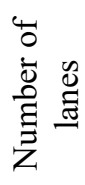 & $\begin{array}{c}\text { Land } \\
\text { Use }\end{array}$ & $\begin{array}{l}\text { Traffic } \\
\text { Volume }\end{array}$ & 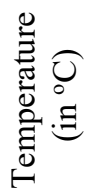 & 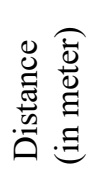 & 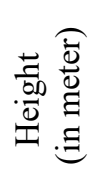 & $\begin{array}{l}\text { CO } \\
\text { (ppm) }\end{array}$ & $\begin{array}{l}\mathrm{NO}_{2} \\
(p p b)\end{array}$ & $\begin{array}{l}P M_{2.5} \\
\left(\mu g / m^{3}\right)\end{array}$ \\
\hline 1 & 1 & $3 \times 2$ & CBD & 5085 & 32.5 & 1 & 1.8 & 50.8 & 180 & 258 \\
\hline 2 & 20 & $2 \times 3$ & CBD & 5168 & 15 & 1 & 1 & 16.7 & 110 & 373 \\
\hline 3 & 3 & $2 \times 3$ & CBD & 5168 & -25 & 5 & 4 & 28.5 & 90 & 233 \\
\hline 4 & 3 & $2 \times 3$ & CBD & 5168 & -25 & 30 & 1.8 & 17.6 & 70 & 129 \\
\hline 5 & 1 & $3 \times 2$ & CBD & 5085 & 32.5 & 5 & 4 & 29.6 & 120 & 220 \\
\hline 6 & 29 & $3 \times 2$ & CBD & 5168 & -5 & 5 & 1.8 & 11.6 & 80 & 257 \\
\hline
\end{tabular}




\begin{tabular}{|c|c|c|c|c|c|c|c|c|c|c|}
\hline 7 & 4 & $2 \times 2$ & Urban & 5350 & 40 & 50 & 1.8 & 5.8 & 50 & 104 \\
\hline 8 & 20 & $2 \times 3$ & CBD & 5168 & 15 & 5 & 1.8 & 11.3 & 100 & 261 \\
\hline 9 & 23 & $4 \times 2$ & CBD & 5538 & 22.5 & 0 & 0 & 23.9 & 130 & 461 \\
\hline 10 & 29 & $3 \times 2$ & CBD & 5168 & -5 & 15 & 1.8 & 8.6 & 70 & 176 \\
\hline 11 & 4 & $2 \times 2$ & Urban & 5350 & 40 & 5 & 1.8 & 14.1 & 100 & 292 \\
\hline 12 & 24 & $3 \times 2$ & CBD & 5620 & 27.5 & 1 & 1 & 29.1 & 120 & 391 \\
\hline 13 & 2 & $3 \times 3$ & Urban & 5830 & 40 & 5 & 7 & 12.4 & 70 & 224 \\
\hline 14 & 2 & $3 \times 3$ & Urban & 5830 & 40 & 50 & 1.8 & 6.6 & 50 & 122 \\
\hline 15 & $8 \mathrm{R}$ & $3 \times 2$ & Urban & 5085 & -5 & 5 & 1 & 19.1 & 80 & 257 \\
\hline 16 & $8 \mathrm{R}$ & $3 \times 2$ & Urban & 5085 & -5 & 0 & 1.8 & 32.7 & 120 & 383 \\
\hline 17 & 18 & $4 \times 2$ & CBD & 5538 & 32.5 & 5 & 1.8 & 13.2 & 110 & 278 \\
\hline 18 & 1 & $3 \times 2$ & CBD & 5085 & 32.5 & 100 & 1.8 & 11.3 & 50 & 18 \\
\hline 19 & $8 \mathrm{~L}$ & $2 \times 2$ & Urban & 5350 & -5 & 0 & 1.8 & 35.5 & 120 & 408 \\
\hline 20 & $8 \mathrm{~L}$ & $2 \times 2$ & Urban & 5350 & -5 & 5 & 1 & 21 & 90 & 275 \\
\hline 21 & 4 & $2 \times 2$ & Urban & 5350 & 40 & 0 & 0 & 30.1 & 160 & 501 \\
\hline 22 & 23 & $4 \times 2$ & CBD & 5538 & 22.5 & 2.5 & 1.8 & 15.3 & 90 & 339 \\
\hline 23 & 3 & $2 \times 3$ & CBD & 5168 & -25 & 15 & 1.8 & 23.2 & 80 & 170 \\
\hline 24 & 6 & $3 \times 2$ & Urban & 5444 & 27.5 & 100 & 1.8 & 2.1 & 30 & 73 \\
\hline 25 & 18 & $4 \times 2$ & CBD & 5538 & 32.5 & 2.5 & 1.8 & 15.8 & 120 & 335 \\
\hline 26 & 24 & $3 \times 2$ & CBD & 5620 & 27.5 & 100 & 1.8 & 5.2 & 30 & 72 \\
\hline 27 & 20 & $2 \times 3$ & CBD & 5168 & 15 & 0 & 0 & 19.9 & 120 & 427 \\
\hline 28 & 3 & $2 \times 3$ & CBD & 5168 & -25 & 1 & 1.8 & 47.1 & 130 & 357 \\
\hline 29 & 23 & $4 \times 2$ & CBD & 5538 & 22.5 & 1 & 1.8 & 19.3 & 110 & 391 \\
\hline 30 & 6 & $3 \times 2$ & Urban & 5444 & 27.5 & 2.5 & 1 & 10.4 & 90 & 367 \\
\hline
\end{tabular}

Table 10-8: Pollution concentrations for an intersection with collector road vs collector road with four way crossing (4-leg type) 


\begin{tabular}{|c|c|c|c|c|c|c|c|c|c|c|}
\hline $\begin{array}{l}\text { S.L. } \\
\text { No. }\end{array}$ & 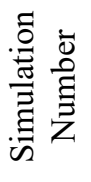 & 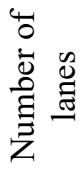 & $\begin{array}{l}\text { Land } \\
\text { Use }\end{array}$ & $\begin{array}{l}\text { Traffic } \\
\text { Volume }\end{array}$ & 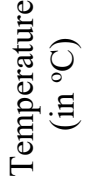 & 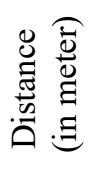 & 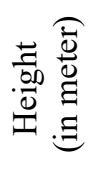 & $\begin{array}{l}\text { CO } \\
(\text { ppm) }\end{array}$ & $\begin{array}{l}\mathrm{NO}_{2} \\
(p p b)\end{array}$ & $\begin{array}{l}P M_{2.5} \\
\left(\mu g / m^{3}\right)\end{array}$ \\
\hline 1 & 19 & $3 \times 2$ & CBD & 4136 & 40 & 0 & 0 & 57.1 & 180 & 342 \\
\hline 2 & 19 & $3 \times 2$ & CBD & 4136 & 40 & 1 & 1 & 46.6 & 150 & 296 \\
\hline 3 & 27 & $3 \times 2$ & Urban & 3304 & 40 & 5 & 1.8 & 16.7 & 100 & 139 \\
\hline 4 & 19 & $3 \times 2$ & CBD & 4136 & 40 & 30 & 1.8 & 16.7 & 50 & 99 \\
\hline 5 & 19 & $3 \times 2$ & CBD & 4136 & 40 & 5 & 4 & 27.6 & 90 & 187 \\
\hline 6 & 27 & $3 \times 2$ & Urban & 3304 & 40 & 5 & 4 & 14.9 & 90 & 126 \\
\hline 7 & 19 & $3 \times 2$ & CBD & 4136 & 40 & 50 & 1.8 & 10.3 & 40 & 74 \\
\hline 8 & 27 & $3 \times 2$ & Urban & 3304 & 40 & 0 & 1.8 & 27.1 & 150 & 206 \\
\hline 9 & 19 & $3 \times 2$ & CBD & 4136 & 40 & 0 & 1.8 & 53.7 & 170 & 316 \\
\hline 10 & 27 & $3 \times 2$ & Urban & 3304 & 40 & 2.5 & 1.8 & 20.3 & 120 & 161 \\
\hline 11 & 19 & $3 \times 2$ & CBD & 4136 & 40 & 5 & 1 & 28.8 & 100 & 205 \\
\hline 12 & 19 & $3 \times 2$ & CBD & 4136 & 40 & 5 & 7 & 25.5 & 80 & 154 \\
\hline 13 & 27 & $3 \times 2$ & Urban & 3304 & 40 & 1 & 1.8 & 24.3 & 140 & 188 \\
\hline 14 & 27 & $3 \times 2$ & Urban & 3304 & 40 & 50 & 1.8 & 6.6 & 40 & 56 \\
\hline 15 & 19 & $3 \times 2$ & CBD & 4136 & 40 & 10 & 1.8 & 21.8 & 80 & 156 \\
\hline 16 & 27 & $3 \times 2$ & Urban & 3304 & 40 & 30 & 1.8 & 8.3 & 50 & 72 \\
\hline 17 & 19 & $3 \times 2$ & CBD & 4136 & 40 & 2.5 & 1 & 36.0 & 120 & 249 \\
\hline 18 & 27 & $3 \times 2$ & Urban & 3304 & 40 & 100 & 1.8 & 5.0 & 30 & 40 \\
\hline 19 & 19 & $3 \times 2$ & CBD & 4136 & 40 & 15 & 1.8 & 18.5 & 70 & 138 \\
\hline 20 & 27 & $3 \times 2$ & Urban & 3304 & 40 & 15 & 1.8 & 11.2 & 70 & 95 \\
\hline 21 & 13 & $3 \times 2$ & CBD & 4136 & 15 & 100 & 1.8 & 4.2 & 30 & 49 \\
\hline 22 & 13 & $3 \times 2$ & CBD & 4136 & 15 & 2.5 & 1.8 & 20.2 & 110 & 244 \\
\hline 23 & 19 & $3 \times 2$ & CBD & 4136 & 40 & 20 & 1.8 & 16.2 & 60 & 122 \\
\hline 24 & 27 & $3 \times 2$ & Urban & 3304 & 40 & 10 & 1.8 & 18.4 & 80 & 113 \\
\hline 25 & 13 & $3 \times 2$ & CBD & 4136 & 15 & 1 & 1.8 & 25.8 & - & 286 \\
\hline 26 & 13 & $3 \times 2$ & CBD & 4136 & 15 & 10 & 1.8 & 12.4 & 70 & 156 \\
\hline 27 & 27 & $3 \times 2$ & Urban & 3304 & 40 & 0 & 0 & 30.2 & 160 & 228 \\
\hline
\end{tabular}




\begin{tabular}{|c|c|c|c|c|c|c|c|c|c|c|}
\hline 28 & 19 & $3 \times 2$ & CBD & 4136 & 40 & 10 & 4 & $\mathbf{2 1 . 4}$ & $\mathbf{7 0}$ & $\mathbf{1 4 4}$ \\
\hline 29 & 13 & $3 \times 2$ & CBD & 4136 & 15 & 30 & 1.8 & $\mathbf{7 . 6}$ & $\mathbf{4 0}$ & $\mathbf{9 9}$ \\
\hline 30 & 19 & $3 \times 2$ & CBD & 4136 & 40 & 5 & 1.8 & $\mathbf{2 8 . 6}$ & $\mathbf{1 0 0}$ & $\mathbf{2 0 2}$ \\
\hline
\end{tabular}

Table 10-9: Pollution concentrations for an intersection with collector road vs collector road with three way crossing (' $T$ ' type)

\begin{tabular}{|c|c|c|c|c|c|c|c|c|c|c|}
\hline & \multicolumn{7}{|c|}{ INPUT } & \multicolumn{3}{|c|}{ OUTPUT } \\
\hline $\begin{array}{l}\text { S.L. } \\
\text { No. }\end{array}$ & 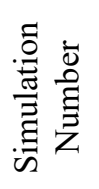 & 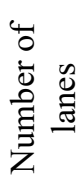 & $\begin{array}{l}\text { Land } \\
\text { Use }\end{array}$ & $\begin{array}{l}\text { Traffic } \\
\text { Volume }\end{array}$ & 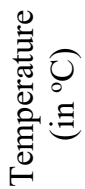 & 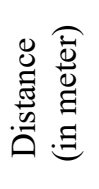 & 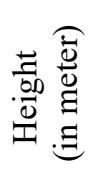 & $\begin{array}{l}\text { CO } \\
(\text { ppm) }\end{array}$ & $\begin{array}{l}\mathrm{NO}_{2} \\
(p p b)\end{array}$ & $\begin{array}{l}P M_{2.5} \\
\left(\mu g / m^{3}\right)\end{array}$ \\
\hline 1 & 25 & $3 \times 2$ & Urban & 4818 & 40 & 20 & 1.8 & 17.4 & 90 & 147 \\
\hline 2 & 22 & $2 \times 2$ & CBD & 3411 & 5 & 1 & 1 & 24.6 & 120 & 266 \\
\hline 3 & $26 \mathrm{R}$ & $2 \times 2$ & CBD & 2855 & -15 & 5 & 1.8 & 24.5 & 80 & 156 \\
\hline 4 & $26 \mathrm{~L}$ & $3 \times 2$ & CBD & 4289 & -15 & 30 & 1.8 & 19.6 & 60 & 112 \\
\hline 5 & 22 & $2 \times 2$ & CBD & 3411 & 5 & 5 & 4 & 13.7 & 80 & 156 \\
\hline 6 & $26 \mathrm{R}$ & $2 \times 2$ & CBD & 2855 & -15 & 5 & 4 & 20.1 & 70 & 123 \\
\hline 7 & 22 & $2 \times 2$ & CBD & 3411 & 5 & 50 & 1.8 & 7.0 & 50 & 75 \\
\hline 8 & $26 \mathrm{~L}$ & $3 \times 2$ & CBD & 4289 & -15 & 5 & 1.8 & 34.5 & 100 & 208 \\
\hline 9 & 25 & $3 \times 2$ & Urban & 4818 & 40 & 0 & 0 & 50.8 & 180 & 417 \\
\hline 10 & 25 & $3 \times 2$ & Urban & 4818 & 40 & 2.5 & 1.8 & 33.4 & 140 & 296 \\
\hline 11 & $26 \mathrm{R}$ & $2 \times 2$ & CBD & 2855 & -15 & 5 & 1 & 25.4 & 90 & 162 \\
\hline 12 & 25 & $3 \times 2$ & Urban & 4818 & 40 & 5 & 7 & 22.7 & 80 & 188 \\
\hline 13 & $26 \mathrm{~L}$ & $3 \times 2$ & CBD & 4289 & -15 & 1 & 1.8 & 55.6 & 130 & 294 \\
\hline 14 & 22 & $2 \times 2$ & CBD & 3411 & 5 & 20 & 1.8 & 10.4 & 70 & 114 \\
\hline 15 & 20 & $3 \times 3$ & CBD & 4020 & 15 & 5 & 1 & 30.9 & 130 & 234 \\
\hline 16 & 27 & $2 \times 2$ & Urban & 2987 & 40 & 5 & 1.8 & 18.4 & 110 & 162 \\
\hline 17 & $26 \mathrm{R}$ & $2 \times 2$ & CBD & 2855 & -15 & 2.5 & 1.8 & 27.3 & 90 & 170 \\
\hline 18 & 21 & $2 \times 2$ & Urban & 2861 & 50 & 1 & 1 & 24.0 & 150 & 231 \\
\hline 19 & 27 & $2 \times 2$ & Urban & 2987 & 40 & 10 & 1.8 & 15.7 & 100 & 142 \\
\hline 20 & 22 & $2 \times 2$ & CBD & 3411 & 5 & 15 & 1.8 & 11.6 & 70 & 126 \\
\hline
\end{tabular}




\begin{tabular}{|c|c|c|c|c|c|c|c|c|c|c|}
\hline 21 & $26 \mathrm{R}$ & $2 \times 2$ & CBD & 2855 & -15 & 100 & 1.8 & $\mathbf{7 . 5}$ & $\mathbf{3 0}$ & $\mathbf{4 2}$ \\
\hline 22 & 21 & $2 \times 2$ & Urban & 2861 & 50 & 2.5 & 1.8 & $\mathbf{2 0 . 7}$ & $\mathbf{1 3 0}$ & $\mathbf{2 0 5}$ \\
\hline 23 & 27 & $2 \times 2$ & Urban & 2987 & 40 & 15 & 1.8 & $\mathbf{1 3 . 9}$ & $\mathbf{9 0}$ & $\mathbf{1 2 2}$ \\
\hline 24 & 21 & $2 \times 2$ & Urban & 2861 & 50 & 1 & 1.8 & $\mathbf{2 2 . 2}$ & $\mathbf{1 4 0}$ & $\mathbf{2 1 6}$ \\
\hline 25 & 25 & $3 \times 2$ & Urban & 4818 & 40 & 1 & 1.8 & $\mathbf{4 4 . 2}$ & $\mathbf{1 6 0}$ & $\mathbf{3 5 0}$ \\
\hline 26 & 25 & $3 \times 2$ & Urban & 4818 & 40 & 10 & 1.8 & $\mathbf{2 2 . 2}$ & $\mathbf{1 1 0}$ & $\mathbf{1 9 5}$ \\
\hline 27 & 20 & $3 \times 3$ & CBD & 4020 & 15 & 0 & 0 & $\mathbf{4 1 . 5}$ & $\mathbf{1 6 0}$ & $\mathbf{2 9 6}$ \\
\hline 28 & $26 \mathrm{~L}$ & $3 \times 2$ & CBD & 4289 & -15 & 15 & 1.8 & $\mathbf{2 5 . 9}$ & $\mathbf{8 0}$ & $\mathbf{1 5 1}$ \\
\hline 29 & 25 & $3 \times 2$ & Urban & 4818 & 40 & 30 & 1.8 & $\mathbf{1 4 . 7}$ & $\mathbf{7 0}$ & $\mathbf{1 2 5}$ \\
\hline 30 & 27 & $2 \times 2$ & Urban & 2987 & 40 & 2.5 & 1 & $\mathbf{2 2 . 2}$ & $\mathbf{1 2 0}$ & $\mathbf{1 9 8}$ \\
\hline
\end{tabular}

\subsection{SIMULATION RESULTS FOR FREEWAY}

Table 10-10 shows inputs for 30 simulation runs and their corresponding outputs. In this table, traffic capacity for the simulated freeway segment is $2 \times 7188$ vehicles $/ \mathrm{h}$. The composite emission factor for $\mathrm{CO}=136.042 \mathrm{~g} / \mathrm{veh}-\mathrm{mile}$, for $\mathrm{NO}_{\mathrm{x}}=4.362 \mathrm{~g} / \mathrm{veh}-\mathrm{mile}$, and for $P M_{2.5}=1.0 \mathrm{~g} / \mathrm{veh}$-mile. Using these emission factors for gaseous and dust pollutants, the pollution concentrations were calculated and shown in Table 10-10.

Table 10-10: Input variables and their corresponding outputs

\begin{tabular}{|c|c|c|c|c|c|c|c|}
\hline Simulation & \multicolumn{4}{|c|}{ INPUTS } & \multicolumn{3}{|c|}{ OUTPUTS } \\
\hline $\begin{array}{l}\text { Number/ } \\
\text { Sample } \\
\text { Number }\end{array}$ & $\begin{array}{l}\text { Traffic } \\
\text { volume }\end{array}$ & 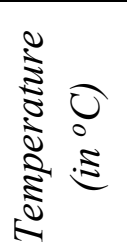 & 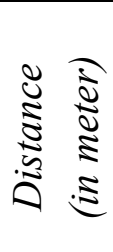 & 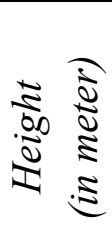 & $\begin{array}{c}C O \\
(p p m)\end{array}$ & $\begin{array}{l}\mathrm{NO}_{2} \\
(p p b)\end{array}$ & $\begin{array}{c}P M_{2.5} \\
\left(\mu g / m^{3}\right)\end{array}$ \\
\hline 1 & 14376 & 27.5 & 10 & 0 & 148.5 & 270 & 976 \\
\hline 2 & 14376 & 27.5 & 50 & 1.8 & 87.9 & 160 & 538 \\
\hline 3 & 14376 & -5 & 20 & 6 & 107.9 & 200 & 752 \\
\hline 4 & 14376 & 40 & 30 & 1.8 & 111.9 & 200 & 702 \\
\hline 5 & 14376 & 27.5 & 100 & 1.8 & 60.9 & 110 & 391 \\
\hline 6 & 14376 & 40 & 500 & 1.8 & 18.7 & 30 & 103 \\
\hline
\end{tabular}




\begin{tabular}{|c|c|c|c|c|c|c|c|}
\hline 7 & 14376 & -25 & 20 & 6 & $\mathbf{9 9 . 8}$ & $\mathbf{1 8 0}$ & $\mathbf{7 5 2}$ \\
\hline 8 & 14376 & 22.5 & 10 & 0 & $\mathbf{1 4 6 . 1}$ & $\mathbf{2 6 0}$ & $\mathbf{9 7 6}$ \\
\hline 9 & 14376 & 5 & 100 & 1.8 & $\mathbf{5 6 . 3}$ & $\mathbf{1 0 0}$ & $\mathbf{3 9 1}$ \\
\hline 10 & 14376 & 22.5 & 500 & 1.8 & $\mathbf{1 7 . 7}$ & $\mathbf{3 0}$ & $\mathbf{1 0 3}$ \\
\hline 11 & 14376 & 40 & 50 & 1.8 & $\mathbf{9 1 . 6}$ & $\mathbf{1 6 0}$ & $\mathbf{5 3 9}$ \\
\hline 12 & 14376 & 5 & 20 & 6 & $\mathbf{1 1 1 . 9}$ & $\mathbf{2 0 0}$ & $\mathbf{7 5 2}$ \\
\hline 13 & 14376 & -25 & 40 & 1.8 & $\mathbf{7 9 . 8}$ & $\mathbf{1 5 0}$ & $\mathbf{6 1 1}$ \\
\hline 14 & 14376 & 15 & 30 & 1.8 & $\mathbf{1 0 3}$ & $\mathbf{1 9 0}$ & $\mathbf{7 0 2}$ \\
\hline 15 & 14376 & 50 & 100 & 1.8 & $\mathbf{6 5 . 4}$ & $\mathbf{1 2 0}$ & $\mathbf{3 9 1}$ \\
\hline 16 & 14376 & -15 & 100 & 1.8 & $\mathbf{5 2 . 3}$ & $\mathbf{1 0 0}$ & $\mathbf{3 9 1}$ \\
\hline 17 & 14376 & 22.5 & 200 & 1.8 & $\mathbf{3 6 . 2}$ & $\mathbf{7 0}$ & $\mathbf{2 3 2}$ \\
\hline 18 & 14376 & -5 & 50 & 1.8 & $\mathbf{7 8 . 4}$ & $\mathbf{1 4 0}$ & $\mathbf{5 3 9}$ \\
\hline 19 & 14376 & 5 & 40 & 1.8 & $\mathbf{8 9 . 5}$ & $\mathbf{1 6 0}$ & $\mathbf{6 1 1}$ \\
\hline 20 & 14376 & 50 & 10 & 1.8 & $\mathbf{1 5 9 . 1}$ & $\mathbf{2 8 0}$ & $\mathbf{9 6 4}$ \\
\hline 21 & 14376 & 32.5 & 30 & 1.8 & $\mathbf{1 0 9 . 2}$ & $\mathbf{2 0 0}$ & $\mathbf{7 0 2}$ \\
\hline 22 & 14376 & -15 & 20 & 3 & $\mathbf{1 0 5 . 6}$ & $\mathbf{1 9 0}$ & $\mathbf{8 0 5}$ \\
\hline 23 & 14376 & 22.5 & 20 & 6 & $\mathbf{1 1 9}$ & $\mathbf{2 1 0}$ & $\mathbf{7 5 2}$ \\
\hline 24 & 14376 & 27.5 & 20 & 3 & $\mathbf{1 2 3}$ & $\mathbf{2 2 0}$ & $\mathbf{8 0 5}$ \\
\hline 25 & 14376 & 50 & 30 & 1.8 & $\mathbf{1 1 5 . 5}$ & $\mathbf{2 1 0}$ & $\mathbf{7 0 2}$ \\
\hline 26 & 14376 & 50 & 500 & 1.8 & $\mathbf{1 9 . 3}$ & $\mathbf{3 0}$ & $\mathbf{1 0 3}$ \\
\hline 27 & 14376 & -25 & 100 & 1.8 & $\mathbf{5 0 . 2}$ & $\mathbf{9 0}$ & $\mathbf{3 9 1}$ \\
\hline 28 & 14376 & 50 & 40 & 1.8 & $\mathbf{1 0 3 . 9}$ & $\mathbf{1 9 0}$ & $\mathbf{6 1 1}$ \\
\hline 29 & 14376 & 40 & 100 & 1.8 & $\mathbf{6 3 . 4}$ & $\mathbf{1 1 0}$ & $\mathbf{3 9 1}$ \\
\hline 30 & 14376 & 50 & 20 & 6 & $\mathbf{1 3 0}$ & $\mathbf{2 3 0}$ & $\mathbf{7 5 2}$ \\
\hline
\end{tabular}

There are thirty simulation results in the above table. The last three columns represent outputs for three pollutants. Among the above simulation results, sample number three is illustrated below for $\mathrm{PM}_{2.5}$ pollution concentrations. 


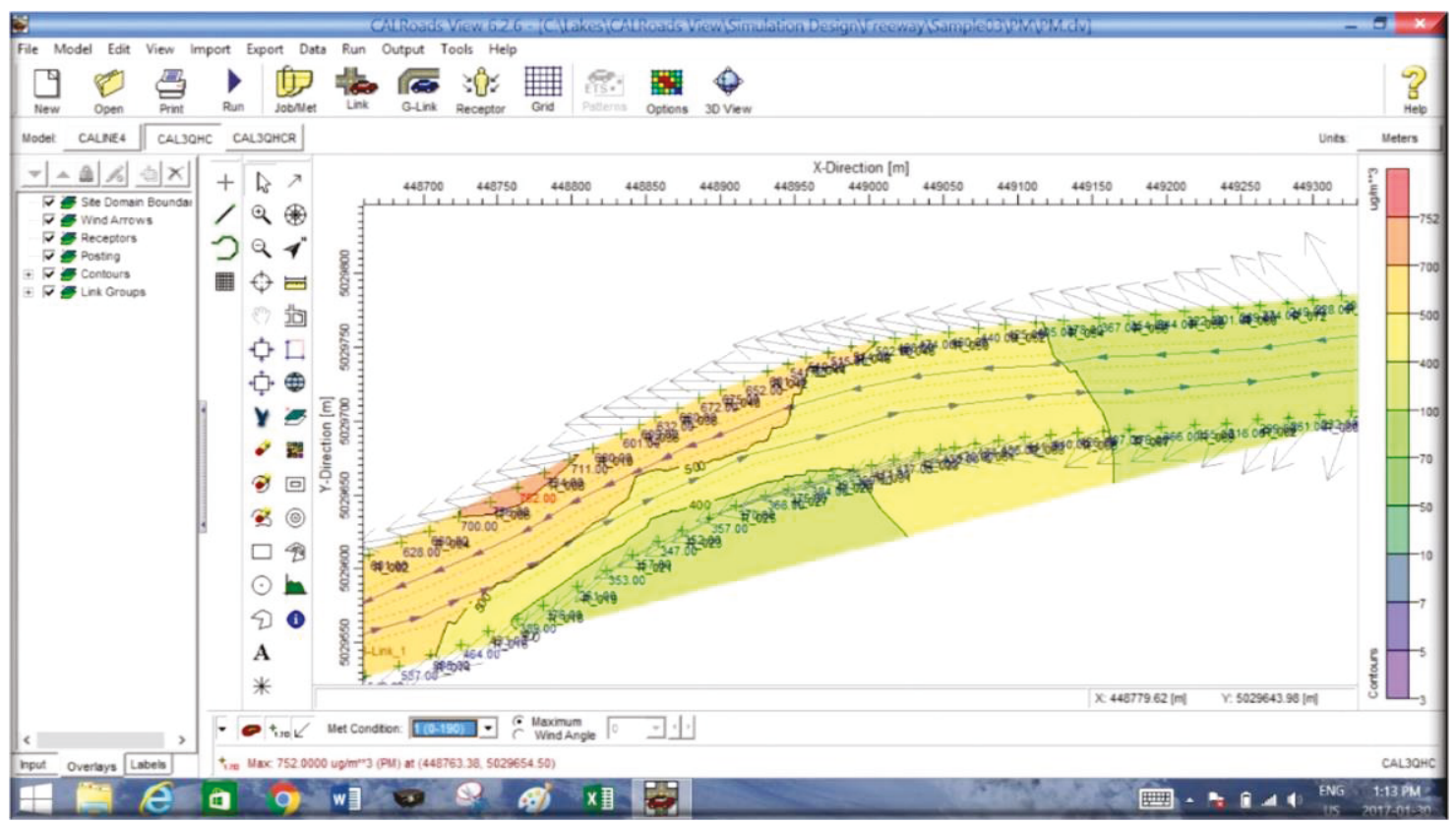

Figure 10-3: Simulation run for sample number three for PM2.5 concentrations

Figure 10-3 illustrates that the maximum $\mathrm{PM}_{2.5}$ concentration is 752 micro-gram per cubic meter. The maximum concentration location (long/ latitude) is displayed at the bottom of the map. Appendix XII shows the model results, where receptor seven has maximum concentration. 


\section{Chapter 11: STATISTICAL MODEL DEVELOPMENT}

\subsection{INTRUDUCTION}

Simulation results were used to develop linear as well as non-linear statistical models. Also in selected cases, regression models were compared with the artificial neural network (ANN) models. The comparison of regression model vs ANN model is presented at the end of this chapter.

Regression model are developed based on simulation results and simulations are designed under worst-case traffic and wind conditions. The regression equations can be developed based on field observed data, but worst-case condition will not be represented in such models. The purpose of predictive model development was to incorporate the air quality criterion in land use planning for sustainable development. The observed data will not fulfill the purpose of this research.

The developed models can be used by planners in any location in North America (i.e. Canada and USA), because the emission models are developed based on valid variables and their values obtained from scientific methods. For other regions of the world, it is important to check inputs.

The developed models are original and no known research has ever developed such models for use by professionals in the field. An attempt was made to avoid unnecessary sophistication of model form for the reason that these are mainly intended for use by planners and municipal officials. These models have the capability to explain the 
phenomenon of variation in emission concentrations with respect to known causal factors. In addition, these can serve as predictive tools to produce answers required to questions regarding the implementation of air quality standards.

\subsection{TYPES OF EQUATIONS}

Several types of regression equations can be developed. The simple and straight forward, but most useful regression model for use by professionals in the field is the linear regression model. In some cases, if the data do not result in a promising linear regression model, nonlinear models can be investigated.

\subsection{MULTIPLE LINEAR REGRESSION EQUATIONS}

The initial step carried out was the study of simple correlations between variables. These were useful for obtaining ideas on the types of equations to be developed and to be aware of the problem of multi-collinearity.

There are several statistical software packages available in the market for the development of regression equations and ANN models. Following a check on software capability and availability on campus, the SPSS software was selected for model development. In simulation results table, pollution concentrations $\left(\mathrm{CO}, \mathrm{NO}_{2}, \mathrm{PM}_{2.5}\right)$ become the dependent variables. It is intended to use these variables in association with independent variables to develop models with the capability to predict these pollutants for specified inputs. The independent variables are capacity level traffic, land use, temperature, distance from road edge, and height from road surface, etc. 
Initially, linear regression equations were studied. The following multi-linear regression equations were developed for roadside pollutants. These equations are broadly classified as freeway and urban road models.

\subsubsection{Linear Regression Equations for Freeway}

Three equations represent three different pollutants. The independent variables are shown in the statistical model with their coefficients. The multiple correlation coefficient (R) and the co-efficient of determination $\left(\mathrm{R}^{2}\right)$ are the indicators of goodness of fit.

$\mathrm{CO}=94.889-0.224$ Distance +2.173 Height +0.488 Temperature, where $R=0.850 R^{2}=0.722$

$\mathrm{NO}_{2}=173.504-0.409$ Distance +3.461 Height +0.820 Temperature, whereas $R=0.856$

$\mathrm{PM}_{2.5}=666.523-1.445$ Distance +11.149 Height +1.224 Temperature, whereas $R=0.833$

It is noted that capacity level traffic is not included in the equation since it is held constant. However, the effect of traffic is included in the above models.

\subsubsection{Multiple Linear Regression Equations for Urban Road Network}

Linear regression equations were developed for urban road network. Equations are further classified into two different groups. The first group represents the equations for road links, such as arterial road and collector road. The second group applies to intersection types.

\subsubsection{Linear Regression Equations Urban Roads}

$\underline{\text { Arterial Road }}$ 
CO Pollution Concentration $=2.204+0.009$ Traffic Volume -5.795 Land Use -0.239 Temperature -0.262 Crossword Distance -2.120 Height

Whereas, $R=0.666, R^{2}=0.443$ and " $t$ " values are: for Constant $=0.111$, Land use $(L U)=-0.849$, Traffic $=$ 2.521, Temperature $=-1.070$, Distance $=-2.390$, and Height $=-0.758$

$\mathrm{NO}_{2}$ Concentration $=67.350+0.013$ Traffic Volume +2.716 Land Use +0.149 Temperature - 1.069 Crossword Distance - 9.014 Height

Whereas, $R=0.798, R^{2}=0.638$ and " $t$ " values are: for Const. $=1.937, L U=0.228$, Traffic $=1.942$, Temp. $=$ 0.381, Distance $=-5.577$, and Height $=-1.845$

$\mathrm{PM}_{2.5}$ Concentration $=92.950+0.078$ Traffic Volume +4.861 Land Use -0.495 Temperature - 3.041 Crossword Distance - 26.305 Height

Whereas, $R=0.876, R^{2}=0.768$ and " $t$ " values are: for Const. $=1.058, L U=0.161$, Traffic $=4.694$, Temp.$=$ -0.561, Distance $=-6.282$, and Height $=-2.132$

\section{Collector Road}

CO Pollution Concentration $=10.071+0.007$ Traffic Volume +8.668 Land Use -0.014 Temperature - 0.190 Crossword Distance -5.673 Height

Whereas, $R=0.682, R^{2}=0.465$ and " $t$ " values are: for Const. $=0.921$, Traffic $=2.205, L U=1.036$, Temp. $=$ -0.110, Distance $=-1.674$, and Height $=-2.495$

$\mathrm{NO}_{2}$ Concentration $=74.265+0.012$ Traffic Volume +15.289 Land Use +0.372 Temperature - 0.897 Crossword Distance -15.726 Height 
Whereas, $R=0.743, R^{2}=0.552$ and " $t$ " values are: for Const. $=2.579$, Traffic $=1.452, L U=0.694$, Temp. $=$ 1.096, Distance $=-2.995$, and Height $=-2.627$

$\mathrm{PM}_{2.5}$ Concentration $=111.117+0.066$ Traffic Volume +56.869 Land Use -0.067 Temperature - 2.149 Crossword Distance -35.329 Height

Whereas, $R=0.831, R^{2}=0.691$ and " $t$ " values are: for Const. $=1.912$, Traffic $=3.818, L U=1.279$, Temp. $=$ -0.098, Distance $=-3.555$, and Height $=-2.925$

Linear regression models were developed for both applicable urban roads, namely arterial and collector roads. The statistical significance indicators are reported for each case. The general indicators are $\mathrm{R}$-value and $\mathrm{R}$-square. In addition, $\mathrm{t}$-values for each variable are presented after each statistical equation. Table 11-1 presents a sample statistical report for CO pollutants for the arterial road. Multiple correlation coefficient (R) and co-efficient of determination $\left(\mathrm{R}^{2}\right)$ are noted in the summery part. The model co-efficient and 't-values' are presented in the second part of the table.

Table 11-1: Statistical summary report for CO pollution for urban road

\begin{tabular}{|c|c|c|c|c|c|c|c|c|c|c|c|c|}
\hline \multicolumn{13}{|c|}{ Model Summary ${ }^{b}$} \\
\hline \multirow[b]{2}{*}{ Model } & \multirow[b]{2}{*}{$R$} & \multirow{2}{*}{\multicolumn{2}{|c|}{$\begin{array}{c}R \\
\text { Square }\end{array}$}} & \multirow{2}{*}{\multicolumn{2}{|c|}{$\begin{array}{l}\text { Adjusted } \\
R \text { Square }\end{array}$}} & \multirow{2}{*}{\multicolumn{2}{|c|}{$\begin{array}{c}\text { Std. Error } \\
\text { of the } \\
\text { Estimate }\end{array}$}} & \multicolumn{5}{|c|}{ Change Statistics } \\
\hline & & & & & & & & $\begin{array}{r}R \text { Squa } \\
\text { Chang }\end{array}$ & & $F C$ & hange & $d f 1$ \\
\hline 1 & $.666^{\mathrm{a}}$ & \multicolumn{2}{|c|}{.443} & \multicolumn{2}{|c|}{.327} & \multicolumn{2}{|c|}{18.28887} & .443 & \multicolumn{3}{|c|}{3.818} & 5 \\
\hline \multicolumn{12}{|c|}{ Coefficients $^{a}$} & \\
\hline \multirow{2}{*}{\multicolumn{3}{|c|}{ Model }} & \multicolumn{4}{|c|}{$\begin{array}{c}\text { Unstandardized } \\
\text { Coefficients }\end{array}$} & \multicolumn{2}{|c|}{$\begin{array}{c}\text { Standardized } \\
\text { Coefficients }\end{array}$} & \multirow{2}{*}{\multicolumn{2}{|c|}{$T$}} & \multirow[b]{2}{*}{ Sig. } & \\
\hline & & & \multicolumn{2}{|c|}{$B$} & \multicolumn{2}{|c|}{$\begin{array}{c}\text { Std. } \\
\text { Error }\end{array}$} & \multicolumn{2}{|c|}{ Beta } & & & & \\
\hline \multirow[t]{3}{*}{1} & \multicolumn{2}{|c|}{ (Constant) } & 2.2 & 204 & \multicolumn{2}{|c|}{19.903} & & & \multicolumn{2}{|c|}{.111} & .913 & \\
\hline & \multicolumn{2}{|l|}{$\mathrm{LU}$} & \multicolumn{2}{|c|}{-5.795} & \multicolumn{2}{|c|}{6.826} & \multicolumn{2}{|c|}{-.132} & \multicolumn{2}{|c|}{-.849} & .404 & \\
\hline & \multicolumn{2}{|l|}{ Traffic } & \multicolumn{2}{|c|}{.009} & \multicolumn{2}{|c|}{.004} & \multicolumn{2}{|c|}{.397} & 2.52 & & .019 & \\
\hline
\end{tabular}




\begin{tabular}{|l|l|c|c|c|c|c|}
\hline & $\begin{array}{l}\text { Temperat } \\
\text { ure }\end{array}$ & -.239 & .224 & -.166 & -1.070 & .295 \\
\cline { 2 - 7 } & Distance & -.262 & .110 & -.371 & -2.390 & .025 \\
\cline { 2 - 7 } & Height & -2.120 & 2.795 & -.116 & -.758 & .456 \\
\hline
\end{tabular}

Appendix XIII(A) presents the detail report of linear regression model for $\mathrm{CO}$ pollutants for the collector road. The model summary reports the multiple correlation coefficient (R) and co-efficient of determination $\left(\mathrm{R}^{2}\right)$. The model co-efficient, ' $\mathrm{t}$-values' for independent variables, and correlations are available in the report. The last part of the report illustrates the graphical representations. The histogram chart, normal P-P plot of regression standardized residual chart, and scatter plot show the significance value of the dependent variable. The histogram shows the frequency distribution of data, whereas P-P plot represents the expected values verses observed values.

\subsubsection{Linear Regression Equations for Intersections}

\section{A 4-leg intersection of Arterial Road with Arterial Road}

CO Pollution Concentration $=15.061+0.002$ Traffic Volume +8.821 Land Use -0.008 Temperature -0.418 Crossword Distance -2.919 Height

Where $R=0.894, R^{2}=0.799$ and " $t$ " values are: for Const. $=1.827$, Traffic $=1.620, L U=3.621$, Temp. $=$ 0.100, Distance $=-6.181$, and Height $=-4.325$

$\mathrm{NO}_{2}$ Concentration $=104.382+0.006$ Traffic Volume +23.349 Land Use +0.081 Temperature - 1.918 Crossword Distance - 10.661 Height

Where, $R=0.922, R^{2}=0.849$ and " $t$ " values are: for Const. $=3.897$, Traffic $=1.339, L U=2.950$, Temp. $=$ 0.305, Distance $=-8.733$, and Height $=-4.860$ 
$\mathrm{PM}_{2.5}$ Concentration $=123.207+0.032$ Traffic Volume +31.732 Land Use -0.426 Temperature - 3.701 Crosswind Distance - 23.276 Height

Where, $R=0.936, R^{2}=0.876$ and " $t$ " values are: for Const. $=2.542$, Traffic $=3.848, L U=2.215$, Temp. $=$ 0.893, Distance $=-9.310$, and Height $=-5.864$

\section{A 3-leg (T type) intersection of Arterial Road with Arterial Road}

CO Pollution Concentration $=99.811-0.002$ Traffic Volume -36.194 Land Use -1.665 Temperature - 0.302 Crossword Distance - 3.186 Height

Where, $R=0.854, R^{2}=0.729$ and " $t$ " values are: for Const. $=3.954$, Traffic $=-1.159, L U=-3.992$, Temp. $=$ -3.213, Distance $=-6.412$, and Height $=-2.765$

$\mathrm{NO}_{2}$ Concentration $=279.427-0.008$ Traffic Volume +70.679 Land Use -2.935 Temperature -1.082 Crossword Distance -10.850 Height

Where, $R=0.862, R^{2}=0.742$ and " $t$ " values are: for Const. $=3.627$, Traffic $=-1.217, L U=-2.554$, Temp. $=$ -1.855, Distance $=-7.528$, and Height $=-3.085$

$\mathrm{PM}_{2.5}$ Concentration $=573.390+0.005$ Traffic Volume -117.452 Land Use -7.703 Temperature - 2.891 Crossword Distance - 32.163 Height

Where, $R=0.901, R^{2}=0.811$ and " $t$ " values are: for Const. $=3.174$, Traffic $=0.356, L U=-1.810$, Temp. $=$ -2.076, Distance $=-8.581$, and Height $=-3.900$

A 4-leg intersection of Arterial Road vs Collector Road

CO Pollution Concentration $=(-) 29.241+0.010$ Traffic Volume +1.476 Land Use -0.111 Temperature -0.160 Crossword Distance -0.345 Height 
Whereas, $R=0.716, R^{2}=0.513$ and " $t$ " values are: for Const. $=-1.441$, Traffic $=2.544, L U=0.417$, Temp . $=-1.535$, Distance $=-3.102$, and Height $=0.295$

$\mathrm{NO}_{2}$ Concentration $=2.228+0.021$ Traffic Volume +13.403 Land Use -0.078 Temperature - 0.966 Crossword Distance -7.152 Height

Whereas, $R=0.779, R^{2}=0.609$ and " $t$ " values are: for Const. $=0.032$, Traffic $=1.606, L U=1.097$, Temp. $=$ -0.311, Distance $=-5.428$, and Height $=-1.775$

$\mathrm{PM}_{2.5}$ Concentration $=(-) 10.005+0.056$ Traffic Volume +26.178 Land Use +0.016 Temperature - 2.498 Crossword Distance - 20.447 Height

Where $R=0.823, R^{2}=0.677$ and " $t$ " values are: for Const. $=-0.063$, Traffic $=1.903, L U=0.951$, Temp. $=$ 0.029, Distance $=-6.231$, and Height $=-2.253$

\section{A 3-leg (T type) intersection of Arterial Road vs Collector Road}

CO Pollution Concentration $=101.332-0.015$ Traffic Volume -1.006 Land Use -0.031

Temperature -0.181 Crossword Distance +0.186 Height

Where $R=0.618, R^{2}=0.382$ and " $t$ " values are: for Const. $=1.888$, Traffic $=-1.419, L U=-0.252$, Temp.$=$ -0.301, Distance $=-2.879$, and Height $=0.127$

$\mathrm{NO}_{2}$ Concentration $=333.375-0.041$ Traffic Volume -9.793 Land Use +0.585

Temperature -0.890 Crossword Distance -4.840 Height

Where $R=0.852, R^{2}=0.726$ and " $t$ " values are: for Const. $=3.134$, Traffic $=-2.006, L U=-1.239$, Temp. $=$ 2.849, Distance $=-7.142$, and Height $=-1.658$

$\mathrm{PM}_{2.5}$ Concentration $=(-) 92.433+0.089$ Traffic Volume +8.084 Land Use +0.542

Temperature - 3.330 Crossword Distance - 35.849 Height 
Whereas, $R=0.892, R^{2}=0.795$ and " $t$ " values are: for Const. $=-0.283$, Traffic $=1.419, L U=0.333$, Temp . $=0.860$, Distance $=-8.707$, and Height $=-4.001$

A 4-leg intersection with Collector Road vs Collector Road

CO Pollution Concentration $=19.959+($ Constant Traffic Volume $)-11.295$ Land Use + 0.465 Temperature -0.267 Crossword Distance -2.904 Height

$\mathrm{NO}_{2}$ Concentration $=95.940+($ Constant Traffic Volume $)+1.830$ Land Use +0.913 Temperature - 1.061 Crossword Distance - 10.661 Height

Whereas, $R=0.769, R^{2}=0.592$ and " $t$ " values are: for Const. $=0.3 .948, L U=0.150$, Temp.$=1.427$, Distance $=-4.911$, and Height $=-2.486$

$\mathrm{PM}_{2.5}$ Concentration $=265.189+($ Constant Traffic Volume $)-50.804$ Land Use -0.185 Temperature - 2.217 Crossword Distance - 19.208 Height

Where $R=0.819, R^{2}=0.670$ and " $t$ " values are: for Const. $=6.492, L U=-2.480$, Temp. $=-0.174$, Distance $=-5.858$, and Height $=-2.665$

A 3-leg (T type) intersection of Collector Road vs Collector Road

CO Pollution Concentration $=9.862-0.007$ Traffic Volume +10.411 Land Use -0.311 Temperature - 0.337 Crossword Distance -3.322 Height

Where $R=0.795, R^{2}=0.631$ and " $t$ " values are: for Const. $=1.352$, Traffic $=3.564, L U=1.246$, Temp. $=$ 1.874, Distance $=-4.405$, and Height $=-2.788$ 
$\mathrm{NO}_{2}$ Concentration $=103.184+0.007$ Traffic Volume -8.194 Land Use +0.618

Temperature -1.005 Crossword Distance -11.793 Height

Where, $R=0.880, R^{2}=0.774$ and " $t$ " values are: for Const. $=5.971$, Traffic $=1.636, L U=-0.414$, Temp. $=$ 1.571, Distance $=-5.538$, and Height $=-4.178$

$\mathrm{PM}_{2.5}$ Concentration $=102.465+0.041$ Traffic Volume -7.222 Land Use +0.449

Temperature - 2.289 Crossword Distance -21.790 Height

Where, $R=0.814, R^{2}=0.662$ and " $t$ " values are: for Const. $=2.123$, Traffic $=3.261, L U=-0.131$, Temp. $=$ 0.408, Distance $=-4.515$, and Height $=-2.764$

The quantitative evaluation of linear regression model can be based among other statistics, on their multiple correlation coefficient $(\mathrm{R})$, or $\mathrm{R}^{2}$ which is coefficient of multiple determination. The best R-value indicates 'goodness-of-fit' of an equation. The value of R can be from 0 to 1 . (Walpole, 1982). The co-efficient of determination $\left(\mathrm{R}^{2}\right)$ must be between zero and one, whereas $\mathrm{R}^{2}=1$ indicates a perfect best fit (i.e. 100 percent deviation is explained by the independent variables. The R-square equal to 0.90 means $90 \%$ of the variation in the values of dependent variable (Y) is accounted for by a linear relationship with independent variables (X).

\subsection{REQUIREMENT OF DATA TRANSFORMATION}

The above linear regression models were based on simulation results. Among models, the best model developed for $\mathrm{PM}_{2.5}$ concentrations is for an intersection with 4-leg arterial verses arterial road. For this model, the correlation coefficient, $\mathrm{R}=0.936$ and the co- 
efficient of determination, $\mathrm{R}^{2}=0.876$. But, some of the developed models can be improved with data transformation or non-linear forms. As an example, the correlation coefficient (R) and co-efficient of determination $\left(\mathrm{R}^{2}\right)$ for $\mathrm{CO}$ pollutants for collector roads are 0.682 and 0.465 respectively. See Appendix-XIII (A). The worse model developed for $\mathrm{PM}_{2.5}$ concentrations is for an intersection with 4-leg arterial verses collector road. The correlation coefficient $(\mathrm{R})$ and co-efficient of determination $\left(\mathrm{R}^{2}\right)$ for this case are 0.682 and 0.465 respectively. Moreover, the graphical representations of those models are not satisfactory. Therefore, data transformation can be tried.

The independent variables are to be tested in order to establish whether or not transformation is required. This test is called 'Test of Normality'. The skewness is an indicator of test of normality. A comparison of the mean and median provides an indication of skewness of a data set. For symmetric data sets, the mean is equal to the median. (McClave and Dietrich, 1988). The binomial distribution of data set is symmetric if $\mathrm{p}=$ 0.5 , positively skewed if $p<0.5$, and negatively skewed if $p>0.5$ (Hays and Winkler, 1970). The following statistical values imply the normality test.

1. Skewness value should be between -1 to +1 . Note that the skewness should not be more than twice the error value.

2. Significance probability should be more than 0.05 . This value is available in the 'test of normality table', whereas both Kolmogorov significant probability and Shapiro significant probability is to be checked.

In addition to the statistical value, the following graphs also help to understand the normal distribution of data. These are:

1. Normal Q-Q plot, 
2. Histogram plot, and

3. Outlier presence test, which checks if any values are outside of interquartile range (IQR). There is an outlier value if any of the data are more than 1.5 times the average value.

\subsection{TYPES OF DATA TRANSFORMATION}

The types of non-linear equation depends on the correlation between scalar dependent variable and explanatory variable. In this simulation table, the independent variables have different characteristics including negative values.

Several types of transformations can be carried out. The transformation methodology depends entirely on data types. The following transformation is very common in practice.

1. + ve skewed/ - ve skewed value

2. Log transformation

3. SQRT transformation

Although there are some rules applicable to data transformation, the entire process is a trial and error method. As Draper and Smith (1981, p.221) state: "The choice of what, if any, transformation to make is often difficult to decide." The raw data sets are tested first. If they are not normally distributed, a transformation is required. A sample of transformation development is shown below.

The transformation procedures are entirely different for various independent variables, based on their characteristics. 


\subsubsection{Data Transformation for Freeway case}

14.5.1.1 Temperature

Transformation Type-1: Transform (Temperature) $=26+$ Temperature

Using the above transformation, the following statistical properties for the temperature data sets are observed. Skewness $=-0.522$, which is in the range of -1 to +1 , and less than the double of Error (0.427). Here, the properties are within the range. However, Kolmogorov significant probability $=0.028$ and Shapiro significant probability $=0.011$. Whereas, both the probabilities should be greater than 0.05 . Both probabilities are less than 0.05 in this case. Therefore, there is a need of further modification.

Transformation Type-2: $\quad$ Transform $($ Temperature $)=[26+\text { Temperature }]^{* * 1.5}$
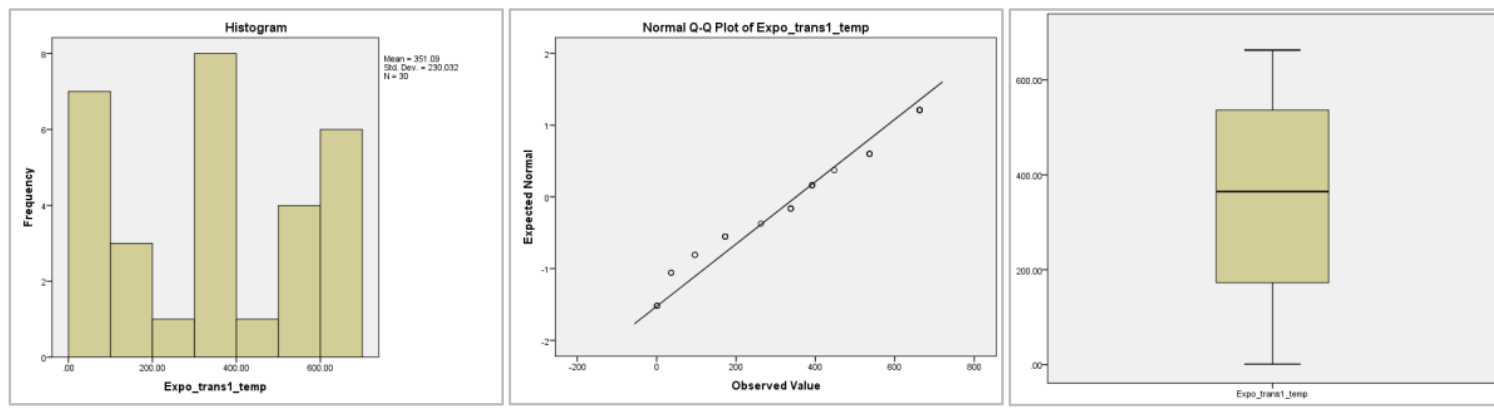

Figure 11-1: Graphical representations of normality test with temperature data sets after transformation for the freeway case

After transformation, the Skewness is equals to -0.103 , which is negatively skewed, but within the range of -1 to +1 , and the skewness value is less than the double of Error $(0.427)$. Moreover, the Kolmogorov significant probability $=0.2$, which is greater than 0.05 . Figure 11-1 represents the graphical representations of temperature data after transformation. The 
histogram shows that the maximum values are in the middle, but some values are available on each end. The normal Q-Q plot, which illustrates the expected values over observed values, shows that the values are close to straight lines, but there are some openings at the end. The good point is that there is no outlier. Therefore, this type of transformation is accepted.

\subsubsection{Distance}

Transform $($ Distance $)=$ Sqrt $[\log ($ Distance $)]$

The Skewness $=0.482$, which is in the range of -1 to +1 , and less than the double of Error (0.427). Here, Kolmogorov significant probability $=0.2>0.05$ and Shapiro significant probability $=0.056>0.05$.

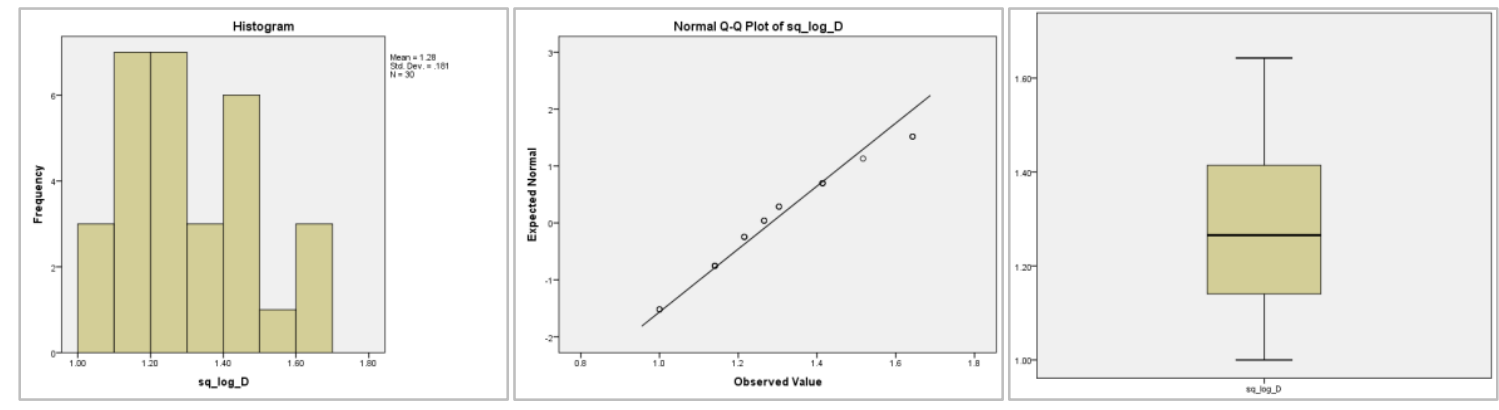

Figure 11-2: Graphical representations of normality test with distance data sets after transformation in freeway case

The above analysis illustrates that the data sets are positively skewed and skewness value is reasonable. Moreover, both probabilities are greater than 0.05 . The graphs shown in figure 14-2 are reasonable. Therefore, these data sets are acceptable. 


\subsubsection{Height}

Transform $($ Height $)=(\text { Height })^{0.75}$

Here, the Skewness $=0.882$, which is within the range of -1 to +1 , and not less than the double of error (0.427), but it is very close. Although both Kolmogorov and Shapiro significant probability are not significant, the graphs represent a significant distribution of data sets.

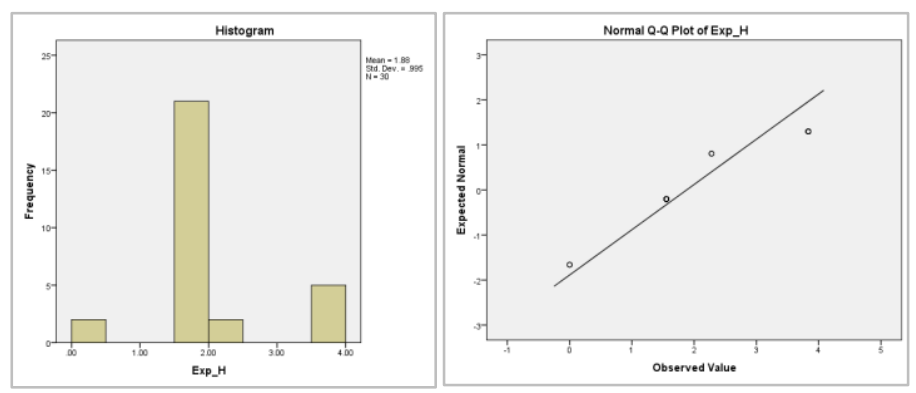

Figure 11-3: Graphical representations of normality test with height data sets after transformation in freeway case

Figure 11-3 shows that the data variation for height is low. Considering limited data, the histogram and Q-Q plot show that the transformation could be accepted.

\subsubsection{Carbon Mono-Oxide (CO)}
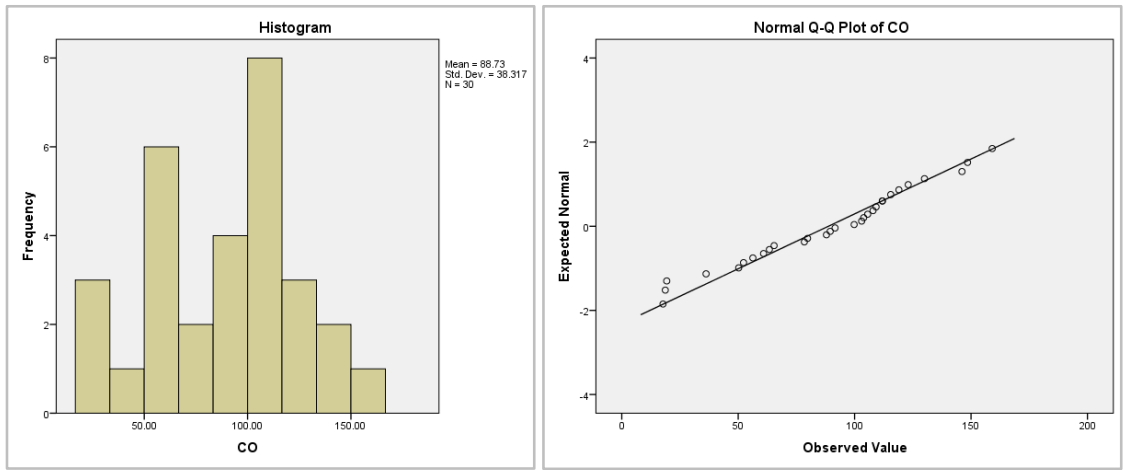

Figure 11-4: Graphical representations of normality test with CO pollution concentrations data sets without transformation in freeway case 
The raw data set analysis shows that the Skewness $=-0.271$, which is in the range of -1 to +1 , and less than the double of Error $(0.427)$. The Kolmogorov significance probability $=$ $0.200>0.05$, and the Shapiro significance probability $=0.421>0.05$. The graphical representation implies that data sets are normally distributed. Figure 11-4 shows the normality test with $\mathrm{CO}$ pollution concentration data sets without transformation for the freeway case. Histogram shows that maximum values are lying in the middle of the graph except few data points in the left hand side. Normal Q-Q plot shows that values are very close to the line. Moreover, there is no outlier. Therefore, it is concluded that no transformation is required.

\subsubsection{Nitrogen Di-Oxides $\left(\mathrm{NO}_{2}\right)$}
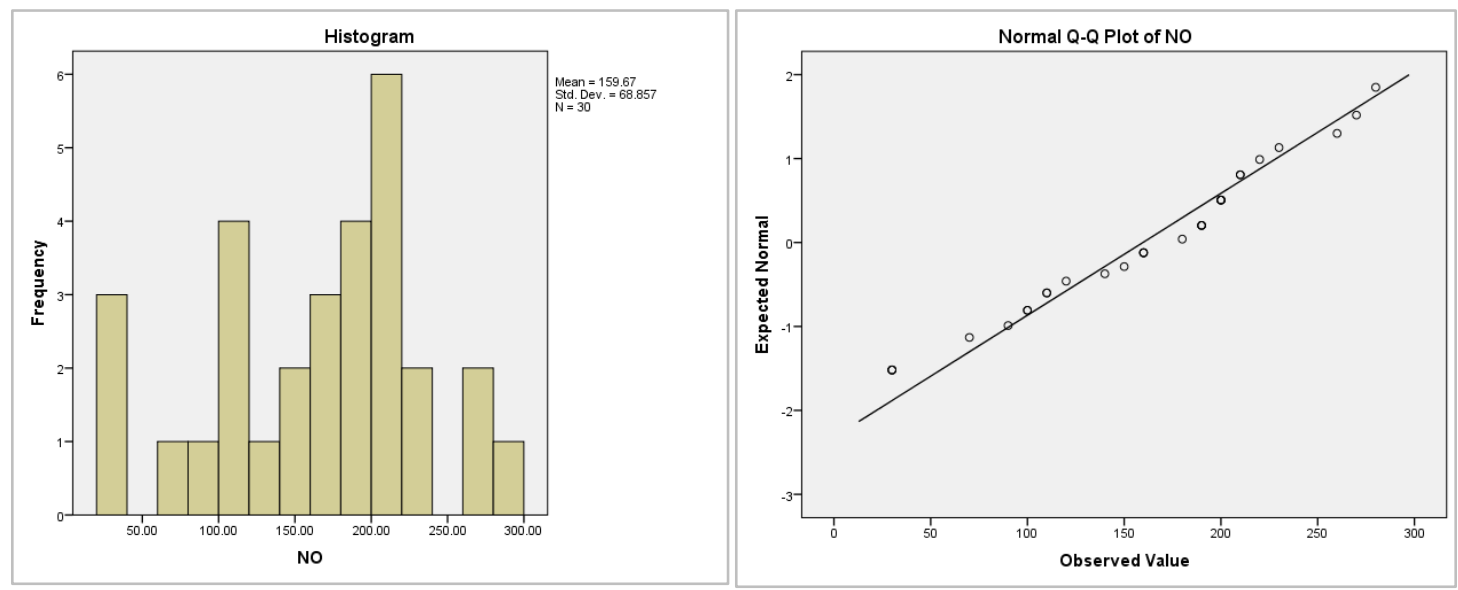

Figure 11-5: Graphical representations of normality test with NO2 pollution concentrations data sets without transformation in freeway case

The raw data for $\mathrm{NO}_{2}$ pollutants illustrates that the Skewness $=-0.347$, which is in the range of -1 to +1 , and less than the double of Error (0.427). Here, the Kolmogorov significance probability $=0.158>0.05$, and Shapiro significance probability $=0.250>$ 
0.05 , but there are no outliers. Figure $11-5$ shows that the raw data sets are almost normally distributed and no transformation is required for these data sets.

\subsubsection{Particular Matter (PM2.5)}

Here, raw data give the skewness $=-0.425$, which is in the range of -1 to +1 , and less than the double of error (0.427) and the Kolmogorov and Shapiro significant probabilities are 0.070 and 0.074 , respectively. However, the histogram shows that the data distribution is not normal. Therefore, a transformation would be require.

$$
\text { Transform }(\mathrm{PM})=(\mathrm{PM})^{\mathbf{1 . 3}}
$$

Using this transformation, the Skewness $=-0.131$, which is in the range of -1 to +1 , and less than the double of Error (0.427). Both Kolmogorov significance probability $=0.133>$ 0.05 , and Shapiro significance probability $=0.142>0.05$, are statistically significant.

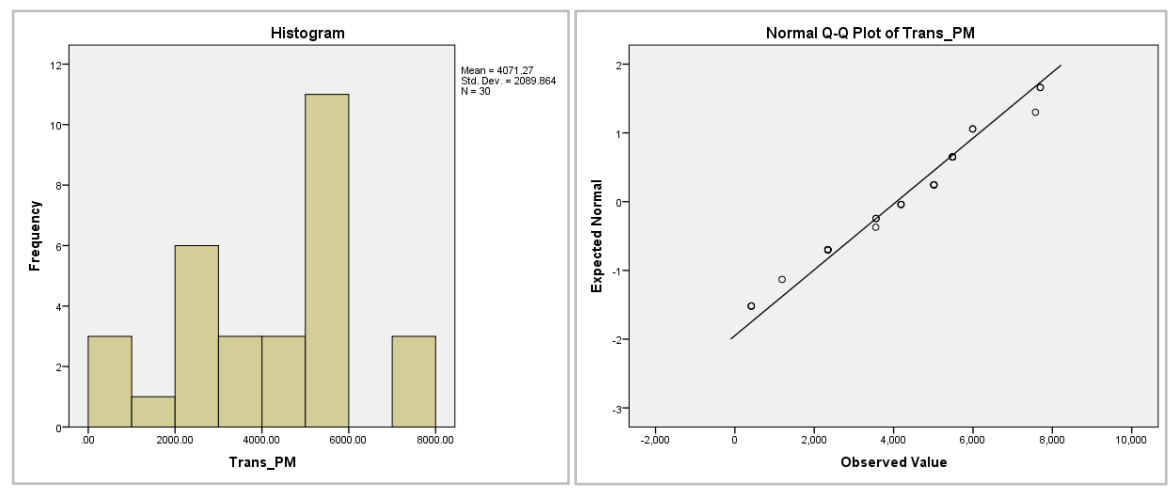

Figure 11-6: Graphical representations of normality test with PM2.5 pollution concentrations data sets using transformation in freeway case

Figure 11-6 represents the graphical demonstration of particular matter data distributions after transformation. The expected verses observed value graph shows that most of the 
points are lying close to the straight line. There is no outlier present. Based on the above analysis, it is concluded that the data sets are normally distributed after transformation.

\subsubsection{Data Transformation for Urban Road Network}

The input variables and their distributions for the urban road network are different from the freeway case. The transformation procedure used for variables in urban roads case is illustrated below.

\subsubsection{Capacity Level Traffic}

The capacity-level traffic data sets are tested for their normal distribution characteristics. The statistical report after test of normality is noted below.

1. Skewness $=-0.255$, which is in the range of -1 to +1

2. Kolmogorov significant probability $=0.065>0.05$

3. Shapiro significant probability $=0.124>0.05$
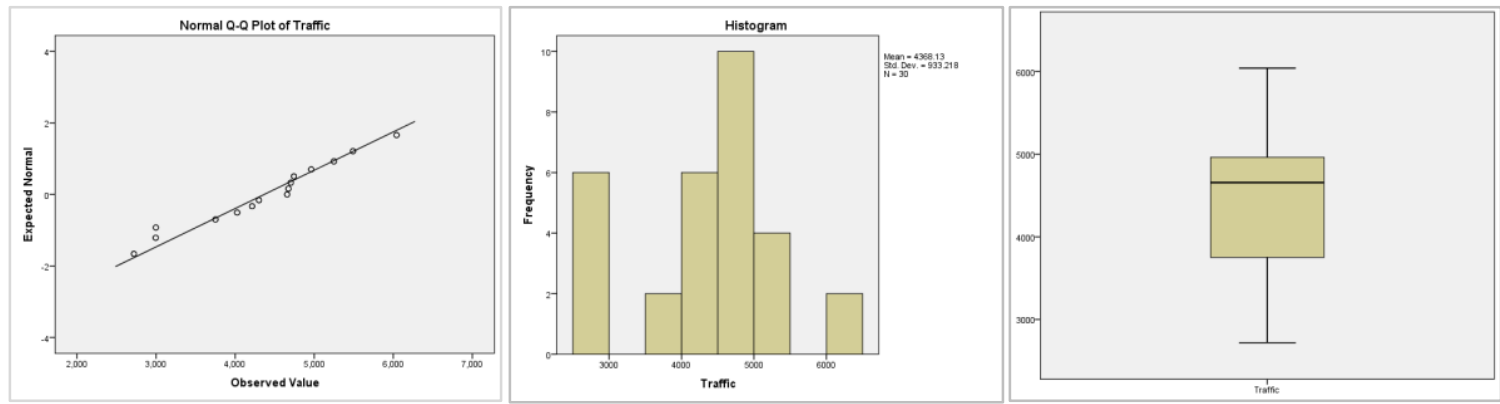

Figure 11-7: Graphical representations of normality test of capacity level traffic data sets without transformation for urban road network

The following tests imply that the values are normally distributed. The statistical reports are significant. Figure 11-7 presents three graphs. These show that data are normally distributed. Therefore, no transformation is required. 
It should be noted that some of the transformations were done to check if any improvements result from transformation. Results of two types of transformations are shown below.

1. Log normal distribution: Skewness $=-0.658$, Kolmogorov p-value $=0.012$ and Shapiro $\mathrm{p}$-value $=0.017$. Both P-values are not satisfying the normality test.

2. SQRT: Skewness $=-0.464$, Kolmogorov $\mathrm{p}$-value $=0.027$ and Shapiro $\mathrm{p}$-value $=$ 0.054 .

After transforming the data sets using the above two transformation processes, it is observed that although the Skewness and Shapiro tests show that values are normally distributed, the Kolmogorov p-value indicates that the data are not normally distributed. Therefore, it is concluded that there is no transformation required for traffic data.

\subsubsection{Temperature}

The following report generated after checking the test of normality on temperature data without transformation.

1. Kolmogorov significant probability $=0.003$, which is less than 0.05 . Therefore, data are not normal.

2. Shapiro significance probability $=0.000$, which is less than 0.05 . Therefore, data are not normal.

3. Skewness $=-1.287$, which is not within the range of -1 to +1 , and Error $=0.427$. Here, Skewness is greater than the double of Error value. Therefore, data are not normal. 
In the above case, the p-values are less than 0.05 and skewness is out of range. Moreover, skewness value implies that data are negatively skewed. It also fails the outlier test. Therefore, temperature data are not normally distributed.

Some samples fall out of the range. Figure 11-8 shows that item number 9, 10, 17, and 18 are out of the interquartile range. Therefore, it fails the outlier test.

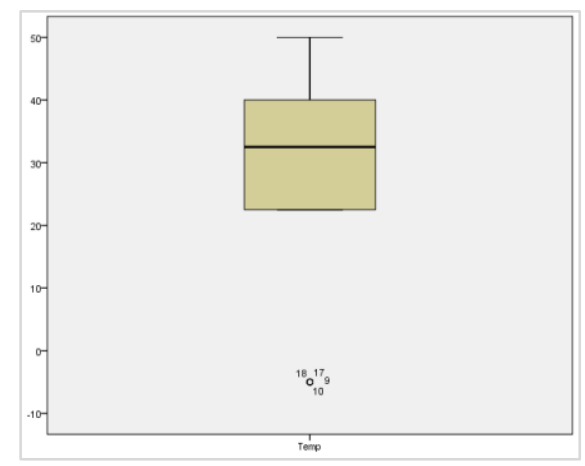

Figure 11-8: Graphical representations of normality test of temperature data

The main difficulties with the temperature data is that negative values are present in data sets. Some of the transformations (e.g. logarithmic and square root transformation) could not be done using negative values. The following transformation was done and the statistical report was checked. This transformation follows two steps.

Step 1 Change the values for exempting the -ve skewness

Step 2 Use of functional transformation

Log Transformation: $\log (6+$ temp)

Skewness $=-2.176$, both significant probability becomes zero. i.e. worse than the original case.

SQRT Transformation: sqrt (6+temp)

Skewness $=-1.862$, both significant probability becomes zero. i.e. worse than the original case. 
Exponential Transformation: Fails to do the transformation.

Log Transformation: $\log [(1+$ maximum value $)$-value $]$.

This transformation is called 'reflection'. In this case, the Skewness $=-1.623$, both significant probability becomes zero. Even, item number 25 and 26 is in outlier. i.e. worse than the original case.

\section{SQRT Transformation: sqrt [(1+maximum value)-value], REFLECTION}

After the reflection transformation, the Skewness $=0.274$, less than the double of error. The P-value for Kolmogorov $=0.008$ and P-Shapiro $=0.007$. Although both probabilities are less than 0.05 , the diagram shows transforming data are more normal in comparison to the original dataset.
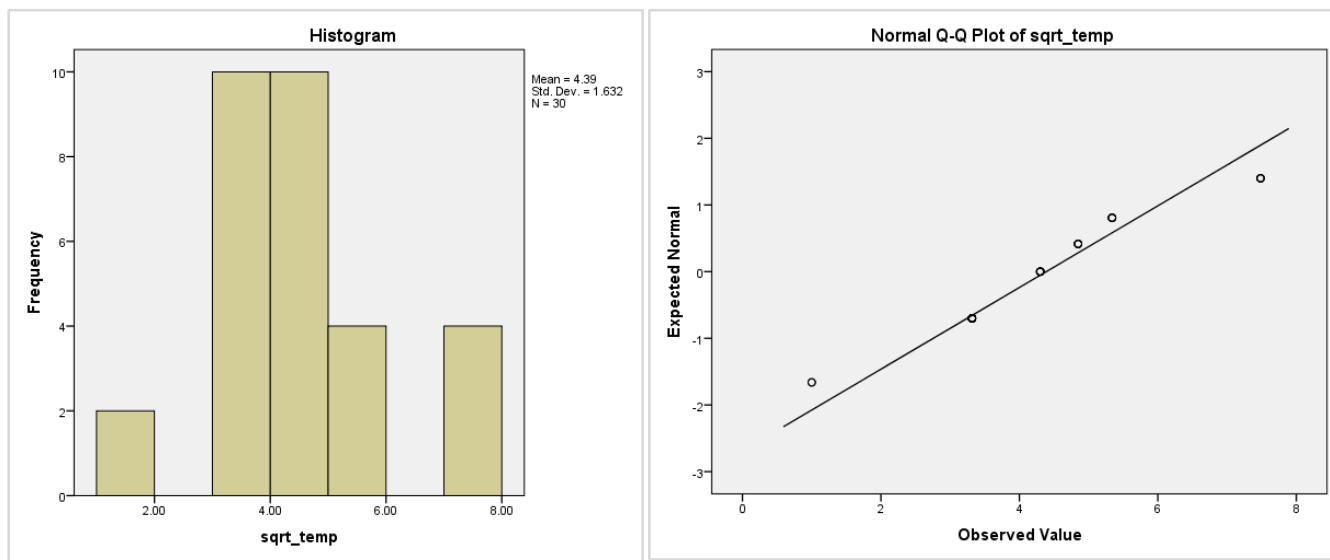

Figure 11-9: Graphical representations of normality test of temperature data with reflected square root transformation

With the following transformation and analysis of statistical significance values, finally the reflected square root transformation is accepted and considered as final transformation. 


\subsubsection{Cross-ward Distance}

The input datasets for cross-ward distance are tested for normal distribution. The test shows that the skewness $=2.017$, which is positively skewed, but out of range. Moreover, the skewness is more than two times of standard error. The Kolmogorov-Smirnov and ShapiroWilk probabilities are tabulated below.

Table 11-2: Statistical summary report

\begin{tabular}{|c|c|c|c|c|c|c|}
\hline \multirow{2}{*}{} & \multicolumn{3}{|c|}{ Kolmogorov-Smirnov } & \multicolumn{3}{c|}{ Shapiro-Wilk } \\
\cline { 2 - 7 } & Statistic & Df & Sig. & Statistic & df & Sig. \\
\hline D & .419 & 30 & .000 & .571 & 30 & .000 \\
\hline
\end{tabular}

Table 11-2 shows that both the probabilities are zero. Therefore, a transformation is very necessary for cross-ward distance datasets in urban road network. Several transformation methods are available. Here, a logarithmic transformation and square root transformation was carried out. The statistical properties show that the transformation is acceptable in both cases.

The reason for failure of transformation noted earlier is the availability of zero value in the data set. It was mentioned in last section (in the case of temperature) that transformation has two steps. Similar to exempting the negative skewness, it is required that zero values be removed from the data set. For the freeway, the distance transformation looks as follows.

$$
\text { Transform }(\text { Distance })=\text { SQRT }[\log (\text { Distance })]
$$

However, for the urban road network, this transformation process is not acceptable. Table 11-9 demonstrates the properties considered for cross-ward distances in urban road networks. The data properties corresponding to the first random sample is zero meter. To 
remove the zero values from data set, a modification has been done by adding one. Then functional transformation applies for the data set. Therefore, the transformation for distance for the urban road becomes

$$
\text { Transform }(\text { Distance })=\text { SQRT }[\log (1+\text { distance })]
$$

After Transformation, the statistics are within the ranges and therefore this transformation process is considered as final. It should be noted that the transformation procedure used in the freeway case for height data set is the same as for the urban road network.

\subsection{DEVELOPMENT OF NON-LINEAR EQUATIONS}

Several types of non-linear equations were considered. It was found that some of the variables correlate well in polynomial equations, but others correlate better in exponential equations. In the following subsections, the non-linear equations for the freeway are presented first, followed by the non-linear equations for urban roads.

\subsubsection{Non-Linear Equations for Freeway}

Non-linear equations can be developed using the linear platform. That is, transformed versions of independent variables are used to develop equations using the linear format. This approach was used for the $\mathrm{CO}$ pollution concentration model. On the other hand, $\mathrm{NO}_{2}$ and $\mathrm{PM}_{2.5}$ models were developed using the non-linear platform. The basic difference is that the linear platform provides both the correlation coefficient $(\mathrm{R})$ and co-efficient of

determination $\left(\mathrm{R}^{2}\right)$, whereas the nonlinear model generates the co-efficient of determination only. 
In the review of the following equations, it should be noted that in these linear equations, the independent variables were transformed first. Therefore, these are treated as non-linear equations in software application. It is noticed that after few iteration steps, the coefficient values become fixed. As an example, a statistical report is attached in the Appendix for the collector road link. Please refer to Appendix-III (B) for the report generated as a part of the non-linear regression model development process. In this Appendix, the iteration history table shows that the co-efficient values became fixed after three iterations.

\subsubsection{Non-Linear Equations for CO Pollutants}

$\mathrm{CO}=349.152-211.309 \sqrt{ } \log ($ Distance $)-0.545 \mathrm{H}^{0.75}+0.033[26+\text { Temperature }]^{1.5}$

The statistical properties for non-linear regression equation for $\mathrm{CO}$ pollution concentrations, namely the correlation coefficient $(\mathrm{R})$ and the co-efficient of determination $\left(\mathrm{R}^{2}\right)$ are 0.997 and 0.994 , respectively. The histogram plot and normal P-P plot for carbon monoxide pollutant is illustrated figure 11-10.
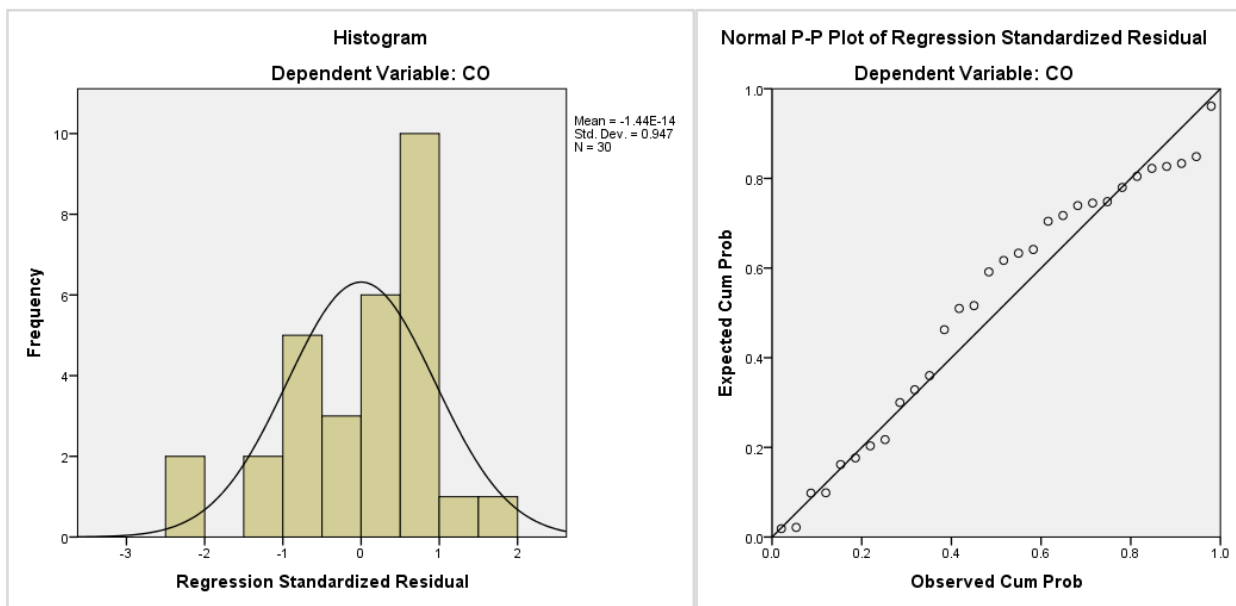

Figure 11-10: Histogram plot and normal P-P plot developed for CO pollutants in nonlinear regression model 
Table 11-3 shows the correlation coefficients between independent variables. It can be observed that the correlation between independent variables is low, which is statistically desirable, except the correlation between height and the constant. An explanation is that the capacity level traffic is not considered as a variable in the above equation since its value is held constant. Further development of non-linear equation is demonstrated later.

Table 11-3: Correlations of parameter estimates for CO pollutants

\begin{tabular}{|ll|l|l|l|l|}
\hline & & $\mathrm{a}$ & $\mathrm{b} 1$ & $\mathrm{~b} 2$ & $\mathrm{~b} 3$ \\
\hline Asymptotic & $\mathrm{A}$ & 1.000 & -.189 & -.933 & -.432 \\
& $\mathrm{~b} 1$ & -.189 & 1.000 & -.058 & .190 \\
& $\mathrm{~b} 2$ & -.933 & -.058 & 1.000 & .167 \\
& $\mathrm{~b} 3$ & -.432 & .190 & .167 & 1.000 \\
\hline Bootstrap & $\mathrm{A}$ & 1.000 & -.346 & -.972 & -.440 \\
& $\mathrm{~b} 1$ & -.346 & 1.000 & .237 & -.034 \\
& $\mathrm{~b} 2$ & -.972 & .237 & 1.000 & .291 \\
& $\mathrm{~b} 3$ & -.440 & -.034 & .291 & 1.000 \\
\hline
\end{tabular}

11.6.1.2 Non-Linear Equations for $\mathrm{NO}_{2}$ Pollutants

$\mathrm{NO}_{2}=632.241-380.628 \sqrt{ } \log ($ Distance $)-1.583 \mathrm{H}^{0.75}+0.053[26+\text { Temperature }]^{1.5}$

Where the co-efficient of determination $\mathrm{R}^{2}=0.996$, which is a very good indicator of the goodness of fit. Furthermore, the graphical representations imply that the equation is satisfactory. 

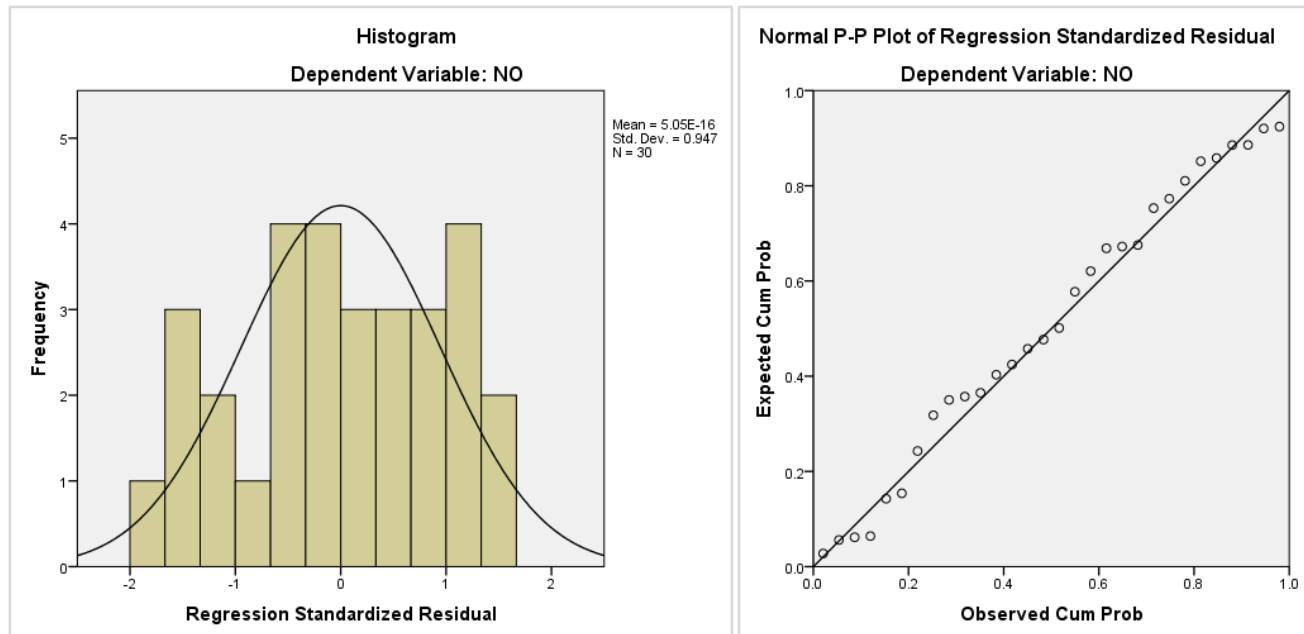

Figure 11-11: Histogram and normal P-P plot for NO2 using non-linear regression model

\subsubsection{Non-Linear Equations for Particular Matter (PM2.5) Pollutants}

$\mathrm{PM}_{2.5}=2365.532-1381.298 \sqrt{ } \log ($ Distance $)-8.666 \mathrm{H}^{\mathbf{0 . 7 5}}+0.010[26+\text { Temperature }]^{\mathbf{1 . 5}}$ Where the co-efficient of determination $\mathrm{R}^{2}=0.998$, which indicates the statistical equation correlates well. Figure 11-12 represents the graphical correlation and implies that this is one of the best equations. All independent variables were transformed here, and the coefficient of determination shows the best results. However, the histogram plot shows that data are slightly weighted in the left hand side. The equation is further developed for improved result.
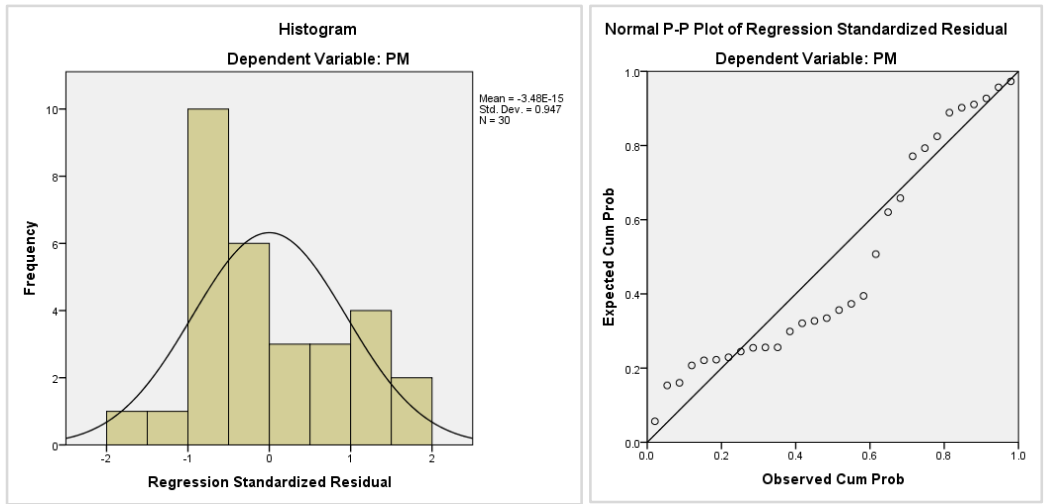

Figure 11-12: Histogram and normal P-P plot for PM2.5 using non-linear regression 


\subsubsection{Summary of further developed Non-Linear Equations in Freeway Case}

\section{Non-Linear Regression (Power Equation)}

$\mathrm{CO}=0.0000005473$ Traffic $^{2.134}$ Distance $^{-0.44}$ Height $^{-0.018}$ Temperature $^{0.044}$, where $R^{2}=0.967$

The equations presented illustrate the attempt to improve models by applying the nonlinear approach.

Further Development of Non-Linear Equation using Transformation of PM2.5 values

$$
\left[\mathrm{PM}_{2.5}\right]^{1.3}=19045.133-11589.942 \sqrt{ } \log (\text { Distance })-105.086 \mathrm{H}^{\mathbf{0 . 7 5}}+0.260[26+
$$

$$
\text { Temperature }]^{1.5}
$$

This is the product of further research using transformation of the dependent variable (i.e. pollution concentration). The graphs show slightly better results. Figure 14-13 illustrates that there is no such improvements in the histogram, but the standardize residuals in normal P-P plot shows that the points are closer to straight line. Therefore, the dependent variable $\left(\mathrm{PM}_{2.5}\right)$ datasets are tested for their normal distribution. The power transformation of particular matter illustrates that datasets are normally distributed. It is found that the coefficient of determination $\mathrm{R}^{2}=0.993$, which indicates that although the coefficient of determination is very high, this equation is not as good as the earlier $\mathrm{PM}_{2.5}$ concentrations equation. Moreover, the constant term is higher than before. 

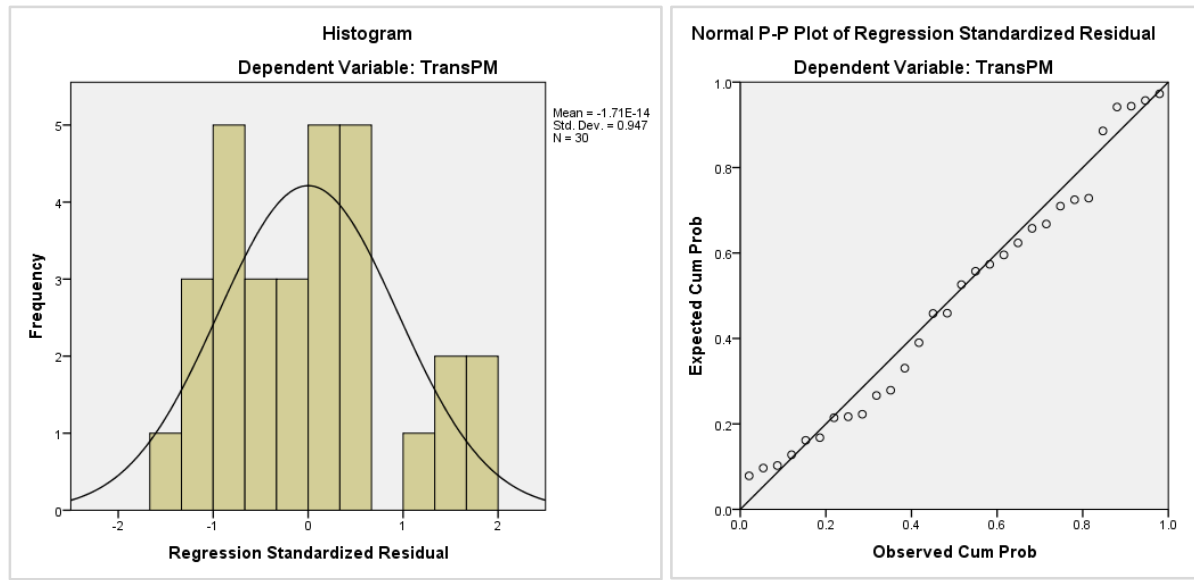

Figure 11-13: Histogram and normal P-P plot for PM2.5 using non-linear regression

It is clear from the above three pollution concentration equations (in section 11.6.1.1-3) that the constant term is high. The main intention of further research is to aim for lower values for the constant in the equations.

\section{Advanced Non-Linear Regression for CO pollination concentrations}

$\mathrm{CO}=-0.01+0.024$ Traffic $-211.309 \sqrt{ } \log ($ Distance $)-0.545 \mathrm{H}^{\mathbf{0 . 7 5}}+0.033[26+$ Temperature $]^{1.5}$ Whereas, $\mathrm{R}^{2}=0.994$

The $\mathrm{CO}$ pollution concentration equation developed includes traffic as a variable. It can be seen that the equation developed well with a lower value of the constant term, whereas the co-efficient of determination is the same as for the earlier equation. Therefore, here is the best statistical model using all independent variables.

\subsubsection{Non-Linear Equations for Urban Road Network}

Although a power equation is examined in this research, the above section provides ideas that high quality non-linear equations can be developed using data transformation. The 
second consideration is the use of all independent variables. Based on these considerations, the following non-linear equations were developed for urban roads. This section focuses on those cases (for either road or intersection) for which the linear regression equations showed rather low correlation coefficient $(R)$ and co-efficient of determination $\left(R^{2}\right)$ values. It was noted earlier that the linear regression equation for $\mathrm{CO}$ pollution concentration for the collector road exhibited low values of applicable statistics. Therefore, this equation is further developed below using non-linear case.

Non-Linear CO Pollutants Equations for Collector Road

$\mathrm{CO}=10.071+0.07$ Traffic $-0.19 \sqrt{ } \log (1+$ Distance $)-5.673 \mathrm{H}^{0.75}+8.668$ Land Use $0.14 \sqrt{ }[(1+$ maximum $)$ - temperature $]$

The above equation shows that independent variables are normalized using transformations. Although there is no transformation required for traffic capacity and land use, the other variables were transformed. In some cases, two steps (described earlier) were applied in the transformation process. For the distance case, data were modified first by adding one and then logarithmic transformation was used. For height, a simple power transformation worked well. In the case of temperature, square root transformation was used.

\subsection{ARTIFICIAL NEURAL NETWORK}

\subsubsection{Definition}

There is much scientific literature on the subject of artificial neural network (ANN). Similar to the human brain function, the ANN model is composed of multiple nodes, joined by links so that they can interact with each other. 

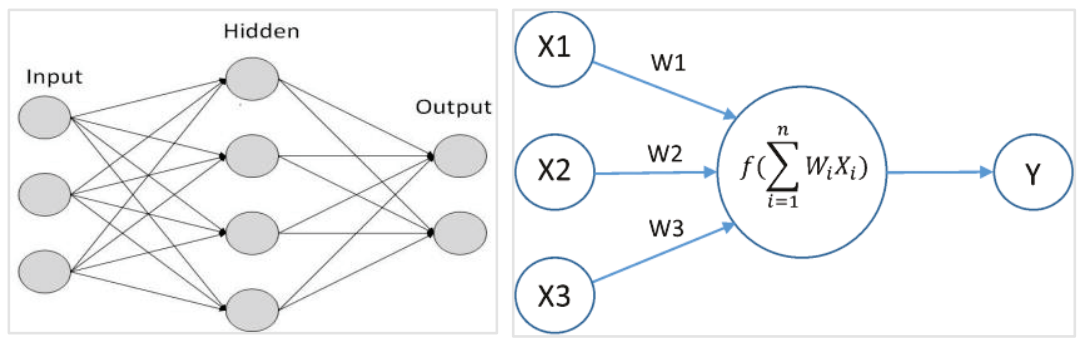

Figure 11-14: The structure of artificial neural network with connection between nodes and links

Figure 11-15 illustrates the basic structure of ANN function, where nodes in the first column represent input nodes and are denoted as $\mathrm{x}\left(\mathrm{x}_{1}, \mathrm{x}_{2}, \mathrm{x}_{3} \ldots . . \mathrm{x}_{\mathrm{n}}\right)$. The end nodes represent output. The middle nodes are called hidden layer, these are basically the transfer function. Moreover, there is an extra bias term available for each node. The output from each node is called node value. Each link corresponds to a weight value ( $\left.w_{\mathrm{ij}}\right)$ from node-i to node-j.

\subsubsection{Need for a Predictive Tool: The ANN Model}

In the statistical models, in some situations, the independent variables may show high correlations among each other. Due to the multi-collinearity problem, the regression models may not work well. On the other hand, artificial neural networks have the potential to serve as a suitable predictive methodology in such cases.

The ANN is used frequently by the scientific community as a substitute for regression models. In the context of this research, the advantage of ANN model is to avoid the issue of multi-collinearity that often becomes an issue in statistical models.

For assessing the quality of predictive models, indicators are available. These are MAE, MSE, and RMSE (Maliki, 2011). The RMSE and R-square are used to compare regression 
and NN models (Bocco, 2010). The ANNs are frequently used in transportation projects. For example, Pourkhorsand (2009) used it in tour based travel demand modelling, whereas Jamie Garcia (2004) used neural network models for prediction of fuel consumption and emission of advance technology vehicles.

For ANN model development, the simulation inputs and results described in previous chapters provide a very large database for analysis. Selected ANN models can be trained and verified using these data.

These data were divided randomly into two parts. One part was used for ANN training and the other part was used for verification. The following sections provide details of the ANN model development.

\subsubsection{Best fit of ANN Model}

The ANN toolbox of MATLAB software is designed very well to offer much flexibility in trying various configurations in order to successfully train and verify ANN neural nets. The R and R-square are the predictive indicators for goodness of fit. Moreover, the neural network components in SPSS software were also tried. Appendix-XIV shows the report presented by the SPSS software package for CO pollutants on collector road. A structural view of variables is available in the network information section of the report presented in the Appendix. Parameter estimates table in the same report illustrates the weight values for each link. Moreover, bias terms are also tabulated.

There are two basic methods for evaluation of ANN results. Those are quantitative evaluation and qualitative evaluation methods. The qualitative evaluation method is a 
collection and plotting of the sum of square error for training and testing data sets. Moreover, model residuals can be compared. However, in quantitative evaluation, the value of $\mathrm{R}$ and $\mathrm{R}^{2}$ are compared. For variation and consequences of 'goodness-of-fit' of ANN, the testing data set can be presented as inputs to the trained $\mathrm{NN}$ model and their results can be compared (Jaime Gracia, 2004).

\subsubsection{ANN Model for Freeway}
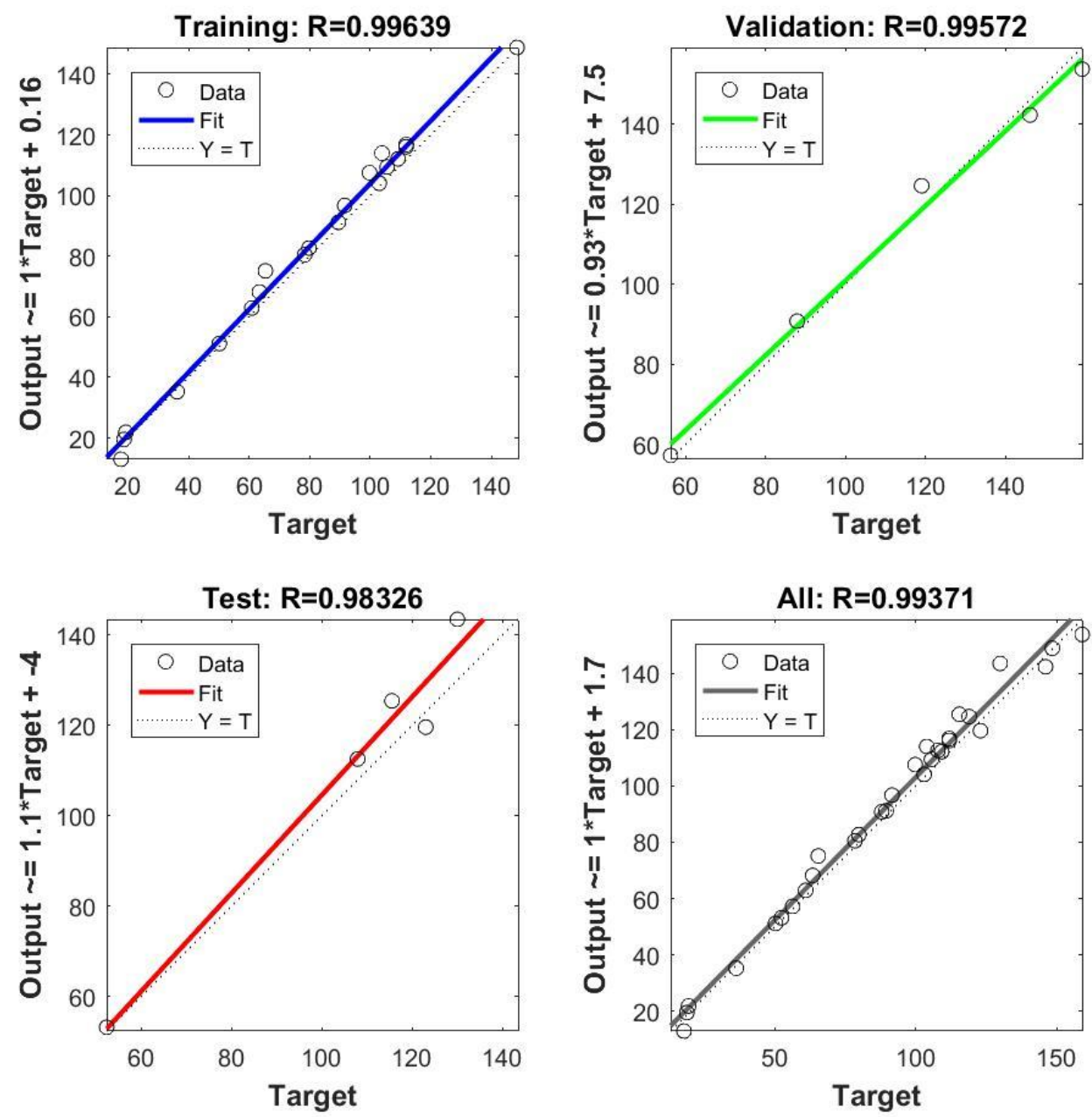

Figure 11-15: Predictive 'goodness-of-fit' using ANN for CO pollutants in freeway case 
Figure 11-15 shows the indicators generated using ANN toolbox in MATLAB. For example, in the freeway case, the R-value and R-square equals to 0.9937 and 0.987 , respectively. The overall figure shows different graphs for model training, testing, and validation.

\subsubsection{ANN Model for Urban Collector Road}

The ANN model for urban road network offers improvements over the linear regression model, which shows rather low $\mathrm{R}^{2}$. It was noted earlier that the linear regression model shows a rather low $\mathrm{R}^{2}$ for $\mathrm{CO}$ pollution concentration for collector road. Therefore, the ANN model can be used in this case since it shows the R equals to 0.8411 and the sum of square error equals to 0.460 (figure 11-16).
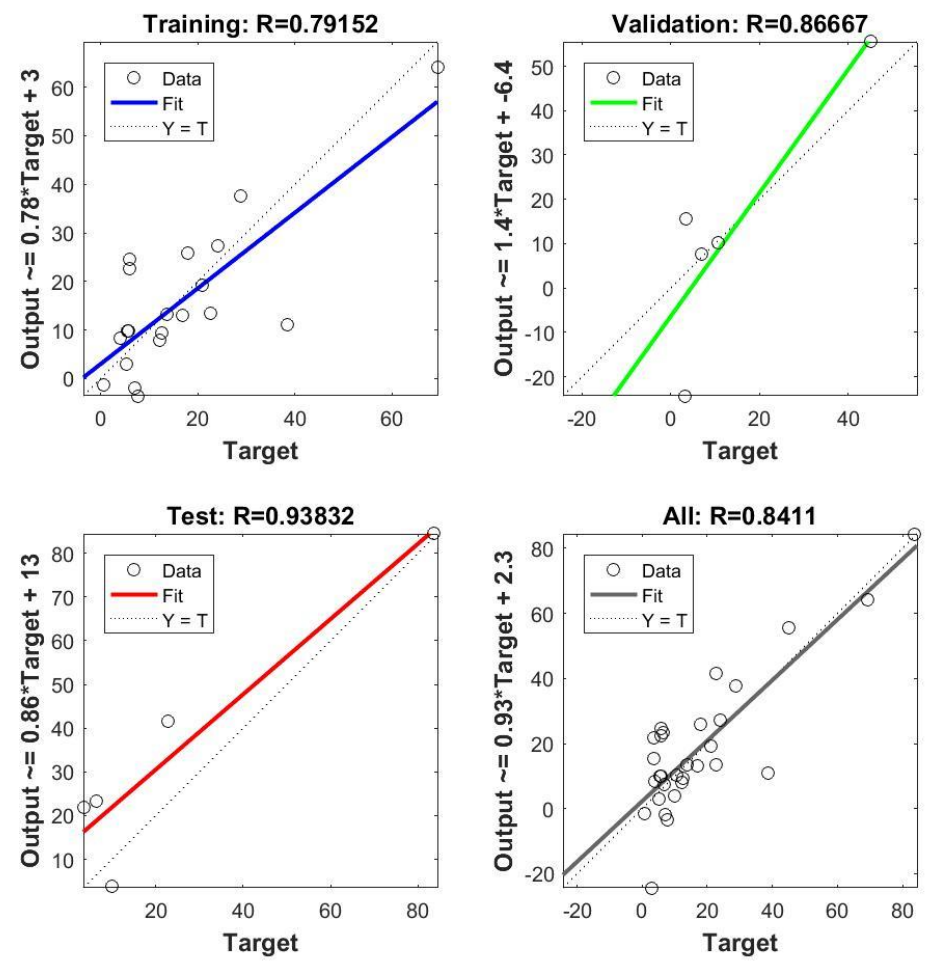

Figure 11-16: Predictive 'goodness-of-fit' using ANN for CO pollutants on collector road 


\subsubsection{ANN for PM2.5 pollutants in a 4-leg Arterial Vs Collector Intersection}

The particulate matter pollution concentration regression model for the arterial verses collector road four-leg intersection shows somewhat low $\mathrm{R}$ and $\mathrm{R}$-square values. The ANN models provide very good results. See figures 11-17 and 11-18.
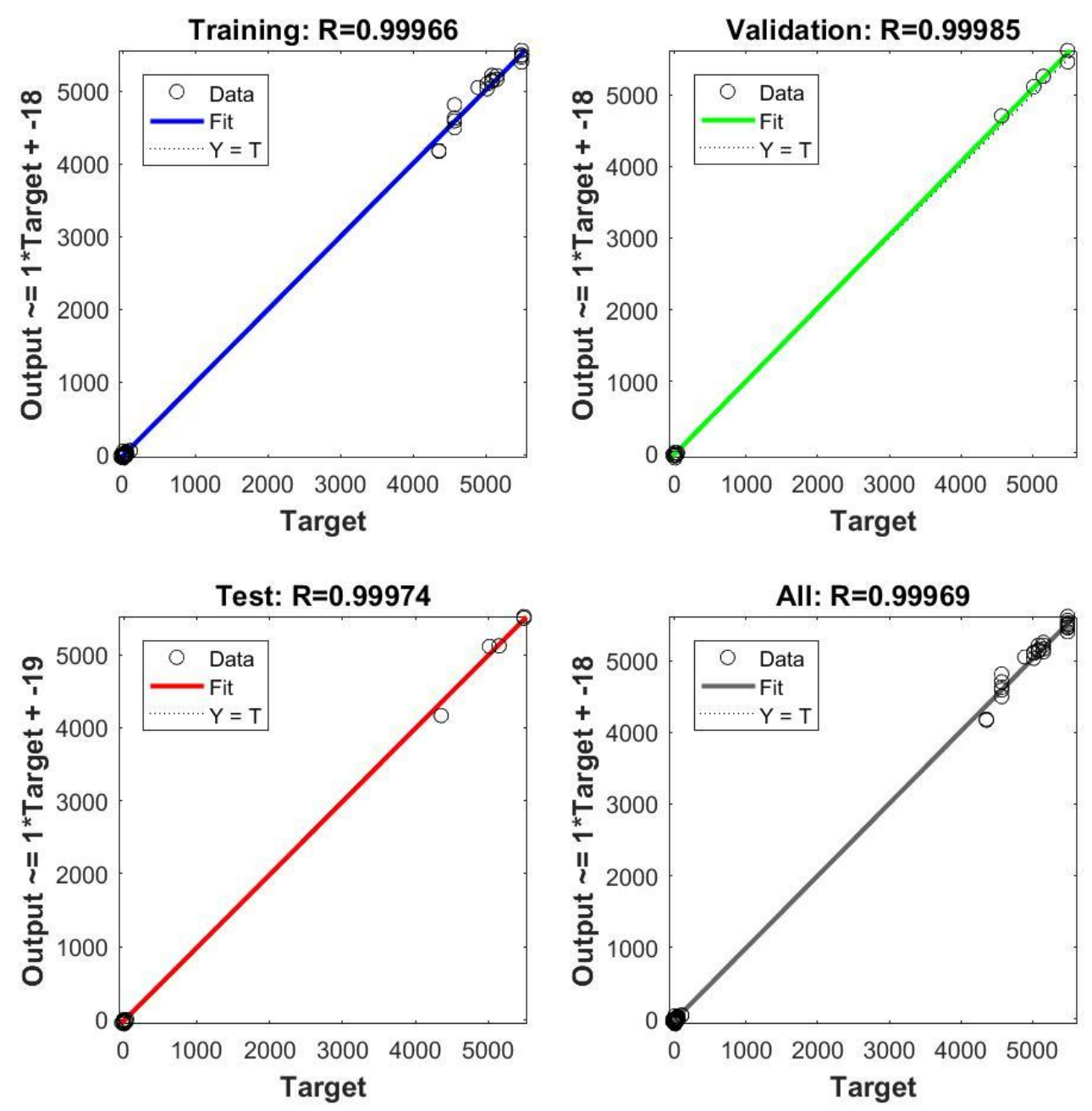

Figure 11-17: Predictive 'goodness-of-fit' using ANN for PM2.5 pollutants 


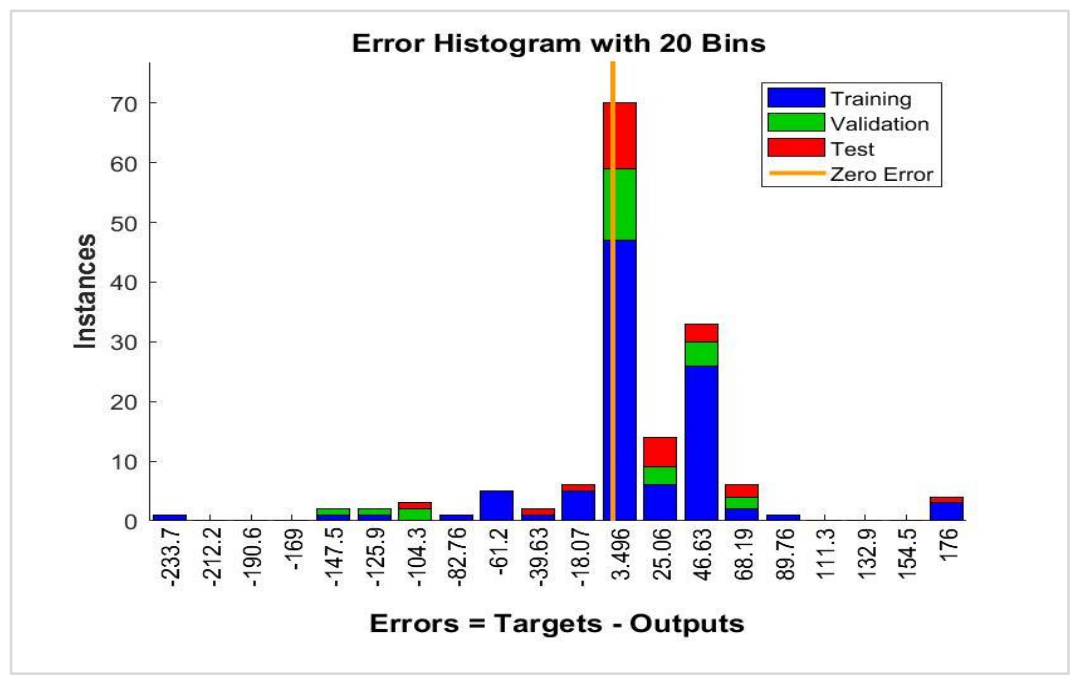

Figure 11-18: Errors in histogram using ANN for PM2.5 pollutants in a 4-leg arterial vs collector intersection

\subsection{ANALYSIS AND MODEL SELECTION}

Regression models were developed for each types of road and intersection based on simulation results. The linear regression model provides rather poor statistical properties for some cases. In order to improve models, non-linear regression models were developed for those cases. For example, for the CO pollutants model for collector road, the correlation coefficient $(\mathrm{R})$ and co-efficient of determination $\left(\mathrm{R}^{2}\right)$ from linear regression model are 0.682 and 0.465 , respectively. Whereas, the co-efficient of determination $\left(\mathrm{R}^{2}\right)$ from nonlinear regression model is 0.783 . These results indicate that the non-linear regression model is the best fit in terms of $\mathrm{R}$-square value for $\mathrm{CO}$ pollutants for the collector road.

The above sections illustrate the ANN model development. The results from neural networks are compared with the regression model results. The regression model produced a satisfactory statistical indicator in some cases, whereas in few cases the results were not 
good. On the other hand, the ANN provides a better model in some cases. However, in other cases the ANN models are not as good as regression models.

Drawing on international literature, further comparisons can be made between regression and ANN models. Narayan (2012) compared regression and ANN impact assessment models in case of micro-watershed management study in India and found that the performance reliability using ANN model is much better than regression model. An estimation of solar radiation using both models was reported in a journal of agriculture research. The co-efficient of determination $\left(\mathrm{R}^{2}\right)$ from linear regression model was 0.88 , whereas the co-efficient of determination $\left(\mathrm{R}^{2}\right)$ from neural network is 0.92 (Chilean, 2010). However, in some other cases, the opposite was the case.

Returning to the models developed in this research, for the freeway CO pollutant case, it is found that the correlation coefficient $(\mathrm{R})$ and co-efficient of determination $\left(\mathrm{R}^{2}\right)$ from linear regression model are 0.850 and 0.722 respectively. On the other hand, the co-efficient of determination $\left(\mathrm{R}^{2}\right)$ from non-linear regression model is 0.994 . However, the ANN tool using MATLAB shows the correlation coefficient (R) to be equal to 0.9937 . Therefore, the co-efficient of determination $\left(\mathrm{R}^{2}\right)$ becomes 0.987 . Based on this analysis, it can be said that the non-linear model provides slightly better predictive indicators than the ANN model.

Another comparison is made for the particulate matter model for the 4-leg intersection of arterial verses collector road. In this case, the ANN model is better for the following reason. The correlation coefficient $(\mathrm{R})$ and co-efficient of determination $\left(\mathrm{R}^{2}\right)$ for ANN model are 0.9997 and 0.9993 respectively, whereas the $\mathrm{R}$ and $\mathrm{R}$-square values from linear regression model are 0.618 and 0.382 respectively. Therefore, in this case the ANN model offers much 
improvement for making predictions. On the other hand, the R-square value for ANN model is $0.7074(\mathrm{R}=0.8411)$ for $\mathrm{CO}$ pollutants for collector road, which is slightly lower that the $\mathrm{R}$-square value $\left(\mathrm{R}^{2}=0.783\right)$ from the non-linear model.

The above analysis implies that model types are generally comparable in terms of goodness-of-fit results. In addition, each model type has limitations as well. Although there is a success story in the arterial verses collector intersection case using the ANN model, the collector road case implies that the non-linear model is better. Therefore, this comparative analysis suggests that the linear regression model should be put into practice first. If the statistical significance values are poor, then review the non-linear model. Furthermore, the ANN can be used for verification purposes. 


\section{Chapter 12: MODEL APPLICATIONS}

\subsection{AREA OF APPLICATION}

In this research, the main emphasis is on philosophy and methodology. However, the integrated simulation model and the developed predictive models can be applied in the real world to estimate setback distance in site plans. In addition, estimated emission concentrations found from case studies are useful in understanding receptor exposure to $\mathrm{CO}, \mathrm{NO}_{2}$ and $\mathrm{PM}_{2.5}$ at various distances and heights near a road or an intersection or a freeway.

As noted previously, the developed models can be used by planners in any location in North America (i.e. Canada and USA), because the emission models are developed based on valid variables and their values obtained from scientific methods. For other regions of the world, it is important to check inputs.

The applications of the developed statistical model are discussed in this chapter. These statistically significant predictive models can be used to predict emission concentrations at selected receptor locations and results can be compared with ambient air quality standards. Rearranged concentration models can be used to find suitable setback distances so that receptors are not subjected to harmful levels of pollutant concentrations as defined by national ambient air quality (NAAQ) standards. 
The land use planners and policy analysts can apply the developed statistical models to predict pollution concentrations at sensitive locations. From repeated applications of models for roads, intersections or freeway, sufficient results can be obtained that planners and policy analysts can use for defining setback distances at sites of interest. Ultimately, it will be helpful for approving a site plan that includes buildings near a road (e.g. an arterial or a collector), an urban intersection, and an urban freeway. Such site plans could involve new construction or re-development of an existing site. The knowledge contributed by this research is a contribution to protecting human health from harmful effects of air pollution produced by road vehicles.

\subsection{DETERMINATION OF SETBACK DISTANCE FOR URBAN ROADS AND FREEWAY}

As previously defined, the setback distance is the distance between the road and a residential or an institutional building whose vulnerable occupants are to be protected from harmful emissions. The literature survey did not uncover any previous research product similar to this thesis. In addition, a survey of urban planning practice suggests that detailed setback criteria based on air quality concerns are generally absent.

This research is an attempt to link the quality of air at selected residential or institutional building sites and health issues. The proxy for health issues are the ambient air quality standards. If these are violated, there could be adverse health effects. For the prediction of pollution concentration near a road or an intersection or a freeway, simulation capability was developed. Additionally, to advance the state of knowledge further, new predictive 
models were developed to study setback distances for use in site planning. These models can apply the national ambient air quality standards with ease.

Statistical models developed in this research are presented in chapter 11, where distance, height, and other explanatory variables serve as inputs and pollution concentration is an output. These equations demonstrate that for specified values of other variables, pollution concentration drops with increasing distance from the road edge and also with increasing elevation. The gradients are reasonable. Selected equations for $\mathrm{CO}$ and $\mathrm{NO}_{2}$ emissions are shown below for illustration purposes. Additional models (available in in Chapter-11) can be reviewed.

$\underline{\text { Urban arterial road }}$

$\mathrm{CO}=2.204+0.009 \mathrm{C}-5.795 \mathrm{~L}-0.239 \mathrm{~T}-0.262 \mathrm{D}-2.120 \mathrm{H}$

Three leg intersection of arterial with another arterial (heavy traffic area)

$\mathrm{CO}=99.811-0.002 \mathrm{C}-36.194 \mathrm{~L}-1.665 \mathrm{~T}-0.302 \mathrm{D}-3.186 \mathrm{H}$

$\mathrm{NO}_{2}=279.427-0.008 \mathrm{C}+70.679 \mathrm{~L}-2.935 \mathrm{~T}-1.082 \mathrm{D}-10.85 \mathrm{H}$

Freeway

$\mathrm{CO}=-0.01+0.024 \mathrm{C}-211.309 \sqrt{ } \log (\mathrm{D})-0.545 \mathrm{H}^{\mathbf{0 . 7 5}}+0.033[26+\mathrm{T}]^{1.5}$

$\underline{\text { Urban collector }}$

$\mathrm{CO}=10.071+0.07 \mathrm{C}-0.19 \sqrt{ } \log (1+\mathrm{D})-5.673 \mathrm{H}^{0.75}+8.668 \mathrm{~L}-0.14 \sqrt{ }[(51)-\mathrm{T}]$

Where, $\mathrm{CO}=$ Carbon monoxide pollution concentration 


$$
\begin{aligned}
& \mathrm{NO}_{2}=\text { Nitrogen di-oxide pollution concentration } \\
& \mathrm{C}=\text { Capacity level vehicular traffic } \\
& \mathrm{D}=\text { Distance, } \mathrm{H}=\text { Height, } \mathrm{L}=\text { Land Use, and } \mathrm{T}=\text { Temperature }
\end{aligned}
$$

Among these equations, the first Equation (12.1) is a linear regression model for urban arterial road, the second Equation (12.2) is a linear model for a three-leg urban intersection of arterial road with another arterial road. The third equation can be used to predict $\mathrm{NO}_{2}$ concentration. It has a linear structure. The fourth Equation (12.4) of non-linear structure applies to a freeway segment and the fifth Equation (12.5) of non-linear structure applies to an urban collector road. The model structure in all cases implies that pollution concentration is a function of distance and other variables.

Pollution concentrations $\left(\mathrm{CO}\right.$ or $\left.\mathrm{NO}_{2}\right)=\mathrm{f}$ (distance, traffic, height, land use, and temperature)

Based on the linear regression Equation 12.1 for the mid block part of an urban arterial road, Table 12-1 reports distance as an input variable and $\mathrm{CO}$ pollution concentration as the output variable, while other input variables are held constant. The constant values are capacity level traffic of $3512 \mathrm{vph}$, urban land use, temperature equal to $20^{\circ} \mathrm{C}$, and human breathing height of $1.8 \mathrm{~m}$ above ground level. Therefore, Table 12-1 serves as an illustration of how $\mathrm{CO}$ pollution concentration (in ppm) will vary with distance (in meter) from road edge at human breathing height. An examination of $\mathrm{CO}$ concentration shows that the Canadian CO 1-hour standard of $31 \mathrm{ppm}$ is met. 
Table 12-1: CO pollution concentrations varies with distances from arterial road at breathing height based on equation-12.1

\begin{tabular}{|c|c|c|c|c|c|}
\hline $\begin{array}{c}\text { Distance } \\
(\mathrm{m})\end{array}$ & $\begin{array}{c}\text { CO pollutants } \\
(\mathrm{ppm})\end{array}$ & $\begin{array}{c}\text { Distance } \\
(\mathrm{m})\end{array}$ & $\begin{array}{c}\text { CO pollutants } \\
(\mathrm{ppm})\end{array}$ & $\begin{array}{c}\text { Distance } \\
(\mathrm{m})\end{array}$ & $\begin{array}{c}\text { CO pollutants } \\
(\mathrm{ppm})\end{array}$ \\
\hline 0 & 19.4 & 5 & 18.1 & 20 & 14.2 \\
\hline 1 & 19.2 & 10 & 16.8 & 30 & 11.5 \\
\hline 2.5 & 18.8 & 15 & 15.5 & 50 & 6.3 \\
\hline
\end{tabular}

Figure 12-1 based on Equation 12-1 illustrates the variation of pollution concentration with distance at human breathing height (1.8 meter) level. The $\mathrm{x}$-axis represents the distance in meter, whereas $\mathrm{y}$-axis presents $\mathrm{CO}$ pollution concentrations. At breathing height, the maximum CO pollution concentrations of 19.4 ppm occurs at road edge. It is clear from the figure that as expected the pollution concentrations show a decreasing trend with increasing distance from road.

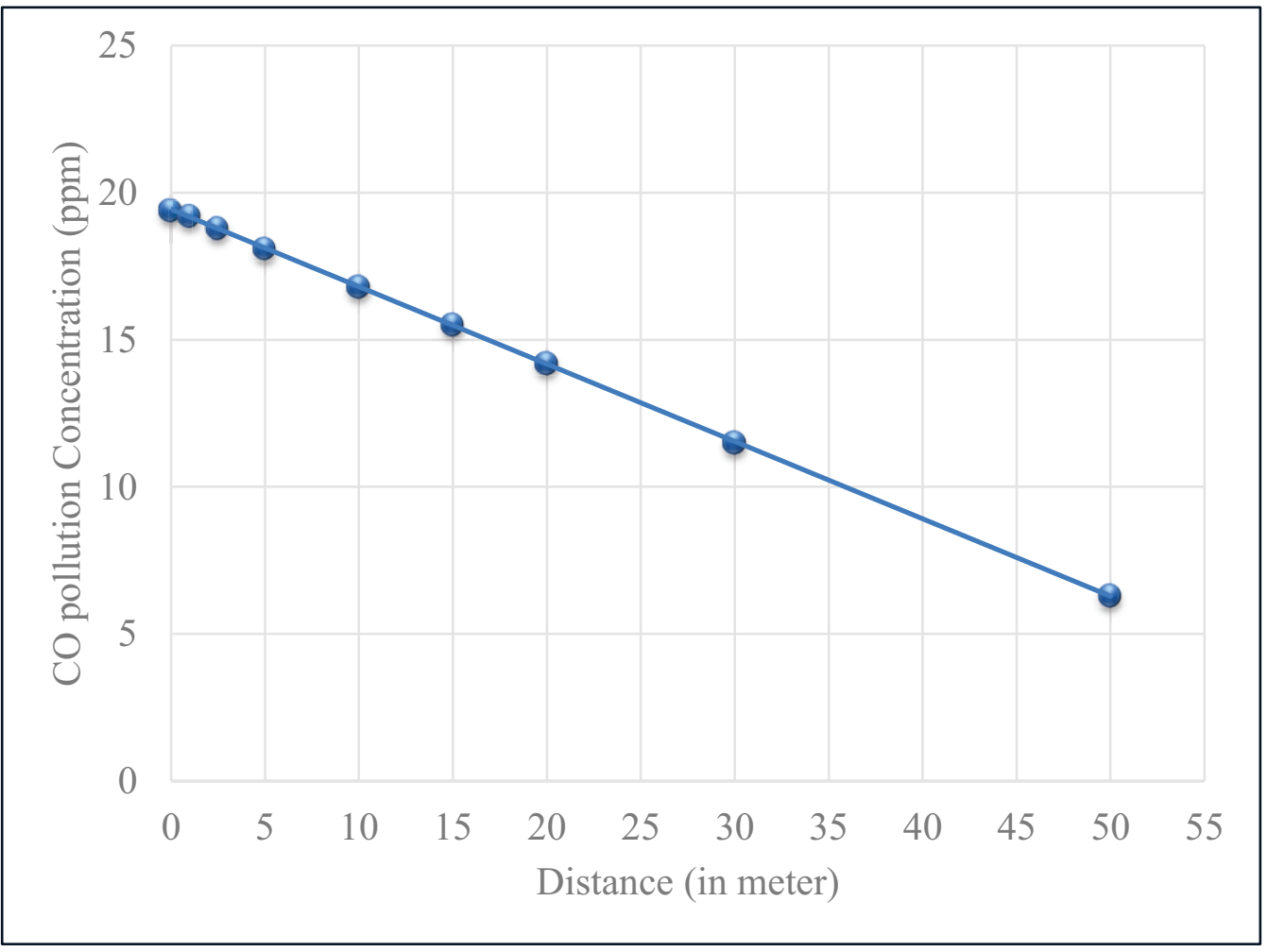


Even the highest $\mathrm{CO}$ is much below the Canadian ambient air quality standard for $\mathrm{CO}$ pollutant of $31 \mathrm{ppm}$. It should be noted that this analysis has been done using regression equation developed for 1-hr CO NAAQ standard. However, the NAAQ standard notes that the CO pollutant for the 8-hr case should not be more than $13 \mathrm{ppm}$. Therefore, further research for 8-hrs case should be carried out.

Equations 12.2 and 12.3 present linear regression equations for a 3-leg intersection of an arterial road with another arterial. Table 12-2 is based on these models (Equation 12.2 for $\mathrm{CO}$ pollutants, and Equation 12.3 for $\mathrm{NO}_{2}$ pollutants). This table illustrates the relationship

Figure 12-1: CO pollution concentration decreases with distances from road edge at breathing height

between distance as input variable and emission concentrations as output variables, whereas the other input variables assume fixed values. These are capacity level traffic at intersection equal to $4783 \mathrm{vph}$, urban land use type, and temperature equal to $20^{\circ} \mathrm{C}$. However, heights are included in calculations. In this illustration, CO concentration (in ppm) and $\mathrm{NO}_{2}$ concentration (in ppb) are shown for combinations of distance (in meter) and height (in meter).

Table 12-2: CO and NO2 pollution concentrations vary with distances and heights

\begin{tabular}{|c|c|c|c|}
\hline Distance $(\mathrm{m})$ & Height $(\mathrm{m})$ & CO pollutants $(\mathrm{ppm})$ & $\mathrm{NO}_{2}$ pollutants $(\mathrm{ppb})$ \\
\hline \multirow{3}{*}{2} & 1.8 & 50.6 & 161 \\
\cline { 2 - 4 } & 4.0 & 43.6 & 137 \\
\cline { 2 - 4 } & 7.0 & 34.0 & 104 \\
\hline & 1.8 & 49.7 & 158 \\
\hline
\end{tabular}




\begin{tabular}{|c|c|c|c|}
\hline \multirow{3}{*}{5} & 4.0 & 42.7 & 134 \\
\cline { 2 - 4 } & 7.0 & 33.1 & 101 \\
\hline \multirow{3}{*}{10} & 1.8 & 48.2 & 152 \\
\cline { 2 - 4 } & 4.0 & 41.2 & 128 \\
\cline { 2 - 4 } & 7.0 & 31.6 & 96 \\
\hline \multirow{3}{*}{20} & 1.8 & 45.2 & 141 \\
\cline { 2 - 4 } & 4.0 & 38.2 & 117 \\
\cline { 2 - 4 } & 7.0 & 28.6 & 85 \\
\hline
\end{tabular}

A graphical illustration of pollution concentration variation with distance and height can be viewed in Figure 12-2. Here, three different heights are considered based on land use activities in and around residential or institutional buildings. In Figure 12-2, red color concentration values indicate the human breathing height (1.8 meters) at ground level, whereas purple and yellow colors indicate receptor location at heights of 4 meters and 7 meters, respectively. The maximum $\mathrm{CO}$ concentration at 10 meters distance and corresponding to human breathing level at 1.8 meter height is $48.2 \mathrm{ppm}$, whereas at 7 meters height the concentration is equal to $31.6 \mathrm{ppm}$. This analysis implies that pollution concentrations decrease with height. Based on 1-hr Canadian CO pollution standards, the second and higher levels of a residential building at 10 meters distance are suitable for living. 


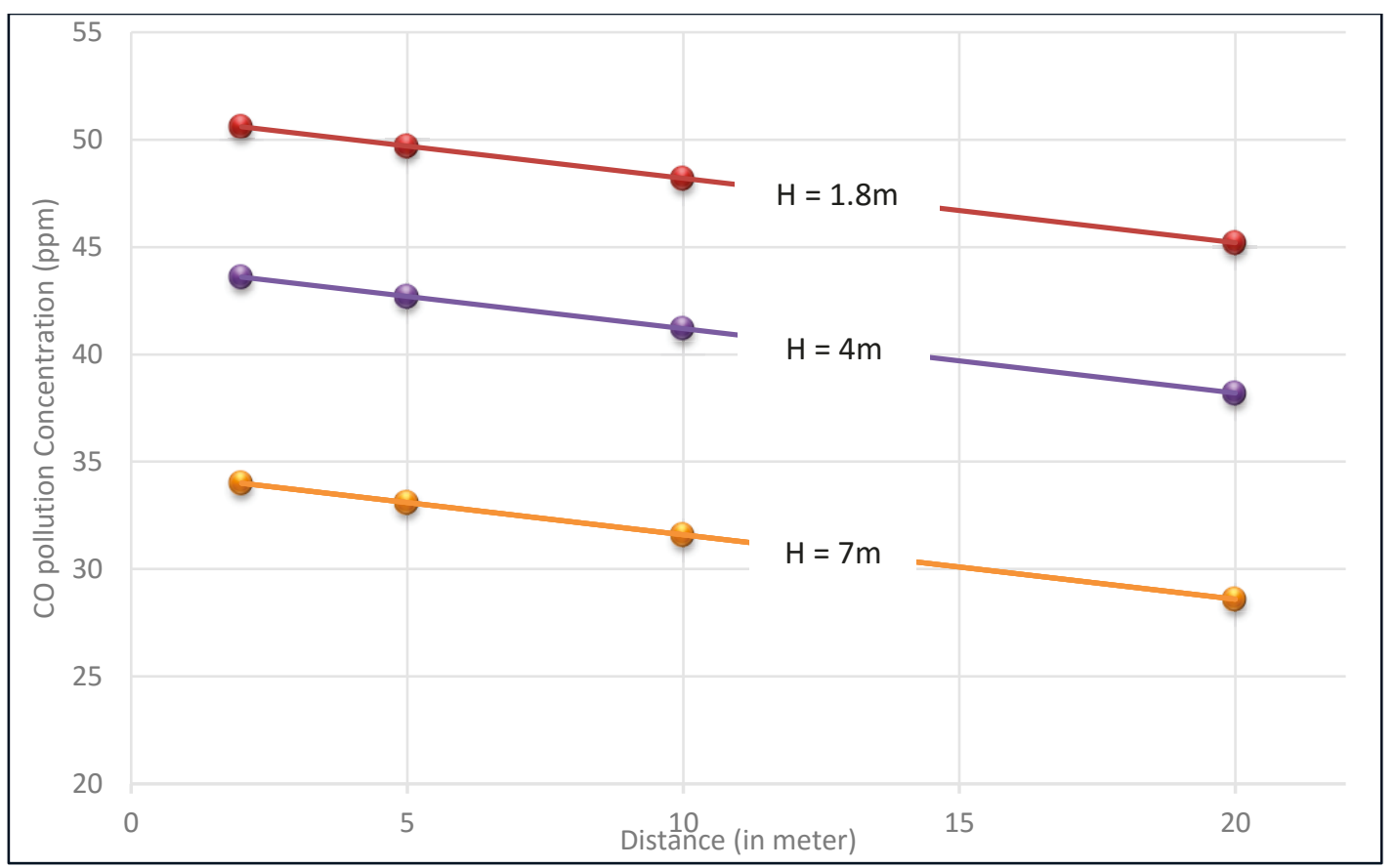

Figure 12-2: CO pollution concentration decreases with distance and height

The graphical representation shows that the relations are in linear form. The explanation is that the results are generated using linear regression equations for a high traffic urban intersection of two arterial roads. If required, the non-linear equations developed in this research can be used.

Our primary concern is with ambient air quality at a proposed building construction site. According to national ambient air quality standards, the emission concentration should not be more than the NAAQ standard. Table 1-1 shows that the pollution concentration is a fixed value according to NAAQ standards. Therefore, the above equations can be rearranged to represent distance as a dependent variable and other variables including pollution concentration as independent variables.

Distance $=\mathrm{f}($ traffic, height, land use, temperature, pollution concentration $)$ 
It should be noted that in Equation-12.6, all the input parameters vary for a specific road type or intersection type. Whereas, in Equation-12.7 pollutant values are fixed at the NAAQ standard and setback distance is computed. The one-hour Canadian ambient air quality standard (NAAQS) for CO pollutant is $31 \mathrm{ppm}$, whereas the $\mathrm{NO}_{2}$ for 1-hr criterion is $100 \mathrm{ppb}$ in US standards and $215 \mathrm{ppb}$ for Canadian standards. Based on the rearranged Equation 12.1, which is the linear regression equation for arterial road, can re-write as

$\mathrm{D}=3.817+0.034 \mathrm{C}-22.118 \mathrm{~L}-0.912 \mathrm{~T}-8.092 \mathrm{H}-3.817 \mathrm{CO}$

Equation 12.8 produces the distance that will correspond to the input variables, which are capacity level traffic, type of land use, ambient temperature, receptor height, and pollution concentration according to NAAQ standard. It is important to use vehicular traffic capacity for two lanes urban arterial road in calculations. The capacity level traffic for a two lane arterial road is 3512 vehicles per hour. The calculated distance is the setback distance for use by urban land use planner.

For the freeway case, the standard setback equations for $\mathrm{CO}$ and $\mathrm{NO}_{2}$ become

$$
\begin{aligned}
& \mathrm{D}=419.6+9.7 \mathrm{H}+2.12 \mathrm{~T}-4.464 \mathrm{CO} \\
& \mathrm{D}=336.2+8.47 \mathrm{H}+2.0 \mathrm{~T}-2.041 \mathrm{NO}_{2}
\end{aligned}
$$

Whereas, $\mathrm{H}=$ breathing height (1.8 meter)

$$
\mathrm{T}=\text { temperature }\left(20^{\circ} \mathrm{C}\right)
$$

$\mathrm{CO}=31 \mathrm{ppm}$ (Canadian/ U.S. 1-hr ambient air quality standards)

$\mathrm{NO}_{2}=100 \mathrm{ppb}$ (the United States 1-hr ambient air quality standards) 
Equation 12.9 is the standard setback distance equation for $\mathrm{CO}$ pollutant, whereas Equation 12.10 is the standard setback distance equation for $\mathrm{NO}_{2}$ pollutant. Based on two equations, the required setback distance are $341 \mathrm{~m}$ for maintaining CO standards and $146.9 \mathrm{~m}$ for maintaining the U.S. $\mathrm{NO}_{2}$ standards. Therefore, approximately 340 meters setback distance is suggested for building sensitive residences or an institutional campus near a high traffic freeway.

It should be noted that the above setback distance is based on linear regression model, but the non-linear model will provide better estimates. Likewise, the ANN model can also provide improved predictions. As for the relevance of the freeway setback distance, Ross et. Al., 2005 found that pollution effects were detected within 500 meters and at some locations 1500 meters away from the expressway. The above results found the required setback distance to be 340 meters, which is a more refined value than the value reported in the above-cited literature. Setbacks that are more reliable can be obtained using the predictive models for the reason that this research has applied mainly microscopic models, which have produced high-resolution results.

\subsection{SETBACK DISTANCE AROUND MAJOR INTERSECTIONS}

Predictive model applications are illustrated in this chapter for an urban road network. Using the previous example, based on the linear regression Equation-12.1 for the mid block part of an urban arterial road, Table 12-1 reports distance as an input variable and CO pollution concentration as the output variable, while other input variables are held constant. Table 12-1 serves as an illustration of how CO pollution concentration (in ppm) will vary 
with distance (in meter) from road edge at human breathing height. An examination of $\mathrm{CO}$ concentration shows that the Canadian CO 1-hour standard of $31 \mathrm{ppm}$ is met.

The predicted concentration of emissions obtained from the statistical models are logical. In this example, applied to the midblock section of an arterial road, the CO and NO2 concentrations do not exceed the standards.

Next, a 3-leg (T type) arterial verses arterial intersection is studied. As an example, the intersection of Carling Avenue and Bronson Avenue in Ottawa (Ontario) can be assumed. Although this is a four-lag intersection in terms of existing road network, the control device operates as three leg (T type) intersection. Given that no vehicular traffic is allowed to join

in the intersection from Glebe Avenue, the one-way flow into the Glebe Avenue is permitted. The intersection traffic capacity was calculated based on available actual infrastructure data. The standard setback equations for $\mathrm{CO}$ and $\mathrm{NO}_{2}$ below.

\section{For CO pollutant}

$\mathrm{D}=330.5-0.0066 \mathrm{C}-119.85 \mathrm{~L}-5.513 \mathrm{~T}-10.55 \mathrm{H}-3.311 \times 31$

For $\mathrm{NO}_{2}$ pollutant

$\mathrm{D}=258.25-0.0074 \mathrm{C}+65.32 \mathrm{~L}-2.712 \mathrm{~T}-10.03 \mathrm{H}-0.924 \times 100$

Where, capacity level traffic $\mathrm{C}=4783$ vph (referring to Appendix I-table A-1), L= 0 for $\mathrm{CBD}$, and rest of variables are the same as noted for other examples.

Equation 12.11 is the standard setback distance equation for $\mathrm{CO}$ pollutant, whereas Equation 12.12 is the standard setback distance equation for $\mathrm{NO}_{2}$ pollutant. Based on these two equations, the required setback distance at the noted intersection are $67.04 \mathrm{~m}$ for 
maintaining $\mathrm{CO}$ standards and $58.16 \mathrm{~m}$ for maintaining $\mathrm{NO}_{2}$ standards. Therefore, approximately 67 meters setback distance is suggested if vulnerable receptors (at the ground level) govern (Table 12-3).

Here, the U.S. ambient $\mathrm{NO}_{2}$ standard is taken into consideration for illustration purposes. It can be seen that the required setback distance for maintaining $\mathrm{NO}_{2}$ standard is less than the CO standard. The results could show the opposite implication if a higher percentage of heavy-duty vehicles use the simulated network.

Table 12-3 presents setback distance for various heights. These results show that pollutant concentrations decrease dramatically with vertical heights. The heights are considered on the basis of human activities. If people live on the ground floor, they are engaged in outdoor activities (such as gardening). Therefore, the human breathing height is considered for people living in the ground floor. However, for people living on upper floors and considering the average height of one floor of a high rise building to be 3 meters, the heights of $4 \mathrm{~m}$ and $7 \mathrm{~m}$ are applicable.

Table 12-3: Approximate setback distance at different heights

\begin{tabular}{|c|c|c|}
\hline $\begin{array}{c}\text { Height (in } \\
\text { meter) }\end{array}$ & $\begin{array}{c}\text { Setback distance (in meter) for } \\
\text { maintaining CO Standards }\end{array}$ & $\begin{array}{c}\text { Setback distance (in meter) for } \\
\text { maintaining } \mathrm{NO}_{2} \text { Standards }\end{array}$ \\
\hline 1.8 & 67.04 & 58.16 \\
\hline 4 & 43.83 & 36.09 \\
\hline 7 & 12.18 & 6.00 \\
\hline
\end{tabular}




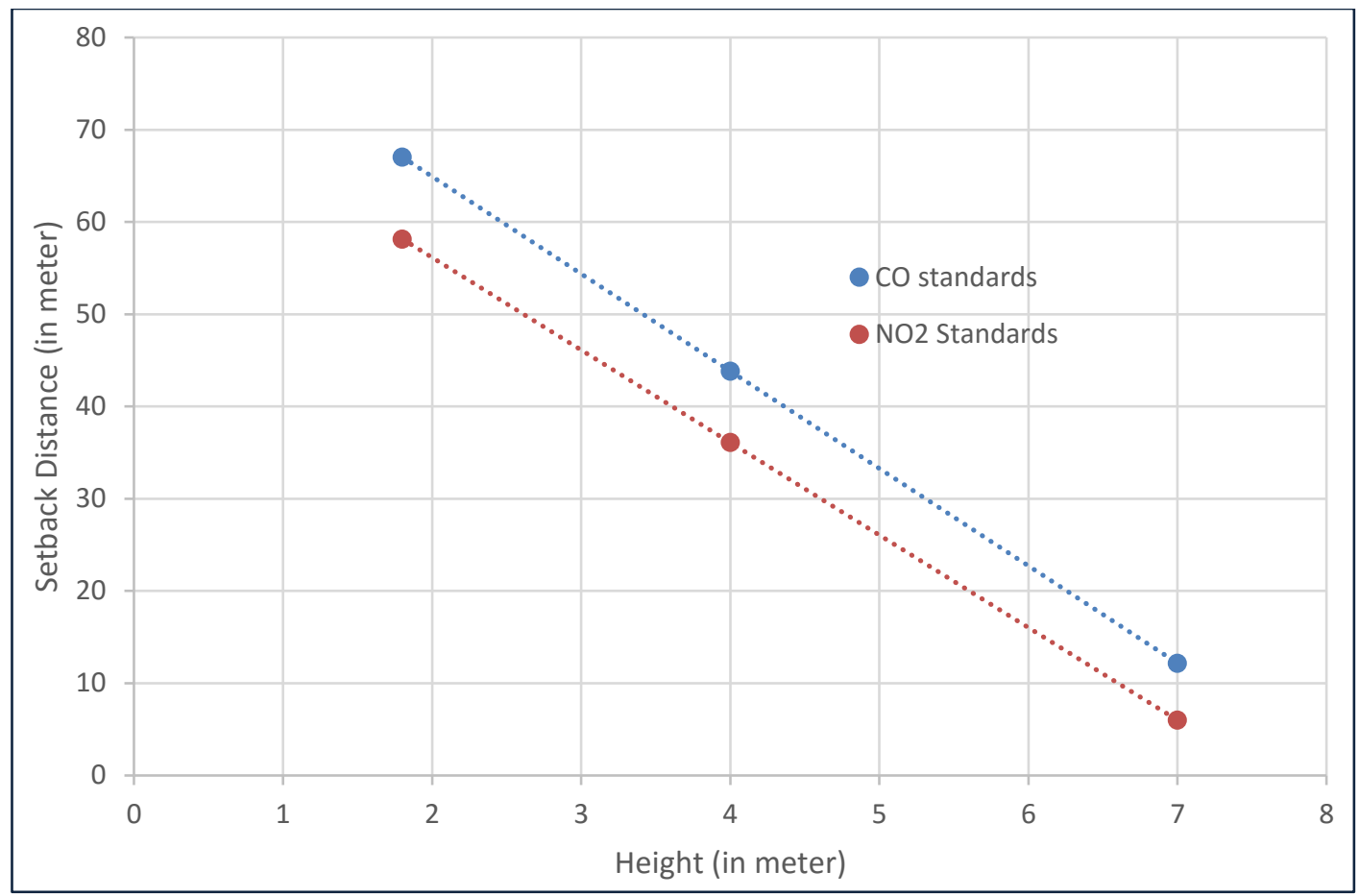

Figure 12-3: The joint effect of setback distance and height

Around a three leg existing intersection of two major arterials with capacity level traffic and adverse wind condition, the receptor will be subjected to pollutant concentrations higher than air quality standards. At such locations, at the ground floor level, nonresidential land use can be specified and windows facing traffic should not be opened during peak traffic conditions. At the second and higher floors, residents will not be subjected to concentrations higher than standards.

Now, if an existing intersection such as Carling avenue verses Bronson Avenue (Ottawa) is analyzed for illustration purposes, 67-meter setback distance suggests that vulnerable receptors should not be located at the ground floor or at the first floor level.

We can infer from example applications that the statistical models developed in this research can be used by planners to explore setbacks around traffic networks. These are 
statistically significant and are ready for immediate application in the real world. Municipal and provincial governments may wish to apply the predictive models in order to develop setback guidelines based on air quality objective and meet standards.

The predictive models reported in this thesis are based on worst-case condition 1-hour pollutant concentration. These enable the application of 1-hour exposure standards. However, further research will be required to develop 8-hour pollution concentration predictive models. Likewise, further research can investigate the development of a function that can modify pollutant concentration predicted by statistical models in order to account for the ventilation system. The methods and developed models reported in this thesis are based on the inhalation of the outdoor air (e.g. during outdoor activity, open window, siting in the balcony, etc.). Adding the ventilation system variable will further enhance the application potential. 


\section{CHAPTER 13: CONCLUSIONS, RECOMMENDATIONS, AND CONTRIBUTIONS}

\subsection{CONCLUSIONS}

There is sufficient scientific evidence that emissions, mainly from road vehicles, significantly effect environment and human health. In order to protect people, especially vulnerable members of population, ambient air quality standards have been defined by governments (e.g. Canada, USA) and the World Health Organization (WHO). Given that for many decades into the future, the internal combustion engine vehicles are likely to continue to be a very high proportion of the vehicle fleet and that only marginal improvements in emission reduction from road transportation can be expected, it is necessary to investigate separation distance between high traffic roads and vulnerable receptors.

It can argued that public transit is a valid way to reduce volume of internal combustion engine vehicles in urban areas. But, even high modal split levels are not likely to prevent "capacity level" worst-traffic condition on urban roads and urban freeways from time to time.

Although the principle of enabling mobility with due consideration to human health is now accepted in developed countries, there is a lack of detailed information on how to meet air quality standards and other guidelines in site planning. Although guidelines are available from municipal and provincial government sources on setback distance from urban roads and highways and the associated land use considerations, these do not take into account air 
quality standards and other guidelines. Also, there is a general lack of well researched information and methods for estimating concentration of harmful pollutants at various distances away from roads and at various heights (e.g. second floor of a building). In the absence of such information and methods, planners may not be in position to assess if a site plan meets the air quality standards.

Literature sources suggest that research has been carried out on area-wide exposure of population to harmful pollutants. Also, general guides have become available on location of institutional building complexes (campuses) such as hospitals and schools. However, there is a lack of research on methods for the estimation of air pollution concentrations under worst traffic and wind conditions so that compliance with air quality standards can be checked in site planning. Since there are standards regarding $\mathrm{CO}$ and $\mathrm{NO}_{2}$, a check on their concentration level assumes much importance. In the case of $\mathrm{PM}_{2.5}$, capability to estimate its concentration is a methodological asset. The purpose of this research is to contribute knowledge and methods in order to overcome information gaps.

Conclusions on methodology are presented first, followed by conclusions based on results obtained.

(1) At the outset, it was recognized that the challenge was to estimate pollutant concentration under worst case condition at the level of a receptor located some distance away from pollution source and at a defined height. To be absolutely certain about emission level at a location of a vulnerable receptor, instruments can be placed there. But, these readings will reflect prevailing conditions and not necessarily the "worst case" condition defined by high traffic and adverse wind condition. Both cannot be controlled. Further, it 
will be very expensive to place instruments at numerous representative sites and record readings over a year.

(2) The modelling and simulation approach is well accepted in the scientific community and it is the correct methodological course of action. Of course, simulators of high resolution have to be validated with field data. This approach is applied in the research and was found to be suitable for the task.

(3) The integrated modelling and simulation approach uses traffic micro-simulator, microscopic and mesoscopic emission factor estimators, and pollutant dispersion (air quality) model. The models used do not have a history of overestimation or underestimation. On the basis of reliability theory, the integrated approach does not propagate errors (if any).

(4) The verification of integrated simulation models was successful. The comparison of field samples with simulations provides differences in results from these two sources. However, these differences are within commonly accepted limits.

(5) Taking into account published guidelines regarding model verification, it is concluded that the research methodology provides results that are similar to field data.

(6) To meet the objective of developing tools that could be used to check pollutant concentrations at various distances and heights or to find setback distance for a specified condition, the simulation design methodology was developed and applied. The design and application of the methodology meets the statistical reliability requirement.

(7) The integrated simulation model when applied to selected building locations in Ottawa produced logical results. The concentration of pollutant drop with distance and height. The 
gradient is reasonable and logical. The results imply that in such situations the setback could be increased or land use could be modified in order to avoid subjecting vulnerable residents to high pollutant concentration.

(8) Simulation results were used to develop $\left(\mathrm{CO}, \mathrm{NO}_{2}, \mathrm{PM}_{2.5}\right)$ worst-case 1-hour emission concentration predictive models that are statistically significant. These non-linear regression models are better in terms of goodness of fit as compared to linear regression models. However, linear models offer ease of application. The ANN models compare well with non-linear models.

(9) The predicted concentration of emissions obtained from the statistical models are logical. For example, when applied to the midblock section of an arterial road, the $\mathrm{CO}$ and $\mathrm{NO}_{2}$ concentrations do not exceed the standards. However, around a three leg existing intersection of two major arterials with capacity level traffic and adverse wind condition, the receptor will be subjected to pollutant concentrations higher than air quality standards. At such locations, at the ground floor level, non-residential land use can be specified and windows facing traffic should not be opened during peak traffic conditions. At second and higher floors, residents will not be subjected to concentrations higher than standards.

\subsection{RECOMMENDATIONS}

(1) The integrated simulation methodology based mainly on microscopic models can be applied to estimate receptor level pollution concentration at specified locations.

(2) Since the site planner and policy analysts in professional practice may not have access to microsimulation models and/or may not have the experience to apply highly 
sophisticated tools, the statistical models developed in this research can be used. These are statistically significant and are ready for immediate application in the real world.

(3) Municipal and provincial governments may wish to apply the predictive models in order to develop set-back guidelines that take into account air quality objective and meet standards.

(4) Further research should be carried out on the development of predictive models with the capability to make 8 -hour pollution concentration predictions.

(5) Further research should consider the development of a function that can modify pollutant concentration predicted by statistical models in order to account for the ventilation system. The methods and developed models reported in this thesis are based on the inhalation of the outdoor air (e.g. during outdoor activity, open window, siting in the balcony, etc.). Adding the ventilation system variable will further enhance the application potential.

\subsection{CONTRIBUTIONS}

(1) No previous research has explored the subject of interrelationship between trafficgenerated pollutants under worst-case condition and setback distance at this level of detail and statistical validity. The integrated modelling and simulation capability applied to the exploration of setback distances is advancing the state of knowledge.

(2) The predictive models developed in this research are new. These can be of immediate interest to the real-world planners and policy analysts. 
(3) Taken together, the methods developed and information produced by case studies are a contribution to knowledge with potential to improve decisions on setback distance in order to protect vulnerable receptors. 


\section{REFERENCES}

AASHTO. (2004). A Policy on Geometric Design of Highways and Streets, Fifth Edition, ISBN: 1-56051-263-6. American Association of State Highway and Transportation Officials, Washington DC, USA.

Afroz, R., Hassan, M. N., \& Ibrahim, N. A. (2003). Review of air pollution and health impacts in Malaysia. Environmental Research, 92, 71-77.

Alberta. (2012, June). Roadside Development Application General Instructions. Government of Alberta, Transportation. Retrieved from http://www.transportation.alberta.ca/content/doctype329/production/rdpinstr.pdf

Alkadry, A., \& Khan, A. . (2001). Methodology for off-line assessment of advanced traffic signal control systems. Canadian Journal of Civil Engineering, 28, 111119.

Alterkawi, M. (2001). Application of GIS in Transportation Planning: The Case of Riyadh, the Kingdom of Saudi Arabia. Global Built Environmental Review (GBER) an international referred journal for architecture, planning, development and the environment, 1(2), 38-46.

Amirjamshidi, G., Mostafa, T., Misra, A., \& Roorda, M., J. (2013). Integrated Model for Microsimulating Vehicle Emissions, Pollutant Dispersion and Population Exposure . Transportation Research Part D: Transport and Environment, 18(1), $16-24$. 
Anderson, H. R., Ponce de Leon, A., Bland, J. M., Bower, J. S., \& Strachan, D. (1996). Air pollution and the daily mortality in London. BMJ Journals, 312, 665-669.

Armstrong, J. M., \& Khan, A. M. (2004). Modelling urban transportation emissions: role of GIS. Computers, Environment and Urban systems, 28, 421-433.

AustraliaAQS. (2014, February 27). Australia: Air Quality Standards. Retrieved from transportpolicy.net: http://transportpolicy.net/index.php?title=Australia:_Air_Quality_Standards

Axhausen, K. S. (2001). Locations, Commitments and Activity Spaces. Swiss Federal Institute of Technology: Bonn.

Bachman, W., Sarasua, W., Hallmark, S., \& Guensler, R. (2000). Modeling regional mobile source emissions in a geographic information system framework. Transportation Research Part C: Emerging Technologies, 8(1-6), 205-229.

Bartonova, A., Clench-Aas, J., Gram, F., Gronskei, K. E., Guerreiro, C., \& Larssen, S. (1999). Air pollution exposure monitoring and estimation traffic exposure in adults. Journal of Environ. Monit., 1(V), 337-340.

Batterman, S., Burke, J., Isakov, V., Lewis, T., Mukherjee, B., \& Robins, T. (2014). A Comparison of Exposure Metrics for Traffic-Related Air Pollutants: Application to Epidemiology Studies in Detroit, Michigan. Int. J. Environ. Res. Public Health, 11(9), 9553-9577.

Bauer, M., Hystad, P., \& Reynolds, C. (2012, March 28). Develop With Care 2012: Environmental Guidelines for Urban and Rural Land Development in British 
Columbia. Supporting Information - Air Quality. Prepared for the British Columbia Ministry of Environment. British Columbia, Canada: School of Population and Public Health, The University of British Columbia.

Bellander, T., Berglind, N., Gustavsson, P., Jonson, T., Nyberg, F., \& Pershagen, G. (2001). Using geographic information systems to assess individual historical exposure to air pollution from traffic and house heating in Stockholm. Environ Health Perspective, 109(6), 633-639.

Benson, P. (1989). CALINE4 - a dispersion model for predicting air pollutant concentrations near roadways. California: California Department of Transportation. Report no. FHWA/CA/TL-84/15.

Boco, A. G. (2010). Individual and Community Level Effects on Child Mortality: An Analysis of 28 Demographic and Health Surveys in Sub-Saharan Africa. Calverton, Maryland, USA: United States Agency for International Development.

Borrego, C., Tchepel, O., Costa, A.M., Amorim, J.H., Miranda, A.I. (2013). Emission and dispersion modelling of Lisbon air quality at local scale. Atmospheric Environment, V.37, Issue 37, Dec. 2003, pp.5197-5205.

Borrego, C., Tchepel, O., Salimim, L., Amorim, J.H., Costa, A.M., Janko, J. (2010). Integrated modeling of road traffic emissions: application to Lisbon air quality management. Cybernetics and Systems, Taylor and Francis.

Boyd, D. R. (2006, August). An International Comparison of Air Quality Standards and Guidelines. Retrieved from 
http://www.davidsuzuki.org/publications/downloads/2006/DSF-HEHC-AirWeb2r.pdf

Brauer, M., Hystad, P., \& Reynolds, C. (2012, March 28). Develop With Care 2012: Environmental Guidelines for Urban and Rural Land Development in British Columbia, Supporting Information - Air Quality. Victoria, B.C: Environmental Standards Branch, British Columbia Ministry of Environment.

Briant, R., Seigneur, C., Gadrat, M., \& Bugajny, C. (2013). Evaluation of Roadway Gaussian Plume Models with large-scale Measurement Campaigns. Geo-Sci. Model Dev., 6, 445-456.

Briggs, D., Collins, S., Elliott, P., Fischer, P., Kingham, S., \& Lebret, E. (1997). Mapping urban air pollution GIS: a regression-based approach. Int. J. Geogr. Inf. Sci., 11(7), 699-718.

Brown, A. L., \& Affum, J. K. (2002). A GIS-based environmental modelling system for transportation planners. Computers, Environment and Urban Systems, 26, 577590.

Cacciola, R. R., Sarva, M., \& Polosa, R. (2002). Adverse respiratory effects and allergic susceptibility in relation to particulate air pollution: flirting with disaster. Allergy, $57,281-286$.

CALRoads. (2014). CALRoads View Version 6.2. Retrieved from Lakes Environmental: https://www.weblakes.com/Newsletter/2014/Feb2014.html 
CanadaAQS. (2013, June 24). Transportpolicy.net. Retrieved from Canada: Air Quality Standards: http://transportpolicy.net/index.php?title=Canada:_Air_Quality_Standards

Charlot, H. M. (2002). Air pollution modeling for Chennai city using GIS as a tool. MapIndia conference. New Delhi, India.

Collins, S. (1998). Modelling spatial variations in air quality using GIS. In T. Gatrell, \& M. Loytonen, (Ed.), GIS and Health Taylor \& Francis (pp. 81-95). Philadelphia.

Dalvi, M., Beig, G., Patil, U., Kaginalkal, A., Sharma, C., \& Mitra, A. P. (2006). A GIS based methodology for gridding of large-scale emission inventories: Application to carbon monoxide emissions over Indian region. Atmospheric Environment, 40, 2995-3007.

de Hoogh, C., Gulliver, J., Briggs, D., \& Mitchell, J. (2002). A comparison of techniques for modelling exposure to traffic-related air pollution in contrasting urban environments. AIRNET Annual Conference. London, UK.

DOT. (2014). U.S. Department of Transportation. Retrieved from Transportation.gov: https://www.transportation.gov

Draper \& Smith. (1981). Applied Regression Analysis. Second Edition.

Dutra, R., \& Szklo, A. (2008). Assessing long-term incentive programs for implementing wind power in Brazil using GIS rule-based methods. Renewable Energy, 33, $2507-2515$. 
EC. (2014). Emission Inventory Report. Environment and Climate Change Canada, Government of Canada. Retrieved from https://www.ec.gc.ca/pollution/default.asp?lang=En\&n=E96450C4-1

EEA. (2016). Air quality in Europe - 2016 report. Copenhagen, Denmark: European Environment Agency, ISSN 1977-8449. Retrieved from Web: eea.europa.eu

EEH. (1976). Environmental Health, Volume 6. National Library of Medicine.

Elliott P., Wakefield J., Best N., \& Briggs, D. (2000). Spatial Epidemiology: Methods and Applications. In D. Briggs (Ed), Exposure assessment (pp. 335-359). Oxford University Press.

English, P., Neutra, R., Scalf, R., Sullivan, M., Waller, L., \& Zhu, L. (1999). Examining associations between childhood asthma and traffic flow using a geographic information system. Environ Health Perspective, 107, 761-767.

EUAQS. (2013, July 17). Transportpolicy.net. Retrieved from European Union: Air Quality Standards: http://transportpolicy.net/index.php?title=EU:_Air_Quality_Standards

FISITA. (2012). Proceedings of the FISITA 2012 World Automotive Congress: Volume 12 . Society of Automative Engineering.

Fukutomi, A. (2004). Simulation Approach to the Study of Driving Behaviour, Fuel Consumption and Emissions. MASc Thesis Dissertation. Ottawa, Ontario, Canada: Carleton University. 
Ganguly, R., \& Broderick, B. M. (2009). Development of models for predicting roadside nitrogen dioxide concentrations and their evaluation against datasets measured in Dublin, Ireland. Transportation Research Part D, 14, 231-239.

Garber, N. J., \& Hoel, L. A. (2013). Traffic and Highway Engineering. Fifth Edition.

Garcia, J. (2004, August). Modelling Fuel Consumption of Advance Technology Vehicles in Traffic Networks Using Artificial Neural Networks. Ph.D. Thesis. Ottawa, Ontario, Canada: Carleton University.

Gifford, G. F. (1985). Watershed Management in the eighties. Watershed Management of the Irrigation and Drainage (pp. 23-31). New York: American Society of Civil Engineers.

Goodchild, M. F. (1980). Statistical aspects of the polygon overlay problem . In G. Dulton, Havard papers on Geographical Information System. 6, Addition Wesley: Reading press.

Guxens, M., \& Sunyer, J. (2012). A review of epidemiological studies on neuropsychological effects of air pollution. Swiss Med. Wkly., 141, 13322.

Hart, J. E., Chiuve, S. E., Laden, F., \& Albert, C. M. (2014, October 13). Roadway Proximity and Risk of Sudden Cardiac Death in Women. Retrieved from https://doi.org/10.1161/CIRCULATIONAHA.114.011489

Hays, W. L. (1970). Statistics: Probability, Inference, and Decision. ISBN 03-085874-7.

HEI. (2010). Traffic-related air pollution: A critical review of the literature on emissions, exposure, and health effects. Report No. 17. Boston: Health Effects Institute. 
Hewitt, C. N. (1991). Spatial variations in nitrogen dioxide concentrations in an urban area. Atmos. Environ., 25(B), 429-434.

Hoek, G., Brunekreef, B., Goldbohm, S., Fischer, P. \& van den Brant, P. (2002, September 24). Association between mortality and indicators of traffic-related air pollution in the Netherlands: a cohort study. Netherland: Lancet published online.

Hulsmann, F., Gerike, R., Ketzel, M. (2014). Modelling traffic and air pollution in an integrated approach - the case of Munich. Urban Climate, V.10, Part 4, Dec. 2014, pp.732-744.

IndianAQS. (2009, November 16). New Delhi: The Gazette of India. Retrieved from http://www.indiaenvironmentportal.org.in/files/826.pdf

Isakov, V., Touma, J. S., Burke, J., Lobdell, D. T., Palma, T., Rosenbaum, A., \& Kozkaynak, H. (2009). Combining Regional- and Local-Scale Air Quality Models with Exposure Models for Use in Environmental Health Studies. Journal of Air \& Waste Manage. Assoc., 59, 461-472.

Jagannathan, R., \& Khan, A. (2001). Methodology for the assessment of traffic adaptive control systems. ITE Journal, 28-32.

JapanMoE. (n.d.). Ministry of Environment . Retrieved from Government of Japan: http://www.env.go.jp/en/air/aq/aq.html

Jayaratne, E. R., Wang, L., Heuff, D., Morawska, L., \& Ferreira, L. (2009). Increase in particular number emissions from motor vehicles due to interruption of steady traffic flow. Transportation Research Part D, 14, 521-526. 
Jerrett, M., Arain, A., Kanaroglou, P., Beckerman, B., Potoglou, D., Sahsuvaroglu, T., Morrison, J., \& Giovis, C. (2005). A review and evaluation of intra-urban air pollution exposure models. Journal of Exposure Analysis and Environmental Epidemiology, 15, 185-204.

Jerrett, M., Burnett, R. T., Kanaroglou, P. S., Eyles, J., Brook, J. R., \& Giovis, C. (2001). A GIS -environmental justice analysis of particulate air pollution in Hamilton, Canada. Environ Plann. -A, 33, 955-973.

Jerrett, M., Sears, M., Giovis, C., Burnett, R., Kanaroglou, P., Elliott, S., Cakmak, S., Gossilin, P., Bedard, Y., Maclachlan, J., \& Cole, D. (2001). Intra-urban Air Pollution Exposure and Asthma Prevalence in Hamilton, Canada. International Society of Exposure Analysis (part-b). Charleston, SC, USA.

Karner, A.A., Eisinger, D.S., Niemeier (2010). Near-Roadway Air Quality: Synthesizing the Findings from Real-World Data. Environ.Sci. Technol. 2010, 44, 5334-5344. Kentucky. (2014, April). 2014 Final Highway Plan. Retrieved from Kentucky Transportation Cabinet: http://transportation.ky.gov/ProgramManagement/Pages/2014-Final-Highway-Plan.aspx

Kirwa, K., Eliot, M. N., Wang, Y., Adams, M. A., Morgan, C. G., Kerr, J., ... \& Wellenius, G. A. (2014). Residential Proximity to Major Roadways and Prevalent Hypertension among Postmenopausal Women: Results from the Women's Health Initiative San Diego Cohort. Journal of the American Heart Association, 3. Retrieved from www.10.1161/JAHA.113.000727 
Klimont, Z., Cofala, J., Scho”pp, W., Amann, M., Streets, D. G., \& Ichikawa, Y. (2001). Projections of SO2, NOx, NH3 and VOC emissions in East Asia up to 2030. Journal of Water Air Soil Pollutant, 130, 193-198.

Kramer, U., Koch, T., Ranft, U., Ring, J., \& Behrendt, H. (2000). Traffic-related air pollution is associated with atopy in children living in urban areas. Epidemiology, 11, 64-70.

Krueckeberg, D. A., \& Silvers, A. L. (n.d.). Urban Planning Analysis: Methods and Models. Toronto: John Wiley \& Sons, Inc.

Lebret, E., Briggs, D., Van Reeuwijk, H., Fischer, P., Smallbone, K., \& Harssema, H. (2000). Small area variations in ambient NO2 concentrations in four European areas. Atmos. Environ., 34, 177-185.

Leech, J. A., Nelson, W. C., Burnett, R. T., Aaron, S., \& Raizenne, M. E. (2002). It's about time: a comparison of Canadian and American time-activity patterns. $J$ Expos Anal Environ Epidemiol., 12(6), 427-432.

Liu, L. J., Delfino, R., \& Koutrakis, P. (1997). Ozone exposure assessment in a southern California community. Environ Health Perspect, 105, 58-65.

Liu, W., Zhang, B., Wang, Z., Song, K., Liu, D., Ren, C., \& Du, J. (2010). Development of a GIS-based decision support system for eco-environment and natural resources of Northeast Asia. Environment Science, 2, 906-913.

Lue, S. H., Wellenius, G. A., Wilker, E. H., Mostofsky, E., \& Mittleman, M.A. (2013 May 13). Residential proximity to major roadways and renal function. $J$ 
Epidemiol Community Health, 67(8), 629-634. Retrieved from 10.1136/jech2012-202307

Ma, X., Huang, Z., Koutsopoulos, H. (2014). Integrated traffic and emission simulation: a model calibration approach using aggregate information. Environmental Modeling \& Assessment, August 2014, V.19, Issue 4, pp.271-282., Springer Link.

Mage, D. T., Wilson, W., Hasselblad, V., \& Grant, L. (1999). Assessment of human exposure to ambient particulate matter. J Air Waste Manage Assoc., 49, 12801291.

Mark, D. M., \& Anonson, P. B. (1984). Scale dependent fractal dimensions of topographic surfaces: an experienced investigation with application in geomorphology and computer mapping. Mathi Geol., 16, 671-683.

McClave, J. T., \& Dietrich, F. H. (1988). Statistics. Fourth Edition. ISBN 0-02-379260-4.

Melnick, A. (2002). Introduction to Geographic Information Systems in Public Health. Maryland: Aspen Publishers.

Ministry of the Environment New Zealand (2004). Good Practice Guide for Atmospheric Dispersion Modelling. National Institute of Water and Atmospheric Research, Aurora Pacific Limited and Earth Tech Incorporated for the Ministry for the Environment, New Zealand (June 2004).

Montana. (2014, March). Traffic Noise impact Assessment, p14. Retrieved from Montaka Department of Transportation:

https://www.mdt.mt.gov/pubinvolve/docs/eis_ea/blg_bypass/feis_blg_bypass_app e.pdf 
MoT. (n.d.). Ministry of Transportation, British Columbia. Retrieved from https://www.th.gov.bc.ca/permits/structures\%20permits.asp

MTO. (2009, June 2). Ministry of Transportation, Ontario. Retrieved from http://www.mto.gov.on.ca/english/engineering/management/corridor/bldg-landuse-policy2009.pdf

Mukala, K., Alm, S., Tiittanen, P., Salonen, R. O., Jantunen, M., \& Pekkanen, J. (2000). Nitrogen dioxide exposure assessment and cough among preschool children. Arch Environ Health, 55, 431-438.

Mulholland, J. A., Butler, A. J., Wilkinson, J. G., Russell, A. G., \& Tolbert, P. E. (1998). Temporal and spatial distributions of ozone in Atlanta: regulatory and epidemiologic implications. J Air Waste Manage Assoc., 48, 418-426.

Nafstad, P., Haheim, L. L., Oftedal, B., Gram, F., Holme, I., Hijermann, I., \& Leren, P. (2003). Lung cancer and air pollution: a 27 year follow up of 16209 Norwegian men. Thorax, 58, 1071-1076.

Narayana, S., Kumar, J. A., \& Kant, P. K. (2012). Comparison of Regression and Artificial Neural Network Impact Assessment Models: A Case Study of MicroWatershed Management in India. International Environmental Modelling and Software Society (iEMSs). International Congress on Environmental Modelling and Software. Retrieved from http://www.iemss.org/society/index.php/iemss2012-proceedings 
NAS. (1977). Annual Report - National Academy of Sciences. The National Academic Press.

Nijkamp, P. (1994). Roads toward environmentally sustainable transport. Transportation Research Part A: Policy and Practice, 28 (4), 261-271.

Pandian, S., Gokhale, S., \& Ghosal, A. K. (2009). Evaluating effects of traffic and vehicle characteristics on vehicular emissions near traffic intersections. Transportation Research Part D, 14, 180-196.

Park, B. B., Won, J., \& Yun, I. (n.d.). Application of microscopic Simulation Model Calibration and Validation Procedure: A case study of Coordinated Actuated Signal System.

Patil, U., Ravan, S., \& Kaushal, A. (2003, August). GIS-based air pollution surface modeling. GIS @ Development.

Peavy, H. S., \& Rowe, D. R. (1985). Environmental Engineering. McGraw-Hill. ISBN 0070491348 TD 145.P43 1985628 84-3854.

Pellakuri, V., Rao, R., Prasanna, L., \& Santhi, M. V. B. T. (2015, July 20). A Concentual Framework for Approaching Predictive Modeling Using Multivariate Regression Analysis vs Artificial Neural Network. Journal of Theoretical and Applied Information Technology, 77(2), ISSN: 1992-8645.

Potoglou, D., \& Kanaroglou, P. (2002). Spatial variation estimation of CO concentration from mobile sources in the city of Hamilton. Hamilton, Canada: Center for Spatial Analysis, McMaster University . 
Pourkhorsand, H. (2009, August). A Comparison of Neural Networks and Statistical Methods in Tour-Based Travel Demand Modeling. Master of Applied Science (M.A.Sc.) Thesis. Ottawa, ON, Canada: Carleton University.

Rebolj, D., \& Sturm, P. J. (1999). A GIS based component-oriented integrated system for estimation, visualization and analysis of road traffic air pollution. Environmental Modelling \& Software, 14, 531-539.

Reddy, G. P. (2011). Spatial databases and their analysis in GIS. Lecture notes for participants of NNRMS (ISRO) - Sponsored training program on Remote Sensing and GIS applications in Land Evaluation for Land Use Planning organized by GIS section, National Bure.

Ritz, B., Yu, F., Chapa, G., \& Fruin, S. (2000). Effects of air pollution on preterm birth among children born in Southern California between 1989 and 1993. Epidemiology, 11, 502-511.

Rivas, I., Viana, M., Moreno, T., Pandolfi, M., Amato, F., Reche, C., ... \& Querol, X. (2014). Child exposure to indoor and outdoor air pollutants in schools in Barcelona, Spain. Environ. Int., 69, 200-212.

Rosenbloom, J. I., Wilker, E. H., Mukamal, K. J., Schwartz, J., \& Mittleman, M. A. (2012). Residential Proximity to Major Roadway and 10-Year All-Cause Mortality After Myocardial Infarction. Circulation, 125, (pp. 2197-2203). Retrieved from https://doi.org/10.1161/CIRCULATIONAHA.111.085811 
Ross, Z., English, P. B., Scalf, R., Gunier, R., Smorodinsky, S., Wall, S., \& Jerret, M. (2006). Nitrogen dioxide prediction in Southern California using land use regression modeling: potential for environmental health analyses. Journal of Exposure Science and Environmental Epidemiology, 16, 106-114.

Rowe, D. R. (1970). Instrumental Methods for Monitoring Oxidants and Oxides of Nitrogen. Report for Nat Air Pol Cont Admin.

Rrecaj, A. A., \& Bombol, K. M. (n.d.). Calibration and Validation of the VISSIM parameters - State of the Art. TEM Journal, 4(3), 255-269.

Scire, J. S., Robe, F., Fernau, M. E., Insley, E. M. \& Yamartino, R. J. (1997). A user's guide for the CALMET Meteorological Model (version 5). Concord, Massachusetts: Earth Tech, Inc: .

Seinfeld, J. H., \& McRae, G. J. (1979, May 2-4). Use of models to established sourcereceptor relationships and estimate relative source contributions of NOx to air quality problem. Technical Symposium on the Implications of low NOx vehicle emission standard. Reston: U.S. Environmental Protection Agency.

Shayko, S., Vesely, J., \& Hains, H. (2014, June 11). Local Air Quality Assessment Scott Street/Albert Street Bus Detour and LRT Construction, Ottawa, Reference No. 140021(2). Ottawa, Ontario, Canada: Novus Environment.

Shekarrizfard, M., \& Hatzopoulou, M. (2015). Air Quality Simulation of Traffic Related Emissions: Application of Fine-Scaled Dispersion Modelling. Canadian Transportation Research Forum Annual Conference . Montreal. 
Sikdar, P. K. (2001, December 4-5). A framework for evaluation of transport development and management option using pollution profile technique. Workshop on land use, transport and environment. Pune, India.

Silverman, F. \&. (2007). Cardiovascular Toxicity of Concentrated Ambient Fine, Ultrafine and Coarse Particles in Controlled Human Exposures. Harvard School of Public Health. Retrieved from https://www.hsph.harvard.edu/epacenter/projects.html

TAC. (1995). Urban Supplement to The Geometric Design Guide for Canadian Roads. Transportation Association of Canada.

ThailandAQS. (n.d.). Thailand: Air Quality Standards. Retrieved from http://www.pcd.go.th/info_serv/reg_std_airsnd01.html

Thiering, E., Cyrys, J., Kratzsch, J., Meisinger, C., Hoffmann, B., Berdel, D., ... \& Heinrich, J. (2013, April 12). Long-term exposure to traffic-related air pollution and insulin resistance in children: results from the GINIplus and LISAplus birth cohorts Diabetologia. doi:10.1007/s00125-013-2925-x

Thill, J. C. (2000). Geographic Information Systems for Transportation Research. Pergamon: Oxpord, 3- 12.

TRB. (2017, January 11). Near-road Pollution Concentrations Monitoring. Presentation by the representative of the U.S. EPA in the committee meeting on Transportation and Air Quality. Transportation Research Board Annual Conference 2017. 
UEMI. (2014, September 23). Transport Action Plan: Urban Electric Mobility Initiative. New York: Climate Summit 2014, UN Headquarters . Retrieved from http://www.un.org/climatechange/summit/wpcontent/uploads/sites/2/2014/09/TRANSPORT-Action-Plan-UEMI.pdf

UoT. (2015, April 21). Traffic emissions may pollute 1 in 3 Canadian homes, University of Toronto News. Toronto: University of Toronto.

USEPA. (1971). EPA Takes National Action on Air Quality. United States Environmental Protection Agency. Retrieved from https://www.epa.gov/History

USEPA. (1975). Effects of Air Pollution. Atlanta: Air Pollution Control Oriented Course, (422-A), U.S. EPA.

USEPA. (1997). An office building occupants guide to indoor air quality. Tech. rep. United States Environmental Protection Agency.

USEPA. (2014). EPA 2014 Plan. Washington DC: U.S. Environmental Protection Agency . Retrieved from https://nepis.epa.gov/Exe/ZyPDF.cgi/P100DFCQ.PDF?Dockey=P100DFCQ.PDF

USEPA. (2017). National Ambient Air Quality Standards. United States Environmental Protection Agency.

USEPA. (n.d.). U.S. Environmental Protection Agency Third Annual Report. United States Environmental Protection Agency. Retrieved from https://www.epa.gov/research/annual-reports.

Vardoulakis, S., Fisher, K.P., Gonzalez-Flesca, G. (2003). Modelling air quality in street 
canyons: a review. Atmospheric environment, Elsevier, 2003, 37(2), pp.155-182.

Venkatrama, A., \& Horstb, T. W. (2006). Approximating dispersion from a finite line source. Atmospheric Environment 40, 2401-2408.

Wald, M. L. (2010, January 12). Vehicle Exhaust to health problems . The New York Times.

Walpole, R. E. (1982). Introduction to Statistics. New York: Macmillan Publishing Co., Inc. ISBN 0-02-977650-3.

Wang, G., van den Bosch, F. H. M., Kuffer, M. (2008). Modelling Urban Traffic Air Pollution Dispersion. The International Archives of the Photogrammetry, Remote Sensing and Spatial Information Sciences, XXXVII (B8) . Beijing.

Weidmann74. (n.d.). Analysis of the Wiedemann Car Following Model over Different Speeds using Naturalistic Data . Higgs, Abbas, and Medina . Federal Highway Administration under Agreement No. DTFH 61-09-H-00007.

Wolf, P. C. (1971). Carbon monoxide measurement and monitoring in urban air. Environ. Sci. Technol., 5 (3), 212-218.

Woody, T. (2006). Weidmann99: Calibrating Freeway Simulation Model in VISSIM.

WorldBank. (2010). Air Pollution in World Cities (PM10 Concentrations). Research and Development, The World Bank. Retrieved from http://econ.worldbank.org/WBSITE/EXTERNAL/EXTDEC/EXTRESEARCH/0, contentMDK:20785646 pagePK:64214825 piPK:64214943 theSitePK:469382, 00.html 
Y, G. (2008, September 5). Calibration and Comparison of the VISSIM and INTEGRATION Microscopic Traffic Simulation Models . Master of Science Thesis. Blacksburg, Virginia: Virginia Polytechnic Institute and State University.

Zhong, J., Cai, X-M., Bloss, W.J. (2016). Coupling dynamics and chemistry in the air pollution modelling of street canyons: A review. Environmental Pollution, V.214, July 2016, pp.690-704.

Zhu, Y., \& Zhang, Q. (2014). Characterizing Ultrafine Particles and Other Air Pollutants In and Around School Buses. California-Los Angeles: University of California-Los Angeles. Health Effects Institute Research Report No. 180.

Zhu, Y., Hinds, W., Kim, S., Shen, S., \& Sioutas, C. (2002). Study of ultrafine particulars near a major highway with heavy-duty diesel traffic. Atmos. Environ., 36, 43234335 . 


\section{APPENDIX: Background Information on}

- Emissions

- Air pollution

- Health Effects

- Ambient Air Quality Standards 


\section{BACKGROUND}

\section{A.1 ROAD TRANSPORTATION EMISSIONS}

The major sources of primary pollutants are from the transportation sector. These pollutants are carbon monoxide $(\mathrm{CO})$, oxides of nitrogen $\left(\mathrm{NO}_{\mathrm{x}}\right)$, hydrocarbon $(\mathrm{HC})$, and particulate matter (PM). (Table A1-1, Figures A1-1 to A1-2). According to Environment Canada's 2014 emissions inventory report, the major source of two most important primary gaseous pollutants is the transportation sector. A recent statistical report published by the European Environmental Agency presents road transportation emissions for 15 European countries. See Figure A1-2. It can be observed that about 70 percent of $\mathrm{CO}$ emission is generated by road transportation. The corresponding share for $\mathrm{NO}_{\mathrm{X}}$ is about 63 percent $(E E A, 2016)$.

\section{Table A1-1: Sources of pollutants}

(Source: Twelfth Annual Report, US EPA)

\begin{tabular}{|l|c|c|c|c|c|c|}
\hline \multicolumn{1}{|c|}{ Pollutants (in million tonnes per year) } \\
\hline \multicolumn{1}{|c|}{ Source } & $\mathbf{C O}$ & Particulates & $\mathbf{S O}_{\mathbf{x}}$ & $\mathbf{H C}$ & $\mathbf{N O}_{\mathbf{x}}$ & Total \\
\hline Transportation & 69.1 & 1.4 & 0.9 & 7.8 & 9.1 & 88.3 \\
\hline $\begin{array}{l}\text { Combustion from stationary } \\
\text { sources (power, heating) }\end{array}$ & 2.1 & 1.4 & 19.0 & 0.2 & 10.6 & 33.3 \\
\hline Industrial Processes & 5.8 & 3.7 & 3.8 & 10.8 & 0.7 & 24.8 \\
\hline Solid-waste disposal & 2.2 & 0.4 & 0.0 & 0.6 & 0.1 & 3.3 \\
\hline $\begin{array}{l}\text { Miscellaneous (forest fires, } \\
\text { agriculture, etc.) }\end{array}$ & 6.2 & 0.9 & 0.0 & 2.4 & 0.2 & 9.7 \\
\hline Total & 85.4 & 7.8 & 23.7 & 21.8 & 20.7 & 159.4 \\
\hline
\end{tabular}




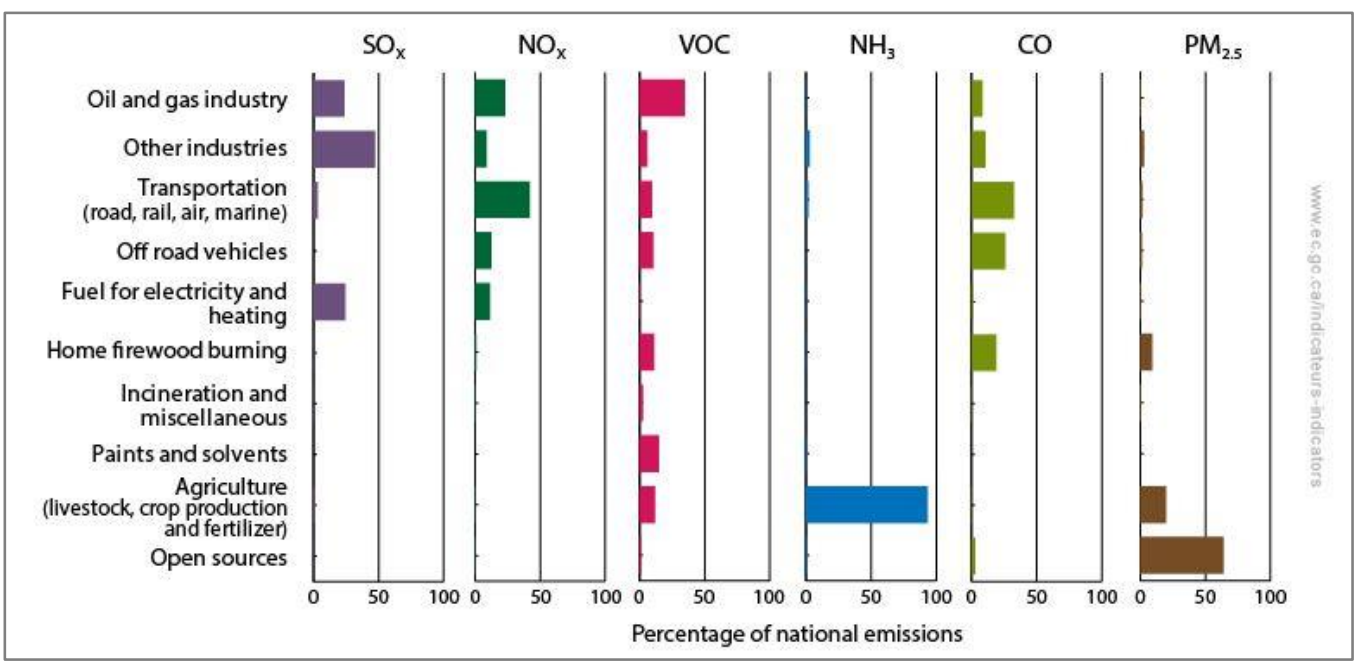

Figure A1-1: Distribution of air pollutant emissions

(Source: Environment Canada, 2014)

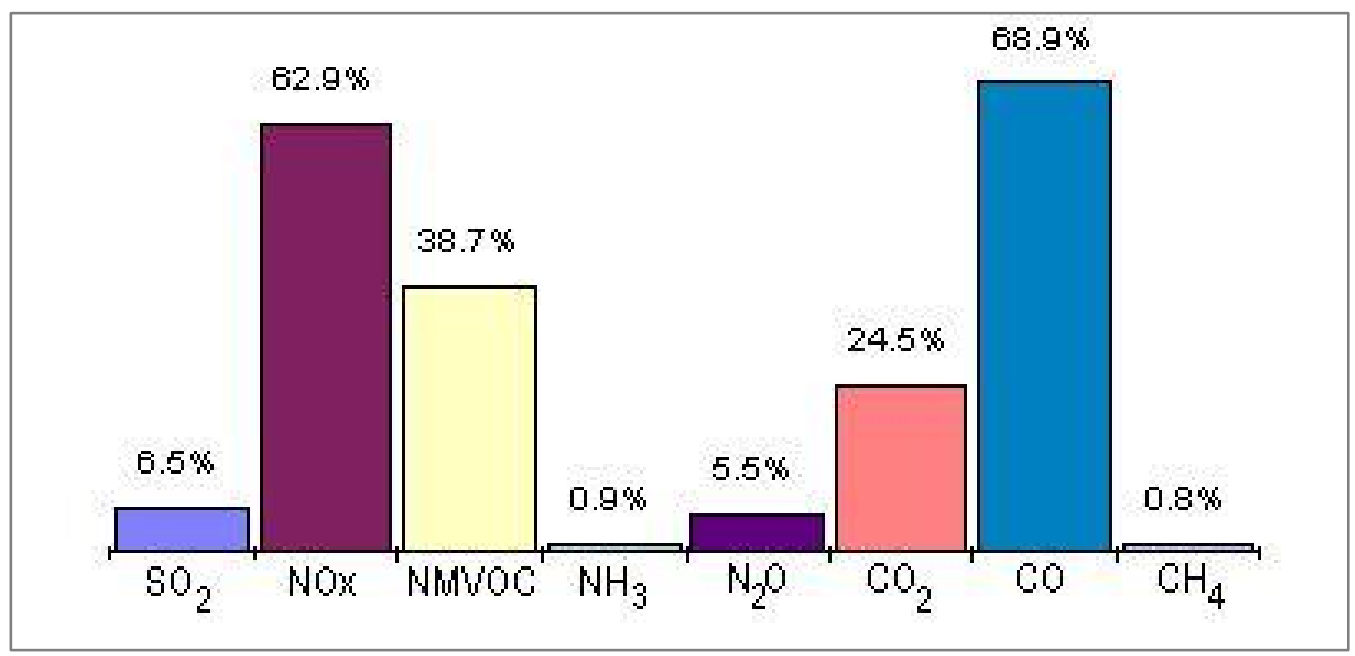

Figure A1-2: Primary air pollution sources from road transportation (Source: European Environmental Agency, 2016)

A majority of urban residents live close to major roads. More than 45 million people in the United States live, work, or attend school within 300 feet (100 meter) of a major road, airport or railroad (USEPA, 2014). Exposure to pollution is even more dangerous for Canada. One in three Canadian homes receives traffic emissions. In Toronto, about half of 
the population lives within 250 metres of major roads (UoT, 2015). For a number of reasons including building setback distances, there has been a growing concern about the health impacts of roadway traffic dating back to many decades (USEPA, 1975). This concern continues to date. If this were the scenario in developed countries such as Canada and the USA, where land use is generally well planned, what would be effects in developing countries?

The ventilation in buildings is also an important factor in pollutant exposure studies and related dose calculation. Figures A1-3 and A1-4 show the contrast in the land use pattern between developed countries and developing countries. Although Figure A1-4 shows the on-road land use and activities in Philippines, this scenario is also common in the Indian sub-continent. People spend most of their time near roads for either living or business. As an example, traffic police officers stand in an intersection about 8 hours a day to manually control traffic. Moreover, conducting street business is common activity in those regions. In most slum areas, people spend their entire life near roads and breathe poor quality air.

Health effects of vehicular emissions near roads can be studied in qualitative as well as in quantitative terms. According to the United Nations sources, over 600 million people in urban areas around the world were exposed to high levels of traffic-generated air pollutants (Cacciola et al., 2002). The Canadian Medical Association suggested that there are 21,000 premature deaths in Canada each year due to air pollution. A 2010 World Bank report indicates that as compared to on-going studies carried out in the developed world, exposure assessment studies in developing countries are relatively scarce (See Table A1-2). 
Table A1-2: Worse pollution levels in cities

(Source: World Bank Statistics, 2010)

\begin{tabular}{|c|c|}
\hline Most Polluted World Cities by Particulate Matter(PM) \\
\hline $\boldsymbol{P M}, \boldsymbol{\mu g} \mathbf{m}^{\mathbf{3}} \mathbf{( 2 0 0 4 )}$ & City \\
\hline 168 & Cairo, Egypt \\
\hline 150 & Delhi, India \\
\hline 128 & Kolkata, India (Calcutta) \\
\hline 125 & Tianjin, China \\
\hline 123 & Chongqing, China \\
\hline 109 & Kanpur, India \\
\hline 109 & Lucknow, India \\
\hline 104 & Jakarta, Indonesia \\
\hline 101 & Shenyang, China \\
\hline
\end{tabular}

Although latest emission standards and technical improvement in pollution control measures have the potential to reduce emissions, rapidly expanding industrialization and increasing traffic volumes in the developing countries are expected to drastically increase total emissions of many air pollutants (Klimont et. al., 2001).

According to literature, sampling of air pollutants is very expensive and time consuming. In 2001, the U.S.EPA carried out various epidemiological studies in the San Diego area. A large number of locations (i.e. 1300) were considered (e.g. police stations, libraries, and religious institutions) for $\mathrm{NO}_{2}$ monitoring using passive diffusion tubes. Due to financial constraints, they were able to monitor only 39 sites successfully and concluded that $\mathrm{NO}_{2}$ concentrations vary throughout the year. The lowest levels were recorded in June to August and highest levels in December to January periods. 
A similar research study was carried out in Toronto by using the dispersion model and emissions were analysed by buffer tool in geographical information system (GIS). Although an examination of dispersion model results suggests that $80-90 \%$ of the decay of pollutants occurred within 150-200 m, model results suggested that detectable effect could be identified at higher distances. This observation implies the inclusion of wider buffers. In particular, researchers found $\mathrm{NO}_{2}$ concentrations within $500 \mathrm{~m}$ and at some locations within $1500 \mathrm{~m}$ (downwind) of an expressway. (Ross et. al., 2005).

\section{A.2 AIR POLLUTION}

Air pollution implies the presence of foreign substances in the outdoor atmospheric air (e.g. dust, fumes, gas, mist, smoke or vapour). Air pollution has severe adverse health effects. Depending upon characteristics and duration, air pollutants have adverse effects on human health. According to the Indian Standards Institute IS-4167-1966 "Air pollution is the presence in ambient atmosphere of substances, generally resulting from the activity of man, in sufficient concentration, present for the sufficient time and under circumstances which interfere significantly with the comfort, health or welfare of persons" (ISI, 1966). This applies to all human activities (e.g. to provide food, shelter, amenities and transport).

The sources of these pollutants are categorized into two main groups - mobile transportation (i.e. motor vehicles, rail, and evaporation of gasoline), and stationary sources, (e.g. point sources such as industrial processes, and area sources like residential heating). See Figure A1-5 for an illustration of these emission sources. 
As shown in Table A1-3, pollutants can be further classified as particulate or gaseous. Particulate pollutants are finely divided as solid and liquid. Under proper conditions, particulate pollutants will settle out of the atmosphere. Gaseous pollutants completely occupy the space into which they are released, and behave much as air and do not settle out of the atmosphere.

Table A1-3: Classification of pollutants

(Source: Peavy and Rowe, 1985)

\begin{tabular}{|c|l|l|}
\hline Major Classes & \multicolumn{1}{|c|}{ Subclasses } & \multicolumn{1}{c|}{ Typical members of subclasses } \\
\hline Particulates & Solid & Dust, smoke, fumes, fly ash \\
\cline { 2 - 3 } & Liquid & Mist, spray \\
\hline \multirow{4}{*}{ Grganic } & Hydrocarbon & $\begin{array}{l}\text { Hexagon, benzene, ethylene, methane, } \\
\text { butane, butadiene }\end{array}$ \\
\cline { 2 - 3 } & $\begin{array}{l}\text { Aldehydes and } \\
\text { ketones }\end{array}$ & Formaldehyde, acetone \\
\cline { 2 - 3 } & Other organics & Chlorinated hydrocarbons, alcohols \\
\hline \multirow{2}{*}{ Inorganic } & Oxides of Carbon & Carbon monoxide, carbon dioxide \\
\cline { 2 - 3 } & Oxides of sulfur & Sulfur dioxide, sulfur trioxide \\
\cline { 2 - 3 } & Oxides of nitrogen & Nitrogen dioxide, nitric oxide \\
\cline { 2 - 3 } & Other inorganics & $\begin{array}{l}\text { Hydrogen sulfide, hydrogen fluoride, } \\
\text { ammonia }\end{array}$ \\
& &
\end{tabular}

Gaseous pollutants are further classified according to their chemical composition, as either organic or inorganic. Organic compounds mainly contain carbon and hydrogen, and many contain elements such as oxygen, nitrogen, phosphorus, and sulfur. Inorganic materials 
found in contaminated atmosphere include carbon monoxide $(\mathrm{CO})$, carbon dioxide $\left(\mathrm{CO}_{2}\right)$, carbonates, nitrogen oxides, ozone, hydrogen fluoride, and hydrogen chloride.

It is useful to introduce classification of air pollutants according to origin, chemical composition, and state of matter. As for origin, pollutants are considered as either primary or secondary contaminants. Primary pollutants are those sent directly to the atmosphere and found there in the form in which they are emitted. On the other hand, secondary pollutants such as ozone $\left(\mathrm{O}_{3}\right)$ and peroxyacetyl nitrate $(\mathrm{PAN})$ are formed in the atmosphere by a photochemical reaction or by hydrolysis or oxidation.

For air quality research, it is understood that motor vehicles are not the only source of pollutants. For an appreciation of the amount of pollutants generated by various sources, Table A1-1 can be examined.

\section{A.2.1 Air Pollution from Mobile Sources}

Air pollution from stationary sources are pollutants from stationary combustion (e.g. residential, commercial, and industrial power and heating, including steam powered electric power plant), and industrial processes (e.g. chemical, metallurgical, pulp-paper industries, and petroleum refineries), whereas mobile sources of air pollution are motor vehicles, aircraft, railways, ships, and the handling and/or evaporation of gasoline. Air pollutants from mobile sources account for a major share of total air pollution. Among the mobile sources of air pollution, emissions from motor vehicles have a direct impact on human health. 
Table A1-4: Basic characteristics and related parameters responsible for vehicular emissions

(Source: Pandian et. al., 2009)

\begin{tabular}{|c|c|c|}
\hline Characteristics & Parameters & Role in emission generation \\
\hline \multirow{6}{*}{ Traffic } & Traffic-flow rate & $\begin{array}{l}\text { More vehicle flow more than the capacity of road } \\
\text { leads to severe congestion and in turn affects driving } \\
\text { pattern and there by increases emissions }\end{array}$ \\
\hline & Fleet speed & $\begin{array}{l}\text { Correlated with traffic density as well traffic-flow } \\
\text { rate, and affects the emissions }\end{array}$ \\
\hline & $\begin{array}{l}\text { Queue length } \\
\text { and mean-delay }\end{array}$ & Measures of effectiveness of signal controls \\
\hline & Driving mode & $\begin{array}{l}\text { Rate of change of velocity of a vehicle is the criterion } \\
\text { to define driving mode. Rapid acceleration and } \\
\text { deceleration emits more emission than cruising } \\
\text { followed by idle driving mode }\end{array}$ \\
\hline & $\begin{array}{l}\text { Vehicle mix } \\
\text { (traffic fleet) }\end{array}$ & $\begin{array}{l}\text { Cars contribute more to } \mathrm{CO} \text { emissions whereas } \\
\text { heavy-duty vehicles emit more PM, while two- } \\
\text { wheelers contribute to HC and NOx emissions }\end{array}$ \\
\hline & Traffic density & $\begin{array}{l}\text { Described by the number vehicles per-unit distance. } \\
\text { More density increases the mean residence time of } \\
\text { the vehicles on the road causing higher pollutant } \\
\text { concentrations }\end{array}$ \\
\hline \multirow{4}{*}{ Road } & Type of road & $\begin{array}{l}\text { If not overloaded, major streets help to reduce } \\
\text { congestion therefore may result in lower level of } \\
\text { pollutants/vehicle-km as compared to overcrowded } \\
\text { smaller roads }\end{array}$ \\
\hline & $\begin{array}{l}\text { Type of } \\
\text { intersection }\end{array}$ & $\begin{array}{l}\text { Roundabout intersections are subject to lesser } \\
\text { emissions than other intersections }\end{array}$ \\
\hline & Speed hump & $\begin{array}{l}\text { Helps to reduce the speed of vehicles in optimum } \\
\text { range to emit lower level of pollutants }\end{array}$ \\
\hline & Driving style & $\begin{array}{l}\text { Aggressive driving style generates more emissions } \\
\text { and is less economical in fuel Consumption }\end{array}$ \\
\hline \multirow{5}{*}{ Vehicle } & Type of vehicle & $\begin{array}{l}\text { Heavy-duty vehicles emit more } \mathrm{NO} x \text { and } \mathrm{PM} \\
\text { compared to light duty vehicles, which are } \\
\text { responsible for more } \mathrm{CO} \text { and } \mathrm{HC} \text { emissions }\end{array}$ \\
\hline & Age of vehicle & $\begin{array}{l}\text { Older vehicles produce more emissions than new } \\
\text { vehicles. }\end{array}$ \\
\hline & Engine capacity & Has negative effect on $\mathrm{CO}$ emissions \\
\hline & Mileage & Has positive effect on emissions \\
\hline & $\begin{array}{l}\text { Emission control } \\
\text { equipment }\end{array}$ & Has negative effect on emissions \\
\hline
\end{tabular}




\begin{tabular}{|l|l|l|}
\hline $\begin{array}{l}\text { Ambient } \\
\text { temperature }\end{array}$ & $\begin{array}{l}\text { Lower ambient temperature affects ignition } \\
\text { temperature and also it cools down the vehicle } \\
\text { rapidly from hot mode to cold mode which enhances } \\
\text { the emission }\end{array}$ \\
\cline { 2 - 3 } Engine load & $\begin{array}{l}\text { Mainly increases the fuel consumption and } \\
\text { emissions of NOx }\end{array}$ \\
\cline { 2 - 3 } & $\begin{array}{l}\text { Vehicle weight } \\
\text { and size }\end{array}$ & $\begin{array}{l}\text { Increased fuel consumption and emissions of PM and } \\
\text { NOx }\end{array}$ \\
\hline Maintenance & $\begin{array}{l}\text { Frequent maintenance helps to reduce emission and } \\
\text { delays the vehicle deterioration }\end{array}$ \\
\hline
\end{tabular}

\section{A.2.2 Motor Vehicles Emissions}

Motor vehicles burn fuel in the engine for propulsion purpose. A part of the fuel is used efficiently, but due to low efficiency of the internal combustion engine, a high proportion of fuel is wasted. As a result, tailpipe type of pollutants are generated from vehicles. Moreover, there are also evaporative type of emissions, but their magnitude is very low as compared to tailpipe. Traffic control devices interrupt flow of vehicles (e.g. Signal system). Table A1-4 represents the influencing parameters and their role in the production of pollutants.

Characteristics of vehicles, roads and traffic are useful to study in terms of their role in emission generation (Pandian et. al., 2009). The same study suggests that a number of disciplines can play a role in researching vehicular emissions. Mechanical engineers are very keen to develop technologies to control emissions from vehicles. Engine modifications, pollution control equipment, etc. are many contributions made by mechanical engineers. The quality of fuel used in engines is also an important variable in controlling emissions from mobile sources. Logically, chemical engineers are keen on finding the optimum quality of fuels for use in vehicle. Civil engineers contribute research 
on emission reduction by improving design of road infrastructure and enhancing traffic flow.

\section{A.2.3 Mobility and Human Health: Effect of Traffic-related Air Pollution}

As noted earlier, emissions from motor vehicles have a direct impact on human health. For this reason, setback distance of residential buildings and other land uses that are situated very close to roadways require research. Therefore, this study is investigating motor vehicle emissions near roads and background emissions are to be considered in order to correctly address health effects for the residents.

Although all disciplines have a role to play in controlling road traffic-related air pollution and minimizing human health effects, civil engineers are well equipped to do so through multimodal transportation, land use planning, and traffic and infrastructure management. Environmental quality receives due attention in integrated land use and transportation planning in urban areas, but there is a need for joint study of the mobility function of a road, its characteristics, volume of traffic served, land use, and location of buildings.

\section{A.3 HEALTH EFFECT}

Human health is affected by vehicular emissions. The science has advanced in quantifying pollutant exposure as a measurable index for assessing health impact. Motor vehicular emissions result in adverse health effects on those peoples who spend most of their time near roads on a daily basis. Some of residential buildings, commercial places, and sensitive areas, like retirement homes, hospitals, schools, etc., are located close to roads for ease of 
access or space constraints. In addition, business places are situated mostly near the roads. To make matters worse, in developing countries, such as in the Indian subcontinent (e.g. India, Pakistan, and Bangladesh), people use footpath as a business space. Small towns or parts of cities in developing countries have no traffic signal control facilities. Traffic police personnel control traffic movements. Pedestrians share the road with multimodal traffic including non-motorized rickshaw. This causes high emissions that are inhaled by the road users. Most hazardous zones are slum areas that develop in semi-urban areas in developing countries and residents of those areas are spending their whole life adjacent to the road for living and business. As a result, they are exposed to vehicular emissions that come from the tail pipes of vehicles. Ultimately, those people suffer adverse health effects.

\section{A.3.1 Effects of Carbon Monoxide}

Carbon monoxide $(\mathrm{CO})$ at high concentrations has a serious effect on human aerobic metabolism due to its high affinity for hemoglobin, the component of the blood that is responsible for the transport of oxygen. It reacts with the hemoglobin $(\mathrm{Hb})$ of blood to give carboxyhemoglobin $(\mathrm{COHb})$, thus reducing the capability of the blood to carry oxygen.

$$
\mathrm{CO}+\mathrm{Hb}(\text { Blood }) \longrightarrow \text { Carboxyhemoglobin }(\mathrm{COHb})
$$

Given that the affinity of hemoglobin for carbon monoxide is more than 200 times as great as its affinity for oxygen, $\mathrm{CO}$ can seriously impair the transport of $\mathrm{O}_{2}$, even at low concentrations.

Literature sources indicate that Carbon monoxide levels in downtown Louisville, Kentucky, during peak traffic periods ranged from 3.5 to $8.7 \mathrm{mg} / \mathrm{m}^{3}$ (4 to $10 \mathrm{ppm}$ ). A 
mathematical model was used to estimate $\mathrm{CO}$ concentration and the result was that it could reach $48 \mathrm{mg} / \mathrm{m}^{3}(55 \mathrm{ppm})$ for $1 \mathrm{hr}$ at some street-crossing sites $(E E H, 1976)$. According to medical literature sources, a person in a traffic jam at such a location for an hour would show a COHb blood level close to 2.3 percent. This level of exposure would affect the central nervous system impairment of time interval discrimination, visual acuity, brightness discrimination.

\section{A.3.2 Effects of Oxides of Nitrogen}

Oxides of nitrogen $\left(\mathrm{NO}_{\mathrm{x}}\right)$ are commonly noted as emissions of concern. These include six known gaseous components. The oxides of nitrogen of primary concern in air pollution are nitric oxide $(\mathrm{NO})$ and nitrogen dioxide $\left(\mathrm{NO}_{2}\right)$. These only two oxides of nitrogen are emitted in significant quantities to the atmosphere. $\mathrm{NO}_{2}$ is heavier than air and is readily soluble in water. It is responsible for acid rain in form of either nitric acid or nitrous acid, as indicated in the following equations. Additionally, $\mathrm{NO}_{2}$ plays a major role in the production of secondary air contaminant such as ozone $\left(\mathrm{O}_{3}\right)$.

$$
\begin{aligned}
& 2 \mathrm{NO}_{2}+\mathrm{H}_{2} \mathrm{O} \rightarrow \mathrm{HNO}_{3}+\mathrm{HNO}_{2} \quad \text { (nitrous acid) } \\
& 3 \mathrm{NO}_{2}+\mathrm{H}_{2} \mathrm{O} \rightarrow 2 \mathrm{HNO}_{3}+\mathrm{NO} \quad \text { (nitric acid) }
\end{aligned}
$$

Nitric oxide (NO) is a relatively inert gas and only moderately toxic. It is emitted to the atmosphere in much larger quantities than $\mathrm{NO}_{2}$. Although $\mathrm{NO}$, like $\mathrm{CO}$, can combine with hemoglobin to reduce the oxygen carrying capacity of the blood, its concentrations are generally less than $1.22 \mathrm{mg} / \mathrm{m}^{3}(1 \mathrm{ppm})$ in the ambient air and is not considered a health hazard. However, $\mathrm{NO}$ is readily oxidized to $\mathrm{NO}_{2}$, which can become an issue as noted below.

$$
\mathrm{NO}+\frac{1}{2} \mathrm{O}_{2} \rightleftharpoons \mathrm{NO}_{2}
$$


$\mathrm{NO}_{2}$ irritates the alveoli of the lungs.

\section{A.3.3 Effects of Particulate Matter}

Particulates can be classified according to their physical, chemical, or biological characteristics. Physical characteristics have been defined in terms of size (in micrometers, $\mu \mathrm{m})$, mode of formation (e.g. dust, smoke, fumes, fly ash, etc.), and settling properties. The settling phenomenon is a natural self-cleaning process that removes particulates from the atmosphere. These can also be classified as suspended or settle-able. Suspended particulate matter (SPM) remain suspended in the atmosphere for a long period. These vary in size from less than $1 \mu \mathrm{m}$ to approximately $20 \mu \mathrm{m}$. Research studies indicate that some of the common organics found in particulates include organic acids, and alcohols. In the case of inorganics found in particulates, these include nitrates, sulfates, and metals such as lead, magnesium, zinc, and vanadium.

SPMs pose health hazards to humans at high concentrations. Those susceptible to respiratory illness can be affected.

\section{A.4 RECEPTOR TYPE}

Health effects of air pollutants depend on receptor type and their activities. Receptors are generally classified as sensitive or non-sensitive. Sensitive receptors are infants, children, old-age people, and people with illnesses. Accordingly, in land use classification, sensitive receptors include, but are not limited to, hospitals, schools, daycare facilities, elderly housing and convalescent facilities. 
Exhaust from the vehicles exacerbates asthma in children, may cause respiratory illness, and cause heart problem. Children are particularly more at risk than adults because of their immature respiratory systems and higher breathing rates per body mass.

\section{A.5 NATIONAL AMBIENT AIR QUALITY STANDARDS (NAAQS)}

Although this research has addressed harmful emissions near roads, it is useful to describe the management of air quality at a broader spatial scale. Air quality control regulations and strategies are of interest in almost all countries. Most countries follow the United States Environmental Protection Agency's air quality guidelines.

The Canadian air quality standards are in general similar to the US standards. The US national primary and secondary ambient air quality standards were set and incorporated into the Clean Air Act amendments of 1970 . The primary standards, based on air quality criteria, allow an adequate margin of safety to protect public health, while the secondary standards, also based on air quality criteria, were intended to protect public welfare, i.e. plants, animals, property, and materials.

Table A1-5: National ambient air quality standards (NAAQS)

\begin{tabular}{|c|c|c|c|c|c|c|c|c|c|}
\hline & & $\bar{s}$ & 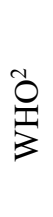 & 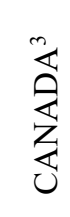 & 党 & 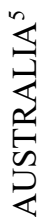 & 艺 & $\begin{array}{l}z \\
z \\
z\end{array}$ & 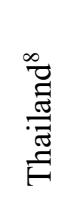 \\
\hline \multirow{3}{*}{$8 \widehat{\overline{0}}$} & $8-\mathrm{hr}$ & 9 & 9 & 13 & $\begin{array}{c}9 \\
(10 \mathrm{mg} / \mathrm{m} 3)\end{array}$ & 9 & $\begin{array}{c}1.75 \\
(2 \mathrm{mg} / \mathrm{m} 3)\end{array}$ & 20 & 9 \\
\hline & $1-\mathrm{hr}$ & 35 & & 31 & & & $\begin{array}{c}3.5 \\
(4 \mathrm{mg} / \mathrm{m} 3)\end{array}$ & - & 30 \\
\hline & 24-hr & - & - & - & - & - & - & 10 & - \\
\hline
\end{tabular}




\begin{tabular}{|c|c|c|c|c|c|c|c|c|c|}
\hline \multirow{3}{*}{ ठิ है } & annual & 53 & 21 & 53 & $\begin{array}{c}21 \\
(40 \mu \mathrm{g} / \mathrm{m} 3)\end{array}$ & 30 & $\begin{array}{c}21 \\
(40 \mu \mathrm{g} / \mathrm{m} 3)\end{array}$ & & 30 \\
\hline & $1-\mathrm{hr}$ & 100 & & 213 & $\begin{array}{c}106 \\
(200 \mu \mathrm{g} / \mathrm{m} 3)\end{array}$ & 120 & & & 170 \\
\hline & 24-hr & & & 106 & & & $\begin{array}{c}42 \\
(80 \mu \mathrm{g} / \mathrm{m} 3)\end{array}$ & $40-60$ & \\
\hline \multirow{2}{*}{$\begin{array}{c}\mathrm{PM}_{10} \\
\left(\mu \mathrm{g} / \mathrm{m}^{3}\right)\end{array}$} & annual & & & & 40 & & 60 & & 50 \\
\hline & 24-hr & 150 & & & 50 & 50 & 100 & & 120 \\
\hline \multirow{3}{*}{$\begin{array}{c}\mathrm{PM}_{2.5} / \text { Fine } \\
\text { Particulate/ } \\
\text { SPM } \\
\left(\mu \mathrm{g} / \mathrm{m}^{3}\right) \\
\end{array}$} & 24-hr & 65 & 25 & 30 & 50 & 25 & 60 & & 50 \\
\hline & annual & 12 & & 10 & 25 & 8 & 40 & 100 & 25 \\
\hline & $1-\mathrm{hr}$ & 35 & & & 120 & & & 200 & \\
\hline
\end{tabular}

(Sources: 1. U.S.EPA (2017), 2. Boyd, D.R. (2006), 3. Canada AQS (2013), 4. EU AQS (2013), 5. Australia AQS (2014), 6. Indian AQS (2009), 7. Japan MoE, 8. Thailand AQS)

Standards for key emissions for Canada, the World Health Organization (WHO) and the USA are summarized in Table 1-1. For further information on these standards, the reader may wish to refer Table A1-5: National ambient air quality standards (NAAQS) for different countries or please refer to published sources. 


\section{APPENDIX GROUP 1}

\section{APPENDIX-I: CAPACITY LEVEL TRAFFIC CALCULATIONS}

\section{The following notes are applicable to calculate the capacity level traffic volume:}

1. The capacity level through traffic is equals to 80 percentage of the total capacity level flow rate in directional flow on lane group.

2. The standard amber time is $4 \mathrm{sec}$ and red is $2 \mathrm{sec}$. * amber time is 3 seconds.

3. Capacity level traffic volume sample calculation

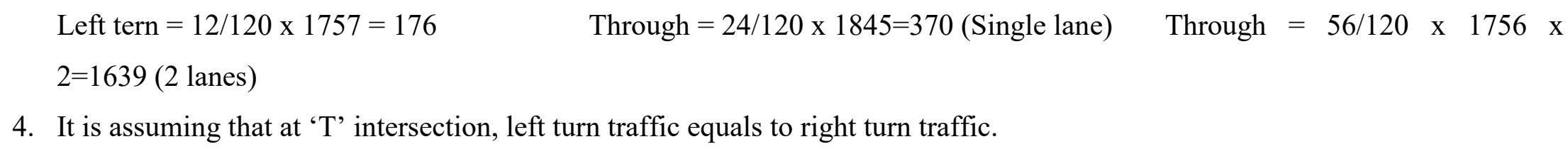

4. It is assuming that at ' $\mathrm{T}$ ' intersection, left turn traffic equals to right turn traffic.

The geometric design of the road at intersection approach are following

\begin{tabular}{|c|c|c|c|}
\hline $\begin{array}{c}\text { S.L. } \\
\text { No. }\end{array}$ & Lane Group & Description & Descriptive design \\
\hline 1. & $\mathrm{~L}+\mathrm{Th}+\mathrm{R}$ & Exclusive left +1 through lanes + exclusive right \\
\hline 2. & $\mathrm{~L}+2-\mathrm{Th}+\mathrm{R}$ & Exclusive left +2 through lanes + exclusive right & \\
\hline
\end{tabular}




\begin{tabular}{|c|c|c|c|}
\hline 3. & L+Th+TR & Exclusive left +1 through lanes +1 shared lane (through and \\
right)
\end{tabular}

The Road Types are: $\mathrm{A}=$ Arterial, $\mathrm{C}=$ Collector, and $\mathrm{L}=$ Local Road

Exclusive Left Turning: L = Protected left turn, L (Per) = Permitted left turn (Assuming, left turn vehicle $=1 \%$ of through turn vehicle, which is approximately one vehicle in one cycle).

Table A-1 (A): An intersection with an Arterial Vs Arterial Road 4-leg intersection

\begin{tabular}{|c|c|c|c|c|c|c|c|c|c|c|c|c|}
\hline \multirow[b]{2}{*}{$\underset{\dot{z}}{\dot{j}}$} & \multirow{2}{*}{ 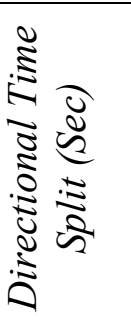 } & \multicolumn{5}{|c|}{ Major Road } & \multicolumn{6}{|c|}{ Minor Road } \\
\hline & & 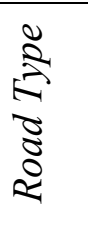 & $\begin{array}{c}-1 \\
0 \\
0 \\
0 \\
0 \\
0 \\
0 \\
0\end{array}$ & 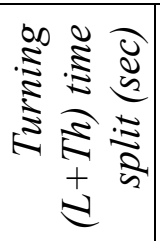 & $\begin{array}{c}\text { Capacity } \\
(L+T h+R) \\
\text { or } \\
(L+T h+T R)\end{array}$ & 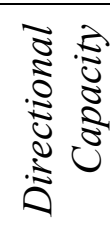 & 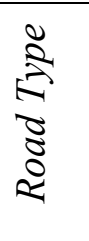 & $\begin{array}{c}-1 \\
\vdots \\
0 \\
0 \\
0 \\
0 \\
5 \\
5\end{array}$ & 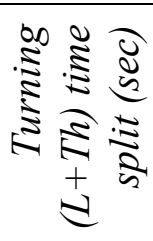 & $\begin{array}{c}\text { Capacity } \\
(L+T h+R) \\
o r \\
(L+T h+T R)\end{array}$ & 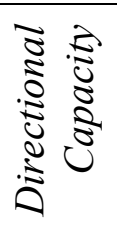 & 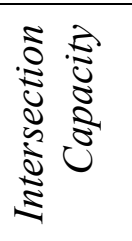 \\
\hline 1 & $60-60$ & A-1 & $\mathrm{L}+3 \mathrm{Th}+\mathrm{R}$ & $15+45$ & $132+1713+295$ & 2140 & A-2 & $\mathrm{L}+2 \mathrm{Th}+\mathrm{R}$ & $15+45$ & $132+1142+154$ & 1428 & 7136 \\
\hline 2 & $60-60$ & A-1 & $\mathrm{L}+3 \mathrm{Th}+\mathrm{R}$ & $15+45$ & $132+1713+295$ & 2140 & A-2 & $\mathrm{L}+2 \mathrm{Th}+\mathrm{R}$ & $20+40$ & $205+995+44$ & 1244 & 6768 \\
\hline 3 & $60-60$ & A-1 & $\mathrm{L}+3 \mathrm{Th}+\mathrm{R}$ & $15+45$ & $132+1713+295$ & 2140 & A-2 & $\mathrm{L}+2 \mathrm{Th}+\mathrm{R}$ & $16+44$ & $142+1112+136$ & 1390 & 7060 \\
\hline 4 & $60-60$ & A-1 & $\mathrm{L}+3 \mathrm{Th}+\mathrm{R}$ & $20+40$ & $205+1494+187$ & 1886 & A-2 & $\mathrm{L}+2 \mathrm{Th}+\mathrm{R}$ & $15+45$ & $132+1142+154$ & 1428 & 6628 \\
\hline 5 & $60-60$ & A-1 & $\mathrm{L}+3 \mathrm{Th}+\mathrm{R}$ & $20+40$ & $205+1494+187$ & 1886 & $\mathrm{~A}-2$ & $\mathrm{~L}+2 \mathrm{Th}+\mathrm{R}$ & $20+40$ & $205+995+44$ & 1244 & 6260 \\
\hline 6 & $60-60$ & A-1 & $\mathrm{L}+3 \mathrm{Th}+\mathrm{R}$ & $20+40$ & $205+1494+187$ & 1886 & A-2 & $\mathrm{L}+2 \mathrm{Th}+\mathrm{R}$ & $16+44$ & $142+1112+136$ & 1390 & 6552 \\
\hline 7 & $60-60$ & A-1 & $\mathrm{L}+3 \mathrm{Th}+\mathrm{R}$ & $16+44$ & $142+1668+275$ & 2085 & A-2 & $\mathrm{L}+2 \mathrm{Th}+\mathrm{R}$ & $15+45$ & $132+1142+154$ & 1428 & 7026 \\
\hline 8 & $60-60$ & A-1 & $\mathrm{L}+3 \mathrm{Th}+\mathrm{R}$ & $16+44$ & $142+1668+275$ & 2085 & A-2 & $\mathrm{L}+2 \mathrm{Th}+\mathrm{R}$ & $20+40$ & $205+995+44$ & 1244 & 6658 \\
\hline
\end{tabular}




\begin{tabular}{|c|c|c|c|c|c|c|c|c|c|c|c|c|}
\hline 9 & $60-60$ & A-1 & $\mathrm{L}+3 \mathrm{Th}+\mathrm{R}$ & $16+44$ & $142+1668+275$ & 2085 & A-2 & $\mathrm{L}+2 \mathrm{Th}+\mathrm{R}$ & $16+44$ & $142+1112+136$ & 1390 & 6950 \\
\hline 10 & $60-60$ & A-2 & $\mathrm{L}+2 \mathrm{Th}+\mathrm{R}$ & $15+45$ & $132+1142+154$ & 1428 & A-4 & $\mathrm{L}+\mathrm{Th}+\mathrm{TR}$ & $15+45$ & $132+571+508$ & 1211 & 5278 \\
\hline 11 & $60-60$ & A-2 & $\mathrm{L}+2 \mathrm{Th}+\mathrm{R}$ & $15+45$ & $132+1142+154$ & 1428 & A-4 & $\mathrm{L}+\mathrm{Th}+\mathrm{TR}$ & $20+40$ & $205+498+443$ & 1146 & 5148 \\
\hline 12 & $60-60$ & A-2 & $\mathrm{L}+2 \mathrm{Th}+\mathrm{R}$ & $15+45$ & $132+1142+154$ & 1428 & A-4 & $\mathrm{L}+\mathrm{Th}+\mathrm{TR}$ & $16+44$ & $146+556+495$ & 1197 & 5250 \\
\hline 13 & $60-60$ & A-2 & $\mathrm{L}+2 \mathrm{Th}+\mathrm{R}$ & $15+45$ & $132+1142+154$ & 1428 & A-2 & $\mathrm{L}+2 \mathrm{Th}+\mathrm{R}$ & $16+44$ & $142+1112+136$ & 1390 & 5636 \\
\hline 14 & $60-60$ & A-2 & $\mathrm{L}+2 \mathrm{Th}+\mathrm{R}$ & $15+45$ & $132+1142+154$ & 1428 & A-2 & $\mathrm{L}+2 \mathrm{Th}+\mathrm{R}$ & $15+45$ & $132+1142+154$ & 1428 & 5712 \\
\hline 15 & $60-60$ & A-2 & $\mathrm{L}+2 \mathrm{Th}+\mathrm{R}$ & $15+45$ & $132+1142+154$ & 1428 & A-2 & $\mathrm{L}+2 \mathrm{Th}+\mathrm{R}$ & $20+40$ & $205+995+44$ & 1244 & 5344 \\
\hline 16 & $60-60$ & A-2 & $\mathrm{L}+2 \mathrm{Th}+\mathrm{R}$ & $20+40$ & $205+995+44$ & 1244 & A-2 & $\mathrm{L}+2 \mathrm{Th}+\mathrm{R}$ & $20+40$ & $205+995+44$ & 1244 & 4976 \\
\hline 17 & $60-60$ & A-2 & $\mathrm{L}+2 \mathrm{Th}+\mathrm{R}$ & $20+40$ & $205+995+44$ & 1244 & A-4 & $\mathrm{L}+\mathrm{Th}+\mathrm{TR}$ & $15+45$ & $132+571+508$ & 1211 & 4910 \\
\hline 18 & $60-60$ & A-2 & $\mathrm{L}+2 \mathrm{Th}+\mathrm{R}$ & $20+40$ & $205+995+44$ & 1244 & A-4 & $\mathrm{L}+\mathrm{Th}+\mathrm{TR}$ & $20+40$ & $205+498+443$ & 1146 & 4780 \\
\hline 19 & $60-60$ & A-2 & $\mathrm{L}+2 \mathrm{Th}+\mathrm{R}$ & $20+40$ & $205+995+44$ & 1244 & A-4 & $\mathrm{L}+\mathrm{Th}+\mathrm{TR}$ & $16+44$ & $146+556+495$ & 1197 & 4882 \\
\hline 20 & $60-60$ & A-2 & $\mathrm{L}+2 \mathrm{Th}+\mathrm{R}$ & $16+44$ & $142+1112+136$ & 1390 & A-4 & $\mathrm{L}+\mathrm{Th}+\mathrm{TR}$ & $15+45$ & $132+571+508$ & 1211 & 5202 \\
\hline 21 & $60-60$ & A-2 & $\mathrm{L}+2 \mathrm{Th}+\mathrm{R}$ & $16+44$ & $142+1112+136$ & 1390 & A-4 & $\mathrm{L}+\mathrm{Th}+\mathrm{TR}$ & $20+40$ & $205+498+443$ & 1146 & 5072 \\
\hline 22 & $60-60$ & A-2 & $\mathrm{L}+2 \mathrm{Th}+\mathrm{R}$ & $16+44$ & $142+1112+136$ & 1390 & A-4 & $\mathrm{L}+\mathrm{Th}+\mathrm{TR}$ & $16+44$ & $146+556+495$ & 1197 & 5174 \\
\hline 23 & $60-60$ & A-2 & $\mathrm{L}+2 \mathrm{Th}+\mathrm{R}$ & $16+44$ & $142+1112+136$ & 1390 & A-2 & $\mathrm{L}+2 \mathrm{Th}+\mathrm{R}$ & $16+44$ & $142+1112+136$ & 1390 & 5560 \\
\hline 24 & $60-60$ & A-2 & $\mathrm{L}+2 \mathrm{Th}+\mathrm{R}$ & $16+44$ & $142+1112+136$ & 1390 & A-2 & $\mathrm{L}+2 \mathrm{Th}+\mathrm{R}$ & $20+40$ & $205+995+44$ & 1244 & 5268 \\
\hline 25 & $60-60$ & A-5 & $\mathrm{L}+2 \mathrm{Th}+\mathrm{TR}$ & $20+40$ & $205+995+443$ & 1643 & A-2 & $\mathrm{L}+2 \mathrm{Th}+\mathrm{R}$ & $20+40$ & $205+995+44$ & 1244 & 5774 \\
\hline 26 & $60-60$ & A-5 & $\mathrm{L}+2 \mathrm{Th}+\mathrm{TR}$ & $15+45$ & $132+1141+508$ & 1781 & A-2 & $\mathrm{L}+2 \mathrm{Th}+\mathrm{R}$ & $15+45$ & $132+1142+154$ & 1428 & 6418 \\
\hline 27 & $60-60$ & A-5 & $\mathrm{L}+2 \mathrm{Th}+\mathrm{TR}$ & $20+40$ & $205+995+443$ & 1643 & A-2 & $\mathrm{L}+2 \mathrm{Th}+\mathrm{R}$ & $15+45$ & $132+1142+154$ & 1428 & 6142 \\
\hline 28 & $60-60$ & A-5 & $\mathrm{L}+2 \mathrm{Th}+\mathrm{TR}$ & $15+45$ & $132+1141+508$ & 1781 & A-2 & $\mathrm{L}+2 \mathrm{Th}+\mathrm{R}$ & $20+40$ & $205+995+44$ & 1244 & 6050 \\
\hline
\end{tabular}


Table A-1 (B): An intersection with an Arterial Vs Arterial Road ' $T$ ' intersection

\begin{tabular}{|c|c|c|c|c|c|c|c|c|c|c|c|c|}
\hline \multirow[b]{2}{*}{$\begin{array}{l}\sum_{i}^{0} \\
\text { vi }\end{array}$} & \multirow{2}{*}{ 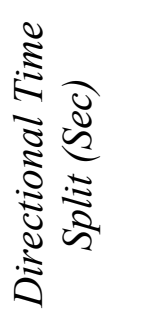 } & \multicolumn{5}{|c|}{ Major Road } & \multicolumn{6}{|c|}{ Minor Road } \\
\hline & & 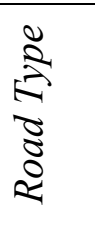 & $\begin{array}{c}-1 \\
3 \\
0 \\
0 \\
0 \\
0 \\
5 \\
5\end{array}$ & 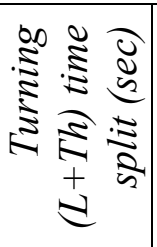 & $\begin{array}{c}\text { Capacity } \\
(L+T h+R) \\
\text { or } \\
(T h+T R)\end{array}$ & 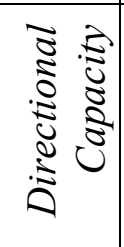 & 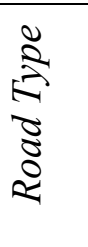 & $\begin{array}{c}-1 \\
5 \\
0 \\
0 \\
0 \\
0 \\
5\end{array}$ & 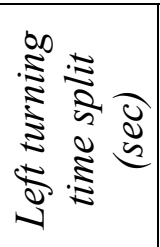 & $\begin{array}{c}\text { Capacity } \\
(L+R)\end{array}$ & 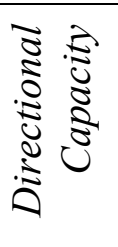 & 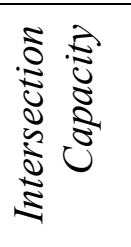 \\
\hline 1 & $90-30$ & A-1 & $\begin{array}{r}\mathbf{L + T h + T R} \\
* * \mathbf{T h}+\mathbf{T R}\end{array}$ & $20+70$ & $\begin{array}{r}205+\underline{\mathbf{1 7 7 1}} \\
937+834\end{array}$ & $\begin{array}{l}1976 \\
\underline{\mathbf{1 7 7 1}} \\
\end{array}$ & A-2 & $\mathrm{L}+\mathrm{LT}+\mathrm{R}$ & 30 & $682+495$ & 1177 & 4924 \\
\hline 2 & $60-60$ & A-1 & $\mathrm{L}+\mathrm{Th}+\mathrm{TR}$ & $20+40$ & $205+941$ & 1146 & A-2 & $\mathrm{L}+\mathrm{LT}+\mathrm{R}$ & 60 & $1535+686$ & 2221 & 4308 \\
\hline 3 & $70-50$ & A-1 & $\mathrm{L}+\mathrm{Th}+\mathrm{TR}$ & $20+50$ & $205+1217$ & 1422 & A-2 & $\mathrm{L}+\mathrm{LT}+\mathrm{R}$ & 50 & $1251+573$ & 1824 & 4463 \\
\hline 4 & $80-40$ & A-1 & $\mathrm{L}+\mathrm{Th}+\mathrm{TR}$ & $20+60$ & $205+1493$ & 1698 & A-2 & $\mathrm{L}+\mathrm{LT}+\mathrm{R}$ & 40 & $967+625$ & 1592 & 4783 \\
\hline 5 & $100-20$ & A-3 & $\begin{array}{c}2 \mathrm{~L}+2 \mathrm{Th} \\
2 \mathrm{Th}+\mathrm{R}\end{array}$ & $30+70$ & $682+1873$ & 2555 & A-4 & $\mathrm{L}+\mathrm{R}$ & 20 & $205+495$ & 700 & 5128 \\
\hline 6 & $90-30$ & A-3 & $2 \mathrm{~L}+2 \mathrm{Th}$ & $15+75$ & $256+\mathbf{2 0 2 0}$ & 2276 & A-4 & $\mathrm{L}+\mathrm{R}$ & 30 & $351+430$ & 781 & 5077 \\
\hline 7 & $95-25$ & A-3 & $2 \mathrm{~L}+2 \mathrm{Th}$ & $15+80$ & $256+2166$ & 2422 & A-4 & $\mathrm{L}+\mathrm{R}$ & 25 & $278+417$ & 695 & 5283 \\
\hline 8 & $100-20$ & A-3 & $2 \mathrm{~L}+2 \mathrm{Th}$ & $15+85$ & $256+\mathbf{2 3 1 2}$ & 2568 & A-4 & $\mathrm{L}+\mathrm{R}$ & 20 & $205+300$ & 505 & 5385 \\
\hline 9 & $60-60$ & A-5 & $\begin{array}{l}\mathrm{L}+2 \mathrm{Th} \\
2 \mathrm{Th}+\mathrm{R}\end{array}$ & $10+50$ & $60+1228$ & 1288 & A-6 & $2 \mathrm{~L}+2 \mathrm{R}$ & 60 & $1535+1337$ & 2872 & 5448 \\
\hline 10 & $70-50$ & A-5 & $\mathrm{L}+2 \mathrm{Th}$ & $15+55$ & $132+1368$ & 1500 & A-6 & $2 \mathrm{~L}+2 \mathrm{R}$ & 50 & - & 2473 & 5473 \\
\hline 11 & $80-40$ & A-5 & $\mathrm{L}+2 \mathrm{Th}$ & $15+65$ & $132+1647$ & 1779 & A-6 & $2 \mathrm{~L}+2 \mathrm{R}$ & 40 & $967+991$ & 1958 & 5516 \\
\hline
\end{tabular}




\begin{tabular}{|c|c|c|c|c|c|c|c|c|c|c|c|c|}
\hline 12 & $100-20$ & A-5 & $\mathrm{L}+2 \mathrm{Th}$ & $10+90$ & $58+2458$ & 2516 & A-6 & $2 \mathrm{~L}+2 \mathrm{R}$ & 20 & - & 813 & 5845 \\
\hline 13 & $100-20$ & $A-5$ & $\mathrm{~L}+2 \mathrm{Th}$ & $15+85$ & $132+2075$ & 2207 & A-6 & $2 L+2 R$ & 20 & $398+530$ & 928 & 5342 \\
\hline 14 & $60-60$ & A-7 & $\begin{array}{l}\mathrm{L}+3 \mathrm{Th} \\
3 \mathrm{Th}+\mathrm{R}\end{array}$ & $10+50$ & $60+1842$ & 1902 & A-6 & $2 \mathrm{~L}+2 \mathrm{R}$ & 60 & $1535+1337$ & 2872 & 6676 \\
\hline 15 & $70-50$ & A-7 & $\mathrm{L}+3 \mathrm{Th}$ & $15+55$ & $132+2052$ & 2184 & A-6 & $2 \mathrm{~L}+2 \mathrm{R}$ & 50 & $1251+1222$ & 2473 & 6841 \\
\hline 16 & $80-40$ & A-7 & $\mathrm{L}+3 \mathrm{Th}$ & $15+65$ & $132+2471$ & 2603 & A-6 & $2 \mathrm{~L}+2 \mathrm{R}$ & 40 & $967+991$ & 1958 & 7164 \\
\hline 17 & $60-60$ & A-3 & $\begin{array}{c}2 \mathrm{~L}+2 \mathrm{Th} \\
2 \mathrm{Th}+\mathrm{R}\end{array}$ & $20+40$ & $\begin{array}{l}398+882 \\
882+612\end{array}$ & $\begin{array}{l}1280 \\
1494\end{array}$ & A-6 & $2 \mathrm{~L}+2 \mathrm{R}$ & 60 & $1551+1567$ & 3118 & 5892 \\
\hline 18 & $70-50$ & A-3 & $\begin{array}{c}2 \mathrm{~L}+2 \mathrm{Th} \\
2 \mathrm{Th}+\mathrm{R}\end{array}$ & $20+50$ & $\begin{array}{l}398+1288 \\
1288+573\end{array}$ & $\begin{array}{l}1686 \\
1861\end{array}$ & A-6 & $2 \mathrm{~L}+2 \mathrm{R}$ & 50 & $1251+1337$ & 2588 & 6135 \\
\hline 19 & $80-40$ & A-3 & $\begin{array}{c}2 \mathrm{~L}+2 \mathrm{Th} \\
2 \mathrm{Th}+\mathrm{R}\end{array}$ & $30+50$ & $\begin{array}{c}682+1288 \\
1288+1016\end{array}$ & $\begin{array}{l}1970 \\
2304\end{array}$ & A-6 & $2 \mathrm{~L}+2 \mathrm{R}$ & 40 & $967+1337$ & 2304 & 6578 \\
\hline
\end{tabular}

** There is no left turn in opposite direction.

A-1\&A-2 is an intersection of Bronson Ave and Carling Ave, whereas A-3\&A-4 is an intersection of Riverside Drive and Walkley Road.

Table A-1 (C): An intersection with an Arterial Vs Collector Road 4-leg intersection

\begin{tabular}{|c|c|c|c|c|c|c|c|c|c|c|c|c|}
\hline \multirow[b]{2}{*}{$\begin{array}{l}\sum_{i}^{\circ} \\
\dot{y}\end{array}$} & \multirow{2}{*}{ 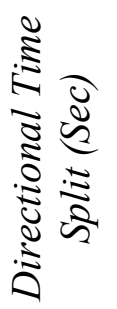 } & \multicolumn{5}{|c|}{ Major Road } & \multicolumn{6}{|c|}{ Minor Road } \\
\hline & & 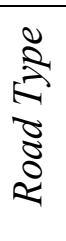 & 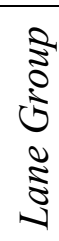 & 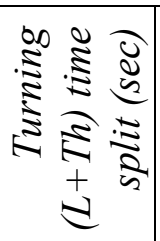 & $\begin{array}{c}\text { Capacity } \\
(L+T h+R) \\
\text { or } \\
(L+T h+T R)\end{array}$ & 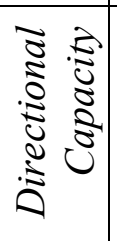 & 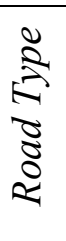 & 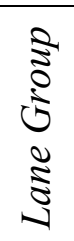 & 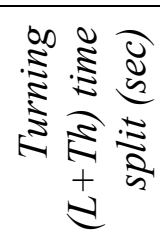 & $\begin{array}{c}\text { Capacity } \\
(L+T h+R) \\
\text { or } \\
(L+T h+T R)\end{array}$ & 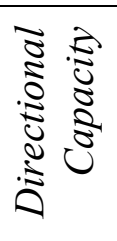 & 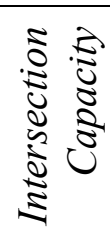 \\
\hline
\end{tabular}




\begin{tabular}{|c|c|c|c|c|c|c|c|c|c|c|c|c|}
\hline 1 & $80-40$ & A-1 & $\mathrm{L}+2 \mathrm{Th}+\mathrm{R}$ & $20+60$ & $205+1580+190$ & 1975 & $\mathrm{C}-2$ & $\mathrm{~L}+\mathrm{Th}+\mathrm{R}$ & $10+30$ & $58+370+32$ & 460 & 4870 \\
\hline 2 & $80-40$ & A-1 & $\mathrm{L}+2 \mathrm{Th}+\mathrm{R}$ & $20+60$ & $205+1580+190$ & 1975 & $\mathrm{C}-2$ & $\mathrm{~L}+\mathrm{Th}+\mathrm{R}$ & $12+28$ & $88+336+0$ & 424 & 4798 \\
\hline 3 & $80-40$ & A-1 & $\mathrm{L}+2 \mathrm{Th}+\mathrm{R}$ & $20+60$ & $205+1580+190$ & 1975 & C-1 & $\mathrm{L}+2 \mathrm{Th}+\mathrm{R}$ & $10+30$ & $58+702+118$ & 878 & 5706 \\
\hline 4 & $80-40$ & A-1 & $\mathrm{L}+2 \mathrm{Th}+\mathrm{R}$ & $20+60$ & $205+1580+190$ & 1975 & C-1 & $\mathrm{L}+2 \mathrm{Th}+\mathrm{R}$ & $12+28$ & $88+644+73$ & 805 & 5560 \\
\hline 5 & $80-40$ & A-1 & $\mathrm{L}+2 \mathrm{Th}+\mathrm{R}$ & $20+60$ & $205+1580+190$ & 1975 & C-3 & $\mathrm{L}+\mathrm{Th}+\mathrm{TR}$ & $10+30$ & $58+351+313$ & 722 & 5394 \\
\hline 6 & $80-40$ & A-1 & $\mathrm{L}+2 \mathrm{Th}+\mathrm{R}$ & $20+60$ & $205+1580+190$ & 1975 & C-3 & $\mathrm{L}+\mathrm{Th}+\mathrm{TR}$ & $12+28$ & $88+322+287$ & 697 & 5344 \\
\hline 7 & $80-40$ & A-1 & $\mathrm{L}+2 \mathrm{Th}+\mathrm{R}$ & $18+62$ & $176+1639+233$ & 2048 & $\mathrm{C}-2$ & $\mathrm{~L}+\mathrm{Th}+\mathrm{R}$ & $10+30$ & $58+370+32$ & 460 & 5016 \\
\hline 8 & $80-40$ & A-1 & $\mathrm{L}+2 \mathrm{Th}+\mathrm{R}$ & $18+62$ & $176+1639+233$ & 2048 & $\mathrm{C}-2$ & $\mathrm{~L}+\mathrm{Th}+\mathrm{R}$ & $12+28$ & $88+336+0$ & 424 & 4944 \\
\hline 9 & $80-40$ & A-1 & $\mathrm{L}+2 \mathrm{Th}+\mathrm{R}$ & $18+62$ & $176+1639+233$ & 2048 & $\mathrm{C}-1$ & $\mathrm{~L}+2 \mathrm{Th}+\mathrm{R}$ & $10+30$ & $58+702+118$ & 878 & 5852 \\
\hline 10 & $80-40$ & A-1 & $\mathrm{L}+2 \mathrm{Th}+\mathrm{R}$ & $18+62$ & $176+1639+233$ & 2048 & C-1 & $\mathrm{L}+2 \mathrm{Th}+\mathrm{R}$ & $12+28$ & $88+644+73$ & 805 & 5706 \\
\hline 11 & $80-40$ & A-1 & $\mathrm{L}+2 \mathrm{Th}+\mathrm{R}$ & $18+62$ & $176+1639+233$ & 2048 & $\mathrm{C}-3$ & $\mathrm{~L}+\mathrm{Th}+\mathrm{TR}$ & $10+30$ & $58+351+313$ & 722 & 5540 \\
\hline 12 & $80-40$ & A-1 & $\mathrm{L}+2 \mathrm{Th}+\mathrm{R}$ & $18+62$ & $176+1639+233$ & 2048 & $\mathrm{C}-3$ & $\mathrm{~L}+\mathrm{Th}+\mathrm{TR}$ & $12+28$ & $88+322+287$ & 697 & 5490 \\
\hline 13 & $90-30$ & A-1 & $\mathrm{L}+2 \mathrm{Th}+\mathrm{R}$ & $20+70$ & $205+1875+268$ & 2348 & $\mathrm{C}-2$ & $\mathrm{~L}+\mathrm{Th}+\mathrm{R}$ & $8 *+22$ & $44+246+18$ & 308 & 5312 \\
\hline 14 & $90-30$ & A-1 & $\mathrm{L}+2 \mathrm{Th}+\mathrm{R}$ & $20+70$ & $205+1875+268$ & 2348 & $\mathrm{C}-1$ & $\mathrm{~L}+2 \mathrm{Th}+\mathrm{R}$ & $8 *+22$ & $44+468+73$ & 585 & 5866 \\
\hline 15 & $90-30$ & A-1 & $\mathrm{L}+2 \mathrm{Th}+\mathrm{R}$ & $20+70$ & $205+1875+268$ & 2348 & $\mathrm{C}-3$ & $\mathrm{~L}+\mathrm{Th}+\mathrm{TR}$ & $8 *+22$ & $44+234+208$ & 486 & 5668 \\
\hline 16 & $60-30$ & A-2 & $\mathrm{L}+2 \mathrm{Th}+\mathrm{TR}$ & $15+45$ & $132+1089+508$ & 1729 & $\mathrm{C}-3$ & $\mathrm{~L}+\mathrm{Th}+\mathrm{TR}$ & $8 *+22$ & $44+234+208$ & 486 & 5150 \\
\hline 17 & $90-30$ & A-3 & $\mathrm{L}+\mathrm{Th}+\mathrm{TR}$ & $20+70$ & $205+937+834$ & 1976 & $\mathrm{C}-3$ & $\mathrm{~L}+\mathrm{Th}+\mathrm{TR}$ & $8 *+22$ & $44+234+208$ & 486 & 4924 \\
\hline 18 & $90-30$ & A-3 & $\mathrm{L}+\mathrm{Th}+\mathrm{TR}$ & $20+70$ & $205+937+834$ & 1976 & $\mathrm{C}-2$ & $\mathrm{~L}+\mathrm{Th}+\mathrm{R}$ & $8 *+22$ & $44+246+18$ & 308 & 4568 \\
\hline 19 & $60-60$ & A-3 & $\mathrm{L}+\mathrm{Th}+\mathrm{TR}$ & $15+45$ & $132+571+506$ & 1209 & $\mathrm{C}-2$ & $\mathrm{~L}+\mathrm{Th}+\mathrm{R}$ & $15+45$ & $132+600+18$ & 750 & 3918 \\
\hline 20 & $60-60$ & A-3 & $\mathrm{L}+\mathrm{Th}+\mathrm{TR}$ & $10+50$ & $59+644+573$ & 1276 & $\mathrm{C}-2$ & $\mathrm{~L}+\mathrm{Th}+\mathrm{R}$ & $10+50$ & $59+677+110$ & 846 & 4244 \\
\hline
\end{tabular}




\begin{tabular}{|c|c|c|c|c|c|c|c|c|c|c|c|c|}
\hline 21 & $60-60$ & A-1 & $\mathrm{L}+2 \mathrm{Th}+\mathrm{R}$ & $15+45$ & $132+1142+153$ & 1427 & $\mathrm{C}-2$ & $\mathrm{~L}+\mathrm{Th}+\mathrm{R}$ & $10+50$ & $59+677+110$ & 846 & 4546 \\
\hline 22 & $60-60$ & A-1 & $\mathrm{L}+2 \mathrm{Th}+\mathrm{R}$ & $15+45$ & $132+1142+153$ & 1427 & $\mathrm{C}-2$ & $\mathrm{~L}+\mathrm{Th}+\mathrm{R}$ & $15+45$ & $132+600+18$ & 750 & 4354 \\
\hline 23 & $70-50$ & A-1 & $\mathrm{L}+2 \mathrm{Th}+\mathrm{R}$ & $20+50$ & $205+1288+117$ & 1610 & $\mathrm{C}-2$ & $\mathrm{~L}+\mathrm{Th}+\mathrm{R}$ & $10+40$ & $59+523+72$ & 654 & 4528 \\
\hline 24 & $70-50$ & A-1 & $\mathrm{L}+2 \mathrm{Th}+\mathrm{R}$ & $15+55$ & $132+1434+226$ & 1792 & $\mathrm{C}-2$ & $\mathrm{~L}+\mathrm{Th}+\mathrm{R}$ & $10+40$ & $59+523+72$ & 654 & 4892 \\
\hline
\end{tabular}

Table A-1 (D): An intersection with an Arterial Vs Collector Road 'T' intersection

\begin{tabular}{|c|c|c|c|c|c|c|c|c|c|c|c|c|}
\hline \multirow[b]{2}{*}{$\begin{array}{l}\dot{z} \\
\dot{1} \\
\dot{4}\end{array}$} & \multirow{2}{*}{ 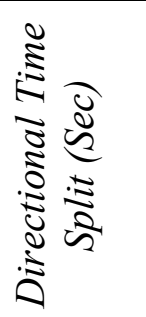 } & \multicolumn{5}{|c|}{ Major Road } & \multicolumn{6}{|c|}{ Minor Road } \\
\hline & & 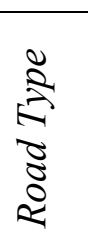 & $\begin{array}{c}\sqrt{3} \\
5 \\
0 \\
0 \\
0 \\
5\end{array}$ & 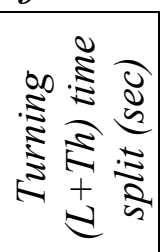 & $\begin{array}{c}\text { Capacity } \\
(L+T h) \\
o r \\
(R+T h)\end{array}$ & 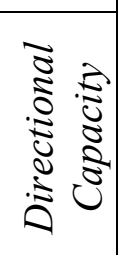 & 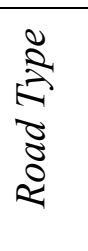 & 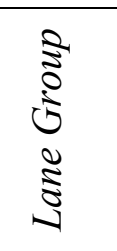 & 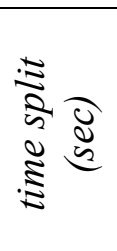 & $\begin{array}{c}\text { Capacity } \\
(L+R)\end{array}$ & 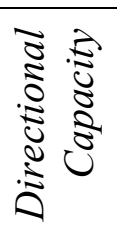 & 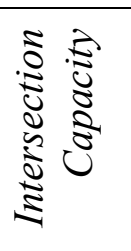 \\
\hline 1 & $90-30$ & A-1 & $2 \mathrm{~L}+2 \mathrm{Th}$ & $20+70$ & $398+1873$ & 2271 & $\mathrm{C}-1$ & $\mathrm{~L}+\mathrm{R}$ & 30 & $352+352$ & 704 & 5246 \\
\hline 2 & $100-20$ & A-1 & $2 \mathrm{~L}+2 \mathrm{Th}$ & $20+80$ & $398+2166$ & 2564 & $\mathrm{C}-1$ & $\mathrm{~L}+\mathrm{R}$ & 20 & $205+205$ & 410 & 5538 \\
\hline 3 & $100-20$ & A-1 & $2 \mathrm{~L}+2 \mathrm{Th}$ & $15+85$ & $256+2312$ & 2568 & $\mathrm{C}-1$ & $\mathrm{~L}+\mathrm{R}$ & 20 & $205+205$ & 410 & 5546 \\
\hline 4 & $90-30$ & $\mathrm{~A}-2$ & $\mathrm{~L}+2 \mathrm{Th}$ & $15+85$ & $132+2094$ & 2226 & $\mathrm{C}-1$ & $\mathrm{~L}+\mathrm{R}$ & 30 & $352+364$ & 716 & 5168 \\
\hline 5 & $100-20$ & A-3 & $\mathrm{L}($ per $)+2 \mathrm{Th}$ & 100 & $28+2723$ & 2751 & $\mathrm{C}-1$ & $\mathrm{~L}+\mathrm{R}$ & 20 & $205+205$ & 410 & 5912 \\
\hline 6 & $90-30$ & A-3 & $\mathrm{L}($ per $)+2 \mathrm{Th}$ & 90 & $25+2433$ & 2458 & $\mathrm{C}-1$ & $\mathrm{~L}+\mathrm{R}$ & 30 & $352+352$ & 704 & 5620 \\
\hline 7 & $90-30$ & A-2 & $\mathrm{L}+2 \mathrm{Th}$ & $10+80$ & $59+2093$ & 2152 & $\mathrm{C}-1$ & $\mathrm{~L}+\mathrm{R}$ & 30 & $352+429$ & 781 & 5085 \\
\hline 8 & $100-20$ & A-2 & $\mathrm{L}+2 \mathrm{Th}$ & $10+90$ & $59+2458$ & 2517 & C-1 & $\mathrm{L}+\mathrm{R}$ & 20 & $205+205$ & 410 & 5444 \\
\hline 9 & $100-20$ & A-2 & $\mathrm{L}+2 \mathrm{Th}$ & $10+90$ & $59+2458$ & 2517 & $\mathrm{C}-2$ & $2 \mathrm{~L}+\mathrm{R}$ & 20 & $398+398$ & 796 & 5830 \\
\hline
\end{tabular}




\begin{tabular}{|c|c|c|c|c|c|c|c|c|c|c|c|c|}
\hline 10 & $100-20$ & A-4 & $\begin{array}{c}\text { Th+TR/ } \\
\text { Th+TL }\end{array}$ & 100 & $1376+1224$ & 2600 & C-1 & L+R & 20 & $205+205$ & 410 & 5610 \\
\hline 11 & $80-40$ & A-4 & Th+TR & 80 & $1083+964$ & 2047 & C-1 & L+R & 40 & $498+498$ & 996 & 5090 \\
\hline 12 & $90-30$ & A-4 & Th+TR & 90 & $1229+1094$ & 2323 & C-1 & L+R & 30 & $352+352$ & 704 & $\mathbf{5 3 5 0}$ \\
\hline
\end{tabular}

Table A-1 (E): An intersection with a Collector Vs Collector Road 4-leg intersection

\begin{tabular}{|c|c|c|c|c|c|c|c|c|c|c|c|c|}
\hline \multirow[b]{2}{*}{$\begin{array}{l}\dot{z} \\
\dot{y} \\
\dot{3}\end{array}$} & \multirow{2}{*}{ 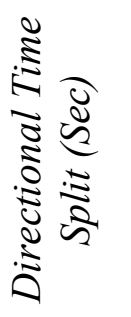 } & \multicolumn{5}{|c|}{ Major Road } & \multicolumn{6}{|c|}{ Minor Road } \\
\hline & & 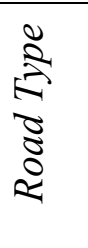 & $\begin{array}{c}\sqrt{3} \\
0 \\
0 \\
0 \\
0 \\
0 \\
5\end{array}$ & 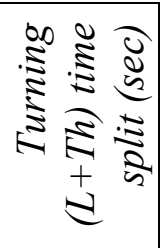 & $\begin{array}{c}\text { Capacity } \\
(L+T h) \\
\text { or } \\
(L+T h+T R)\end{array}$ & 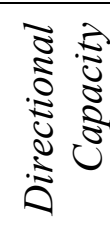 & 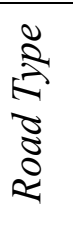 & 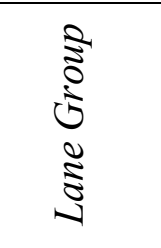 & 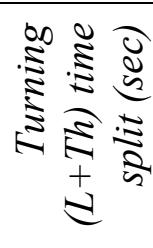 & $\begin{array}{c}\text { Capacity } \\
(L+T h) \\
\text { or } \\
(L+T h+T R)\end{array}$ & 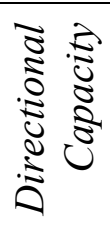 & 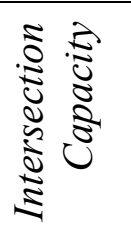 \\
\hline 1 & $64-26$ & $\mathrm{C}-1$ & $\mathrm{~L}+2 \mathrm{Th}+\mathrm{R}$ & $13+51$ & $136+1706$ & 1974 & $\mathrm{C}-2$ & $\mathrm{~L}+\mathrm{Th}+\mathrm{R}$ & $10+16$ & $97+205$ & 399 & 4746 \\
\hline 2 & $45-45$ & $\mathrm{C}-3$ & $\mathrm{~L}+\mathrm{Th}+\mathrm{TR}$ & $15+30$ & $175+468+417$ & 1060 & $\mathrm{C}-2$ & $\mathrm{~L}+\mathrm{Th}+\mathrm{R}$ & $15+30$ & $175+492$ & 842 & 3804 \\
\hline 3 & $64-26$ & $\mathrm{C}-3$ & $\mathrm{~L}+\mathrm{Th}+\mathrm{TR}$ & $13+51$ & $137+878+781$ & 1796 & $\mathrm{C}-2$ & $\mathrm{~L}+\mathrm{Th}+\mathrm{R}$ & $10+16$ & $98+205$ & 401 & 4394 \\
\hline 4 & $45-45$ & $\mathrm{C}-2$ & $\mathrm{~L}+\mathrm{Th}+\mathrm{R}$ & $15+30$ & $175+492$ & 842 & $\mathrm{C}-2$ & $\mathrm{~L}+\mathrm{Th}+\mathrm{R}$ & $15+30$ & $175+492$ & 842 & 3368 \\
\hline 5 & $64-26$ & $\mathrm{C}-2$ & $\mathrm{~L}+\mathrm{Th}+\mathrm{R}$ & $13+51$ & $137+922$ & 1196 & $\mathrm{C}-2$ & $\mathrm{~L}+\mathrm{Th}+\mathrm{R}$ & $10+16$ & $98+205$ & 401 & 3194 \\
\hline 6 & $45-45$ & $\mathrm{C}-3$ & $\mathrm{~L}+\mathrm{Th}+\mathrm{TR}$ & $15+30$ & $175+468+417$ & 1060 & C-4 & $\mathrm{L}+\mathrm{TR}$ & $15+30$ & $175+417$ & 592 & 3304 \\
\hline 7 & $64-26$ & $\mathrm{C}-3$ & $\mathrm{~L}+\mathrm{Th}+\mathrm{TR}$ & $13+51$ & $137+878+781$ & 1796 & C-4 & $\mathrm{L}+\mathrm{TR}$ & $10+16$ & $98+174$ & 272 & 4136 \\
\hline 8 & $64-26$ & $\mathrm{C}-3$ & $\mathrm{~L}+\mathrm{Th}+\mathrm{TR}$ & $14+50$ & $156+858+764$ & 1778 & C-4 & $\mathrm{L}+\mathrm{TR}$ & $10+16$ & $98+174$ & 272 & 4100 \\
\hline 9 & $45-45$ & $\mathrm{C}-4$ & $\mathrm{~L}+\mathrm{TR}$ & $15+30$ & $175+417$ & 592 & $\mathrm{C}-4$ & $\mathrm{~L}+\mathrm{TR}$ & $15+30$ & $175+417$ & 592 & 2368 \\
\hline
\end{tabular}




\begin{tabular}{|c|c|c|c|c|c|c|c|c|c|c|c|c|}
\hline 10 & $64-26$ & C-4 & $\mathrm{L}+\mathrm{TR}$ & $13+51$ & $137+781$ & 918 & C-4 & $\mathrm{L}+\mathrm{TR}$ & $10+16$ & $98+174$ & 272 & 2380 \\
\hline 11 & $45-45$ & $\mathrm{C}-2$ & $\mathrm{~L}+\mathrm{Th}+\mathrm{R}$ & $15+30$ & $175+492$ & 842 & $\mathrm{C}-4$ & $\mathrm{~L}+\mathrm{TR}$ & $15+30$ & $175+417$ & 592 & 2868 \\
\hline 12 & $64-26$ & C-2 & $\mathrm{L}+\mathrm{Th}+\mathrm{R}$ & $13+51$ & $137+922$ & 1196 & $\mathrm{C}-4$ & $\mathrm{~L}+\mathrm{TR}$ & $10+16$ & $98+174$ & 272 & 2736 \\
\hline
\end{tabular}

Table A-1 (F): An intersection with an Arterial Vs Local Road 4-leg intersection

\begin{tabular}{|c|c|c|c|c|c|c|c|c|c|c|}
\hline \multirow[b]{2}{*}{$\begin{array}{l}\dot{z} \\
\dot{z} \\
\dot{v}\end{array}$} & \multirow{2}{*}{ 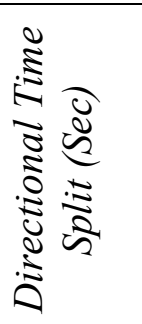 } & \multicolumn{5}{|c|}{ Major Road } & \multicolumn{4}{|c|}{ Minor Road } \\
\hline & & 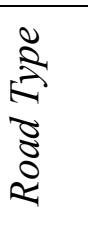 & $\begin{array}{c}-1 \\
3 \\
0 \\
0 \\
0 \\
0 \\
5 \\
5\end{array}$ & 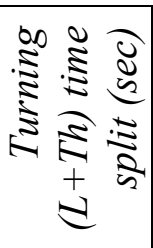 & $\begin{array}{c}\text { Capacity } \\
(L+T h+R) \\
\text { or } \\
(L+T h+T R)\end{array}$ & 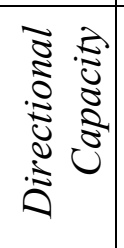 & Road Type & Time Split (Sec) & 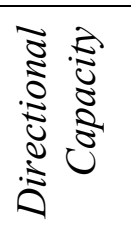 & 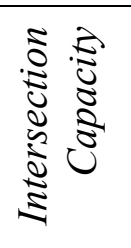 \\
\hline 1 & $90-30$ & A-1 & $\mathrm{L}+3 \mathrm{Th}+\mathrm{R}$ & $10+80$ & $73+3099+964$ & 4136 & $\mathrm{~L}$ & 30 & 313 & 8898 \\
\hline 2 & $90-30$ & A-1 & $\mathrm{L}+3 \mathrm{Th}+\mathrm{R}$ & $15+75$ & $132+2890+899$ & 3921 & $\mathrm{~L}$ & 30 & 313 & 8468 \\
\hline 3 & $94-26$ & A-1 & $\mathrm{L}+3 \mathrm{Th}+\mathrm{R}$ & $14+80$ & $117+3099+964$ & 4180 & $\mathrm{~L}$ & 26 & 260 & 8880 \\
\hline 4 & $100-20$ & A-1 & $\mathrm{L}+3 \mathrm{Th}+\mathrm{R}$ & $15+85$ & $132+3308+1029$ & 4469 & $\mathrm{~L}$ & 20 & 182 & 9302 \\
\hline 5 & $64-26$ & A-1 & $\mathrm{L}+3 \mathrm{Th}+\mathrm{R}$ & $13+51$ & $102+1884+586$ & 2572 & $\mathrm{~L}$ & 26 & 260 & 5664 \\
\hline 6 & $70-20$ & A-1 & $\mathrm{L}+3 \mathrm{Th}+\mathrm{R}$ & $10+60$ & $73+2261+703$ & 3037 & $\mathrm{~L}$ & 20 & 182 & 6438 \\
\hline 7 & $100-20$ & $\mathrm{~A}-2$ & $\mathrm{~L}+2 \mathrm{Th}+\mathrm{R}$ & $15+85$ & $132+2312+1029$ & 3473 & $\mathrm{~L}$ & 20 & 182 & 7310 \\
\hline 8 & $94-26$ & A-2 & $\mathrm{L}+2 \mathrm{Th}+\mathrm{R}$ & $14+80$ & $117+2166+964$ & 3247 & $\mathrm{~L}$ & 26 & 260 & 7014 \\
\hline 9 & $90-30$ & A-2 & $\mathrm{L}+2 \mathrm{Th}+\mathrm{R}$ & $15+75$ & $132+2019+899$ & 3050 & $\mathrm{~L}$ & 30 & 313 & 6726 \\
\hline 10 & $64-26$ & A-2 & $\mathrm{L}+2 \mathrm{Th}+\mathrm{R}$ & $13+51$ & $102+1317+586$ & 2005 & $\mathrm{~L}$ & 26 & 260 & 4530 \\
\hline
\end{tabular}




\begin{tabular}{|c|c|c|c|c|c|c|c|c|c|c|}
\hline 11 & $70-20$ & A-2 & L+2Th+R & $10+60$ & $73+1580+703$ & 2356 & L & 20 & 182 & 5076 \\
\hline 12 & $100-20$ & A-3 & L+Th+TR & $15+85$ & $132+1156+1029$ & 2317 & L & 20 & 182 \\
\hline 13 & $70-20$ & A-3 & L+Th+TR & $10+60$ & $73+790+703$ & 1566 & L & 20 & 182 \\
\hline 14 & $64-26$ & A-3 & L+Th+TR & $13+51$ & $102+658+586$ & 1346 & L & 26 & 3498 \\
\hline
\end{tabular}

Table A-1 (G): An intersection with an Arterial Vs Local Road 3-leg (T) intersection

\begin{tabular}{|c|c|c|c|c|c|c|c|c|c|c|}
\hline \multirow[b]{2}{*}{$\frac{\dot{z}}{\dot{i}}$} & \multirow{2}{*}{ 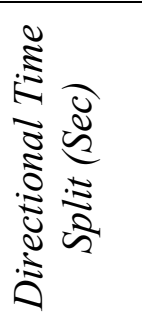 } & \multicolumn{5}{|c|}{ Major Road } & \multicolumn{4}{|c|}{ Minor Road } \\
\hline & & 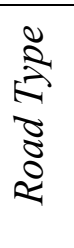 & 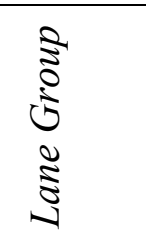 & 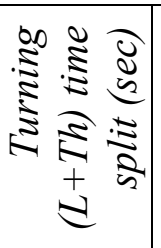 & $\begin{array}{c}\text { Capacity } \\
(L+T h+R) \\
o r \\
(T h+R / T R)\end{array}$ & 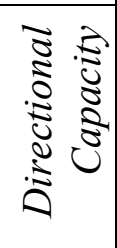 & Road Type & Time Split (Sec) & 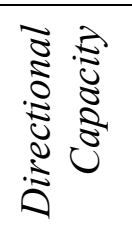 & 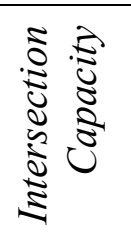 \\
\hline 1 & $70-20$ & $\mathrm{~A}$ & $\begin{array}{l}\mathrm{L}+2 \mathrm{Th} \\
\mathrm{Th}+\mathrm{TR}\end{array}$ & $10+60$ & $\begin{array}{l}73+1582 \\
791+703\end{array}$ & $\begin{array}{l}1655 \\
1494\end{array}$ & $\mathrm{~L}$ & 20 & 182 & 3331 \\
\hline 2 & $64-26$ & $\mathrm{~A}$ & $\begin{array}{l}\mathrm{L}+2 \mathrm{Th} \\
2 \mathrm{Th}+\mathrm{R}\end{array}$ & $13+51$ & $\begin{array}{l}102+1317 \\
1317+586\end{array}$ & $\begin{array}{l}1419 \\
1903\end{array}$ & $\mathrm{~L}$ & 26 & 260 & 3582 \\
\hline 3 & $70-20$ & $\mathrm{~A}$ & $\begin{array}{l}\mathrm{L}+2 \mathrm{Th} \\
2 \mathrm{Th}+\mathrm{R}\end{array}$ & $10+60$ & $\begin{array}{c}73+1580 \\
1580+703\end{array}$ & $\begin{array}{l}1653 \\
2283\end{array}$ & $\mathrm{~L}$ & 20 & 182 & 4118 \\
\hline 4 & $100-20$ & $\mathrm{~A}$ & $\begin{array}{l}\mathrm{L}+2 \mathrm{Th} \\
\mathrm{Th}+\mathrm{TR}\end{array}$ & $15+85$ & $\begin{array}{c}132+2312 \\
1156+1029\end{array}$ & $\begin{array}{l}2444 \\
2185\end{array}$ & $\mathrm{~L}$ & 20 & 182 & 4811 \\
\hline 5 & $70-20$ & $\mathrm{~A}$ & $\begin{array}{l}\mathrm{L}+3 \mathrm{Th} \\
3 \mathrm{Th}+\mathrm{R}\end{array}$ & $10+60$ & $\begin{array}{l}73+2261 \\
2261+703\end{array}$ & $\begin{array}{l}2334 \\
2964\end{array}$ & $\mathrm{~L}$ & 20 & 182 & 5480 \\
\hline
\end{tabular}




\begin{tabular}{|c|c|c|c|c|c|c|c|c|c|c|}
\hline 6 & $100-20$ & $\mathrm{~A}$ & $\begin{array}{l}\mathrm{L}+2 \mathrm{Th} \\
2 \mathrm{Th}+\mathrm{R}\end{array}$ & $15+85$ & $\begin{array}{c}132+2312 \\
2312+1029\end{array}$ & $\begin{array}{l}2444 \\
3341\end{array}$ & $\mathrm{~L}$ & 20 & 182 & 5967 \\
\hline 7 & $90-30$ & $\mathrm{~A}$ & $\begin{array}{l}\mathrm{L}+3 \mathrm{Th} \\
3 \mathrm{Th}+\mathrm{R}\end{array}$ & $15+75$ & $\begin{array}{l}132+2890 \\
2890+132\end{array}$ & 3022 & $\mathrm{~L}$ & 30 & 313 & 6357 \\
\hline 8 & $90-30$ & $\mathrm{~A}$ & $\begin{array}{l}\mathrm{L}+3 \mathrm{Th} \\
3 \mathrm{Th}+\mathrm{R}\end{array}$ & $10+80$ & $\begin{array}{l}73+3099 \\
3099+73\end{array}$ & 3172 & $\mathrm{~L}$ & 30 & 313 & 6657 \\
\hline 9 & $90-30$ & $\mathrm{~A}$ & $\begin{array}{l}\mathrm{L}+3 \mathrm{Th} \\
3 \mathrm{Th}+\mathrm{R}\end{array}$ & $15+75$ & $\begin{array}{l}132+2890 \\
2890+899\end{array}$ & $\begin{array}{l}3022 \\
3789\end{array}$ & $\mathrm{~L}$ & 30 & 313 & 7124 \\
\hline 10 & $100-20$ & A & $\begin{array}{l}\mathrm{L}+3 \mathrm{Th} \\
3 \mathrm{Th}+\mathrm{R}\end{array}$ & $15+85$ & $\begin{array}{c}132+3308 \\
3308+1029\end{array}$ & $\begin{array}{l}3440 \\
4337\end{array}$ & $\mathrm{~L}$ & 20 & 182 & 7959 \\
\hline
\end{tabular}

Table A-1 (H): An intersection with a Collector Vs Local Road 4-leg intersection

\begin{tabular}{|c|c|c|c|c|c|c|c|c|c|c|c|}
\hline \multirow[b]{2}{*}{$\begin{array}{l}\dot{z} \\
\dot{1} \\
\dot{4}\end{array}$} & \multirow{2}{*}{ 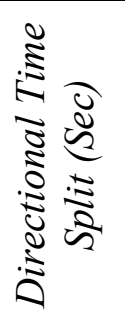 } & \multicolumn{5}{|c|}{ Major Road } & \multicolumn{5}{|c|}{ Minor Road } \\
\hline & & 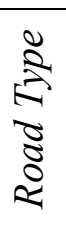 & $\begin{array}{c}-1 \\
0 \\
0 \\
0 \\
0 \\
0 \\
0 \\
0 \\
0\end{array}$ & 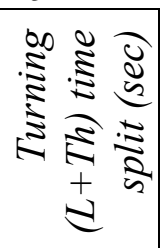 & $\begin{array}{c}\text { Capacity } \\
(L+T h) \\
\text { or } \\
(L+T h+T R)\end{array}$ & 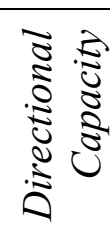 & 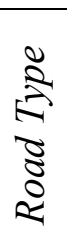 & 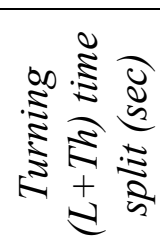 & $\begin{array}{c}\text { Capacity } \\
(L+T h+R) \\
\text { or } \\
(L+T R)\end{array}$ & 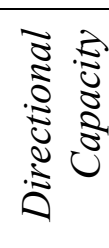 & 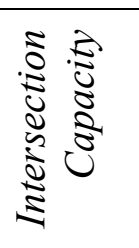 \\
\hline 1 & $60-30$ & $\mathrm{C}$ & $\mathrm{L}+2 \mathrm{Th}+\mathrm{R}$ & $15+45$ & $175+1522$ & 1872 & $\mathrm{~L}$ & 30 & - & 417 & 4578 \\
\hline 2 & $64-26$ & $\mathrm{C}$ & $\mathrm{L}+2 \mathrm{Th}+\mathrm{R}$ & $13+51$ & $136+1756$ & 2028 & $\mathrm{~L}$ & 26 & - & 347 & 4750 \\
\hline 3 & $70-20$ & $\mathrm{C}$ & $\mathrm{L}+2 \mathrm{Th}+\mathrm{R}$ & $10+60$ & $98+2107$ & 2303 & $\mathrm{~L}$ & 20 & - & 243 & 5092 \\
\hline
\end{tabular}




\begin{tabular}{|c|c|c|c|c|c|c|c|c|c|c|c|}
\hline 4 & $60-30$ & $\mathrm{C}$ & $\mathrm{L}+2 \mathrm{Th}+\mathrm{R}$ & $15+45$ & $175+1522+500$ & 2197 & $\mathrm{~L}$ & 30 & - & 417 & 5228 \\
\hline 5 & $64-26$ & $\mathrm{C}$ & $\mathrm{L}+\mathrm{Th}+\mathrm{TR}$ & $13+51$ & $136+878+781$ & 1795 & $\mathrm{~L}$ & 26 & - & 373 & 4336 \\
\hline 6 & $70-20$ & $\mathrm{C}$ & $\mathrm{L}+\mathrm{Th}+\mathrm{TR}$ & $10+60$ & $97+1054+938$ & 2089 & $\mathrm{~L}$ & 20 & - & 243 & 4664 \\
\hline 7 & $60-30$ & $\mathrm{C}$ & $\mathrm{L}+\mathrm{Th}+\mathrm{R}$ & $15+45$ & $175+800$ & 1150 & $\mathrm{~L}$ & 30 & - & 417 & 3134 \\
\hline 8 & $64-26$ & $\mathrm{C}$ & $\mathrm{L}+\mathrm{Th}+\mathrm{R}$ & $13+51$ & $136+922$ & 1150 & $\mathrm{~L}$ & 26 & - & 347 & 2994 \\
\hline 9 & $70-20$ & $\mathrm{C}$ & $\mathrm{L}+\mathrm{Th}+\mathrm{R}$ & $10+60$ & $98+1107$ & 1303 & $\mathrm{~L}$ & 20 & - & 243 & 3092 \\
\hline 10 & $60-30$ & $\mathrm{C}$ & $\mathrm{L}+\mathrm{TR}$ & $15+45$ & $175+677$ & 852 & $\mathrm{~L}$ & 30 & - & 417 & 2538 \\
\hline 11 & $64-26$ & $\mathrm{C}$ & $\mathrm{L}+\mathrm{TR}$ & $13+51$ & $136+781$ & 917 & $\mathrm{~L}$ & 26 & - & 347 & 2528 \\
\hline 12 & $70-20$ & $\mathrm{C}$ & $\mathrm{L}+\mathrm{TR}$ & $10+60$ & $98+938$ & 1036 & $\mathrm{~L}$ & 20 & - & 243 & 2558 \\
\hline 13 & $64-26$ & $\mathrm{C}$ & $\mathrm{L}+\mathrm{Th}+\mathrm{TR}$ & $13+51$ & $136+878+781$ & 1795 & $\mathrm{~L}$ & $8+18$ & $58+208$ & 266 & 4122 \\
\hline 14 & $60-30$ & $\mathrm{C}$ & $\mathrm{L}+\mathrm{Th}+\mathrm{TR}$ & $15+45$ & $175+761+677$ & 1613 & $\mathrm{~L}$ & $10+20$ & $78+243$ & 321 & 3868 \\
\hline
\end{tabular}

Table A-1 (I): An intersection with a Collector Vs Local Road 3-leg (T) intersection

\begin{tabular}{|c|c|c|c|c|c|c|c|c|c|c|c|}
\hline \multirow[b]{2}{*}{$\frac{\dot{z}}{\dot{i}}$} & \multirow{2}{*}{ 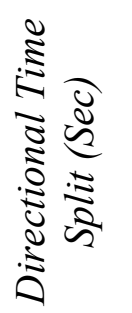 } & \multicolumn{5}{|c|}{ Major Road } & \multicolumn{5}{|c|}{ Minor Road } \\
\hline & & 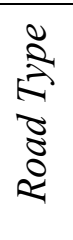 & 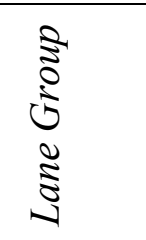 & 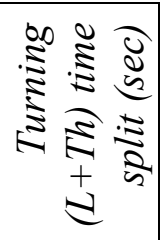 & $\begin{array}{c}\text { Capacity } \\
(L+T h)+ \\
(T h+R) / \\
(T h+T R)\end{array}$ & 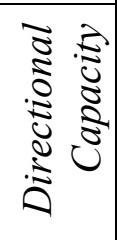 & 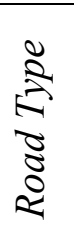 & 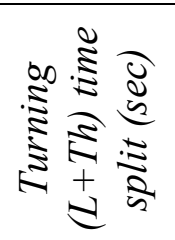 & $\begin{array}{c}\text { Capacity } \\
(L+T h+R) \\
\text { or } \\
(L+T h+T R)\end{array}$ & 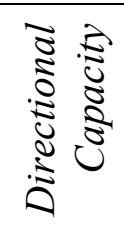 & 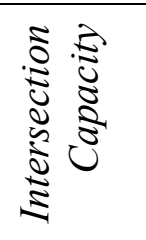 \\
\hline 1 & $60-30$ & $\mathrm{C}$ & $\begin{array}{l}\mathrm{L}+2 \mathrm{Th} \\
2 \mathrm{Th}+\mathrm{R}\end{array}$ & $15+45$ & $\begin{array}{l}175+1522 \\
1522+175\end{array}$ & $\begin{array}{l}1697 \\
1697\end{array}$ & $\mathrm{~L}$ & 30 & - & 417 & 3811 \\
\hline
\end{tabular}




\begin{tabular}{|c|c|c|c|c|c|c|c|c|c|c|c|}
\hline 2 & $64-26$ & $\mathrm{C}$ & $\mathrm{L}+2 \mathrm{Th}$ & $13+51$ & $136+1756$ & 1892 & $\mathrm{~L}$ & 26 & - & 347 & 4131 \\
\hline 3 & $70-20$ & $\mathrm{C}$ & $\mathrm{L}+2 \mathrm{Th}$ & $10+60$ & $98+2107$ & 2205 & $\mathrm{~L}$ & 20 & - & 243 & 4653 \\
\hline 4 & $64-26$ & $\mathrm{C}$ & $\begin{array}{l}\mathrm{L}+2 \mathrm{Th} \\
\mathrm{Th}+\mathrm{TR}\end{array}$ & $13+51$ & $\begin{array}{c}136+1756 \\
878+781\end{array}$ & $\begin{array}{l}1892 \\
1659\end{array}$ & $\mathrm{~L}$ & 26 & - & 373 & 3924 \\
\hline 5 & $60-30$ & $\mathrm{C}$ & $\mathrm{L}+\mathrm{Th}$ & $15+45$ & $175+800$ & 975 & $\mathrm{~L}$ & 30 & - & 417 & 2367 \\
\hline 6 & $64-26$ & $\mathrm{C}$ & $\mathrm{L}+\mathrm{Th}$ & $13+51$ & $136+922$ & 1058 & $\mathrm{~L}$ & 26 & - & 347 & 2463 \\
\hline 7 & $70-20$ & $\mathrm{C}$ & $\mathrm{L}+\mathrm{Th}$ & $10+60$ & $98+1107$ & 1205 & $\mathrm{~L}$ & 20 & - & 243 & 2653 \\
\hline 8 & $60-30$ & $\mathrm{C}$ & $\begin{array}{c}\mathrm{L}+\mathrm{Th} \\
\mathrm{TR}\end{array}$ & $15+45$ & $\begin{array}{c}175+677 \\
677\end{array}$ & $\begin{array}{l}852 \\
677\end{array}$ & $\mathrm{~L}$ & 30 & - & 417 & 1946 \\
\hline 9 & $64-26$ & $\mathrm{C}$ & $\begin{array}{c}\mathrm{L}+\mathrm{Th} \\
\mathrm{TR}\end{array}$ & $13+51$ & $136+781$ & $\begin{array}{l}917 \\
781\end{array}$ & $\mathrm{~L}$ & 26 & - & 347 & 2045 \\
\hline 10 & $70-20$ & $\mathrm{C}$ & $\begin{array}{c}\mathrm{L}+\mathrm{Th} \\
\mathrm{TR}\end{array}$ & $10+60$ & $98+938$ & $\begin{array}{c}1036 \\
938\end{array}$ & $\mathrm{~L}$ & 20 & - & 243 & 2217 \\
\hline 11 & $64-26$ & $\mathrm{C}$ & $\begin{array}{l}\mathrm{L}+2 \mathrm{Th} \\
\mathrm{Th}+\mathrm{TR}\end{array}$ & $13+51$ & $\begin{array}{c}136+1659 \\
878+781\end{array}$ & $\begin{array}{l}1795 \\
1659\end{array}$ & $\mathrm{~L}$ & $8+18$ & $58+208$ & 266 & 3720 \\
\hline 12 & $60-30$ & $\mathrm{C}$ & $\begin{array}{c}\mathrm{L}+2 \mathrm{Th} \\
\mathrm{Th}+\mathrm{TR}\end{array}$ & $15+45$ & $\begin{array}{c}175+1438 \\
677+761\end{array}$ & $\begin{array}{l}1613 \\
1438\end{array}$ & $\mathrm{~L}$ & $10+20$ & $78+243$ & 321 & 3372 \\
\hline
\end{tabular}

Table A-2: Capacity level directional flow rate 


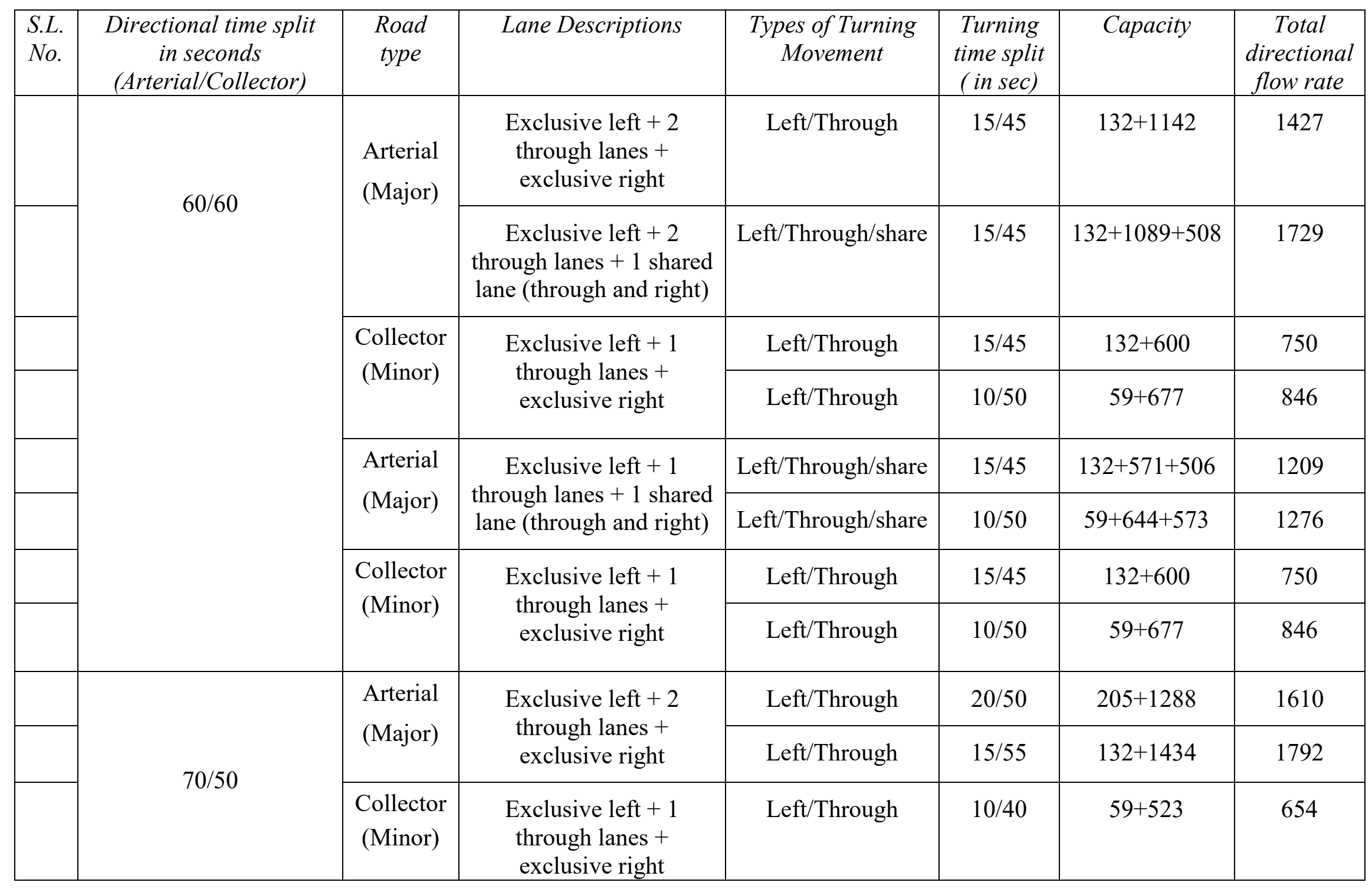




\begin{tabular}{|c|c|c|c|c|c|c|c|}
\hline 2 & \multirow{6}{*}{$80 / 40$} & $\begin{array}{l}\text { Arterial } \\
\text { (Major) }\end{array}$ & $\begin{array}{c}\text { Exclusive left }+2 \\
\text { through lanes }+ \\
\text { exclusive right }\end{array}$ & Left/Through & $18 / 62$ & $176+1639$ & 2048 \\
\hline 3 & & \multirow{5}{*}{$\begin{array}{c}\text { Collector } \\
\text { (Minor) }\end{array}$} & \multirow{2}{*}{$\begin{array}{c}\text { Exclusive left }+1 \\
\text { through lanes }+ \\
\text { exclusive right }\end{array}$} & Left/Through & $10 / 30$ & $58+370$ & 460 \\
\hline 4 & & & & Left/Through & $12 / 28$ & $88+338$ & 422 \\
\hline 6 & & & $\begin{array}{c}\text { Exclusive left }+2 \\
\text { through lanes }+ \\
\text { exclusive right }\end{array}$ & Left/Through & $12 / 28$ & $88+644$ & 805 \\
\hline 7 & & & \multirow{2}{*}{$\begin{array}{l}\text { Exclusive left }+1 \\
\text { through lanes }+1 \text { shared } \\
\text { lane (through and right) }\end{array}$} & Left/Through/share & $10 / 30$ & $58+351+313$ & 722 \\
\hline 8 & & & & Left/Through/share & $12 / 28$ & $88+322+287$ & 697 \\
\hline 10 & \multirow{3}{*}{$90 / 30$} & \multirow{3}{*}{$\begin{array}{c}\text { Collector } \\
\text { (Minor) }\end{array}$} & $\begin{array}{c}\text { Exclusive left }+1 \\
\text { through lanes }+ \\
\text { exclusive right }\end{array}$ & Left/Through & $8 * / 22$ & $44+246$ & 308 \\
\hline 11 & & & $\begin{array}{c}\text { Exclusive left }+2 \\
\text { through lanes }+ \\
\text { exclusive right }\end{array}$ & Left/Through & $8 * / 22$ & $44+468$ & 585 \\
\hline 12 & & & $\begin{array}{l}\text { Exclusive left }+1 \\
\text { through lanes }+1 \text { shared } \\
\text { lane (through and right) }\end{array}$ & Left/Through/share & $8 * / 22$ & $44+234+208$ & 486 \\
\hline
\end{tabular}




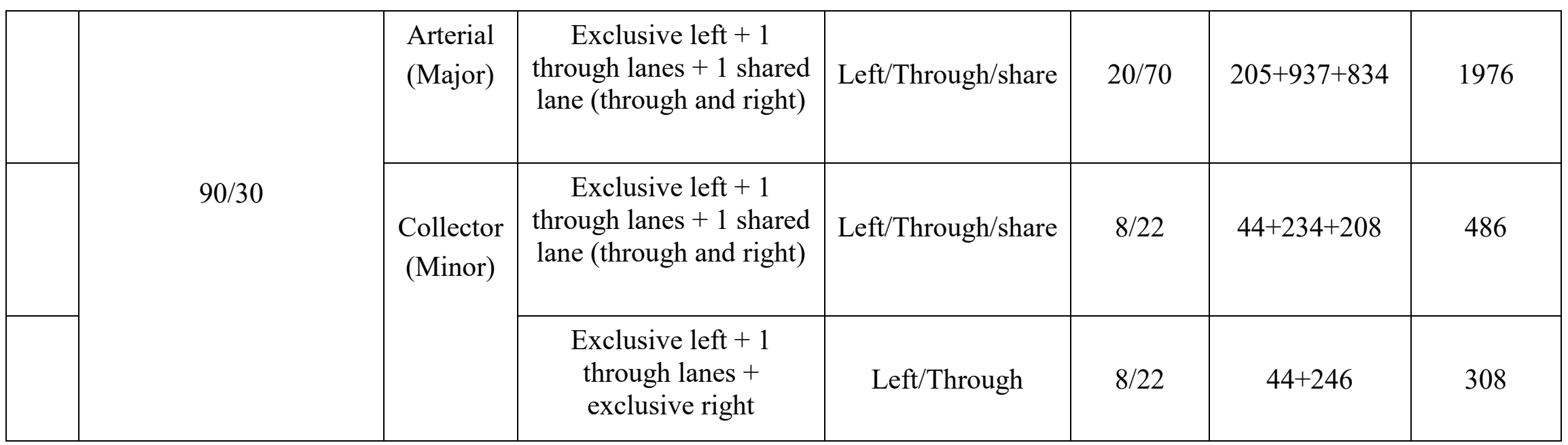

Table A-3 (A): Capacity level traffic volume ranges in an arterial vs arterial 4 leg intersection

\begin{tabular}{|c|c|c|c|}
\hline \multirow{2}{*}{ S.L. No. } & \multicolumn{2}{|c|}{ Capacity level directional flow } & \multirow{2}{*}{ Intersection Capacity } \\
\cline { 2 - 4 } & Major Arterial & Minor Arterial & 4976 \\
\hline 1 & 1244 & 1244 & 5344 \\
\hline 2 & 1244 & 1428 & 5268 \\
\hline 3 & 1244 & 1390 & 5712 \\
\hline 4 & 1428 & 1428 & 5636 \\
\hline 5 & 1428 & 1390 & 5560 \\
\hline 6 & 1390 & 1390 & \\
\hline
\end{tabular}




\begin{tabular}{|c|c|c|c|}
\hline 7 & 1244 & 1146 & 4780 \\
\hline 8 & 1244 & 1211 & 4910 \\
\hline 9 & 1244 & 1197 & 4882 \\
\hline 10 & 1428 & 1146 & 5148 \\
\hline 11 & 1428 & 1211 & 5278 \\
\hline 12 & 1428 & 1197 & 5250 \\
\hline 13 & 1390 & 1146 & 5072 \\
\hline 14 & 1390 & 1211 & 5202 \\
\hline 15 & 1390 & 1197 & 5174 \\
\hline 16 & 1886 & 1244 & 6260 \\
\hline 17 & 2140 & 1244 & 6768 \\
\hline 18 & 2085 & 1244 & 6658 \\
\hline 19 & 1886 & 1428 & 6628 \\
\hline 20 & 2140 & 1428 & 7136 \\
\hline 21 & 2085 & 1428 & 7026 \\
\hline 22 & 1886 & 1390 & 6552 \\
\hline 23 & 2140 & 1390 & 7060 \\
\hline 24 & 2085 & 1390 & 6950 \\
\hline 25 & 1437 & 1244 & 5362 \\
\hline 26 & 1437 & 1428 & 5730 \\
\hline 27 & 1437 & 1390 & 5654 \\
\hline
\end{tabular}




\begin{tabular}{|l|l|l|l|}
\hline 28 & 1552 & 1244 & 5592 \\
\hline 29 & 1552 & 1428 & 5960 \\
\hline 30 & 1528 & 1428 & 5912 \\
\hline
\end{tabular}

Table $A-3$ (B): Capacity level traffic volume ranges in an arterial vs collector 4 leg intersection

\begin{tabular}{|c|c|c|c|c|}
\hline \multirow[t]{2}{*}{ S.L. No. } & \multirow{2}{*}{$\begin{array}{l}\text { Directional time split } \\
\text { in seconds } \\
\text { (Arterial/ Collector) }\end{array}$} & \multicolumn{2}{|c|}{$\begin{array}{l}\text { Capacity level directional } \\
\text { flow }\end{array}$} & \multirow[t]{2}{*}{ Intersection Capacity } \\
\hline & & Arterial & Collector & \\
\hline & \multirow{5}{*}{$60 / 60$} & 1209 & 750 & 3918 \\
\hline & & 1276 & 846 & 4244 \\
\hline & & 1427 & 750 & 4354 \\
\hline & & 1427 & 846 & 4546 \\
\hline & & 1729 & 846 & 5150 \\
\hline & \multirow[t]{2}{*}{$70 / 50$} & 1610 & 654 & 4528 \\
\hline & & 1792 & 654 & 4892 \\
\hline 1 & \multirow{4}{*}{$80 / 40$} & \multirow{4}{*}{1975} & 460 & 4870 \\
\hline 2 & & & 422 & 4794 \\
\hline 3 & & & 878 & 5706 \\
\hline 4 & & & 805 & 5560 \\
\hline
\end{tabular}




\begin{tabular}{|c|c|c|c|c|}
\hline 5 & & & 722 & 5394 \\
\hline 6 & & & 697 & 5344 \\
\hline 7 & & \multirow{6}{*}{2048} & 460 & 5016 \\
\hline 8 & & & 422 & 4940 \\
\hline 9 & & & 878 & 5852 \\
\hline 10 & & & 805 & 5706 \\
\hline 11 & & & 722 & 5540 \\
\hline 12 & & & 697 & 5490 \\
\hline 13 & \multirow{5}{*}{$90 / 30$} & \multirow{3}{*}{2348} & 308 & 5312 \\
\hline 14 & & & 585 & 5866 \\
\hline \multirow[t]{3}{*}{15} & & & 486 & 5668 \\
\hline & & \multirow[t]{2}{*}{1976} & 486 & 4924 \\
\hline & & & 308 & 4568 \\
\hline
\end{tabular}

Note:

1. Intersection capacity for 4 leg intersection $=2 x$ (flow rate on major road + flow rate on minor road $)=2(1975+460)=4870$

2. Intersection capacity at $T$ intersection $=(2 x$ flow rate on major road $)+$ flow rate on minor road

3. The details of calculation part including lane specifications are in Table A-1 
Table A-3 (A): Capacity level traffic volume ranges in an arterial vs arterial 4 leg intersection

\begin{tabular}{|c|c|c|c|}
\hline \multirow{2}{*}{ S.L. No. } & \multicolumn{2}{|c|}{ Capacity level directional flow } & \multirow{2}{*}{ Intersection Capacity } \\
\cline { 2 - 3 } & Major Arterial & Minor Arterial & \multicolumn{2}{|c|}{5976} \\
\hline 1 & 1244 & 1244 & 5344 \\
\hline 2 & 1244 & 1428 & 5268 \\
\hline 3 & 1244 & 1390 & 5712 \\
\hline 4 & 1428 & 1428 & 5636 \\
\hline 5 & 1428 & 1390 & 5560 \\
\hline 6 & 1390 & 1390 & 4780 \\
\hline 7 & 1244 & 1146 & 4910 \\
\hline 8 & 1244 & 1211 & 4882 \\
\hline 9 & 1244 & 1197 & 5148 \\
\hline 10 & 1428 & 1146 & 5278 \\
\hline 11 & 1428 & 1211 & 5250 \\
\hline 12 & 1428 & 1197 & 5072 \\
\hline 13 & 1390 & 1146 & 5202 \\
\hline 14 & 1390 & 1211 & 5174 \\
\hline 15 & 1390 & 1197 & 6260 \\
\hline 16 & 1886 & 1244 & 6768 \\
\hline 17 & 2140 & 1244 & \\
\hline
\end{tabular}




\begin{tabular}{|l|l|l|l|}
\hline 18 & 2085 & 1244 & 6658 \\
\hline 19 & 1886 & 1428 & 6628 \\
\hline 20 & 2140 & 1428 & 7136 \\
\hline 21 & 2085 & 1428 & 7026 \\
\hline 22 & 1886 & 1390 & 6552 \\
\hline 23 & 2140 & 1390 & 7060 \\
\hline 24 & 2085 & 1390 & 6950 \\
\hline 25 & 1437 & 1244 & 5362 \\
\hline 26 & 1437 & 1428 & 5730 \\
\hline 27 & 1437 & 1390 & 5654 \\
\hline 28 & 1552 & 1244 & 5592 \\
\hline 29 & 1552 & 1428 & 5960 \\
\hline 30 & 1528 & 1428 & 5912 \\
\hline
\end{tabular}

Table $A-3$ (B): Capacity level traffic volume ranges in an arterial vs collector 4 leg intersection

\begin{tabular}{|l|c|c|c|c|}
\hline \multirow{2}{*}{ S.L. No. } & $\begin{array}{c}\text { Directional time split } \\
\text { in seconds } \\
\text { (Arterial/Collector) }\end{array}$ & $\begin{array}{c}\text { Capacity level directional } \\
\text { flow }\end{array}$ & Intersection Capacity \\
\cline { 3 - 4 } & & Arterial & Collector & \\
\hline & & 1209 & 750 & 3918 \\
\hline
\end{tabular}




\begin{tabular}{|c|c|c|c|c|}
\hline & \multirow{4}{*}{$60 / 60$} & 1276 & 846 & 4244 \\
\hline & & 1427 & 750 & 4354 \\
\hline & & 1427 & 846 & 4546 \\
\hline & & 1729 & 846 & 5150 \\
\hline & \multirow[t]{2}{*}{$70 / 50$} & 1610 & 654 & 4528 \\
\hline & & 1792 & 654 & 4892 \\
\hline 1 & \multirow{12}{*}{$80 / 40$} & \multirow{6}{*}{1975} & 460 & 4870 \\
\hline 2 & & & 422 & 4794 \\
\hline 3 & & & 878 & 5706 \\
\hline 4 & & & 805 & 5560 \\
\hline 5 & & & 722 & 5394 \\
\hline 6 & & & 697 & 5344 \\
\hline 7 & & \multirow{6}{*}{2048} & 460 & 5016 \\
\hline 8 & & & 422 & 4940 \\
\hline 9 & & & 878 & 5852 \\
\hline 10 & & & 805 & 5706 \\
\hline 11 & & & 722 & 5540 \\
\hline 12 & & & 697 & 5490 \\
\hline 13 & \multirow[b]{3}{*}{$90 / 30$} & \multirow{3}{*}{2348} & 308 & 5312 \\
\hline 14 & & & 585 & 5866 \\
\hline 15 & & & 486 & 5668 \\
\hline
\end{tabular}




\begin{tabular}{|l|l|l|l|l|}
\hline & \multirow{2}{*}{$*$} & 1976 & 486 & 4924 \\
\cline { 1 - 2 } & & & 308 & 4568 \\
\hline
\end{tabular}

Note:

1. Intersection capacity for 4 leg intersection $=2 x$ (flow rate on major road + flow rate on minor road $)=2(1975+460)=4870$

2. Intersection capacity at $T$ intersection $=(2 x$ flow rate on major road $)+$ flow rate on minor road

3. The details of calculation part including lane specifications are in Table A-1 


\section{APPENDIX GROUP 2}

\section{APENDIX II to XII}

- APPENDIX-II (A): RANDOM NUMBER GENERATED IN EXCEL FOR SIMULATION RUN

- APPENDIX-II (B): RANDOM NUMBER FROM RANDOM DIGITS

- APPENDIX-III: DUST METER READING

- APPENDIX-IV: GAS ANALYZER READING

- APPENDIX-V: VELOCITY METER READING

- APPENDIX-VI: OUTPUT FROM VISSIM (TRAFFIC SIMULATION) MODEL

- APPENDIX-VII: INPUT FILES FOR MOVES EMISSION MODEL

- APPENDIX-VIII: COMPOSITE EMISSION FACTORS FOR GASEOUS POLLUTANTS USING CMEM EMISSION MODEL

- APPENDIX-IX: EMISSION RATES FROM MOVES EMISSION MODEL

- APPENDIX-X: SIMULATION 18 AC 15 CO

- APPENDIX-XI: SIMULATION 12 AC $19 \mathrm{NO}_{2}$

- APPENDIX-XII: FREEWAY SAMPLE \#3 FOR PM2.5 CONCENTRATIONS 


\section{Appendix-II (A): RANDOM NUMBER GENERATED IN EXCEL FOR SIMULATION RUN}

Event Number Land Use Road Type Road intersect with intersection type

\begin{tabular}{|c|c|c|c|c|}
\hline 1 & 0 & 1 & 2 & 1 \\
\hline 2 & 0 & 0 & 1 & 3 \\
\hline 3 & 1 & 0 & 3 & 3 \\
\hline 4 & 0 & 0 & 1 & 2 \\
\hline 5 & 0 & 0 & 3 & 3 \\
\hline 6 & 1 & 0 & 3 & 2 \\
\hline 7 & 1 & 1 & 2 & 1 \\
\hline 8 & 1 & 1 & 2 & 1 \\
\hline 9 & 0 & 1 & 3 & 3 \\
\hline 10 & 1 & 1 & 1 & 2 \\
\hline 11 & 0 & 1 & 3 & 2 \\
\hline 12 & 1 & 0 & 2 & 1 \\
\hline 13 & 1 & 0 & 3 & 2 \\
\hline 14 & 1 & 1 & 1 & 1 \\
\hline 15 & 1 & 0 & 2 & 2 \\
\hline 16 & 0 & 1 & 3 & 1 \\
\hline 17 & 1 & 1 & 1 & 2 \\
\hline 18 & 0 & 0 & 2 & 2 \\
\hline 19 & 0 & 0 & 3 & 1 \\
\hline 20 & 0 & 1 & 2 & 2 \\
\hline 21 & 1 & 1 & 1 & 1 \\
\hline 22 & 1 & 1 & 1 & 2 \\
\hline 23 & 0 & 1 & 2 & 3 \\
\hline 24 & 1 & 1 & 2 & 2 \\
\hline 25 & 0 & 0 & 3 & 1 \\
\hline 26 & 1 & 0 & 2 & 3 \\
\hline
\end{tabular}


27

28

29

30

$\underline{\text { Note }}$
3

1

1

3
1

2

3

3

Land use type: $\mathrm{CBD}$ - central city $=0$, Urban - Outside $\mathrm{CBD}=1$

Road Type: Arterial $=0$, Collector $=1$

Road intersect with: Arterial $=1$, Collector $=2$, and Local $=3$

Intersection Type: 4-leg $=0, \mathrm{~T}$-type $=1$ 


\section{Appendix-II (B): RANDOM NUMBER FROM RANDOM DIGITS}

\section{Random Digits}

\begin{tabular}{llllllllll}
03991 & 10461 & 93716 & 16894 & 98953 & 73231 & 39528 & 72484 & 82474 & 25593 \\
38555 & 95554 & 32886 & 59780 & 09958 & 18065 & 81616 & 18711 & 53342 & 44276 \\
17546 & 73704 & 92052 & 46215 & 15917 & 06253 & 07586 & 16120 & 82641 & 22820 \\
32643 & 52861 & 95819 & 06831 & 19640 & 99413 & 90767 & 04235 & 13574 & 17200 \\
69572 & 68777 & 39510 & 35905 & 85244 & 35159 & 40188 & 28193 & 29593 & 88627 \\
24122 & 86591 & 27699 & 06494 & 03152 & 19121 & 34414 & 82157 & 86887 & 55087 \\
61196 & 30231 & 92962 & 61773 & 22109 & 78508 & 63439 & 75363 & 44989 & 16822 \\
30532 & 21704 & 10274 & 12202 & 94205 & 20380 & 67049 & 09070 & 93399 & 45547 \\
03788 & 97599 & 75867 & 20717 & 82037 & 10268 & 79495 & 04146 & 52162 & 90286 \\
48228 & 63379 & 85783 & 47619 & 87481 & 37220 & 91704 & 30552 & 04737 & 21031 \\
88618 & 19161 & 41290 & 67312 & 71857 & 15957 & 48545 & 35247 & 18619 & 13674 \\
71299 & 23853 & 05870 & 01119 & 92784 & 26340 & 75122 & 11724 & 74627 & 73707 \\
27954 & 58909 & 82444 & 99005 & 04921 & 73701 & 92904 & 13141 & 32392 & 19763 \\
80863 & 00514 & 20247 & 81759 & 45197 & 25332 & 69902 & 63742 & 78464 & 22501 \\
33564 & 60780 & 48460 & 85558 & 15191 & 18782 & 94972 & 11598 & 62095 & 36787 \\
90899 & 75754 & 60833 & 25983 & 01291 & 41349 & 19152 & 00023 & 12302 & 80783 \\
78038 & 70267 & 43529 & 06318 & 38384 & 74761 & 36024 & 00867 & 76378 & 41605 \\
55986 & 66485 & 88722 & 56736 & 66164 & 49431 & 94458 & 74284 & 05041 & 49807 \\
87539 & 08823 & 94813 & 31900 & 54155 & 83436 & 54158 & 34243 & 46978 & 35482 \\
16818 & 60311 & 74457 & 90561 & 72848 & 11834 & 75051 & 93029 & 47665 & 64382 \\
34677 & 58300 & 74910 & 64345 & 19325 & 81549 & 60365 & 94653 & 35075 & 33949 \\
45305 & 07521 & 61318 & 31855 & 14413 & 70951 & 83799 & 42402 & 56623 & 34442 \\
59747 & 67277 & 76503 & 34513 & 39663 & 77544 & 32960 & 07405 & 36409 & 83232 \\
16520 & 69676 & 11654 & 99893 & 02181 & 68161 & 19322 & 53845 & 57620 & 52606 \\
68652 & 27376 & 92852 & 55866 & 88448 & 03584 & 11220 & 94747 & 07399 & 37408 \\
\hline
\end{tabular}




\section{Appendix-III: DUST METER READING}

TrakPro Version 4.61 ASCII Data File

Model: Dust Trak

Model Number: 8520

Serial Number: 85203346

Test ID:

1

Test Abbreviation:

Start Date: $\quad 04 / 13 / 2016$

Start Time: $\quad 8: 14: 39$

Duration (dd:hh:mm:ss): $\quad$ 0:00:52:00

Time constant (seconds): $\quad 10$

Log Interval (mm:ss): 1:00

Number of points: $\quad 52$

Notes:

Statistics Channel: Aerosol

Units: $\mathrm{mg} / \mathrm{m}^{\wedge} 3$

Average: $\quad 0.012$

Minimum: $\quad 0.002$

Time of Minimum: $\quad 8: 16: 39$

Date of Minimum: $\quad 04 / 13 / 2016$

Maximum: $\quad 0.02$

Time of Maximum: $\quad 8: 20: 39$

Date of Maximum: $\quad$ 04/13/2016

\begin{tabular}{|c|c|c|}
\hline Calibration & Sensor: Aerosol & $01 / 04 / 2016$ \\
\hline Date Time & Aerosol & \\
\hline MM/dd/yyyy & hh:mm:ss & \\
\hline $04 / 13 / 2016$ & $8: 15: 390.009$ & \\
\hline $04 / 13 / 2016$ & $8: 16: 390.002$ & \\
\hline $04 / 13 / 2016$ & $8: 17: 390.011$ & \\
\hline $04 / 13 / 2016$ & $8: 18: 390.014$ & \\
\hline $04 / 13 / 2016$ & $8: 19: 390.009$ & \\
\hline $04 / 13 / 2016$ & $8: 20: 390.02$ & \\
\hline $04 / 13 / 2016$ & $8: 21: 390.011$ & \\
\hline $04 / 13 / 2016$ & $8: 22: 390.01$ & \\
\hline $04 / 13 / 2016$ & $8: 23: 390.01$ & \\
\hline $04 / 13 / 2016$ & $8: 24: 390.013$ & \\
\hline $04 / 13 / 2016$ & $8: 25: 390.01$ & \\
\hline $04 / 13 / 2016$ & $8: 26: 390.01$ & \\
\hline $04 / 13 / 2016$ & $8: 27: 390.013$ & \\
\hline $04 / 13 / 2016$ & $8: 28: 390.018$ & \\
\hline 04/13/2016 & $8: 29: 390.011$ & \\
\hline $04 / 13 / 2016$ & $8: 30: 390.012$ & \\
\hline $04 / 13 / 2016$ & $8: 31: 390.011$ & \\
\hline $04 / 13 / 2016$ & $8: 32: 390.012$ & \\
\hline \multicolumn{2}{|c|}{........... Continue } & \\
\hline $04 / 14 / 2016$ & $8: 31: 520.079$ & \\
\hline $04 / 14 / 2016$ & $8: 32: 52 \quad 0.221$ & \\
\hline $04 / 14 / 2016$ & $8: 33: 520.025$ & \\
\hline $04 / 14 / 2016$ & $8: 34: 520.03$ & \\
\hline $04 / 14 / 2016$ & $8: 35: 520.042$ & \\
\hline
\end{tabular}




$\begin{array}{lll}\text { 04/14/2016 } & 8: 36: 520.023 & \\ 04 / 14 / 2016 & 8: 37: 520.072 & \\ 04 / 14 / 2016 & 8: 38: 520.05 & \\ 04 / 14 / 2016 & 8: 39: 520.026 & \\ 04 / 14 / 2016 & 8: 40: 520.046 & \\ 04 / 14 / 2016 & 8: 41: 520.02 & \\ \text { 04/14/2016 } & 8: 42: 520.045 & \\ 04 / 14 / 2016 & 8: 43: 520.021 & \\ 04 / 14 / 2016 & 8: 44: 520.032 & \\ 04 / 14 / 2016 & 8: 45: 520.085 & \\ \ldots \ldots \ldots \ldots \text { Continue } \ldots \ldots \ldots \ldots \ldots & \\ 04 / 19 / 2016 & 17: 34: 51 & 0.021 \\ 04 / 19 / 2016 & 17: 35: 51 & 0.022 \\ 04 / 19 / 2016 & 17: 36: 51 & 0.021 \\ 04 / 19 / 2016 & 17: 37: 51 & 0.012 \\ 04 / 19 / 2016 & 17: 38: 51 & 0.011 \\ 04 / 19 / 2016 & 17: 39: 51 & 0.023 \\ 04 / 19 / 2016 & 17: 40: 51 & 0.014 \\ 04 / 19 / 2016 & 17: 41: 51 & 0.01 \\ 04 / 19 / 2016 & 17: 42: 51 & 0.011 \\ 04 / 19 / 2016 & 17: 43: 51 & 0.006 \\ 04 / 19 / 2016 & 17: 44: 51 & 0.008\end{array}$

\section{Appendix-IV: GAS ANALYZER READING}

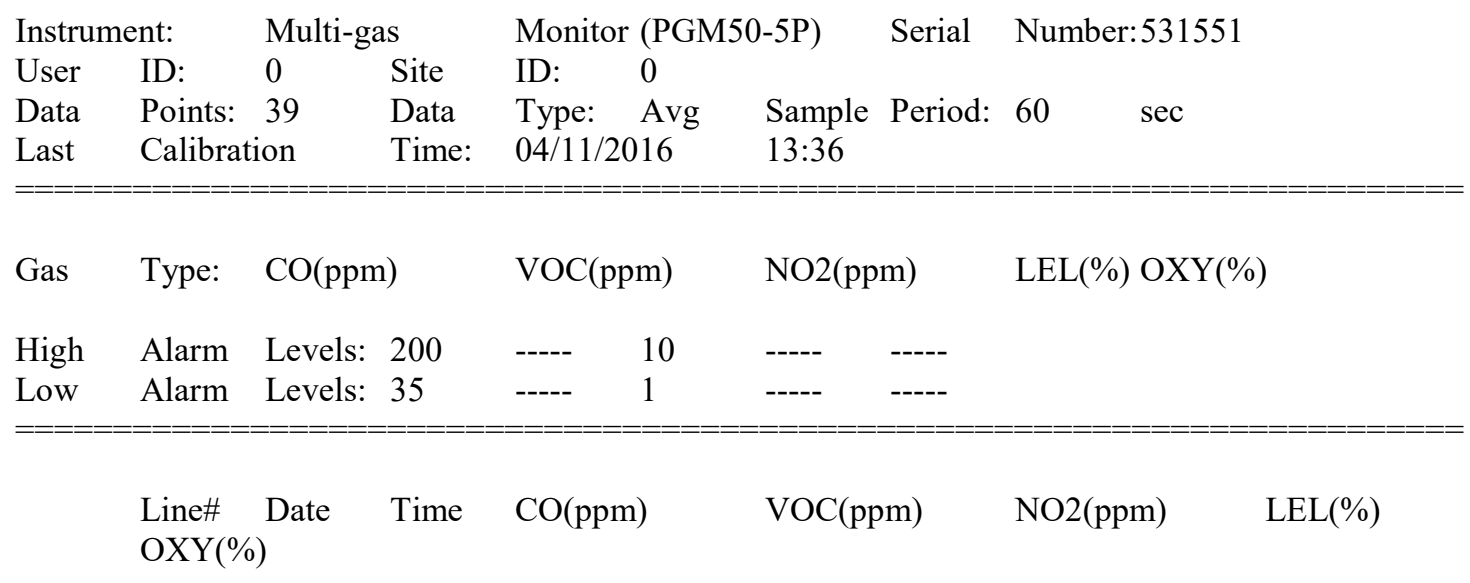

\begin{tabular}{|c|c|c|c|c|c|c|c|}
\hline 1 & $04 / 12 / 2016$ & $16: 32$ & 0.1 & ----- & 0 & ----- & ----- \\
\hline 2 & $04 / 12 / 2016$ & $16: 33$ & 0 & ----- & 0 & ----- & ----- \\
\hline 3 & $04 / 12 / 2016$ & $16: 34$ & 0 & ----- & 0 & ----- & ----- \\
\hline 4 & $04 / 12 / 2016$ & $16: 35$ & 0 & ----- & 0 & ----- & ----- \\
\hline \multirow[t]{2}{*}{5} & $04 / 12 / 2016$ & $16: 36$ & 0 & ----- & 0 & ----- & ----- \\
\hline & \multicolumn{2}{|c|}{$04 / 14 / 2016$} & & & & & \\
\hline 7 & $04 / 14 / 2016$ & $17 \cdot 15$ & 0 & $\ldots$ & 01 & 0.1 & 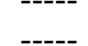 \\
\hline 8 & $04 / 14 / 2016$ & $17: 16$ & 0 & ----- & 0.1 & ----- & ------ \\
\hline
\end{tabular}




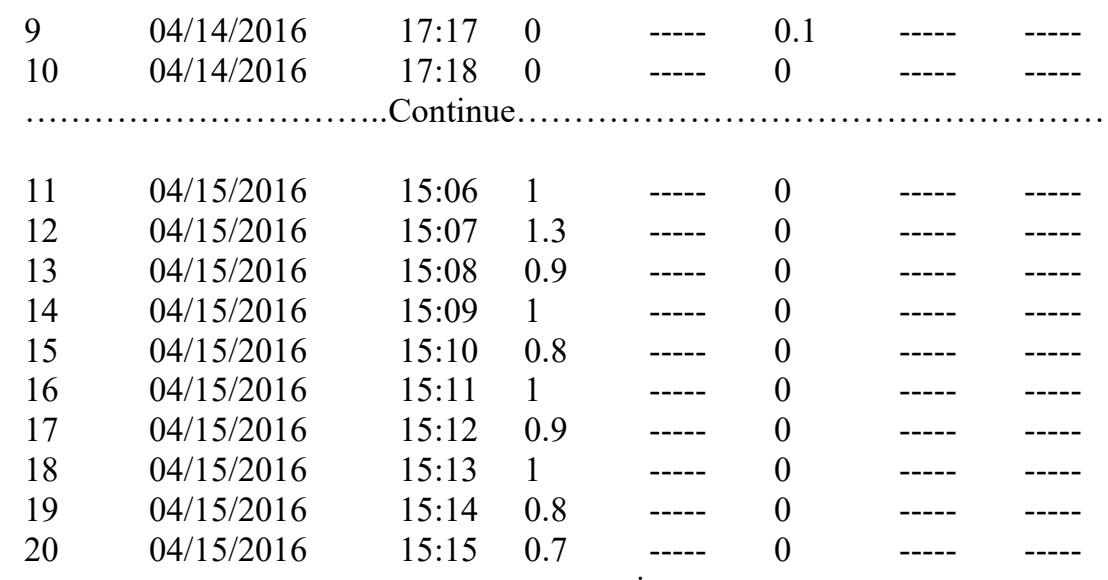

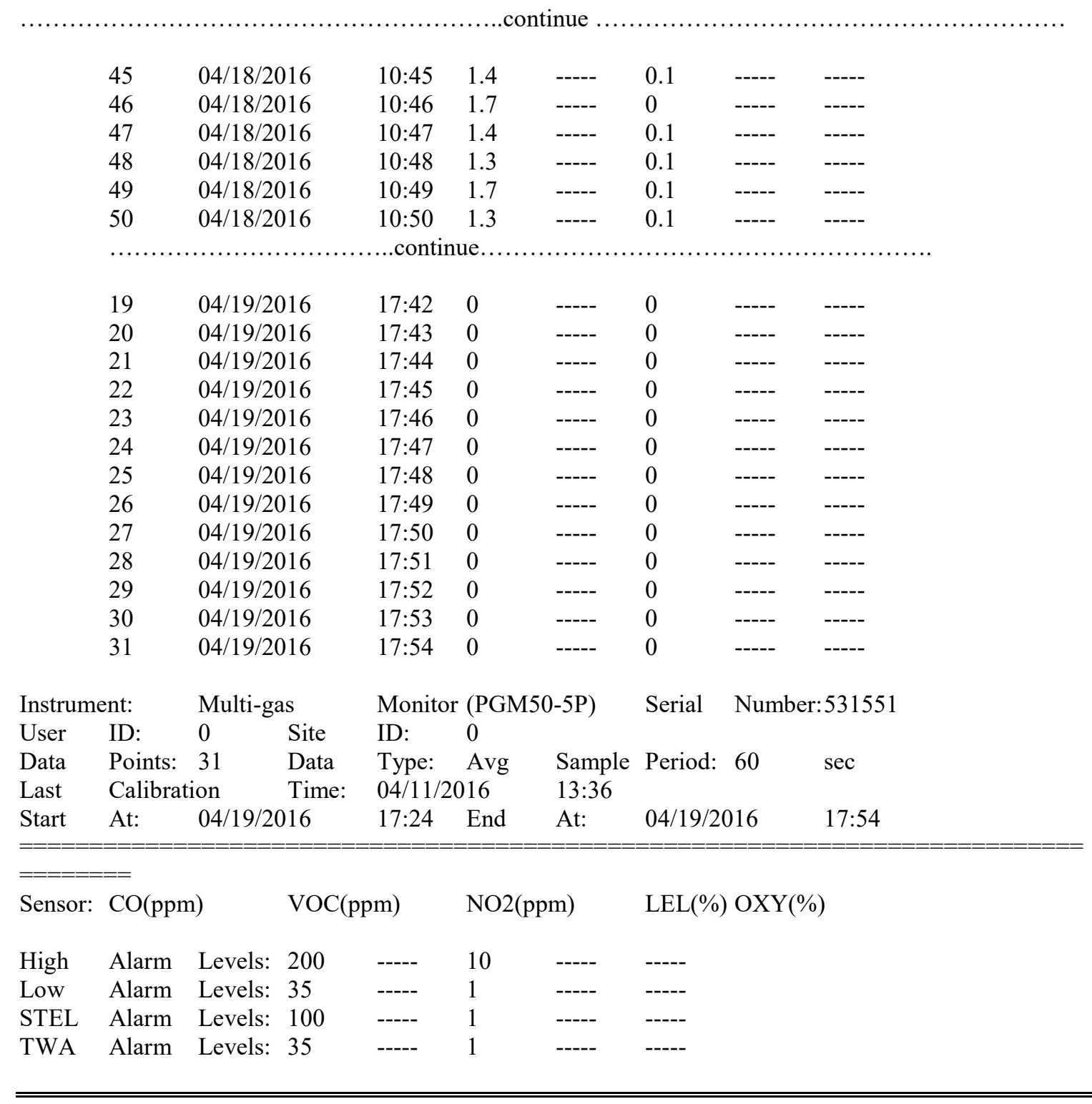




\section{Appendix-V: VELOCITY METER READING}

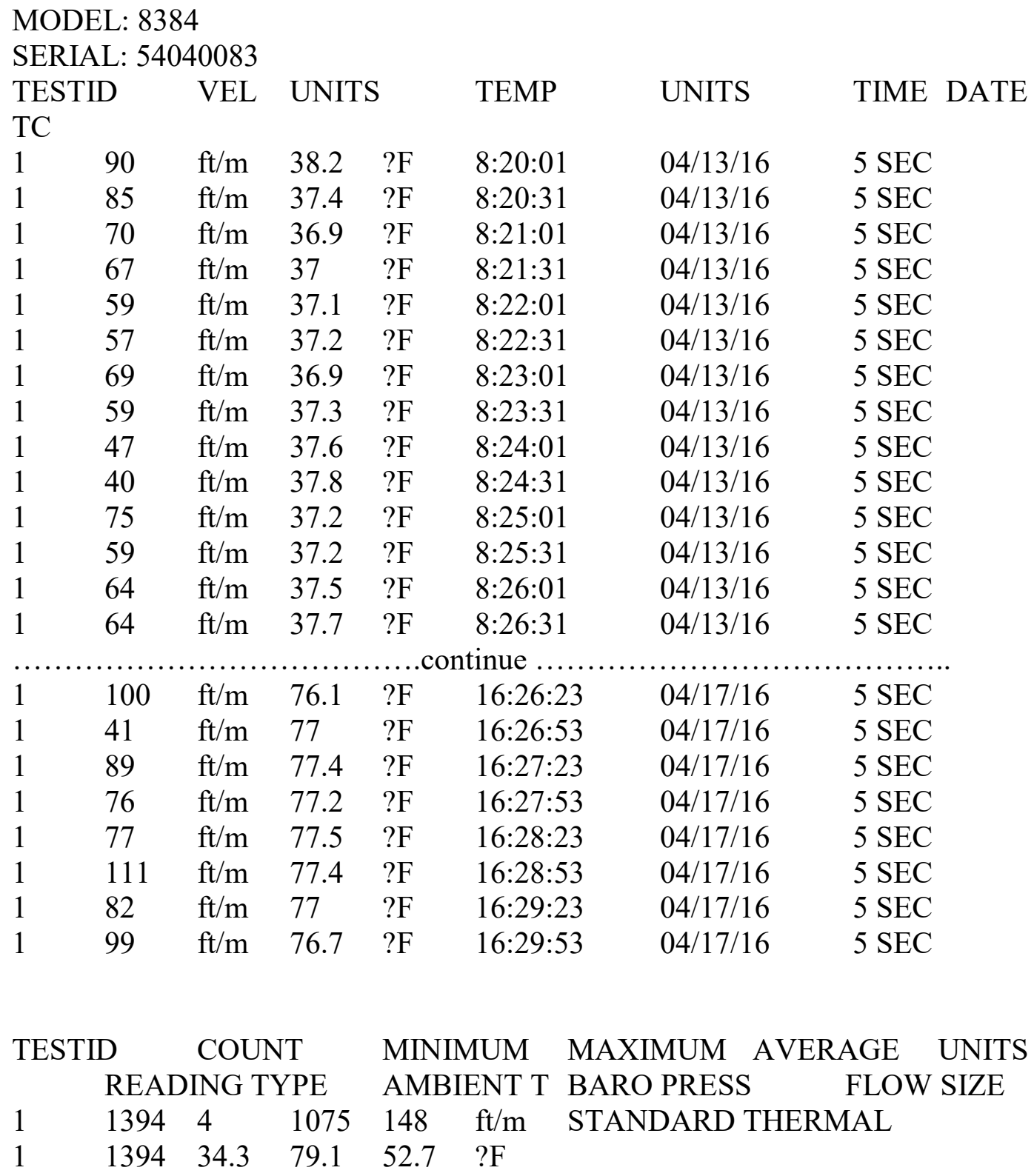




\section{Appendix-VI: OUTPUT FROM VISSIM (TRAFFIC SIMULATION) MODEL}

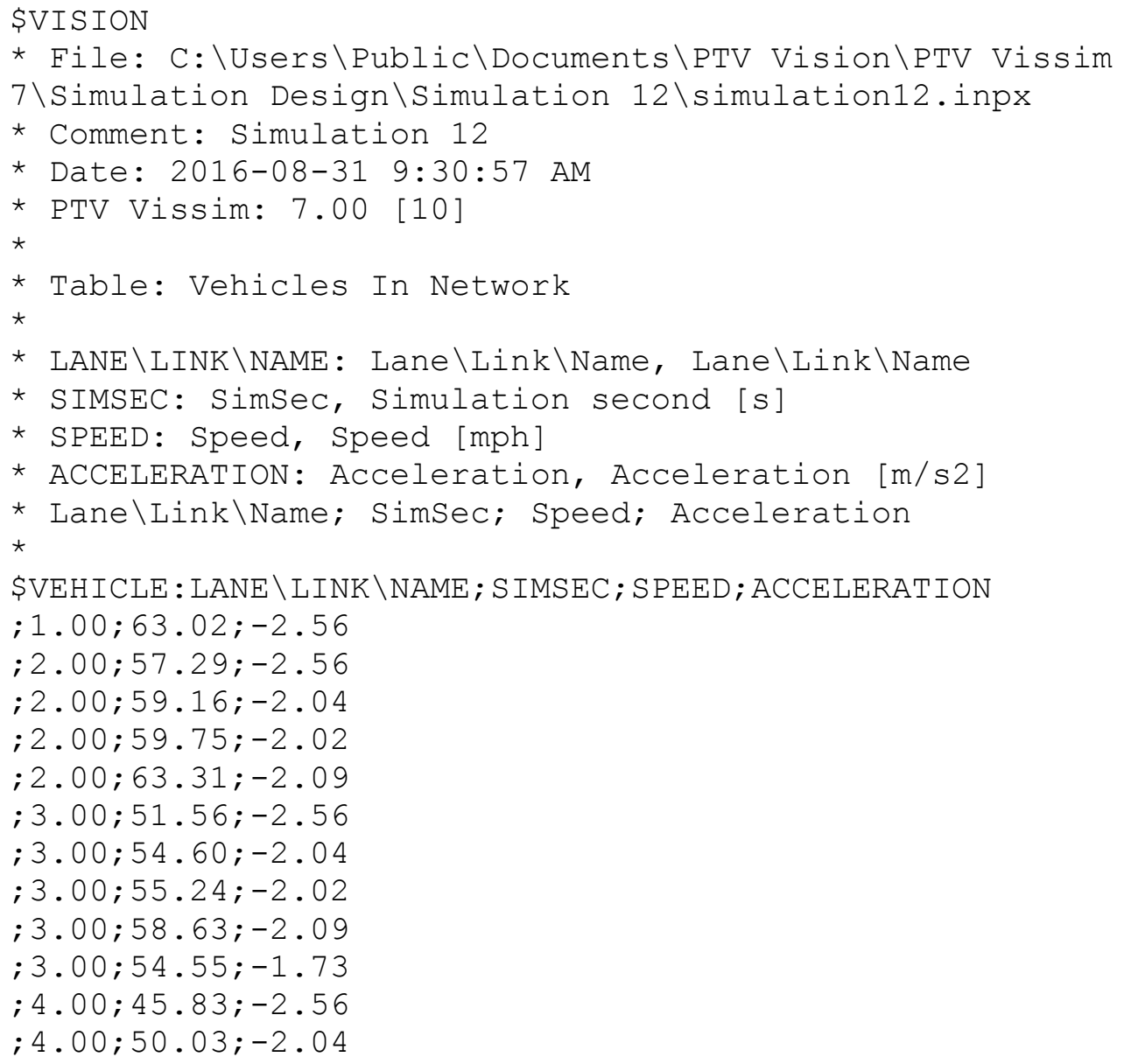




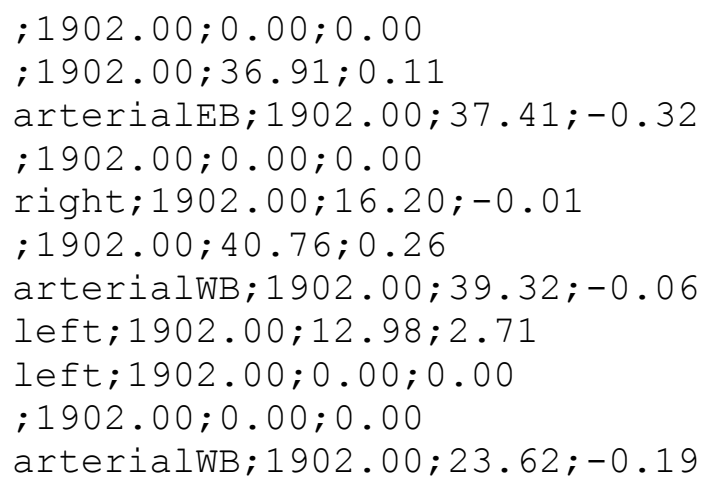

left; $3600.00 ; 9.29 ;-1.43$

$; 3600.00 ; 11.05 ;-0.01$

$; 3600.00 ; 12.05 ;-0.90$

right; $3600.00 ; 0.00 ; 0.00$

$; 3600.00 ; 11.89 ; 2.69$

right $; 3600.00 ; 0.00 ; 0.00$

left; $3600.00 ; 11.36 ;-1.45$

left; $3600.00 ; 17.89 ;-0.79$

right $; 3600.00 ; 0.00 ; 0.00$

left; $3600.00 ; 16.14 ;-0.98$

right $; 3600.00 ; 0.00 ; 0.00$

$; 3600.00 ; 6.98 ;-0.31$

right; $3600.00 ; 15.90 ;-0.33$

right $; 3600.00 ; 0.00 ; 0.00$

right $; 3600.00 ; 0.00 ; 0.00$

right $; 3600.00 ; 0.00 ;-0.50$

right $; 3600.00 ; 17.08 ;-0.20$

right $; 3600.00 ; 0.00 ; 0.00$

$; 3600.00 ; 0.00 ; 0.00$

$; 3600.00 ; 18.73 ;-0.75$

$; 3600.00 ; 22.66 ;-0.17$

right; $3600.00 ; 0.00 ;-3.67$

$; 3600.00 ; 6.76 ; 3.02$

$; 3600.00 ; 0.00 ;-7.21$

$; 3600.00 ; 11.98 ;-0.78$

$; 3600.00 ; 16.98 ;-0.40$

$; 3600.00 ; 12.78 ;-0.67$

$; 3600.00 ; 17.65 ; 1.93$ 


\title{
APPENDIX-VII: INPUT FILES FOR MOVES EMISSION MODEL
}

\author{
VII (A) Source Type Populations \\ sourceTypeID sourceTypeName \\ 21 Passenger Car \\ 42 Transit Bus
}

VII (B) Zone

$$
\begin{array}{crll}
\text { ZonelD } & \text { countyID } & \text { stateName } & \text { countyName } \\
360830 & 36083 & \text { Ontario } & \text { Ottawa }
\end{array}
$$

\section{VII (C) Age Distributions}

\begin{tabular}{rrrr} 
sourceTypeID & yearlD & \multicolumn{1}{c}{ agelD } & ageFraction \\
21 & 2013 & 1 & 0.0146 \\
21 & 2013 & 2 & 0.0117 \\
21 & 2013 & 3 & 0.0127 \\
21 & 2013 & 4 & 0.011 \\
21 & 2013 & 5 & 0.0089 \\
21 & 2013 & 6 & 0.018 \\
21 & 2013 & 7 & 0.0157 \\
21 & 2013 & 8 & 0.0188 \\
21 & 2013 & 9 & 0.0127 \\
21 & 2013 & 10 & 0.0069 \\
21 & 2013 & 11 & 0.0088 \\
21 & 2013 & 12 & 0.0152 \\
21 & 2013 & 13 & 0.013 \\
21 & 2013 & 14 & 0.0223 \\
21 & 2013 & 15 & 0.053 \\
21 & 2013 & 20 & 0.2675 \\
21 & 2013 & 25 & 0.2734 \\
21 & 2013 & 30 & 0.2158 \\
42 & 2013 & 1 & 0.0146 \\
42 & 2013 & 2 & 0.0117 \\
42 & 2013 & 3 & 0.0127 \\
42 & 2013 & 4 & 0.011 \\
42 & 2013 & 5 & 0.0089
\end{tabular}

Whereas,

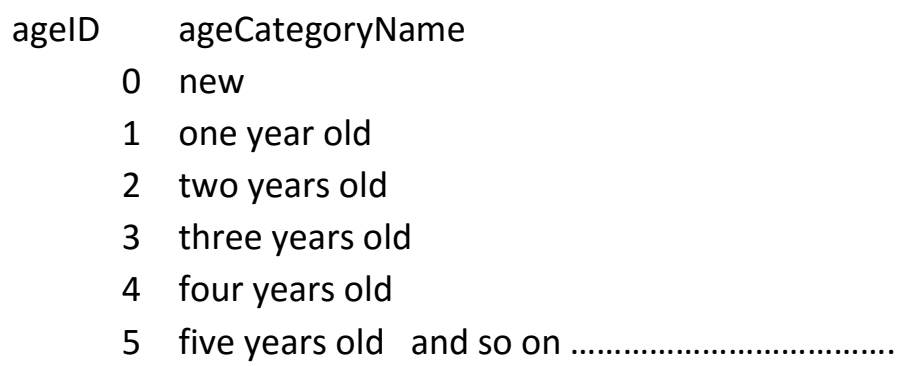




\section{VII (D) Average Speed Distributions} sourceTypeID roadTypeID

21
21
21
21
21
21
21
21
21
21

hourDayID
avgSpeedFraction

Whereas,

$\begin{array}{rrl}\text { avgSpeedBinID } & \text { avgBinSpeed } & \text { avgSpeedBinDesc } \\ 1 & 2.5 & \text { speed }<2.5 \mathrm{mph} \\ 2 & 5 & 2.5 \mathrm{mph}<=\text { speed }<7.5 \mathrm{mph} \\ 3 & 10 & 7.5 \mathrm{mph}<=\text { speed }<12.5 \mathrm{mph} \\ 4 & 15 & 12.5 \mathrm{mph}<=\text { speed }<17.5 \mathrm{mph} \\ 5 & 20 & 17.5 \mathrm{mph}<=\text { speed }<22.5 \mathrm{mph} \\ 6 & 25 & 22.5 \mathrm{mph}<=\text { speed }<27.5 \mathrm{mph} \\ 7 & 30 & 27.5 \mathrm{mph}<=\text { speed }<32.5 \mathrm{mph} \\ 8 & 35 & 32.5 \mathrm{mph}<=\text { speed }<37.5 \mathrm{mph} \\ 9 & 40 & 37.5 \mathrm{mph}<=\text { speed }<42.5 \mathrm{mph} \\ 10 & 45 & 42.5 \mathrm{mph}<=\text { speed }<47.5 \mathrm{mph} \\ 11 & 50 & 47.5 \mathrm{mph}<=\text { speed }<52.5 \mathrm{mph} \\ 12 & 55 & 52.5 \mathrm{mph}<=\text { speed }<57.5 \mathrm{mph} \\ 13 & 60 & 57.5 \mathrm{mph}<=\text { speed }<62.5 \mathrm{mph} \\ 14 & 65 & 62.5 \mathrm{mph}<=\text { speed }<67.5 \mathrm{mph} \\ 15 & 70 & 67.5 \mathrm{mph}<=\text { speed }<72.5 \mathrm{mph} \\ 16 & 75 & 72.5 \mathrm{mph}<=\text { speed }\end{array}$

and

$\begin{array}{rr}5 & 1 \\ 5 & 2 \\ 5 & 3 \\ 5 & 4 \\ 5 & 5 \\ 5 & 6 \\ 5 & 7 \\ 5 & 8 \\ 5 & 9 \\ 5 & 10\end{array}$

$\begin{array}{rrlrl}\text { hourDayID } & \text { daylD } & \text { dayName } & \text { hourlD } & \begin{array}{l}\text { hourname } \\ \text { Hour beginning at 12:00 Mid- }\end{array} \\ 15 & 5 & \text { Weekdays } & 1 & \text { Night } \\ 25 & 5 & \text { Weekdays } & 2 & \text { Hour beginning at 1:00 AM } \\ 35 & 5 & \text { Weekdays } & 3 & \text { Hour beginning at 2:00 AM } \\ 45 & 5 & \text { Weekdays } & 4 & \text { Hour beginning at 3:00 AM } \\ 55 & 5 & \text { Weekdays } & 5 & \text { Hour beginning at 4:00 AM }\end{array}$

\section{VII (E) Fuel}

Fuel supply

$\begin{array}{rrrrrr}\text { fuelRegionID } & \text { fuelYearID } & \text { monthGroupID } & \text { fuelFormulationID } & \text { marketShare } & \text { marketShareCV } \\ 100010000 & 2013 & 1 & 20011 & 1 & 0.5 \\ 100010000 & 2013 & 1 & 3889 & 1 & 0.5 \\ 100010000 & 2013 & 2 & 3889 & 1 & 0.5 \\ 100010000 & 2013 & 2 & 20011 & 1 & 0.5 \\ 100010000 & 2013 & 3 & 20011 & 1 & 0.5\end{array}$




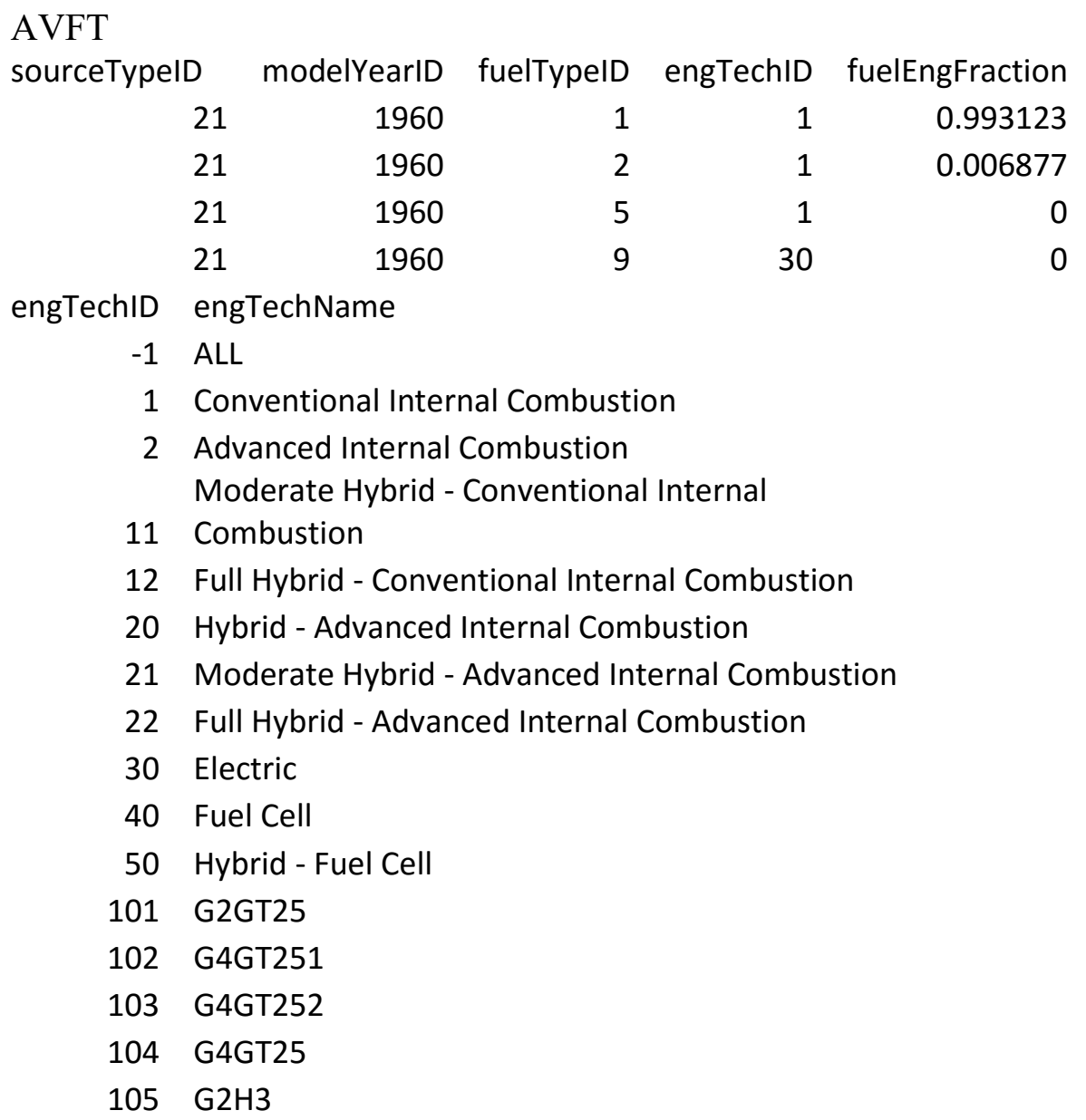

Fuel Type

$\begin{array}{rlrr}\text { fuelTypeID } & \text { fuelTypeDesc } & \text { humidityCorrectionCoeff } & \text { fuelDensity } \\ 1 & \text { Gasoline } & 0.0038 & 2839 \\ 2 & \text { Diesel Fuel } & 0.0026 & 3167\end{array}$




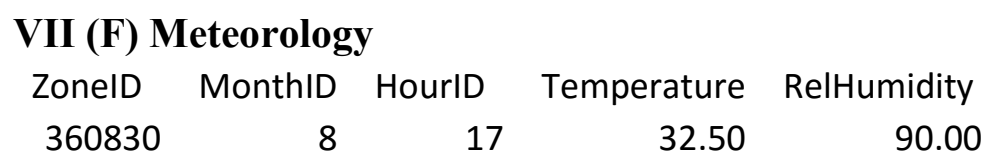

\section{VII (G) Road Type Distributions}

$\begin{array}{rrr}\text { sourceTypeID } & \text { roadTypeID } & \text { roadTypeVMTFraction } \\ 21 & 5 & 1 \\ 42 & 5 & 1\end{array}$

Where,

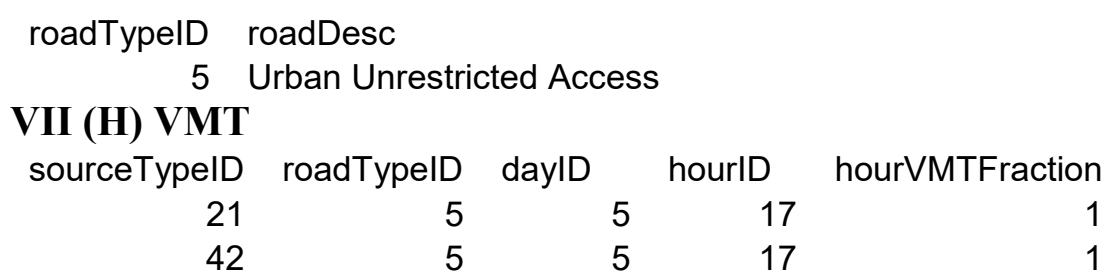

Whereas, HPMSVtypeID

$$
\text { sourceTypeID yearID }
$$
25

50

\section{1}

42

$\begin{array}{rr} & \text { HPMSBaseYearVMT } \\ 2013 & 1 \\ 2013 & 1\end{array}$

dayID

dayName noOfRealDays

5 Weekdays

6 Weekend

Note: VMT fractions for Hour, Day, Months, and Year has separate tables. 


\section{APPENDIX-VIII: COMPOSITE EMISSION FACTORS FOR GASEOUS POLLUTANTS USING CMEM EMISSION MODEL}
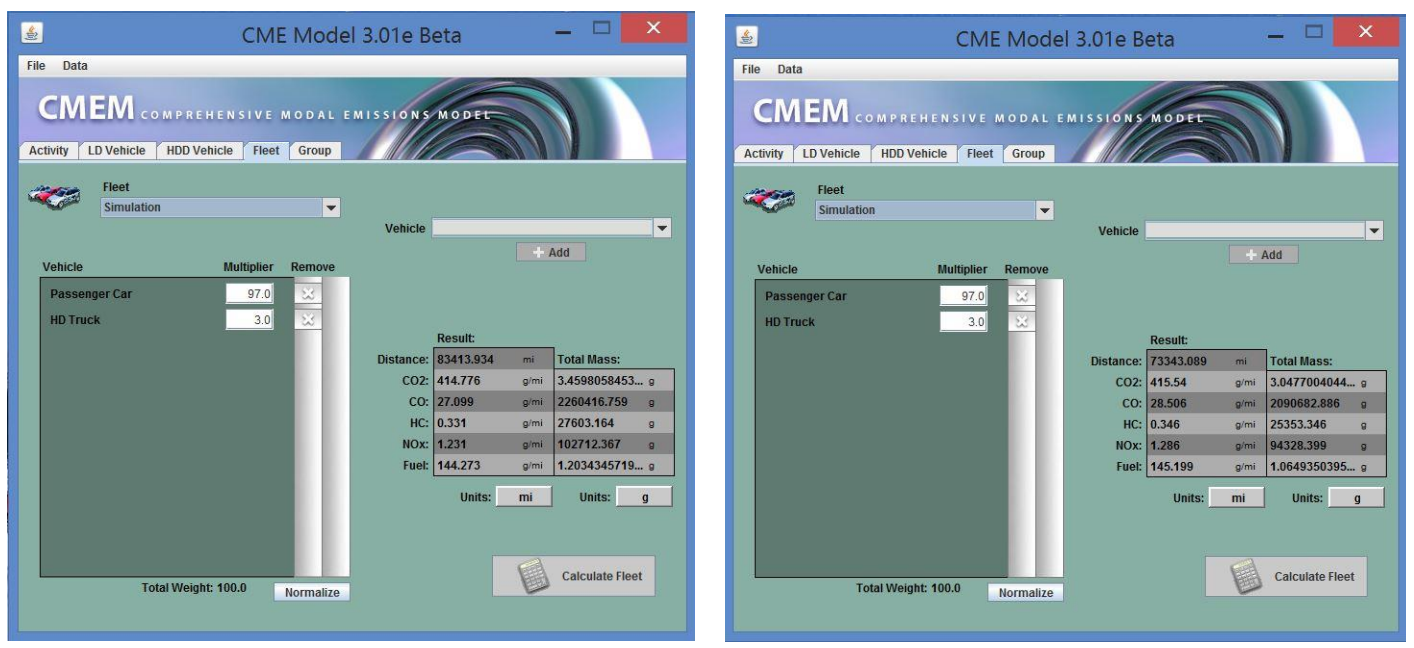

Figure A-1 (A): Gaseous Pollutants for either Directional Road Link
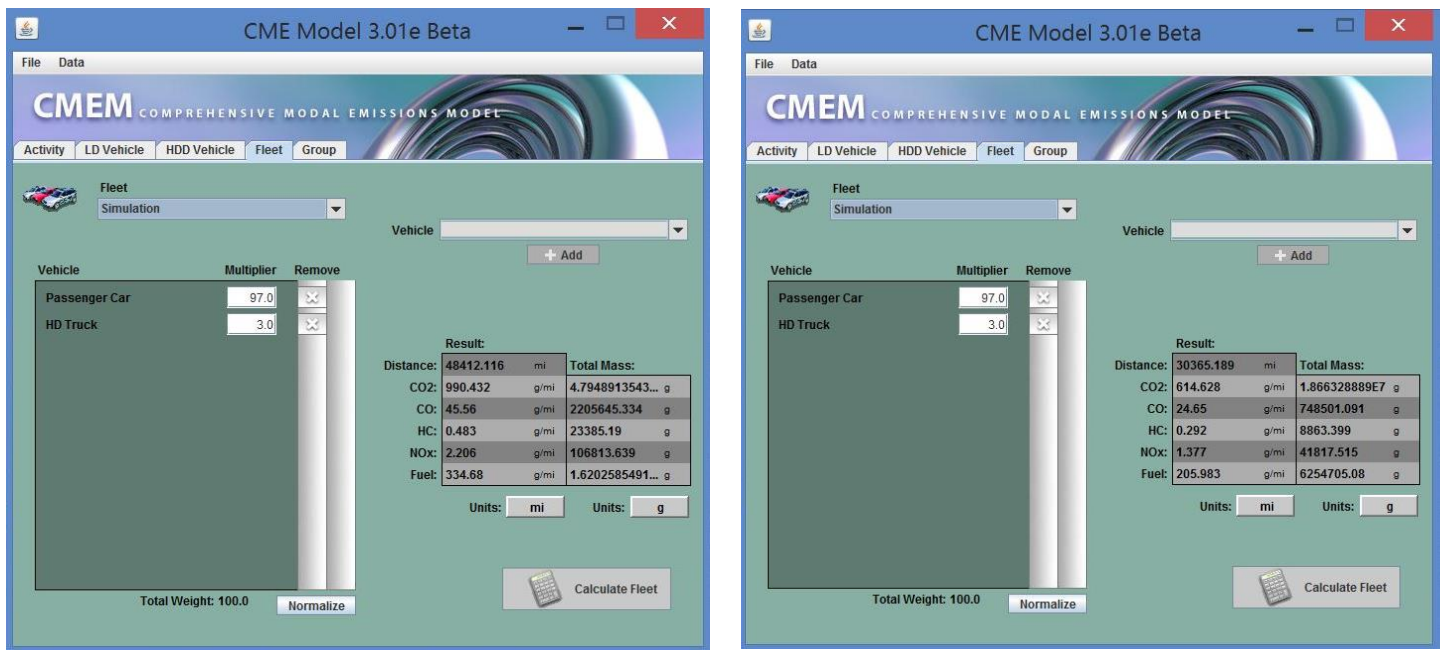

Figure A-1 (B): Gaseous Pollutants for left and right Intersections 


\section{APPENDIX-IX: EMISSION RATES FROM MOVES EMISSION MODEL}

MOVES Output Summary Results (Composite Emission Factor in gram/vehiclemile)

Emission Rates at the Intersection of Rideau Street and Wurtemburg Street in between 9-10 AM

$\begin{array}{llll}\text { Hour } & \text { CO } & \text { NO2 } & \text { Total_PM25 } \\ 10 & 39 & 3 & 1\end{array}$

Emission Rates in details on Hwy-417 East Bound Traffic

\begin{tabular}{lllllll} 
Hour & \multicolumn{2}{l}{ Source Fuel } & CO & NO2 & NOx & Total_PM25 \\
18 & 21 & 1 & 12 & 0 & 2 & 0 \\
18 & 31 & 1 & 26 & 0 & 4 & 0 \\
18 & 42 & 2 & 6 & 1 & 24 & 1 \\
18 & 62 & 2 & 6 & 2 & 32 & 1
\end{tabular}

Note: fuel type 1 means gasoline fuel and 2 means diesel fuel, and source code 21 means passenger cars and 31 means passenger trucks.

\section{APPENDIX-X: SIMULATION 18 AC 15 CO}

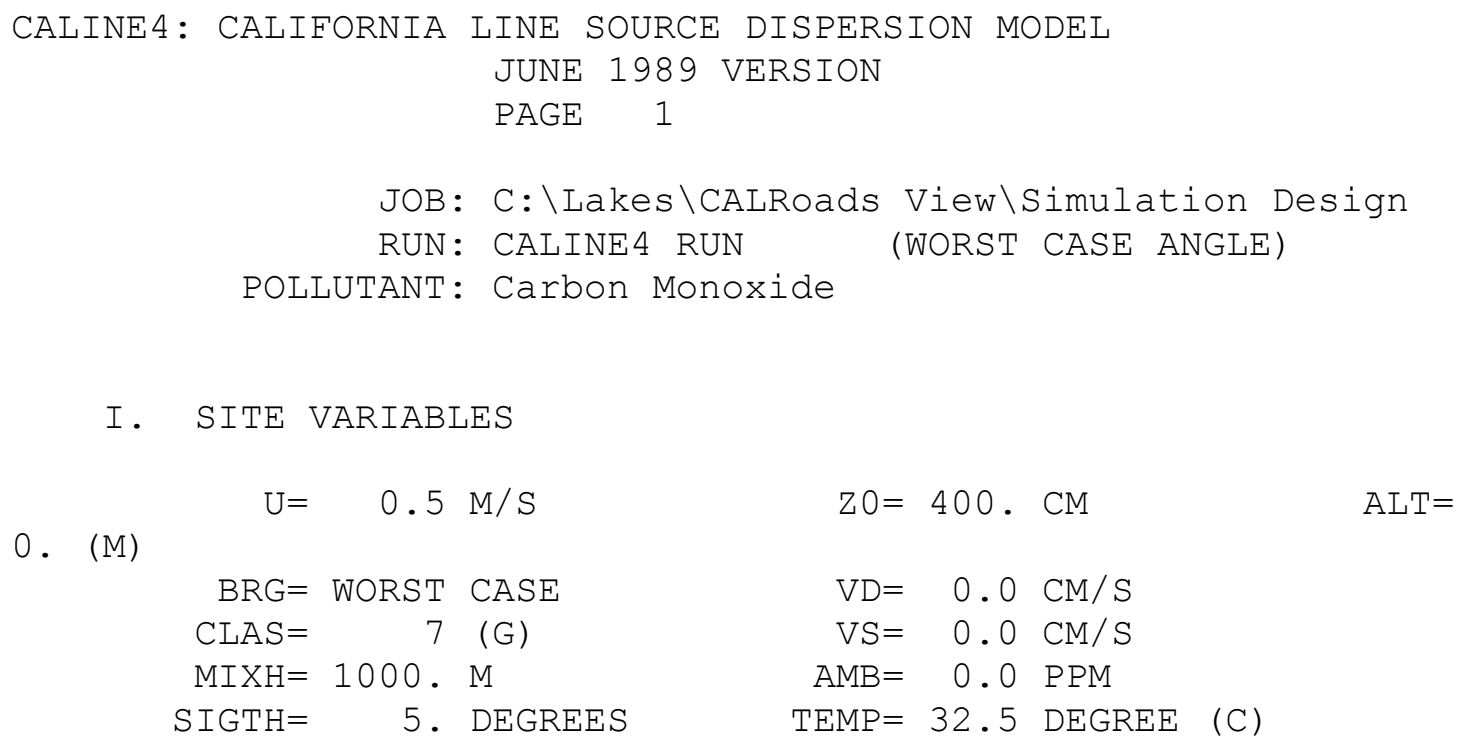


II. LINK VARIABLES

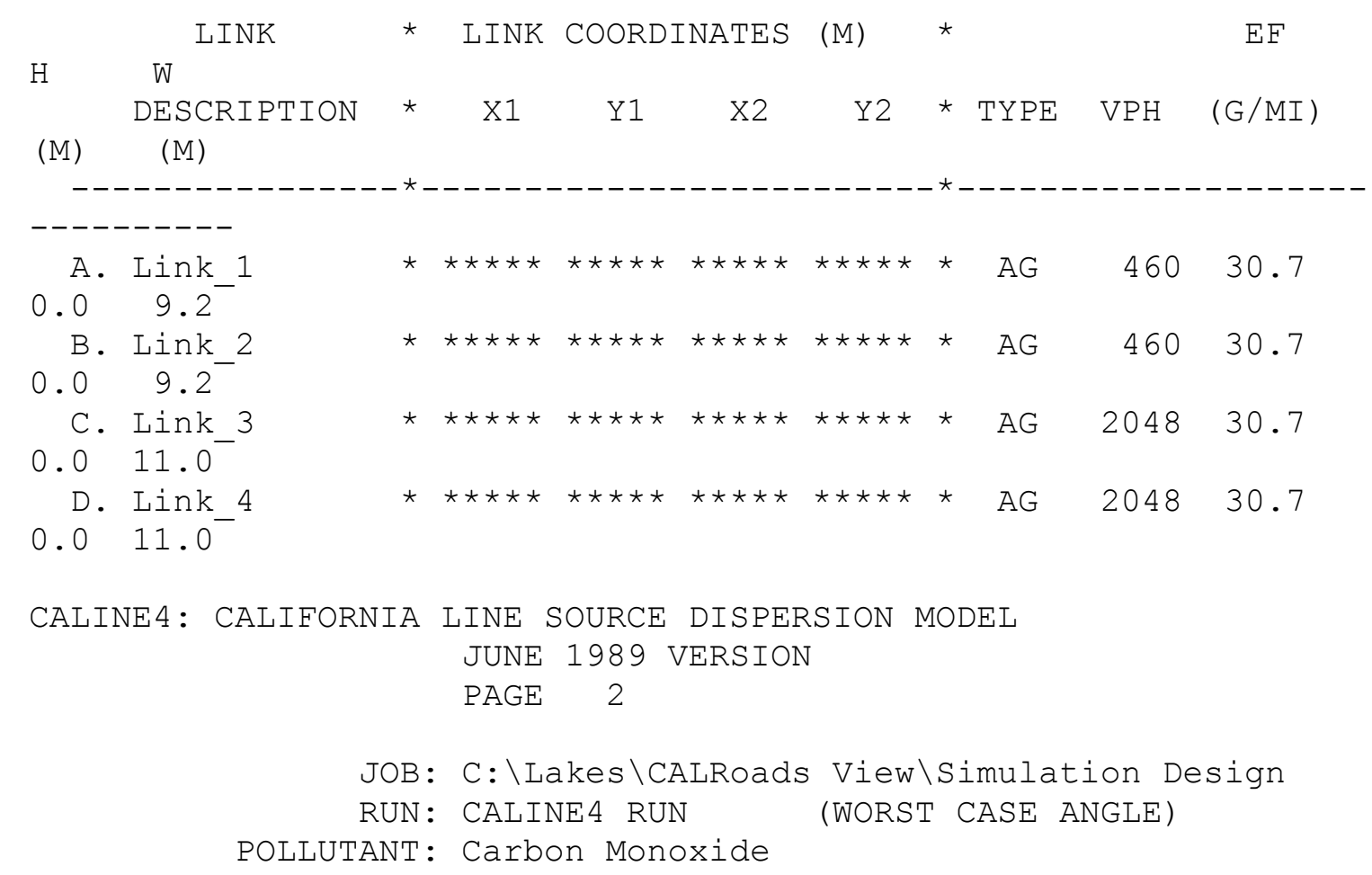

III. RECEPTOR LOCATIONS

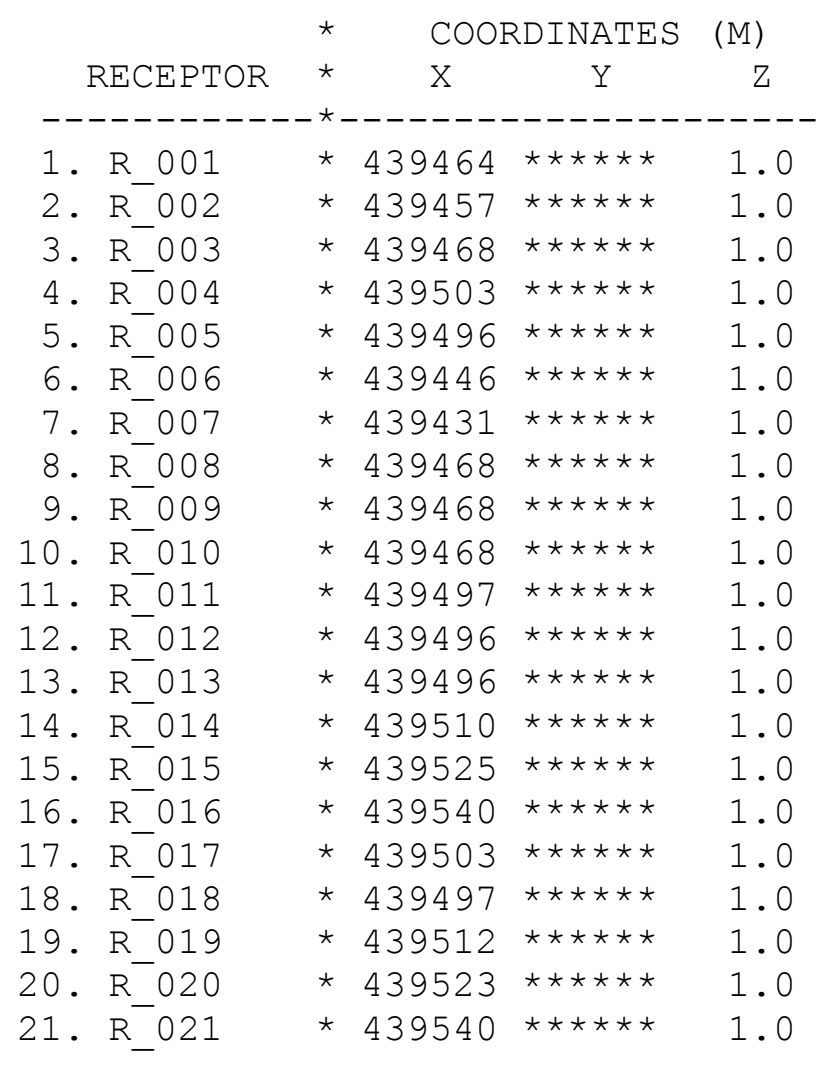




\begin{tabular}{|c|c|c|}
\hline 22. R_022 & * 439497 & $\star \star \star \star \star * * *$ \\
\hline 23. $\mathrm{R}-023$ & * 439496 & 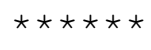 \\
\hline 4. $\mathrm{R}^{-} 024$ & * 439468 & 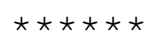 \\
\hline 5. $R^{-} 025$ & * 439465 & 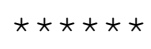 \\
\hline 6. $\mathrm{R}^{-} 026$ & * 439468 & 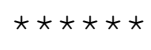 \\
\hline . $R^{-} 027$ & * 439468 & 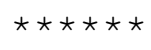 \\
\hline$R_{-}^{-} 028$ & * 439468 & 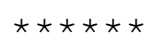 \\
\hline R_029 & * 439496 & 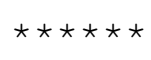 \\
\hline . $R-030$ & * 439455 & 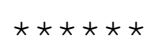 \\
\hline$R_{-}^{-} 031$ & * 439433 & 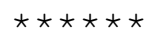 \\
\hline 2. $\mathrm{R}^{-} 032$ & * 439444 & 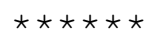 \\
\hline 3. $R^{-} 033$ & * 439468 & 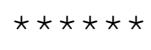 \\
\hline $\mathrm{R}^{-} 034$ & * 439468 & 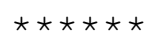 \\
\hline . $R-035$ & * 439552 & 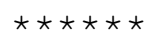 \\
\hline R_036 & * 439566 & 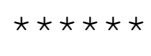 \\
\hline . $R^{-0} 037$ & * 439566 & 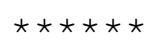 \\
\hline R_038 & * 439555 & 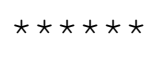 \\
\hline R_039 & * 439393 & 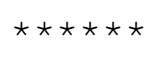 \\
\hline $\mathrm{R}^{-} 040$ & * 439408 & 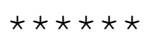 \\
\hline R_041 & * 439421 & 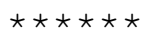 \\
\hline $\mathrm{R}^{-} 042$ & * 439392 & 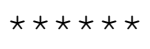 \\
\hline$R^{-} 043$ & * 439410 & 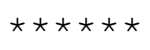 \\
\hline $\mathrm{R}^{-} 044$ & * 439497 & 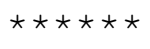 \\
\hline $\mathrm{R}^{-} 045$ & * 439468 & 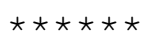 \\
\hline $\mathrm{R}^{-} 046$ & * 439497 & 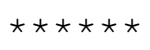 \\
\hline $\mathrm{R}^{-} 047$ & * 439468 & 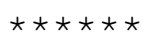 \\
\hline R_048 & * 439496 & 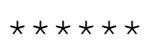 \\
\hline$R^{-} 049$ & * 439496 & 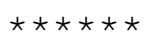 \\
\hline$R_{-}^{-} 050$ & * 439468 & 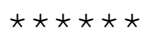 \\
\hline$R_{-}^{-} 051$ & * 439496 & 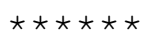 \\
\hline$R^{-} 052$ & * 439497 & 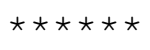 \\
\hline$R^{-} 053$ & * 439496 & 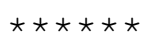 \\
\hline$R^{-} 054$ & * 439468 & 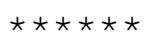 \\
\hline $\mathrm{R}-05$ & * 439468 & 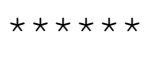 \\
\hline$R-05$ & * 439468 & 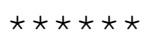 \\
\hline
\end{tabular}

CALINE4: CALIFORNIA LINE SOURCE DISPERSION MODEL JUNE 1989 VERSION

PAGE 3

JOB : C: \Lakes \CALRoads View \Simulation Design RUN: CALINE4 RUN (WORST CASE ANGLE)

POLLUTANT: Carbon Monoxide

IV. MODEL RESULTS (WORST CASE WIND ANGLE)

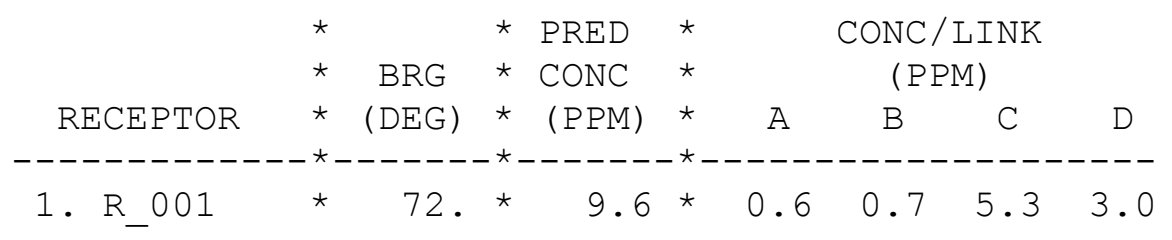




\begin{tabular}{|c|c|c|c|c|c|c|c|c|c|}
\hline 2. R_002 & * & 74. & * & 9.5 & * & 0.5 & 0.6 & 5.4 & 3.0 \\
\hline 3. R-003 & * & 67. & * & 7.3 & * & 0.6 & 0.9 & 3.4 & 2.4 \\
\hline 4. R_-004 & * & 286. & * & 9.5 & * & 0.7 & 0.5 & 5.3 & 3.0 \\
\hline 5. R_005 & * & 294. & * & 6.8 & * & 0.9 & 0.6 & 3.0 & 2.3 \\
\hline 6. R-006 & * & 75. & * & 9.5 & * & 0.4 & 0.5 & 5.5 & 3.1 \\
\hline 7. $R_{-}^{-} 007$ & $\star$ & 76. & * & 9.5 & * & 0.4 & 0.4 & 5.6 & 3.2 \\
\hline 8. R-008 & * & 58. & * & 5.5 & * & 0.7 & 1.0 & 2.1 & 1.8 \\
\hline 9. R-009 & $\star$ & 13. & * & 5.0 & * & 1.0 & 1.6 & 1.2 & 1.1 \\
\hline 10. R-010 & * & 165. & * & 5.1 & * & 0.9 & 1.5 & 1.2 & 1.4 \\
\hline 11. R 011 & * & 196. & * & 5.1 & $\star$ & 1.5 & 0.9 & 1.3 & 1.4 \\
\hline 12. R-012 & * & 347. & * & 5.0 & * & 1.6 & 1.0 & 1.2 & 1.1 \\
\hline 13. R-013 & * & 346. & * & 5.4 & * & 1.6 & 0.9 & 1.5 & 1.3 \\
\hline 14. R-014 & $\star$ & 285. & * & 9.4 & * & 0.5 & 0.5 & 5.4 & 3.0 \\
\hline 15. R-015 & * & 284. & * & 9.4 & * & 0.4 & 0.4 & 5.5 & 3.1 \\
\hline 16. R_016 & * & 283. & * & 9.4 & $\star$ & 0.4 & 0.3 & 5.6 & 3.1 \\
\hline 17. R 017 & * & 253. & * & 9.9 & * & 0.7 & 0.5 & 3.1 & 5.6 \\
\hline 18. R-018 & * & 248. & * & 7.8 & * & 0.9 & 0.6 & 2.6 & 3.7 \\
\hline 19. R-019 & * & 255. & * & 9.8 & * & 0.5 & 0.4 & 3.1 & 5.7 \\
\hline 20. $R^{-} 020$ & * & 256. & * & 9.8 & * & 0.4 & 0.4 & 3.2 & 5.8 \\
\hline 21. R-021 & * & 257. & * & 9.9 & * & 0.4 & 0.3 & 3.2 & 6.0 \\
\hline 22. R_o22 & * & 240 . & * & 5.6 & * & 0.9 & 0.6 & 1.8 & 2.2 \\
\hline 23. R-023 & * & 194. & * & 5.0 & * & 1.6 & 0.9 & 1.2 & 1.3 \\
\hline 24. R-024 & * & 108. & * & 10.1 & * & 0.6 & 0.9 & 3.1 & 5.5 \\
\hline 25. R_025 & * & 108. & * & 9.9 & * & 0.6 & 0.8 & 3.1 & 5.5 \\
\hline 26. R_026 & * & 166. & * & 5.0 & * & 1.0 & 1.6 & 1.2 & 1.3 \\
\hline 27. R-027 & * & 121. & * & 5.5 & * & 0.6 & 1.0 & 1.8 & 2.1 \\
\hline 28. R-028 & * & 113. & * & 7.1 & * & 0.6 & 0.9 & 2.3 & 3.2 \\
\hline 29. $R-029$ & * & 349. & * & 4.7 & * & 1.6 & 1.0 & 1.1 & 1.1 \\
\hline 30. $R^{-} 030$ & $\star$ & 105. & * & 9.7 & $\star$ & 0.5 & 0.6 & 3.0 & 5.6 \\
\hline 31. R-031 & $\star$ & 103. & * & 9.6 & * & 0.4 & 0.4 & 3.1 & 5.8 \\
\hline 32. R-032 & * & 104. & * & 9.6 & * & 0.4 & 0.4 & 3.1 & 5.7 \\
\hline 33. $\mathrm{R}-033$ & * & 11. & * & 4.7 & * & 1.0 & 1.5 & 1.1 & 1.1 \\
\hline 34. R-034 & * & 110. & * & 8.6 & * & 0.6 & 0.9 & 2.8 & 4.3 \\
\hline 35. R_035 & $\star$ & 258. & * & 9.7 & * & 0.3 & 0.3 & 3.2 & 5.8 \\
\hline 36. R-036 & * & 259. & * & 9.8 & * & 0.3 & 0.3 & 3.2 & 6.0 \\
\hline 37. R-037 & * & 281 . & * & 9.8 & * & 0.3 & 0.3 & 5.9 & 3.2 \\
\hline 38. $R-038$ & $\star$ & 282 . & * & 9.7 & * & 0.3 & 0.3 & 5.9 & 3.2 \\
\hline 39. $R^{-} 039$ & * & 101. & * & 9.5 & * & 0.3 & 0.3 & 3.2 & 5.7 \\
\hline 40. R-040 & * & 102. & * & 9.4 & * & 0.3 & 0.3 & 3.2 & 5.6 \\
\hline 41. R-041 & * & 103. & * & 9.4 & 夫 & 0.3 & 0.4 & 3.2 & 5.6 \\
\hline 42. R-042 & * & 79. & * & 9.8 & 夫 & 0.3 & 0.3 & 6.0 & 3.3 \\
\hline 43. R-043 & * & 78 & * & 10.0 & * & 0.3 & 0.3 & 6.1 & 3.3 \\
\hline 44. R_044 & * & 251. & * & 10.1 & * & 0.9 & 0.6 & 3.1 & 5.5 \\
\hline 45. R-045 & * & 71 & * & 9.8 & * & 0.6 & 0.9 & 5.2 & 3.0 \\
\hline 46. R-046 & * & 289. & * & 9.7 & * & 0.9 & 0.6 & 5.2 & 3.1 \\
\hline 47. R 047 & $\star$ & 13. & $\star$ & 5.1 & * & 0.9 & 1.6 & 1.3 & 1.2 \\
\hline 48. R-048 & * & 347 & * & 5.1 & * & 1.6 & 1.0 & 1.3 & 1.2 \\
\hline 49. R-049 & * & 351. & * & 4.4 & * & 1.5 & 0.9 & 1.0 & 1.0 \\
\hline 50. R-050 & * & & * & 4.4 & * & 0.9 & 1.5 & 1.1 & 1.0 \\
\hline 51. R-051 & * & 19 & * & 4.9 & * & 1.6 & 1.0 & 1.1 & 1.2 \\
\hline 52. R-052 & * & 192 & * & 4.7 & * & 1.6 & 0.9 & 1.0 & 1.1 \\
\hline 53. R-053 & * & 191. & * & 4.5 & * & 1.5 & 1.0 & 1.0 & 1.1 \\
\hline
\end{tabular}




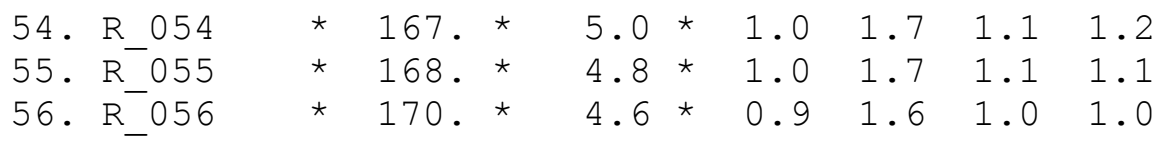

\section{APPENDIX-XI: SIMULATION 12 AC $19 \mathrm{NO}_{2}$}

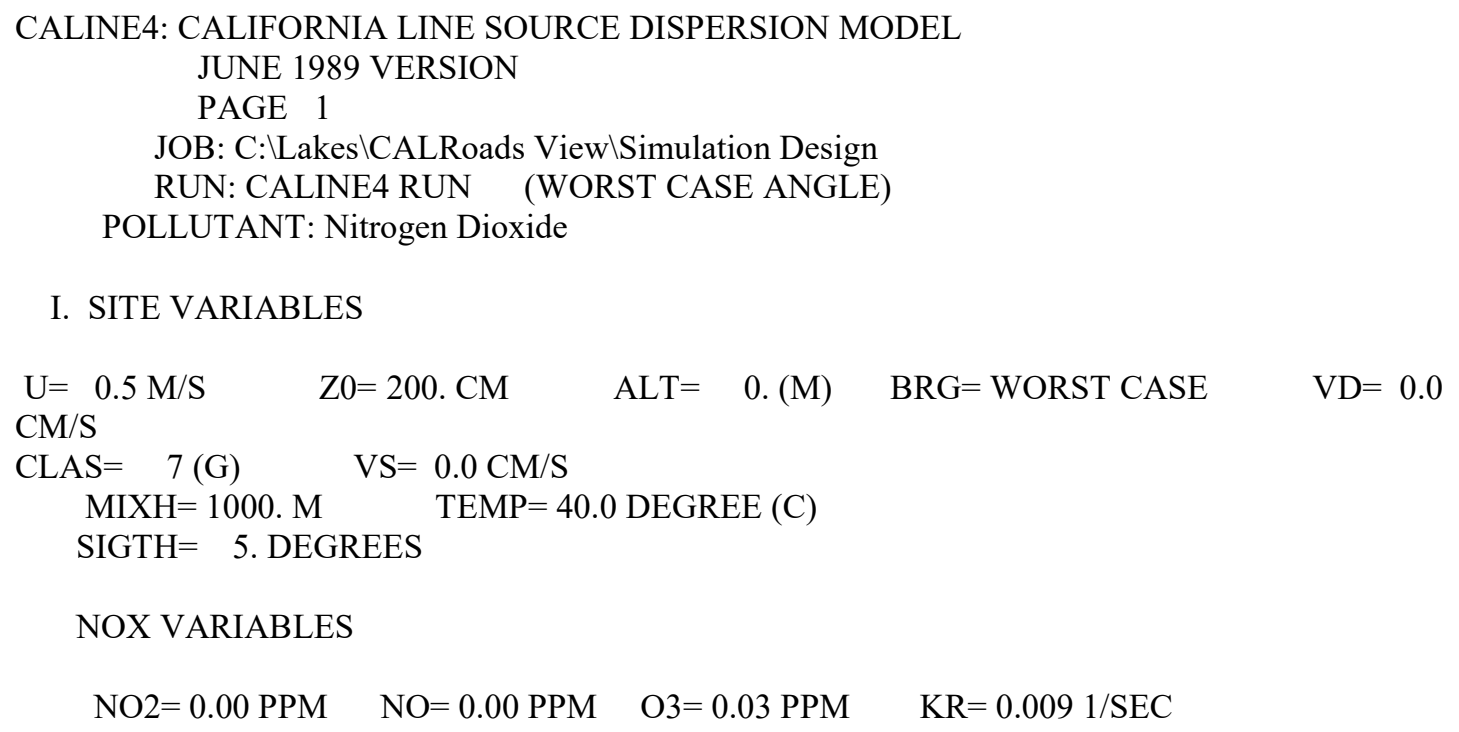

II. LINK VARIABLES

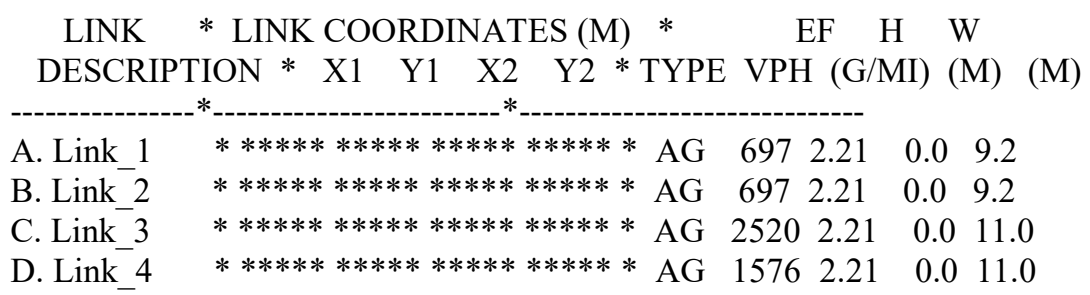

CALINE4: CALIFORNIA LINE SOURCE DISPERSION MODEL JUNE 1989 VERSION

PAGE 3

JOB: C:LLakes \CALRoads View $\backslash$ Simulation Design

RUN: CALINE4 RUN (WORST CASE ANGLE)

POLLUTANT: Nitrogen Dioxide

IV. MODEL RESULTS (WORST CASE WIND ANGLE )

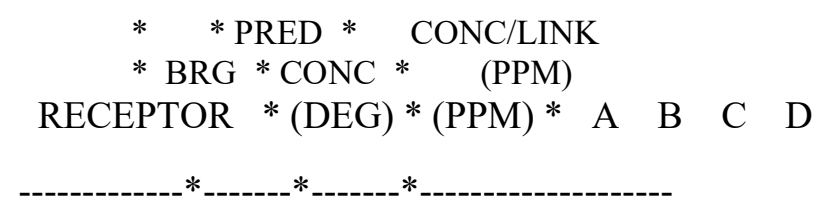


1. R_001 * 71. * $0.10 * 0.010 .020 .050 .02$

2. R_002 * 74. * $0.10 * 0.010 .010 .050 .02$

3. R_003 * 14. * $0.10 * 0.020 .040 .020 .01$

4. R_004 * 286. * $0.10 * 0.010 .010 .050 .02$

5. R_005*347. *0.10*0.040.020.020.01

6. $\mathrm{R} \_006 * 75 . * 0.09 * 0.010 .010 .050 .03$

7. R_007 * 76. * $0.09 * 0.010 .010 .050 .03$

8. R_008* 13. * $0.09 * 0.020 .040 .010 .01$

9. R_009 * 11. * $0.08 * 0.020 .040 .010 .01$

10. $\mathrm{R} \_010 * 169 . * 0.08 * 0.020 .040 .010 .01$

11. R_011*192.*0.08*0.040.020.010.01

12. $\mathrm{R} \_012 * 349 . * 0.08 * 0.040 .020 .010 .01$

13. $\mathrm{R} \_013 * 349 . * 0.09 * 0.040 .020 .010 .01$

14. R_014 * 285. *0.10*0.010.010.050.02

15. $\mathrm{R} \_015 * 284 . * 0.09 * 0.010 .010 .050 .03$

16. R_016*283. *0.09*0.010.010.050.03

17. $\mathrm{R} \_017 * 253 . * 0.10 * 0.010 .010 .030 .04$

18. R_018*194. *0.10*0.040.020.020.02

19. R_019 * 255. * $0.10 * 0.010 .010 .030 .05$

20. R_020 * 256. * $0.09 * 0.010 .010 .030 .05$

21. R_021 * 257. * $0.09 * 0.010 .010 .030 .05$

22. R_022*193.*0.09*0.040.020.010.01

23. $\mathrm{R} \_023 * 191 . * 0.08 * 0.040 .020 .010 .01$

24. R_024 * 165. * $0.11 * 0.020 .040 .020 .03$

25. R_025*108.*0.10*0.010.020.030.04

26. R_026*169.*0.09*0.020.040.010.01

27. R_027 * 167. * $0.09 * 0.020 .040 .010 .01$

28. R_028*166. * $0.09 * 0.020 .040 .020 .02$

29. R_029 * 349. * $0.08 * 0.040 .030 .010 .01$

30. $\mathrm{R} \_030 * 105 . * 0.10 * 0.010 .010 .030 .04$ 
31. R_031 * 103. * $0.09 * 0.010 .010 .030 .05$

32. R_032 * 104. * $0.09 * 0.010 .010 .030 .05$

33. R_033* 11. * $0.08 * 0.030 .040 .010 .01$

34. $\mathrm{R} \_034 * 166 . * 0.10 * 0.020 .040 .020 .02$

35. R_035*258. * $0.09 * 0.010 .010 .030 .05$

36. $\mathrm{R} \_036 * 259 . * 0.09 * 0.010 .010 .030 .05$

37. $\mathrm{R} \_037 * 281 . * 0.09 * 0.010 .010 .050 .03$

38. $\mathrm{R} \_038 * 282 . * 0.09 * 0.010 .010 .050 .03$

39. R_039*101.*0.09*0.010.010.030.05

40. $\mathrm{R} \_040 * 102 . * 0.09 * 0.010 .010 .030 .05$

41. R_041 * 103. * $0.09 * 0.010 .010 .030 .04$

42. R_042 * 79. * $0.09 * 0.010 .010 .050 .03$

43. $\mathrm{R} \_043 * 78 . * 0.10 * 0.010 .010 .050 .03$

44. R_044 * 195.*0.11*0.040.020.020.03

45. R_045*15. *0.11*0.020.040.030.02

46. R_046*345.*0.11*0.040.020.030.02

47. R_047 * 11. * $0.09 * 0.020 .040 .010 .01$

48. R_048 * 349. * $0.09 * 0.040 .020 .010 .01$

49. R_049 *350. * $0.08 * 0.040 .020 .010 .01$

50. R_050 * 10. * $0.08 * 0.020 .040 .010 .01$

\section{APPENDIX-XII: FREEWAY SAMPLE \#3 FOR PM2.5 CONCENTRATIONS}

$* * * * * * * * * * * * * * * * * * * * * * * * * * * * * * * * * * * * * * * * * * * * * * *$

$* *$

** CAL3QHC COMBINED OUTPUT FILE PRODUCED BY:

** CALROADS VIEW VER. 6.2.6

** LAKES ENVIRONMENTAL SOFTWARE INC.

** DATE: 2017-01-30 1:17:11 PM

** FILE: C: $\quad$ LAKES $\backslash$ CALROADS $\quad$ VIEW $\backslash$ SIMULATION

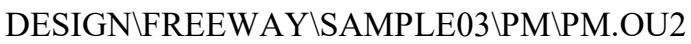

$* *$

$* * * * * * * * * * * * * * * * * * * * * * * * * * * * * * * * * * * * * * * * * * * * * * *$ 

1

JOB: C:ILAKES\CALROADS VIEW $\backslash$ SIMULATION DESIGN

RUN: CAL3QHC RUN

DATE : $1 / 30 / 17$

TIME : $13: 17: 10$

THE MODE FLAG HAS BEEN SET TO P FOR CALCULATING PM AVERAGES.

SITE \& METEOROLOGICAL VARIABLES

$\mathrm{VS}=0.0 \mathrm{CM} / \mathrm{S} \quad \mathrm{VD}=0.0 \mathrm{CM} / \mathrm{S} \quad \mathrm{Z} 0=200 . \mathrm{CM}$

$\mathrm{U}=1.0 \mathrm{M} / \mathrm{S} \quad \mathrm{CLAS}=6(\mathrm{~F}) \quad \mathrm{ATIM}=60$. MINUTES $\quad \mathrm{MIXH}=1000 . \mathrm{M} \quad \mathrm{AMB}=0.0$ $\mathrm{UG} / \mathrm{M}^{* *} 3$

LINK VARIABLES

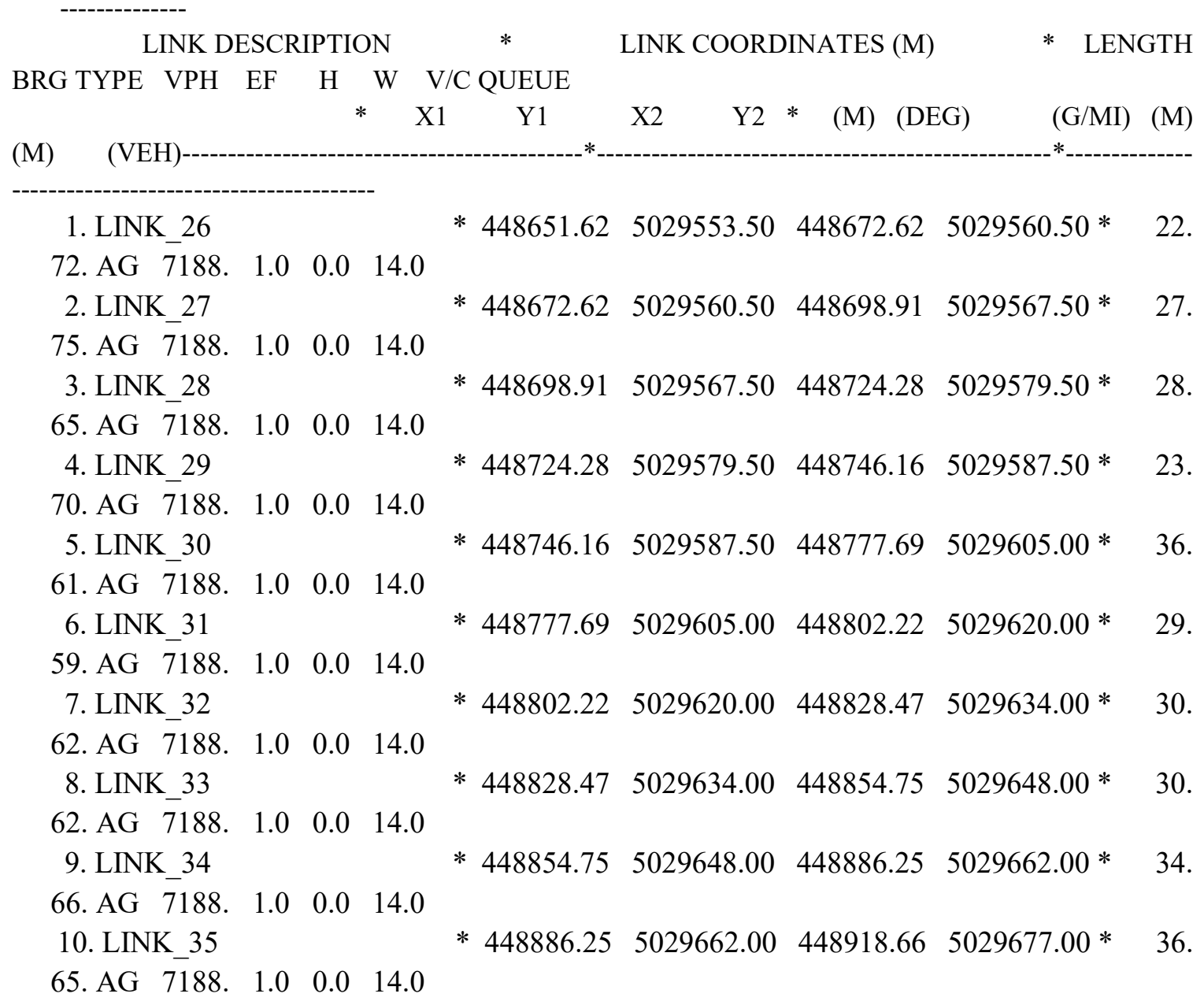

PAGE 2 


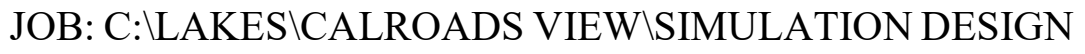

RUN: CAL3QHC RUN

DATE : $1 / 30 / 17$

TIME : 13:17:10

\section{RECEPTOR LOCATIONS}

\begin{tabular}{|c|c|c|c|c|c|c|}
\hline \multirow{2}{*}{\multicolumn{2}{|c|}{ ECEPTOR }} & \multirow[t]{2}{*}{$*$} & \multicolumn{3}{|c|}{ COORDINATES (M) } & \multirow[b]{2}{*}{$*$} \\
\hline & & & $X$ & $\mathrm{Y}$ & $\mathrm{Z}$ & \\
\hline 1. R_001 & $*$ & 448633.94 & 5029597.50 & 6.0 & $*$ & \\
\hline 2. R_002 & $*$ & 448663.06 & 5029609.00 & 6.0 & $*$ & \\
\hline 3. R_003 & $*$ & 448685.16 & 5029617.50 & 6.0 & $*$ & \\
\hline 4. R_004 & $*$ & 448703.97 & 5029625.50 & 6.0 & $*$ & \\
\hline 5. R_005 & $*$ & 448724.09 & 5029635.00 & 6.0 & $*$ & \\
\hline 6. R_006 & $*$ & 448744.88 & 5029645.00 & 6.0 & $*$ & \\
\hline 7. R_007 & $*$ & 448763.38 & 5029654.50 & 6.0 & $*$ & \\
\hline 8. R_008 & $*$ & 448781.84 & 5029665.00 & 6.0 & $*$ & \\
\hline 9. R_009 & $*$ & 448798.34 & 5029674.00 & 6.0 & $*$ & \\
\hline 10. R_010 & * & 448814.16 & 5029681.50 & 6.0 & $*$ & \\
\hline
\end{tabular}

MODEL RESULTS

REMARKS : IN SEARCH OF THE ANGLE CORRESPONDING TO THE MAXIMUM CONCENTRATION, ONLY THE FIRST ANGLE, OF THE ANGLES WITH SAME MAXIMUM CONCENTRATIONS, IS INDICATED AS MAXIMUM.

WIND ANGLE RANGE: .-190.

WIND * CONCENTRATION

ANGLE * (UG/M**3)

(DEGR)* REC1 REC2 REC3 REC4 REC5 REC6 REC7 REC8 REC9 REC10 REC11 REC12 REC13 REC14 REC15 REC16 REC17 REC18 REC19 REC20 


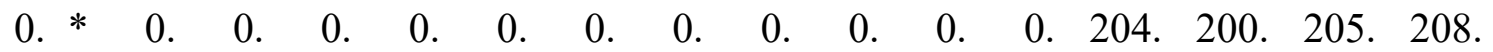
209. 214. 215. 210. 213.

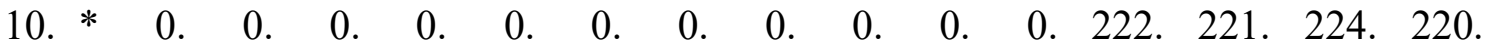
231. 241. 240. 229. 229.

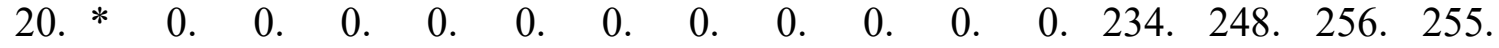
274. 276. 275. 266. 259 .

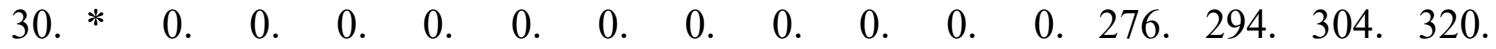
336. 320. 309. 304. 297.

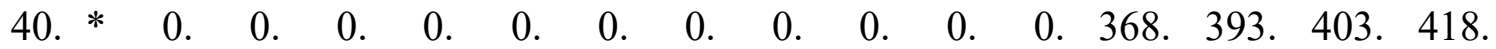
406. 375. 362. 343. 335 .

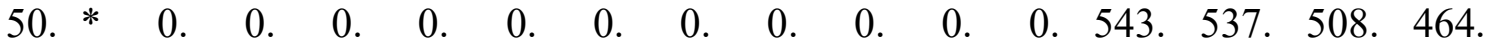
433. 389. 376. 361. 353.

60. * 32. 34. 36. 35. 30. 24. $18.10 . \quad 6 . \quad 3 . \quad 2 . \quad 512.447 . \quad 384.344$. 331. 312. 313. 318. 326 .

70. * 422. 428. 436. 431. 408. 368. 315. 247. 188. 146. 93. 209.197. 190. 190. 200. 204. 218. 238. 258.

80. * 575. 601. 628. 660. 700. 736. 752. 734. 711. 680. 601. 18.19. 20. 22. 25.28 .34 .44 .56$.

90. * 359. 351. 352. 354. 362. 395. 428. 465. 504. 545. 587. 0.0 .0$. $0 . \quad 0 . \quad 0 . \quad 0 . \quad 0 . \quad 0$.

100. * 304. 291. 287. 282. 282. 282. 292. 305. 309. 320. 350. 0. 0. 0. $0 . \quad 0 . \quad 0 . \quad 0 . \quad 0 . \quad 0$.

110. * 268. 264. 254. 245. 246. 236. 248. 254. 257. 259. 263. 0.0 .0$. $0 . \quad 0 . \quad 0 . \quad 0 . \quad 0 . \quad 0$.

120. * 234. 232. 226. 223. 220. 219. 221. 222. 225. 225. 229.0 .0 .0$. $0 . \quad 0 . \quad 0 . \quad 0 . \quad 0 . \quad 0$.

130. * 219. 208. 211. 211. 207. 202. 202. 206. 207. 212. 212. 0. 0. 0. $0 . \quad 0 . \quad 0 . \quad 0 . \quad 0 . \quad 0$.

140. * 206. 201. 203. 201. 198. 196. 195. 197. 197. 200. 199. 0. 0.0. $0 . \quad 0 . \quad 0 . \quad 0 . \quad 0 . \quad 0$.

150. * 175. 196. 192. 193. 191. 192. 193. 193. 193. 193. 194. 0. 0.0. $0 . \quad 0 . \quad 0.0 .0 .0$. 


\section{APPENDIX GROUP 3}

- APPENDIX-XIII: STATISTICAL MODEL REPORT

- APPENDIX-XIV: ANN MODEL REPORT FOR COLLECTOR ROAD LINK CASE 
APPENDIX-XIII: STATISTICAL MODEL REPORT

Appendix-XIII (A): Report of Linear Regression Model for Collector Road Link Case

REGRESSION

/MISSING LISTWISE

/STATISTICS COEFF OUTS CI(95) R ANOVA COLLIN TOL CHANGE ZPP

$/$ CRITERIA $=$ PIN $(.05)$ POUT(.10)

/NOORIGIN

/DEPENDENT CO

/METHOD=ENTER Traffic LU Temperature Distance Height

/SCATTERPLOT $=(*$ SRESID,$*$ ZPRED $)$

/RESIDUALS DURBIN HISTOGRAM(ZRESID) NORMPROB(ZRESID).

\section{Regression}

\begin{tabular}{|c|c|c|}
\hline \multicolumn{2}{|r|}{ Notes } & \multirow[b]{2}{*}{ 11-OCT-2016 20:59:00 } \\
\hline Output Created & & \\
\hline \multicolumn{3}{|l|}{ Comments } \\
\hline \multirow[t]{6}{*}{ Input } & Data & $\begin{array}{l}\text { C: } \backslash \text { Users } \backslash O W N E R \backslash \text { Desktop } \backslash \text { Sta } \\
\text { tistical } \\
\text { Equation } \backslash S P S S \backslash \text { CollectorRoad. } \\
\text { sav }\end{array}$ \\
\hline & Active Dataset & DataSet1 \\
\hline & Filter & $<$ none $>$ \\
\hline & Weight & $<$ none $>$ \\
\hline & Split File & $<$ none $>$ \\
\hline & $\begin{array}{l}\mathrm{N} \text { of Rows in Working Data } \\
\text { File }\end{array}$ & 30 \\
\hline
\end{tabular}




\begin{tabular}{|c|c|c|}
\hline \multirow[t]{2}{*}{ Missing Value Handling } & Definition of Missing & $\begin{array}{l}\text { User-defined missing values } \\
\text { are treated as missing. }\end{array}$ \\
\hline & Cases Used & $\begin{array}{l}\text { Statistics are based on cases } \\
\text { with no missing values for any } \\
\text { variable used. }\end{array}$ \\
\hline Syntax & & $\begin{array}{l}\text { REGRESSION } \\
\text { /MISSING LISTWISE } \\
\text { /STATISTICS COEFF OUTS } \\
\text { CI(95) R ANOVA COLLIN } \\
\text { TOL CHANGE ZPP } \\
\text { /CRITERIA=PIN(.05) } \\
\text { POUT(.10) } \\
\text { /NOORIGIN } \\
\text { /DEPENDENT CO } \\
\text { /METHOD=ENTER Traffic } \\
\text { LU Temperature Distance } \\
\text { Height } \\
\text { /SCATTERPLOT=(*SRESID } \\
\text {,ZZPRED) } \\
\text { /RESIDUALS DURBIN } \\
\text { HISTOGRAM(ZRESID) } \\
\text { NORMPROB(ZRESID). }\end{array}$ \\
\hline \multirow[t]{4}{*}{ Resources } & Processor Time & 00:00:06.91 \\
\hline & Elapsed Time & 00:00:03.30 \\
\hline & Memory Required & 4880 bytes \\
\hline & $\begin{array}{l}\text { Additional Memory Required } \\
\text { for Residual Plots }\end{array}$ & 616 bytes \\
\hline
\end{tabular}

Variables Entered/Removed ${ }^{\text {a }}$ 


\begin{tabular}{ll|l|l} 
Model & Variables Entered & $\begin{array}{l}\text { Variables } \\
\text { Removed }\end{array}$ & Method \\
\hline 1 & $\begin{array}{l}\text { Height, } \\
\text { Temperature, } \\
\text { Distance, Traffic, } \\
\text { LU }\end{array}$ & & \\
& & \\
\hline
\end{tabular}

a. Dependent Variable: CO

b. All requested variables entered.

\begin{tabular}{|c|c|c|c|c|c|c|c|c|c|c|}
\hline \multicolumn{11}{|c|}{ Model Summary } \\
\hline & & & & Std. Error & & Cha & e Statis & & & \\
\hline $\begin{array}{l}\text { Mode } \\
1\end{array}$ & $\mathrm{R}$ & $\begin{array}{c}\mathrm{R} \\
\text { Square }\end{array}$ & $\begin{array}{l}\text { Adjusted R } \\
\text { Square }\end{array}$ & $\begin{array}{c}\text { of the } \\
\text { Estimate }\end{array}$ & $\begin{array}{l}\text { R Square } \\
\text { Change }\end{array}$ & $\begin{array}{c}\mathrm{F} \\
\text { Change }\end{array}$ & df1 & $\mathrm{df} 2$ & $\begin{array}{l}\text { Sig. F } \\
\text { Change }\end{array}$ & $\begin{array}{l}\text { Durbin- } \\
\text { Watson }\end{array}$ \\
\hline 1 & $.682^{\mathrm{a}}$ & .465 & .354 & 15.55588 & .465 & 4.173 & 5 & 24 & .007 & 2.210 \\
\hline
\end{tabular}

a. Predictors: (Constant), Height, Temperature, Distance, Traffic, LU

b. Dependent Variable: CO

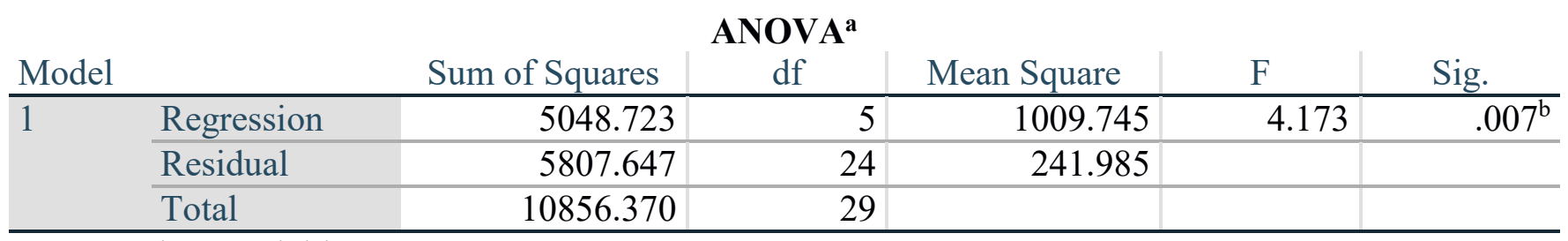

a. Dependent Variable: CO

b. Predictors: (Constant), Height, Temperature, Distance, Traffic, LU 


\begin{tabular}{|c|c|c|c|c|c|c|c|c|c|c|c|c|c|}
\hline \multicolumn{14}{|c|}{ Coefficients $^{a}$} \\
\hline \multirow{2}{*}{\multicolumn{2}{|c|}{ Model }} & \multicolumn{2}{|c|}{$\begin{array}{l}\text { Unstandardized } \\
\text { Coefficients }\end{array}$} & \multirow{2}{*}{$\begin{array}{l}\text { Standard } \\
\text { ized } \\
\text { Coefficie } \\
\text { nts } \\
\text { Beta }\end{array}$} & \multirow[b]{2}{*}{$\mathrm{t}$} & \multirow[b]{2}{*}{ Sig. } & \multicolumn{2}{|c|}{$\begin{array}{l}95.0 \% \text { Confidence } \\
\text { Interval for B }\end{array}$} & \multicolumn{3}{|c|}{ Correlations } & \multicolumn{2}{|c|}{$\begin{array}{l}\text { Collinearity } \\
\text { Statistics }\end{array}$} \\
\hline & & $\mathrm{B}$ & $\begin{array}{l}\text { Std. } \\
\text { Error }\end{array}$ & & & & $\begin{array}{l}\text { Lower } \\
\text { Bound }\end{array}$ & $\begin{array}{l}\text { Upper } \\
\text { Bound }\end{array}$ & $\begin{array}{l}\text { Zero- } \\
\text { order }\end{array}$ & $\begin{array}{c}\text { Partia } \\
\quad 1\end{array}$ & Part & $\begin{array}{c}\text { Tolera } \\
\text { nce }\end{array}$ & VIF \\
\hline 1 & $\begin{array}{l}\text { (Constan } \\
\text { t) }\end{array}$ & 10.071 & 10.936 & & .921 & .366 & -12.499 & 32.641 & & & & & \\
\hline & Traffic & .007 & .003 & .342 & 2.205 & .037 & .000 & .014 & .476 & .410 & .329 & .927 & 1.079 \\
\hline & LU & 8.668 & 8.366 & .193 & 1.036 & .311 & -8.600 & 25.935 & .244 & .207 & .155 & .644 & 1.552 \\
\hline & $\begin{array}{l}\text { Tempera } \\
\text { ture }\end{array}$ & -.014 & .129 & -.020 & -.110 & .913 & -.281 & .252 & .173 & -.023 & -.016 & .664 & 1.505 \\
\hline & Distance & -.190 & .114 & -.261 & $\begin{array}{r}- \\
1.674\end{array}$ & .107 & -.425 & .044 & -.372 & -.323 & -.250 & .920 & 1.087 \\
\hline & Height & -5.673 & 2.274 & -.381 & $\begin{array}{r}- \\
2.495 \\
\end{array}$ & .020 & -10.365 & -.980 & -.425 & -.454 & -.373 & .956 & 1.046 \\
\hline
\end{tabular}

a. Dependent Variable: CO

\section{Collinearity Diagnostics ${ }^{a}$}

\begin{tabular}{|c|c|c|c|c|c|c|c|c|c|}
\hline \multirow[b]{2}{*}{ Model } & \multirow[b]{2}{*}{ Dimension } & \multirow[b]{2}{*}{ Eigenvalue } & \multirow{2}{*}{$\begin{array}{l}\text { Condition } \\
\text { Index }\end{array}$} & \multicolumn{6}{|c|}{ (a) } \\
\hline & & & & (Constant) & Traffic & LU & Temperature & Distance & Height \\
\hline 1 & 1 & 3.671 & 1.000 & .00 & .01 & .02 & .02 & .01 & .02 \\
\hline & 2 & 1.156 & 1.782 & .00 & .00 & .13 & .11 & .22 & .01 \\
\hline & 3 & .538 & 2.612 & .01 & .02 & .05 & .12 & .67 & .07 \\
\hline & 4 & .329 & 3.339 & .00 & .02 & .67 & .55 & .02 & .09 \\
\hline & 5 & .264 & 3.727 & .01 & .09 & .13 & .20 & .00 & .62 \\
\hline
\end{tabular}




\begin{tabular}{|c|c|c|c|c|c|}
\hline 6 & \multicolumn{2}{|c|}{9.375} & .87 & .00 & 00 \\
\hline \multicolumn{6}{|l|}{ a. Dependent Variable: CO } \\
\hline \multicolumn{6}{|c|}{ Residuals Statistics ${ }^{a}$} \\
\hline & Minimum & Maximum & Mean & Std. Deviation & $\mathrm{N}$ \\
\hline Predicted Value & -8.7401 & 47.4986 & 17.3633 & 13.19446 & 30 \\
\hline Std. Predicted Value & -1.978 & 2.284 & .000 & 1.000 & 30 \\
\hline $\begin{array}{l}\text { Standard Error of Predicted } \\
\text { Value }\end{array}$ & 3.696 & 12.548 & 6.697 & 1.915 & 30 \\
\hline Adjusted Predicted Value & -38.7285 & 40.6439 & 15.8161 & 16.67410 & 30 \\
\hline Residual & -17.60845 & 39.40714 & .00000 & 14.15146 & 30 \\
\hline Std. Residual & -1.132 & 2.533 & .000 & .910 & 30 \\
\hline Stud. Residual & -1.298 & 2.777 & .038 & 1.060 & 30 \\
\hline Deleted Residual & -23.15267 & 52.42846 & 1.54726 & 19.93938 & 30 \\
\hline Stud. Deleted Residual & -1.318 & 3.300 & .077 & 1.162 & 30 \\
\hline Mahal. Distance & .671 & 17.904 & 4.833 & 3.571 & 30 \\
\hline Cook's Distance & .000 & 1.232 & .085 & .237 & 30 \\
\hline Centered Leverage Value & .023 & .617 & .167 & .123 & 30 \\
\hline
\end{tabular}

a. Dependent Variable: CO 


\section{Charts}
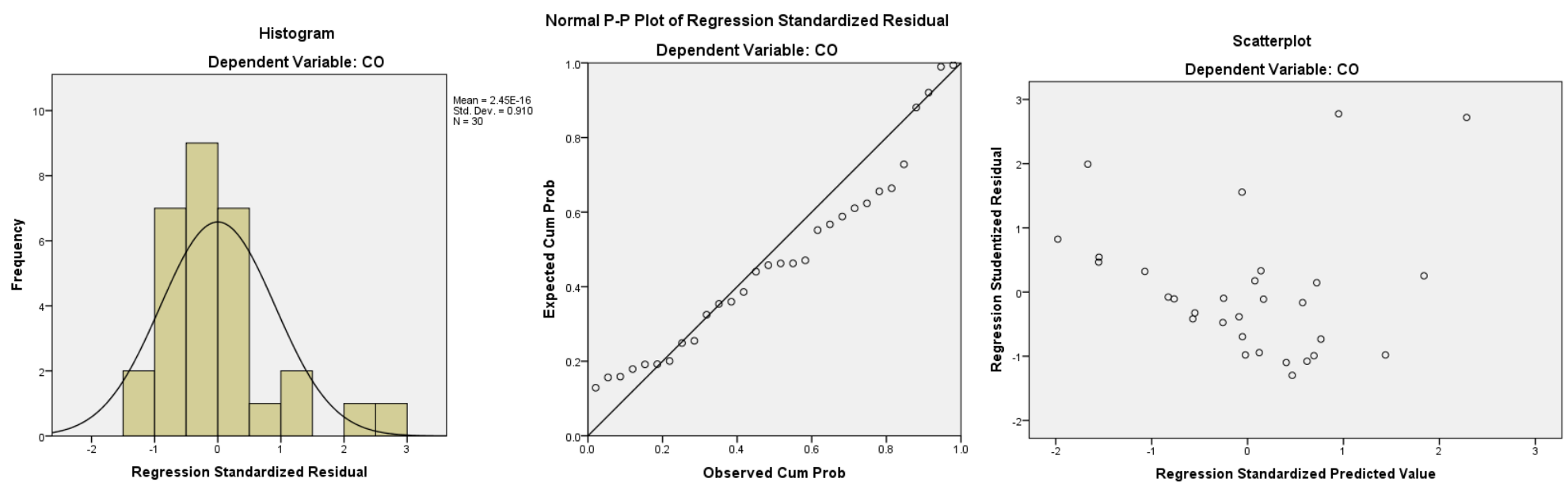

\section{Appendix-XIII (B): Report of Non-Linear Regression Model for Collector Road Link Case}

* NonLinear Regression.

MODEL PROGRAM a=0 b1=1 b2=1 b3=1 b4=1 b5=1.

COMPUTE PRED_ $=\mathrm{a}+\mathrm{b} 1 * \operatorname{Tr}+\mathrm{b} 2 *$ TransD $+\mathrm{b} 3 * \operatorname{TransH}+\mathrm{b} 4 * \mathrm{LU}+\mathrm{b} 5 *$ TransT.

NLR CO

/OUTFILE='C: \Users $\backslash$ sujitdas $\backslash A p p D a t a \backslash$ Local $\backslash T e m p \backslash$ spss $8540 \backslash$ SPSSFNLR.TMP' /PRED PRED

/CRITERIA SSCONVERGENCE 1E-8 PCON 1E-8.

\section{Nonlinear Regression Analysis}

\section{Notes}




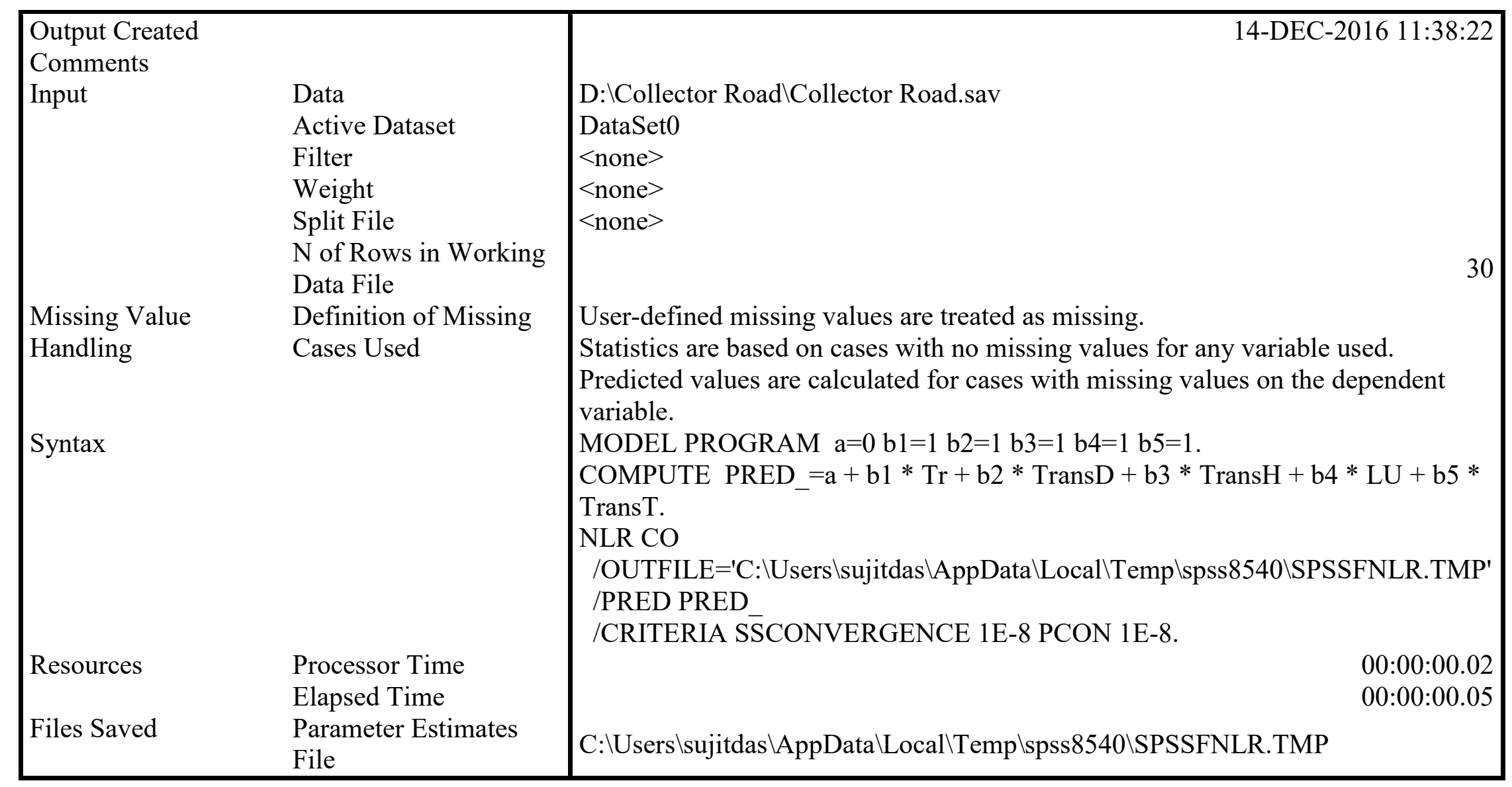

Iteration History ${ }^{b}$

\begin{tabular}{|c|c|c|c|c|c|c|c|}
\hline \multirow{2}{*}{$\begin{array}{l}\text { Iteration } \\
\text { Number }^{\mathrm{a}}\end{array}$} & \multirow{2}{*}{$\begin{array}{c}\text { Residual } \\
\text { Sum of } \\
\text { Squares }\end{array}$} & \multicolumn{6}{|c|}{ Parameter } \\
\hline & & $\mathrm{a}$ & b1 & $\mathrm{b} 2$ & b3 & b4 & b5 \\
\hline
\end{tabular}




\begin{tabular}{|l|r|r|r|r|r|r|r|}
\hline 1.0 & 232773632.6 & 000 & 1.000 & 1.000 & 1.000 & 1.000 & 1.000 \\
1.1 & 2357.168 & 30.712 & .007 & -32.676 & -4.223 & 5.262 & .088 \\
2.0 & 2357.168 & 30.712 & .007 & -32.676 & -4.223 & 5.262 & .088 \\
2.1 & 2357.168 & 30.712 & .007 & -32.676 & -4.223 & 5.262 & .088 \\
\hline
\end{tabular}

Derivatives are calculated numerically. ${ }^{\mathrm{b}}$

a. Major iteration number is displayed to the left of the decimal, and minor iteration number is to the right of the decimal.

b. Run stopped after 4 model evaluations and 2 derivative evaluations because the relative reduction between successive residual sums of squares is at most SSCON $=1.000 \mathrm{E}-8$.

Parameter Estimates

\begin{tabular}{|l|r|r|r|r|}
\hline & & & \multicolumn{2}{|c|}{$95 \%$ Confidence Interval } \\
\cline { 3 - 5 } Parameter & Estimate & Std. Error & $\begin{array}{l}\text { Lower } \\
\text { Bound }\end{array}$ & \multicolumn{1}{c|}{ Upper Bound } \\
\hline a & 30.712 & 9.064 & 12.005 & 49.419 \\
b1 & .007 & .002 & .003 & .011 \\
b2 & -32.676 & 5.688 & -44.416 & -20.936 \\
b3 & -4.223 & 2.633 & -9.657 & 1.212 \\
b4 & 5.262 & 5.494 & -6.078 & 16.601 \\
b5 & .088 & .842 & -1.649 & 1.825 \\
\hline
\end{tabular}

\begin{tabular}{|l|l|r|r|r|r|r|}
\hline & \multicolumn{1}{|c|}{ Correlations of Parameter Estimates } \\
\hline a & \multicolumn{1}{c|}{ b1 } & \multicolumn{1}{c|}{ b2 } & \multicolumn{1}{c|}{ b3 } & \multicolumn{1}{c|}{ b4 } & \multicolumn{1}{c|}{ b5 } \\
\hline b1 & 1.000 & -.622 & -.369 & -.222 & -.364 & -.503 \\
b2 & -.622 & 1.000 & .031 & .155 & -.145 & -.079 \\
b3 & -.369 & .031 & 1.000 & -.479 & .166 & .009 \\
b4 & -.222 & .155 & -.479 & 1.000 & -.160 & -.060 \\
& -.364 & -.145 & .166 & -.160 & 1.000 & .597
\end{tabular}




\begin{tabular}{|l|l|l|l|l|l|l|}
$\mathrm{b} 5$ & -.503 & -.079 & .009 & -.060 & .597 & 1.000 \\
\hline
\end{tabular}

\begin{tabular}{|c|c|c|c|}
\hline \multicolumn{4}{|c|}{ ANOVA $^{a}$} \\
\hline Source & $\begin{array}{l}\text { Sum of } \\
\text { Squares }\end{array}$ & df & $\begin{array}{c}\text { Mean } \\
\text { Squares }\end{array}$ \\
\hline Regression & 17543.762 & 6 & 2923.960 \\
\hline Residual & 2357.168 & 24 & 98.215 \\
\hline Uncorrected & 19900.930 & 30 & \\
\hline $\begin{array}{l}\text { Total } \\
\text { Corrected Total }\end{array}$ & 10856370 & 29 & \\
\hline 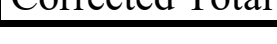 & & & \\
\hline
\end{tabular}

Dependent variable: $\mathrm{CO}^{\mathrm{a}}$

a. R squared $=1$ - (Residual Sum of Squares) / (Corrected

Sum of Squares) $=.783$.

\section{APPENDIX-XIV: ANN MODEL REPORT FOR COLLECTOR ROAD LINK CASE}

*Multilayer Perceptron Network.

MLP CO (MLEVEL=S) WITH Tr D T H LU

/RESCALE COVARIATE=STANDARDIZED

/PARTITION TRAINING $=7$ TESTING $=3$ HOLDOUT $=0$

/ARCHITECTURE AUTOMATIC $=$ YES (MINUNITS=1 MAXUNITS=50)

/CRITERIA TRAINING=BATCH OPTIMIZATION=SCALEDCONJUGATE LAMBDAINITIAL $=0.0000005$

SIGMAINITIAL $=0.00005$ INTERVALCENTER $=0$ INTERVALOFFSET $=0.5$ MEMSIZE $=1000$

/PRINT CPS NETWORKINFO SUMMARY SOLUTION IMPORTANCE

/PLOT NETWORK PREDICTED RESIDUAL

/STOPPINGRULES ERRORSTEPS $=1($ DATA=AUTO $)$ TRAININGTIMER=ON (MAXTIME=15) MAXEPOCHS=AUTO 
ERRORCHANGE $=1.0 \mathrm{E}-4$ ERRORRATIO $=0.001$ /MISSING USERMISSING=EXCLUDE .

Case Processing Summary

\begin{tabular}{|ll|r|r|}
\hline & & $\mathrm{N}$ & Percent \\
\hline Sample & Training & 25 & $83.3 \%$ \\
& Testing & 5 & $16.7 \%$ \\
Valid & & 30 & $100.0 \%$ \\
Excluded & 0 & \\
Total & 30 & \\
\hline
\end{tabular}

\begin{tabular}{|c|c|c|c|c|}
\hline \multicolumn{5}{|c|}{ Network Information } \\
\hline \multirow[t]{7}{*}{ Input Layer } & Covariates & 1 & $\operatorname{Tr}$ & \\
\hline & & 2 & $\mathrm{D}$ & \\
\hline & & 3 & $\mathrm{~T}$ & \\
\hline & & 4 & $\mathrm{H}$ & \\
\hline & & 5 & LU & \\
\hline & Number of & & & 5 \\
\hline & Rescaling $\mathrm{N}$ & or Covariates & Standardized & \\
\hline Hidden & Number of & Layers & & 1 \\
\hline \multirow{2}{*}{ Layer(s) } & Number of & Hidden Layer $1^{\mathrm{a}}$ & & 5 \\
\hline & Activation I & & Hyperbolic tangent & \\
\hline \multirow[t]{5}{*}{ Output Layer } & $\begin{array}{l}\text { Dependent } \\
\text { Variables }\end{array}$ & 1 & $\mathrm{CO}$ & \\
\hline & Number of & & & 1 \\
\hline & Rescaling $\mathrm{N}$ & or Scale Dependents & Standardized & \\
\hline & Activation I & & Identity & \\
\hline & Error Funct & & Sum of Squares & \\
\hline
\end{tabular}


a. Excluding the bias unit

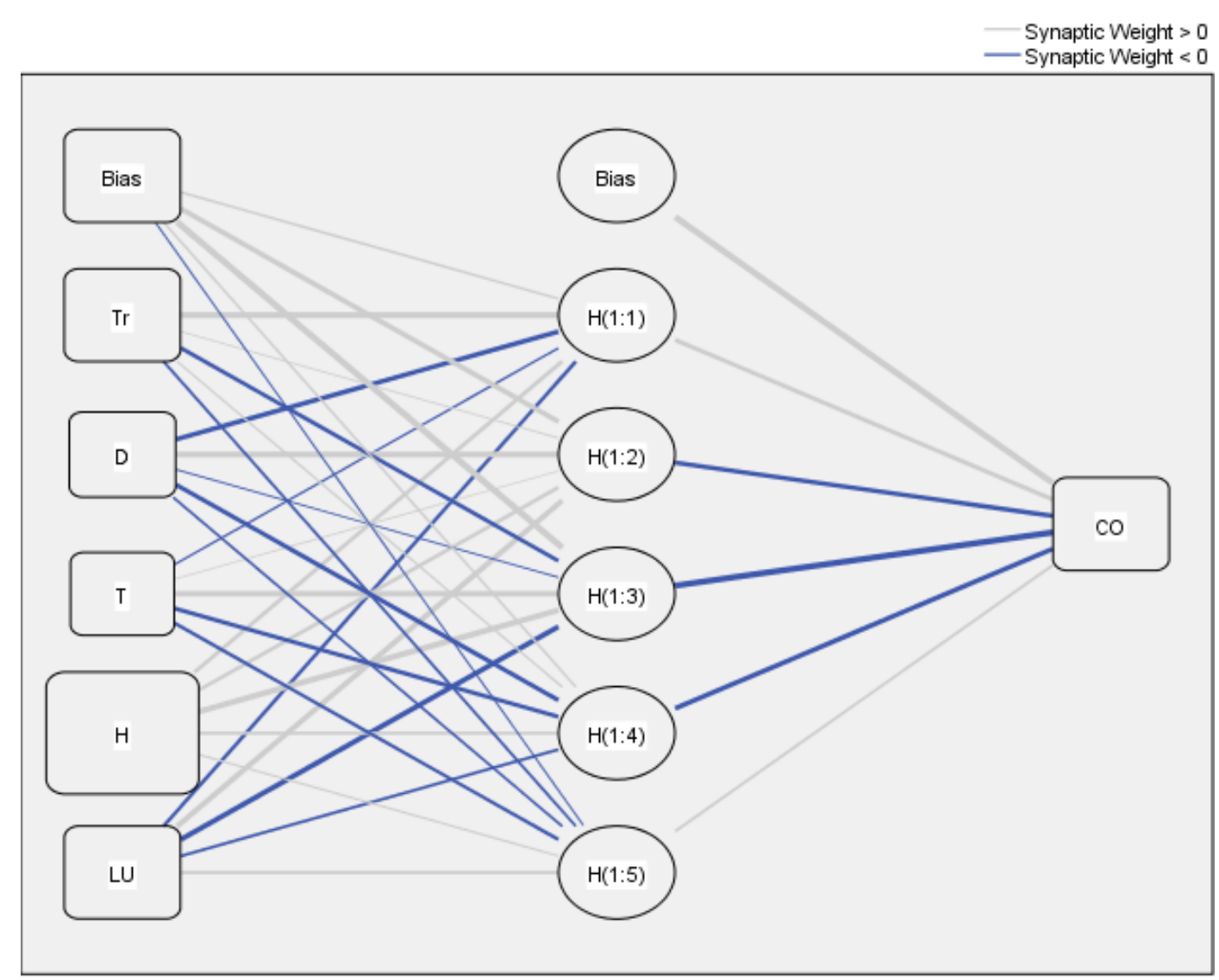

Hidden layer activation function: Hyperbolic tangent

Output layer activation function: Identity

\section{Model Summary}




\begin{tabular}{|c|c|c|}
\hline Training & $\begin{array}{l}\text { Sum of Squares } \\
\text { Error } \\
\text { Relative Error } \\
\text { Stopping Rule Used } \\
\text { Training Time }\end{array}$ & $\begin{array}{l}.460 \\
1 \text { consecutive } \\
\text { step(s) with no } \\
\text { decrease in error }{ }^{\mathrm{a}} \\
\text { 0:00:00.00 }\end{array}$ \\
\hline Testing & $\begin{array}{l}\text { Sum of Squares } \\
\text { Error } \\
\text { Relative Error }\end{array}$ & $\begin{array}{l}.086 \\
.362\end{array}$ \\
\hline
\end{tabular}

Dependent Variable: CO

a. Error computations are based on the testing sample.

Parameter Estimates

\begin{tabular}{|c|c|c|c|c|c|c|c|}
\hline \multirow[b]{3}{*}{ Predictor } & & \multicolumn{6}{|c|}{ Predicted } \\
\hline & & \multicolumn{5}{|c|}{ Hidden Layer 1} & \multirow{2}{*}{$\frac{\text { Output Layer }}{\mathrm{CO}}$} \\
\hline & & $\mathrm{H}(1: 1)$ & $\mathrm{H}(1: 2)$ & $\mathrm{H}(1: 3)$ & $\mathrm{H}(1: 4)$ & $\mathrm{H}(1: 5)$ & \\
\hline \multirow[t]{6}{*}{ Input Layer } & (Bias) & .226 & .914 & 2.688 & .181 & -.152 & \\
\hline & $\operatorname{Tr}$ & 1.439 & .126 & -.548 & .163 & -.236 & \\
\hline & $\mathrm{D}$ & -.744 & 1.201 & -.151 & -.655 & -.234 & \\
\hline & $\mathrm{T}$ & -.178 & .041 & 1.160 & -.610 & -.412 & \\
\hline & $\mathrm{H}$ & .548 & .513 & 1.396 & .296 & .157 & \\
\hline & LU & -.448 & 1.036 & -1.025 & -.281 & .302 & \\
\hline
\end{tabular}




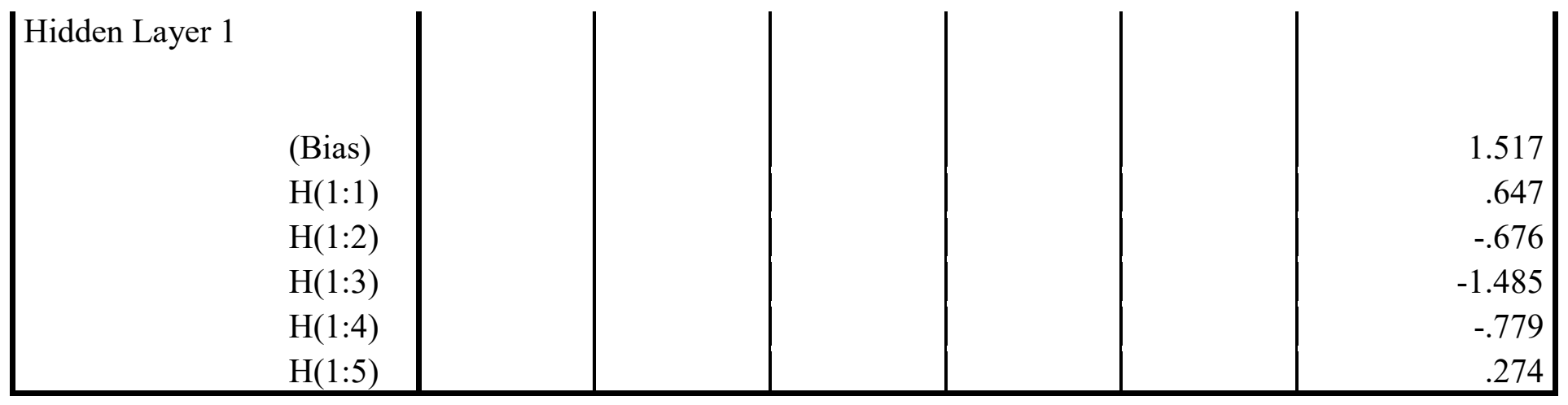

Independent Variable Importance

\begin{tabular}{|l|r|r|}
\hline & Importance & $\begin{array}{c}\text { Normalized } \\
\text { Importance }\end{array}$ \\
\hline $\mathrm{Tr}$ & .185 & $49.6 \%$ \\
$\mathrm{D}$ & .136 & $36.5 \%$ \\
$\mathrm{~T}$ & .122 & $32.6 \%$ \\
$\mathrm{H}$ & .372 & $100.0 \%$ \\
$\mathrm{LU}$ & .185 & $49.8 \%$ \\
\hline
\end{tabular}
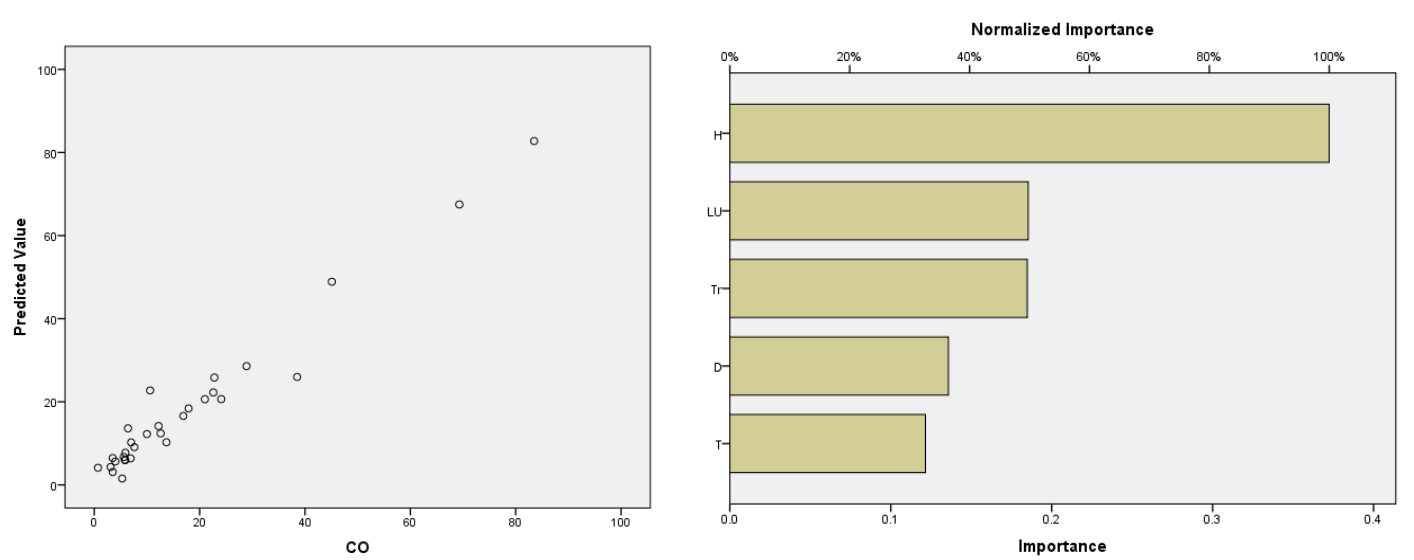